\title{
ASSESSMENT OF THE PCFBC-EXPOSED AND ACCELERATED LIFE-TESTED CANDLE FILTERS
}

Topical Report

DOE/NETL Contract No. DE-AC21-94MC31147

September 30, 1999

\author{
by \\ M. A. Alvin \\ Siemens Westinghouse Power Corporation \\ Science and Technology Center \\ 1310 Beulah Road \\ Pittsburgh, PA 15235-5098
}

\author{
Prepared for \\ U.S. Department of Energy \\ National Energy Technology Laboratory \\ 3610 Collins Ferry Road \\ P. O. Box 880 \\ Morgantown, WV 26507-0880
}

R. A. Dennis - DOE/NETL Project Manager 


\section{DISCLAIMER}

This report was prepared as an account of work sponsored by the United States Government. Neither the United States nor the United States Department of Energy, nor any of their employees, makes any warranty, expressed or implied, or assumes any legal liability or responsibility for the accuracy, completeness, or usefulness of any information, apparatus, product, or process disclosed, or represents that its use would not infringe privately owned rights. Reference herein to any specific commercial product, process, or service by trade name, mark, manufacturer, or otherwise, does not necessarily constitute or imply its endorsement, recommendation, or favoring by the United States Government or any agency thereof. The views and opinions of authors expressed herein do not necessarily state or reflect those of the United States Government or any agency thereof. 


\begin{abstract}
The Siemens Westinghouse Power Corporation (SWPC) ${ }^{\dagger}$ and the Department of Energy/National Energy Technology Laboratory (DOE/NETL) have been involved in the development of the hot gas filtration technology during the past twenty years. Development during this time has successfully lead to the design and construction of high temperature Siemens Westinghouse particulate filtration systems that have been operated at Demonstration Plant sites. Concurrently, development has advanced the use of commercially available porous oxide- and nonoxide-based monolithic ceramic materials for fabrication of candle filter elements used in these facilities, and has fostered the manufacture and use of second generation, oxide-based, continuous fiber reinforced ceramic composite and filament wound materials.

This report summarizes the material characterization efforts conducted by SWPC on commercially available and second generation filter materials tested in Siemens Westinghouse's advanced, high temperature, particulate removal system at the Foster Wheeler, pressurized circulating fluidized-bed combustion (PCFBC), pilot-scale test facility in Karhula, Finland. Material characterization efforts similarly conducted on filter elements which experienced extended accelerated aging in Siemens Westinghouse's pressurized fluidized-bed combustion (PFBC) simulator test facility in Pittsburgh, PA, are also described. The viability of successfully utilizing candle filters in PCFBC or PFBC systems for over one year of service life has been demonstrated via accelerated life testing performed in this program. Continued testing to demonstrate the feasibility of achieving three years of service operation on aged filter elements is recommended.
\end{abstract}

\footnotetext{
${ }^{\dagger}$ Formerly the Westinghouse Electric Corporation.
} 


\section{TABLE OF CONTENTS}

Abstract

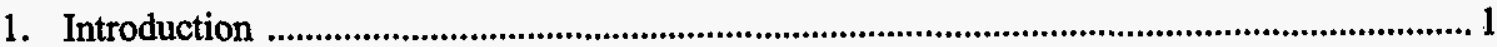

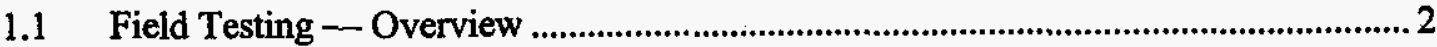

1.2 Foster Wheeler PCFBC Test Campaigns ............................................................................. 4

2. Characterization of PCFBC-Exposed Filter Elements ........................................................... 21

2.1 Room Temperature Gas Flow Resistance.................................................................. 21

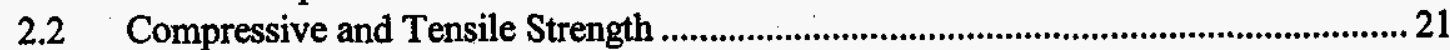

2.3 Hoop Stress, Elastic Modulus, and Poisson's Ratio................................................... 38

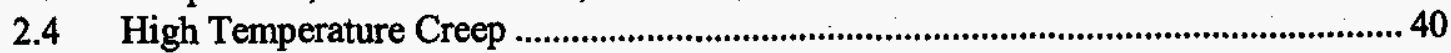

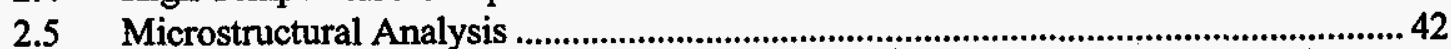

2.5.1 Schumacher Dia Schumalith FT20 Candle Filters......................................... 42

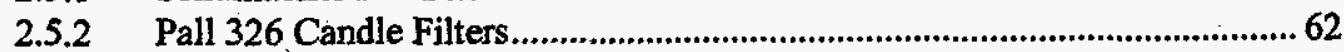

2.5.3 Coors P-100A-1 Alumina/Mullite Candle Filters......................................... 82

2.5.4 3M CVI-SiC Composite Candle Filters .................................................... 107

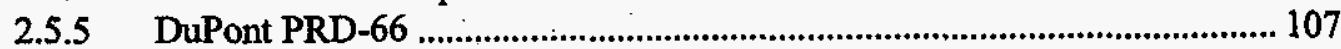

2.5.5.1 As-Manufactured Filter Matrix .................................................. 107

2.5.5.2 PCFBC-Exposed Filter Matrix ..................................................... 127

2.5.6 McDermott CFCC .................................................................................... 135

2.5.6.1 As-Manufactured Filter Matrix …................................................ 135

2.5.6.2 PCFBC-Exposed Filter Matrix................................................. 135

2.5.7 Blasch Mullite-Bonded Alumina .............................................................. 156

2.5.7.1 As-Manufactured Filter Matrix ............................................... 156

2.5.7.2 PCFBC-Exposed Filter Matrix ................................................... 168

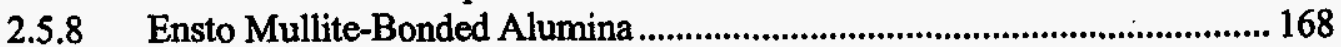

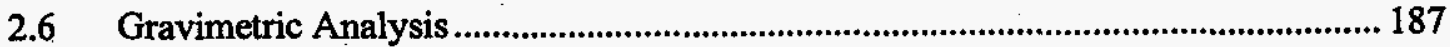

2.7 High Temperature Oxidation vs Creep.................................................................... 199

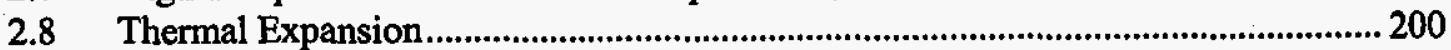

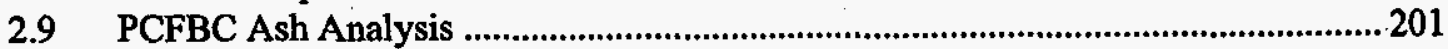

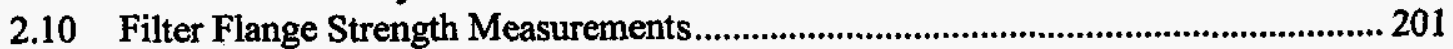

3. Accelerated Life Testing of PCFBC-Exposed Filter Elements ............................................ 206

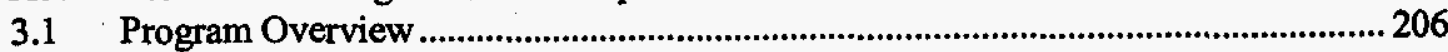

3.1.1 Steady State Testing................................................................................. 210

3.1.2 Accelerated Pulse Cycling ...................................................................... 210

3.1.3 Thermal Transient Testing .................................................................... 220

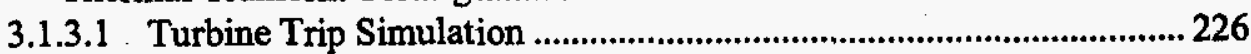

3.1.3.2 Characterization of Temperature Transients during Pulse Cycling... 237

3.1.3.3 Continuation of Turbine Trip Simulations........................................... 238

3.1.3.4 Combined Pulse Cycling and Thermal Transient Testing .................. 242

3.1.4 Post-Test Inspection.............................................................................. 247

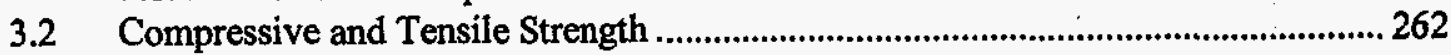

3.3 Hoop Stress, Elastic Modulus, and Poisson's Ratio.................................................. 273

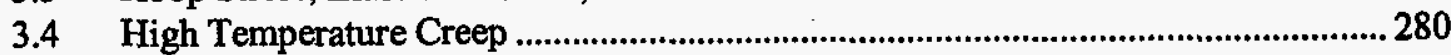

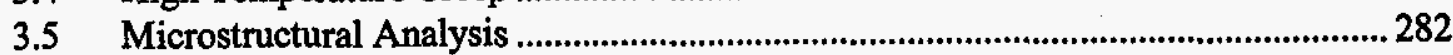

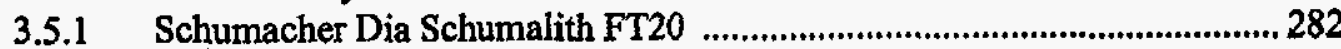




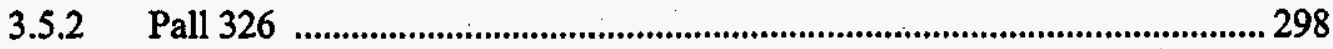

3.5.3 Coors P-100A-1 Alumina/Mullite.................................................................. 314

3.5.4 McDermott CFCC...................................................................................... 327

3.5.5 Blasch Mullite-Bonded Alumina ................................................................... 357

4. Impact of Process Aging on the Stability of Porous Ceramic Filter Materials ..................... 374

4.1 Oxide-Based Ceramic Filter Materials........................................................................ 374

4.2 Nonoxide-Based Ceramic Filter Materials.................................................................... 375

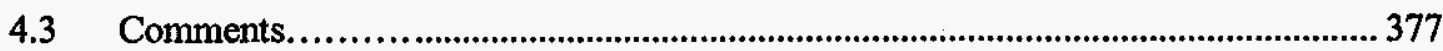

5. Thermal Transients, Stress, and Filter Life............................................................................. 379

5.1 Pulse Cycling:...................................................................................................... 379

5.2 Thermal Transient Testing ..................................................................................... 379

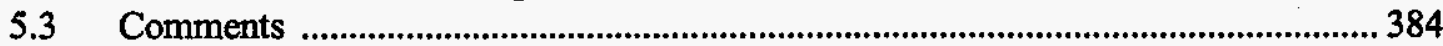

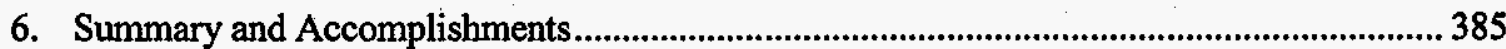

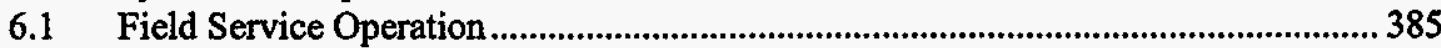

6.2 Accelerated Life Testing ………................................................................................ 388

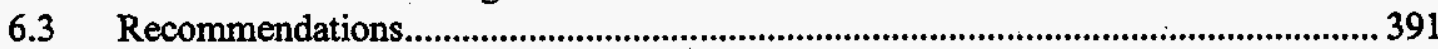

6.3.1 Extended Accelerated Life Testing ........................................................................ 391

6.3.2 Material/Component Optimization.................................................................. 391

6.3.3 Non-Destructive Evaluation ................................................................................. 393

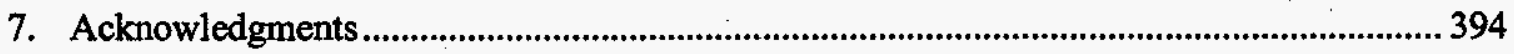

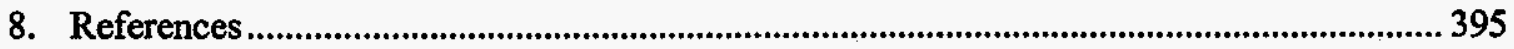

Appendix A - Post-Test Inspection of the PCFBC-Exposed 3M and Techniweave Oxide-Based Candle Filters..................................................................................A-1

Appendix B - Non-Destructive Filter Evaluation ....................................................................... B-1 


\section{LIST OF TABLES}

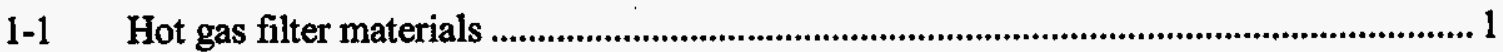

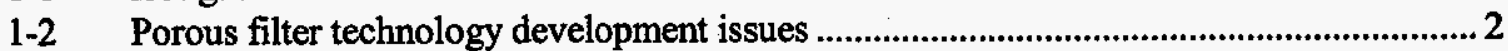

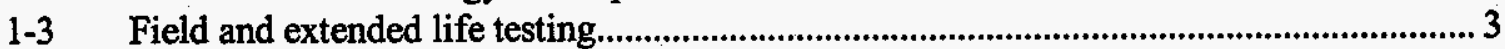

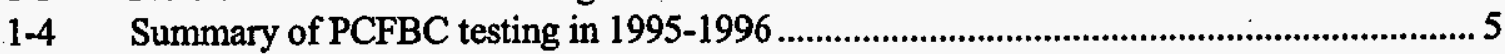

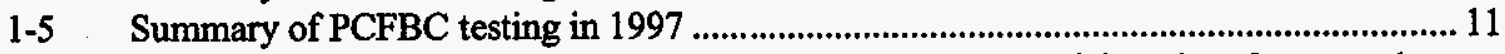

2-1 As-manufactured and residual process temperature strength of the PCFBC-exposed porous ceramic filter materials ............................................................................................25

2-2 Ultimate load applied during strength characterization of the porous ceramic filter

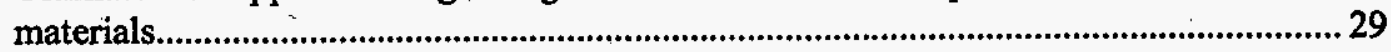

2-3 Fracture characteristics of the porous ceramic filter materials during c-ring

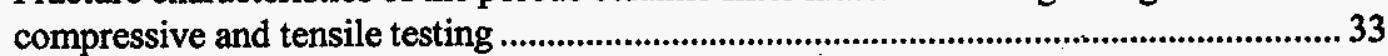

2-4 Comparison of strength measurements...............................................................................37

2-5 Material properties of the as-manufactured and PCFBC-exposed porous ceramic

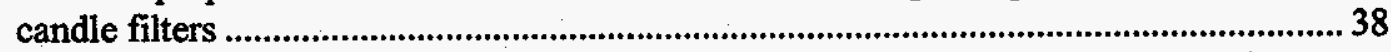

2-6 Percent creep strain and silica concentrations in PCFBC-exposed clay bonded silicon carbide filter matrices .....................................................................................................40 40

2-7 Elongation of clay bonded silicon carbide candle filters .............................................. 41

3-1 Summary of the extended filter life test program............................................................ 207

3-2 Temperature drop throughout the filter array and system during thermal transient testing................................................................................................................................... 233

3-3 Temperature differential along the o.d. and i.d. surfaces of the various candle filters during thermal transient testing .................................................................................... 237

3-4 Maximum temperature differential along the i.d. surface of the ceramic candle filters during pulse cycling............................................................................................................. 238

3-5 Influence of the conditioned ash cake layer on temperature drop along the i.d. surface of the Coors P-100A-1 alumina/mullite filter element during thermal

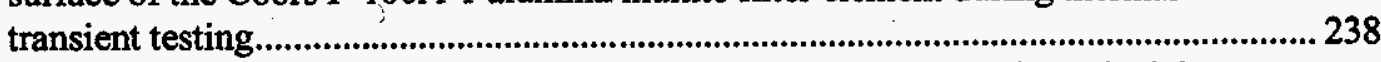

3-6 Influence of the conditioned ash cake layer on temperature drop along the i.d. surface of the various ceramic filter elements during thermal transient testing.............. 241

3-7 Temperature drop along the o.d and i.d. surfaces of the Coors P-100A-1 alumina/ mullite candle filter during thermal transient testing .................................................... 242

3-8 Temperature drop along the o.d. and i.d. surfaces of the various candle filters

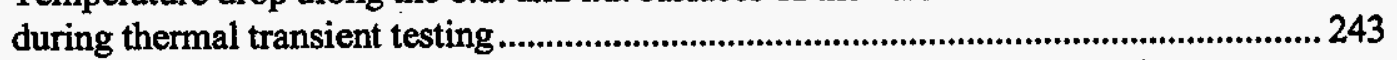

3-9 Influence of ash on the temperature drop along the i.d. surfaces of the various ceramic candle filters during thermal transient testing

3-10 Maximum temperature drop experienced along the top i.d. surface of the porous ceramic filter elements during thermal transient testing with simultaneous pulse cycling

3-11 Temperature drop throughout the filter array as a function of time during thermal transient testing with simultaneous pulse cycling ...........................................................2 245

3-12 Gas flow resistance of the extended life-tested filter elements....................................... 255

3-13 Strength characterization of extended life-tested filter elements ....................................... 264

3-14 Ultimate load-to-failure for the extended life-tested filter elements............................... 265

3-15 Weibull modulus for the PCFBC-exposed and extended life-tested porous ceramic filters. 
3-16 Summary of the hoop strength, Young's Modulus, and Poisson's Ratio for the monolithic filter elements as a function of time/conditions .......................................... 274

3-17 Summary of the hoop strength, Young's Modulus, and Poisson's Ratio for the advanced filter elements as a function of time/conditions .............................................. 278

3-18 Comparison of Young's Modulus data generated via destructive and nondestructive techniques

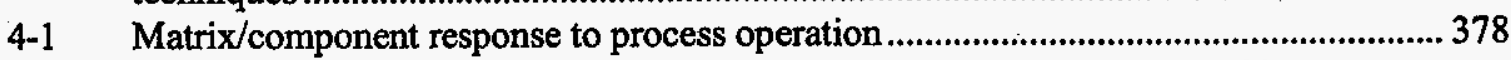

5-1 Material properties of as-manufactured and field-tested porous ceramic filter

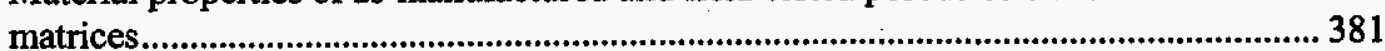

A-1 Layer adherence strength of the 3M oxide-based CFCC filter materials ........................ A-3

A-2 Material properties of the $3 \mathrm{M}$ oxide-based CFCC filter materials.................................... A-4

A-3 Material properties of the Techniweave oxide-based CFCC filter materials ...................A-6

B-1 Natural frequencies of the ceramic candle filter comparing as-received and washed conditions ........................................................................................................ B-6

B-2 Experimental and FEM calculated frequencies........................................................... B-6 


\section{LIST OF FIGURES}

1-1 Siemens Westinghouse Power Corporation Advanced Particulate Filtration system utilized at the Foster Wheeler pressurized circulating fluidized-bed combustion test facility in Karhula, Finland

1-2 Failure of the 3M CVI-SiC composite filter flange............................................................... 6

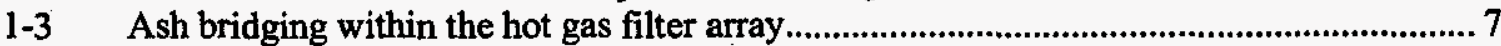

1-4 Crack formations along the flange of the 3M CVI-SiC composite candle filter after 826 hours of PCFBC operation in Test Segment 3.

\section{7}

1-5 Removal of the outer confinement and filtration mat layers in the 626 hour, PCFBCexposed, 3M CVI-SiC composite filter element (Test Segment 3)... 8

1-6 Crack formations around the densified plug insert in the 1166 hour, PCFBC-exposed, Pall 326 filter element (Test Segment 3). 9

1-7 Installation of the advanced monolithic and composite filter elements in the bottom

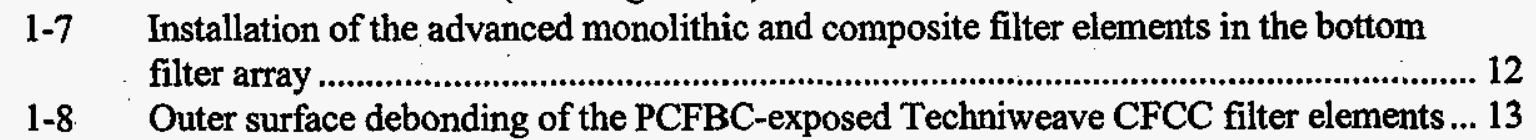

1-9 Outer surface and filtration mat debonding of the PCFBC-exposed oxide-based 3M

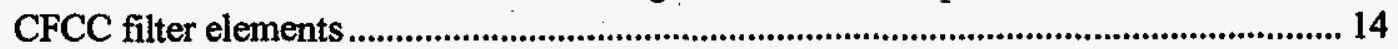

1-10 Flange failure of the PCFBC-exposed DuPont PRD-66 filter element ............................. 15

1-11 Removal of the outer surface membrane layer of the PCFBC-exposed DuPont PRD-66 filter element................................................................................................. 16

1-12 Removal of the outer surface layer of the PCFBC-exposed McDermott CFCC filter

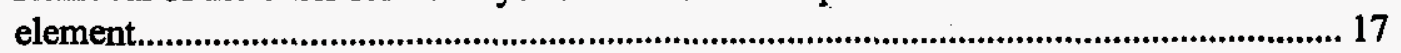

1-13 Separation of the wrapped insert layers along the flange of the PCFBC-exposed McDermott candle filter ........................................................................................................... 17

1-14. Removal of the outer surface fibers along the end cap area of the PCFBC-exposed McDermott candle filters................................................................................................ 18

1-15 Hot gas filter array after completion of PCFBC testing in TS2-97 ................................. 19

2-1 Room temperature gas flow resistance measurements of the as-manufactured and TS3-96 PCFBC-exposed candle filters................................................................................. 22

2-2 Residual strength of the PCFBC-exposed commercially available monolithic filter materials and $3 \mathrm{M} \mathrm{CVI-SiC} \mathrm{composite} \mathrm{filter} \mathrm{matrix} \mathrm{.}$

2-3 Residual strength of the PCFBC-exposed filament wound, continuous fiber ceramic composite, and advanced second generation monolithic filter matrices ............................ 24

2-4 Calculated process temperature strength relationship..................................................... 37

2-5 Creep strain of PCFBC-exposed nonoxide-based candle filters ....................................... 40

2-6 Impact of process operating conditions on clay bonded silicon carbide candle filter elongation

2-7 Microstructure of the 540 hour, PCFBC-exposed, Schumacher Dia Schumalith FT20 filter matrix

2-8 Microstructure of the 1166 hour, PCFBC-exposed, Schumacher Dia Schumalith FT20 filter matrix near the outer surface of the filter element.

2-9 Melt-like appearance of the coating that encapsulated the silicon carbide grains in the 1166 hour, PCFBC-exposed, Schumacher Dia Schumalith FT20 filter matrix near the outer surface of the filter element.

2-10 Microstructure of the 1166 hour, PCFBC-exposed, Schumacher Dia Schumalith FT20 filter matrix near the center of the filter wall. 
2-11 Extensive crystallization that resulted along the coating that encapsulated the silicon carbide grains in the 1166 hour, PCFBC-exposed, Schumacher Dia Schumalith FT20 filter matrix near the center of the filter wall

2-12 Morphology of the mullite-enriched phase that encapsulated the 1166 hour, PCFBCexposed, silicon carbide grains in the Schumacher Dia Schumalith FT20 filter matrix near the center of the filter wall.

2-13 Morphology of the cross-sectioned Schumacher Dia Schumalith FT20 filter matrix after 2201 hours of operation in the PCFBC environment.

2-14 Higher magnification micrograph montage illustrating the affinity of the outer surface membrane to the first structural support grains in the 2201 hour, PCFBC-exposed, Schumacher Dia Schumalith FT20 filter matrix

2-15 Crystallization of the silica-enriched phase that encapsulated the silicon carbide grains in the 2201 hour, PCFBC-exposed, Schumacher Dia Schumalith FT20 filter matrix.

2-16 Higher magnification micrograph montage illustrating the morphology of hexagonal grains within the crystallized silica-enriched outer surface phase that encapsulated the silicon carbide grains in the 2201 hour, PCFBC-exposed, Schumacher Dia Schumalith FT20 filter matrix.

2-17 Higher magnification micrograph montage illustrating the affinity of the hexagonal grains to the underlying silicon carbide grain, as well as potential gas permeation channels

2-18 Micrograph montage illustrating the thickness of the two phase, oxide-enriched encapsulating layer that remained along the outer surface of the silicon carbide grains that were present near the i.d. wall of the 2201 hour, PCFBC-exposed, Schumacher Dia Schumalith FT20 filter matrix

2-19 Micrograph montage illustrating the crystalline, rod-like, aluminosilicate-enriched phase that formed along the outer surface of the binder-containing ligaments in the 2201 hour, PCFBC-exposed, Schumacher Dia Schumalith FT20 filter matrix ................56 56

2-20 Nodular features that resulted at the end of the aluminosilicate-enriched whiskers that formed along the oxide-enriched layer that encapsulated the silicon carbide grains near the i.d. wall of the 2201 hour, PCFBC-exposed, Schumacher Dia Schumalith FT20 filter matrix.

2-21 Micrograph montage illustrating the relatively amorphous feature of the oxide-enriched binder-containing layer that encapsulated the silicon carbide grains, as well as ligament formations in the 2201 hour, PCFBC-exposed Schumacher Dia Schumalith FT20 filter matrix.

2-22 Adherence of fines and pit formations resulted along the outer surface of the binderenriched ligaments in the 2201 hour, PCFBC-exposed, Schumacher Dia Schumalith FT20 filter matrix

2-23 Round depressions resulted along the outer surface of the amorphous, oxide-enriched, encapsulating layer.

2-24 Mottled surface of the silicon carbide grains after removal of the encapsulating oxideenriched layer in the 2201 hour, PCFBC-exposed, Schumacher Dia Schumalith FT20 filter matrix

2-26 Microstructure of the cross-sectioned, 1166 hour, PCFBC-exposed, Pall 326 filter matrix near the outer surface of the filter element

2-27 Extensive crystallization resulted along the coating that encapsulated the silicon carbide grains in the 1166 hour, PCFBC-exposed, Pall 326 filter matrix near the outer surface of the filter wall 
2-28 Higher magnification micrograph montage illustrating the extensive crystallization that resulted along the surface of the binder-enriched oxide coated silicon carbide grains in the 1166 hour, PCFBC-exposed, Pall 326 filter matrix.

2-29 Micrograph illustrating the thickness of the binder-enriched oxide coating that remained along the surface of the silicon carbide grains in the 1166 hour, PCFBCexposed, Pall 326 filter matrix.

2-30 Higher magnification micrograph montage illustrating the melt-like features of the binder-enriched oxide coating that encapsulated the silicon carbide grains near the outer surface of the 1166 hour, PCFBC-exposed, Pall 326 filter element

2-31 Microstructure of the 1166 hour, PCFBC-exposed, Pall 326 filter matrix near the pulse cycled surface of the filter element.

2-32 Morphology of the silica-enriched oxide coating that encapsulated the silicon carbide grains in the 1166 hour, PCFBC-exposed, Pall 326 filter element

2-33 High magnification microgtaph montage illustrating extensive crystallization of the binder-enriched oxide coating that encapsulated the silicon carbide grains along the pulse cycled surface of the 1166 hour, PCFBC-exposed, Pall 326 filter element, and the mottled surface features of the underlying silicon carbide grains.

2-34 Adherence of the outer surface membrane along the 2201 hour, PCFBC-exposed, Pall 326 filter matrix.

2-35 Extensive mottling (oxidation) of the fine silicon carbide grains in the 2201 hour, PCFBC-exposed, Pall 326 outer surface membrane.

2-36 Higher magnification micrograph montage illustrating the extensive mottling that resulted along the binder/oxide-containing shell that encapsulated the silicon carbide grains in the 2201 hour, PCFBC-exposed, Pall 326 filter matrix

2-37 Micrograph illustrating the thickness of the two phase binder/oxide-containing layer that encapsulated the silicon carbide grains in the 2201 hour, PCFBC-exposed, Pall 326 filter matrix.

2-38 High magnification micrograph montage illustrating the extensive crystallization that resulted in the binder/oxide-containing layer that encapsulated the 2201 hour, PCFBC-exposed, silicon carbide grains

2-39 Morphology and adherence of the crystalline binder/oxide-containing layer that encapsulated the silicon carbide grains after 2201 hours of operation in the PCFBC environment...

2-40 Micrograph montage illustrating the remnants of the binder/oxide-containing matrix after removal of the outer encapsulating shell of the 2201 hour, PCFBC-exposed, Pall 326 filter matrix

2-41 Micrograph illustrating the mottled surface characteristics of the binder/oxideenriched encapsulating shell, as well as underlying exposed silicon carbide grain in the 2201 hour, PCFBC-exposed, Pall 326 filter matrix

2-42 Cracks and hole formations were evident along the binder/oxide-containing layer that encapsulated the 2201 hour, PCFBC-exposed, Pall 326 filter matrix

2-43 Micrograph montage illustrating the crystalline features of the binder/oxide-enriched encapsulating layer and ligament, and mottled surface characteristics of the underlying silicon carbide grains in the 2201 hour, PCFBC-exposed, Pall 326 filter matrix

2.44 Microstructure of the 505 hour, PCFBC-exposed, Coors P-100A-1 alumina/mullite filter matrix

2.45 Microstructure of the 1650 hour, PFBC/PCFBC-exposed, Coors P-100A-1

alumina/mullite filter matrix 
2-46 High magnification micrograph montage illustrating the extensive crystallization that resulted throughout the ligaments and along the pore cavity surfaces of the 2276 hour, PFBC/PCFBC-exposed, Coors P-100A-1 alumina/mullite matrix.

2-47 Micrograph montage illustrating the formation of mullite-like rods that resulted along the surface of the pore cavity walls in the PFBC/PCFBC-exposed Coors P-100A-1 alumina/mullite filter matrix.

2-48 High magnification micrograph montage illustrating the formation of a fine grain phase and mullite-like rods that resulted along the pore cavity surfaces of the 1166 hour, PCFBC-exposed, Coors P-100A-1 alumina/mullite filter matrix

2-49. Micrograph illustrating the morphology of the larger grain aluminosilicate phase that resulted along the pore cavity surfaces of the PFBC/PCFBC-exposed Coors P-100A-1 alumina/mullite filter matrix

2-50 Morphology of the crystalline features that typically formed at the tip of the mullite rods which extended into the pore cavities of the PCFBC-exposed Coors P-100A-1 alumina/mullite filter matrix

2-51 Extensive crystallization resulted along the pore cavity surfaces near the o.d. surface of the Coors P-100A-1 alumina/mullite filter wall after 3311 hours of exposure to PFBC/PCFBC operating conditions

2-52 Extensive crystallization resulted throughout the ligaments near the o.d. surface of the Coors P-100A-1 alumina/mullite filter wall after 3311 hours of exposure to PFBC/PCFBC operating conditions

2-53 Extensive crystallization resulted along the pore cavity surfaces near the center of the Coors P-100A-1 alumina/mullite filter wall after 3311 hours of exposure to PFBC/PCFBC operating conditions

2-54 Extensive crystallization resulted throughout the ligaments near the center of the Coors P-100A-1 alumina/mullite filter wall after 3311 hours of exposure to PFBC/PCFBC operating conditions

2-55 Extensive crystallization resulted along the pore cavity surfaces near the i.d. or pulse cycled surface of the Coors P-100A-1 alumina/mullite filter wall after 3311 hours of exposure to PFBC/PCFBC operating conditions

2-56 Extensive crystallization resulted throughout the ligaments near the i.d. or pulse cycled surface of the Coors P-100A-1 alumina/mullite filter wall after 3311 hours of exposure to PFBC/PCFBC operating conditions

2-57 Micrograph montage illustrating the crystalline features that resulted along the surface of the pore cavities near the o.d. surface of the 3311 hour, PFBC/PCFBCexposed, Coors P-100A-1 alumina/mullite filter wall.

2-58 Micrograph montage illustrating clustering and extension of the aluminosilicate rod-like formations across the pore cavities near the center of the 3311 hour, PFBC/PCFBC-exposed, Coors P-100A-1 alumina/mullite filter wall

2-59 Micrograph montage illustrating extensive crystallization that resulted within the ligaments and along the pore cavity walls near the center of the 3311 hour, PFBC/PCFBC-exposed, Coors P-100A-1 alumina/mullite filter wall

2-60 Morphology of the submicron features that formed between the aluminosilicateenriched rods that were present along the pore cavity surfaces in the 3311 hour, PFBC/PCFBC-exposed, Coors P-100A-1 alumina/mullite filter matrix

2-61 Extension of the aluminosilicate rod-like formations across pore cavities within the 3311 hour, PFBC/PCFBC-expōsed, Coors P-100A-1 alumina/mullite filter matrix ..... 102

2-62 Silica-enriched nodular formations resulting at the tip of the aluminosilicateenriched rods that were present along the pore cavity surfaces near the i.d. or pulse 
cycled surface of the 3311 hour, PFBC/PCFBC-exposed, Coors P-100A-1

alumina/mullite filter matrix

2-63 Higher magnification micrographs illustrating the morphology of the angular, nearly round, nodular features that formed at the tip of the aluminosilicate rods that were present along the surface of the i.d or pulse cycled pore cavities in the 3311 hour, PFBCB/PCFBC-exposed, Coors P-100A-1 alumina/mullite filter matrix .

2-64 Morphology of the i.d. or pulse cycled surface pore cavities in the 3311 hour, PFBC/PCFBC-exposed, Coors P-100A-1 alumina/mullite filter matrix

2-65 Micrograph montage illustrating the formation of the angular, nearly round, nodular features that formed along the surface of the pore cavities in the 3311 hour, PFBCB/PCFBC-exposed, Coors P-100A-1 alumina/mullite filter matrix

2-66 Color gradient resulting along the length of the 3M CVI-SiC composite filters after operation in the PCFBC environment

2-67 Oxidation resulting along the outer and inner surfaces of the CVI-SiC encapsulating shell of the filtration mat fibers in the 387 hour, PCFBC-exposed, 3M composite filter matrix.

2-68 Oxidation and pitting resulting along the outer surface of the CVI-SiC shell that encapsulated the Nextel ${ }^{\mathrm{TM}} 312$ filaments in the 387 hour, PCFBC-exposed, $3 \mathrm{M}$ composite filter matrix

2-69 Filament wound structural support matrix in the as-manufactured DuPont PRD-66 filter element.

2-70 Micrograph illustrating the morphology of the cross-sectioned DuPont PRD-66 filter wall

2-71 Higher magnification micrograph montage illustrating the morphology of the fresh fractured filaments in the DuPont PRD-66 filter matrix

2-72 Morphology of the outer surface membrane along the as-manufactured DuPont PRD-66 filter element.

2-73 Higher magnification micrograph montage illustrating the adherence of alumina grains along the cordierite fiber replicas in the thin filament layer that formed the outer surface membrane of the as-manufactured DuPont PRD-66 filter element

2-74 Higher magnification micrographs illustrating the morphology of the slurry matrix grains that were present along the outer surface membrane of the as-manufactured DuPont PRD-66 filter matrix

2-75 Finer slurry alumina-enriched grains coating the outer surface of the fiber replicas in the filament bundles in the as-manufactured DuPont PRD-66 filter matrix

2-76 Sinter bonding of the alumina-enriched, slurry-coated, adjacent filaments in the asmanufactured DuPont PRD-66 filter wall

2-77 Higher magnification micrograph montage illustrating the presence of the aluminaenriched slurry coating along the outer surface of the filament bundles in the asmanufactured DuPont PRD-66 filter matrix.

2-78 Infiltration of the alumina-enriched grains and bonding between fiber replicas along the outer surface of the filament bundles in the as-manufactured DuPont PRD-66 filter matrix

2-79 Micrograph illustrating the formation of discrete fiber replicas in the filament bundles of the as-manufactured DuPont PRD-66 filter matrix

2-80 Micrograph montage illustrating coalescence of the fiber replicas in the filament bundles of the as-manufactured DuPont PRD-66 filter matrix

2-81 Higher magnification micrograph montage illustrating bonding between adjacent fiber replicas in the filament bundles of the as-manufactured DuPont PRD-66 filter matrix. 
2-82 Additional high magnification micrograph montage illustrating bonding between adjacent fiber replicas in the filament bundles of the as-manufactured DuPont PRD-66 filter matrix.

2-83 Crystallization was evident along the outer surface and through the cross-sectioned fiber replicas in the filament bundles of the as-manufactured DuPont PRD-66 filter matrix.

2-84 High magnification micrograph montage illustrating the presence of crystalline calcium aluminosilicate and ash fines along the outer surface membrane fiber replicas and matrix grains in the PCFBC-exposed DuPont PRD-66 filter element ....... 128

2-85 Calcium aluminosilicate and ash fines were retained as agglomerates along the surface of the coarse alumina-enriched grains that were present along the outer surface membrane of the PCFBC-exposed DuPont PRD-66 filter element.

2-86 Micrograph illustrating the crystalline morphology of the deposited calcium aluminosilicate particles.

2-87 Morphology of the ash fines that were retained within the pore cavities along the i.d. or pulse cycled surface of the PCFBC-exposed DuPont PRD-66 filter matrix.

2-88 Micrograph montage illustrating the morphology of the outer surface membrane of the 581 hour, PCFBC-exposed, DuPont PRD-66 filter element

2-89 Micrograph montage illustrating the morphology of the coalesced fiber replicas within the filament bundles in the PCFBC-exposed DuPont PRD-66 filter matrix.

2-90 Additional micrograph montage illustrating the morphology of the coalesced fiber replicas within the filament bundles in the PCFBC-exposed DuPont PRD-66 filter matrix.

2-91 Micrograph montage illustrating the morphology of the outer surface of the asmanufactured McDermott CFCC candle filter.

2-92 Micrograph montage illustrating the morphology of the chopped fiber matrix and exposed filament fiber bundles that were present along the outer surface of the asmanufactured McDermott CFCC candle filter .

2-93 Micrograph montage illustrating the morphology of the mud cracked bonding matrix and chopped fibers that were present along the outer surface of the asmanufactured McDermott CFCC filter element.

2-94 Micrograph montage illustrating the morphology of the chopped fiber matrix that was present along the i.d. surface of the as-manufactured McDermott CFCC filter element.

2-95 Micrograph montage illustrating the morphology of the chopped fibers that were present along the i.d. surface of the as-manufactured McDermott CFCC filter element.

2-96 Cross-sectioned surface of the as-manufactured McDermott CFCC filter wall............. 141

2-97 High magnification micrograph montage illustrating the morphology of the crosssectioned filter fiber bundle within the filter wall of the as-manufactured McDermott CFCC filter element.

2-98 Micrograph illustrating the morphology of the $\sim 10 \mu \mathrm{m}$ diameter alumina-enriched fibers and submicron agglomerated matrix particles that were present in the crosssectioned filament fiber bundle of the as-manufactured McDermott CFCC filter matrix.

2-99 Morphology of the PCFBC-exposed, filament wound, McDermott CFCC candle filter outer surface

2-100 Morphology of the chopped fibers and bonding matrix along the outer surface of the PCFBC-exposed, filament wound, McDermott CFCC candle filter 
2-101 Micrograph montage illustrating the morphology of the crystalline calcium-enriched dendritic formations that resulted along the exposed fiber bundle filaments in the PCFBC-exposed McDermott CFCC candle filter

2-102 Higher magnification micrograph montage illustrating the crystalline nature of the calcium-enriched dendritic formations that resulted within the PCFBC-exposed McDermott CFCC candle filter...

2-103 Micrograph montage illustrating the presence of sorbent and ash fines along the outer surface pore cavities of the PCFBC-exposed McDermott CFCC candle filter.... 149

2-104 Higher magnification micrographs illustrating the morphology of the sorbent and ash fines that were retained along the chopped fiber mat that was present along the outer surface of the PCFBC-exposed McDermott candle filter.

2-105 Filament fiber bundles surrounded by chopped fibers and bonding matrix within the cross-sectioned, PCFBC-exposed, McDermott CFCC filter matrix.

2-106 Higher magnification micrograph montage illustrating the morphology of the crosssectioned filament fiber bundles in the PCFBC-exposed McDermott CFCC candle filter

2-107 Higher magnification micrograph montage illustrating the presence of the slurry bonding matrix media within the filament fiber bundle in the cross-sectioned, PCFBC-exposed, McDermott CFCC candle filter .

2-108 Chopped fibers and bonding matrix which encapsulated the filament fiber bundles in the cross-sectioned, PCFBC-exposed, McDermott CFCC candle filter.

2-109 Morphology of a fractured bonding matrix encapsulating shell that surrounded several chopped fibers in the cross-sectioned, PCFBC-exposed, McDermott CFCC candle filter

2-110 Morphology of the chopped fibers that were present along the i.d. surface of the PCFBC-exposed McDermott candle filter

2-111 Fresh fractured cross-sectioned surface of the as-manufactured monolithic oxidebased Blasch candle filter wall.

2-112 Higher magnification micrographs illustrating the open porosity of the as-manufactured monolithic oxide-based Blasch candle filter matrix near the o.d. surface of the filter element.

2-113 Morphology of the as-manufactured monolithic oxide-based Blasch filter matrix near the center of the fresh fractured filter wall.

2-114 Morphology of the fresh fractured Blasch oxide-based monolithic filter matrix near the i.d. surface of the filter element.

2-115 Morphology of the outer surface of the as-manufactured monolithic oxide-based Blasch filter element

2-116 Morphology of the as-manufactured monolithic oxide-based Blasch filter matrix along the i.d. surface of the filter element

2-117 Flat, plate-like, striated mullite bond posts or ligaments that resulted between adjacent alumina grains within the as-manufactured monolithic oxide-based Blasch filter matrix.

2-118 High magnification micrograph montage illustrating the morphology of the asmanufactured monolithic oxide-based Blasch filter matrix along the o.d. surface of the filter element

2-119 Limited crystallization was evident throughout the ligaments within the asmanufactured monolithic oxide-based Blasch filter matrix

2-120 Limited crystallization was evident along the surface of the mullite-enriched ligaments and alumina grains in the pore cavities of the as-manufactured monolithic oxide-based Blasch filter matrix. 
2-121 Micrograph illustrating the morphology of the cross-sectioned Blasch filter matrix near the o.d. surface of the candle filter

2-122 Higher magnification micrograph montage illustrating the open porosity throughout the PCFBC-exposed Blasch candle filter

2-123 Pulse cycled surface of the PCFBC-exposed Blasch candle filter ................................ 171

2-124 Higher magnification micrograph montage illustrating retention of ash fines along the i.d. or pulse cycled surface of the PCFBC-exposed Blasch oxide-based candle filter

2-125 Micrograph montage illustrating directionality of the ligaments or bond posts within the PCFBC-exposed Blasch filter matrix near the center of the fresh fractured filter wall

2-126 Micrograph montage illustrating directionality of the ligaments or bond posts within the PCFBC-exposed Blasch filter matrix near the i.d. or pulse cycled surface of the filter element.

2-127 Morphology of the o.d. surface of the PCFBC-exposed Blasch filter element

2-128 Extensive crystallization resulted along the o.d. surface grains of the PCFBCexposed Blasch filter element.

2-129 Morphology of the crystalline formations that resulted along the o.d. surface grains of the PCFBC-exposed Blasch filter element.

2-130 High magnification micrograph montage illustrating extensive crystallization that resulted along the surface of the pore cavities near the o.d. surface of the PCFBCexposed Blasch filter matrix.

2-131 Micrograph montage illustrating the extensive crystallization that resulted throughout the PCFBC-exposed Blasch filter matrix

2-132 Higher magnification micrograph montage illustrating the extensive crystallization that resulted along the surface of the bond posts or ligaments in the PCFBC-exposed Blasch filter matrix.

2-133 Micrograph montage illustrating the extensive surface crystallization that resulted within the PCFBC-exposed Blasch filter matrix near the center of the fresh fractured filter wall

2-134 Micrograph montage illustrating the extensive crystallization that resulted along the surface of ligaments and pore cavity walls in the PCFBC-exposed Blasch filter matrix near the i.d. or pulse cycled surface of the filter element

2-135 Crystallization was evident along the outer surface, as well as throughout the fresh fractured mullite-containing ligaments in the PCFBC-exposed Blasch filter matrix..... 183

2-136 Micrograph montage illustrating extensive crystallization throughout the fresh fractured ligaments and pore cavity surfaces in the PCFBC-exposed Blasch filter matrix.

2-137 Micrograph illustrating the morphology of the cross-sectioned as-manufactured Ensto filter matrix.

2-138 Higher magnification micrograph montage illustrating the morphology of the membrane and underlying structural support grains in the as-manufactured Ensto mullite-bonded alumina filter matrix

2-139 Morphology of the outer surface membrane of the as-manufactured Ensto filter element.

2-140 Higher magnification micrograph montage illustrating the morphology of the alumina-enriched grains in the outer surface membrane of the as-manufactured Ensto filter element. 
2-141 Micrograph montage illustrating the submicron nodular features that resulted along the edges of the alumina-enriched grains in the outer surface membrane of the asmanufactured Ensto filter element.

2-142 Striated surface features of the alumina-enriched grains in the outer surface membrane of the as-manufactured Ensto filter element

2-143 Micrographs illustrating the morphology of the as-manufactured porous Ensto filter matrix along the i.d. surface of the candle filter.

2-144 Higher magnification micrograph montage illustrating the needle-like mullite phase formations that encapsulated the alumina-enriched structural support grains

2-145 Higher magnification micrograph montage illustrating the extensive mullite phase formation that resulted along the outer surface of the alumina-enriched grains in the as-manufactured Ensto filter matrix

2-146 Higher magnification micrographs illustrating the morphology of the mullite needle-like formations and precursor phase that formed along the outer surface of the alumina-enriched grains along the i.d. wall of the as-manufactured Ensto filter matrix.

2-147 Micrograph montage illustrating the crystalline mullite needle-like formation that encapsulated the alumina-enriched grains in the fresh fractured as-manufactured Ensto filter matrix.

2-148 Micrograph montage illustrating the morphology of the mullite phase that encapsulated the outer surface of the alumina-enriched grains near the center of the fresh fractured as-manufactured Ensto filter wall

2-149 Micrograph montage illustrating the morphology of the mullite needle-like phase formations that encapsulated the alumina-enriched grains in the structural support wall of the fresh fractured as-manufactured Ensto filter element

2-150 Microstructural changes within the clay bonded silicon carbide candle filters during extended operation in PFBC/PCFBC process gas environments

2-151 Thermal expansion of the porous ceramic filter and ash materials ................................. 200

2-152 PCFBC ash fines collected along the outer surface of the filter elements at the conclusion of TS2-97.

2-153 Micrographs illustrating the morphology of the PCFBC ash fines that remained along the outer surface of the filter elements at the conclusion of TS2-97.

2-154 Additional micrographs illustrating the morphology of the PCFBC ash fines that remained along the outer surface of the filter elements at the conclusion of TS2-97.... 204

2-155 Cross-sectioned wall thickness and strength of the commercially available monolithic and advanced second generation candle filter flanges ....................................................2.205

3-1 Extended filter life test program array.

3-2 Viability of the PCFBC/PFBC-exposed filter elements expressed in equivalent hours achieved to date

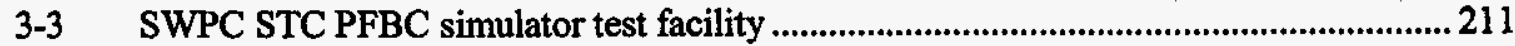

3-4 Thermally worn area along the PCFBC-exposed Pall 326 candle filter .......................... 212

3-5 Temperature profile of the filter array during heat-up from a cold start ......................... 214

3-6 Temperature profile of the filter array during heat-up from a warm restart.................... 214

3-7 Filter array and combustion passage temperature profiles during initiation of testing.. 215

3-8 Fractured PCFBC-exposed Coors P-100A-1 alumina/mullite candle filter .................... 216

3-9 Fractured flange of the DuPont PRD-66 candle filter ....................................................... 216

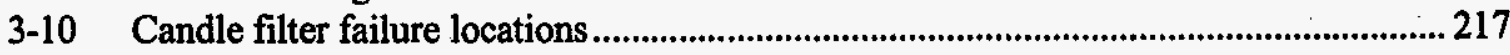

3-11 Debonding of the outer confinement layer and filtration mat, and failure of the flange of the PCFBC-exposed/extended life-tested 3M CVI-SiC composite candle filter. 
3-12 Gas flow resistance of the Coors P-100A-1 alumina/mullite extended life-tested filter elements

3-13 Gas flow resistance measurements of the Pall 326 extended life-tested filter elements

3-14 Gas flow resistance measurements of the Schumacher Dia Schumalith FT20 extended life-tested filter elements.

3-15 Gas flow resistance of the advanced monolithic, filament wound, and composite extended life-tested filter elements.

3-16 Temperature profile throughout the filter array during heating from cold start conditions

3-17 Temperature difference between the outer surface and i.d. bore of the candle during heating of the filter array from cold start conditions..

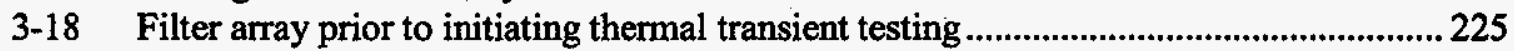

3-19 Temperature profiles generated directly below the flange of the inner row filter elements during conduct of the $200 \mathrm{lb} / \mathrm{hr}$-air thermal transient (Series 1 ).

3-20 Temperature profiles generated directly below the flange of the inner row filter elements during conduct of the $800 \mathrm{lb} / \mathrm{hr}$-air thermal transient (Series 2).

3-21 Temperature profiles generated directly below the flange of the inner row filter elements during conduct of the $1575 \mathrm{lb} / \mathrm{hr}$-air thermal transient (Series 3).

3-22 Temperature profiles generated directly below the flange of the inner row filter elements during conduct of the $1575 \mathrm{lb} / \mathrm{hr}$-air thermal transient (Repeat of Series 3) .. 230

3-23 Temperature profiles generated directly below the flange of the inner row filter elements during conduct of the $1750 \mathrm{lb} / \mathrm{hr}$-air thermal transient (Series 4)................... 231

3-24 Radial and axial temperature profile of the Coors P-100A-1 alumina/mullite filter element during conduct of the $1575 \mathrm{lb} / \mathrm{hr}$-air thermal transient ................................... 232

3-25 Temperature profiles that resulted along the i.d. surface at the base of the flange of the porous ceramic filter elements during pulse cleaning

3-26 Temperature profiles that resulted along the i.d. surface at the base of the flange of the porous ceramic filter elements during the second pulse cleaning cycle.

3-27 Temperature profiles generated directly below the flange of the inner row filter elements during conduct of the $1750 \mathrm{lb} / \mathrm{hr}$-air thermal transient (With and without the o.d. surface dust cake layer)

3-28 Temperature profiles that resulted along the i.d. surface at the base of the flange of the porous ceramic filter elements during delivery of the pulse cleaning cycle after the first minute of thermal transient \#26.

3-29 Temperature profiles that resulted along the i.d. surface at the base of the flange of the porous ceramic filter elements during delivery of the pulse cleaning cycle after the second minute of thermal transient \#27.

3-30 Photographs of the filter array at the conclusion of the thermal transient test program.

3-31 Coors P-100A-1 alumina/mullite candle filter failure

3-32 Longitudinal crack formation along the lower section of the Blasch filter element identified at the conclusion of the thermal transient test program.

3-33 Separation along the flange of the McDermott CFCC filter element at the conclusion of thermal transient testing.

3-34 Removal of the chopped fiber and bonding matrix in localized areas along the outer surface of the McDermott CFCC filter element at the conclusion of the thermal transient test program

3-35 Oxide-based insert bonded to the i.d. surface of the flange of the IF\&P REECER candle filter at the conclusion of the thermal transient test program. 
3-36 Discoloration area along the outer surface of the Schumacher Dia Schumalith FT20 candle filter.

3-37 Longitudinal crack identified along the lower section of the Blasch mullite-bonded

alumina candle filter at the conclusion of the thermal transient test program ................ 256

3-38 Crack formation across the Blasch mullite-bonded alumina filter wall ........................... 256

3-39 Intermittent extension of the externally visible longitudinal crack along the i.d. surface of the Blasch mullite-bonded alumina filter element

3-40 Longitudinal crack formation near the end cap of the Blasch mullite-bonded alumina filter element which propagated through the filter wall thickness

3-41 Longitudinal crack formation near the end cap of the Blasch mullite-bonded alumina filter element which propagated through the filter wall thickness, and extended for $\sim 5 \mathrm{~mm}$ along the i.d. surface of the filter element.

3-42 C-ring section removed from the area of the filter body which contained the longitudinal crack formation. 258

3-43 Fractured filter wall along the hairline crack formation that was $\sim 180^{\circ}$ from the externally visible longitudinal crack

3-44 Sectioned Coors P-100A-1 alumina/mullite filter illustrating the lack of concentricity of the element along the lower section of the candle

3-45 Outer surface of the end cap of the thermal transient-tested McDermott CFCC filter

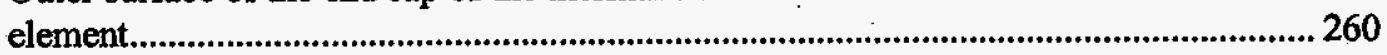

3-46 Internal surface of the end cap of the thermal transient-tested McDermott CFCC

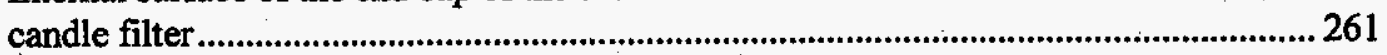

3-47 Plug insert at the tip of the McDermott CFCC filter element ......................................... 261

3-48 Residual o.d. and i.d. tensile strength of the PCFBC-exposed and PCFBCexposed/extended life-tested ceramic filter matrices

3-49 Weibull modulus of the Schumacher Dia Schumalith FT20 filter material as a function of equivalent exposure hours 266

3-50 Weibull modulus of the Pall 326 filter material as a function of equivalent exposure hours

3-51 Weibull modulus of the Coors P-100A-1 alumina/mullite filter material as a function

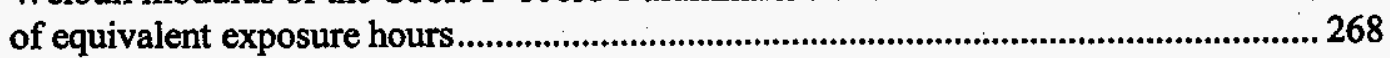

3-52 Weibull modulus of the 3M CVI-SiC filter material as a function of equivalent exposure hours.

3-53 Weibull modulus of the Blasch mullite-bonded alumina filter material as a function of equivalent exposure hours

3-54 Weibull modulus of the McDermott CFCC filter material as a function of equivalent exposure hours................................................................................................................ 271

3-55 Weibull modulus of the DuPont PRD-66 filter material as a function of equivalent exposure hours............................................................................................................. 272

3-56 Young's Modulus as a function of time for the Schumacher Dia Schumalith FT20 filter matrix

3-57 Young's Modulus as a function of time for the Pall 326 filter matrix ........................... 276

3-58 Young's Modulus as a function of time for the Coors P-100A-1 alumina/mullite filter matrix.

3-59 Photographs illustrating the PCFBC-exposed/extended life-tested Schumacher Dia Schumalith FT20 and Pall 326 filter matrices after exposure in static air for a period of $500 \mathrm{hrs}$ at temperatures of $1550^{\circ} \mathrm{F}$ to an applied load of $500 \mathrm{psi}$.

3-60 Micrograph montage illustrating the formation of silica-enriched grains at the base of the binder bond posts or ligaments and the structural support silicon carbide grains 
in the PCFBC-exposed/extended life-tested Schumacher Dia Schumalith FT20 filter matrix

3-61 Higher magnification micrograph montage illustrating the morphology of silicaenriched grains at the base of the binder bond posts or ligaments and the structural support silicon carbide grains in the PCFBC-exposed/extended life-tested Schumacher Dia Schumalith FT20 filter matrix

3-62 High magnification micrograph montage illustrating the morphology of the exposed silicon carbide grain, and associated crystallized binder-containing oxide-enriched encapsulating coating, and fractured bond post or ligament.

3-63 Micrograph montage illustrating the residual oxide-enriched grain formation that remained along the surface of the structural support silicon carbide grains in the fresh fractured, PCFBC-exposed/extended life-tested, Schumacher Dia Schumalith FT20 filter matrix

3-64 Additional micrographs illustrating the residual binder-containing ridges that remained along the surface of the silicon carbide grain after debonding of the binder ligaments or bond posts, as well as crystalline features of the binder-enriched oxidecontaining encapsulating shell.

3-65 Micrograph illustrating the thickness of the crystalline binder-containing/oxideenriched encapsulating layer that remained along the outer surface of the PCFBCexposed/extended life-tested Schumacher Dia Schumalith FT20 filter matrix.

3-66 High magnification micrograph montage illustrating the thickness and morphology of the outer crystallized surface of the binder/oxide-enriched layer that encapsulated the PCFBC-exposed/extended life-tested Schumacher Dia Schumalith FT20 filter matrix, as well as the crystalline binder-containing phase at the grain-ligament interface

3-67 Morphology of the crystallized, binder-containing, oxide-enriched coating that encapsulated the silicon carbide grains in the PCFBC-exposed/extended life-tested Schumacher Dia Schumalith FT20 filter matrix

3-68 High magnification micrograph montage illustrating the various crystalline features that resulted within the binder/oxide-enriched layer that encapsulated the surface of the silicon carbide grains in the PCFBC-exposed/extended life-tested Schumacher Dia Schumalith FT20 filter matrix near the center of the fresh fractured filter wall ..... 291

3-69 Micrograph illustrating the crystalline and amorphous characteristics of the oxideenriched coating that encapsulated the silicon carbide grains in the PCFBCexposed/extended life-tested Schumacher Dia Schumalith FT20 filter matrix near the center of the fresh fractured filter wall.

3-70 Micrograph montage illustrating the extensive crystallization that resulted along the external surface of the silicon carbide grains in the PCFBC-exposed/extended lifetested Schumacher Dia Schumalith FT20 filter matrix along the i.d. or pulse cycled surface of the filter element.

3-71 Higher magnification micrographs illustrating the morphology of the crystallized binder/oxide-containing layer that formed along the outer surface of the silicon carbide grains in the PCFBC-exposed/extended life-tested Schumacher Dia Schumalith FT20 filter matrix along the i.d. or pulse cycled surface of the filter element.

3-72 Micrograph montage illustrating the close association of the amorphous and crystalline features of the binder/oxide-containing encapsulating layer that surrounded the silicon carbide grains along the i.d. or pulse cycled surface of PCFBCexposed/extended life-tested Schumacher Dia Schumalith FT20 filter element 
3-73 Additional micrographs illustrating full crystallization of the PCFBC-exposed/ extended life-tested Schumacher Dia Schumalith FT20 filter matrix along the i.d. or pulse cycled surface of the filter wall.

3-74 Micrograph montage illustrating the extensive crystallization and spherical, angularly-shaped features that formed at the tips of the aluminosilicate rods which resulted along the binder/oxide-containing layer that encapsulated the silicon carbide grains along the i.d. or pulse cycled surface of PCFBC-exposed/extended life-tested Schumacher Dia Schumalith FT20 filter element .

3-75 Micrograph montage illustrating the morphology of the outer crystallized surface of the binder/oxide-enriched layer that encapsulated the PCFBC-exposed/extended lifetested Schumacher Dia Schumalith FT20 filter matrix, as well as the crystalline binder-containing phase at the grain-ligament interface...

3-76 Micrograph montage illustrating the crack formations that resulted along the structural support grains that were located directly below the membrane of the PCFBC-exposed/extended life-tested Schumacher Dia Schumalith FT20 filter matrix

3-77 Higher magnification micrograph illustrating the crack-like formations that resulted along the outer surface of the oxide-enriched coating that encapsulated the structural support silicon carbide grains that were located directly below the membrane of the PCFBC-exposed/extended-life tested Schumacher Dia Schumalith FT20 filter matrix.

3-78 Edge abrasion of the silicon carbide grains along the i.d. or pulse cycled surface of the PCFBC-exposed/extended life-tested Schumacher Dia Schumalith FT20 filter matrix

3-79 Higher magnification micrograph montage illustrating abrasion along the periphery of the silicon carbide grains resulting from extended pulse cycling along the i.d. or pulse cycled surface of the PCFBC-exposed/extended life-tested Schumacher Dia Schumalith FT20 filter matrix

3-80 Higher magnification micrograph montage illustrating the various binder and oxidecontaining layers that remained along the outer surface of the silicon carbide grains that were present along the i.d. surface of the filter element

3.81 Silica-enriched layer that remained along the abraded edges of the silicon carbide grains that were present along the i.d. or pulse cycled surface of the PCFBCexposed/extended life-tested Schumacher Dia Schumalith FT20 filter matrix.

3-82 Higher magnification micrograph illustrating the morphology of the exposed and mottled silicon carbide grains as a result edge abrasion after extended pulse cycling of the Schumacher Dia Schumalith FT20 filter matrix 306

3-83 Negligible penetration of fines resulted within the interior of the PCFBCexposed/extended life-tested Schumacher Dia Schumalith FT20 filter matrix.

3-84 Micrograph montage illustrating the thickness of the melt-like encapsulating layer that surrounded the silicon carbide grains in the outer membrane of the PCFBCexposed/extended life-tested Pall 326 filter element.

3-85 Higher magnification micrographs illustrating the thickness of the melt-like encapsulating layer that surrounded the silicon carbide grains in the outer membrane of the PCFBC-exposed/extended life-tested Pall 326 filter element.

3-86 High magnification micrograph illustrating the morphology of the plate-like hexagonal crystals that formed at the base of the binder ligaments or bond posts within the PCFBC-exposed/extended life-tested Pall 326 filter element.

3-87 Micrograph montage illustrating the melt-like layer that encapsulated the silicon carbide grains in the PCFBC-exposed/extended life-tested Pall 326 filter element 
3-88 Micrograph montage illustrating the plate-like hexagonal crystals, and melt-like features that contained separation cracks along the surface of the silicon carbide grains that were present within the outer surface membrane of the PCFBCexposed/extended life-tested Pall 326 filter element.

3-89 High magnification micrograph montage illustrating the melt-like appearance of the encapsulating layer that surrounded the structural support silicon carbide grains in the PCFBC-exposed/extended life-tested Pall 326 filter element.

3-90 High magnification micrograph montage illustrating the formation of the aluminosilicate rod-like features that formed along the outer surface of the binder/oxideenriched encapsulating layer that surrounded the silicon carbide grains in the PCFBC-exposed/extended life-tested Pall 326 filter matrix

3-91 Micrograph montage illustrating extensive crystallization along the surface of the binder/oxide-containing layer that encapsulated the outer surface of the silicon carbide grains along the mid-section of the PCFBC-exposed/extended life-tested Pall 326 filter matrix.

3-92 Micrograph montage illustrating segregation of the aluminosilicate-enriched and silica-enriched areas along the outer surface of the encapsulating binder/oxidecontaining shell that surrounded the silicon carbide grains that were present along the pulse cycled surface of the PCFBC-exposed/extended life-tested Pall 326 filter matrix.

3-93 High magnification micrograph montage illustrating the crystalline features of the silica-enriched, binder-containing, fractured ligament or bond post that remained along the surface of the silicon carbide grain.

3-94 High magnification micrograph montage illustrating the extensive crystallization that resulted along the surface, as well as throughout the binder ligaments along the pulse cycled surface of the PCFBC-exposed/extended life-tested Pall 326 filter element.

3-95 High magnification micrograph montage illustrating extensive crystallization throughout the binder ligament, as well as crystallization at the interface of the binder ligament and silicon carbide grains that were present along the pulse cycled surface of the PCFBC-exposed/extended life-tested Pall 326 filter matrix

3-96 High magnification micrograph illustrating the crystalline features of the silicaenriched grain formation that resulted at the base of the binder-containing ligaments along the pulse cycled surface of the PCFBC-exposed/extended life-tested Pall 326 filter element.

3-97 High magnification micrograph montage identifying the extensive crystallization that resulted along the binder/oxide coating that encapsulated the silicon carbide grains in the PCFBC-exposed/extended life-tested Pall 326 filter matrix.

3-98 High magnification micrograph montage illustrating extensive crystallization of the binder/oxide-enriched outer encapsulating shell that surrounded the silicon carbide grains in the PCFBC-exposed/extended life-tested Pall 326 filter matrix

3-99 High magnification micrograph montage illustrating the extensive crystallization of the binder/oxide coating and mottled surface of the underlying silicon carbide grains within the PCFBC-exposed/extended life-tested Pall 326 filter matrix

3-100 Micrograph montage illustrating the extensive crystallization that resulted throughout binder/oxide coating that encapsulated the silicon carbide grains in the PCFBCexposed/extended life-tested Pall 326 filter element.

3-101 Micrograph montage illustrating grain growth of an aluminosilicate-enriched phase along the surface of the binder/oxide-containing encapsulating layer within the PCFBC-exposed/extended life-tested Pall 326 filter matrix 
3-102 Micrograph montage illustrating the retention of fines along the first outer surface pore layer of the PCFBC-exposed/extended life-tested Coors P-100A-1 alumina/ mullite filter element

3-103 Higher magnification micrograph montage illustrating the adherence of ash fines, as well as matrix crystallization along the surface of the first pore layer of the PCFBCexposed/extended life-tested Coors P-100A-1 alumina/mullite filter element

3-104 Micrograph montage illustrating extensive crystallization along the surface of the pore cavity walls and throughout the fractured ligaments of the PCFBCexposed/extended life-tested Coors P-100A-1 alumina/mullite filter element

3-105 Higher magnification micrographs illustrating crystallization throughout the fresh fractured ligament, as well as along the pore cavity surface of the PCFBCexposed/extended life-tested Coors P-100A-1 alumina/mullite filter element

3-106 Micrograph montage illustrating extensive crystallization along the pore cavity surface near the mid-section of the fresh fractured, PCFBC-exposed/extended lifetested, Coors P-100A-1 alumina/mullite filter matrix

3-107 High magnification micrograph montage illustrating extensive crystallization along the pore cavity surface near the mid-section of the fresh fractured, PCFBCexposed/extended life-tested, Coors P-100A-1 alumina/mullite filter matrix.

3-108 Additional high magnification micrograph montage illustrating extensive crystallization along the pore cavity surface near the mid-section of the fresh fractured, PCFBC-exposed/extended life-tested, Coors P-100A-1 alumina/mullite filter matrix

3-109 High magnification micrograph montage illustrating the morphology of the mullite, needle-like phase that resulted along the surface of the pore cavity walls near the midsection of the fresh fractured, PCFBC-exposed/extended life-tested, Coors P-100A-1 alumina/mullite filter matrix.

3-110 Micrograph montage illustrating crystallization that resulted along the pore cavity walls of the fresh fractured Coors P-100A-1 alumina/mullite filter matrix near the i.d. surface of the PCFBC-exposed/extended life-tested filter element

3-111 Micrograph illustrating the morphology of the crystallized pore cavity surface near the i.d. surface of the Coors PCFBC-exposed/extended life-tested filter element.

3-112 Micrograph montage illustrating the morphology of the crystalline phase that resulted along the pore cavity surface of the fresh fractured, PCFBC-exposed/ extended life-tested, Coors P-100A-1 alumina/mullite filter matrix near the i.d. surface of the filter element.

3-113 Morphology of the needle-like rod formations and associated coalesced phase that generally resulted along the surface of the pore cavity walls near the pulse cycled surface of the PCFBC-exposed/extended life-tested Coors P-100A-1 alumina/mullite filter matrix

3-114 Morphology of the fresh fractured Nextel ${ }^{\mathrm{TM}} 610$ fibers in the as-manufactured McDermott oxide-based CFCC filter matrix.

3-115 Higher magnification micrograph montage illustrating the morphology of the fresh fractured Nextel ${ }^{\mathrm{TM}} 610$ fibers in the as-manufactured McDermott oxide-based CFCC filter matrix

3-116 Higher magnification micrograph illustrating the presence of negligible crystalline features along the cross-sectioned surface of the Nextel ${ }^{\mathrm{TM}} 610$ fibers in the asmanufactured McDermott oxide-based CFCC filter matrix

3-117 Micrograph montage illustrating the morphology of the cross-sectioned, PCFBCexposed/extended life-tested, McDermott CFCC filter matrix 
3-118 Micrograph montage illustrating the morphology of the fibers within a fractured fiber bundle near the o.d. surface of the cross-sectioned, PCFBC-exposed/extended life- tested, McDermott CFCC filter matrix

3-119 High magnification micrograph montage illustrating the morphology of an array of fibers within a fresh fractured filament bundle near the o.d. surface of the PCFBCexposed/extended life-tested McDermott CFCC filter matrix

3-120 High magnification micrograph montage illustrating the extensive crystallization that resulted throughout the PCFBC-exposed/extended life-tested Nextel'TM 610 fibers in the McDermott CFCC filter element.

3-121 Micrograph montage illustrating the morphology of the fresh fractured fibers within the Nextel ${ }^{\mathrm{TM}} 610$ filaments at approximately the mid-section of the filter wall.

3-122 High magnification micrograph montage illustrating the extensive crystallization that resulted throughout the PCFBC-exposed/extended life-tested Nextel ${ }^{\mathrm{TM}} 610$ fibers within a filament that was located at approximately the mid-section of the filter wall

3-123 High magnification micrograph illustrating the morphology of a crystallized Nextel ${ }^{\mathrm{TM}} 610$ fiber contained within a filament that was located at approximately the mid-section of the PCFBC-exposed/extended life-tested McDermott CFCC filter wall

3-124 Micrograph montage illustrating the morphology of the fresh fractured filament near the i.d. surface of the PCFBC-exposed/extended life-tested McDermott CFCC filter wall

3-125 High magnification micrograph montage illustrating the morphology of a fractured filament fiber bundle that was present along the i.d. surface of the PCFBCexposed/extended life-tested McDermott CFCC filter wall.

3-126 High magnification micrograph montage illustrating the extensive crystallization that resulted throughout the Nextel ${ }^{\mathrm{TM}} 610$ fibers that were present within filament bundles that were located along the i.d. surface of the PCFBC-exposed/extended life-tested McDermott CFCC filter element.

3-127 High magnification micrograph illustrating the adherence of fines along the subsurface chopped Saffil/alumina-enriched mat along the o.d. surface of the PCFBC-exposed/extended life-tested McDermott CFCC filter element

3-128 Higher magnification micrograph illustrating the morphology of the i.d. or pulse cycled surface of the PCFBC-exposed/extended life-tested McDermott CFCC filter element.

3-129 Top photograph identifies the continuous chopped fiber matrix along the i.d. surface of the as-manufactured McDermott CFCC filter wall, while the bottom photograph illustrates removal of the chopped fiber matrix with exposure of the underlying filament fiber bundles after field operation.

3-130 Morphology of the outer surface of the PCFBC-exposed/extended life-tested McDermott oxide-based CFCC filter matrix 355

3-131 Micrograph montage illustrating the morphology of the i.d. or pulse cycled surface of the PCFBC-exposed/extended life-tested McDermott CFCC filter element 356

3-132 Morphology of the outer surface of the PCFBC-exposed/extended life-tested Blasch mullite-bonded alumina filter matrix.

3-133 Higher magnification micrograph illustrating the morphology of the outer surface of the PCFBC-exposed/extended life-tested Blasch mullite-bonded alumina filter matrix.

3-134 Morphology of the cross-sectioned, PCFBC-exposed/extended life-tested, Blasch filter matrix near the outer surface of the filter element 
3-135 Micrograph montage illustrating the morphology of the PCFBC-exposed/extended life-tested Blasch filter matrix at $\sim 500-600 \mu \mathrm{m}$ below the outer surface of the filter element.

3-136 Micrograph montage illustrating the crystalline surface morphology of the nearly rounded grains that were present at $\sim 500-600 \mu \mathrm{m}$ below the surface of the PCFBCexposed/extended life-tested Blasch filter matrix

3-137 Micrograph montage illustrating the morphology of the striated ligament formations that were present within the PCFBC-exposed/extended life-tested Blasch filter matrix near the center of the filter wall

3-138 Micrograph montage illustrating the morphology of the striated features that were present within the cross-sectioned, PCFBC-exposed/extended life-tested, Blasch filter matrix near the inner or pulse cycled surface of the filter element

3-139 Micrograph montage illustrating the morphology and open porosity of the PCFBCexposed/extended life-tested Blasch filter matrix near the outer surface of the filter element.

3-140 Micrograph montage illustrating the morphology of the crystallized surface of the pore cavity walls that resulted within the PCFBC-exposed/extended life-tested Blasch filter matrix near the outer surface of the filter element.

3-141 Higher magnification micrographs illustrating the morphology of the crystals that were formed along the outer surface of the grains which were present near the outer surface of the PCFBC-exposed/extended life-tested Blasch filter element

3-142 Micrograph montage illustrating extensive crystallization that resulted along the outer surface of the pore cavity walls in the PCFBC-exposed/extended life-tested Blasch filter matrix near the outer surface of the filter element.

3-143 Micrograph montage illustrating extensive crystallization that resulted along the surface of the pore cavity walls within the PCFBC-exposed/extended life-tested Blasch filter matrix at $\sim 200 \mu \mathrm{m}$ below the outer surface of the filter element

3-144 Higher magnification micrographs illustrating the morphology of the crystalline features that formed along the surface of the nearly rounded grains that were present at $\sim 500-600 \mu \mathrm{m}$ below the surface of the PCFBC-exposed/extended lifetested Blasch filter matrix.

3-145 High magnification micrograph montage illustrating the morphology of the crystalline features that resulted along the surface of the striated ligaments that were present near the center of the PCFBC-exposed/extended life-tested Blasch filter wall

3-146 Micrograph montage illustrating the limited crystallization that resulted along the surface of the striated ligaments that were present near the inner or pulse cycled surface of the PCFBC-exposed/extended life-tested Blasch filter element

3-147 Micrograph montage illustrating the morphology of the mullite-like rods that had formed along the surface of the alumina-enriched grains which were present near the inner or pulse cycled surface of the PCFBC-exposed/extended life-tested Blasch filter element.

4-1 Microstructural changes within the clay bonded silicon carbide filter materials during extended operation in the PFBC/PCFBC environment......................................... 376

5-1 Temperature profiles resulting along the i.d. surface near the base of the flange of the filter elements during pulse cleaning of a mixed filter array

5-2 Separation of the Coors P-100A-1 alumina/mullite filter matrix along the i.d. wall after extended exposure to pulse cycling.

5-3 Filter temperature profiles along the Coors P-100A-1 alumina/mullite candle during thermal transient testing 
A-1 Room temperature gas flow permeability of the TS2-97 PCFBC-exposed 3M oxidebased Nextel ${ }^{\mathrm{TM}}$ 550/610 candle filter.

A-2 Room temperature gas flow permeability of various as-manufactured, qualified, or PCFBC-exposed 3M oxide-based candle filters

A-3 Room temperature gas flow permeability of various as-manufactured and PCFBCexposed Techniweave oxide-based candle filters.

B-1 Mode shapes of ceramic candle filters tested ............................................................ B-7 


\section{LIST OF ACRONYMS}

\begin{tabular}{|c|c|}
\hline AEP & American Electric Power \\
\hline APF & Advanced Particulate Filtration \\
\hline Btu & British Thermal Unit \\
\hline CFCC & Continuous fiber ceramic composite \\
\hline CVI & Chemical vapor infiltration \\
\hline EDAX & Energy dispersive $\mathrm{x}$-ray analysis \\
\hline FRF & Frequency Response Function \\
\hline i.d. & Inner diameter \\
\hline IGCC & Integrated gasification combined cycle \\
\hline IF\&P & Industrial Filter \& Pump \\
\hline NA & Not available \\
\hline ND & Not determined \\
\hline NDE & Non Destructive Evaluation \\
\hline NETL & National Energy Technology Laboratory \\
\hline o.d. & Outer diameter \\
\hline ORNL & Oak Ridge National Laboratory \\
\hline PCD & Particle Collection Device \\
\hline PCFBC & Pressurized circulating fluidized-bed combustion \\
\hline PFBC & Pressurized fluidized-bed combustion \\
\hline QA/QC & Quality assurance/Quality control \\
\hline REECER & Recrystallized silicon carbide \\
\hline SCS & Southern Company Services \\
\hline SEM & Scanning electron microscopy \\
\hline $\mathrm{SiC}$ & Silicon carbide \\
\hline SPPC & Sierra Pacific Power Company \\
\hline SRI & Southern Research Institute \\
\hline SWPC & Siemens Westinghouse Power Corporation \\
\hline STC & Science and Technology Center \\
\hline TBD & To be determined \\
\hline TS1 & Test Segment 1 \\
\hline TS2 & Test Segment 2 \\
\hline TS3 & Test Segment 3 \\
\hline WVU & West Virginia University \\
\hline $2-\mathrm{D}$ & Two dimensional \\
\hline 3-D & Three dimensional \\
\hline
\end{tabular}




\section{INTRODUCTION}

Siemens Westinghouse Power Corporation (SWPC) has been involved in the hot gas filter materials technology development since 1988. Emphasis was initially focused on the development and use of oxide- and nonoxide-based monolithic filter materials in bench-scale test programs and field applications (Table 1-1). With thermal fatigue issues being encountered by the oxide-based monoliths, and oxidation and/or high temperature creep issues resulting in the nonoxide-based filter matrices during pressurized fluidized-bed combustion (PFBC) and/or pressurized circulating fluidized-bed combustion (PCFBC) operation (Table 1-2), development of fracture toughened, continuous fiber reinforced ceramic composites (CFCC) filters was undertaken in 1994. Several issues were identified with respect to the long-term durability, response, and performance of the CFCC filter elements during extended service life. These included manufacturing and structural integrity, load bearing capability, and ease of fixturing within the filter system.

\section{TABLE 1-1. HOT GAS FILTER MATERIALS}

\begin{tabular}{|c|c|c|}
\hline Monoliths & Fiber Reinforced Composites & $\begin{array}{c}\text { Metal/ } \\
\text { Intermetallics }\end{array}$ \\
\hline $\begin{array}{l}\text { Coors P-100A-1 Alumina/ Mullite } \\
\text { Pall Clay Bonded Silicon Carbide } \\
\text { (442T, 326, 181) } \\
\text { Schumacher Clay Bonded Silicon } \\
\text { Carbide (F40, FT20) } \\
\text { GTE Cordierite and } \\
\text { Cordierite-Silicon Nitride } \\
\text { AiResearch Reaction Bonded and/or } \\
\text { Sintered Silicon Nitride } \\
\text { Ensto Alumina } \\
\text { Blasch Mullite-Bonded Alumina } \\
\text { Specific Surface Cordierite } \\
\text { IF\&P Recrystallized SiC }\end{array}$ & $\begin{array}{l}\text { McDermott Oxide-Based CFCC } \\
\text { Techniweave Oxide-Based CFCC } \\
\text { 3M CVI-SiC } \\
\text { DuPont SiC-SiC } \\
\text { Textron Nonoxide-Based CFCC } \\
\text { Americom Oxide-Based CFCC } \\
\text { 3M Oxide-Based CFCC } \\
\text { Filament Wound } \\
\text { DuPont PRD-66 }\end{array}$ & $\begin{array}{l}\text { Iron Aluminide } \\
\text { New Initiatives }\end{array}$ \\
\hline Vacuum Infiltrated Chopped Fibers [ & \multicolumn{2}{|c|}{ Technology Development and Commercialization Goals } \\
\hline 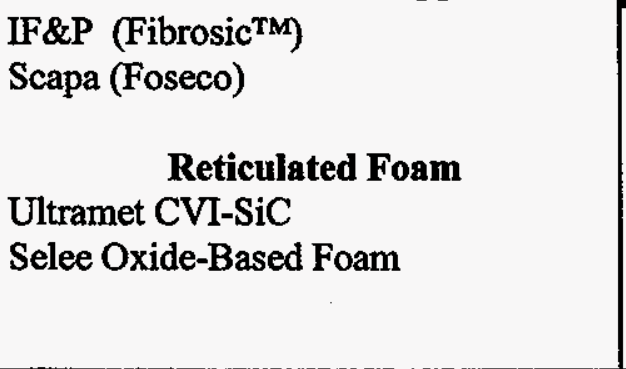 & \multicolumn{2}{|c|}{$\begin{array}{c}\text { System Retrofit Capabilities } \\
\text { Achievement of Design and Material Specifications } \\
\text { Achievement of Performance Specifications } \\
\text { Matrix and Component Operational Stability } \\
\text { QA/QC Manufacturing Capabilities } \\
\text { Commercial Production Capabilities } \\
\text { Initial and Life Cycle Cost Effectiveness } \\
3 \text { Years Warranted Life }\end{array}$} \\
\hline
\end{tabular}

Numerous advancements continued to be made since initiating development and manufacture of the monolithic and composite ceramic filters in 1988 and 1994, respectively. These have included: 
- Development and use of high temperature, creep resistant binders in the clay bonded silicon carbide filter materials.

- Efforts by numerous domestic and foreign suppliers to bring to the market potentially viable filter materials and/or filter elements manufactured by alternate processes and production techniques.

- Development of alternate filter concepts (i.e., sheet filter, inverted candle filter, etc.).

- Development of oxidation resistance coatings for nonoxide matrices.

- Incorporation of a membrane along the o.d./i.d. surfaces of the filter elements.

- Enhanced flange strength and surface abrasion resistance.

\section{TABLE 1-2. POROUS FILTER TECHNOLOGY DEVELOPMENT ISSUES}

\begin{tabular}{|c|c|c|}
\hline \multicolumn{2}{|c|}{ Porous Ceramics } & \multirow{2}{*}{$\begin{array}{c}\text { Metals/ } \\
\text { Intermetallics }\end{array}$} \\
\hline Monoliths & CFCC/Filament Wound & \\
\hline \multicolumn{3}{|l|}{ Advantages } \\
\hline $\begin{array}{l}\text { Ease of Fabrication } \\
\text { Low Cost } \\
\text { Chemical Stability of Oxide- } \\
\text { Based Materials in PFBC/ } \\
\text { PCFBC Applications }\end{array}$ & $\begin{array}{l}\text { Expected Improved Fracture } \\
\text { Toughness } \\
\text { Light Weight } \\
\text { Chemical Stability of Oxide- } \\
\text { Based Materials in PFBC/ } \\
\text { PCFBC Applications }\end{array}$ & $\begin{array}{l}\text { Ductility } \\
\text { Ease of Manufacturing Various } \\
\text { Shapes }\end{array}$ \\
\hline \multicolumn{3}{|c|}{ Development Needs To Be Addressed } \\
\hline $\begin{array}{l}\text { Thermal Fatigue/Shock of } \\
\text { Oxide-Based Materials } \\
\text { Thermal Shock of Nonoxides } \\
\text { during Auto-Ignition Events } \\
\text { Oxidation of Nonoxide-Based } \\
\text { Materials } \\
\text { Potential High Temperature } \\
\text { Creep of Exposed Nonoxides } \\
\text { Alkali Silicate Eutectic } \\
\text { Formation during Exposure of } \\
\text { Nonoxides to Na/K Species } \\
\text { Development of Advanced } \\
\text { Materials/Architecture }\end{array}$ & $\begin{array}{l}\text { Higher Cost (CFCC) } \\
\text { Potential Oxide Fiber } \\
\text { Embrittlement with Time } \\
\text { Low Load Bearing Capability } \\
\text { Low Flange Strength } \\
\text { Outer Surface Abrasion } \\
\text { Oxidation/Embrittlement of } \\
\text { Nonoxides (No Longer } \\
\text { Considered for PFBC/PCFBC } \\
\text { Applications) }\end{array}$ & $\begin{array}{l}\text { Corrosion (TBD) } \\
\text { Oxidation/Accelerated Oxidation } \\
\text { (TBD) } \\
\text { Impact of Gas Phase Sulfur Species, } \\
\text { Steam, Chlorides, Alkalis (TBD) } \\
\text { Metal Blinding (TBD) } \\
\text { Mechanical Properties (TBD) } \\
\text { Cost (TBD) }\end{array}$ \\
\hline
\end{tabular}

TBD: To Be Determined.

\subsection{Field Testing - Overview}

Emphasis at SWPC since 1990 has been focused on the design and operation of Advanced Particulate Filtration (APF) systems. At the American Electric Power (AEP) Tidd Demonstration Plant in Brilliant, Ohio, Westinghouse's APF housed 384 commercially available, $1.5 \mathrm{~m}$ porous ceramic candle filters which were subjected to PFBC conditions. ${ }^{(1)}$ Similarly, 128 commercially available, $1.5 \mathrm{~m}$ candles 
were installed and operated in Westinghouse's APF at the Foster Wheeler PCFBC pilot-scale test facility in Karhula, Finland. The total operating service life of surveillance filters which were installed at these facilities is shown in Table 1-3. In 1997, the opportunity to continue testing commercially available monolithic elements, and introduce the utilization of alternate monolithic and advanced CFCC candles occurred at Karhula. Similar testing is currently on-going in the SWPC Particle Collection Device (PCD) at the Southern Company Services (SCS) test facility in Wilsonville, Alabama.

Achieving three years of operational filter element life is the primary goal of the SWPC hot gas filter material development and component qualification programs. Efforts to demonstrate operation of the plant and filter life are currently the focus of the SWPC APF system at the Sierra Pacific Power Company (SPPC), Piñon Pine, Tracey No. 4 Station in Reno, Nevada, which houses 748 candle filters. Commissioning of the SPPC integrated gasification combined cycle (IGCC) Demonstration Plant was initiated in 1997. In addition, SWPC is currently involved in the Clean Coal Program where $\sim 2500$ candle filters are targeted to be operated in PFBC and carbonizer process gas environments (i.e., McIntosh Unit 4 Demonstration Plant in Lakeland, Florida).

TABLE 1-3. FIELD AND EXTENDED LIFE TESTING

\begin{tabular}{|c|c|c|c|}
\hline \multirow[b]{2}{*}{ Filter Supplier \& Matrix } & \multicolumn{2}{|c|}{$\begin{array}{c}\text { Maximum Operating } \\
\text { Time, Hrs }\end{array}$} & \multirow{2}{*}{$\begin{array}{c}\text { Equivalent Exposure } \\
\text { Time, Hrs } \\
\text { Field \& Accelerated } \\
\text { Testing }\end{array}$} \\
\hline & $\begin{aligned} & \text { PFBC } \\
&-\mathbf{A E P} \\
&\end{aligned}$ & $\begin{array}{c}\text { PCFBC } \\
- \text { FW Karhula - }\end{array}$ & \\
\hline $\begin{array}{l}\text { Schumacher F40 } \\
\text { Schumacher FT20 } \\
\text { Pall Vitropore 442T } \\
\text { Pall 326 } \\
\text { CoorsP-100A-1 Alumina/ } \\
\text { Mullite } \\
\text { 3M CVI-SiC } \\
\text { DuPont PRD-66 } \\
\text { 3M Oxide CFCC } \\
\text { McDermott Oxide CFCC } \\
\text { Techniweave Oxide CFCC } \\
\text { Blasch Mullite-Bonded } \\
\text { Alumina } \\
\text { Ensto } \\
\text { IF\&P REECER } \\
\text { Other }\end{array}$ & $\begin{array}{l}5,855 \\
1,705 \\
1,705 \\
\\
2,815\end{array}$ & $\begin{array}{c}227(1) \\
2,201(2) \\
1,341(1) \\
2,201(2) \\
716(1) \\
2,201(2) \\
3,311(3) \\
627(4) \\
581(5) \\
581(5) \\
581(5) \\
581(5) \\
342(5)\end{array}$ & $\begin{array}{c}11,080 ; 11,080 \\
9,662 ; 11,080 \\
8,485 ; 12,211 \\
13,356 \\
7,517(6) \\
10,626 \\
10,626 \\
5,611 . \\
5,030(6)\end{array}$ \\
\hline
\end{tabular}

(1) 1992-1994 Test Campaign.

(2) 1995-1997 Test Campaign.

(3) 2,201 Hrs of operation under PCFBC conditions and 1,110 Hrs of operation under PFBC conditions.

(4) 1995-1996 Test Campaign.

(5) 1997 Test Campaign.

(6) New element without field exposure. 


\subsection{Foster Wheeler PCFBC Test Campaigns}

Hot gas filtration testing was initiated in the Westinghouse Advanced Particulate Filtration (WAPF) system (Figure 1-1) in November 1995 at the Foster Wheeler PCFBC test facility in Karhula, Finland. Three test campaigns were conducted utilizing $1.5 \mathrm{~m}$, high temperature, creep resistant, clay bonded silicon carbide Schumacher Dia Schumalith FT20 and Pall 326 candle filters in the top and middle arrays, respectively, and a mixture of the $1.5 \mathrm{~m}$ Coors P-100A-1 alumina/mullite and $1.5 \mathrm{~m} 3 \mathrm{M}$ CVI-SiC composite filter elements in the bottom array (Table 1-4). In addition, five Coors P-100A-1 alumina/mullite candle filters which had been operated for a period of 1110 hours in the W-APF system at the AEP PFBC Tidd Demonstration Plant in Brilliant, Ohio, were installed in the bottom array. A total of 1166 hours of hot gas filtration testing was achieved during the 1995-1996 test program in Karhula, Finland.

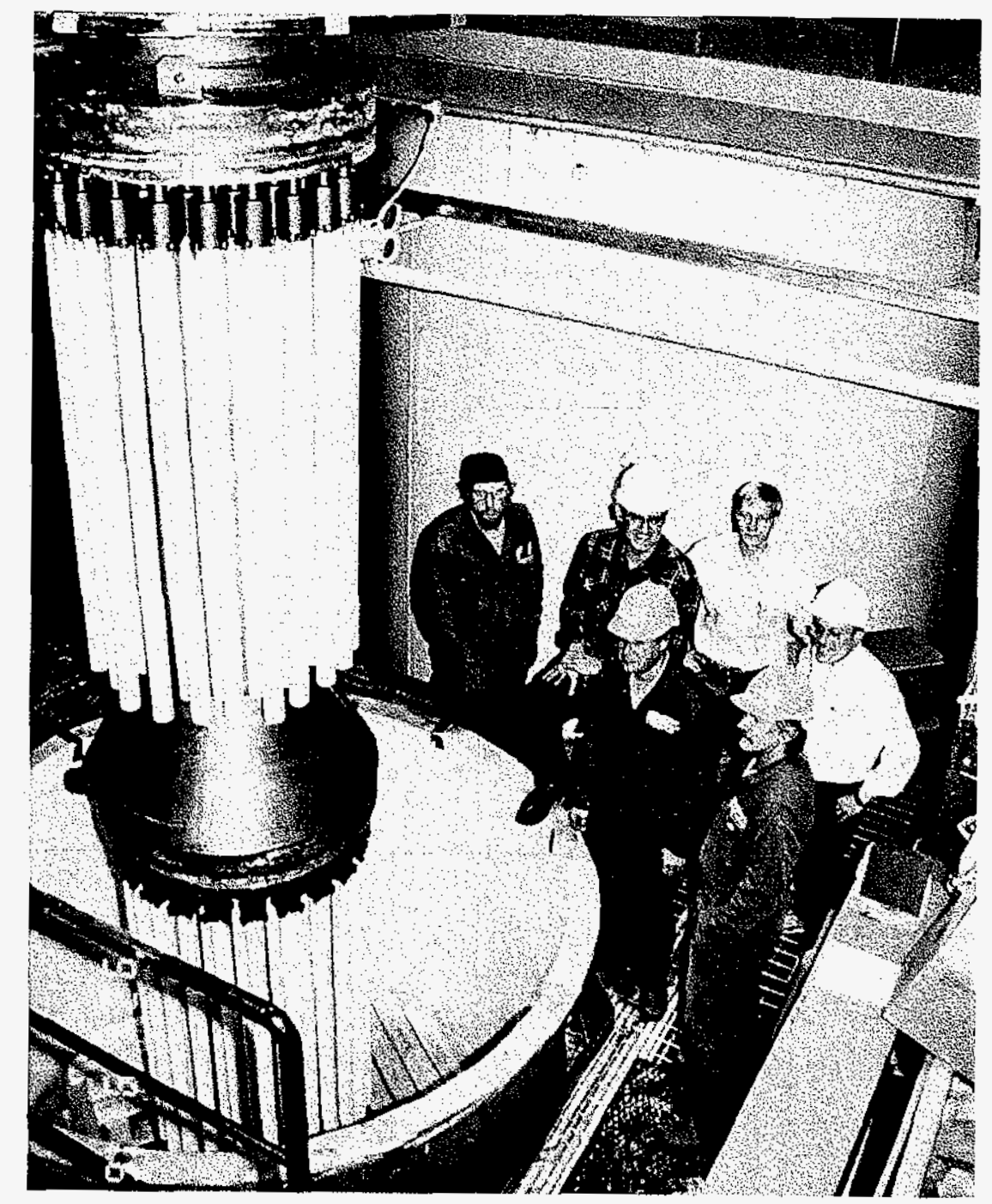

Figure 1-1 - Siemens Westinghouse Power Corporation Advanced Particulate Filtration system utilized at the Foster Wheeler pressurized circulating fluidized-bed combustion test facility in Karhula, Finland. 


\section{TABLE 1-4. SUMMARY OF PCFBC TESTING IN 1995-1996}

\begin{tabular}{|c|c|c|c|}
\hline Test Segment & $\begin{array}{c}1 \\
(11 / 1995-12 / 1995)\end{array}$ & $\begin{array}{c}2 \\
(2 / 1996-4 / 1996)\end{array}$ & $\begin{array}{c}3 \\
(8 / 1996-10 / 1996)\end{array}$ \\
\hline Coal & Illinois No. 6 (Sparta) & Illinois No. 6 (Sparta) & Illinois No. 6 (Sparta) \\
\hline Sorbent & Linwood Limestone & Linwood Limestone & $\begin{array}{c}\text { Linwood Limestone } \\
\text { Iowa Industrial Limestone } \\
\text { Resized Linwood } \\
\text { Limestone }\end{array}$ \\
\hline Number of Candles & 112 & 112 & 128 \\
\hline Schumacher FT20 & $32-35$ & 35 & 46 \\
\hline Pall 326 & $32-35$ & 35 & 45 \\
\hline Coors Alumina/Mullite & $24(5)-42(5)^{(2)}$ & $33(5)^{(a)}$ & $32(4)^{(a)}$ \\
\hline 3M CVI-SiC Composite & $24-0$ & 9 & 5 \\
\hline Operating Hours (Coal) & $153^{(0)}$ & 387 & 626 \\
\hline Operating Temperature, ${ }^{\circ} \mathrm{C}$ & $826-853$ & $818-860$ & $838-860$ \\
\hline Operating Pressure, bar & $10.7-11.1$ & $10.6-11.3$ & $10.5-10.7$ \\
\hline Nominal Face Velocity, $\mathrm{cm} / \mathrm{s}$ & $3.5-4.1$ & $3.1-4.2$ & $3.0-3.4$ \\
\hline Inlet Dust Loading, ppmw & $12,000-13,500$ & $12,000-15,500$ & $11,000-12,500$ \\
\hline $\mathrm{d}_{50}, \mu \mathrm{m}$ (Malvern) & NA & NA & $23(20-26)$ \\
\hline
\end{tabular}

(a) Number of installed PFBC-exposed Coors filter elements (AEP Test Segment 5) shown in parentheses.

(b) Thirty-five hours of initial operation prior to removal of the 3M CVI-SiC composite filters, followed by 118 hours of continuous operation.

NA: Not available.

During Test Segment 1 (TS1-95), the W-APF was filled with 112 filter elements, and was operated for a period of 153 hours at temperatures of $826-853^{\circ} \mathrm{C}$. Illinois No. 6 coal and Linwood limestone were utilized as the feed and sorbent materials. After an initial 22 hours of commissioning, the pressure vessel was slow cooled as a result of plant maintenance, and the three filter arrays were inspected. The $3 \mathrm{M}$ CVI-SiC composite candles which were observed to be somewhat loose within the metal filter holders were remounted and tightened to assure adequate sealing. Testing was reinitiated for a period of $\mathbf{3 5}$ hours, prior to a second maintenance outage. Inspection of the filter arrays indicated that failure along the flange of several $3 \mathrm{M}$ CVI-SiC composite filters resulted due to the tight clamping and fixturing of the elements within the metal holders (Figure 1-2). All of the $3 \mathrm{M}$ CVI-SiC composite filters which had initially been installed within the W-APF were removed in order to eliminate the risk of potential catastrophic failure of the elements during extended PCFBC operation. Testing was reinitiated and continued for an additional 118 hours. After slow cooling of the array in December 1995, post-test inspection of the cluster was conducted which indicated that all filter elements remained intact.

Nine newly manufactured 3M CVI-SiC composite filters were installed in the bottom array, and testing in Test Segment 2 (TS2-96) which was initiated in February 1996 continued for a period of 387 hours prior to shutdown in April 1996. Once again the 112 candle filter cluster assembly was operated at temperatures of $818-860^{\circ} \mathrm{C}$, removing fines generated during the combustion of Illinois No. 6 coal and Linwood limestone. Post-test inspection of the W-APF in April 1996 in'dicated that failure of five Coors P-100A-1 alumina/mullite candle filters, four $3 \mathrm{M} \mathrm{CVI-SiC} \mathrm{composite} \mathrm{filter} \mathrm{elements,} \mathrm{and} \mathrm{one}$ 

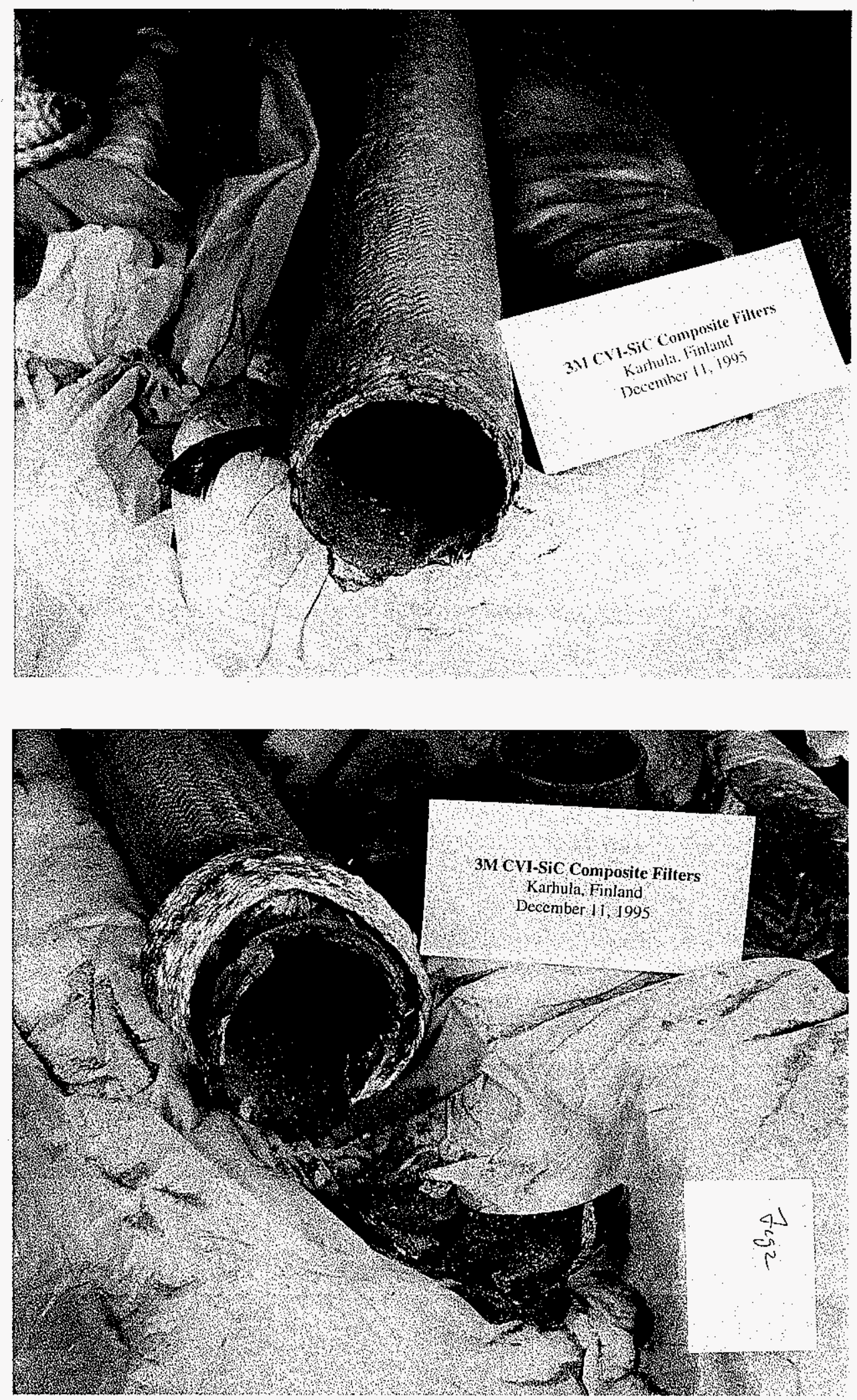

Figure 1-2 - Failure of the 3M CVI-SiC composite filter flange. 
Schumacher Dia Schumalith FT20 filter had occurred during process shutdown primarily as a result of ash bridging between the candles, metal holders, and plenum pipes (Figure 1-3). ${ }^{1}$

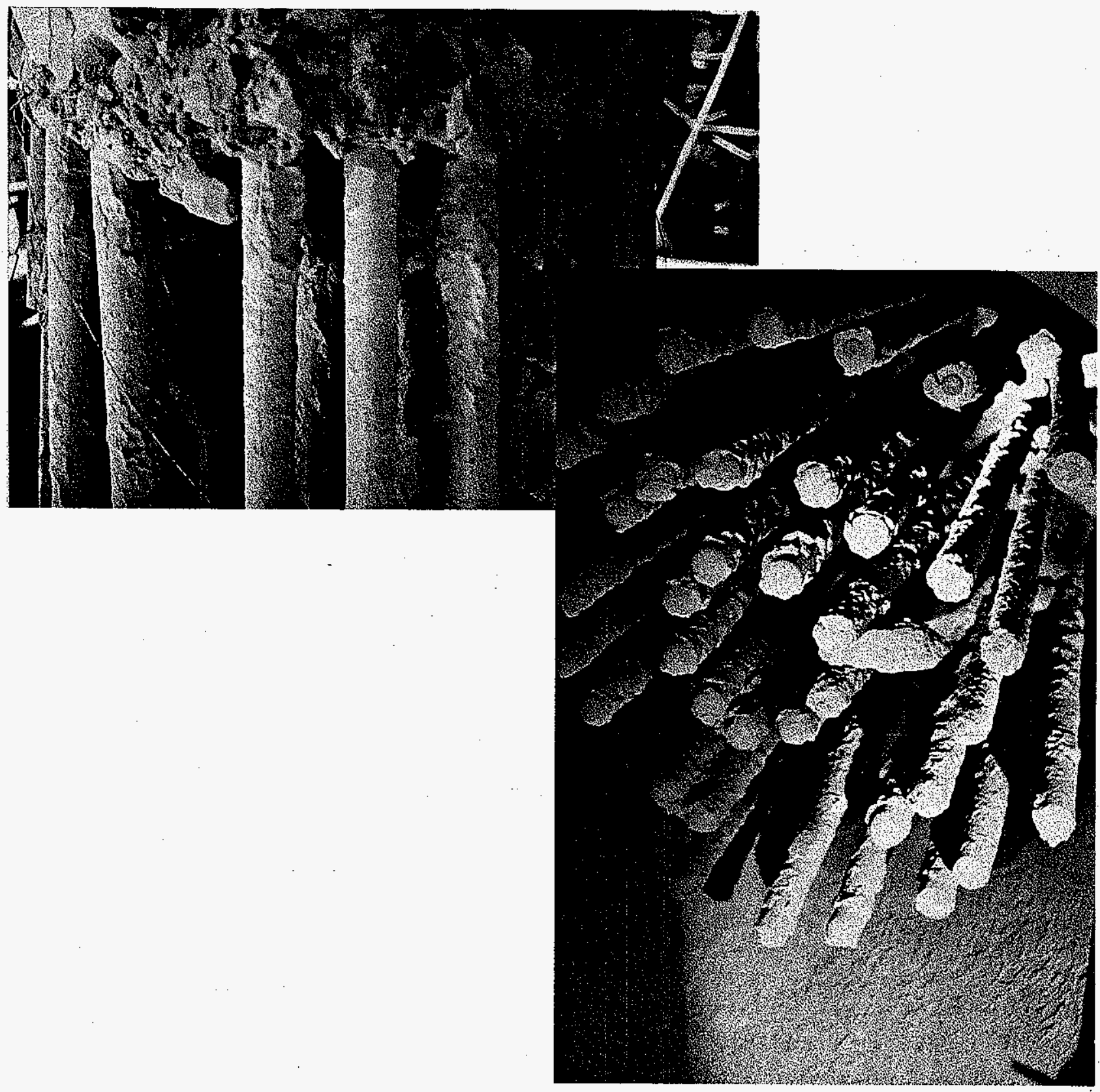

Figure 1-3 - Ash bridging within the hot gas filter array.

\footnotetext{
${ }^{1}$ The fractured surface of the filter elements was ash-free implying that failure of the elements occurred during plant shutdown as opposed to during plant operation.
} 
All filter elements were removed from the W-APF at the conclusion of TS2-96. The cluster was recandled with previously used and newly manufactured filter elements, and testing was reinitiated in August 1996. As in the first two test segments, the high temperature creep resistant clay bonded silicon carbide Schumacher Dia Schumalith FT20 filter elements were positioned within the top array, comparable Pall 326 filters filled the middle array, and a mixture of Coors P-100A-1 alumina/mullite and $3 \mathrm{M}$ CVI-SiC composite elements filled the bottom array. The 128 candle filter cluster assembly was subjected to 626 hours of PCFBC operation, at temperatures of $838-860^{\circ} \mathrm{C}$ during Test Segment 3 (TS396). In this test campaign both Iowa Industrial limestone and resized Linwood limestone were utilized as sorbents in conjunction with Illinois No. 6 coal. Post-test inspection of the array in October 1996 indicated that limited bridging was evident within the various arrays. All elements remained intact and were subsequently removed from the cluster assembly. Post-test inspection of the candle filters at the conclusion of TS3-96 indicated the fragile nature of the $3 \mathrm{M}$ candle filters. Inspection of the clay bonded silicon carbide filter elements indicated that after 1166 hours of PCFBC operation, the $1.5 \mathrm{~m}$ candles elongated by $6-9 \mathrm{~mm}$.

As shown in Figure 1-4, the flange of one of the five 3M CVI-SiC composite filters had cracked, presumably as a result of ash fines becoming wedged in between the holder and the outer surface of the flange wall. Neither penetration of fines into the clean gas stream nor catastrophic failure of the element occurred. Similarly $\sim 5-10 \mathrm{~mm}$ sections of the outer confinement layer were seen to have been removed along several of the 3M filter elements at the conclusion of TS3-96 (Figure 1-5). This most likely occurred during in-situ cleaning of the array during interim inspection and maintenance intervals.

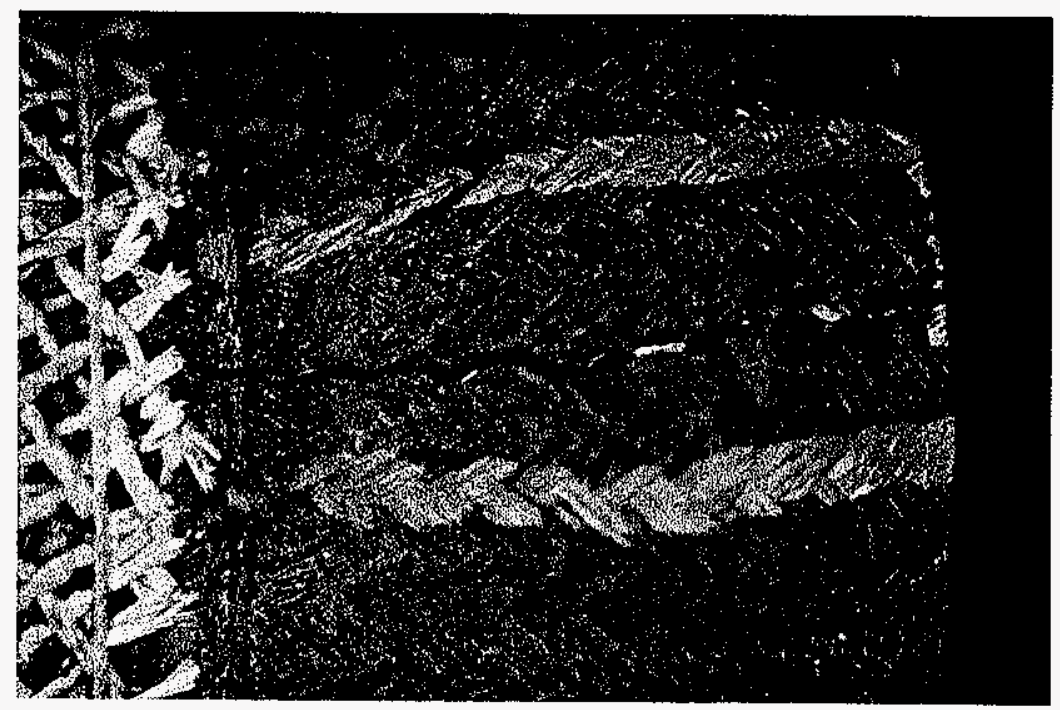

Figure 1-4 - Crack formations along the flange of the 3M CVI-SiC composite candle filter after 826 hours of PCFBC operation in Test Segment 3. 

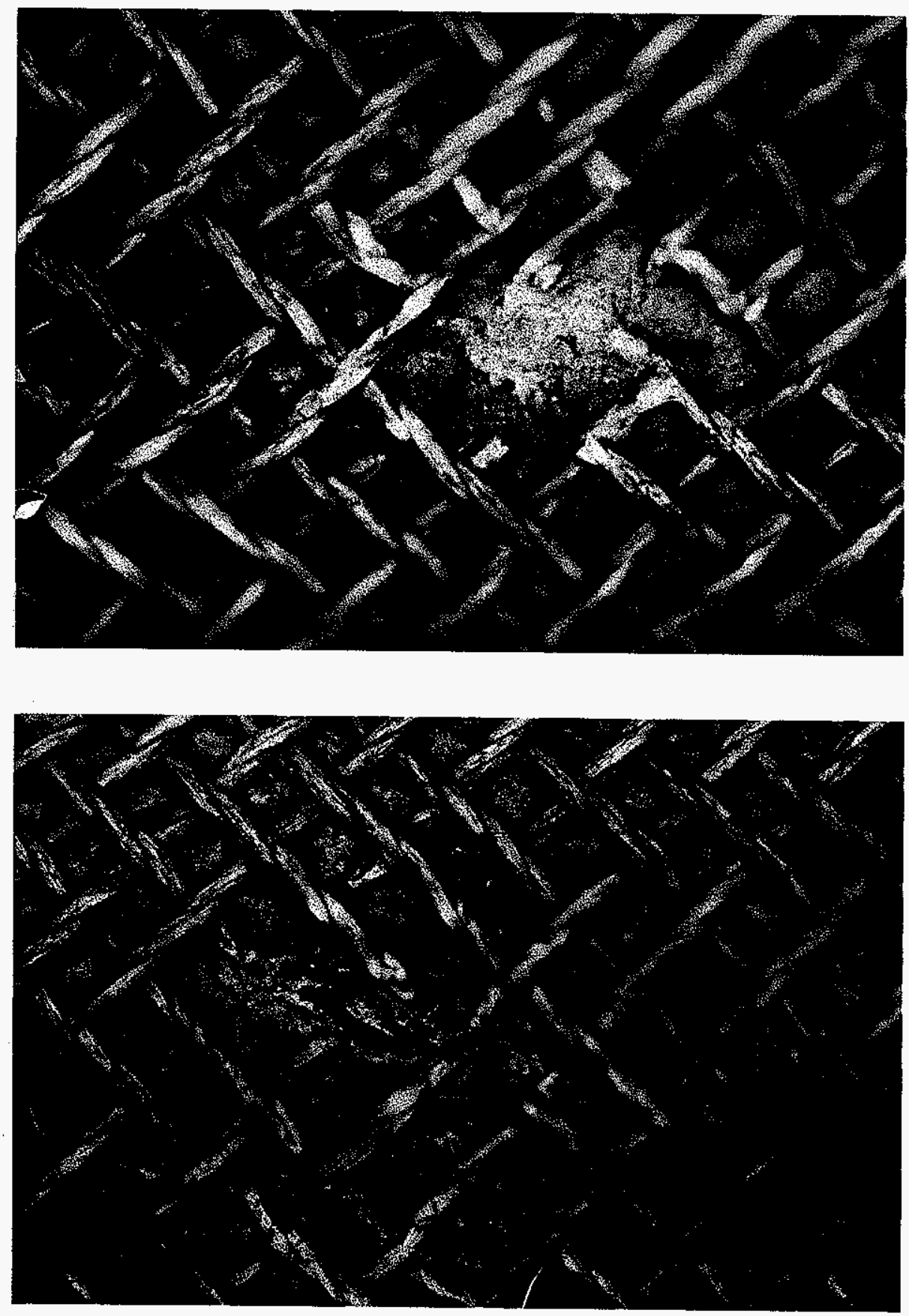

Figure 1-5 - Removal of the outer confinement and filtration mat layers in the 626 hour, PCFBCexposed, 3M CVI-SiC composite filter element (Test Segment 3). 
As shown in Figure 1-6, crack formations were evident near and around the densified plug which formed the closed end cap of three of the forty-five Pall 326 filter elements that were installed and operated in the W-APF during TS3-96. Although fines penetration was not observed through the crack formation after 1166 hours of PCFBC operation, continued use of these elements was not recommended.
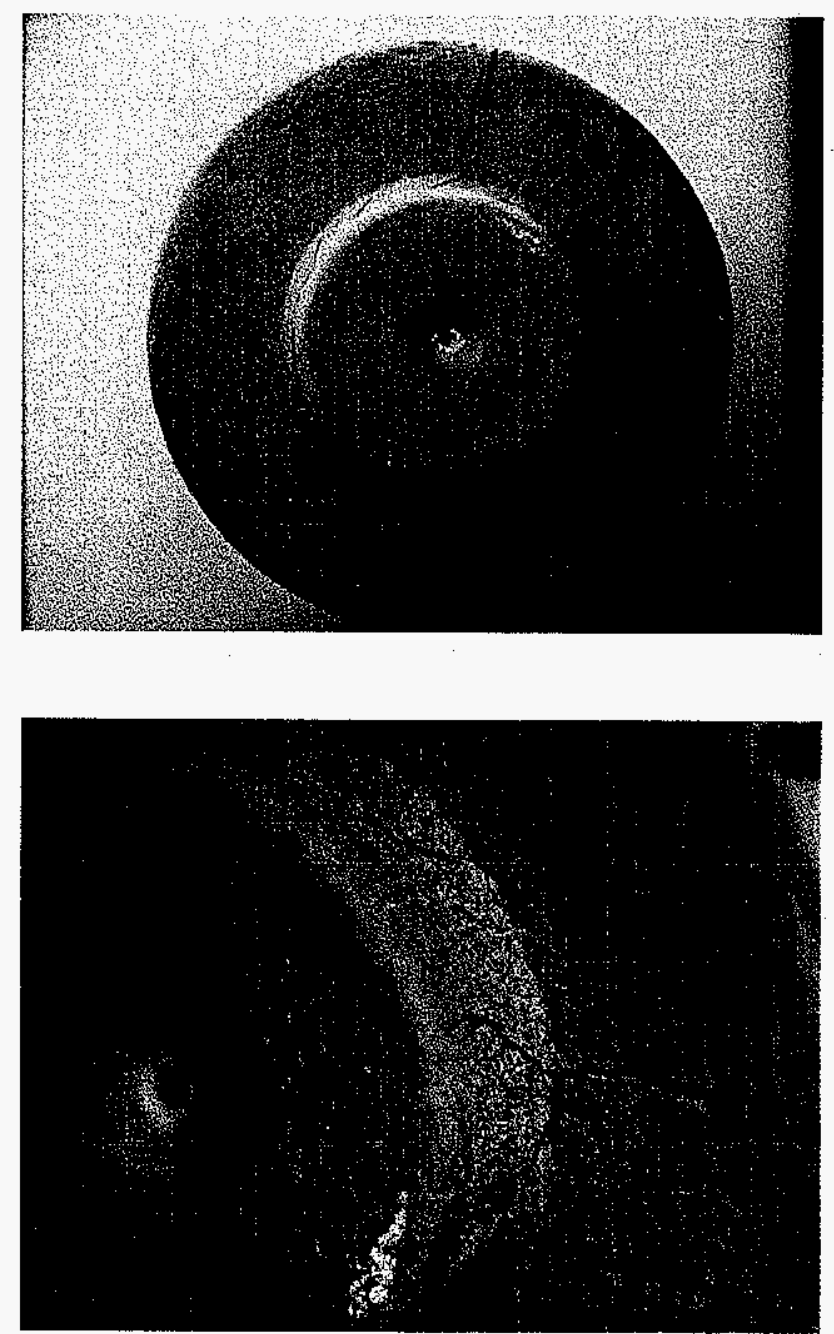

Figure 1-6 - Crack formations around the densified plug insert in the 1166 hour, PCFBCexposed, Pall 326 filter element (Test Segment 3). 
After each test campaign, surveillance filter elements were removed from the cluster and were subjected to both nondestructive and destructive materials characterization in order to identify the overall integrity of each element, as well as to determine the residual strength of the various filter matrices at process operating temperature, and any microstructural changes that may have occurred as a result of operation in the PCFBC environment. Additional analyses were focused on determining the residual high temperature creep characteristics of the PCFBC-exposed clay bonded silicon carbide filter elements, their potential to undergo oxidation which resulted in the elongation of the Schumacher Dia Schumalith FT20 and Pall 326 candles by 6-9 mm after 1166 hours of PCFBC operation, and the associated impact of ash and ash chemistry on the stability of the various filter matrices. The results of these efforts have previously been published. ${ }^{(2)}$

Pilot-scale testing in the W-APF system at the Foster Wheeler test facility in Karhula, Finland, resumed in April 1997 (TS1-97), utilizing previously PCFBC-exposed, commercially available, Coors P100A-1, Schumacher Dia Schumalith FT20, and Pall 326 filter elements (Table 1-5). ${ }^{(3)}$. The 128 candle filter cluster was subjected to $\sim 454$ hours of operation at temperatures of $\sim 850^{\circ} \mathrm{C}$. Eastern Kentucky Beech Fork coal and Gregg Mine Florida limestone were used as feed materials. Testing was terminated in TS1-97 due to failure of three Coors P-100A-1 filter elements which had previously experienced 1110 hours of operation at AEP.

TABLE 1-5. SUMMARY OF PCFBC TESTING IN 1997

\begin{tabular}{|l|c|c|}
\hline \multicolumn{1}{|c|}{ Test Segment } & $\begin{array}{c}1 \\
\text { (4/1997-6/1997) }\end{array}$ & \begin{tabular}{c} 
(9/1997-11/1997) \\
\hline Coal
\end{tabular} \\
\hline Sorbent & Eastern Kentucky & Eastern Kentucky \\
\hline Number of Candles & Florida Limestone & Florida Limestone \\
\hline Coors P-100A-1 & 128 & $90-112$ \\
\hline Schumacher FT20 & 72 & $28-33$ \\
\hline Pall 326 & 28 & $16-28$ \\
\hline 3M Oxide CFCC & 28 & $16-22$ \\
\hline McDermott Oxide CFCC & - & $7-0$ \\
\hline Techniweave Oxide CFCC & - & $6-7$ \\
\hline Blasch Mullite-Bonded Alumina & - & $2-0$ \\
\hline DuPont PRD-66 & - & $4-6$ \\
\hline Ensto Mullite-Bonded Alumina & - & 7 \\
\hline Other & - & $4-6$ \\
\hline Operating Hours (Coal) & - & $0-3$ \\
\hline Operating Temperature, ${ }^{\circ} \mathrm{C}$ & 454 & 581 \\
\hline Operating Pressure, bar & $820-850$ & $700-750$ \\
\hline Nominal Face Velocity, cm/s & $10-11$ & $9.5-11$ \\
\hline Inlet Dust Loading, ppmw & $2.4-3.5$ & $2.8-4.0$ \\
\hline
\end{tabular}

After dismantling and cleaning the entire cluster, 90 candles were installed, and testing resumed in September 1997 (TS2-97). In addition to the Coors P-100A-1, Schumacher Dia Schumalith FT20, and Pall 326 filter elements, seven oxide-based CFCC 3M and McDermott filter elements, as well as seven 
DuPont ${ }^{2}$ PRD-66 filament wound candles, six Blasch mullite-bonded alumina filters, four mullite-bonded alumina filters, and two Techniweave ${ }^{3}$ Nextel $^{\mathrm{TM}} 720$ oxide-based CFCC elements were installed in the bottom filter array (Figure 1-7). The unit was initially operated for a period of 40 hours at temperatures of $700-720^{\circ} \mathrm{C}$ prior to detecting dust in the outlet stream. Testing was subsequently terminated and the vessel was cooled. Post-test inspection of the filter cluster indicated that the two Techniweave and seven $3 \mathrm{M}$ oxide-based CFCC elements had experienced damage during the 40 hours of PCFBC operation. Close inspection of the Techniweave filter elements indicated that sections of the outer membrane through-thickness fibers were removed, and debonding of the outer seam and unwrapping of the 2-D fabric wrap or layered architecture resulted. Pinholes as a result of through-thickness fiber removal permitted ash fines to pass from the o.d. to i.d. surfaces of the PCFBC-exposed filter elements (Figure 18).

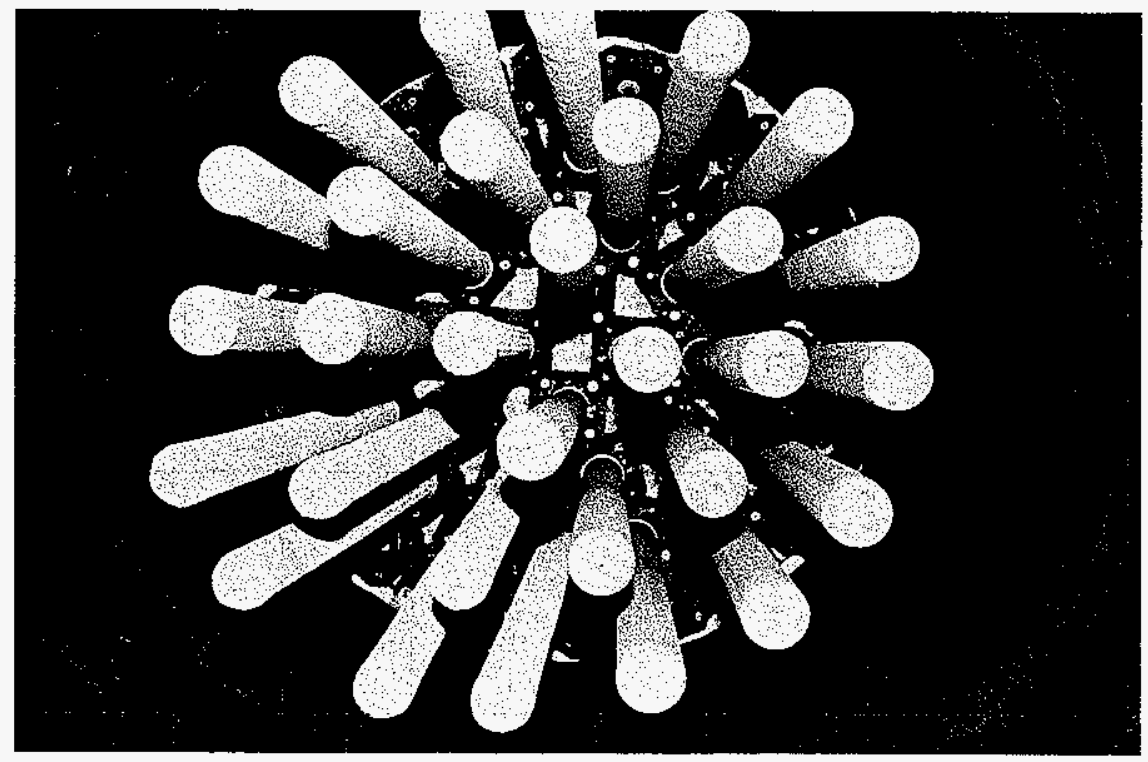

Figure 1-7 - Installation of the advanced monolithic and composite filter elements in the bottom filter array.

Similarly sections from both the outer confinement and filtration mat layers of the $3 \mathrm{M}$ oxidebased CFCC elements were removed, again permitting fines to pass from the o.d. to i.d. surfaces of the PCFBC-exposed filter elements (Figure 1-9). Sections of material beneath the confinement layer were also seen to be removed along the end caps of the $3 \mathrm{M}$ oxide-based CFCC filter elements. Although the Techniweave and $3 \mathrm{M}$ elements suffered damage during the 40 hours of PCFBC operation, all elements remained attached to the metal filter holder mounts. All of the damaged Techniweave and 3M PCFBCexposed filters, and one as-manufactured element of each filter type were returned to Westinghouse for examination. Appendix A summarizes the results of the post-test inspection effort.

\footnotetext{
${ }^{2}$ Currently AlliedSignal/Honeywell

${ }^{3}$ Currently Albany International Techniweave, Inc.
} 

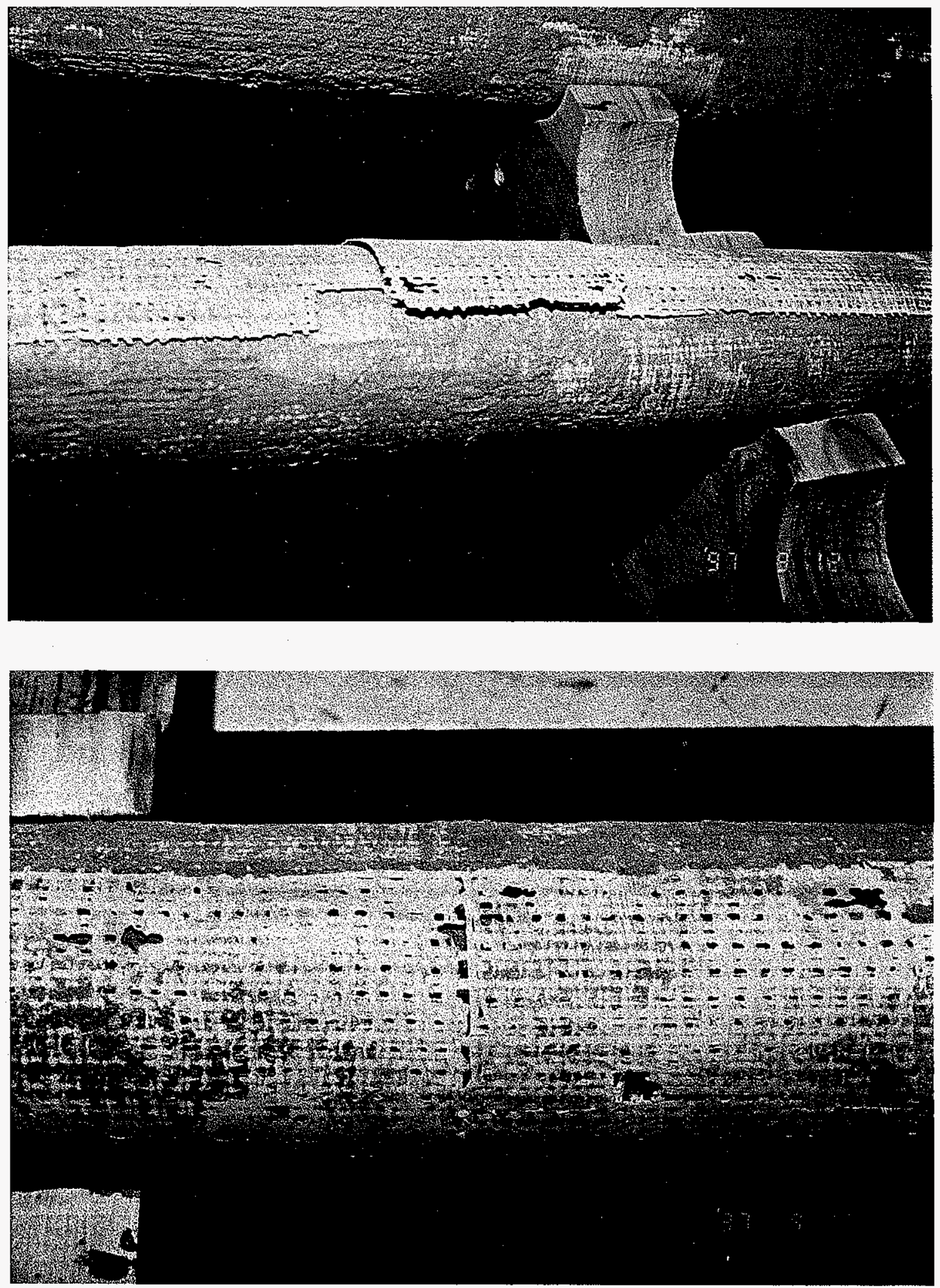

Figure 1-8 - Outer surface debonding of the PCFBC-exposed Techniweave CFCC filter elements. 

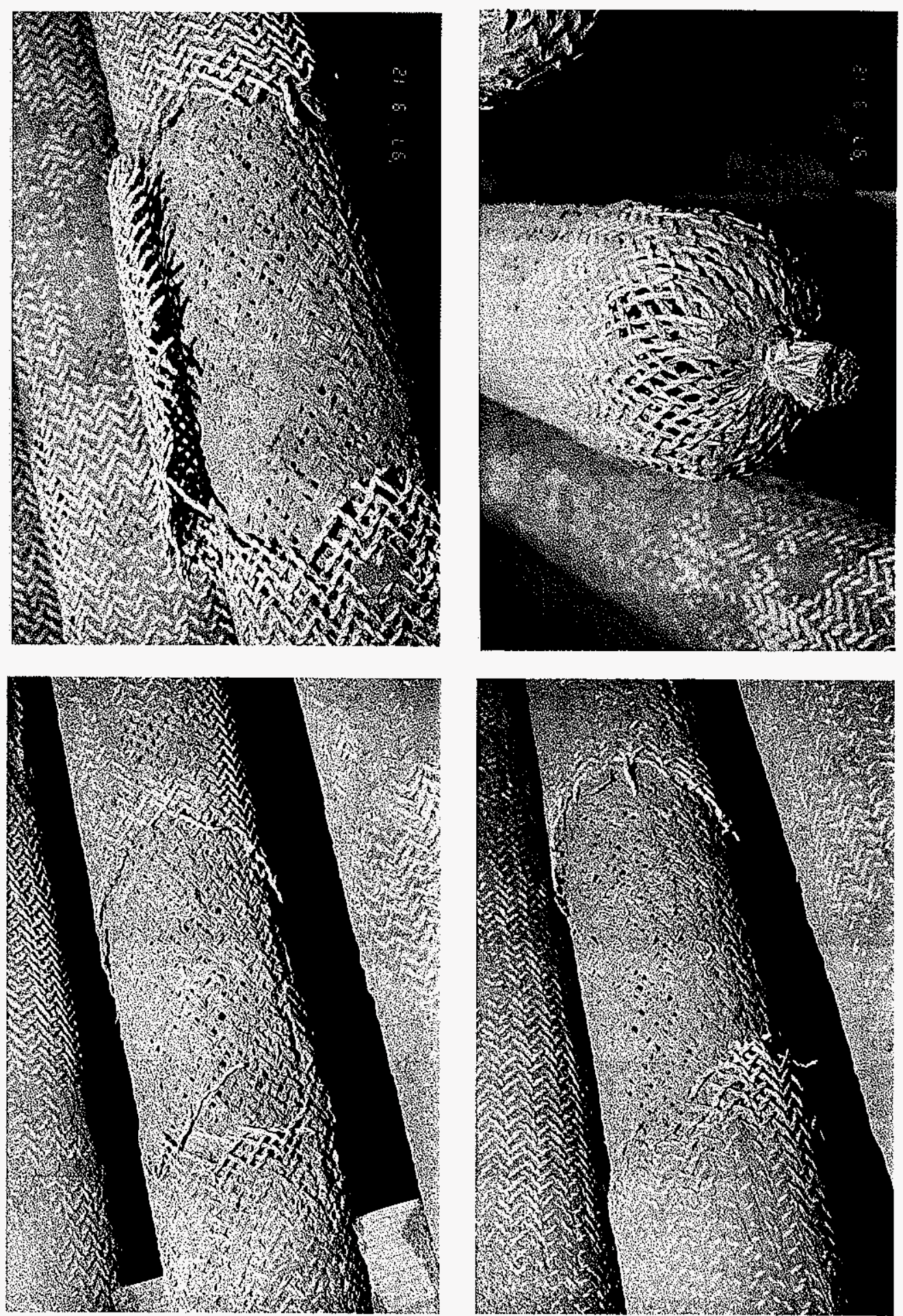

Figure 1-9 - Outer surface and filtration mat debonding of the PCFBC-exposed oxide-based 3M CFCC filter elements. 
Since ash fines had been detected in the outlet gas stream after 40 hours of PCFBC operation, all elements in the bottom array were removed, and cleaned prior to reinstallation. During removal, one of the DuPont PRD-66 filter elements was broken at the base of the flange (Figure 1-10). This resulted due to the tight fit when ash became wedged in between the flange and filter holder mount. The broken element was replaced with an alternate, newly manufactured DuPont PRD-66 filter. As shown in Figure 1-11, areas were also evident along the outer surface of the DuPont PRD-66 filter elements which resembled removal of the outer surface membrane and divot formations that were observed after operation of the oxide-based filament wound filter matrix at the AEP Tidd Demonstration Plant.
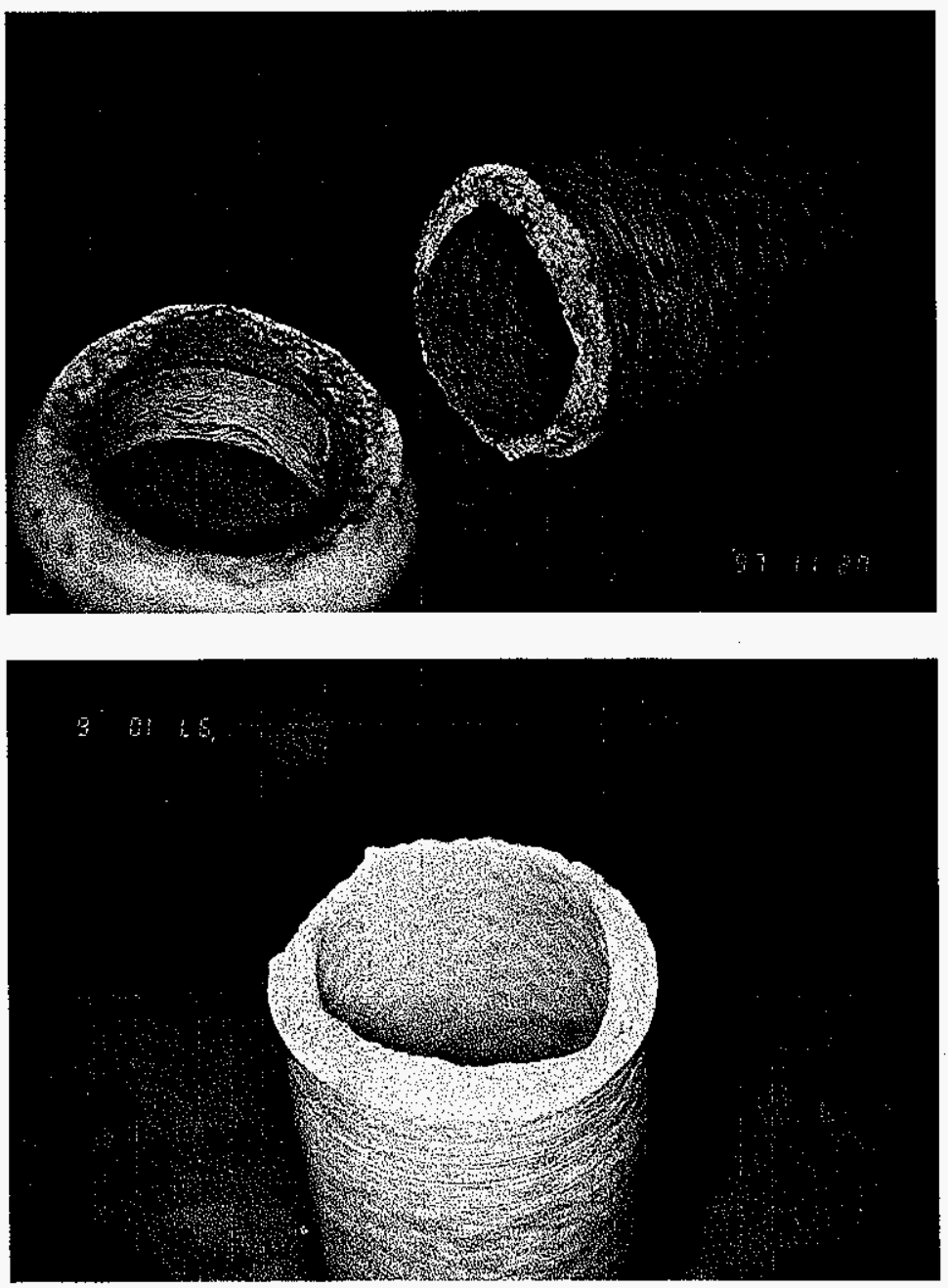

Figure 1-10 - Flange failure of the PCFBC-exposed DuPont PRD-66 filter element. 


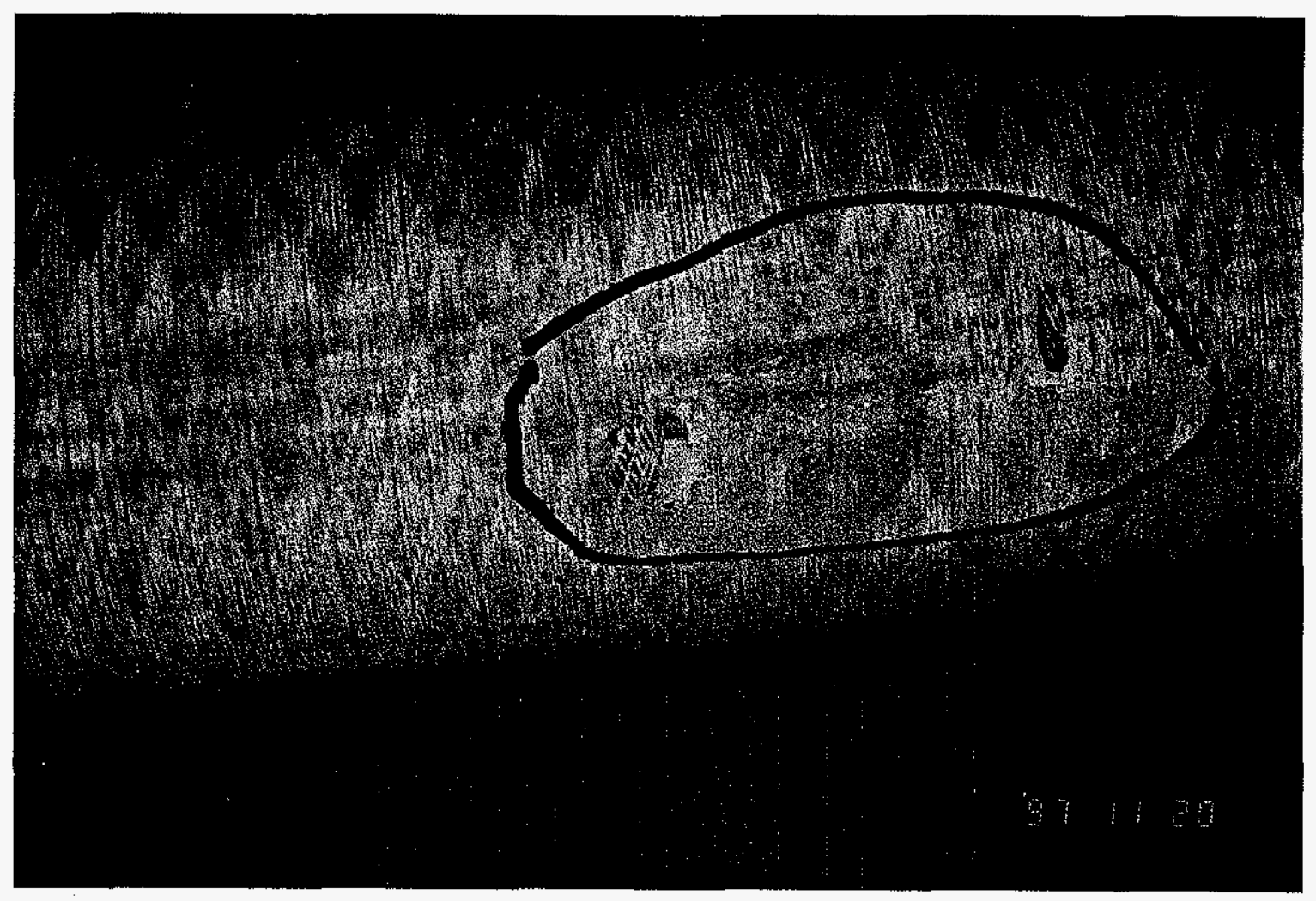

Figure 1-11 - Removal of the outer surface membrane layer of the PCFBC-exposed DuPont PRD66 filter element.

Post-test inspection of the McDermott elements indicated that localized areas of the Saffil and alumina-enriched sol-gel matrix were removed adjacent to and below the outer Nextel ${ }^{\mathrm{TM}} 610$ filament surface (Figure 1-12). During cleaning of the McDermott elements, the relatively soft matrix lead to 'pull-out' of material and/or removal of broken Nextel'TM 610 filaments. Separation of the internal wrapped filament winding layers within the flange was also evident after completion of PCFBC Test Segment 3 (Figure 1-13). Figure 1-14 indicates that outer surface fibers along the end cap area of the PCFBC-exposed McDermott filter element were not completely bonded to the outer surface of the filter element. No apparent damage was experienced by the Blasch or Ensto candles during either PCFBC testing or cleaning of the elements.

Once the bottom filter array and candles were cleaned (i.e., vacuum brushing; water washing), the elements were reinstalled in the array. Coors P-100A-1 alumina/mullite, Schumacher Dia Schumalith FT20, and Pall 326 elements were installed as replacements for the damaged Techniweave and $3 \mathrm{M}$ candles. PCFBC testing was then reinitiated and continued for an additional 199 hours of operation at $700-750^{\circ} \mathrm{C}$ using the Lakeland feed materials.

After 239 hours of service operation in TS2-97, testing was terminated and the unit was slow cooled, prior to inspection of the three filter arrays. During this planned outage, additional candles were 


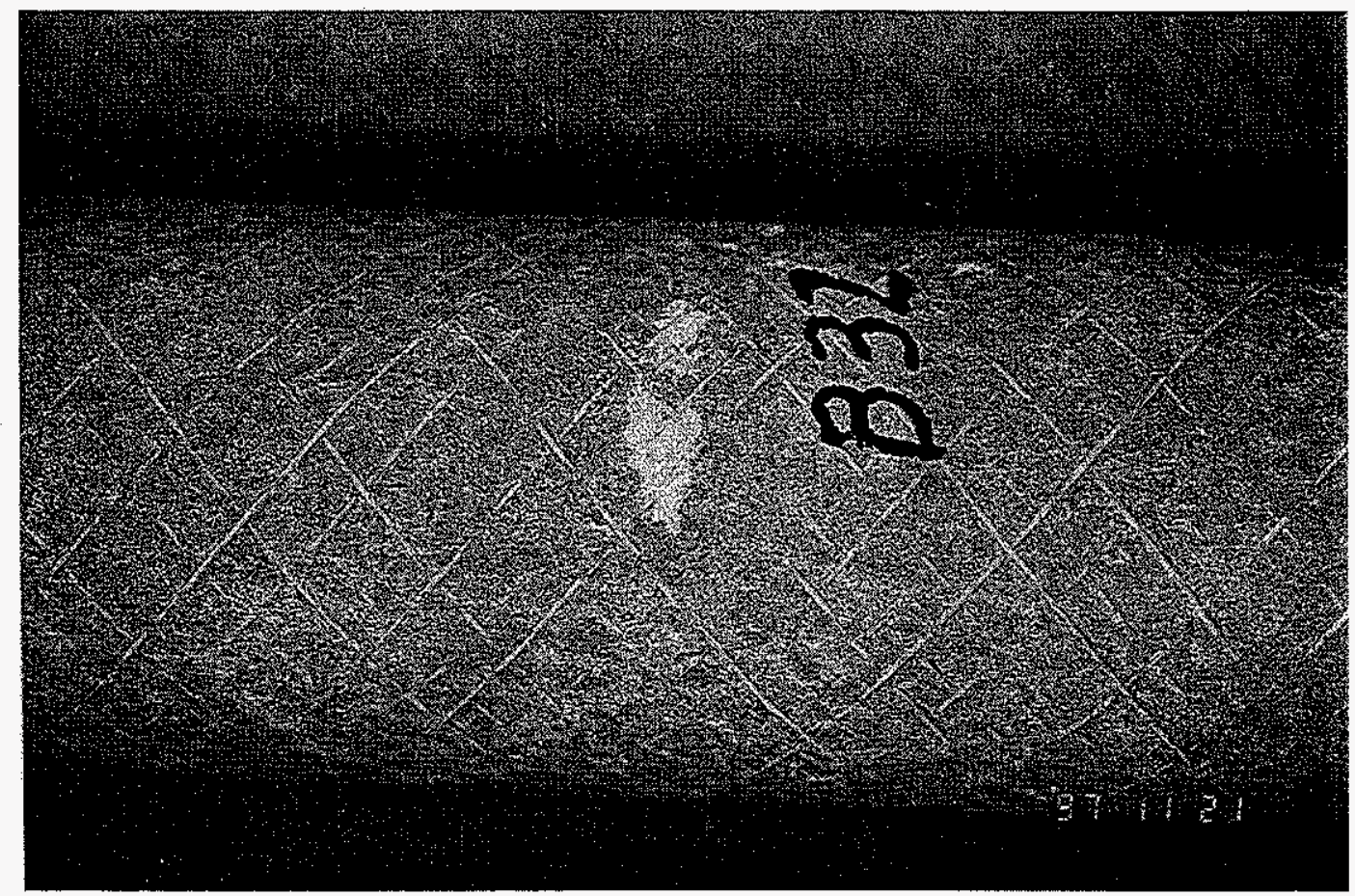

Figure 1-12 - Removal of the outer surface layer of the PCFBC-exposed McDermott CFCC filter element.

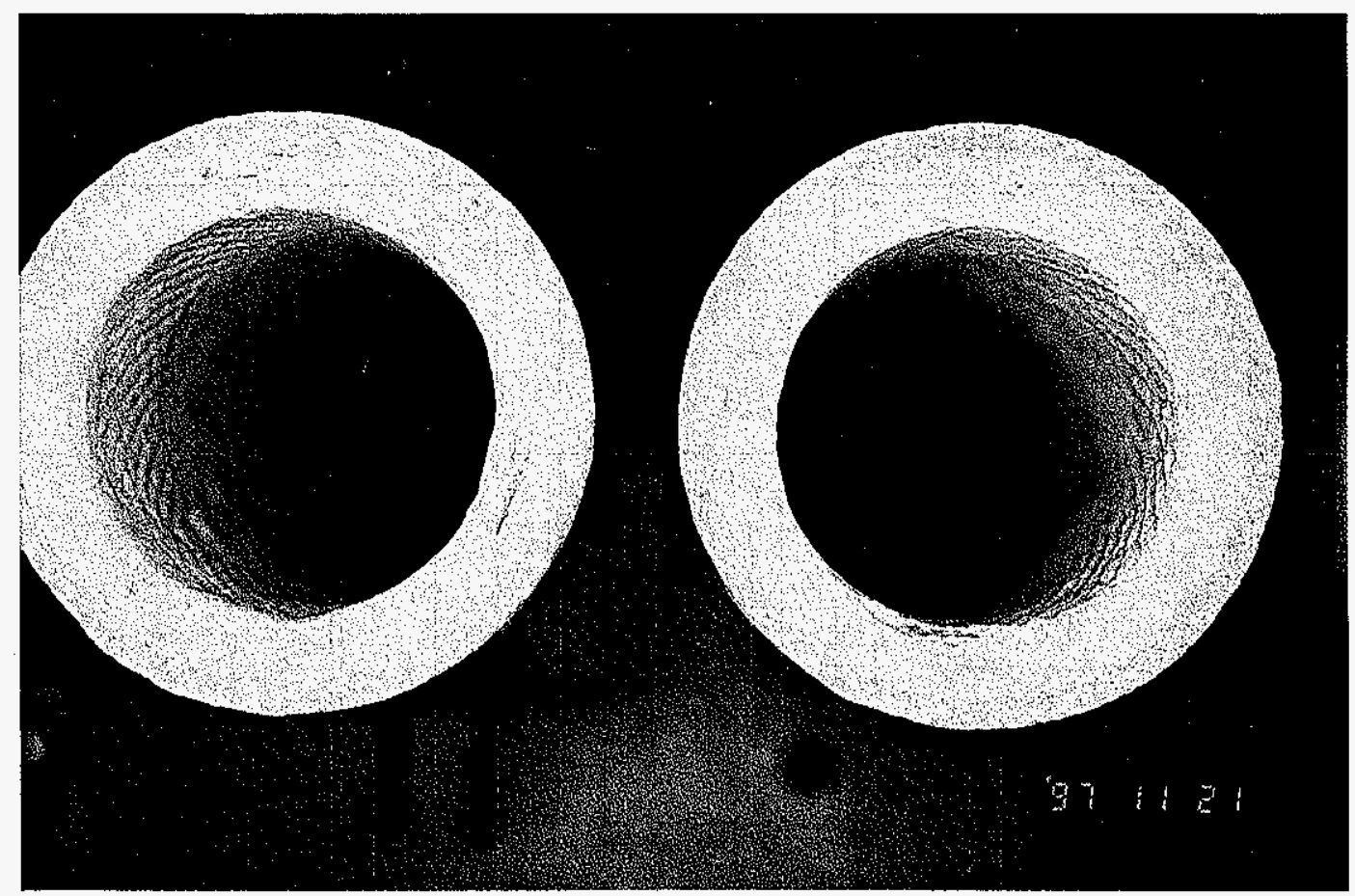

Figure 1-13 - Separation of the wrapped insert layers along the fiange of the PCFBC-exposed McDermott candle filter. 

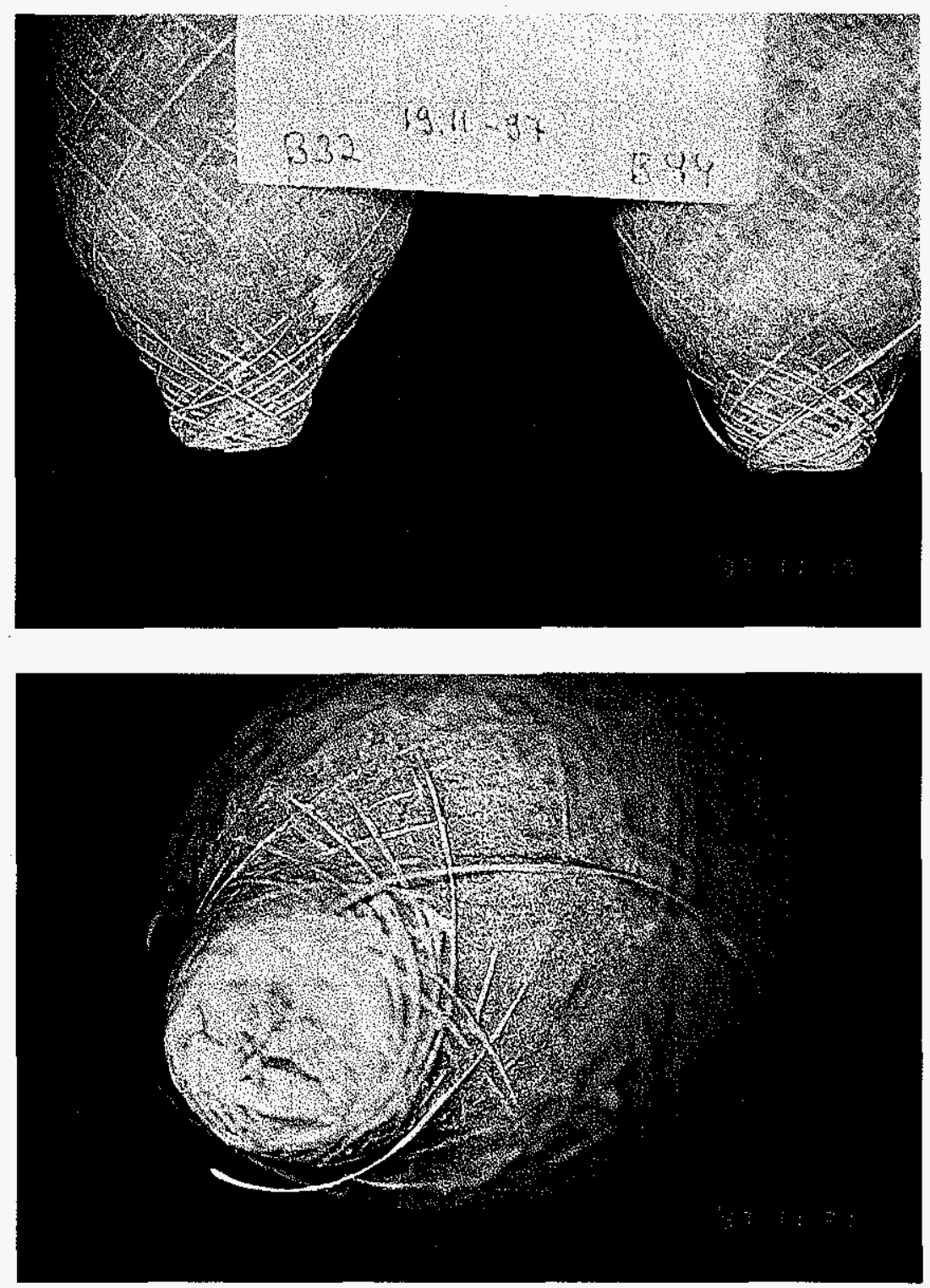

Figure 1-14 - Removal of the outer surface fibers along the end cap area of the PCFBC-exposed McDermott candle filters.

installed to fill the bottom array. Testing was reinitiated and continued for an additional 342 hours of operation at temperatures of $700-750^{\circ} \mathrm{C}$, again utilizing the Lakeland feed materials.

After completion of the PCFBC test campaign in 1997, the vessel was slow cooled, opened, and the filters were subsequently inspected. Post-test inspection of the filter arrays clearly indicated that ash bridging had not occurred (Figure 1-15). The thickness of the dust cake layer along the surface of the top array filter elements was $\sim 2-3 \mathrm{~mm}$, while an $\sim 2-5 \mathrm{~mm}$ thick dust cake layer remained along the outer surface of the middle array elements, and an $\sim 2-3 \mathrm{~mm}$ dust cake layer remained along the outer surface of the bottom array elements.

With the exception of crack formations around the densified plug inserted into the end cap of a Pall 326 filter element, and scratches along the membrane of the clay bonded silicon carbide filter 


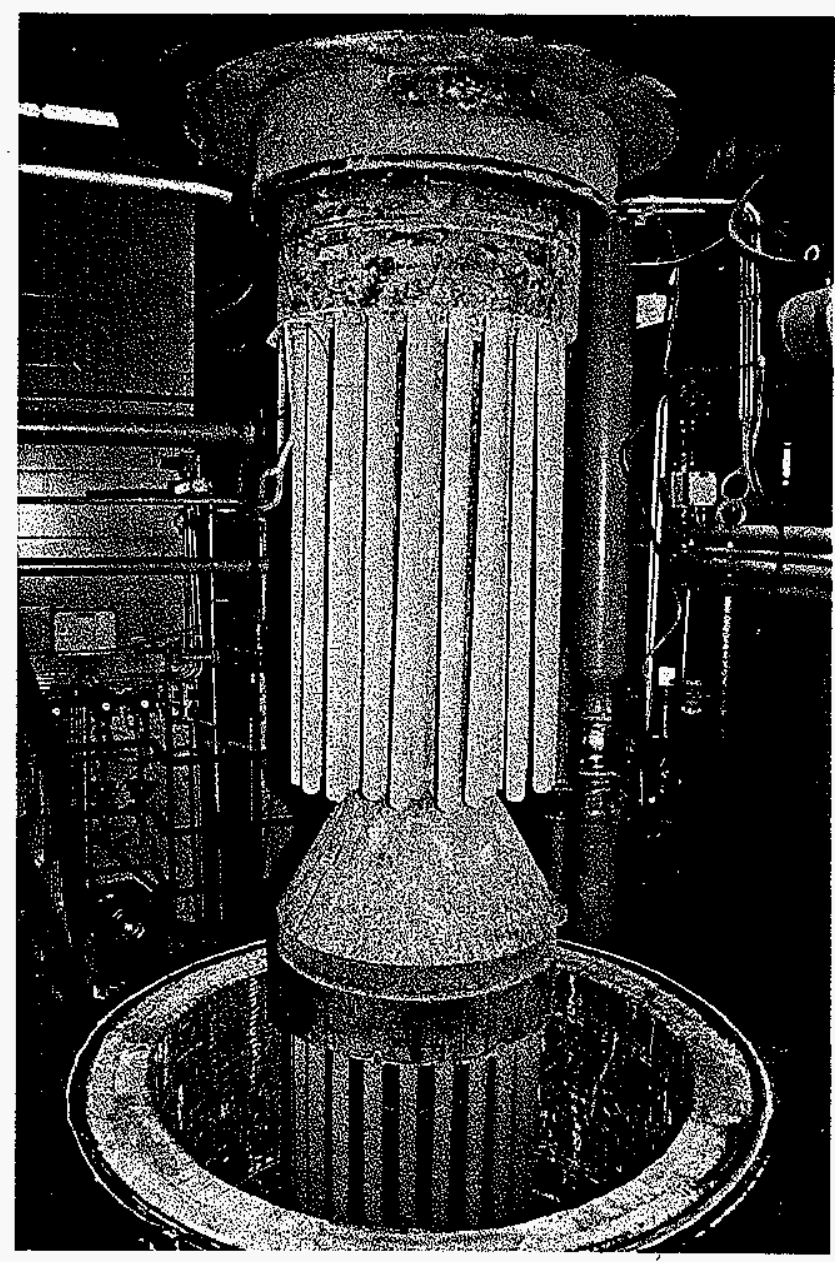

Figure 1-15 - Hot gas filter array after completion of PCFBC testing in TS2-97.

elements, all elements were intact at the conclusion of PCFBC testing in 1997. Although divot formations were not observed along the outer surface of the DuPont PRD-66 filter elements, cleaning and handling frequently lead to the formation of minor abrasions along the outer surface of the DuPont, as well as McDermott elements.

Once again, localized removal of the matrix and fibers along the outer surface of the McDermott candles was identified at the conclusion of PCFBC testing in 1997. Infrequently, fibers along the i.d. wall of the McDermott elements were seen to be torn or were dangling into the i.d. bore of the elements. This most likely resulted from insufficient bonding and adherence of the fibers during pulse cleaning. Thinning along the center of the PCFBC-exposed Blasch end caps resulted in the vicinity of the plug inserts used to cap and seal the filter elements during manufacturing.

Throughout this effort, as in many past programs, SWPC discussed with each filter element supplier, the need, as well as potential manufacturing approaches required to improve the quality, integrity, and performance of the various elements, in order to achieve extended operating material and component life in advanced coal-fired applications. Many of the manufacturing modifications have been either initiated or implemented by the various filter element suppliers. 
As part of SWPC's filter material surveillance program, commercially available, asmanufactured and PCFBC-exposed, Coors P-100A-1, Pall 326, and Schumacher Dia Schumalith FT20 monolithic filter elements, and advanced McDermott composite, DuPont PRD- 66 filament wound, and advanced monolithic Blasch and Ensto filter elements were subjected to residual strength

characterization, creep strain, gravimetric analyses and microstructural characterization. The results of these efforts are presented in Section 2. 


\section{CHARACTERIZATION OF PCFBC-EXPOSED FILTER ELEMENTS}

\subsection{Room Temperature Gas Flow Resistance}

The gas flow resistance of the as-manufactured Schumacher Dia Schumalith FT20, Pall 326, Coors P-100A-1 alumina/mullite, and 3M CVI-SiC composite candle filters is shown in Figure 2-1.(2) All as-manufactured candle filters initially met the SWPC room temperature gas flow resistance specifications of $\leq 10 \mathrm{in}-\mathrm{wg} / 10 \mathrm{fpm}$.

Similar gas flow resistance measurements were obtained for the PCFBC surveillance filter elements that were returned to SWPC at the conclusion of TS2-96 and TS3-96. A significant increase in the room temperature gas flow resistance across each element resulted after testing at Karhula (Figure 21). The nature and thickness of the ash cake layer that remained along the outer surface of each candle typically governed the resulting gas flow resistance of each PCFBC-tested filter element. In contrast, candle filters which had been returned to SWPC STC after PCFBC testing in 1997 were not subjected to room temperature gas flow resistance measurements prior to conduct of destructive testing and evaluation.

\subsection{Compressive and Tensile Strength}

The residual process temperature strength of the PCFBC-exposed monolithic and advanced second generation candle filters is shown in Figures 2-2 and 2-3, and Table 2-1. Tables 2-2 and 2-3 identify the ultimate load to failure and fracture characteristics of each material tested.

Both the Schumacher Dia Schumalith FT20 and Pall 326 elements appeared to have achieved a conditioned strength along their o.d and i.d. surfaces (compressive and tensile strengths, respectively). In contrast, a gradual reduction in strength appeared to continue to occur for the Coors P-100A-1 alumina/mullite filter matrix. A lower initial and residual strength was identified for the advanced second generation porous ceramic matrices in comparison to the commercially available monolithic filter materials. A gradual increase in both compressive and tensile strength of the DuPont PRD-66 filament wound matrix occurred during the initial 581 hours of operation in the PCFBC environment. This has previously been demonstrated by SWPC, ${ }^{(2,4,5)}$ and was considered to result from either penetration of ash fines into the filament wound filter matrix, or crystallization of amorphous phases originally contained in the as-manufactured filter matrix. A gradual loss of matrix strength along the o.d. surface, while a nearly constant retention of strength along the i.d. surface of the McDermott candle occurred during the initial 581 hours of operation in the PCFBC environment. For the Blasch matrix, a slight increase in residual strength along both o.d. and i.d. surfaces occurred.

Many discussions have been focused on the techniques utilized to establish both initial, as well as residual strength of process-exposed porous ceramic filter matrices. SWPC typically utilizes $15 \mathrm{~mm}$ sections cut from candle filters, and tests each section as a c-ring in compression and tension, at room temperature and at process operating temperature. These results are used to monitor the trend or changes in material strength which occur during continued life of the elements in various field service applications. 


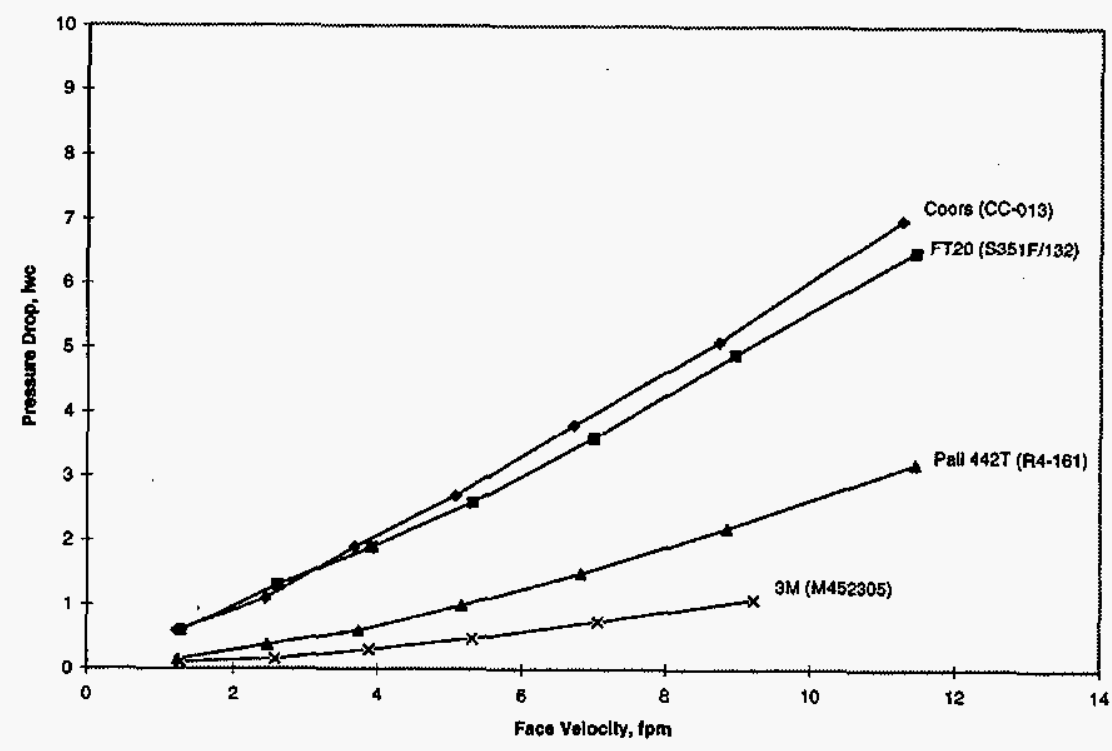

Teat Segment 3

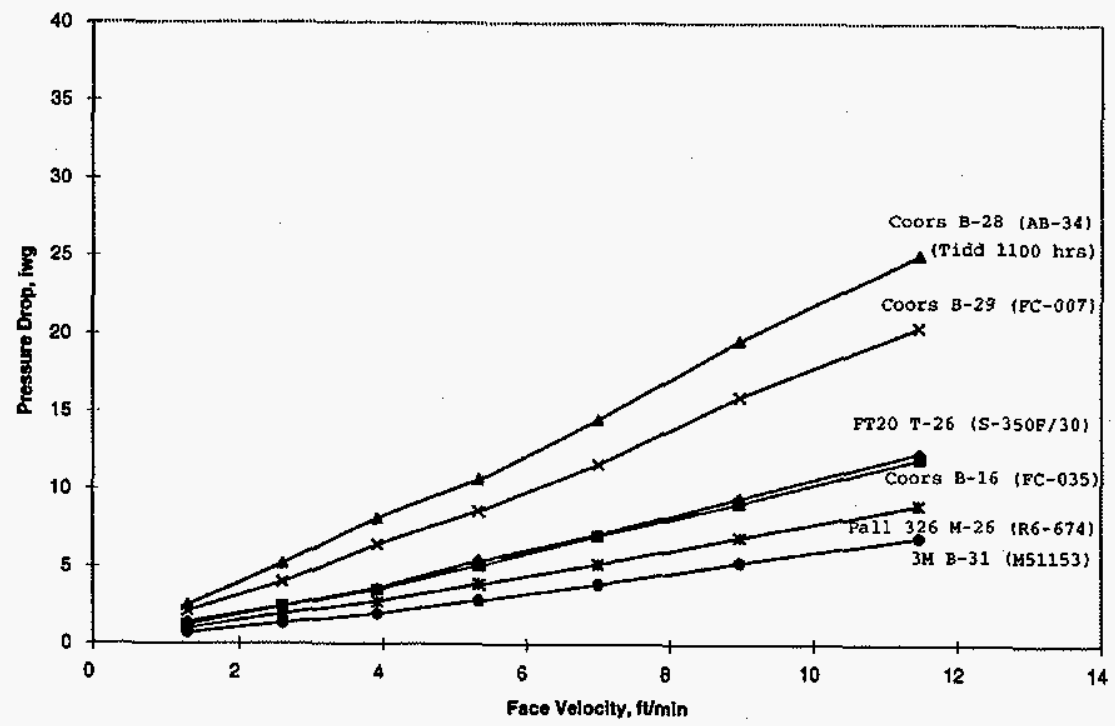

Figure 2-1 - Room temperature gas flow resistance measurements of the as-manufactured and TS3-96 PCFBC-exposed candle filters.

Table 2-4 identifies the calculated strength of the DuPont PRD-66 and McDermott CFCC porous ceramic filter matrices when 15 or $25.4 \mathrm{~mm}$ sections were tested as o-rings, and similarly when $15 \mathrm{~mm}$ cring sections were tested in compression and tension. Negligible differences in the resulting calculated strengths were identified. Figure $2-4$ clearly shows the relationship between c-ring and o-ring calculated strengths for PCFBC-exposed commercially available and second generation filter elements. The manner in which the wall thickness of the sample was measured (i.e., Ave: Average of four locations, $90^{\circ}$ to each 
other, prior to testing; Min: Minimum wall dimension at the fracture site after testing), had a significant impact on the magnitude of the calculated diametral o-ring strength. Utilizing an averaged o-ring wall thickness, a nearly direct correlation between compressive c-ring and o-ring diametral strength resulted. Utilizing the minimum wall thickness at the fracture location identified the apparent lack of concentricity throughout the wall which resulted during manufacture of the filter elements.
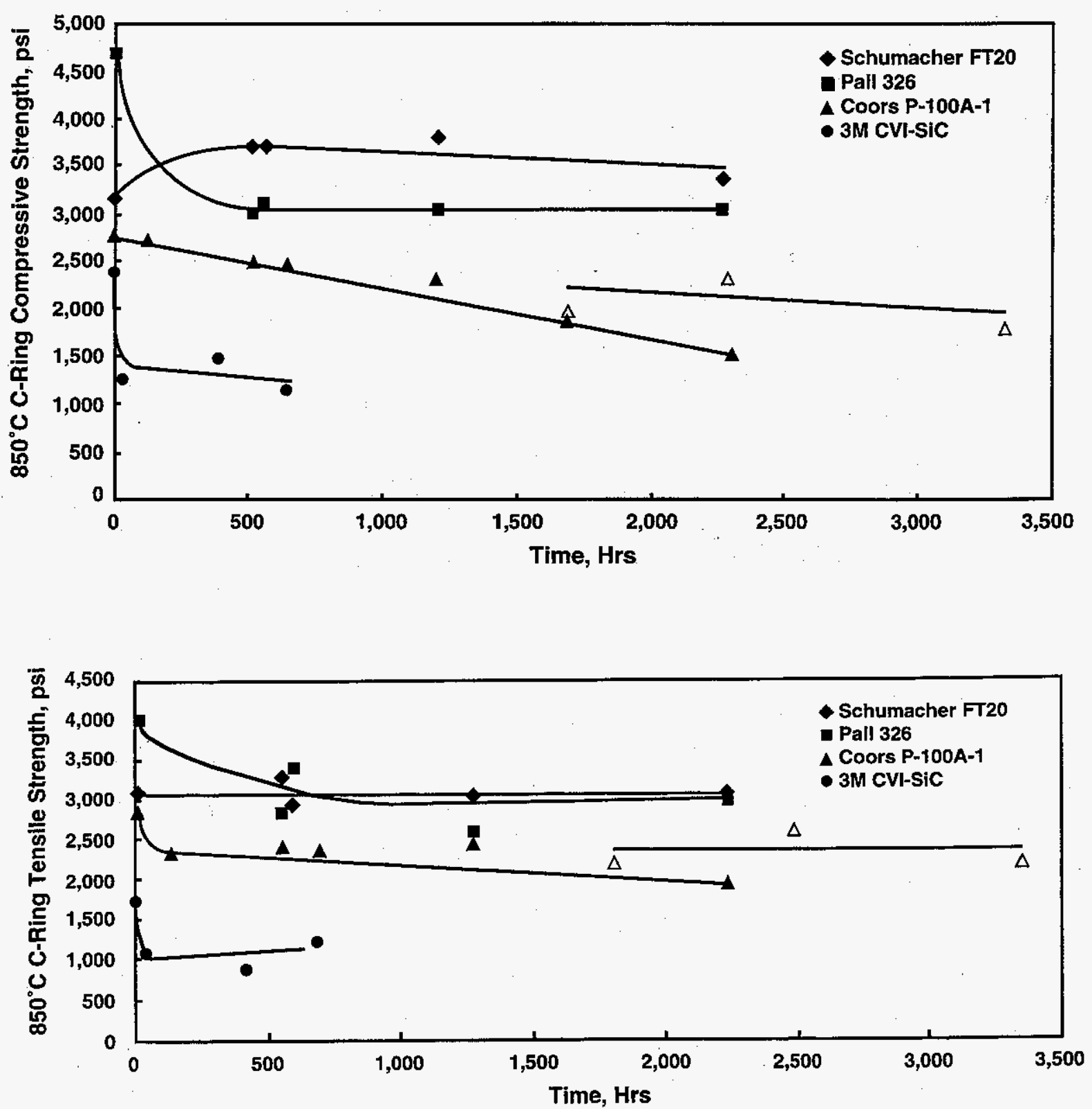

Figure 2-2 - Residual strength of the PCFBC-exposed commercially available monolithic filter materials and 3M CVI-SiC composite filter matrix. 

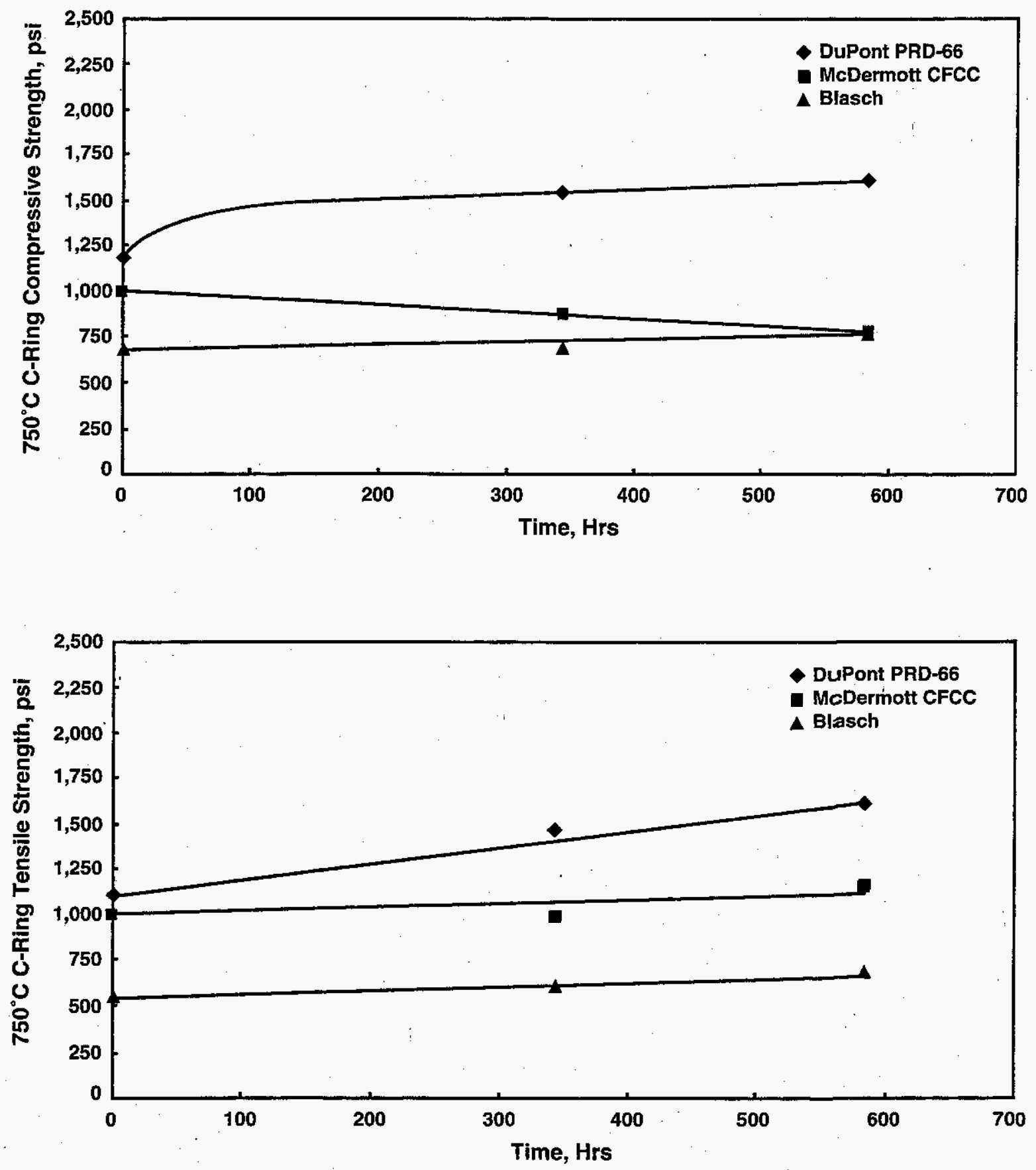

Figure 2-3 - Residual strength of the PCFBC-exposed filament wound, continuous fiber ceramic composite, and advanced second generation monolithic filter matrices. 


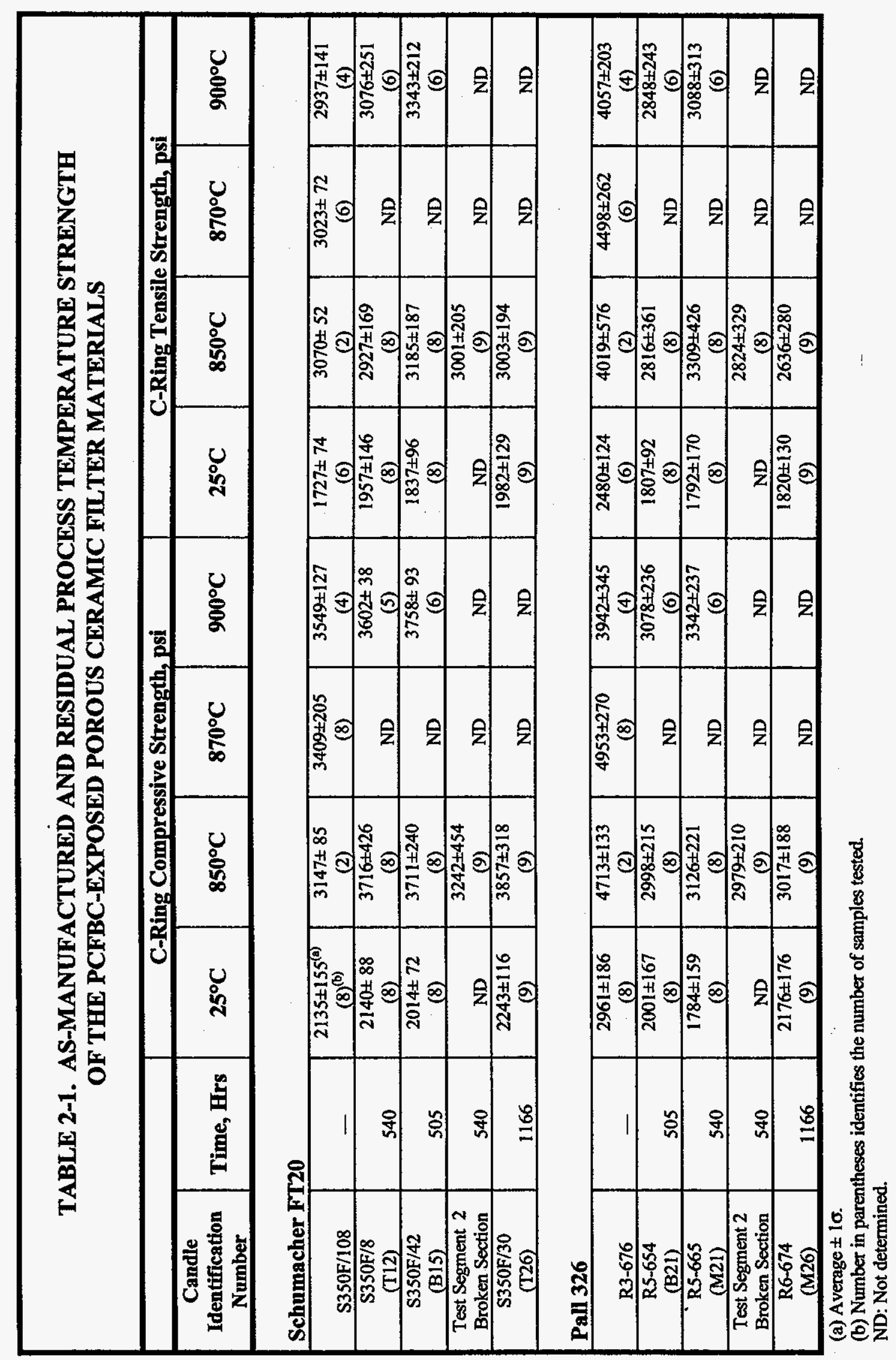




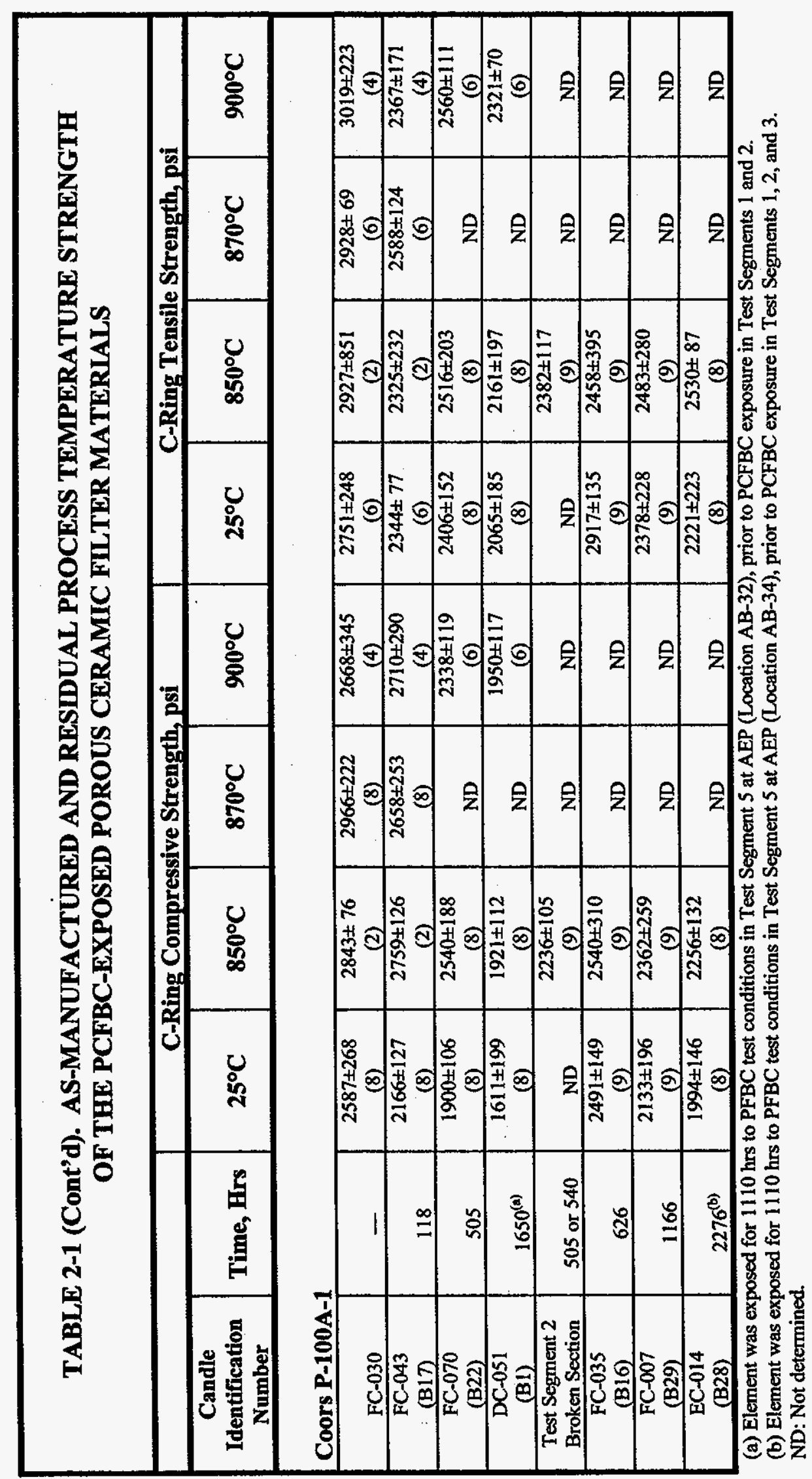




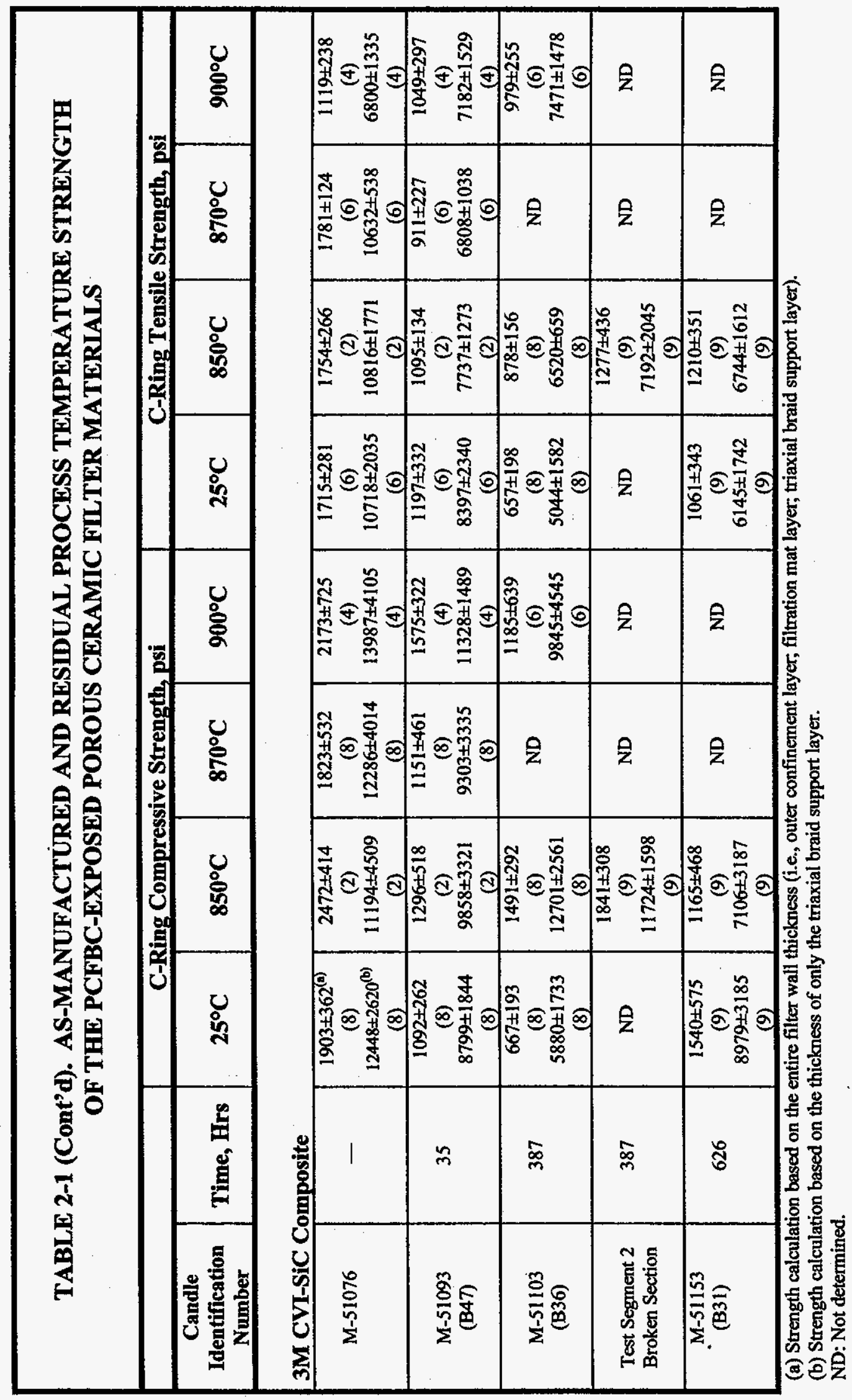




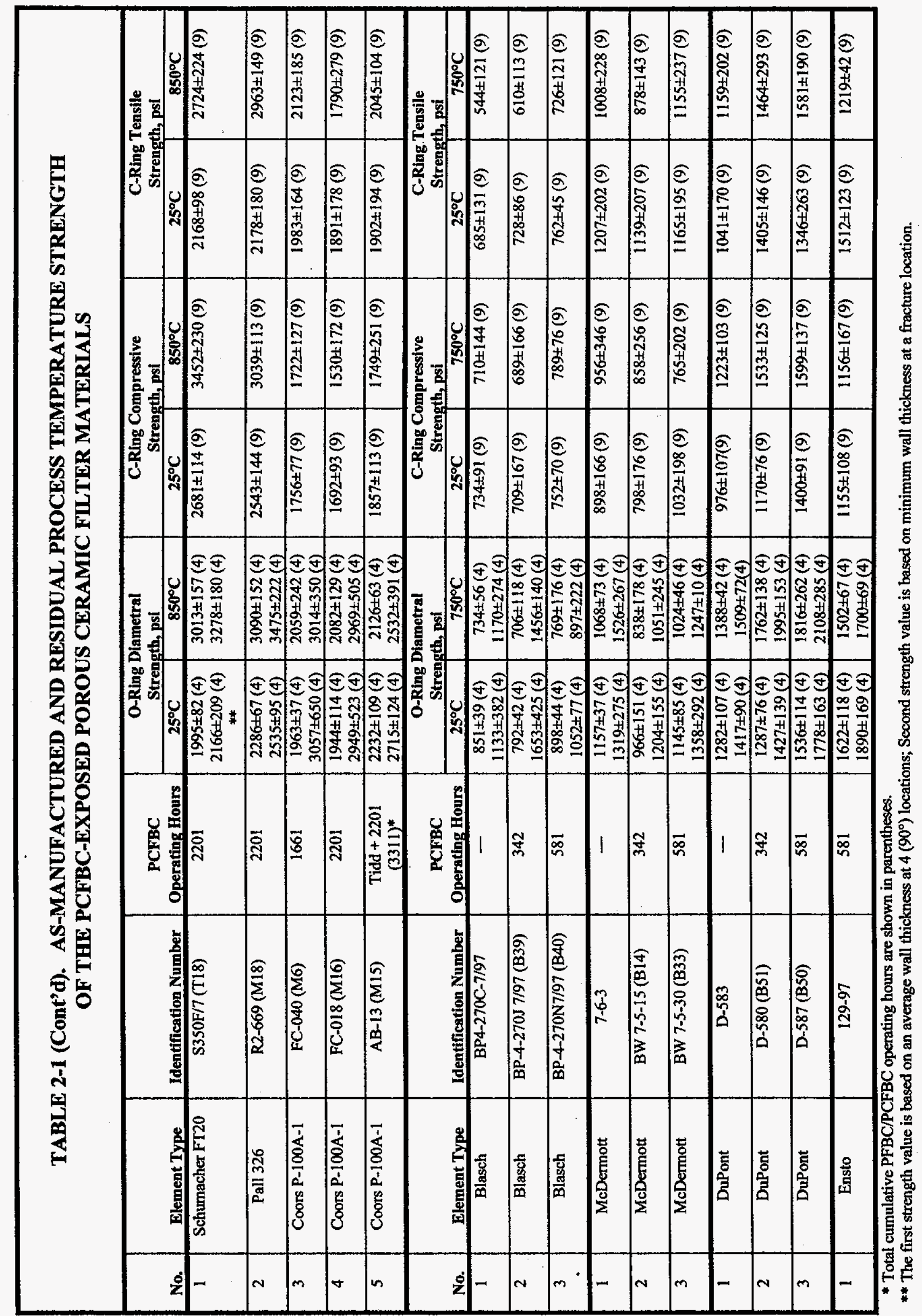




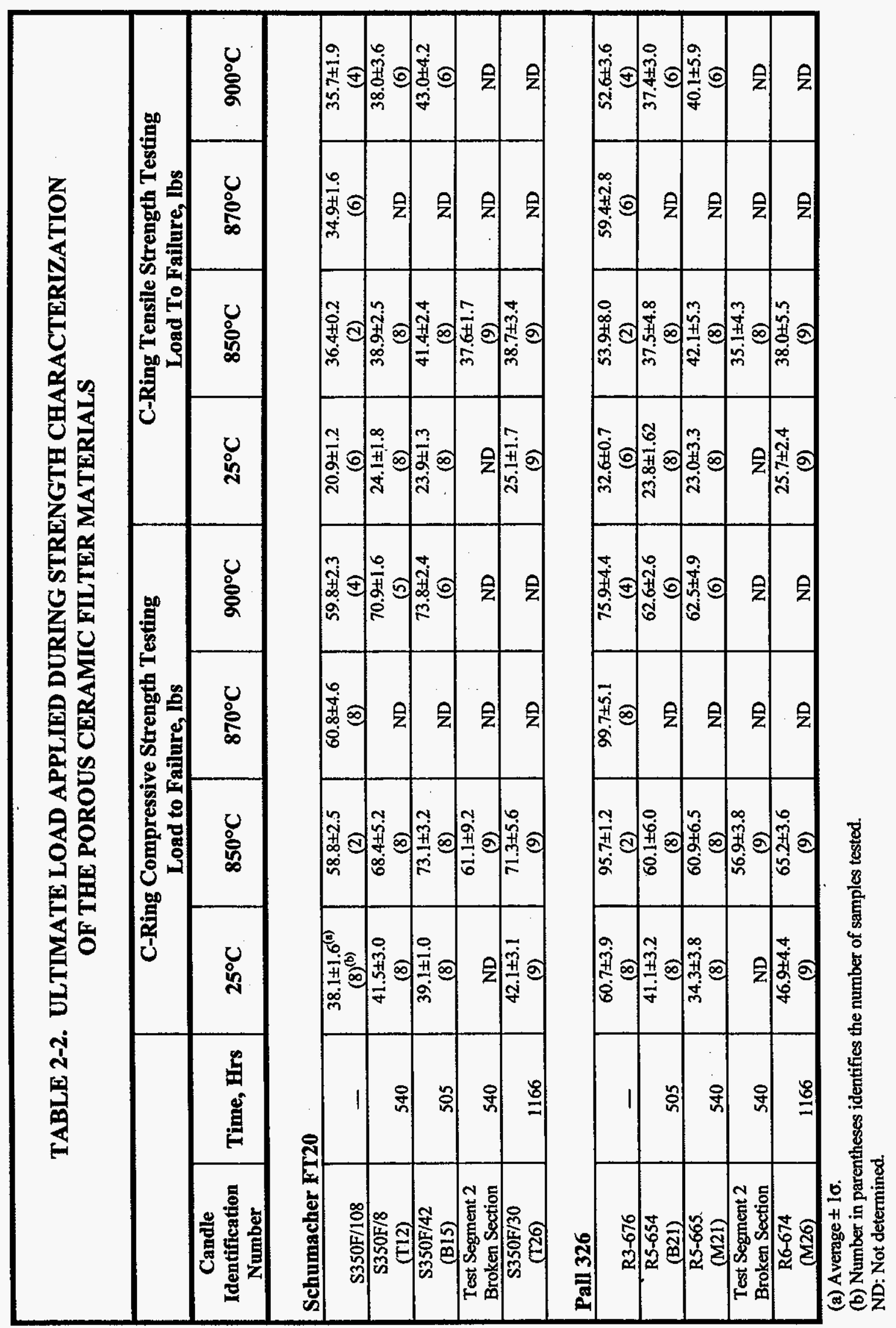




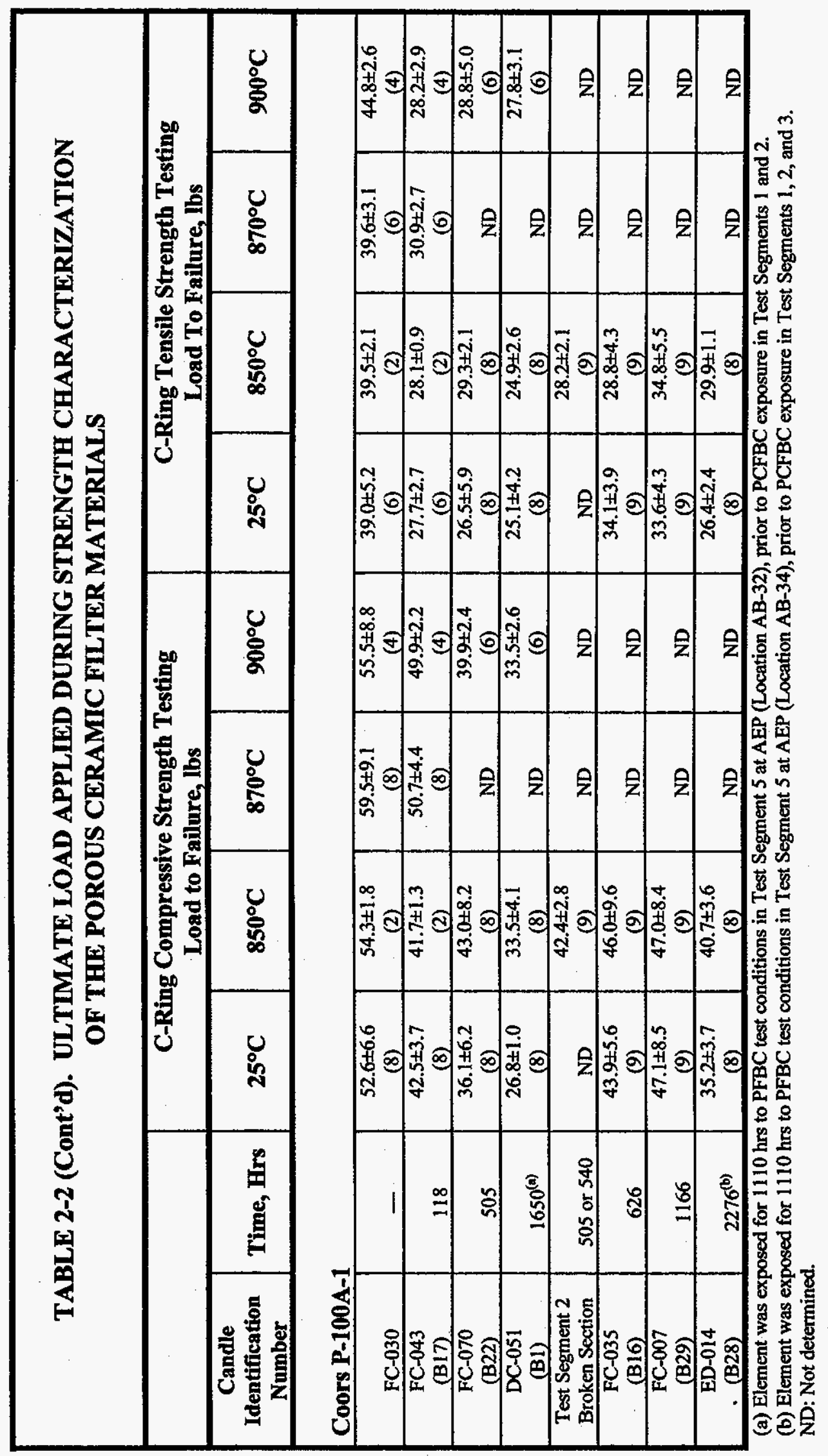




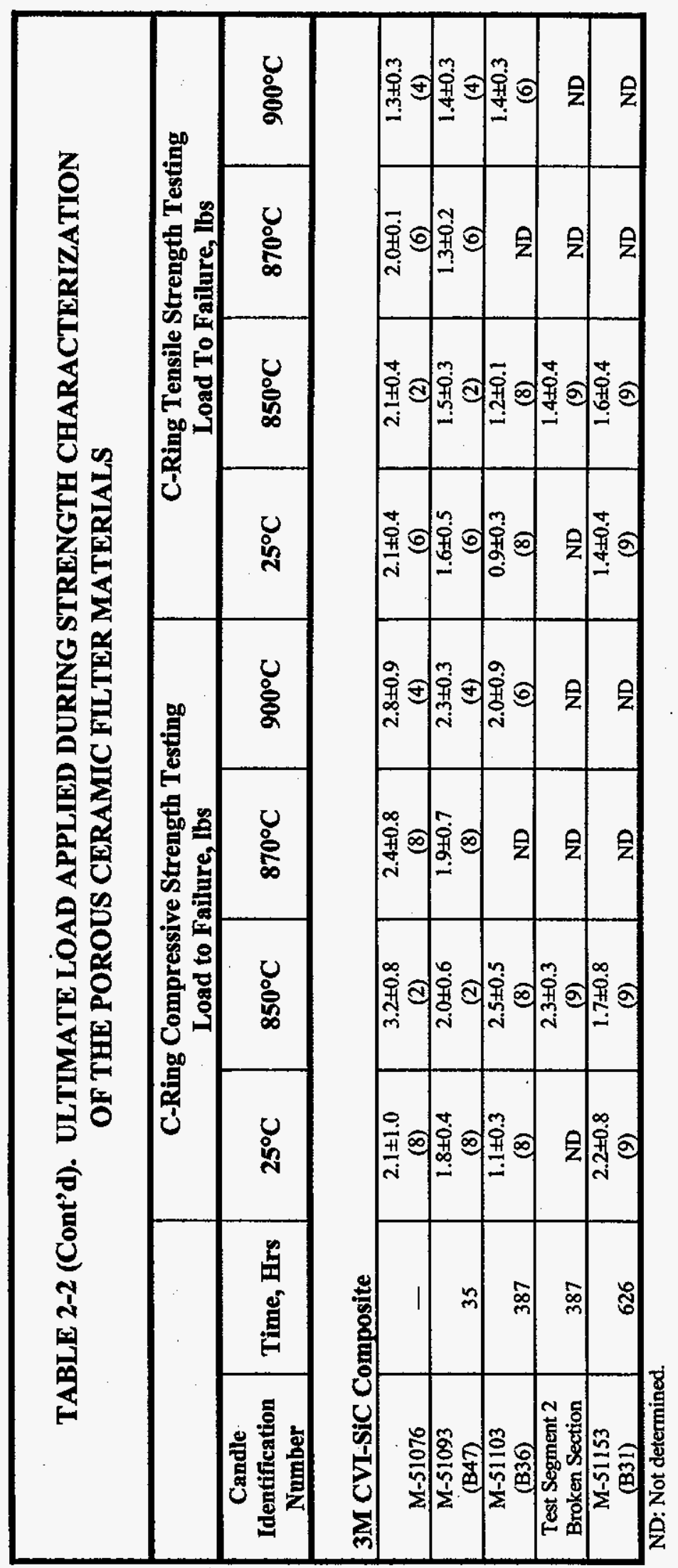




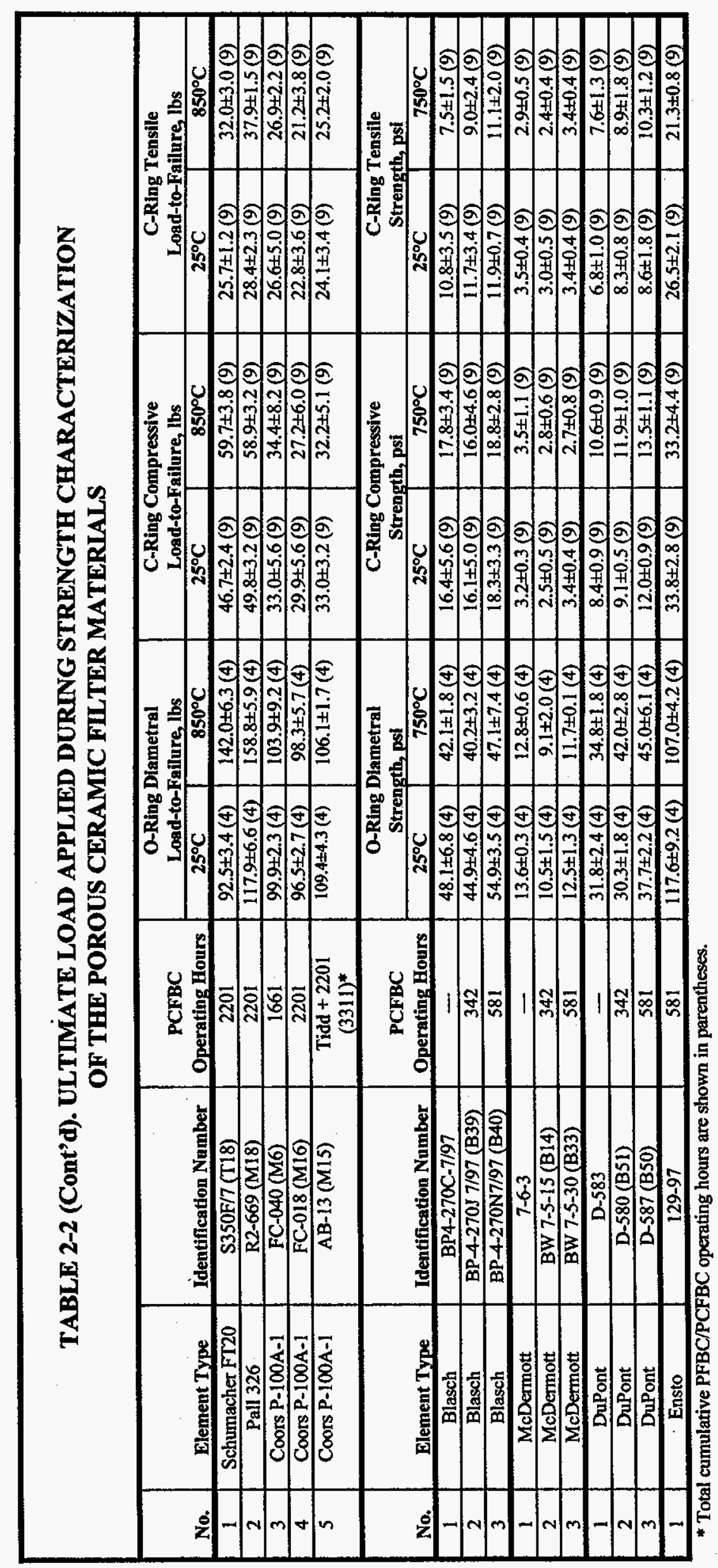




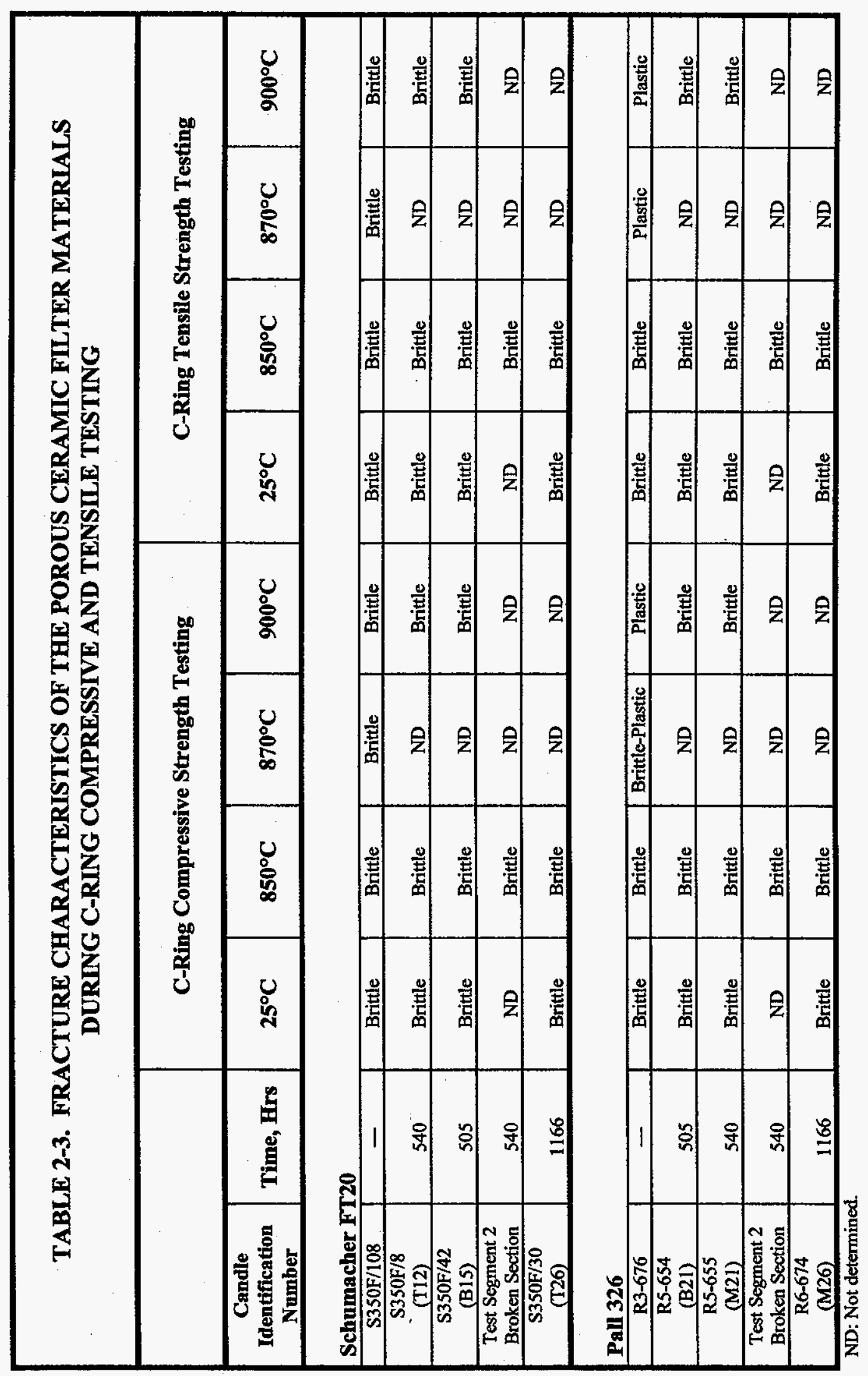




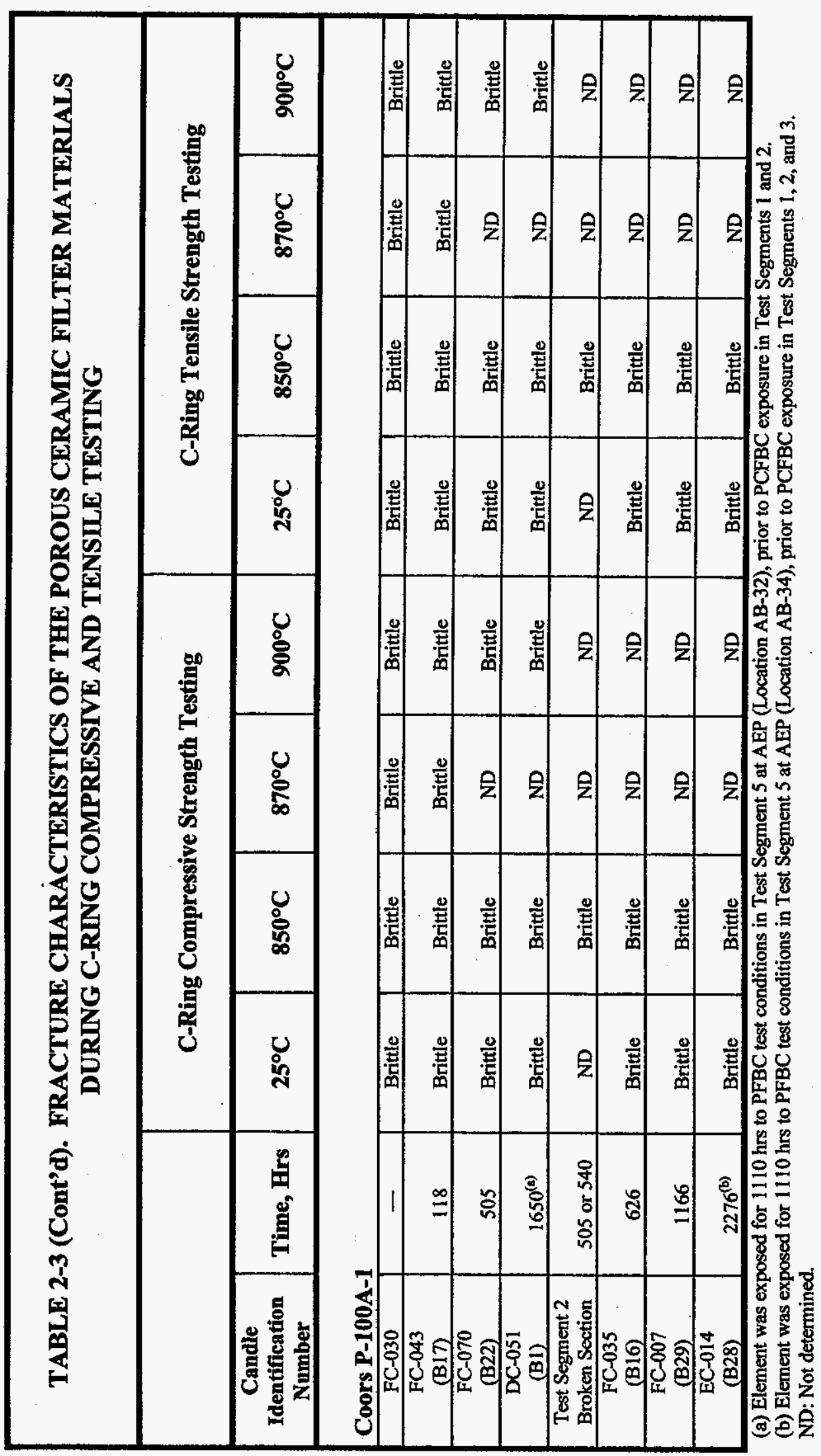




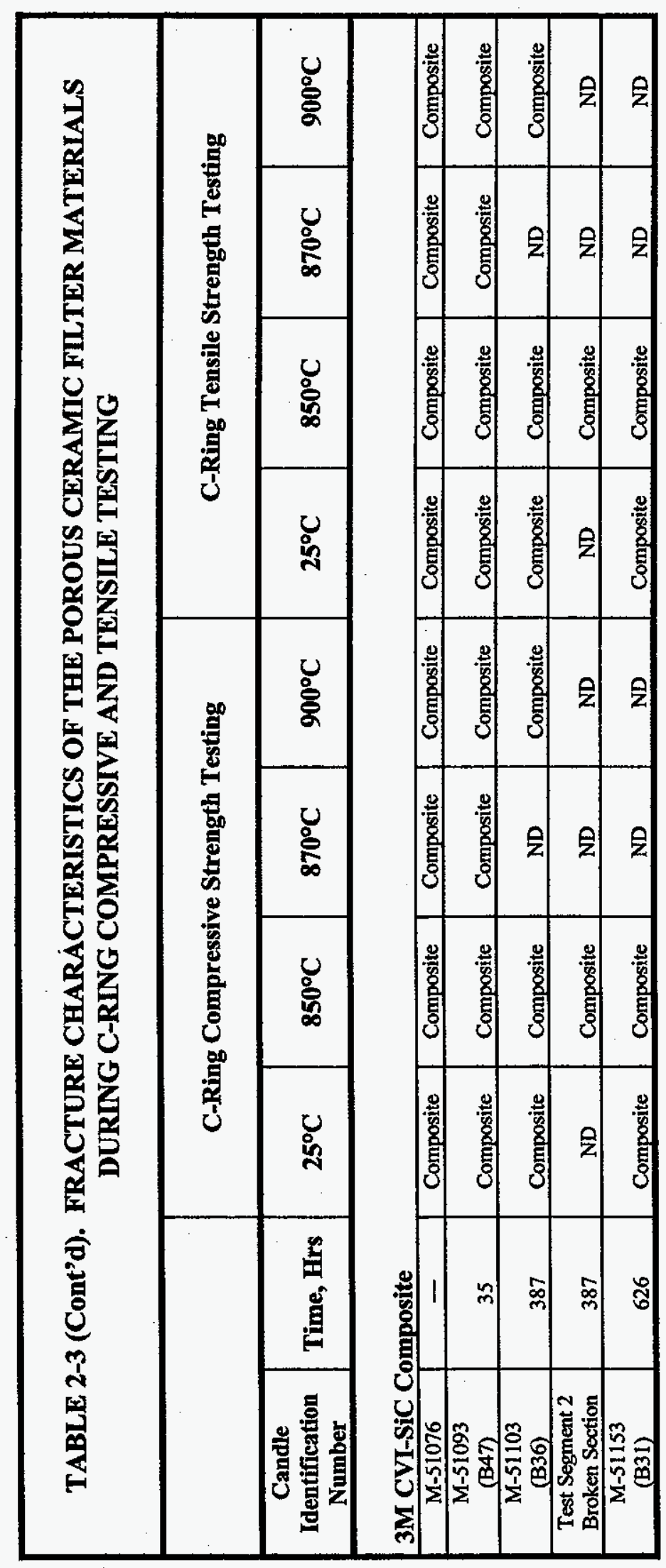




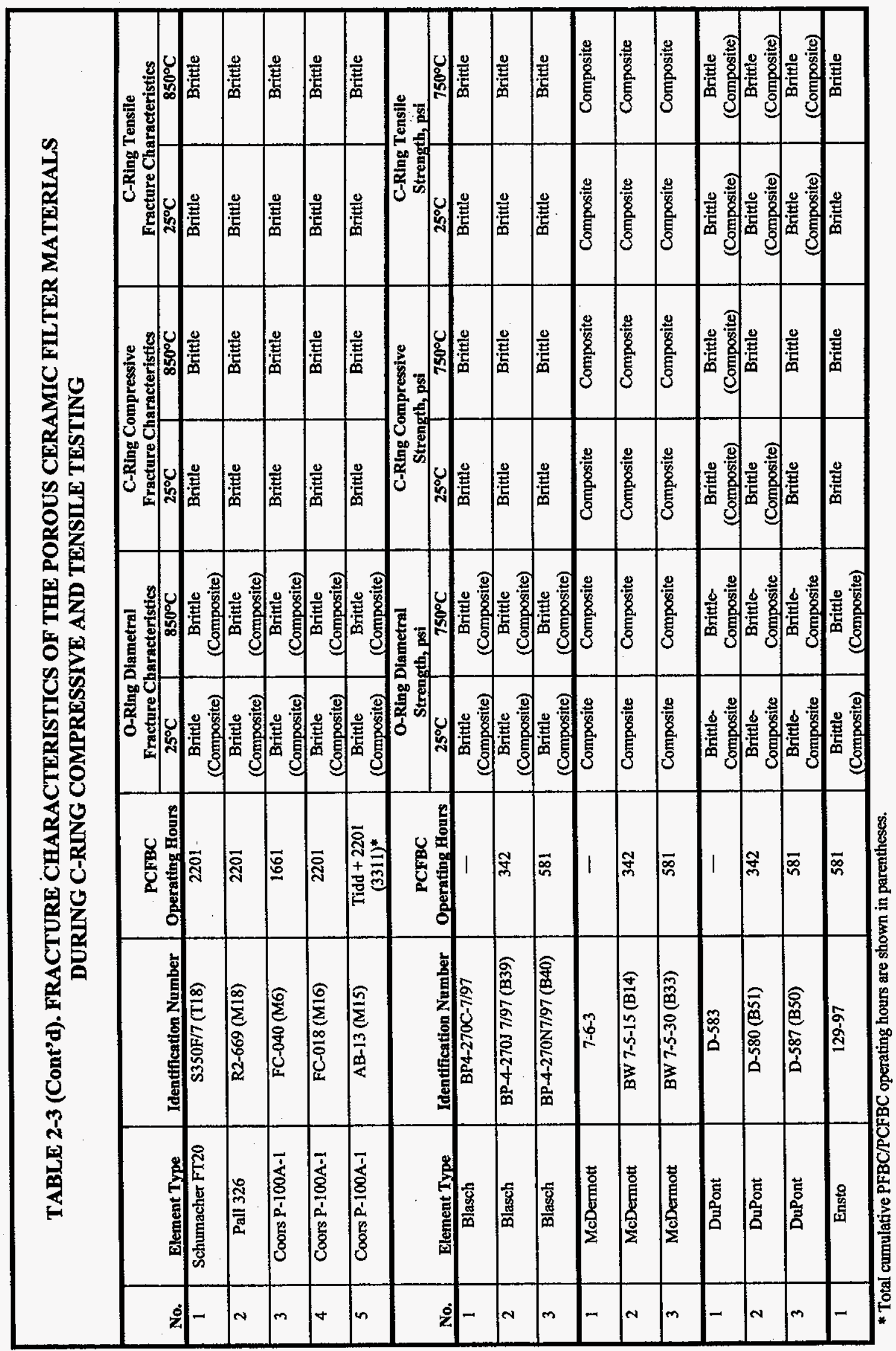


TABLE 2-4. COMPARISON OF STRENGTH MEASUREMENTS

\begin{tabular}{|c|c|c|c|c|}
\hline $\begin{array}{c}\text { As-Manufactured } \\
\text { Materials }\end{array}$ & \multicolumn{2}{|c|}{$\begin{array}{l}\text { O-Ring Diametral } \\
\text { Strength, psi } \\
750^{\circ} \mathrm{C}\end{array}$} & $\begin{array}{c}\text { C-Ring } \\
\text { Compressive } \\
\text { Strength, psi } \\
750^{\circ} \mathrm{C}\left(25^{\circ} \mathrm{C}\right)\end{array}$ & $\begin{array}{c}\text { C-Ring } \\
\text { Tensile } \\
\text { Strength, psi } \\
750^{\circ} \mathrm{C}\left(25^{\circ} \mathrm{C}\right)\end{array}$ \\
\hline DuPont PRD-66 & $1388 \pm 42$ & $1284 \pm 296$ & $\begin{array}{c}1223 \pm 103 \\
(976 \pm 107)\end{array}$ & $\begin{array}{c}1159 \pm 202 \\
(1041 \pm 170)\end{array}$ \\
\hline McDermott CFCC & $1068 \pm 73$ & $1111 \pm 61$ & $\begin{array}{c}956 \pm 346 \\
(898 \pm 166)\end{array}$ & $\begin{array}{c}1008 \pm 228 \\
(1207 \pm 202)\end{array}$ \\
\hline
\end{tabular}

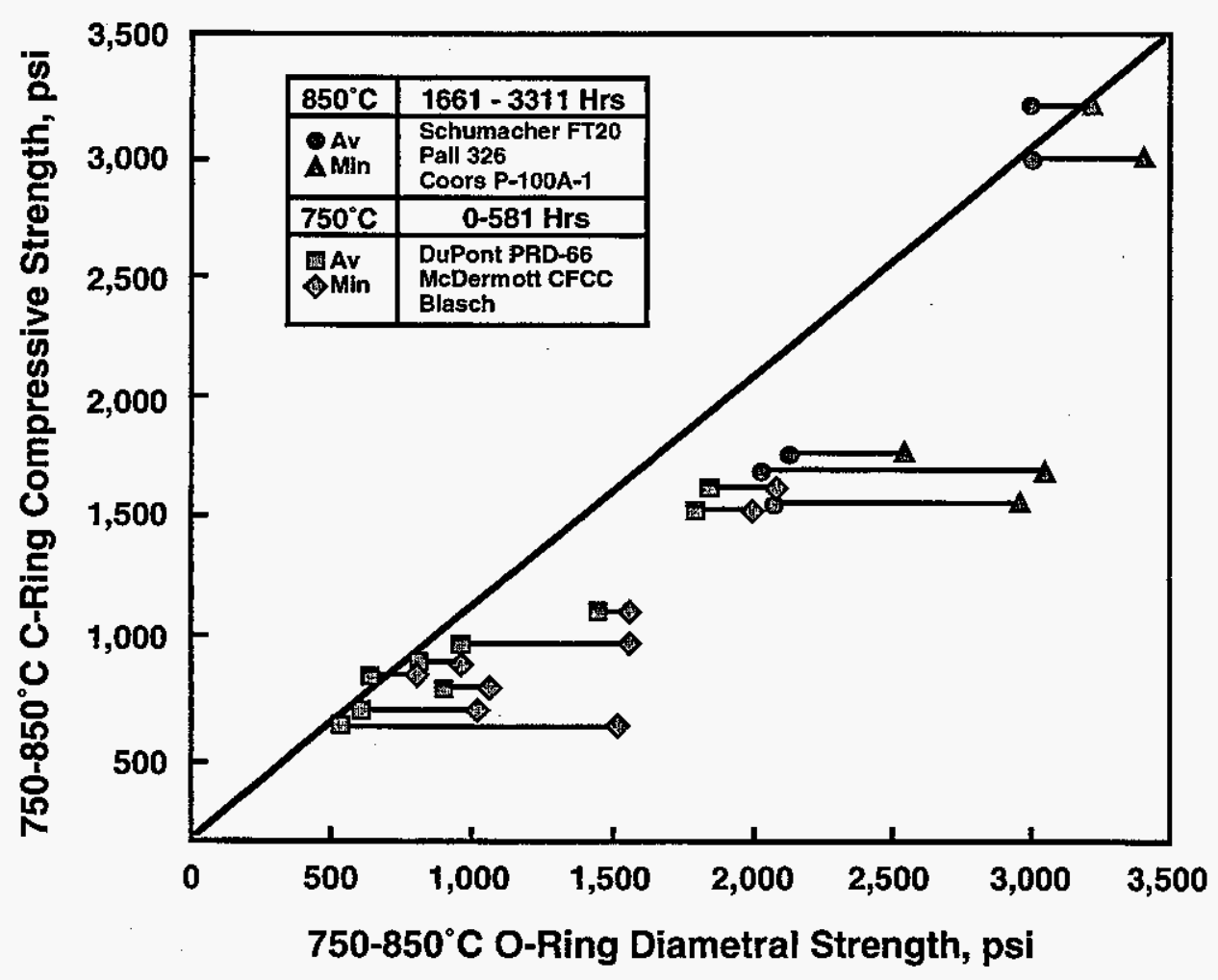

Figure 2-4 - Calculated process temperature strength relationship. 


\subsection{Hoop Stress, Elastic Modulus, and Poisson's Ratio}

A $254 \mathrm{~mm}$ section of material was removed from each of the as-manufactured and PCFBCexposed, commercially available, monolithic and advanced second generation candle filters. Two $90^{\circ}$ strain gage rosettes were installed along both inside and outside surfaces of the filter sections, at approximately the center of each test sample. A water filled bladder was inserted into the i.d. bore of each filter section, and was subsequently pressurized to determine the ultimate hoop strength of the filter material.

The pressure required to fail each filter section, the ultimate hoop stress, elastic modulus, and Poisson's ratio established for the PCFBC-exposed filter sections are presented in Table 2-5. When compared to the porous ceramic filter materials in their as-manufactured state, the general trends identified via c-ring strength determination are identified via the burst strength data for the PCFBCexposed filter matrices.

TABLE 2-5. MATERIAL PROPERTIES OF THE AS-MANUFACTURED AND PCFBC-EXPOSED POROUS CERAMIC CANDLE FILTERS

\begin{tabular}{|c|c|c|c|c|c|}
\hline $\begin{array}{c}\text { Candle } \\
\text { Identification } \\
\text { Number }\end{array}$ & $\begin{array}{l}\text { Operating } \\
\text { Time, Hrs }\end{array}$ & $\begin{array}{c}\text { Burst Pressure, } \\
\text { psi }\end{array}$ & $\begin{array}{c}\text { Ultimate Hoop } \\
\text { Stress, psi }\end{array}$ & $\begin{array}{l}\text { Modulus, } \\
\text { psi x } 10^{6}\end{array}$ & $\begin{array}{l}\text { Poisson's } \\
\text { Ratio }\end{array}$ \\
\hline \multicolumn{6}{|c|}{ Schumacher Dia Schumalith FT20 } \\
\hline $\begin{array}{c}\text { As-Manufactured } \\
\text { S350F/108 (T12) } \\
\text { S350F/42 (B15) } \\
\text { S350F/30 (T26) } \\
\text { S350F/7 (T18) }\end{array}$ & $\begin{array}{c}-\overline{540} \\
505 \\
1166 \\
2201\end{array}$ & $\begin{array}{l}665 \\
555 \\
590 \\
720 \\
585\end{array}$ & $\begin{array}{l}1703 \\
1496 \\
1584 \\
1942 \\
1524\end{array}$ & \begin{tabular}{|c|}
7.3 \\
7.44 \\
7.39 \\
5.77 \\
2.82 \\
\end{tabular} & $\begin{array}{l}0.17 \\
0.21 \\
0.15 \\
0.11 \\
0.13\end{array}$ \\
\hline \multicolumn{6}{|l|}{ Pall 326} \\
\hline $\begin{array}{c}\text { As-Manufactured } \\
\text { R5-655 (M21) } \\
\text { R5-654 (B21) } \\
\text { R6-674 (M26) } \\
\text { R2-669 (M18) }\end{array}$ & $\begin{array}{c}-\overline{5} \\
540 \\
505 \\
1166 \\
2201\end{array}$ & $\begin{array}{l}\mathrm{ND} \\
525 \\
520 \\
650 \\
690\end{array}$ & $\begin{array}{c}\text { ND } \\
1369 \\
1344 \\
1641 \\
1764\end{array}$ & $\begin{array}{l}\text { ND } \\
5.00 \\
5.15 \\
4.83 \\
4.83\end{array}$ & $\begin{array}{l}\text { ND } \\
0.16 \\
0.16 \\
0.13 \\
0.11\end{array}$ \\
\hline \multicolumn{6}{|c|}{ Coors P-100A-1 Alumina/Mullite } \\
\hline $\begin{array}{c}\text { As-Manufactured } \\
\text { FC-070 (B22) } \\
\text { DC-051 (B1) } \\
\text { FC-035 (B16) } \\
\text { FC-007 (B29) } \\
\text { EC-014 (B28) } \\
\text { FC-040 (M6) } \\
\text { FC-018 (M16) } \\
\text { AB-13 (M15) }\end{array}$ & $\begin{array}{c}\overline{505} \\
1650(\mathrm{a}) \\
626(\mathrm{TS} 3) \\
1166 \\
2276(\mathrm{a}) \\
1661 \\
2201 \\
3311(\mathrm{a})\end{array}$ & $\begin{array}{l}860 \\
540 \\
505 \\
520 \\
565 \\
505 \\
588 \\
545 \\
520\end{array}$ & $\begin{array}{l}2317 \\
1503 \\
1373 \\
1425 \\
1402 \\
1380 \\
1599 \\
1473 \\
1441 \\
\end{array}$ & $\begin{array}{l}5.7 \\
4.84 \\
5.18 \\
3.90 \\
3.44 \\
4.37 \\
4.36 \\
5.79 \\
3.99\end{array}$ & $\begin{array}{l}0.23 \\
0.21 \\
0.20 \\
0.18 \\
0.25 \\
0.24 \\
0.12 \\
0.18 \\
0.15\end{array}$ \\
\hline
\end{tabular}

(a) PFBC/PCFBC-exposed candle filter.

ND: Not determined. 


\section{TABLE 2-5 (Cont'd). MATERIAL PROPERTIES OF THE AS-MANUFACTURED AND PCFBC-EXPOSED POROUS CERAMIC CANDLE FILTERS}

\begin{tabular}{|c|c|c|c|c|c|}
\hline $\begin{array}{c}\text { Candle } \\
\text { Identification } \\
\text { Number }\end{array}$ & $\begin{array}{l}\text { Operating } \\
\text { Time, Hrs }\end{array}$ & $\begin{array}{c}\text { Burst Pressure, } \\
\text { psi }\end{array}$ & $\begin{array}{c}\text { Ultimate Hoop } \\
\text { Stress, psi }\end{array}$ & $\begin{array}{l}\text { Modulus, } \\
\text { psi } \times 10^{6}\end{array}$ & $\begin{array}{l}\text { Poisson's } \\
\text { Ratio }\end{array}$ \\
\hline \multicolumn{6}{|l|}{ 3M CVI-SiC Composite } \\
\hline $\begin{array}{l}\text { As-Manufactured } \\
\text { M-51103 (B36) } \\
\text { M-51153 (B31) }\end{array}$ & $\begin{array}{l}-\overline{387} \\
626\end{array}$ & $\begin{array}{l}\text { ND } \\
133 \\
105\end{array}$ & $\begin{array}{l}1.01 \mathrm{ksi} \\
1179 \\
946\end{array}$ & $\begin{array}{l}2.96-3.38 \\
3.35 \\
5.59\end{array}$ & $\begin{array}{l}0.14-0.27 \\
0.22 \\
0.34\end{array}$ \\
\hline \multicolumn{6}{|l|}{ McDermott CFCC } \\
\hline $\begin{array}{c}\text { As-Manufactured BW-7-6-3 } \\
\text { BW-7-5-15 (B14) } \\
\text { BW-7-5-30 (B33) } \\
\end{array}$ & $\begin{array}{l}- \\
342 \\
581\end{array}$ & $\begin{array}{l}220 \\
140 \\
185\end{array}$ & $\begin{array}{c}1256 \\
845 \\
1077 \\
\end{array}$ & $\begin{array}{l}1.61 \\
1.80 \\
1.61\end{array}$ & $\begin{array}{l}0.99 \\
1.04 \\
1.13\end{array}$ \\
\hline \multicolumn{6}{|l|}{ DuPont PRD-66 } \\
\hline $\begin{array}{c}\text { As-Manufactured D-583 } \\
\text { D-580 (B51) } \\
\text { D-587 (B50) }\end{array}$ & $\begin{array}{l}-5 \\
342 \\
581\end{array}$ & $\begin{array}{l}195 \\
190 \\
210\end{array}$ & $\begin{array}{l}731 \\
735 \\
792\end{array}$ & $\begin{array}{l}7.85 \\
8.19 \\
6.57\end{array}$ & $\begin{array}{l}1.09 \\
0.71 \\
0.71\end{array}$ \\
\hline \multicolumn{6}{|l|}{ Techniweave } \\
\hline $\begin{array}{c}\text { As-Manufactured } \\
\mathrm{T} 1 \\
\end{array}$ & $\overline{40}$ & $\begin{array}{c}284 \\
202 \\
\end{array}$ & $\begin{array}{l}3512 \\
2092 \\
\end{array}$ & $\begin{array}{l}12.4 \\
15.7 \\
\end{array}$ & $\overline{0.24}$ \\
\hline \multicolumn{6}{|l|}{ 3M Oxide-Based CFCC } \\
\hline $\begin{array}{c}\text { As-Manufactured (Type A) (b) } \\
710 \text { (Type A) } \\
\text { As-Manufactured (Type B) (c) }\end{array}$ & $\overline{40}$ & $\begin{array}{c}64 \\
54 \\
118\end{array}$ & $\begin{array}{l}572 \\
443 \\
1460\end{array}$ & $\begin{array}{l}6.0 \\
1.8 \\
6.3\end{array}$ & $\begin{array}{l}0.27 \\
0.61 \\
0.32\end{array}$ \\
\hline \multicolumn{6}{|c|}{ Blasch Mullite-Bonded Alumina } \\
\hline $\begin{array}{c}\text { BP4-270C-7/97 } \\
\text { BP-4-270J 7/97(B39) } \\
\text { BP-4-270N 7/97(B40) }\end{array}$ & $\begin{array}{l}\overline{342} \\
581 \\
\end{array}$ & $\begin{array}{l}150 \\
175 \\
205 \\
\end{array}$ & $\begin{array}{l}363 \\
410 \\
485 \\
\end{array}$ & $\begin{array}{l}2.35 \\
1.92 \\
1.26 \\
\end{array}$ & $\begin{array}{l}0.18 \\
0.09 \\
0.10\end{array}$ \\
\hline \multicolumn{6}{|c|}{ Ensto Mullite-Bonded Alumina } \\
\hline $129-97$ & 581 & 505 & 1073 & 5.19 & 0.61 \\
\hline
\end{tabular}

ND: Not determined.

(b) Type A: Outer confinement layer: Coarse Nextel ${ }^{\mathrm{TM}} 550$; Filtration mat: $\alpha-\mathrm{Al}_{2} \mathrm{O}_{3}$; Triaxial support braid: Nextel 610.

(c) Type B: Outer confinement layer: Fine $\mathrm{Nextel}^{\mathrm{TM}} 610$; Filtration mat: $\alpha-\mathrm{Al}_{2} \mathrm{O}_{3}$; Triaxial support braid: Nextel ${ }^{\mathrm{TM}} 610$. 


\subsection{High Temperature Creep}

High temperature creep testing was conducted on $115 \mathrm{~mm} \times 8.5 \mathrm{~mm} \times 12 \mathrm{~mm}$ bars that were removed from the 2201 hour, PCFBC-exposed, Schumacher Dia Schumalith FT20 and Pall 326 candle filters. The Schumacher Dia Schumalith FT20 and Pall 326 filter materials unlike the Schumacher Dia Schumalith F40 and Pall Vitropore 442T filter materials, exhibited negligible high temperature creep when a $500 \mathrm{psi}$, 4-point bend, flexural load was applied to the surface of the bend bars for a period of $50 \mathrm{C}$ hours at temperatures of $750^{\circ} \mathrm{C}$ and $850^{\circ} \mathrm{C}$ (Table 2-6 and Figure 2-5). The enhanced high temperature creep resistance of the Schumacher Dia Schumalith FT20 and Pall 326 filter matrices resulted from manufacturing changes that had been made to the binder phase during production of both filter elements.

\section{TABLE 2-6. PERCENT CREEP STRAIN AND SILICA CONCENTRATIONS IN} PCFBC-EXPOSED CLAY BONDED SILICON CARBIDE FILTER MATRICES

\begin{tabular}{|c|c|c|c|}
\hline Filter & $\begin{array}{c}\text { PCFBC Operating } \\
\text { Time, Hrs }\end{array}$ & \% Silica & \% Creep Strain * \\
\hline \multirow{3}{*}{ Schumacher FT20 } & -- & 11.72 & 0.085 \\
& 540 & 17.23 & 0 \\
& 1166 & 15.51 & 0.038 \\
& 2201 & 10.68 & 0.06 (a) \\
& - & 6.86 & 0.11 (b) \\
\hline \multirow{2}{*}{ Pall 326 } & 540 & 13.75 & 0.085 \\
& 1166 & 9.77 & 0 \\
& 2201 & 9.70 & 0.03 (a) \\
& & & 0.00 (b) \\
\hline
\end{tabular}

* $500 \mathrm{psi}, 843^{\circ} \mathrm{C}, 300-500 \mathrm{hrs}$.

(a) $750^{\circ} \mathrm{C}, 500 \mathrm{psi}$.

(b) $850^{\circ} \mathrm{C}, 500$ psi.

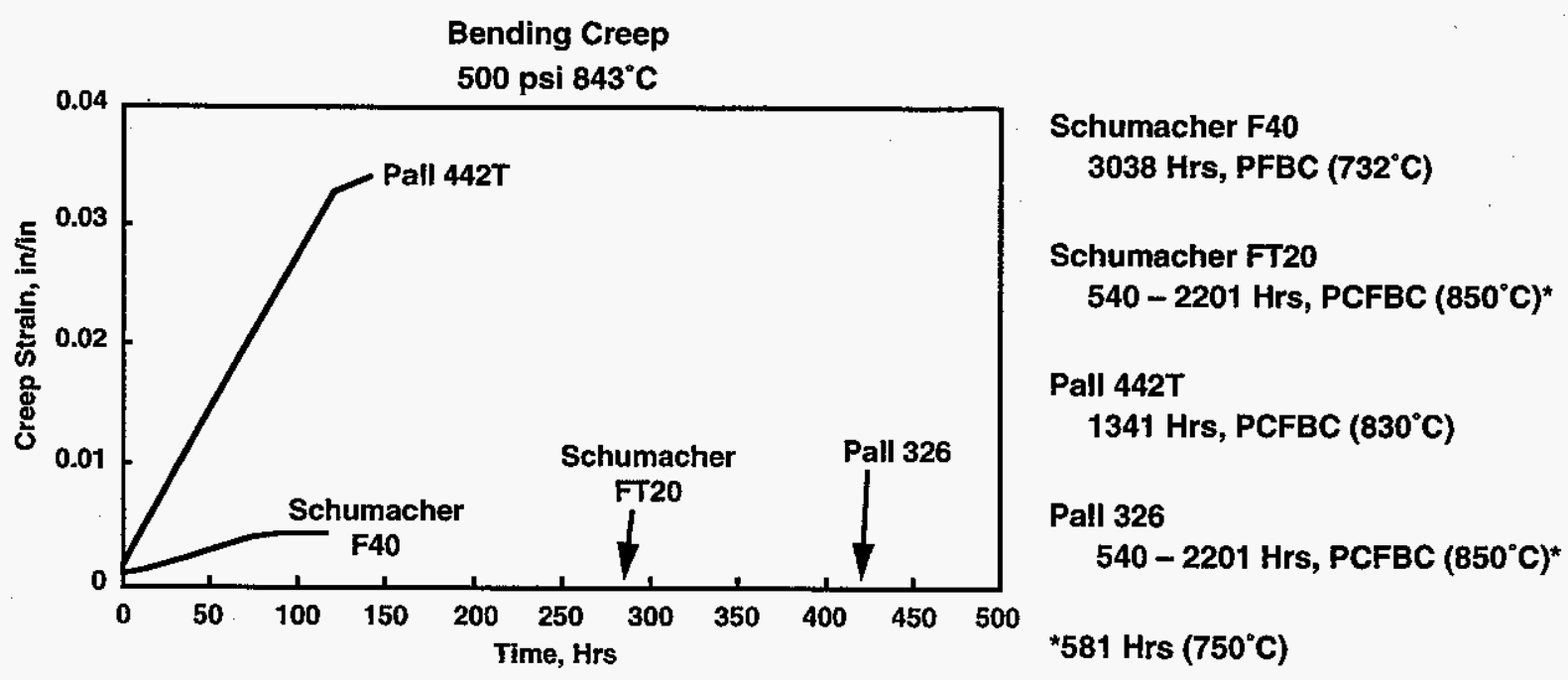

Figure 2-5 - Creep strain of PCFBC-exposed nonoxide-based candle filters. 
During post-test inspection of the 2201 hour, PCFBC-exposed, filter elements, the candles were visually inspected, and the overall lengths of the filter elements were measured. Cracks were not observed along the outer surface of the filter body (i.e., below the flange of the clay bonded silicon carbide candles). An elongation of between 9-11 mm (0.6-0.7\%) was observed for the Schumacher Dia Schumalith FT20 candles, and between 8-9.5 mm (0.5-0.6\%) for the Pall 326 filter elements (Table 2-7 and Figure 2-6). The apparent decrease in the elongation rate was considered to have resulted from reduction in the $\mathrm{PCFBC}$ operating temperature from $850^{\circ} \mathrm{C}$ to $750^{\circ} \mathrm{C}$ during testing in TS2-97. Since high temperature creep testing of the Schumacher Dia Schumalith FT20 and Pall 326 filter materials did not identify significant binder phase creep, the observed candle elongation was attributed to continued oxidation of the silicon carbide grains in the PCFBC environment.

\begin{tabular}{|c|c|c|c|c|}
\hline \multicolumn{5}{|c|}{ TABLE 2-7. ELONGATION OF CLAY BONDED } \\
SILICON CARBIDE CANDLE FILTERS \\
\hline \multirow{3}{*}{ Tilter Element } & \multicolumn{3}{c|}{ Tidd PFBC } & \multicolumn{2}{c|}{ Karhula PCFBC } \\
\cline { 2 - 5 } & Operating & Elongation, & Operating & Elongation, \\
Time, Hrs & mm & Time, Hrs & mm \\
\hline Schumacher Dia Schumalith F40 & 5855 & $5-7$ & 227 & ND \\
Schumacher Dia Schumalith FT20 & 1705 & ND & 1166 & $6-8$ \\
Schumacher Dia Schumalith FT20 & - & - & 1620 & $8-10$ \\
Schumacher Dia Schumalith FT20 & - & - & 2201 & $9-11$ \\
\hline Pall Vitropore 442T & 1110 & $0-4$ & 1341 & $1-26$ \\
Pall 326 & - & - & 1166 & $5-8$ \\
Pall 326 & - & - & 1620 & $7-9$ \\
Pall 326 & - & - & 2201 & $8-9.5$ \\
\hline
\end{tabular}

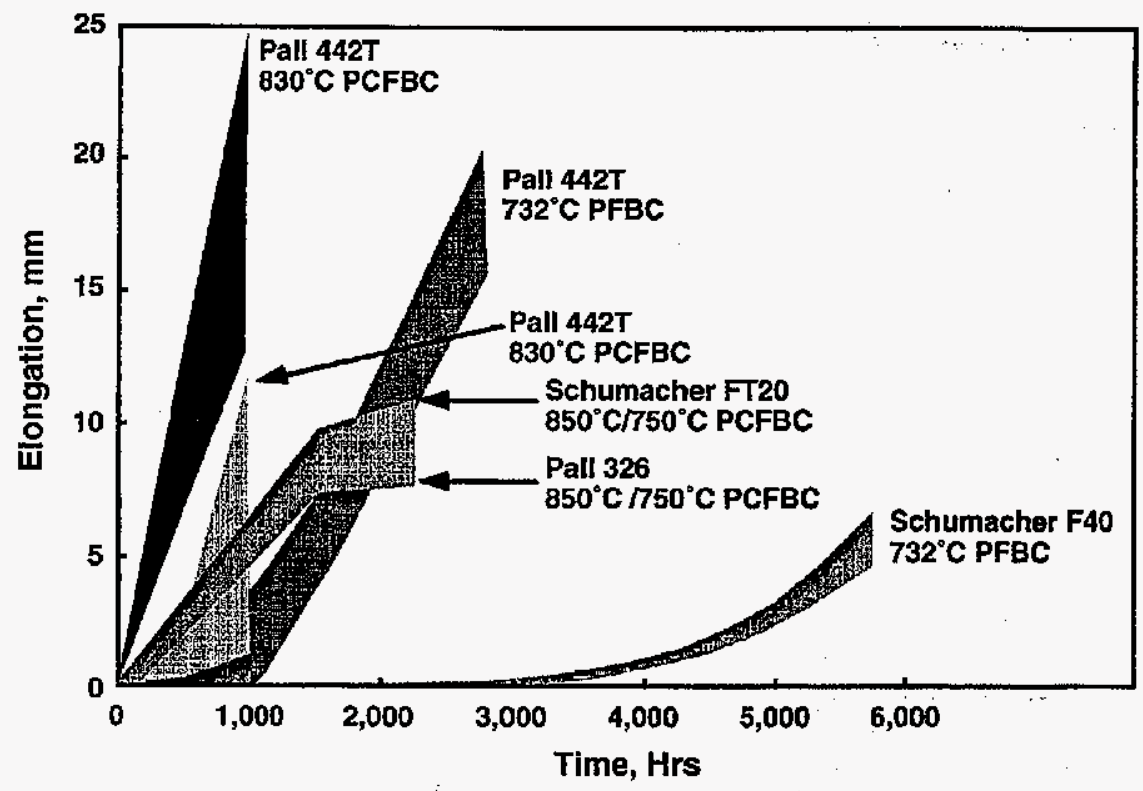

Figure 2-6 - Impact of process operating conditions on clay bonded silicon carbide candle filter elongation. 


\subsection{Microstructural Analysis}

Efforts at SWPC were conducted to monitor the aging process and discern the resulting microstructure of the commercially available monolithic, as well as advanced second generation porous ceramic filter materials after extended operation in the PCFBC process gas environment. By monitoring changes within the microstructure via scanning electron microscopy/energy dispersive $\mathrm{x}$-ray analysis (SEM/EDAX), potential life-limiting material degradation mechanisms are identified and continually assessed. The following sections describe the early stages of the aging process for eight ceramic filter materials, and where appropriate, comment on the implications for extended hot gas filter life.

\subsubsection{Schumacher Dia Schumalith FT20 Candle Filters}

The as-manufactured, $10 \mathrm{~mm}$ thick structural support wall of the monolithic Schumacher Dia Schumalith FT20 filter matrix consists of silicon carbide grains that are bonded together via a high temperature creep resistant binder. An $100 \mu \mathrm{m}$ thick membrane layer was applied to the outer surface of each filter element. The membrane consists of the high temperature binder phase, alumina fibers, as well as fine grains of silicon carbide.

Extensive crystallization of the high temperature creep resistant Schumacher Dia Schumalith FT20 filter matrix occurred after 540 hours of operation in the $850^{\circ} \mathrm{C} \mathrm{PCFBC}$ environment (Figure 2-7). Negligible changes were detected within the fibrous outer membrane.

In contrast after 1166 hours of operation in the PCFBC environment, an amorphous or melt-like phase resulted along the surface of the silicon carbide grains in the support matrix near the o.d. surface of the filter element (Figures 2-8 and 2-9). At the center of the cross-sectioned filter wall and i.d. surface, extensive crystallization of the coating that encapsulated the silicon carbide grains was evident (Figures 2-10, 2-11, 2-12). Although the binder-containing elements (i.e., aluminum, potassium, and sodium) were typically present within the silicon-oxygen-enriched layer that encapsulated the silicon carbide grains in the Schumacher Dia Schumalith FT20 filter matrix, in several areas, the concentration of these elements was relatively low. This implied that oxidation of the silicon carbide grains resulted, leading to the formation of $\mathrm{SiO}_{2}$, and subsequently a reduction in the concentration of the original bindercontaining elements within the layer that encapsulated the support grains.

The clay bonded silicon carbide Schumacher Dia Schumalith FT20 candle filter (S350F/7 (T18)) which had been exposed for 2201 hours to the PCFBC environment was initially subjected to 1620 hours of operation at temperatures of $870^{\circ} \mathrm{C}$, and subsequently to 581 hours of operation at $750^{\circ} \mathrm{C}$.

Microstructural analyses of this element indicated that the membrane coating of the 2201 hour, PCFBCexposed, Schumacher Dia Schumalith FT20 filter matrix was intact at the conclusion of the TS2-97 test campaign (Figure 2-13 and Figure 2-14). Negligible penetration of fines into the o.d. membrane was observed. Three distinct microstructural features resulted within the 2201 hour, PCFBC-exposed, Schumacher Dia Schumalith FT20 filter matrix. These included:

- Near or full crystallization of a silica-enriched phase in the encapsulating layer that surrounded the silicon carbide grains (Figure 2-15).

- The crystallized silica-enriched phase contained $3 \mu \mathrm{m}$ thick x $6 \mu \mathrm{m}$ angularly-shaped grains. 

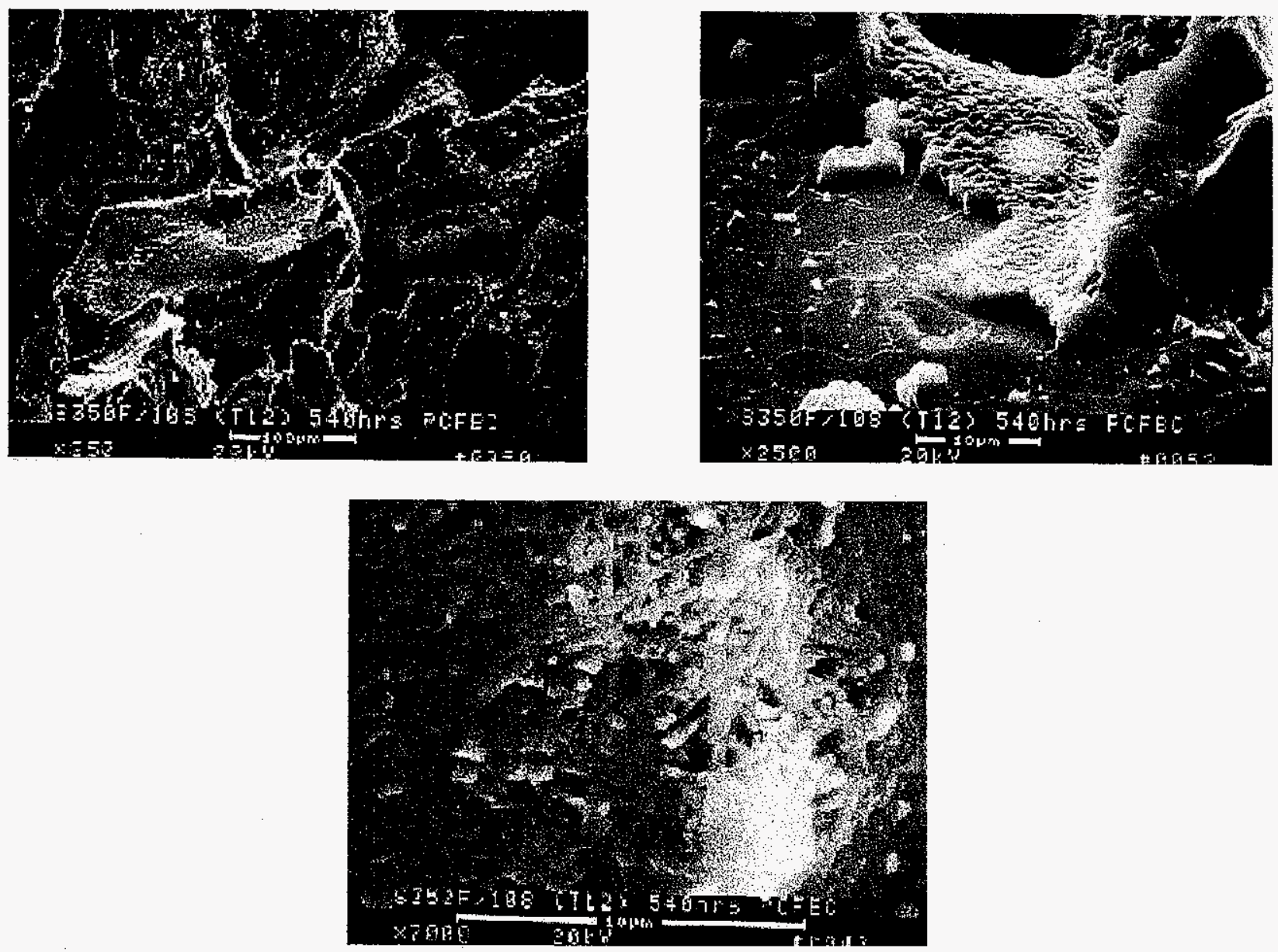

Figure 2-7 - Microstructure of the 540 hour, PCFBC-exposed, Schumacher Dia Schumalith FT20 filter matrix. 


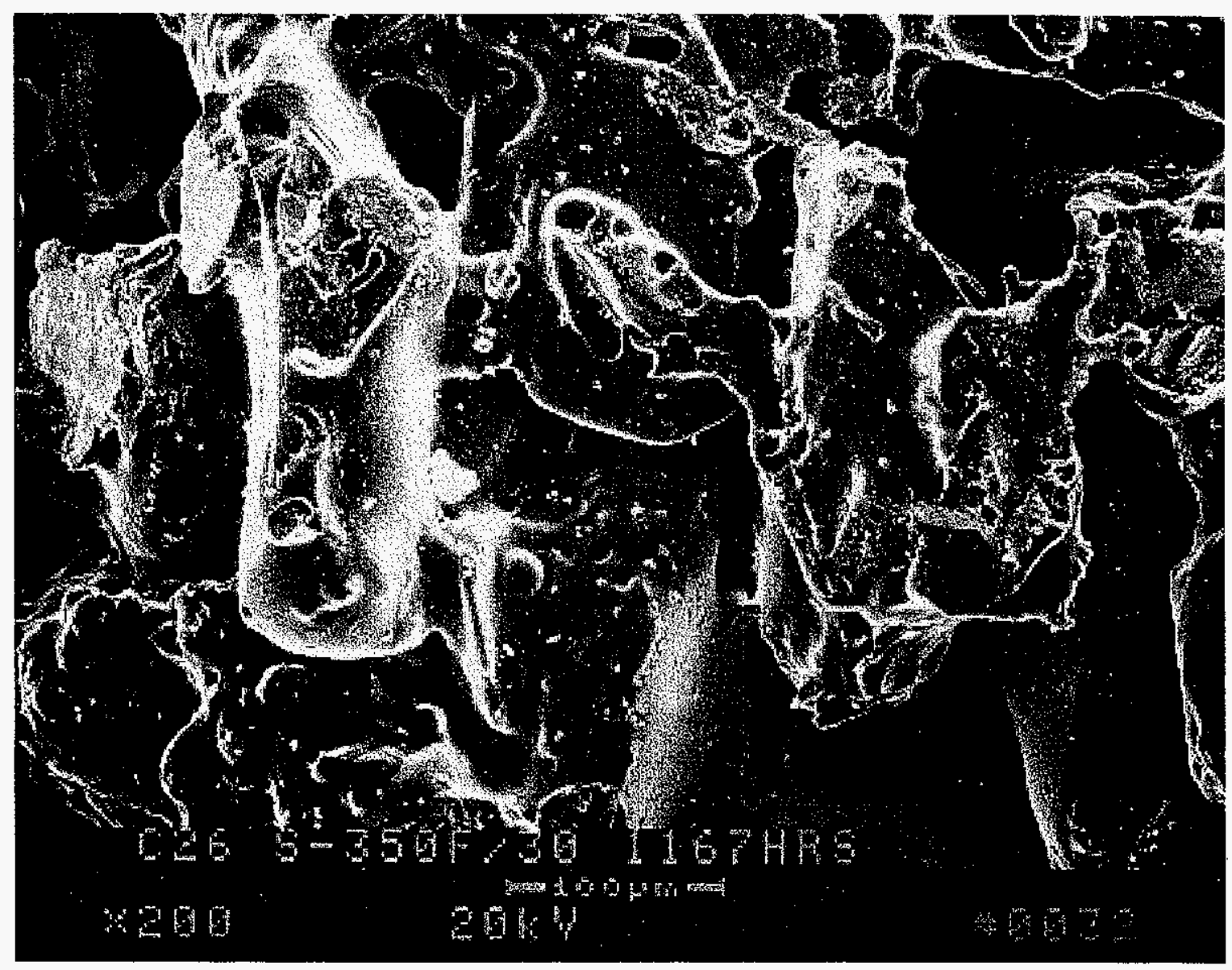

Figure 2-8 - Microstructure of the 1166 hour, PCFBC-exposed, Schumacher Dia Schumalith FT20 filter matrix near the outer surface of the filter element. 


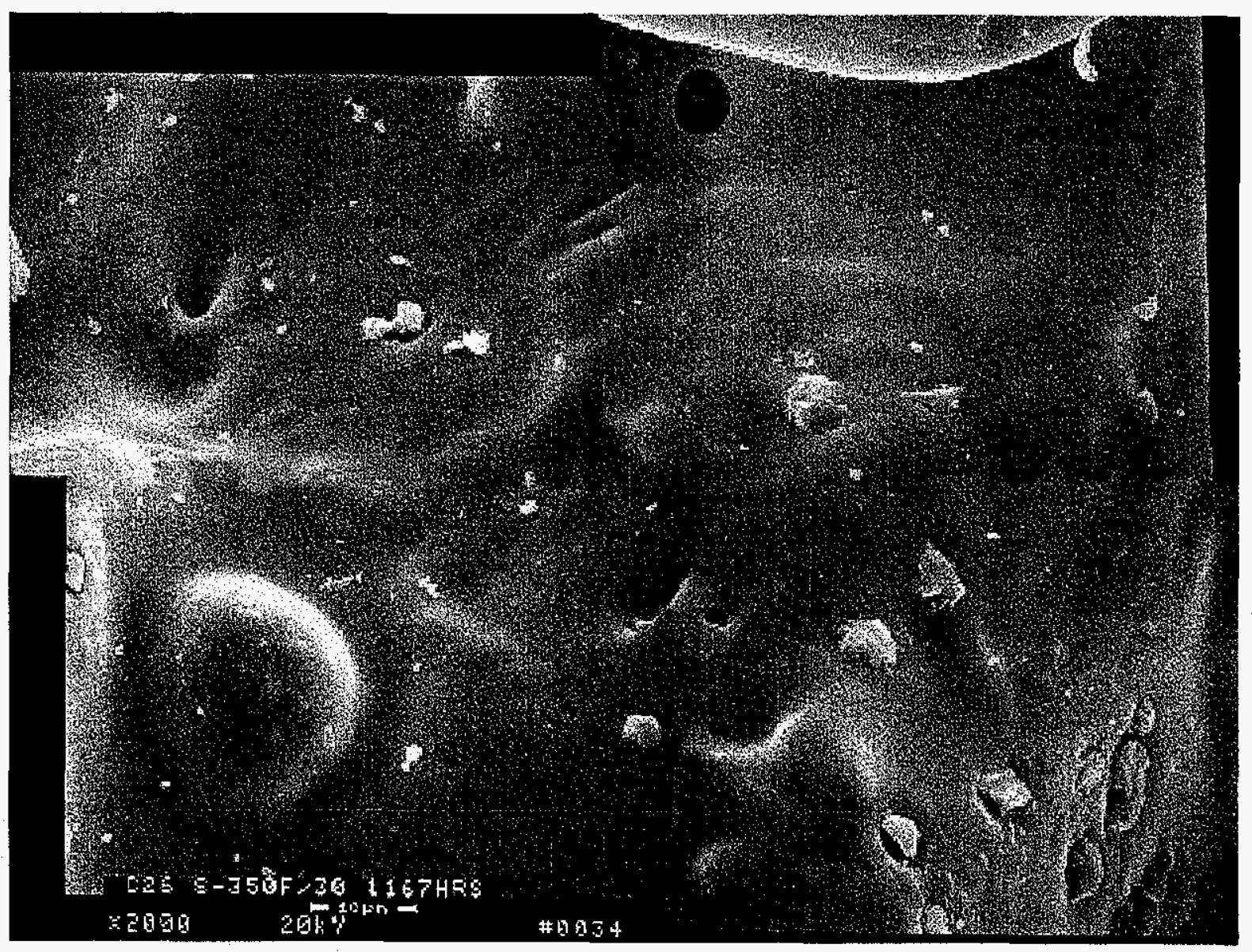

Figure 2-9 - Melt-like appearance of the coating that encapsulated the silicon carbide grains in the 1166 hour, PCFBC-exposed, Schumacher Dia Schumalith FT20 filter matrix near the outer surface of the filter element. 


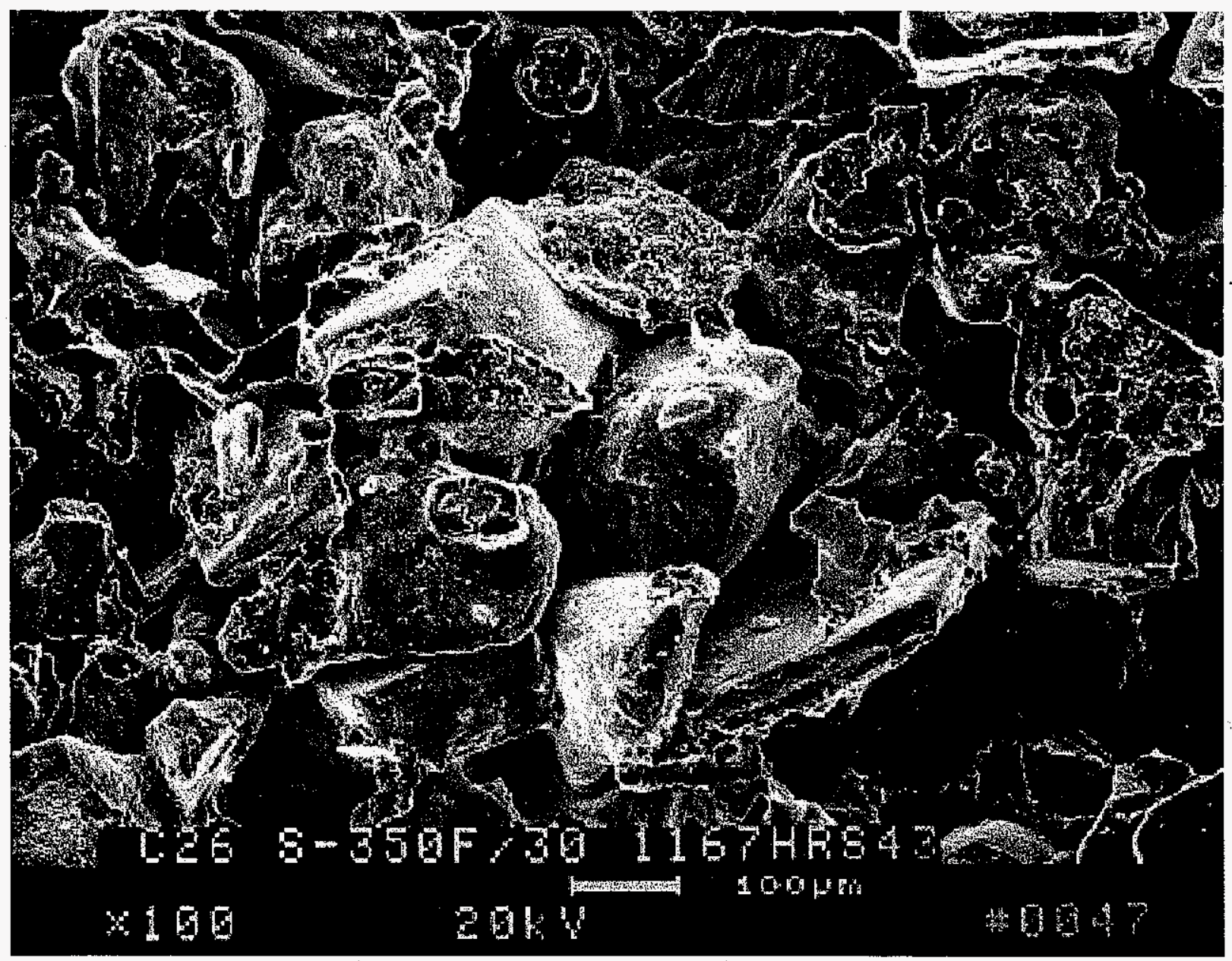

Figure 2-10 - Microstructure of the 1166 hour, PCFBC-exposed, Schumacher Dia Schumalith FT20 filter matrix near the center of the filter wall. 


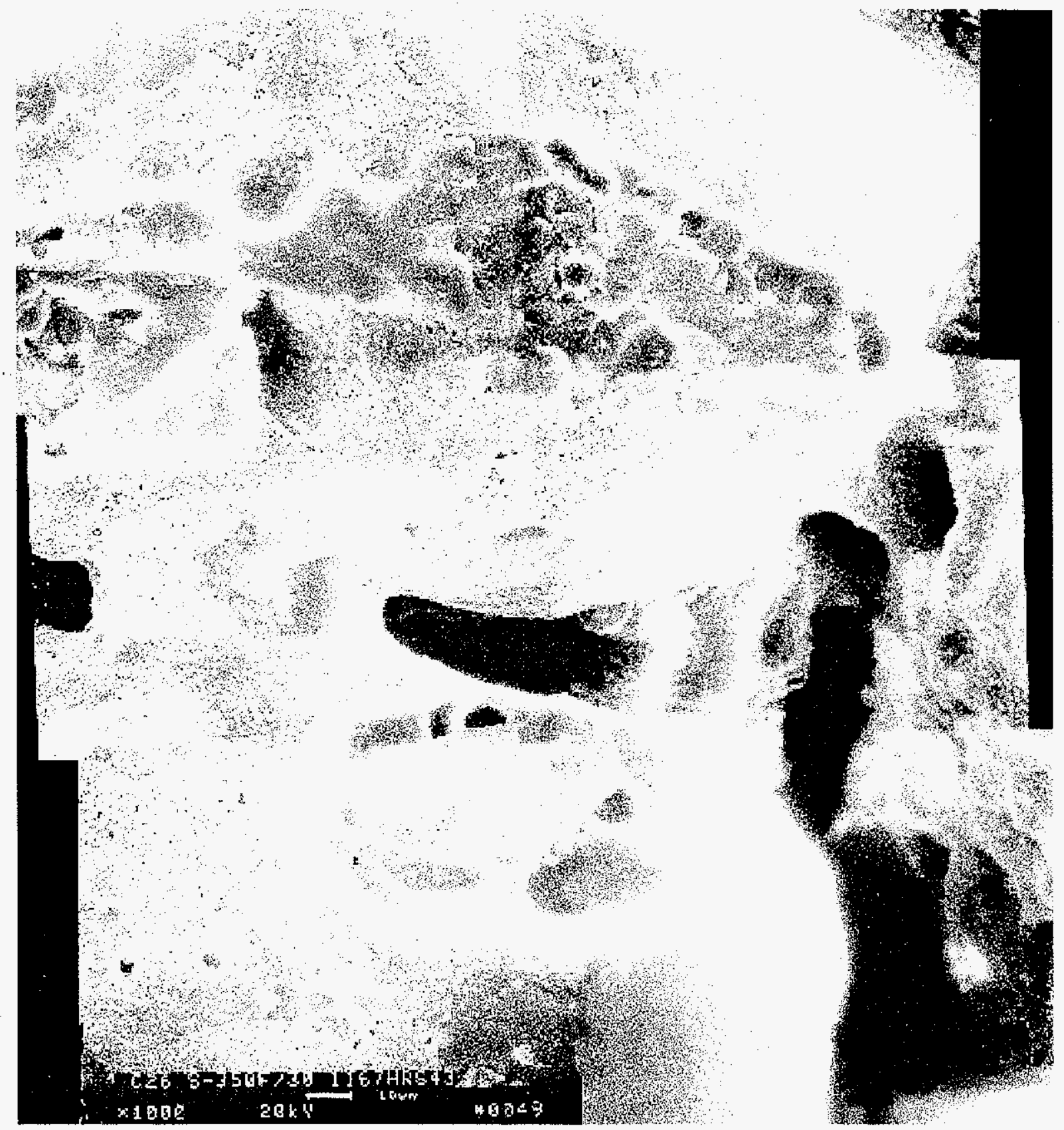

Figure 2-11 - Extensive crystallization that resulted along the coating that encapsulated the silicon carbide grains in the 1166 hour, PCFBC-exposed, Schumacher Dia Schumalith FT20 filter matrix near the center of the filter wall. 


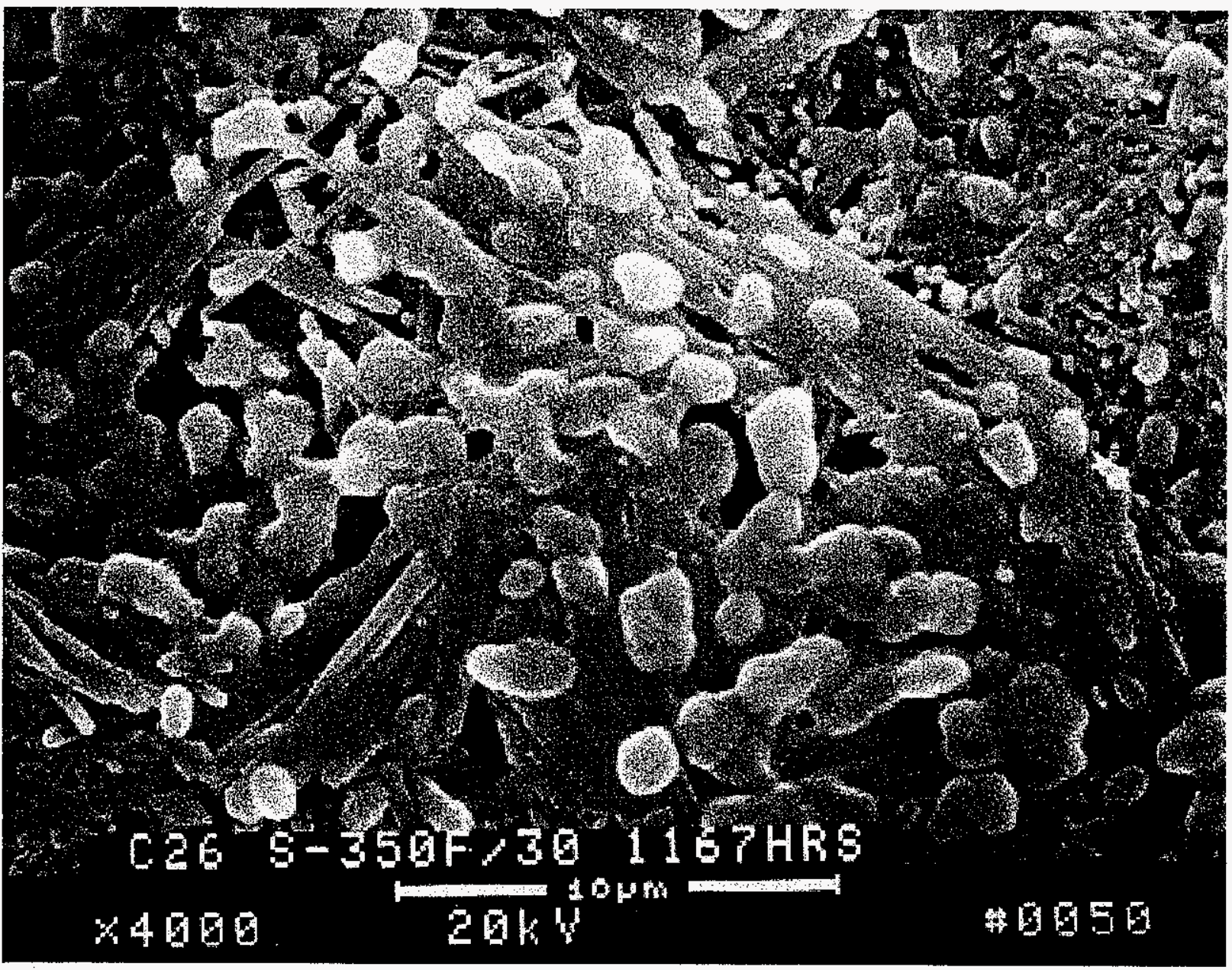

Figure 2-12 - Morphology of the mullite-enriched phase that encapsulated the 1166 hour, PCFBC-exposed, silicon carbide grains in the Schumacher Dia Schumalith FT20 filter matrix near the center of the filter wall. 


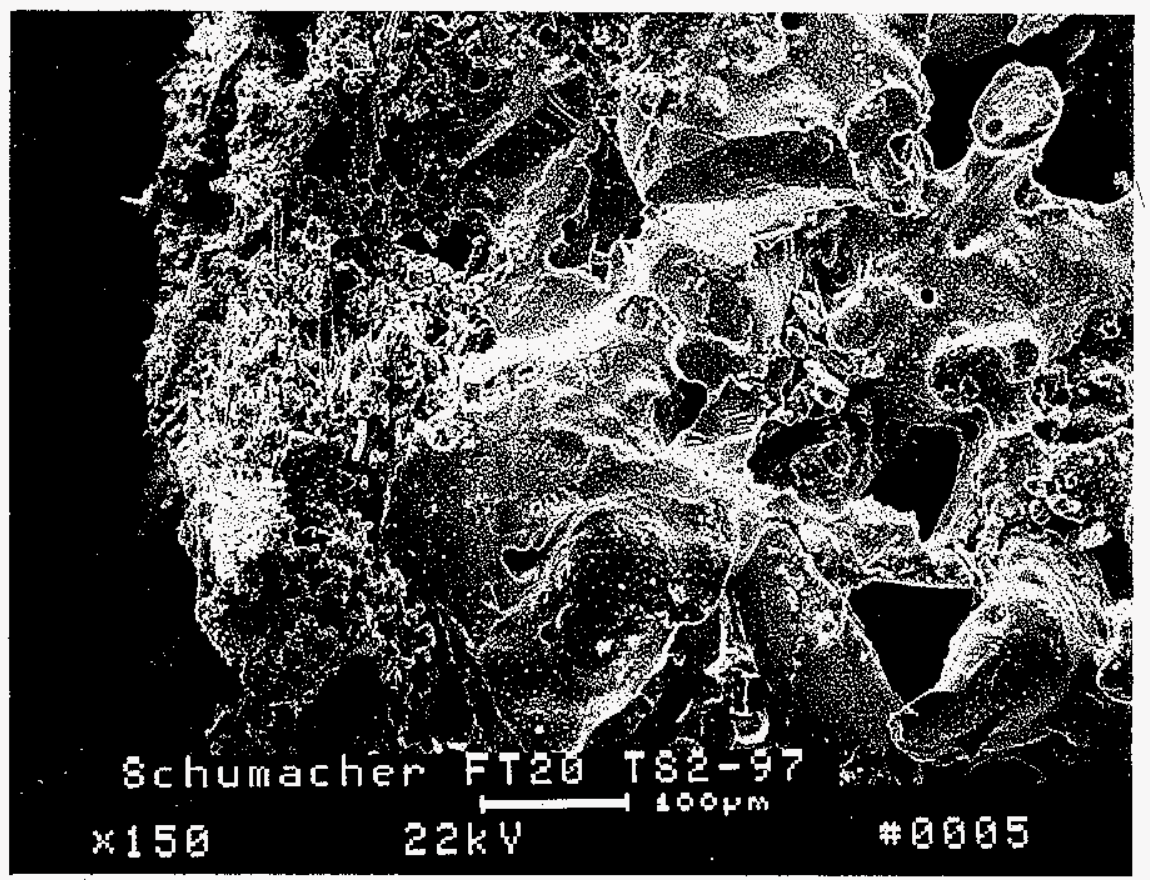

Figure 2-13 - Morphology of the cross-sectioned Schumacher Dia Schumalith FT20 filter matrix after 2201 hours of operation in the PCFBC environment. 


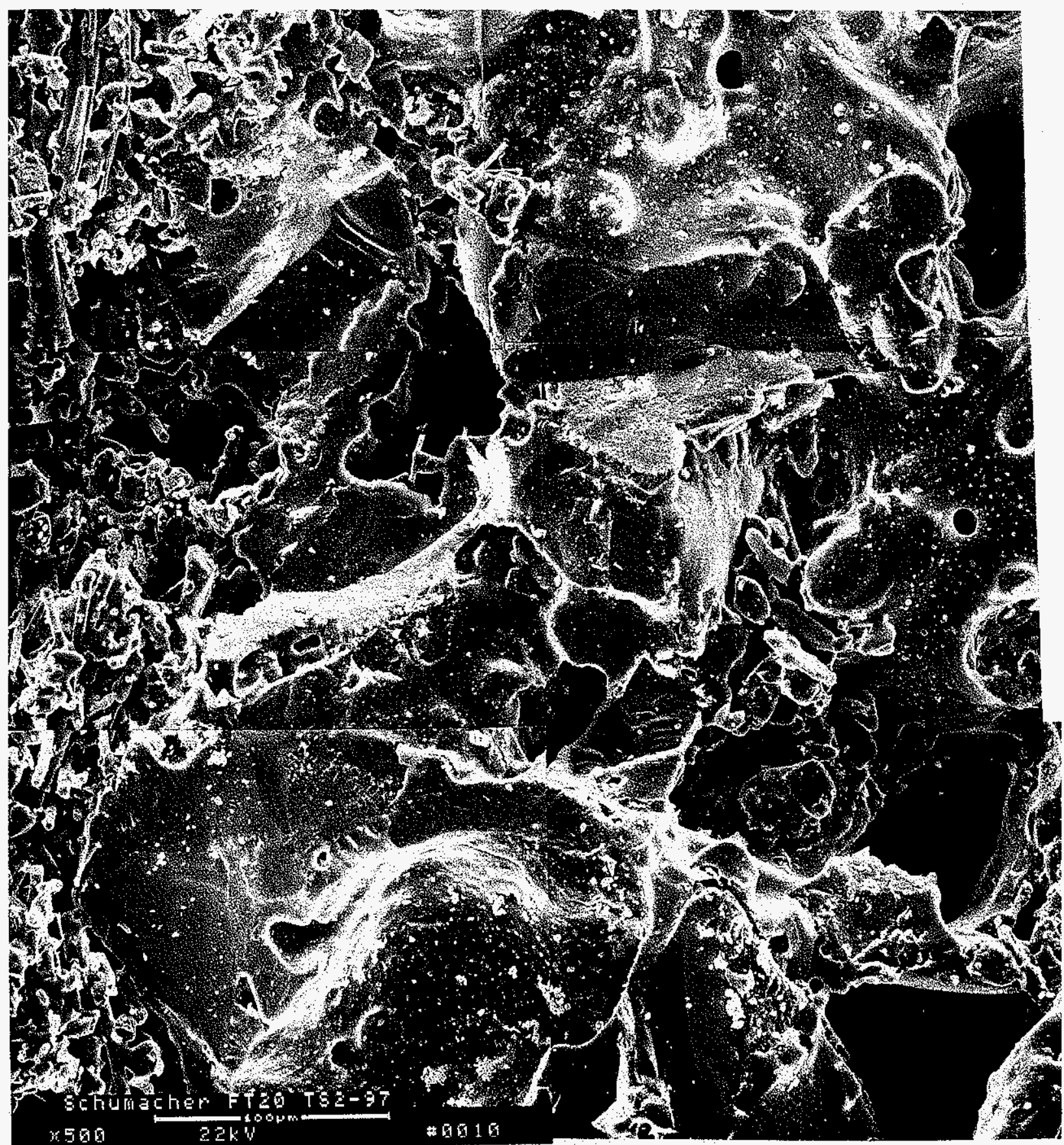

Figure 2-14 - Higher magnification micrograph montage illustrating the affinity of the outer surface membrane to the first structural support grains in the 2201 hour, PCFBCexposed, Schumacher Dia Schumalith FT20 filter matrix. Negligible fines penetration into the porous structural support wall was evident. 


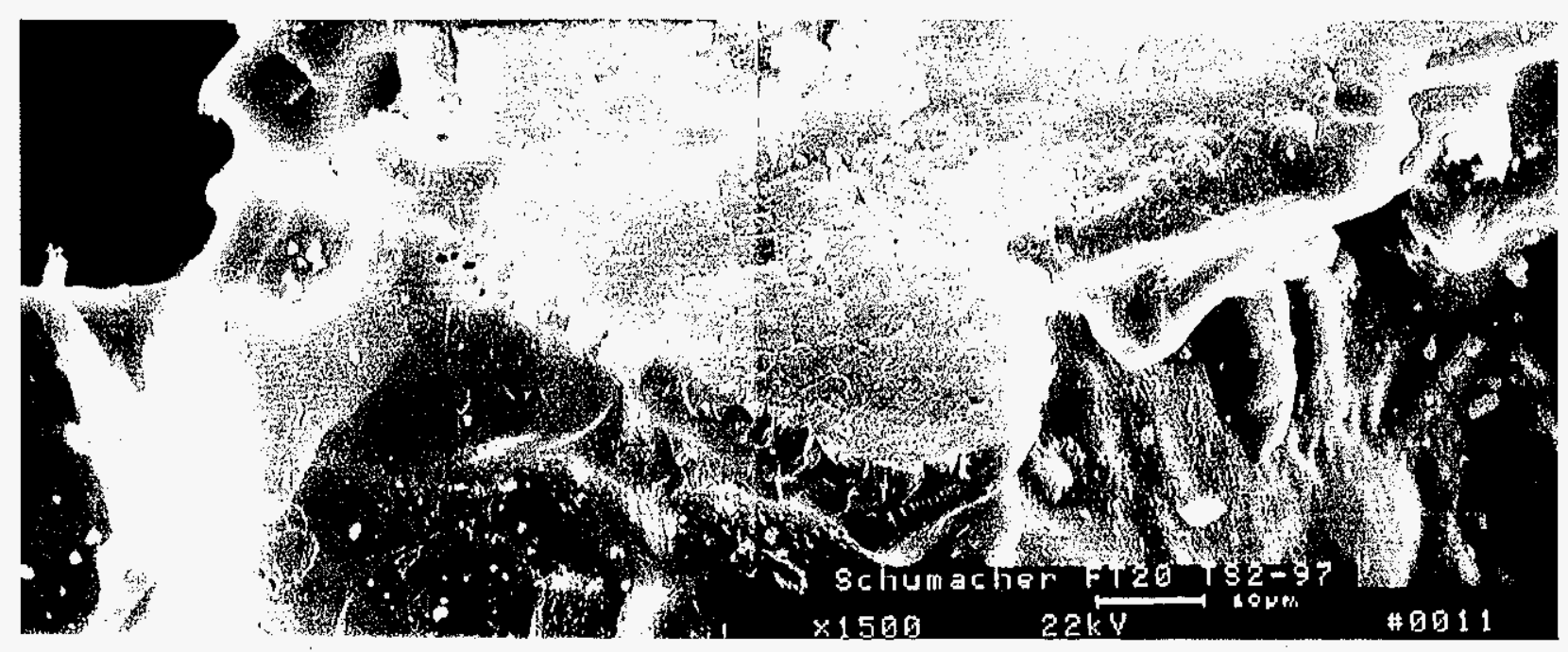

Figure 2-15 - Crystallization of the silica-enriched phase that encapsulated the silicon carbide grains in the 2201 hour, PCFBC-exposed, Schumacher Dia Schumalith FT20 filter matrix. 
- Adjacent silica-enriched grains appeared to be bonded to each other along adjoining sides, with submicron channels formed between adjoining corners (Figure 2-16 and Figure 2-17). The submicron channels were expected to permit continued gas penetration to the underlying surface of the silicon carbide grain, thus leading to further oxidation.

- In many areas, the $3 \mu \mathrm{m}$ thick silica-enriched layer was separated from the underlying silicon carbide grain. In other areas, the silica-enriched layer was either attached via point contacts, or was tenaciously bonded to the underlying silicon carbide grain.

- Two phases were identified within the $3 \mu \mathrm{m}$ thick $\times 6 \mu \mathrm{m}$ angularly-shaped silica grains (Figure 2-18). These included the presence of aluminum within the silicaenriched outer surface (i.e., presence of the binder-containing constituents forming a solid solution aluminosilicate-silica complex), while a silica-enriched phase resulted directly along the surface of the silicon carbide grain (i.e., oxidation of the grain; limited/reduced concentration of the binder constituents).

- Along the outer surface of the structural support ligaments, a crystalline, rod-like, aluminosilicate-enriched phase was evident (Figure 2-19). Limited crystallization was identified below the surface of the binder-containing ligament.

- Near and/or along the i.d. surface, extended, rounded or elliptical, nodular features resulted often at the protruding ends of the aluminosilicate-enriched, rod-like formations (Figure 2-20). Pulse cycling of the filter wall may have induced enhanced crystallization of the aluminosilicate-enriched phase within the bindercontaining material near and/or along the i.d. wall. This implies that a compositional gradient within the structural support ligaments may have been established through the filter wall during extended process operation.

- Infrequently, an amorphous or featureless structure (Figure 2-21) resulted within the oxideenriched, binder-containing layer that encapsulated the silicon carbide grains in the 2201 hour, PCFBC-exposed, Schumacher Dia Schumalith FT20 filter matrix, as well as along the outer surface of the ligaments that bonded adjacent silicon carbide grains to each other.

- In these areas, submicron and micron sorbent-containing ash fines were seen to adhere to the material (Figure 2-22).

- Fluxing of the material around and/or below the adhering particles was considered to have occurred (Figure 2-22).

- Alternately, rounded submicron or micron depressions in the material resulted in the absence of adhering particles (Figure 2-23). Removal of these fines may have occurred during process operation or sample preparation (i.e., wet cutting of 0 rings/c-rings).

Numerous submicron pits or holes resulted along the mottled surface of the silicon carbide grain directly beneath the $\sim 3 \mu \mathrm{m}$ thick, silica-enriched, encapsulating layer (Figure 2-24). Oxygen was 


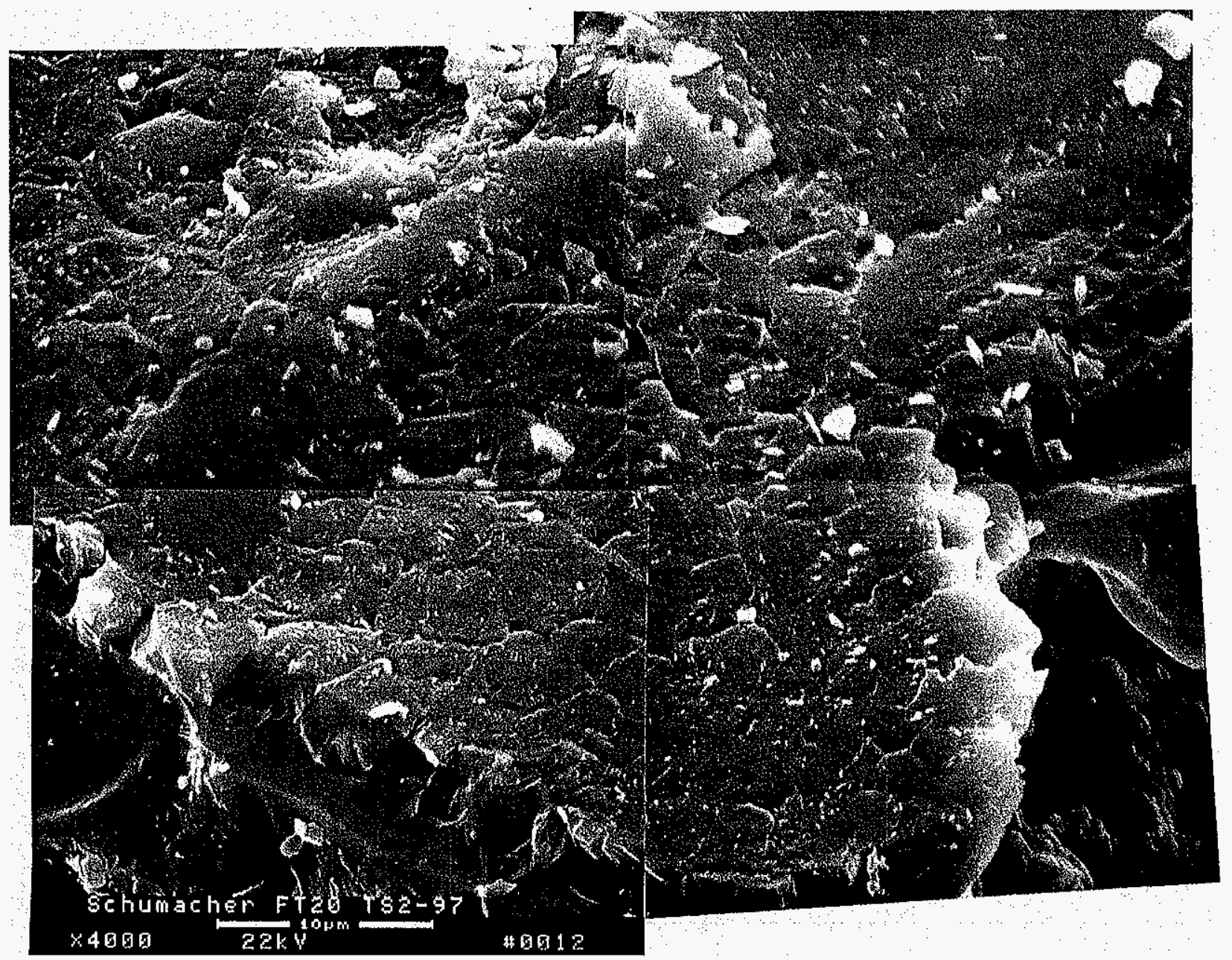

Figure 2-16 - Higher magnification micrograph montage illustrating the morphology of hexagonal grains within the crystallized silica-enriched outer surface phase that encapsulated the silicon carbide grains in the 2201 hour, PCFBC-exposed, Schumacher Dia Schumalith FT20 filter matrix. 


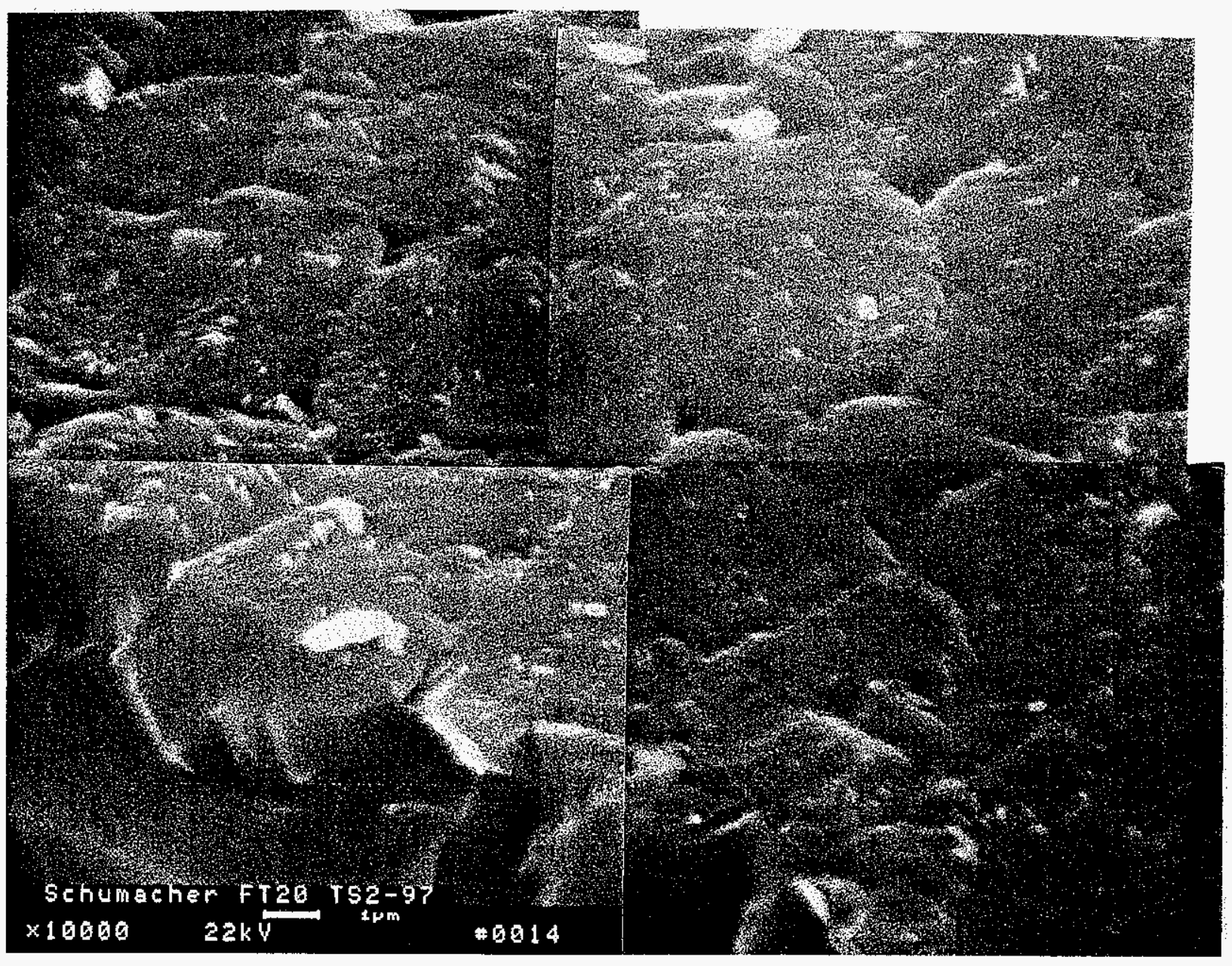

Figure 2-17 - Higher magnification micrograph montage illustrating the affinity of the hexagonal grains to the underlying silicon carbide grain, as well as potential gas permeation channels. 


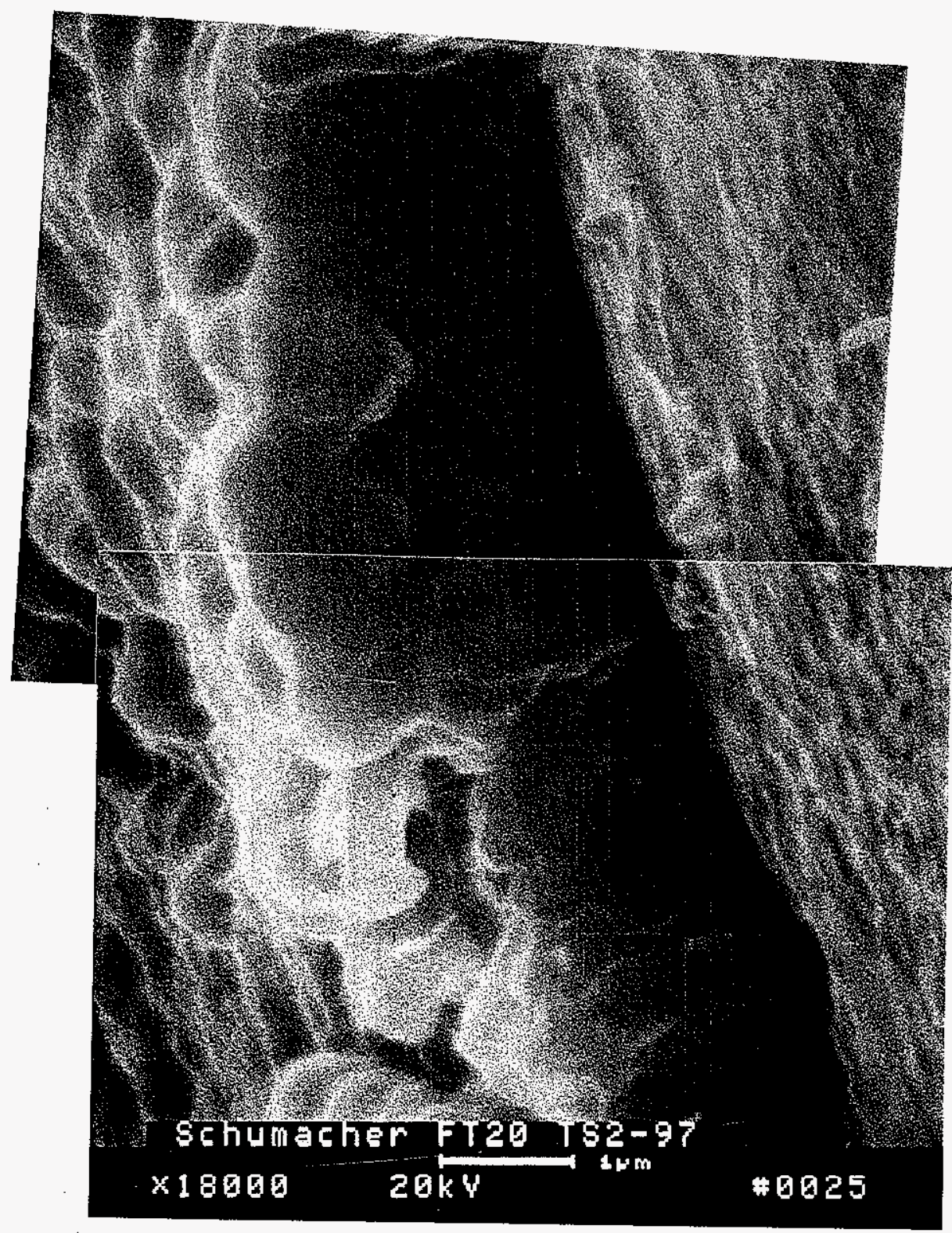

Figure 2-18 - Micrograph montage illustrating the thickness of the two phase, oxide-enriched encapsulating layer that remained along the outer surface of the silicon carbide grains that were present near the i.d. wall of the 2201 hour, PCFBC-exposed,' Schumacher Dia Schumalith FT20 filter matrix. 


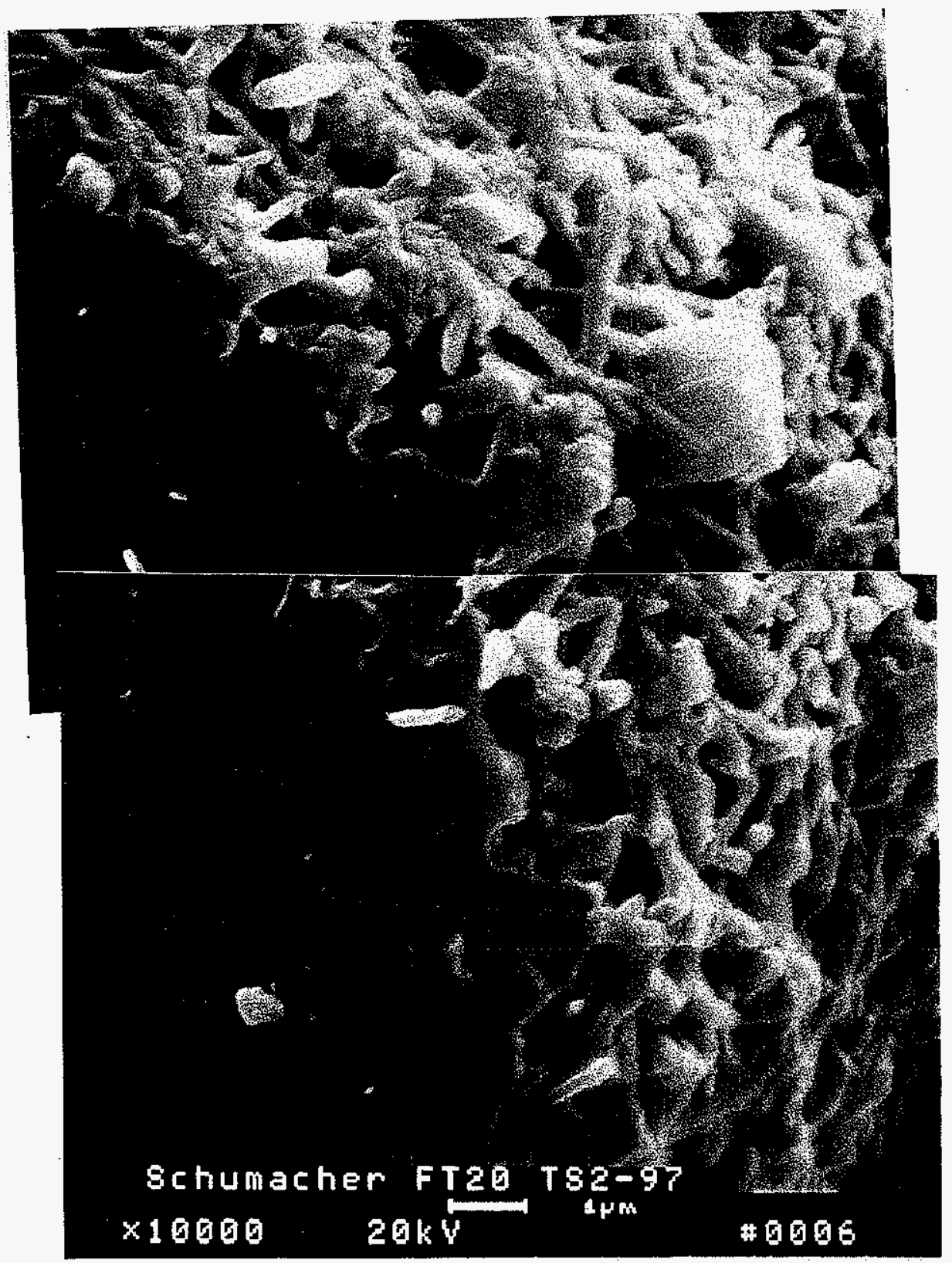

Figure 2-19 - Micrograph montage illustrating the crystalline, rod-like, aluminosilicate-enriched phase that formed along the outer surface of the binder-containing ligaments in the 2201 hour, PCFBC-exposed, Schumacher Dia Schumalith FT20 filter matrix. 


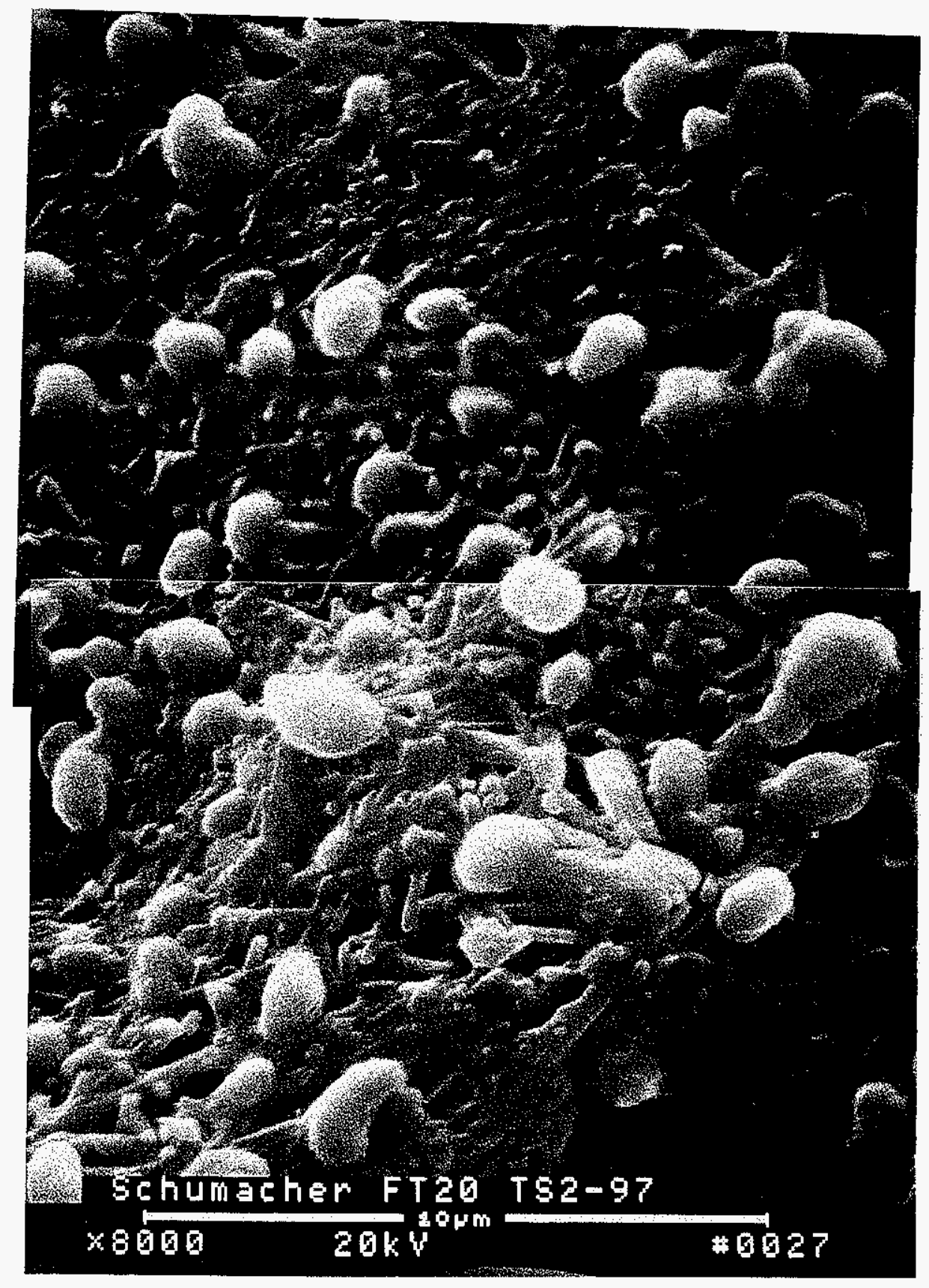

Figure 2-20 - Nodular features that resulted at the end of the aluminosilicate-enriched whiskers that formed along the oxide-enriched layer that encapsulated the silicon carbide grains near the i.d. wall of the 2201 hour, PCFBC-exposed, Schumacher Dia Schumalith FT20 filter matrix. 


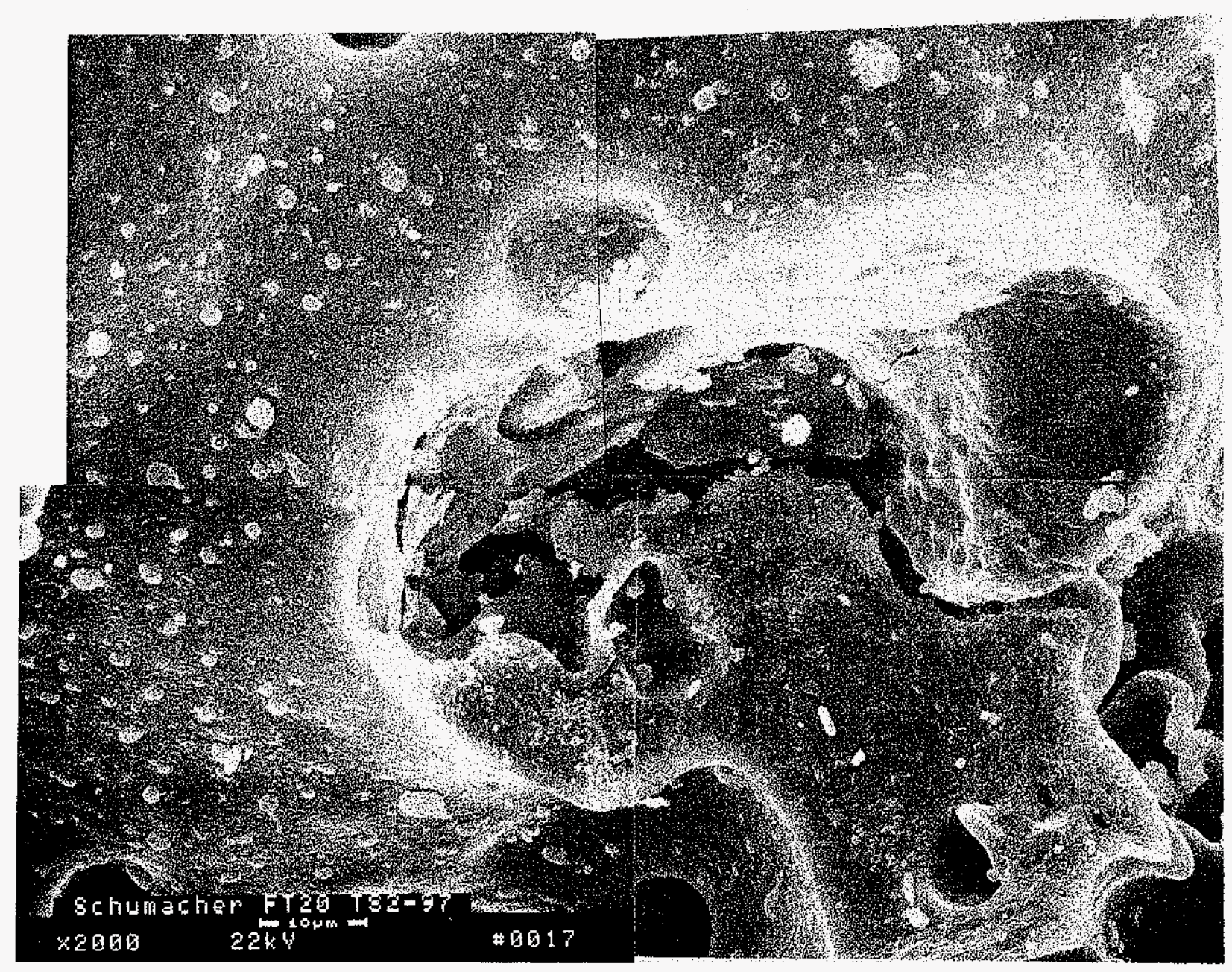

Figure 2-21 - Micrograph montage illustrating the relatively amorphous feature of the oxideenriched binder-containing layer that encapsulated the silicon carbide grains, as well as ligament formations in the 2201 hour, PCFBC-exposed, Schumacher Dia Schumalith FT20 filter matrix. 


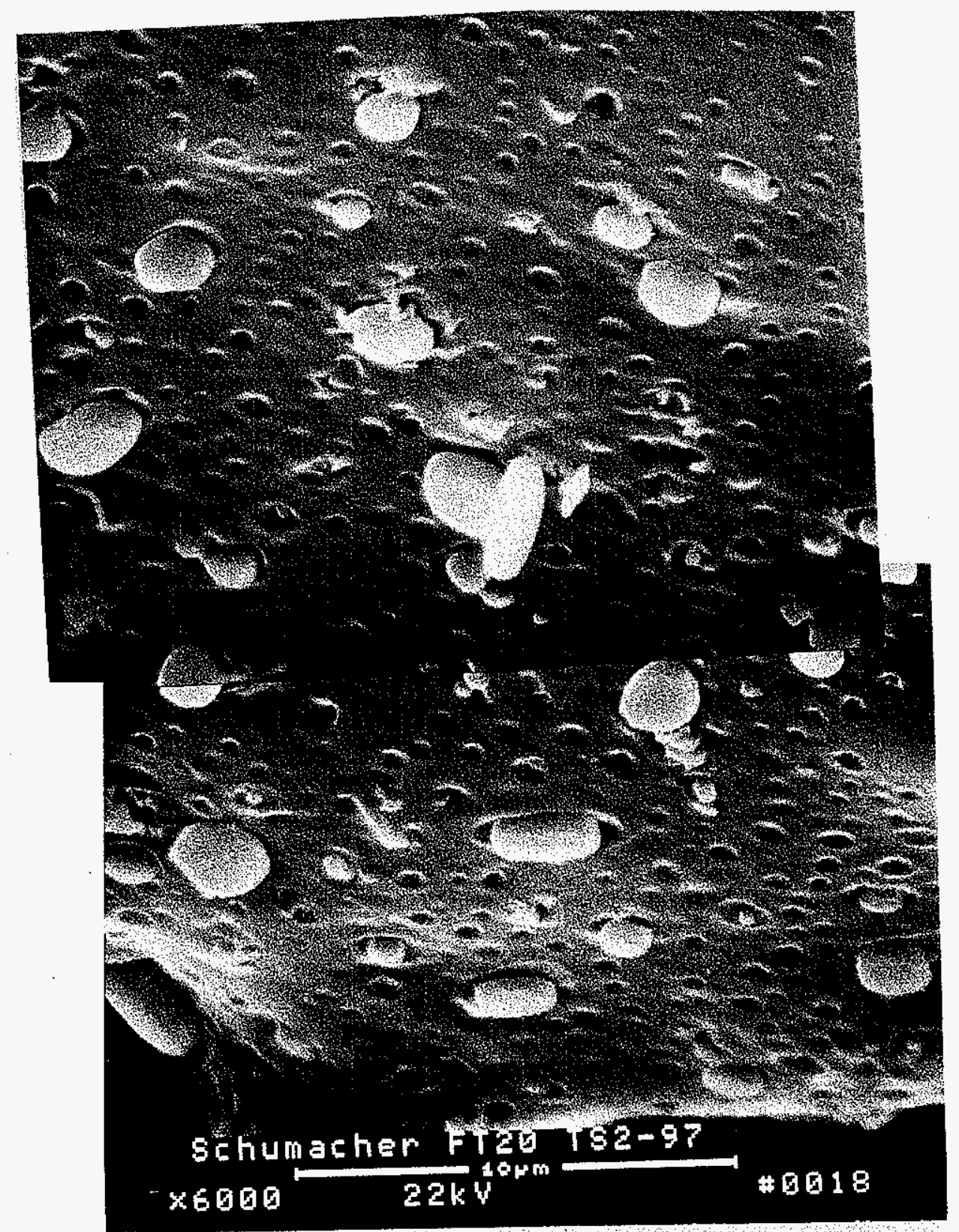

Figure 2-22 - Adherence of fines and pit formations resulted along the outer surface of the binder-enriched ligaments in the 2201 hour, PCFBC-exposed, Schumacher Dia Schumalith FT20 filter matrix. 

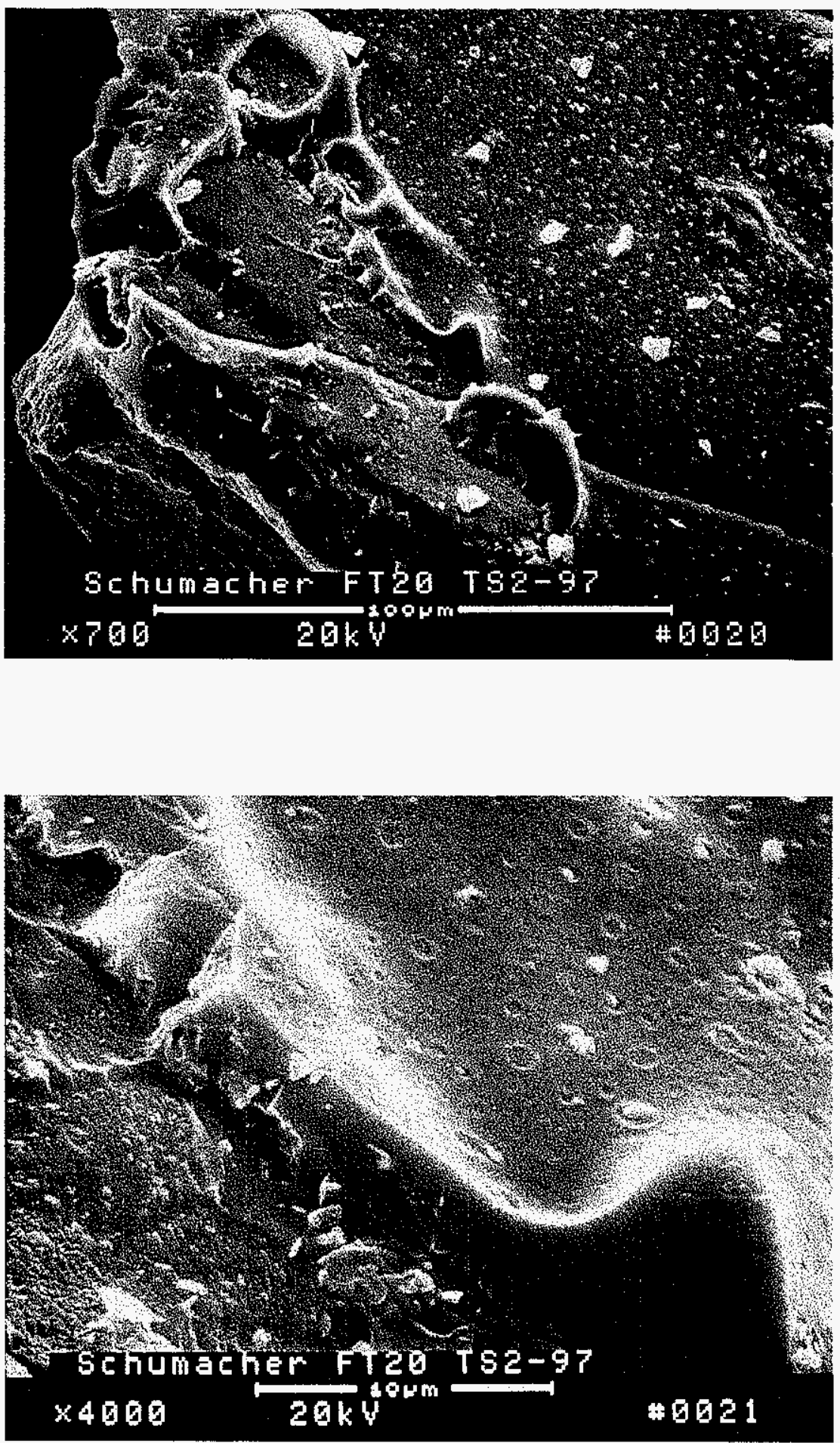

Figure 2-23 - Round depressions resulted along the outer surface of the amorphous, oxideenriched, encapsulating layer. 


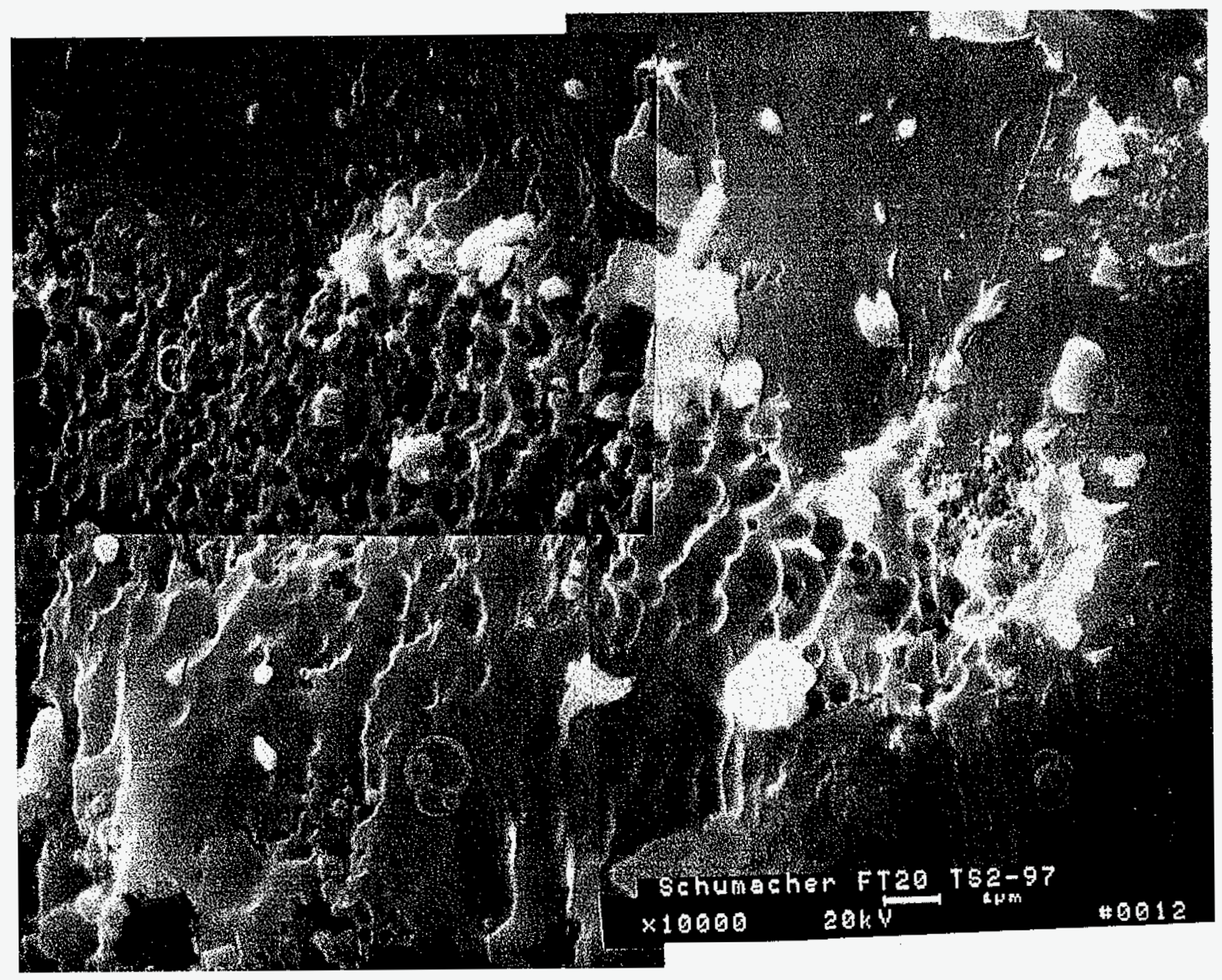

Figure 2-24 - Mottled surface of the silicon carbide grains after removal of the encapsulating oxide-enriched layer in the 2201 hour, PCFBC-exposed, Schumacher Dia Schumalith FT20 filter matrix. 
detected along the mottled grain surface, implying initial stages of oxidation in these areas during process operation.

The formation of a crystallized silica-enriched encapsulating layer along the surface of the silicon carbide grains, and the formation of a crystallized aluminosilicate-enriched binder-containing ligament, may impact the material properties and fracture characteristics of the clay bonded silicon carbide filter materials during extended PFBC or PCFBC service operation. With time, the crystalline silica-enriched phase may tend to fracture in a brittle mode unlike that of the amorphous bindercontaining ligaments. Alternately, if an amorphous, silica-enriched or precursor phase is formed at the encapsulating layer-silicon carbide grain interface, continuity between this phase and the bindercontaining ligament may result, leading to a slight enhancement of the fracture resistance characteristics of the material (i.e., limited but enhanced thermal fatigue capabilities, perhaps comparable to that of the original matrix).

Analysis was also conducted of the residual PCFBC ash cake layer that remained along the outer surface of the 2201 hour, PCFBC-exposed, Schumacher Dia Schumalith FT20 candle filter identified the presence of ash and sorbent particles. The sorbent particles were primarily a partially sulfated, limestone-based material.

Characterization along the i.d. surface of the candle filter indicated that ash fines had been pulsed backed into the porous clay bonded silicon carbide filter matrix to depths of $0.5-0.8 \mathrm{~mm}$. This occurred as a result of the open porosity of the matrix along the non-membrane-coated i.d. bore surface, after failure of an alternate candle(s) had occurred during process operation. Penetration of fines into the i.d. wall lead to an increased pressure drop across the filter wall.

\subsubsection{Pall 326 Candle Filters}

Similar to the Schumacher Dia Schumalith FT20 candle filters, the as-manufactured monolithic Pall 326 barrier filters consist of silicon carbide grains that are bonded together via a high temperature creep resistant binder. A finer grained silicon carbide layer is applied to the outer surface of the $10 \mathrm{~mm}$ thick structural support wall of each filter element, forming an external membrane.

Extensive crystallization of the high temperature creep resistant binder resulted within the Pall 326 filter matrix after 540 hours of operation in the $850^{\circ} \mathrm{C}$ PCFBC environment (Figure 2-25). Changes within the fine grained silicon carbide membrane tended to indicate the presence of silica, implying that oxidation of the fine grains most likely occurred.

After 1166 hours of operation in the PCFBC environment, the Pall 326 filter matrix experienced extensive crystallization throughout the filter wall (Figures 2-26 through 2-28). The crystallized outer coating that encapsulated the silicon carbide grains contained areas that were enriched primarily with silica, while alternate areas predominantly contained mullite-like rod formations. The thickness of the encapsulating layer that typically resulted along the surface of the Pall 326 PCFBC-exposed silicon carbide grains is shown in Figure 2-29. Crystallization along the outer surface, and through the $\sim 7 \mathrm{~m}$ coating was evident. Along alternate grains near the o.d. surface of the 1166 hour, PCFBC-exposed, Pall 326 filter element, an amorphous silica-enriched encapsulating layer was identified (Figure 2-30).

Along the i.d. or pulse cycled surface of the 1166 hour, PCFBC-exposed, Pall 326 filter element, extensive crystallization of the encapsulating shell that coated the silicon carbide grains was clearly evident (Figure 2-31). The melt-like features of the silica-enriched outer coating are shown at higher 

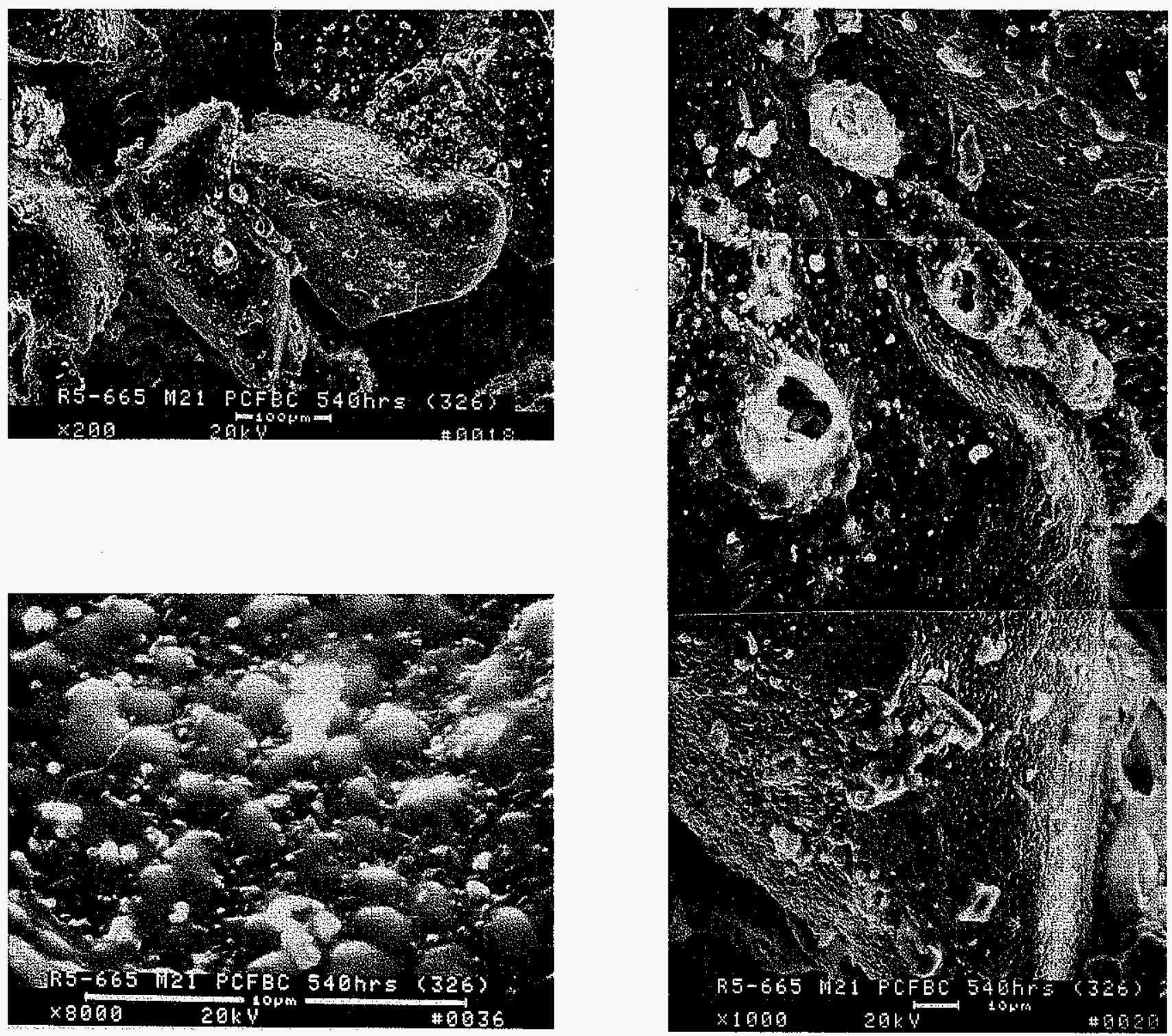

Figure 2-25 - Morphology of the 540 hour, PCFBC-exposed, Pall 326 filter matrix. 


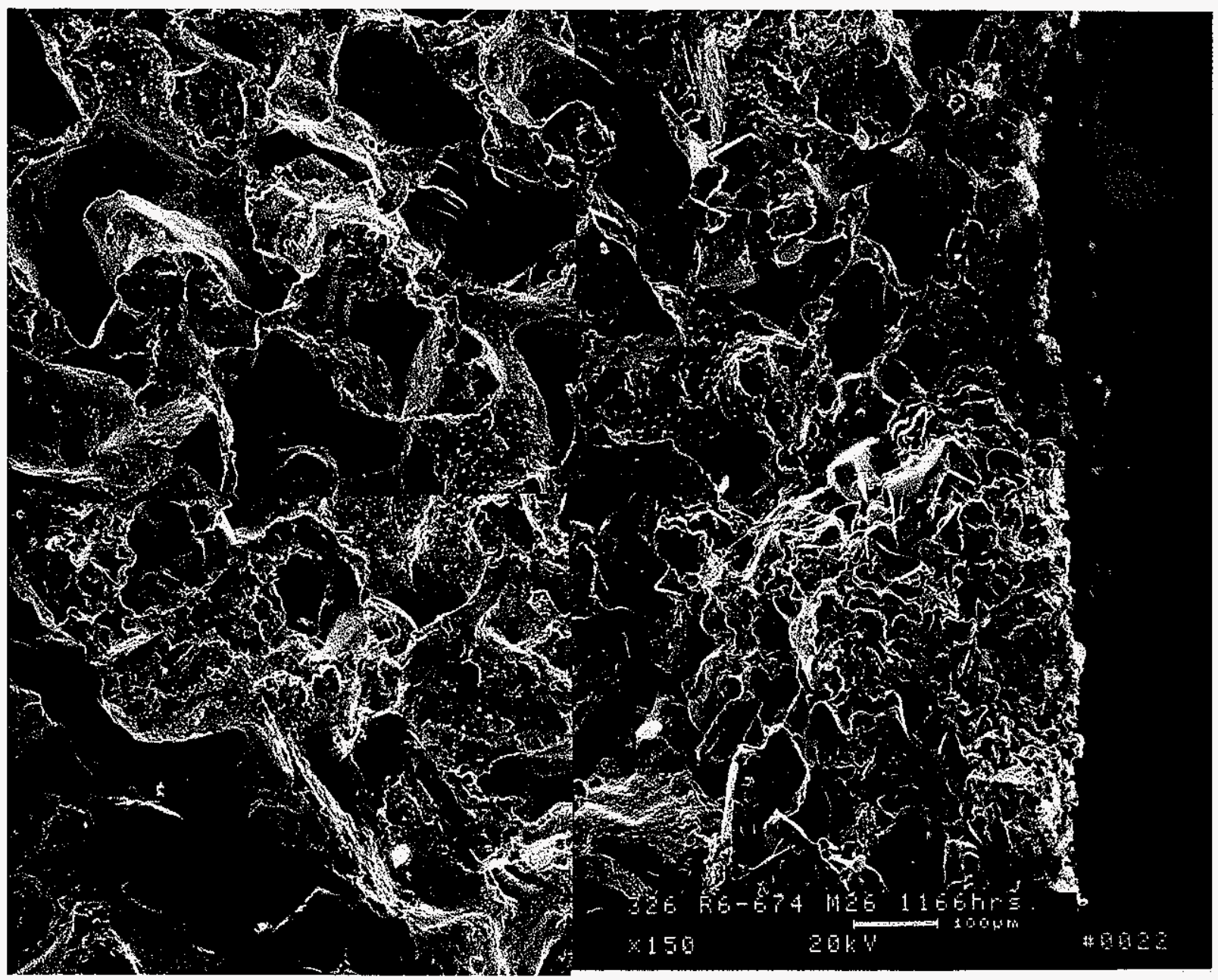

Figure 2-26 - Microstructure of the cross-sectioned, 1166 hour, PCFBC-exposed, Pall 326 filter matrix near the outer surface of the filter element. 


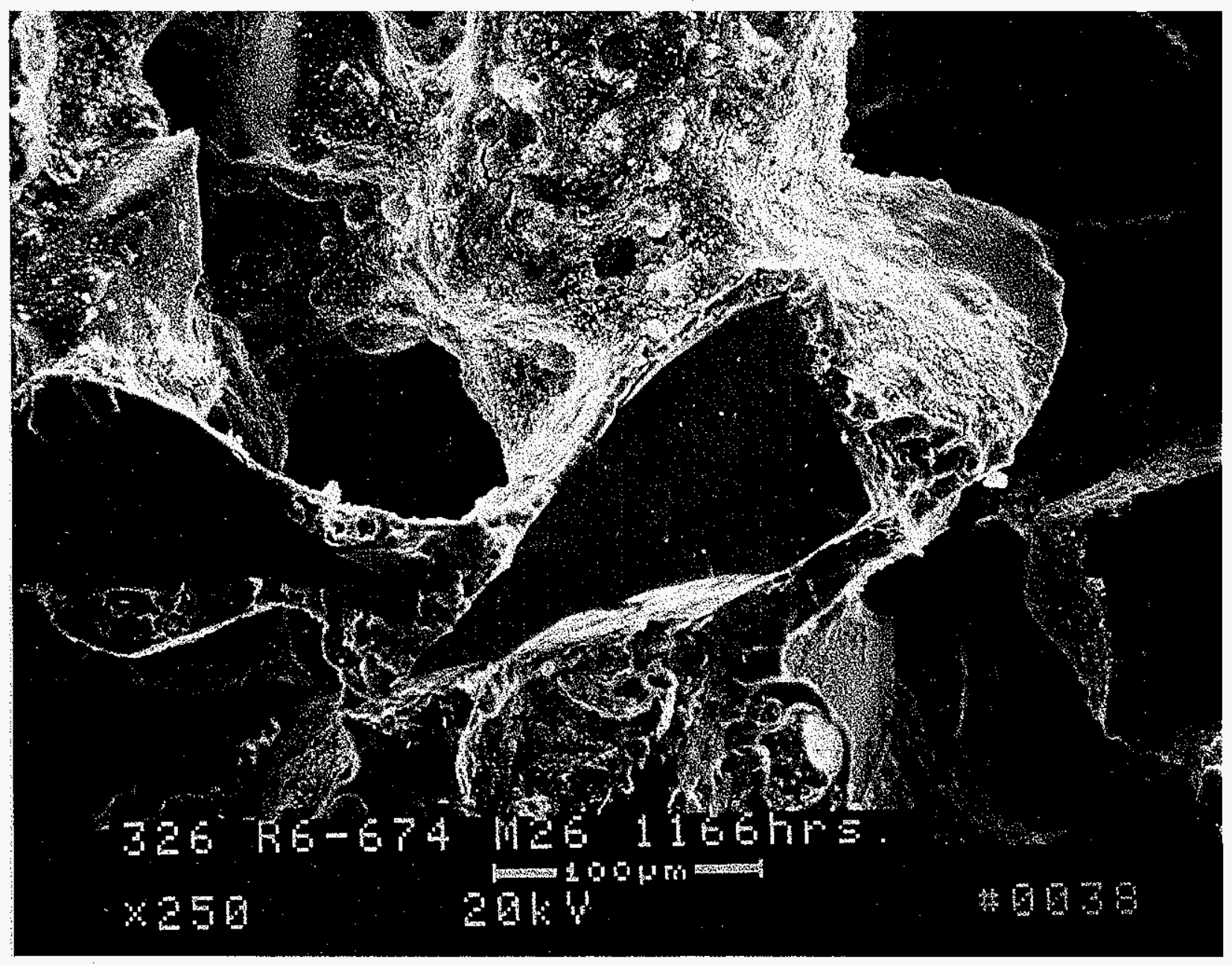

Figure 2-27 - Extensive crystallization resulted along the coating that encapsulated the silicon carbide grains in the 1166 hour, PCFBC-exposed, Pall 326 filter matrix near the outer surface of the filter wall. 


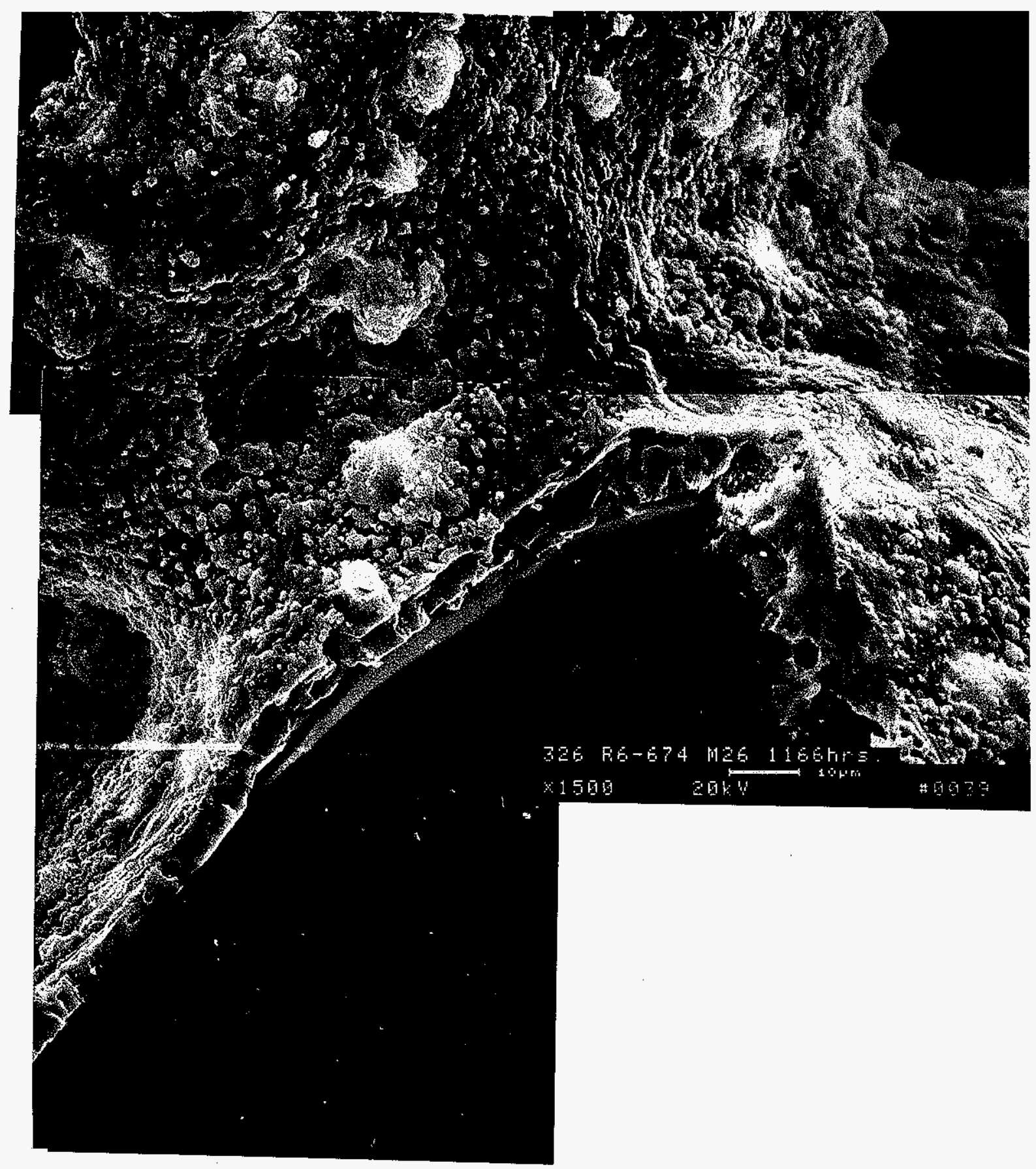

Figure 2-28 - Higher magnification micrograph montage illustrating the extensive crystallization that resulted along the surface of the binder-enriched oxide coated silicon carbide grains in the 1166 hour, PCFBC-exposed, Pall 326 filter matrix. 


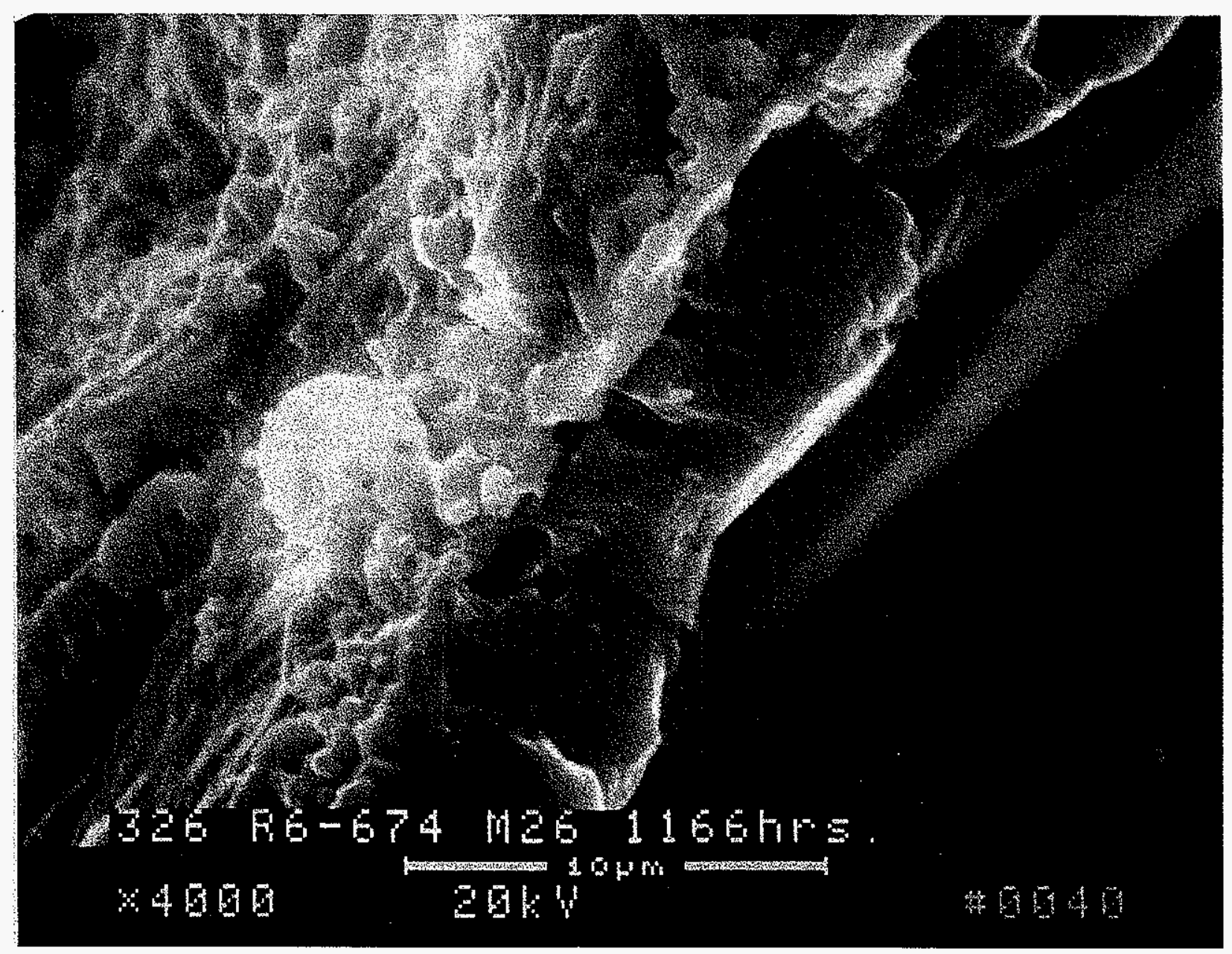

Figure 2-29 - Micrograph illustrating the thickness of the binder-enriched oxide coating that remained along the surface of the silicon carbide grains in the 1166 hour, PCFBCexposed, Pall 326 filter matrix. 


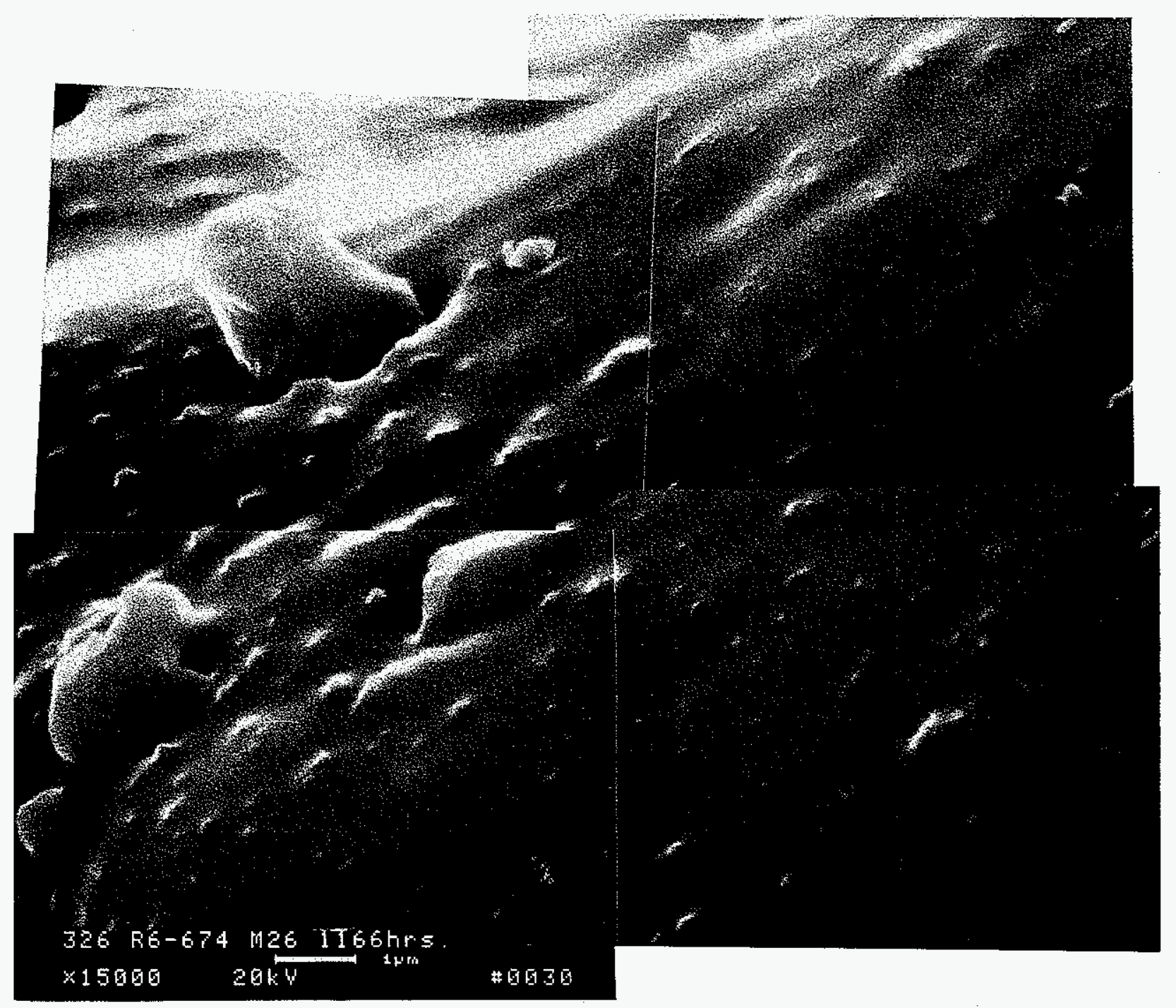

Figure 2-30 - Figher magnification micrograph montage illustrating the melt-like features of the binder-enriched oxide coating that encapsulated the silicon carbide grains near the outer surface of the 1166 hour, PCFBC-exposed, Pall 326 filter element. 


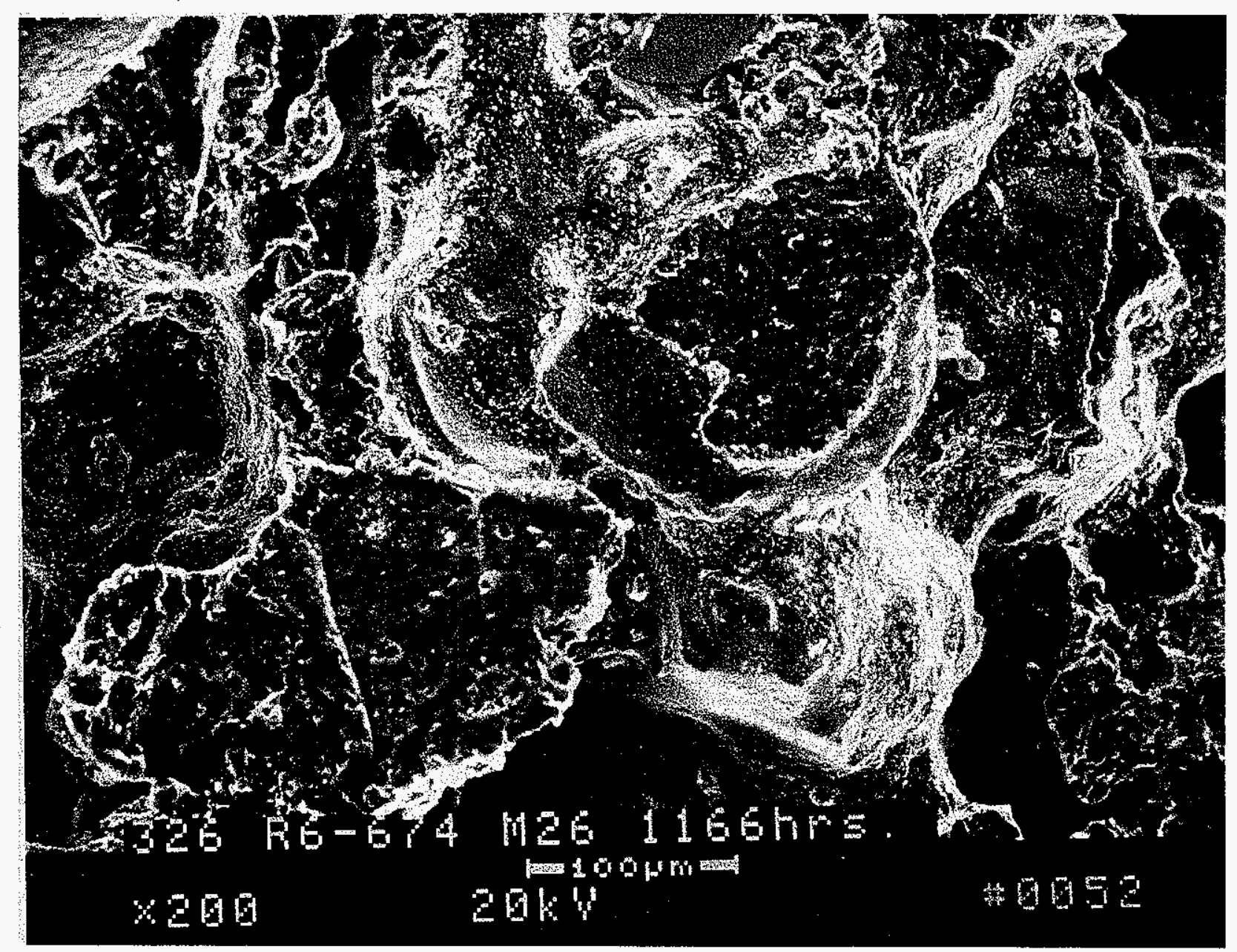

Figure 2-31 - Microstructure of the 1166 hour, PCFBC-exposed, Pall 326 filter matrix near the pulse cycled surface of the filter element. 
magnification in Figure 2-32. Below the encapsulating layer, the surface texture of the underlying silicon carbide grains was mottled resulting from what was considered to be surface oxidation of the grains during extended operation in the PCFBC environment (Figure 2-33).

The clay bonded silicon carbide Pall 326 candle filter R2-669 (M18) which had been exposed for 2201 hours in the PCFBC environment was initially subjected to 1620 hours of operation at temperatures of $870^{\circ} \mathrm{C}$, and subsequently to 581 hours of operation at $750^{\circ} \mathrm{C}$. Microstructural analysis of this element indicated that the residual ash cake layer that remained along the outer surface of the PCFBC-exposed Pall 326 filter element consisted of agglomerated fines that were enriched with sulfated sorbent particles, and amorphous features that were enriched with silicon and aluminum-containing ash constituents.

After cross-sectioning, fines were identified to be present throughout the outer surface membrane of the 2201 hour, PCFBC-exposed, Pall 326 filter element. Although the outer surface membrane remained attached to the underlying support silicon carbide grains (Figure 2-34), discrete silicon carbide grains were no longer clearly evident (Figure 2-35). Oxidation and deformation of the grains were considered to have occurred.

Below the outer surface membrane, the open porosity of the structural support silicon carbide grains was retained within the 2201 hour, PCFBC-exposed, Pall 326 filter element. Extensive mottling of the binder and/or oxide-enriched layer that encapsulated the outer surface of the silicon carbide grains in the Pall 326 filter element was clearly evident (Figure 2-36). This was seen throughout the entire filter wall.

Characterization of the cross-sectioned binder and/or oxide-enriched coating that encapsulated the structural support silicon carbide grains identified the presence of crystalline grain growth within the oxide-enriched encapsulating shell (Figures 2-37 through 2-40). Frequently two distinct phases were seen along the encapsulating layer that surrounded the silicon carbide grains in the 2201 hour, PCFBCexposed, Pall 326 filter matrix. These included

- An outer crystalline surface layer that contained the as-manufactured binder phase species embedded in an enriched silicon and oxygen-containing matrix.

- A thicker subsurface region that was principally identified to contain silicon and oxygen, with minor and/or trace contributions of aluminum and magnesium. The thickness, morphology, as well as composition of the crystalline subsurface layer implied that enhanced grain growth was mainly attributed to oxidation of the underlying silicon carbide grain.

As shown in Figure 2-36 and 2-41, where the outer encapsulating shell had been removed, an underlying mottled surface texture of the silicon carbide support grain was evident which contained low concentrations of oxygen. The mottled surface of the silicon carbide grain frequently contained remnants of the removed encapsulating layer, as well as patterns which replicated the features of the removed crystalline outer surface phase.

At alternate locations along the PCFBC-exposed Pall 326 filter matrix, round holes and crack formations were evident within the encapsulating binder or oxide-enriched layer (Figure 2-42). At higher magnification, the adherence of the outer encapsulating shell to the underlying silicon carbide grain was generally evident, but at various locations, the shell was seen to be lifted and separated from the surface of the underlying silicon carbide grain. 


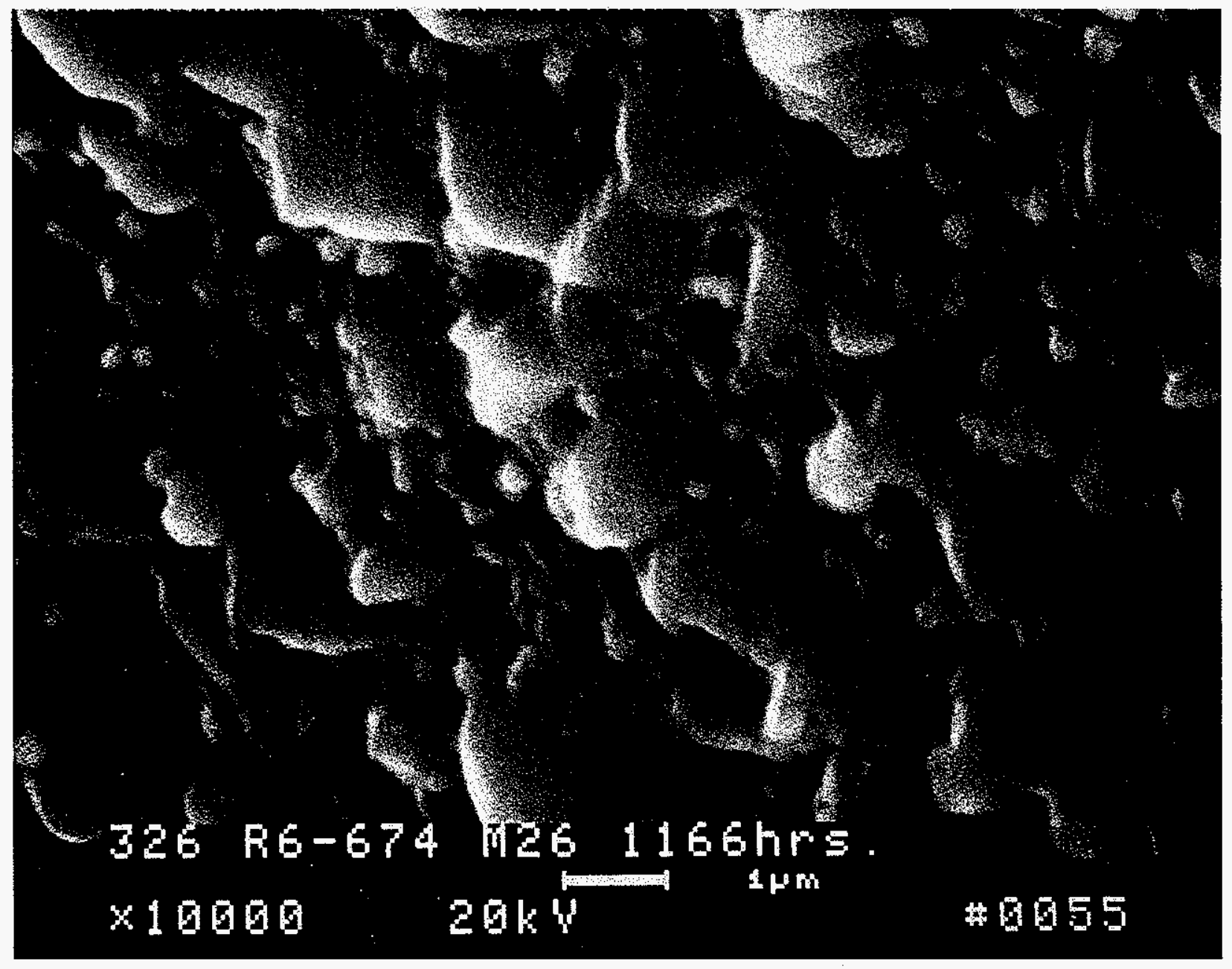

Figure 2-32 - Morphology of the silica-enriched oxide coating that encapsulated the silicon carbide grains in the 1166 hour, PCFBC-exposed, Pall 326 filter element. 


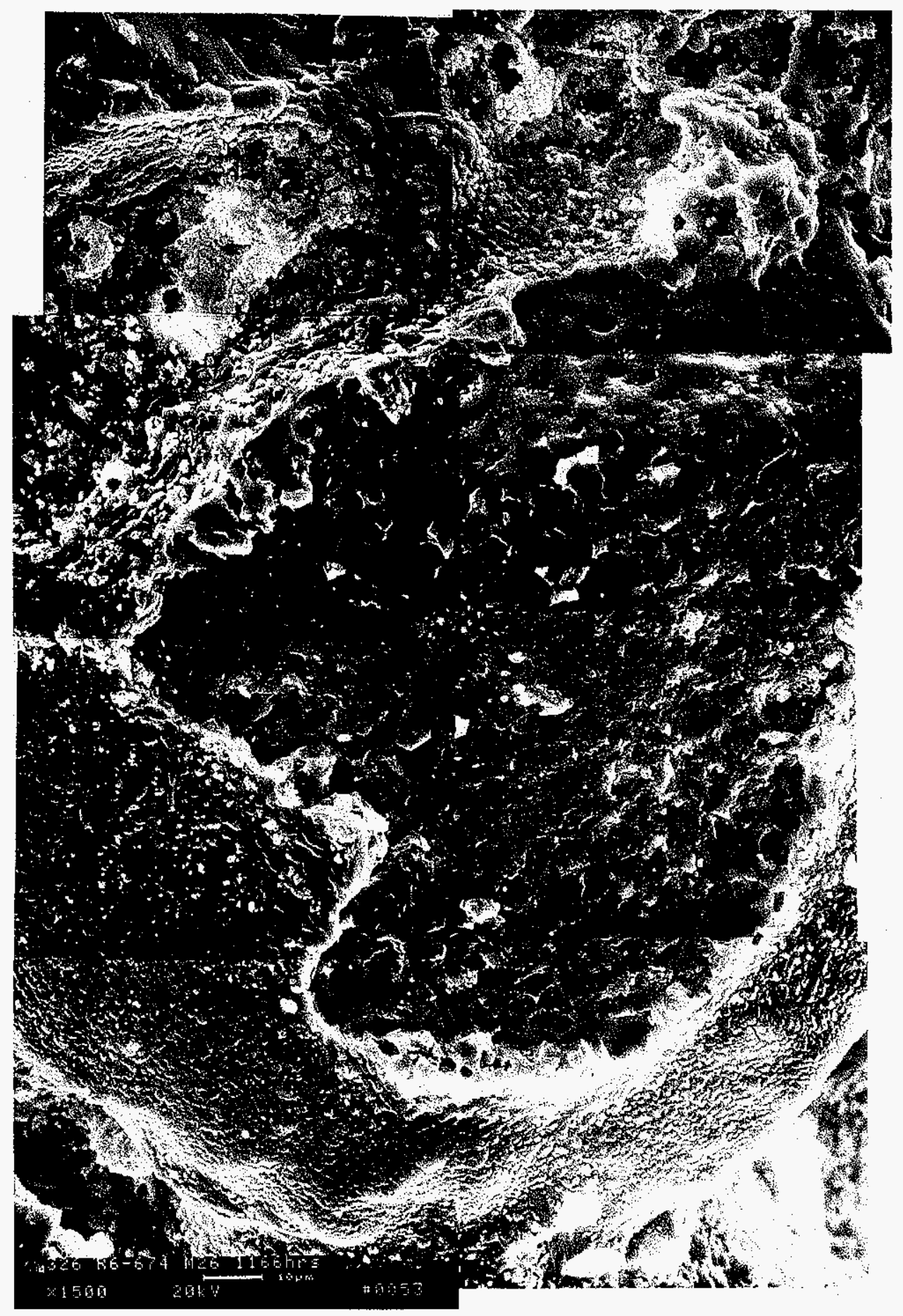

Figure 2-33 - High magnification micrograph montage illustrating extensive crystallization of the binder-enriched oxide coating that encapsulated the silicon carbide grains along the pulse cycled surface of the 1166 hour, PCFBC-exposed, Pall 326 filter element, and the mottled surface features of the underlying silicon carbide grains. 


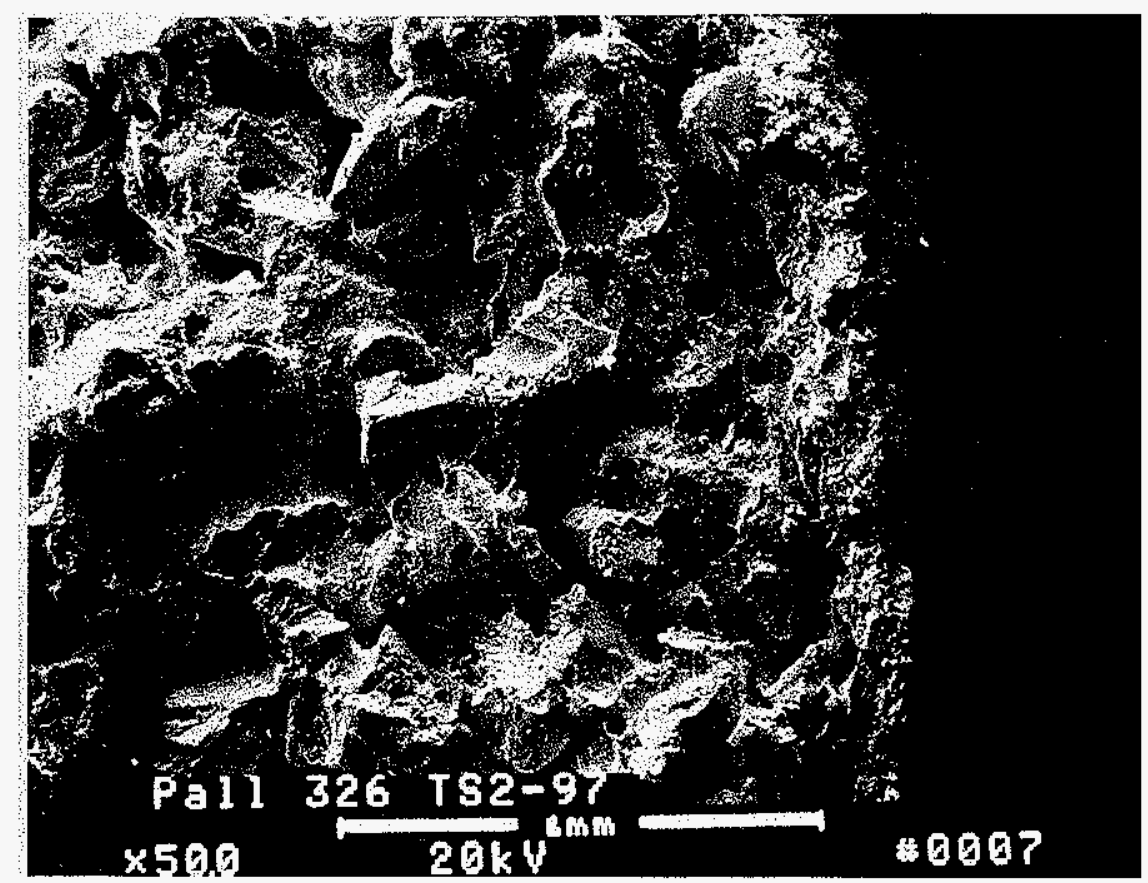

Figure 2-34 - Adherence of the outer surface membrane along the 2201 hour, PCFBC-exposed, Pall 326 filter matrix. 


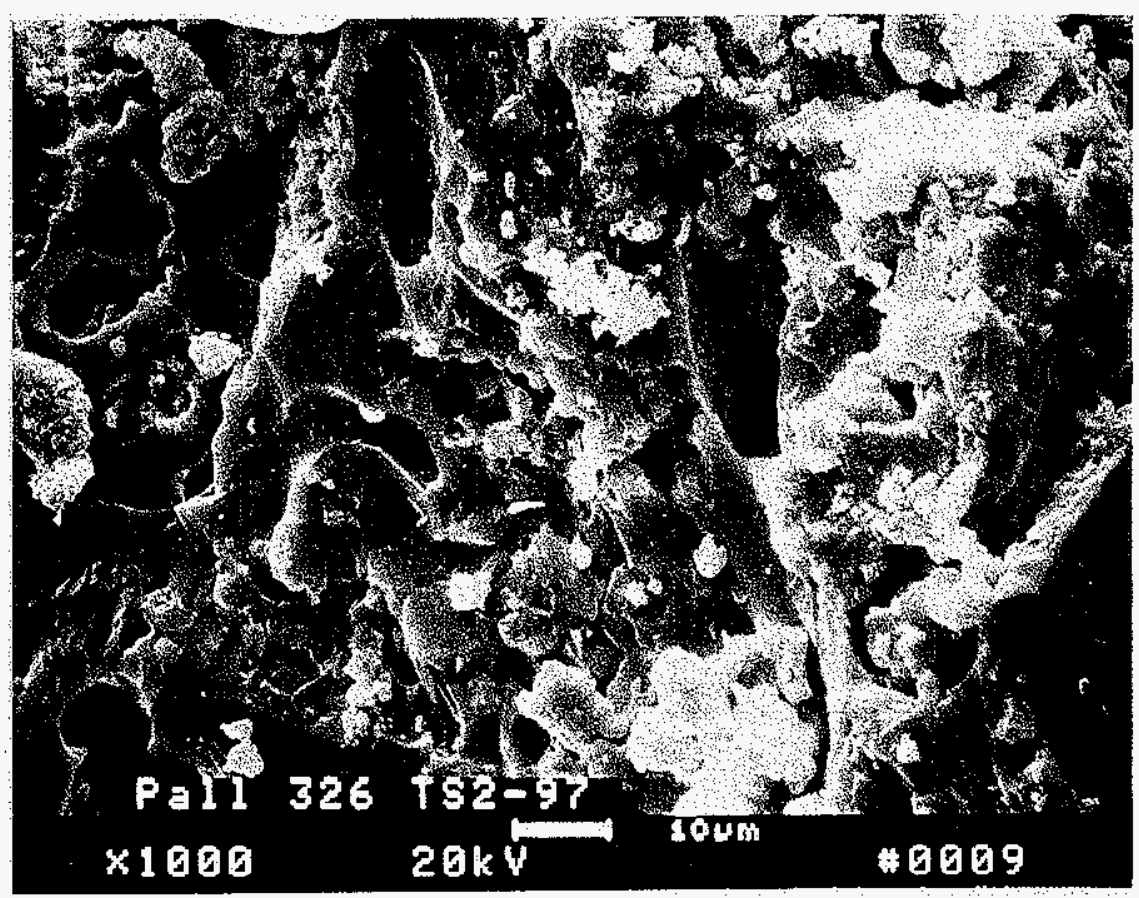

Figure 2-35 - Extensive mottling (oxidation) of the fine silicon carbide grains in the 2201 hour, PCFBC-exposed, Pall 326 outer surface membrane. 


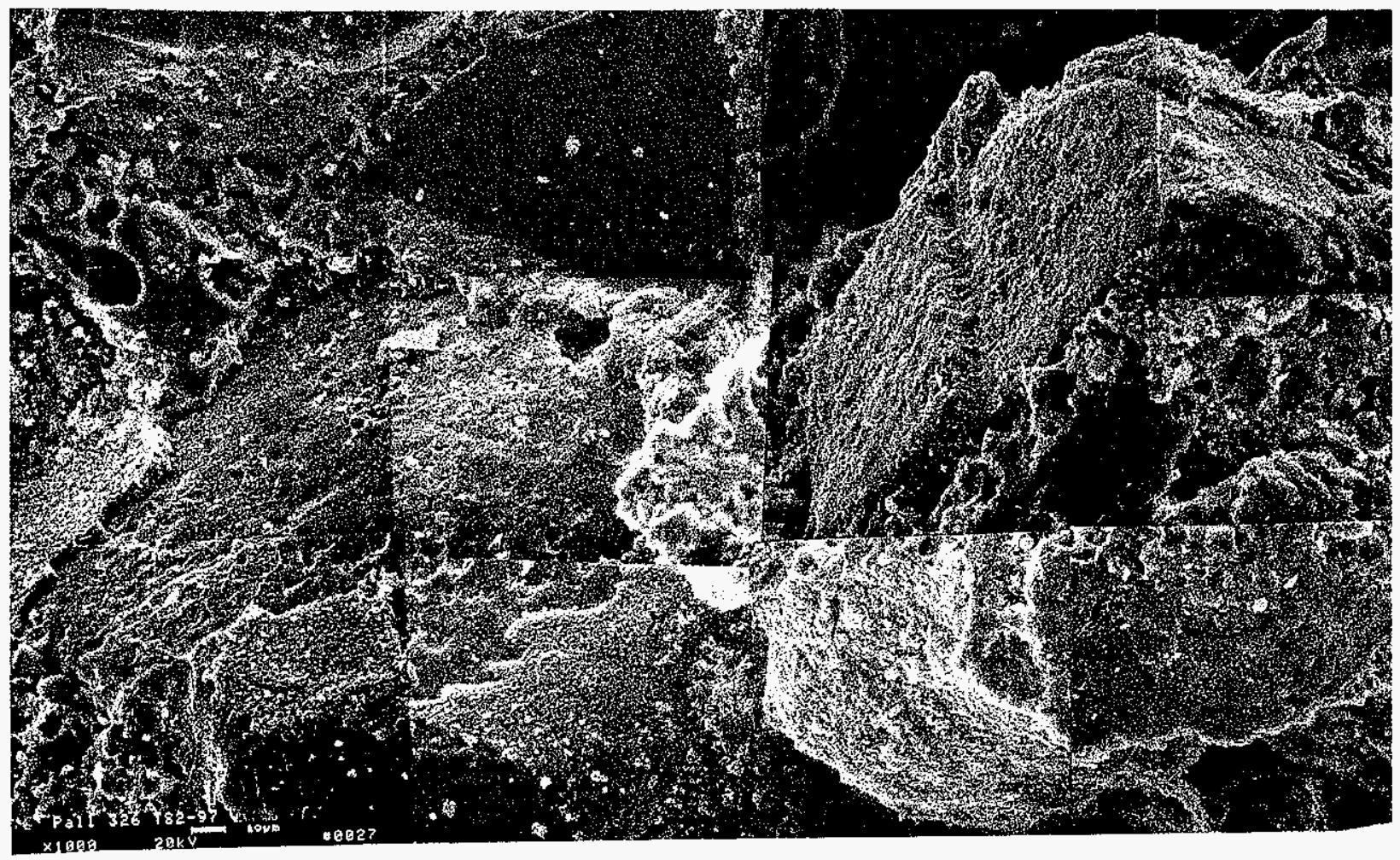

Figure 2-36 - Higher magnification micrograph montage illustrating the extensive mottling that resulted along the binder/oxide-containing shell that encapsulated the silicon carbide grains in the 2201 hour, PCFBC-exposed, Pall 326 filter matrix. 


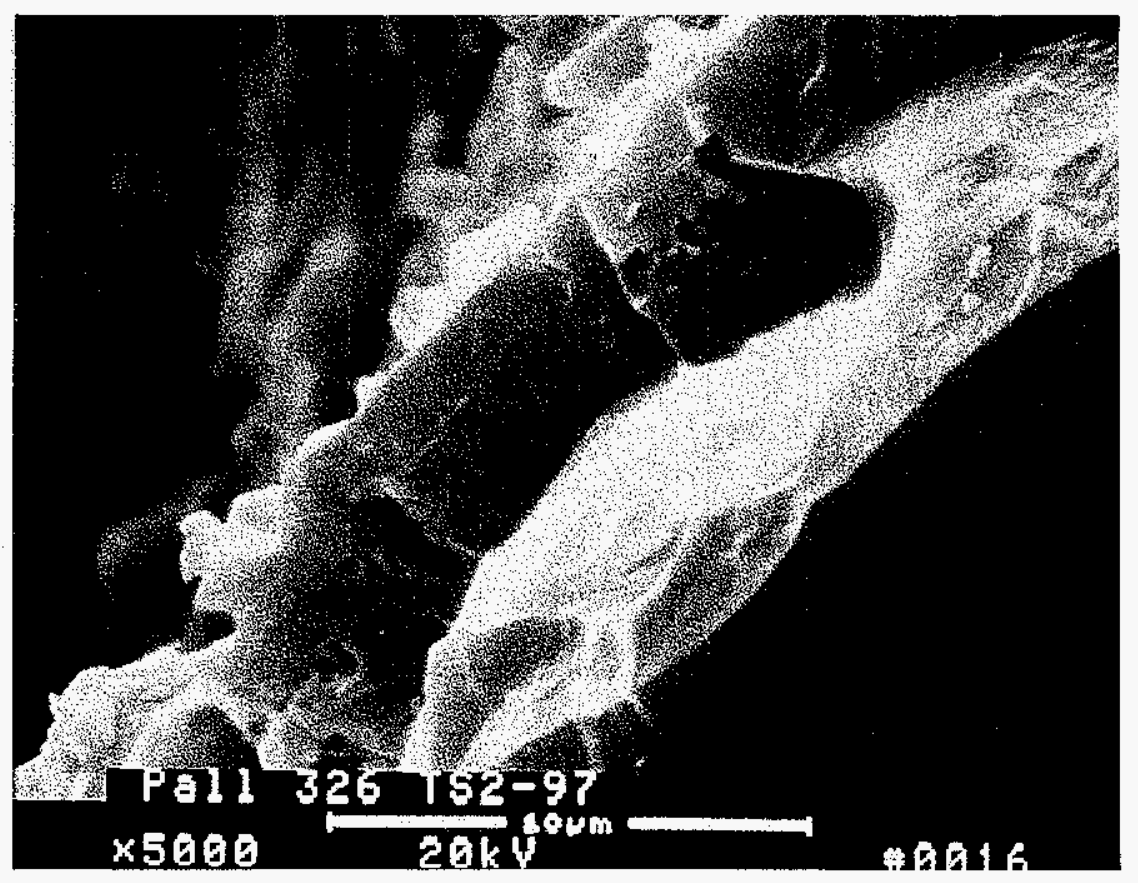

Figure 2-37 - Micrograph illustrating the thickness of the two phase binder/oxide-containing layer that encapsulated the silicon carbide grains in the 2201 hour, PCFBCexposed, Pall 326 filter matrix. 


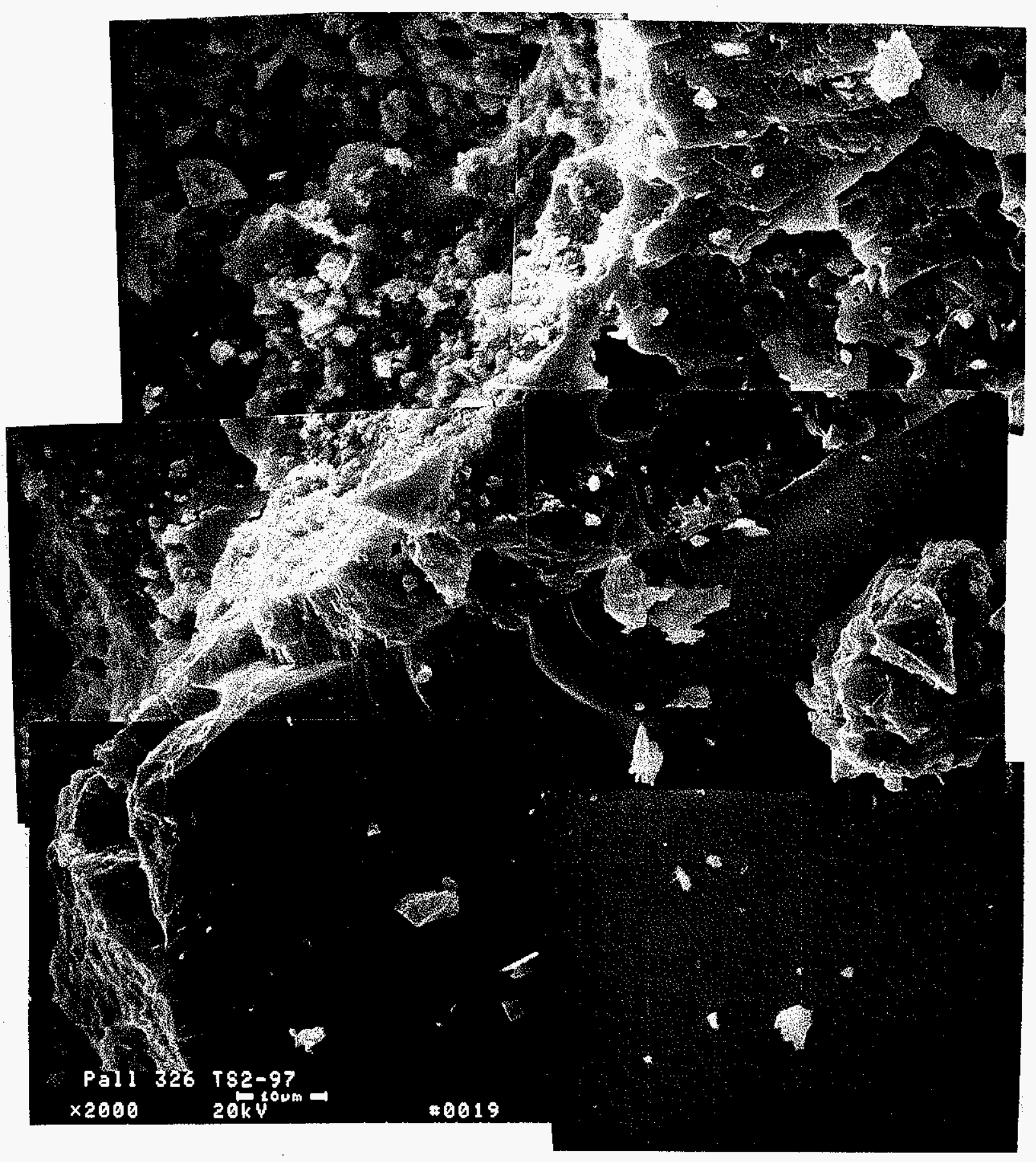

Figure 2-38 - High magnification micrograph montage illustrating the extensive crystallization that resulted in the binder/oxide-containing layer that encapsulated the 2201 hour, PCFBC-exposed, silicon carbide grains. 

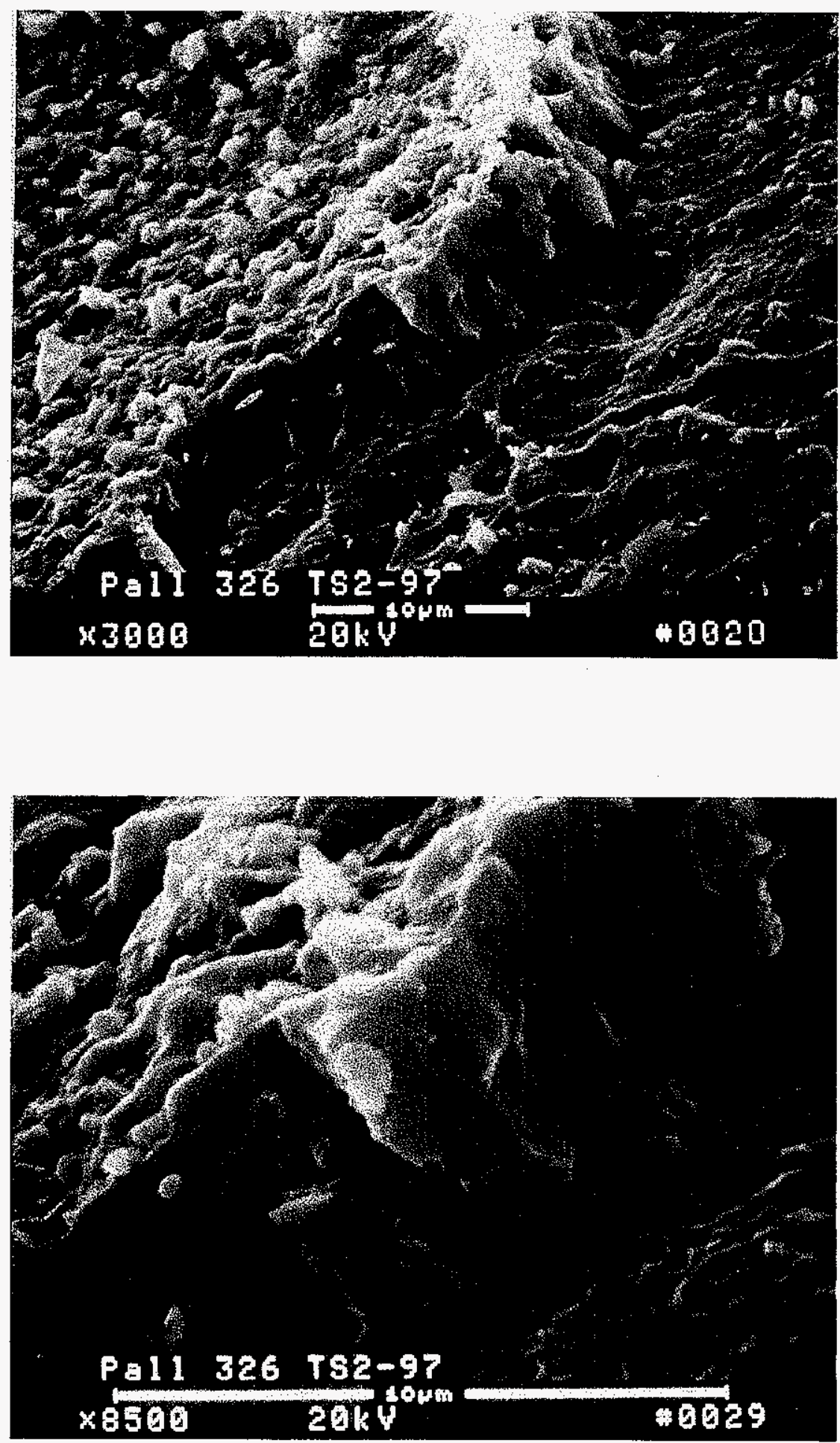

Figure 2-39 - Morphology and adherence of the crystalline binder/oxide-containing layer that encapsulated the silicon carbide grains after 2201 hours of operation in the PCFBC environment. 


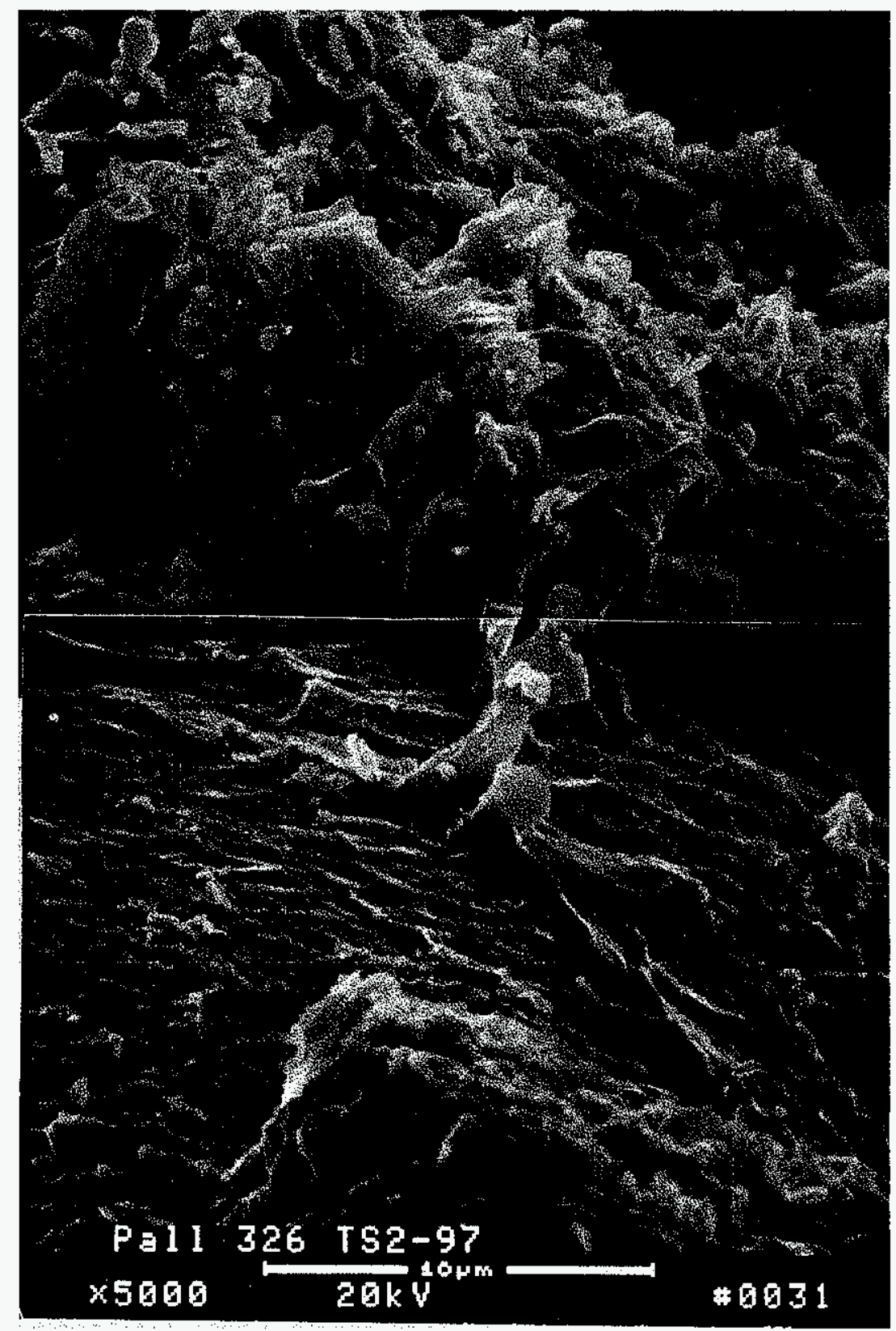

Figure 2-40 - Micrograph montage illustrating the remnants of the binder/oxide-containing matrix after removal of the outer encapsulating shell of the 2201 hour, PCFBCexposed, Pall 326 filter matrix. 


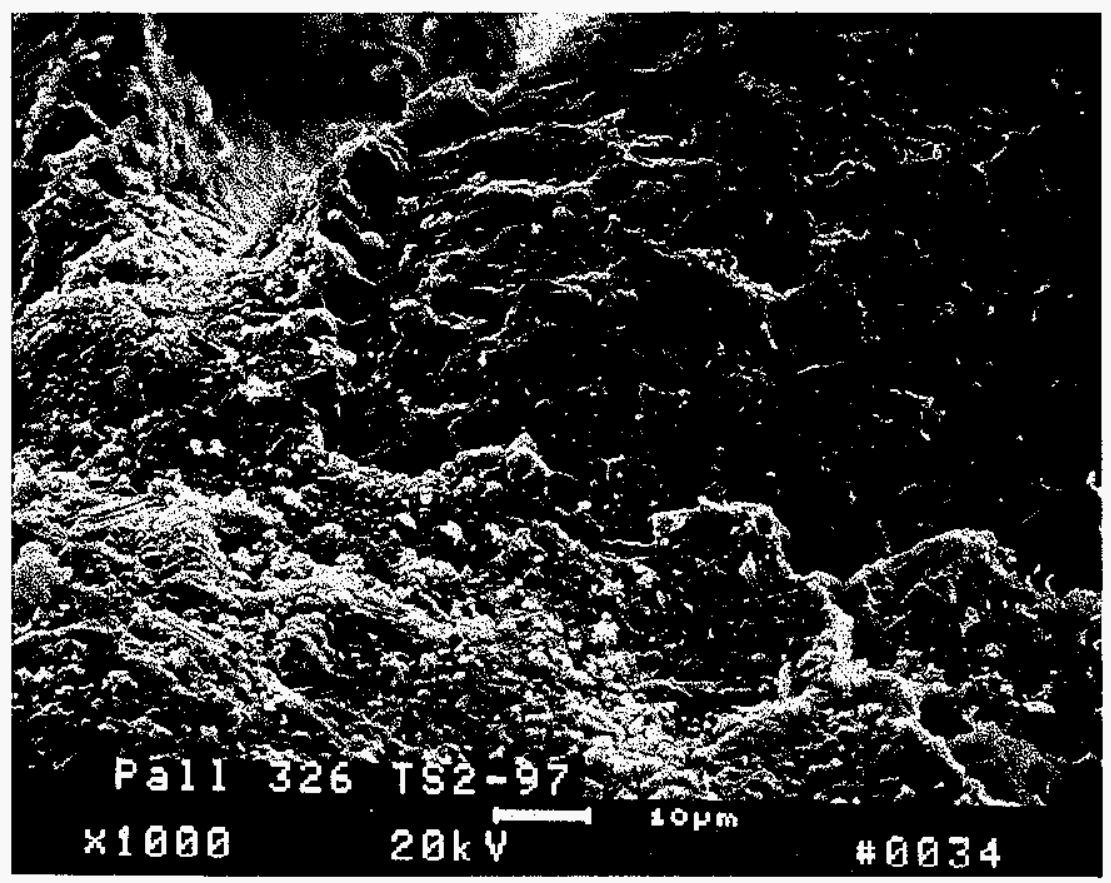

Figure 2-41 - Micrograph illustrating the mottled surface characteristics of the binder/oxideenriched encapsulating shell, as well as underlying exposed silicon carbide grain in the 2201 hour, PCFBC-exposed, Pall 326 filter matrix. 

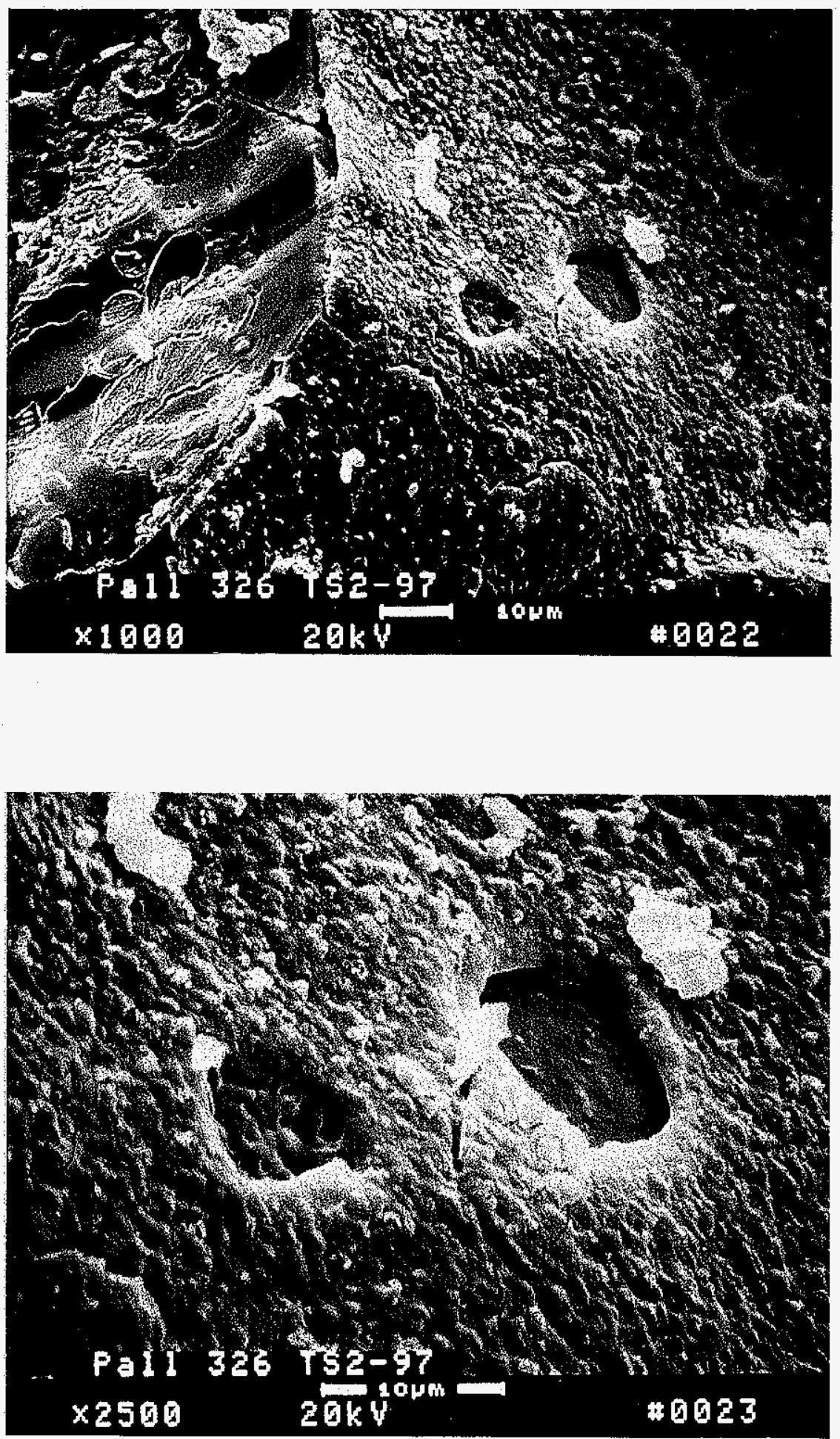

Figure 2-42 - Cracks and hole formations were evident along the binder/oxide-containing layer that encapsulated the 2201 hour, PCFBC-exposed, Pall 326 filter matrix. 
Figure 2-43 identifies many of the previously discussed features that were identified in the 2201 hour, PCFBC-exposed, Pall 326 filter matrix. In addition, crystallization was observed within the binder ligament that had been removed from the surface of an adjacent silicon carbide grain.

When characterized along the i.d. or pulse cycled surface of the PCFBC-exposed Pall 326 filter element, penetration of fines was identified. This resulted during pulse cleaning of the array after failure of an element(s) had occurred. The depth of fines penetration into the $10 \mathrm{~mm}$ thick clay bonded silicon carbide candle filter wall was $1-2 \mathrm{~mm}$.

A higher gas flow resistance across the filter wall was expected to have resulted after 2201 hours of operation in the PCFBC environment, due to the penetration of fines into the Pall 326 matrix along the i.d. surface of the filter element, as well as the relatively dense deposited conditioned ash cake layer along the o.d. surface of the filter element.

\subsubsection{Coors P-100A-1 Alumina/Mullite Candle Filters}

In contrast to the clay bonded silicon carbide filter elements, the Coors P-100A-1 alumina/ mullite filter matrix consists of mullite rods that are embedded within an amorphous phase that contains corundum $\left(\mathrm{Al}_{2} \mathrm{O}_{3}\right)$ and anorthite $\left(\mathrm{CaAl}_{2} \mathrm{Si}_{2} \mathrm{O}_{8}\right)$. The monolithic Coors $\mathrm{P}-100 \mathrm{~A}-1$ alumina/ mullite filter elements are manufactured without an external surface membrane.

Both newly manufactured Coors P-100A-1 alumina/mullite candles, and candles that had been operated in the W-APF system at AEP were installed prior to initiating PCFBC testing in TS1-95 in the Foster Wheeler PCFBC test facility in Karhula, Finland. Post-test SEM/EDAX characterization of the 505 hour PCFBC-exposed, and 1650 hour PFBC/PCFBC-exposed Coors P-100A-1 alumina/mullite filters indicated that crystallization resulted along the pore cavity walls, and throughout the structural ligaments within the $10 \mathrm{~mm}$ thick wall of the filter matrix (Figures 2-44 and 2-45).

At the conclusion of TS3-96, extensive crystallization was again observed along the pore cavity surfaces, and throughout the ligaments in the 1166 hour, PCFBC-exposed, and 2276 hour, PFBC/PCFBC-exposed, Coors P-100A-1 alumina/mullite filter matrices (Figure 2-46). Dendritic-like mullite rod formations protruded into the pore cavities (Figure 2-47), a fine grain phase frequently formed near the surface of the mullite rods (Figure 2-48), and a larger grain aluminosilicate phase formed along the surface of the pore cavities (Figure 2-49). In addition, a 3-4 $\mu \mathrm{m}$ nearly spherical aluminosilicate phase formed at the tip of the mullite rods primarily along the pulse cycled surface of the Coors P-100A-1 alumina/mullite filter matrix (Figure 2-50) .

The oxide-based Coors P-100A-1 alumina/mullite candle filter (AB-13 (M15)) which had been exposed for 1110 hours at the American Electric Power (AEP) PFBC Tidd Demonstration Plant in Brilliant, Ohio (TS4; 1994), was subsequently exposed for an additional 2201 hours of operation in the PCFBC environment in Karhula, Finland (TS1-95 through.TS2-97). After brushing the residual dust cake layer from the outer surface of the filter element, a section of the candle was removed via dry cutting, and subsequently subjected to microstructural analyses. Characterization of the filter matrix indicated that ash and sorbent particles were identified in the residual conditioned dust cake layer that remained along the outer surface of the 3311 hour, PFBC/PCFBC-exposed, Coors P-100A-1 alumina/mullite candle filter. Partial sulfation of the limestone-containing sorbent fines was evident. 


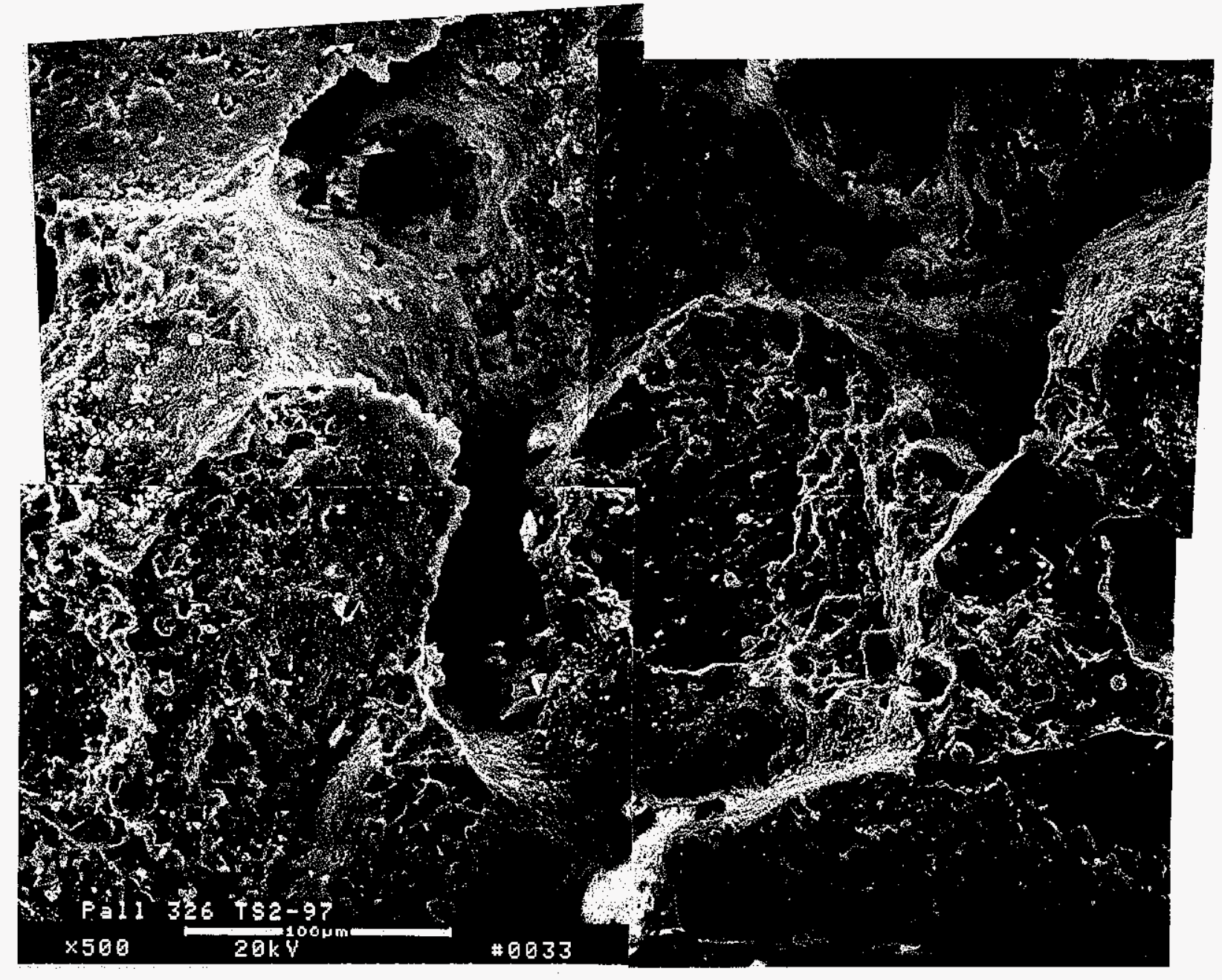

Figure 2-43 - Micrograph montage illustrating the crystalline features of the binder/oxideenriched encapsulating layer and ligament, and mottled surface characteristics of the underlying silicon carbide grains in the 2201 hour, PCFBC-exposed, Pall 326 filter matrix. 

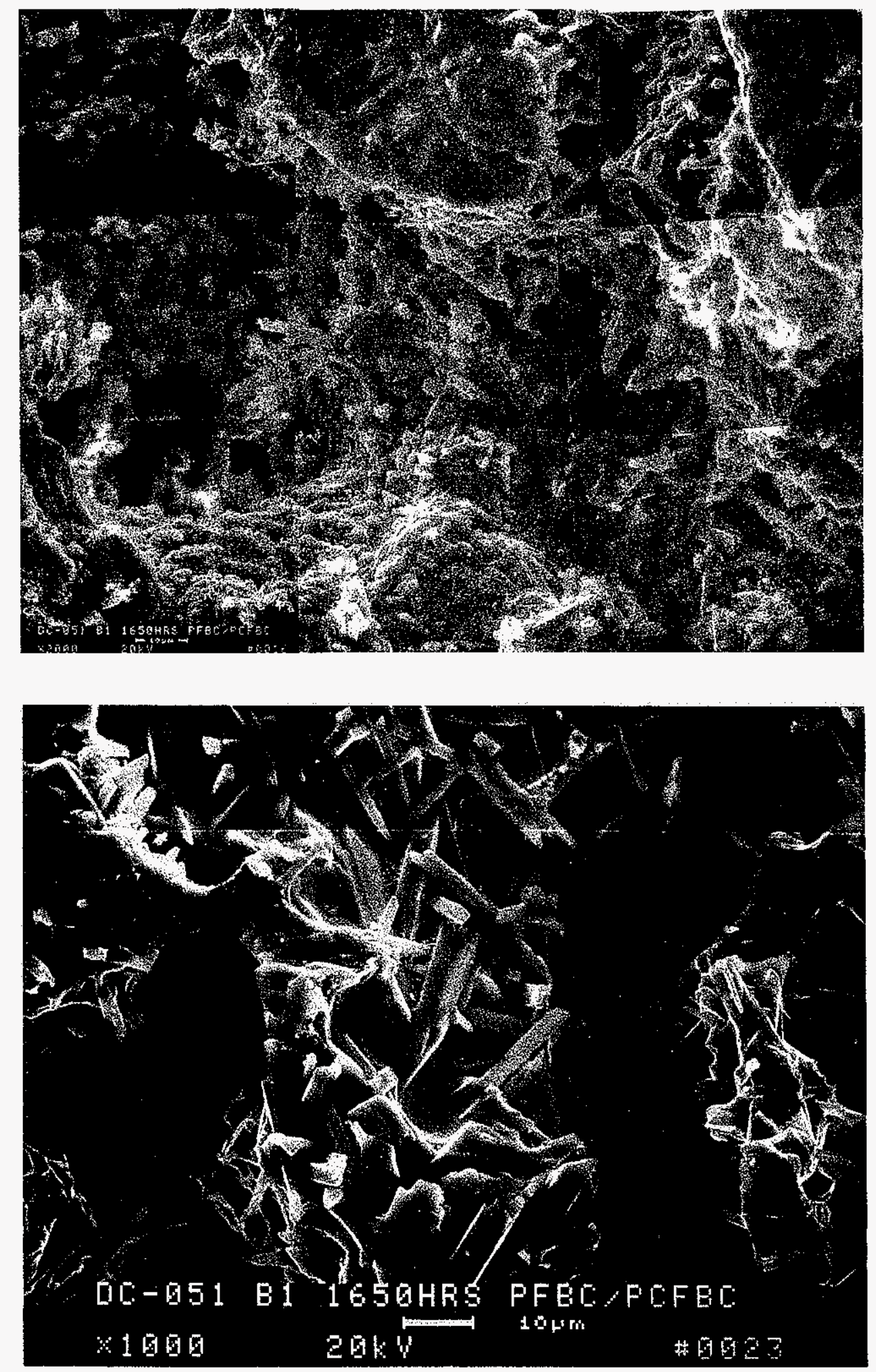

Figure 2-44 - Microstructure of the 505 hour, PCFBC-exposed, Coors P-100A-1 alumina/mullite filter matrix. 

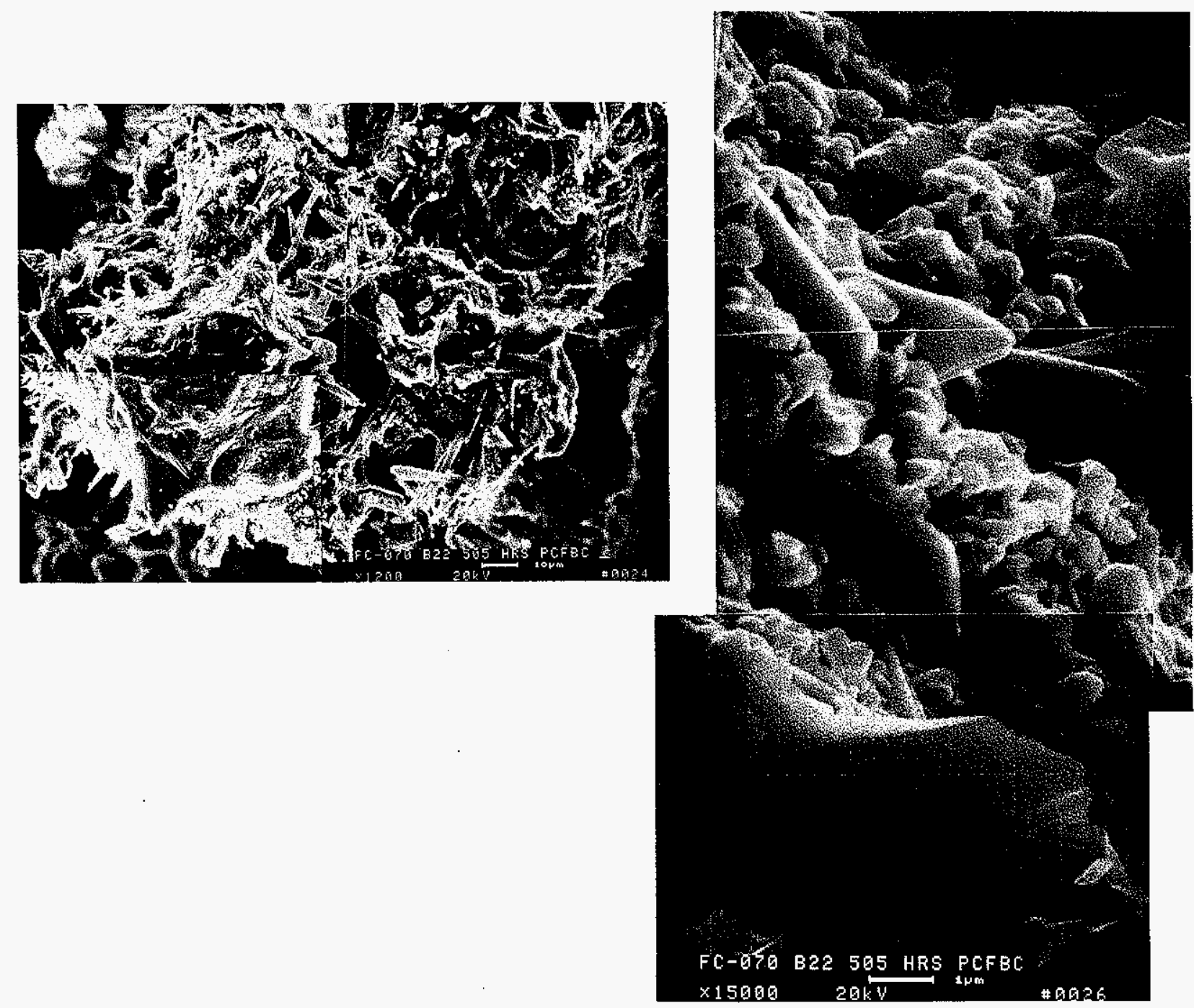

Figure 2-45 - Microstructure of the 1650 hour, PFBC/PCFBC-exposed, Coors P-100A-1 alumina/mullite filter matrix. 


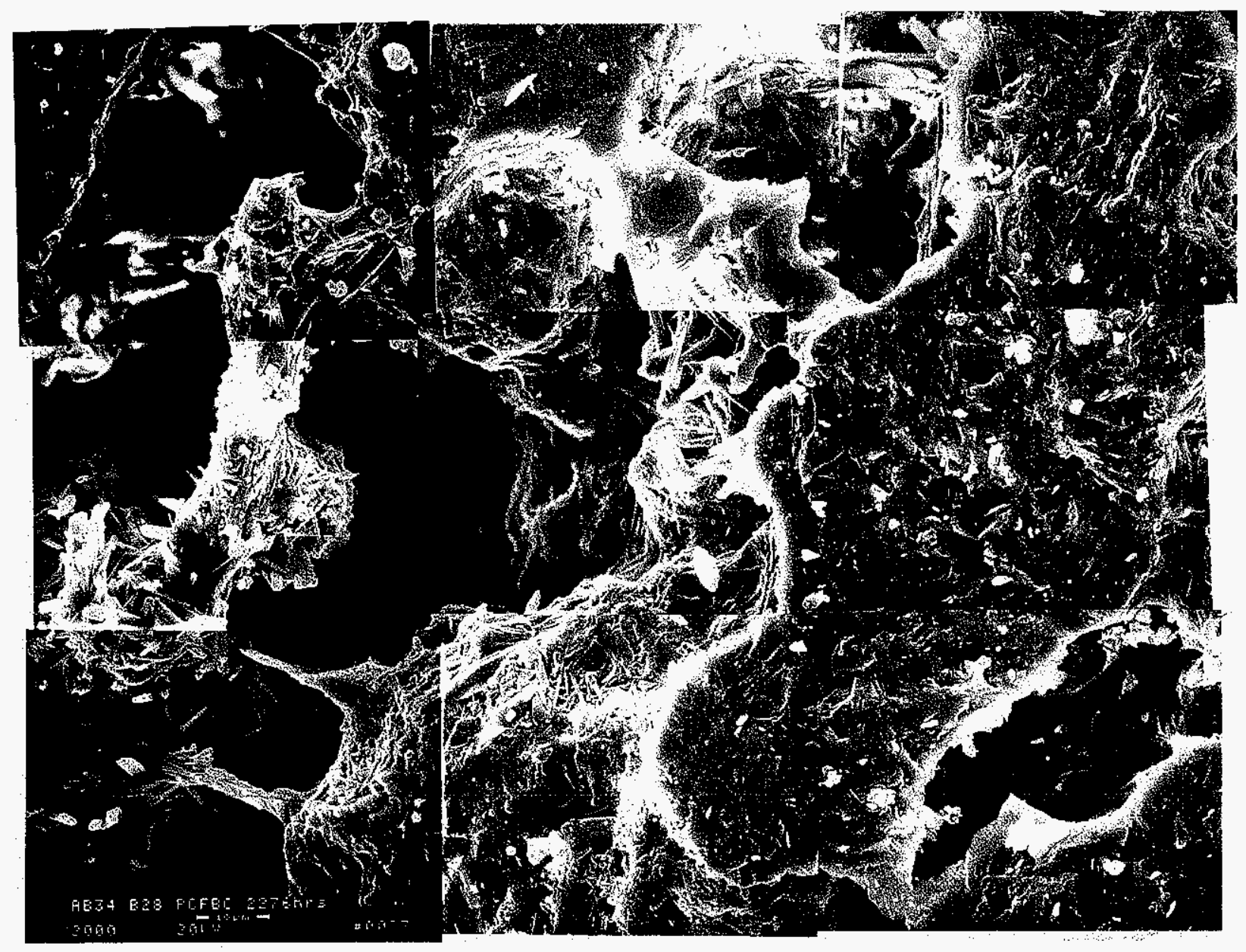

Figure 2-46 - High magnification micrograph montage illustrating the extensive crystallization that resulted throughout the ligaments and along the pore cavity surfaces of the 2276 hour, PFBC/PCFBC-exposed, Coors P-100A-1 alumina/mullite matrix. 


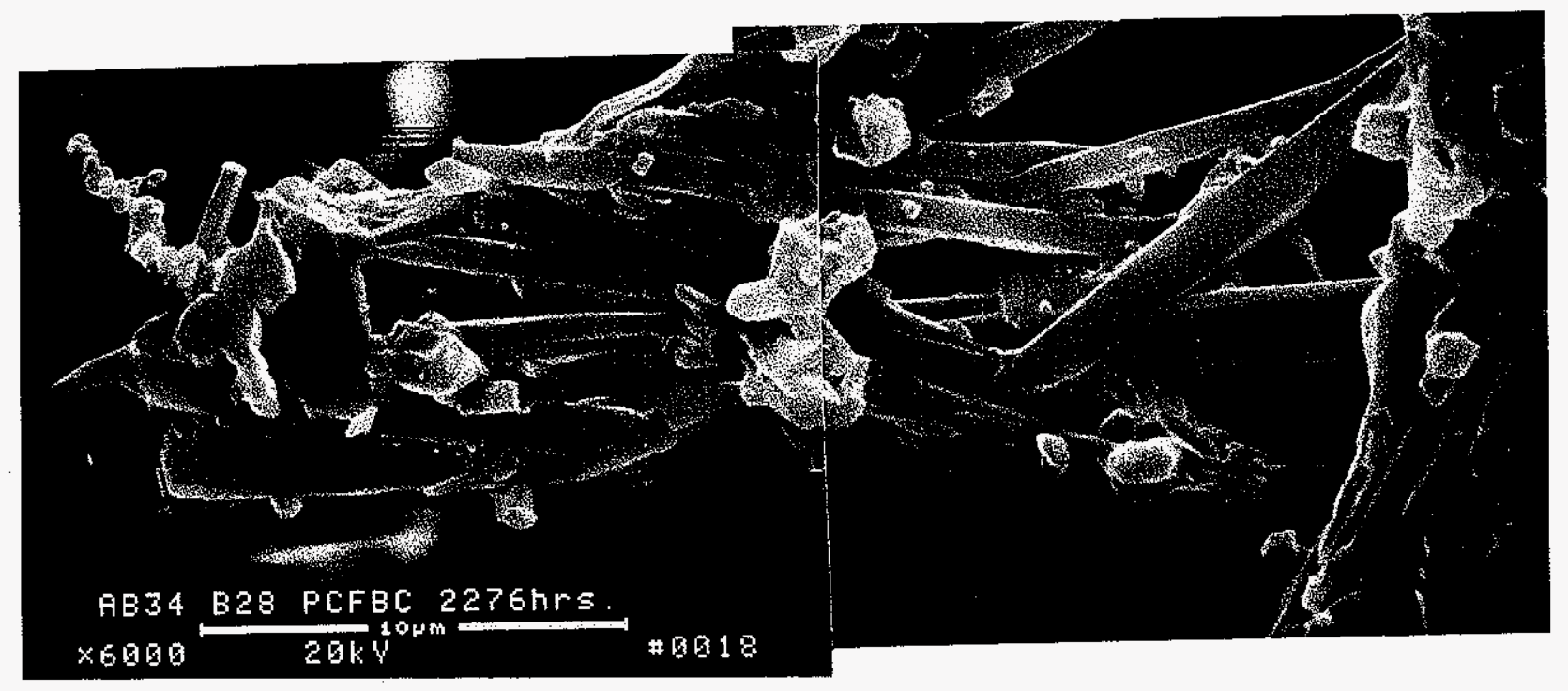

Figure 2-47 - Micrograph montage illustrating the formation of mullite-like rods that resulted along the surface of the pore cavity walls in the PFBC/PCFBC-exposed Coors P-100A-1 alumina/mullite filter matrix. 


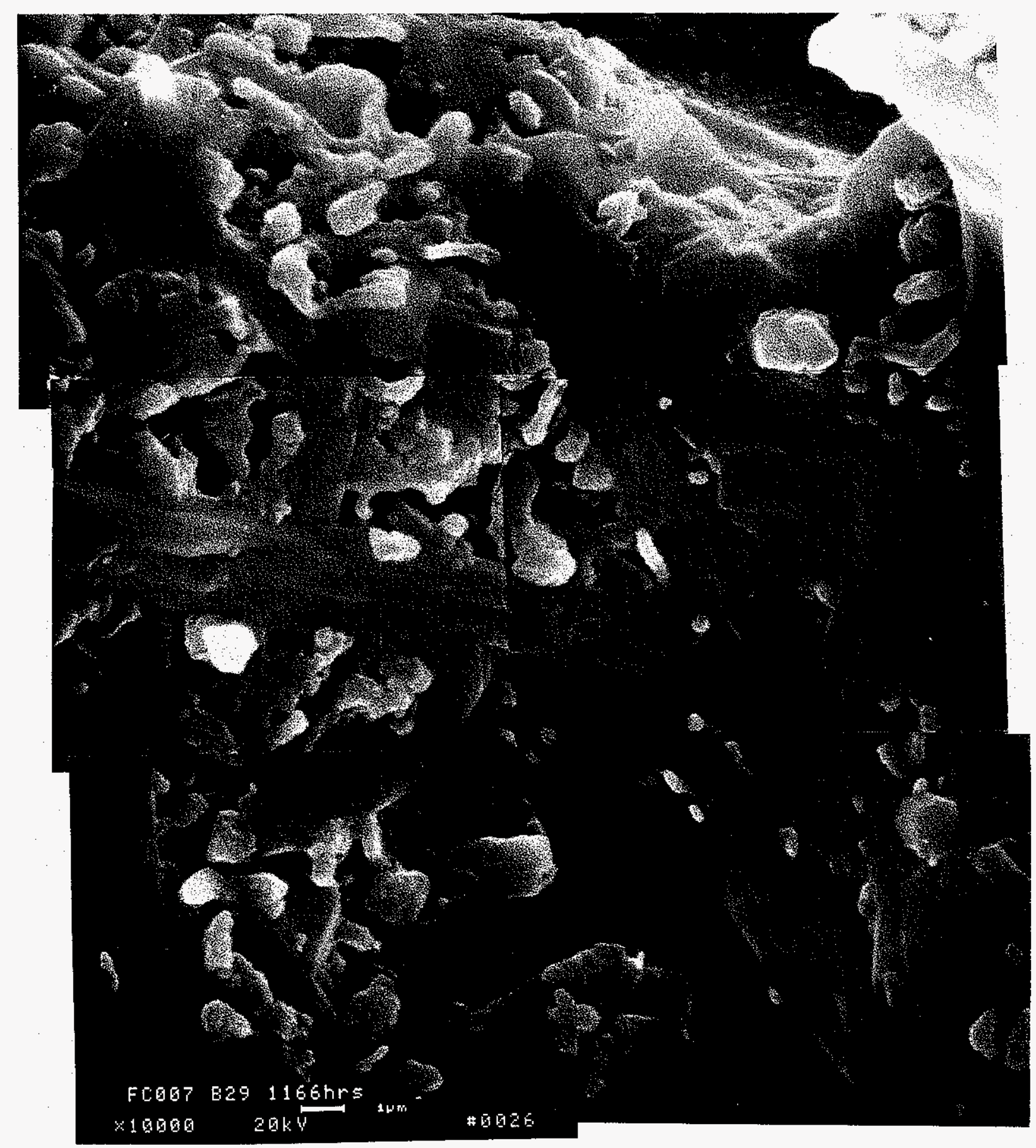

Figure 2-48 - High magnification micrograph montage illustrating the formation of a fine grain phase and mullite-like rods that resulted along the pore cavity surfaces of the 1166 hour, PCFBC-exposed, Coors P-100A-1 alumina/mullite filter matrix. 


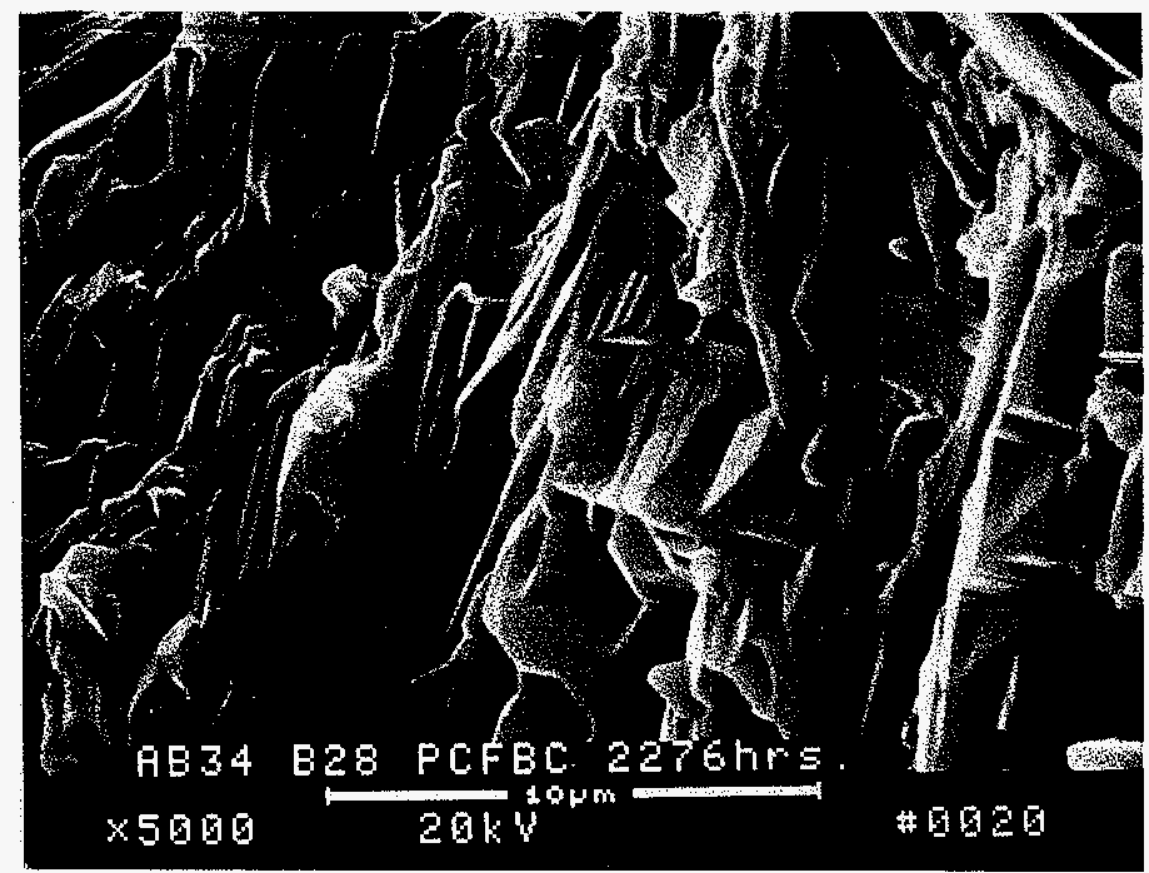

Figure 2-49 - Micrograph illustrating the morphology of the larger grain aluminosilicate phase that resulted along the pore cavity surfaces of the $\mathrm{PFBC} / \mathrm{PCFBC}$-exposed Coors P-100A-1 alumina/mullite filter matrix. 


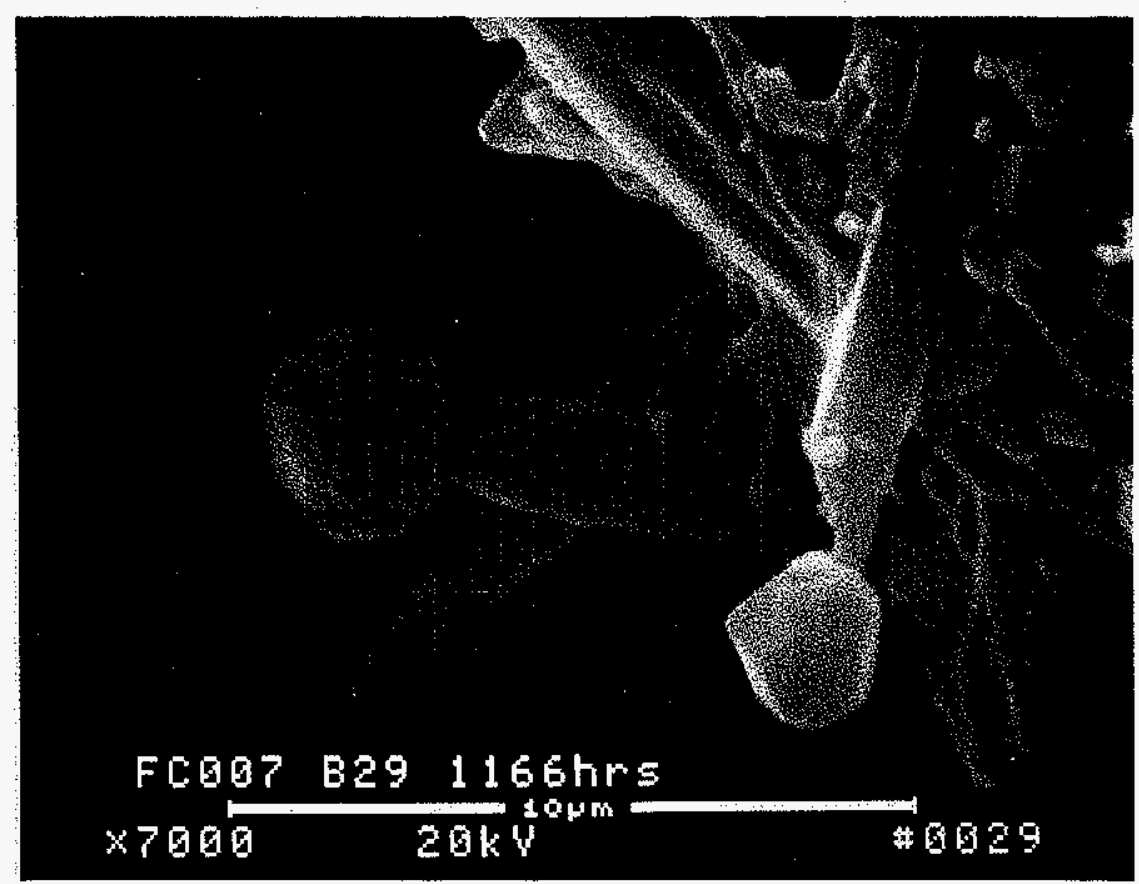

Figure 2-50 - Morphology of the crystalline features that typically formed at the tip of the mullite rods which extended into the pore cavities of the PCFBC-exposed Coors P-100A-1 alumina/mullite filter matrix. 
Along the pulse cycled i.d. surface, fines were present which were enriched with ash particles (i.e., high concentrations of silicon and aluminum). Relative to the ash fines, sorbent fines which contained primarily calcium were also present (i.e., limestone sorbent). Frequently the sorbent fines were $\sim 1 / 2$ to nearly completely sulfated, implying extended residence time of the particles along the i.d. surface of the filter element in comparison to fines that remained within the conditioned dust cake layer along the o.d. surface of the filter element.

Extensive crystallization along the pore cavity surfaces and within the ligaments was observed throughout the 3311 hour, PFBC/PCFBC-exposed, Coors P-100A-1 alumina/mullite filter matrix (Figures 2-51 through 2-56). Several subtle changes within the microstructure of the alumina/mullite filter matrix were, however, evident which tended to be location specific. These included

- The formation of blunted sheets of aluminosilicate-enriched, cubic, rod-like features along the surface of the pore cavities near the o.d. non-membrane-coated surface of the filter wall (Figure 2-57).

- Near the center of the filter wall, aluminosilicate-enriched, rod-like features (i.e., mullite) which clustered and extended across the pore cavities were typically observed (Figure 2-58).

- Infrequently, internal voids were identified within the ligaments which supported growth of the extended crystalline rod-like or mullite phase.

- Along the surface of these ligaments, round, submicron features were identified between adjacent, extended, rod-like crystals (Figures 2-59 and 2-60). The submicron features were enriched with oxygen, silicon, and aluminum, and minor concentrations of magnesium, potassium, and calcium. As the rods extended from the surface of the ligaments, the submicron phase was no longer evident (Figure 2-61).

- As opposed to extension and clustering of the aluminosilicate-enriched, rod-like crystals (i.e., mullite), nearly spherical, somewhat angular, $\sim 4 \mu \mathrm{m}$ wide nodules formed at the tips of the cubic rods along the pulse cycled surface of the filter matrix (Figures 2-62 and 2-63). As a result, the ligaments along the i.d. surface tended to appear more rounded in comparison to those along the o.d. surface or center section of the filter wall (Figures 2-64 and 2-65).

- The somewhat angular, nearly spherical nodules were identified to be enriched with silicon and oxygen, in comparison to the aluminosilicate crystalline rods.

- As a result of contact with the pulse gas, grain growth of the aluminosilicate crystalline rods was suppressed, leading to a coalescence of a silica-enriched phase at the tip of the aluminosilicate rods.

As a result of the microstructural differences identified throughout the filter wall, a compositional, and perhaps strength gradient existed between the outer surface of the filter element which was contacted by ash fines and the PFBC/PCFBC process gases, and the inner surface of the filter element which experienced pulse cycling. 


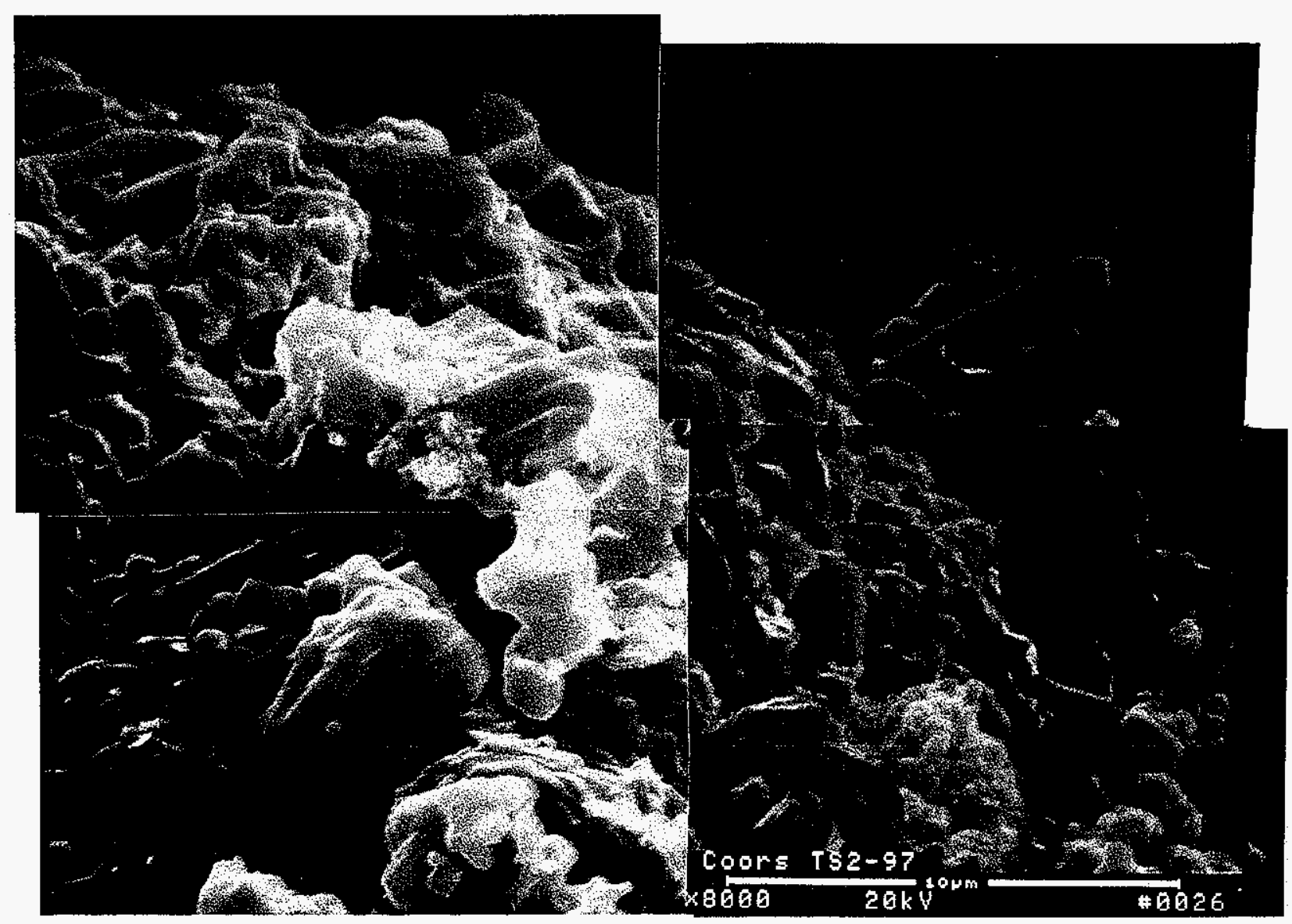

Figure 2-51 - Extensive crystallization resulted along the pore cavity surfaces near the 0.d. surface of the Coors P-100A-1 alumina/mullite filter wall after 3311 hours of exposure to PFBC/PCFBC operating conditions. 


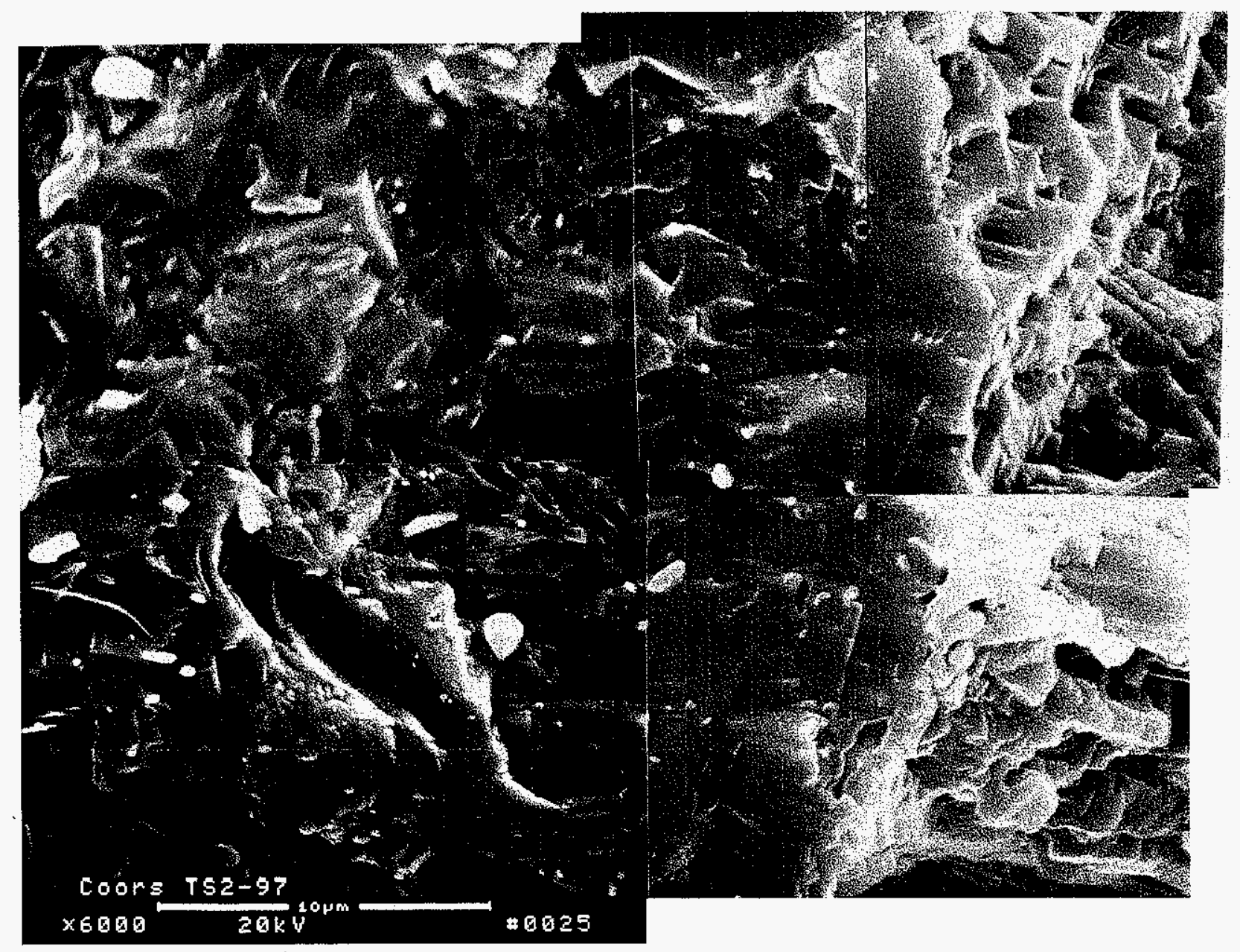

Figure 2-52 - Extensive crystallization resulted throughout the ligaments near the o.d. surface of . the Coors P-100A-1 alumina/mullite filter wall after 3311 hours of exposure to PFBC/PCFBC operating conditions. 


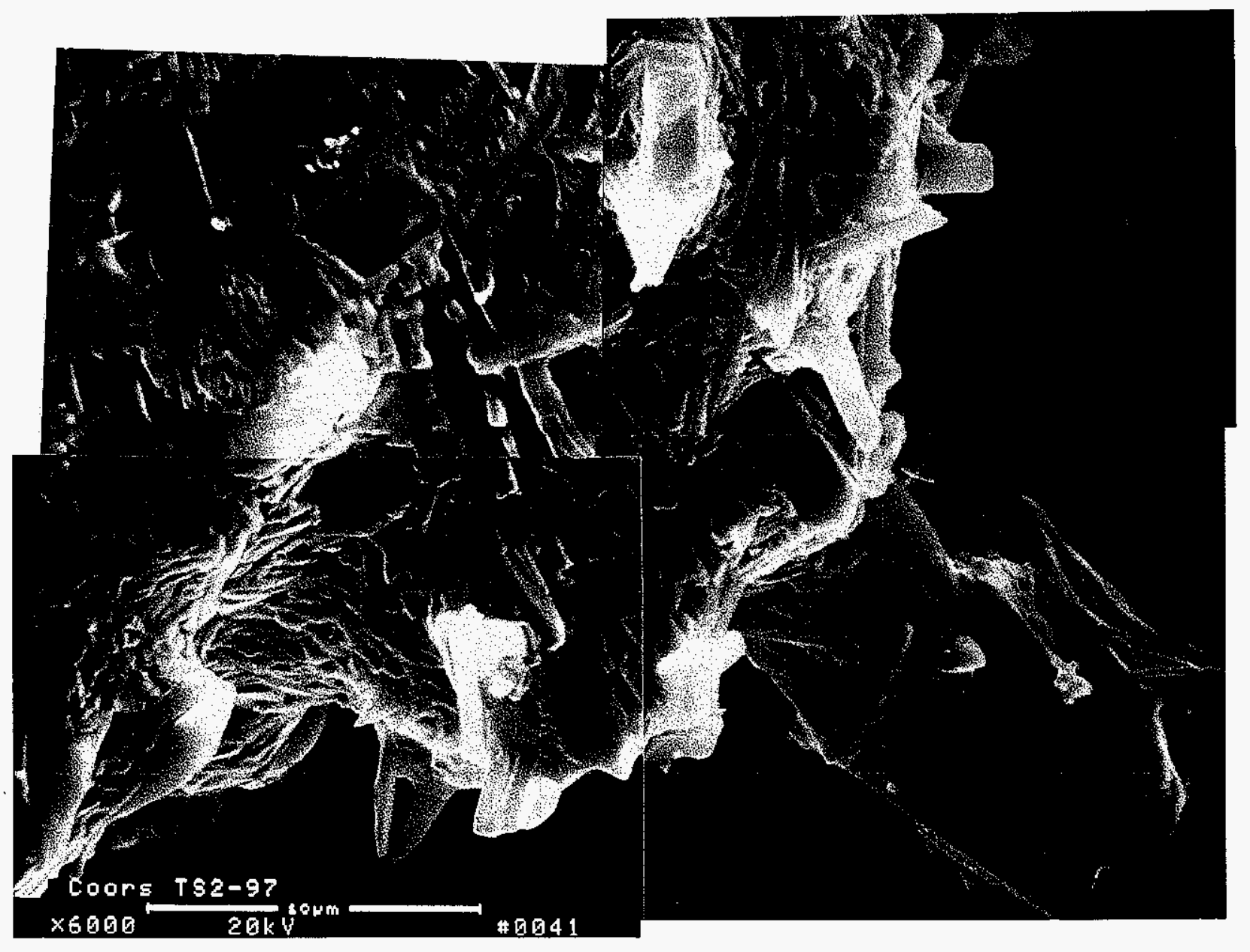

Figure 2-53 - Extensive crystallization resulted along the pore cavity surfaces near the center of the Coors P-100A-1 alumina/mullite filter wall after 3311 hours of exposure to PFBC/PCFBC operating conditions. 


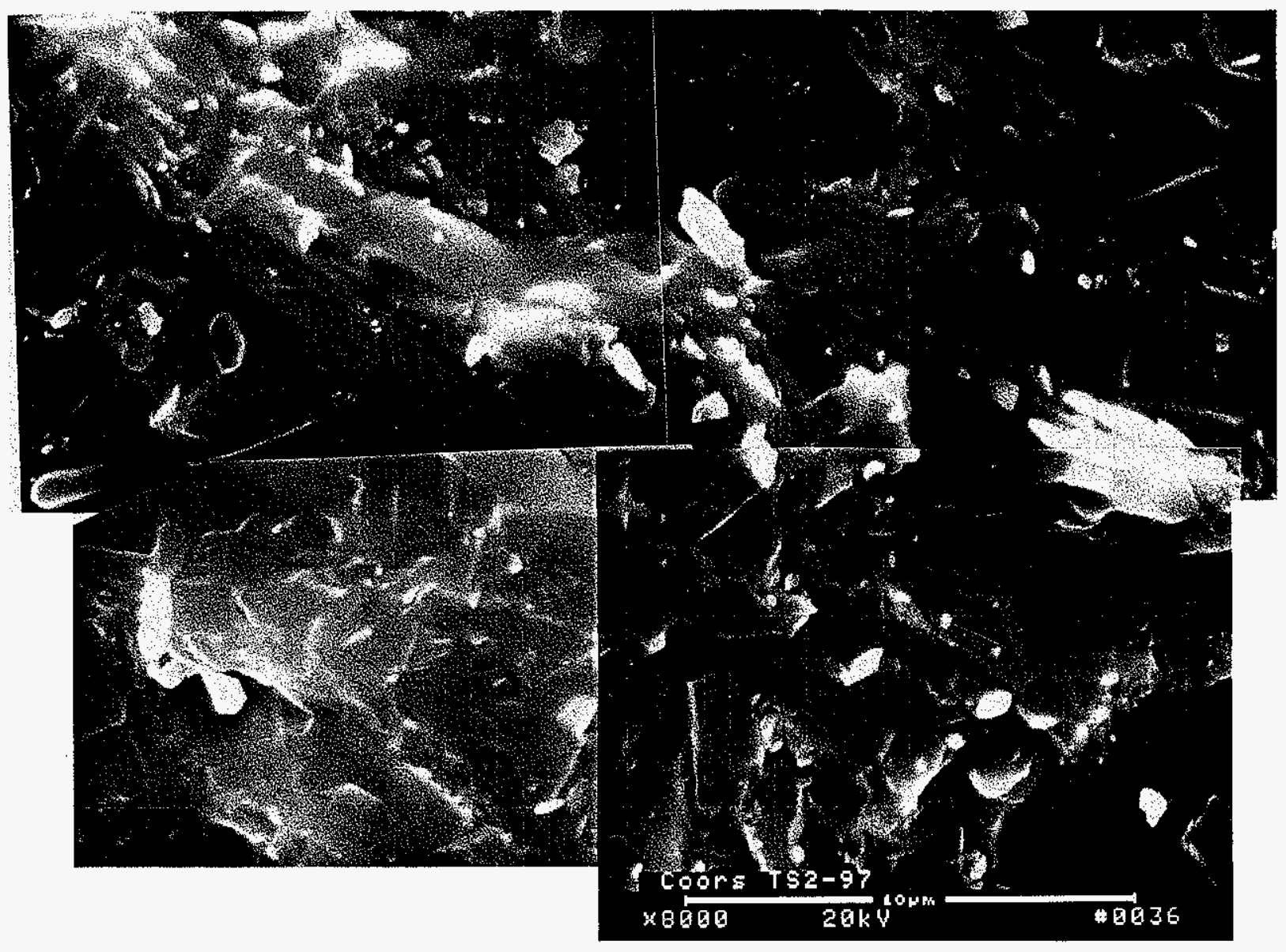

Figure 2-54 - Extensive crystallization resulted throughout the ligaments near the center of the Coors P-100A-1 alumina/mullite filter wall after 3311 hours of exposure to PFBC/PCFBC operating conditions. 


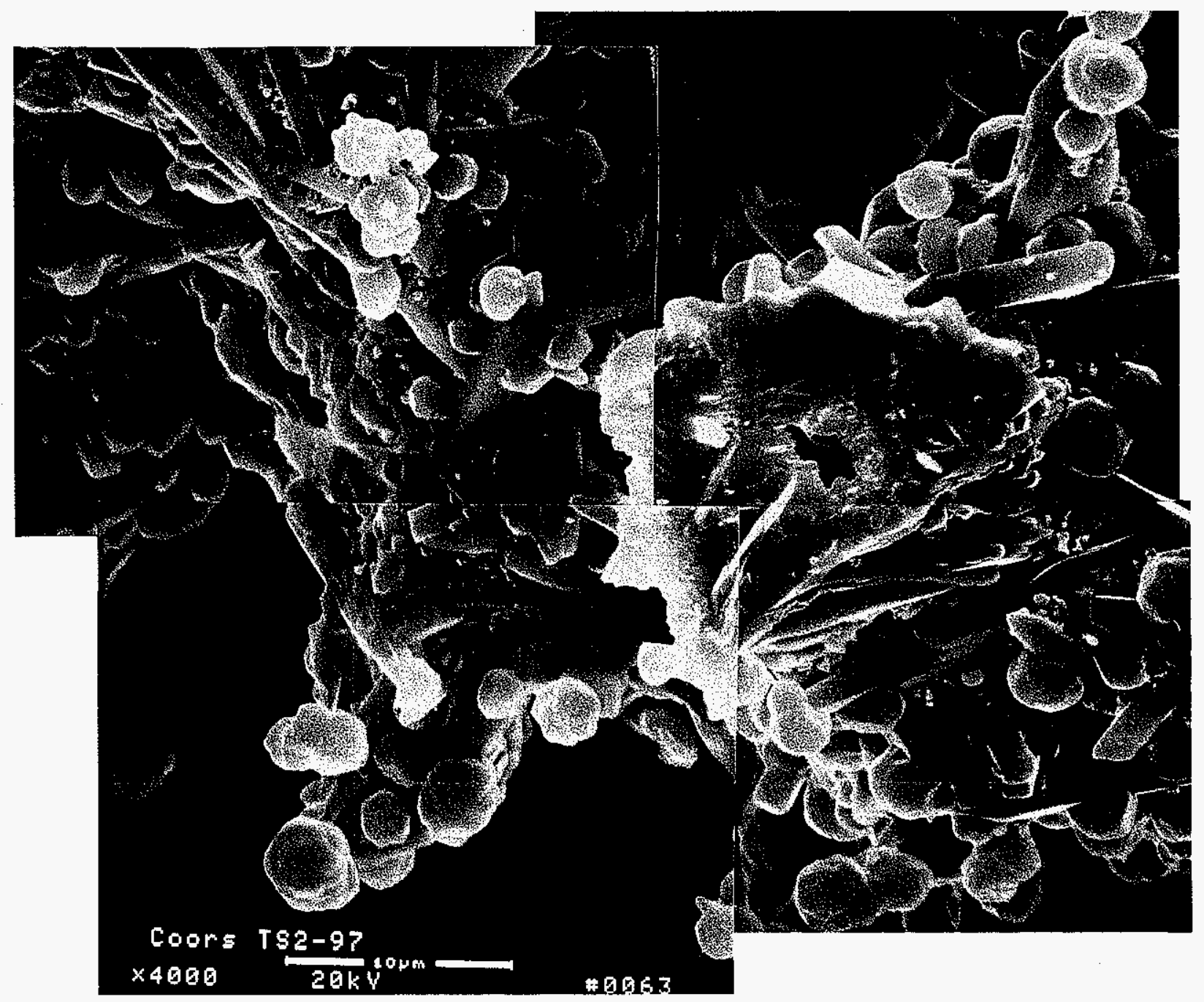

Figure 2-55 - Extensive crystallization resulted along the pore cavity surfaces near the i.d. or pulse cycled surface of the Coors P-100A-1 alumina/mullite filter wall after 3311 hours of exposure to PFBC/PCFBC operating conditions. 


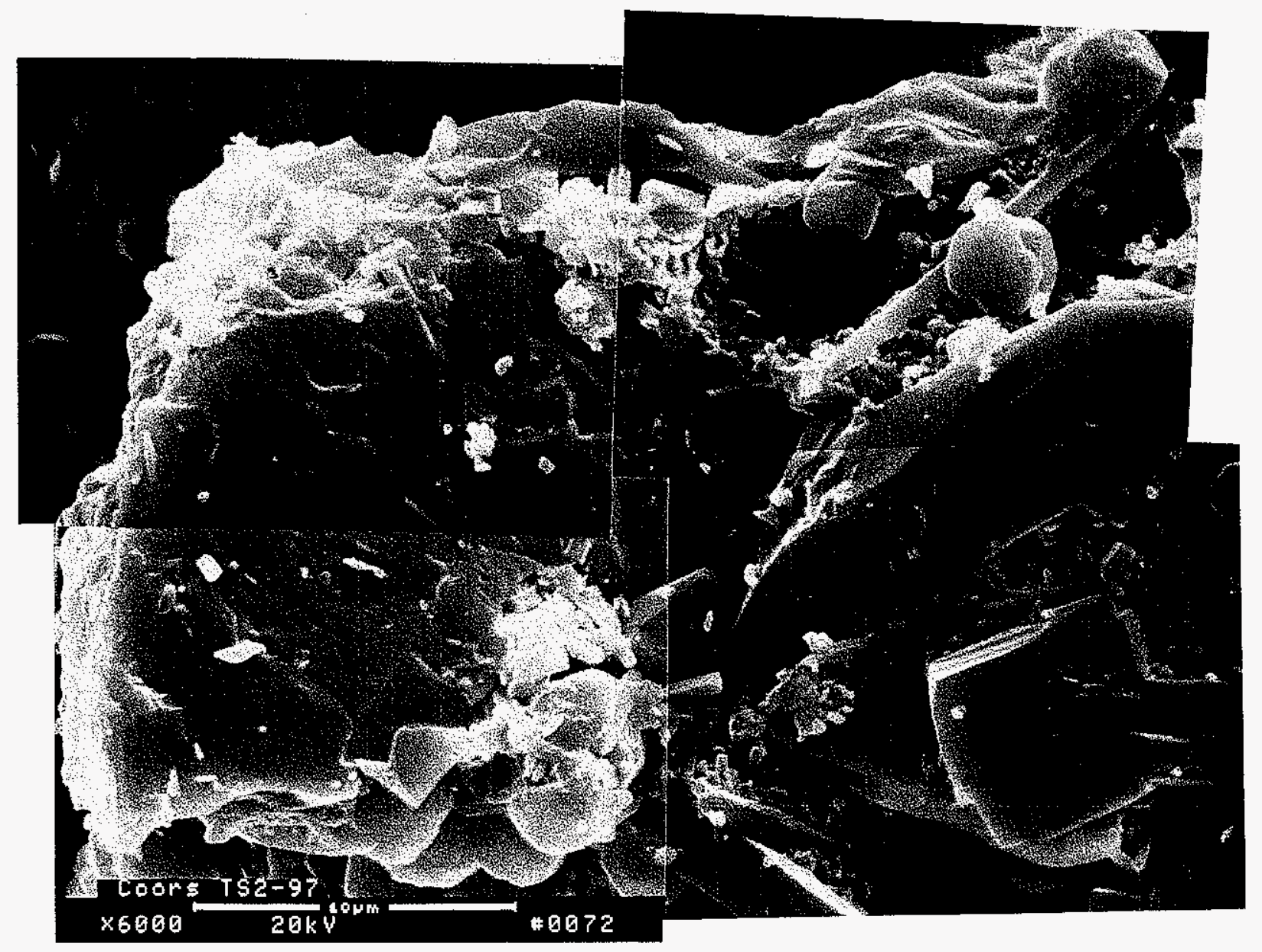

Figure 2-56 - Extensive crystallization resulted throughout the ligaments near the i.d. or pulse cycled surface of the Coors P-100A-1 alumina/mullite filter wall after 3311 hours of exposure to PFBC/PCFBC operating conditions. 


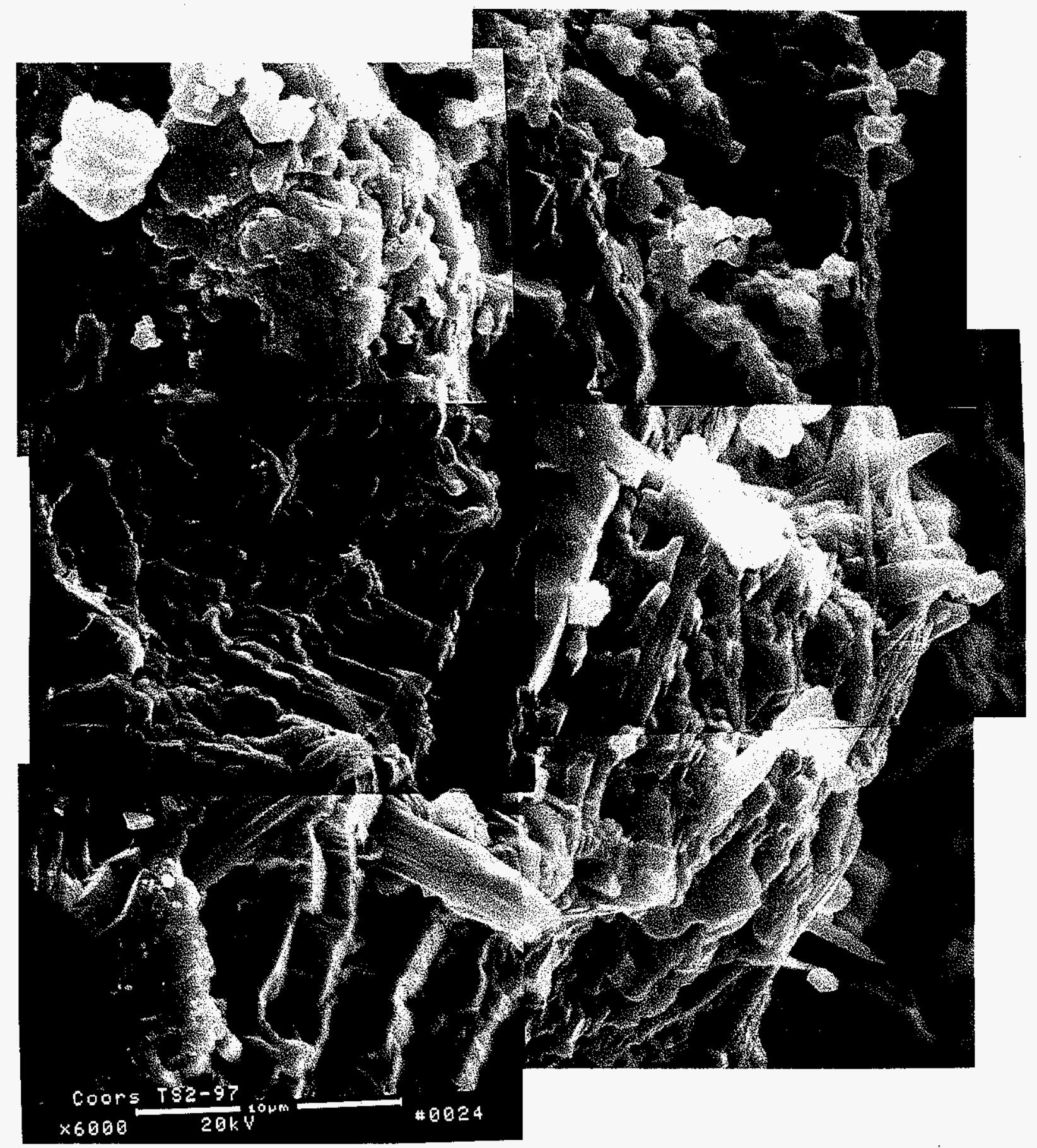

Figure 2-57 - Micrograph montage illustrating the crystalline features that resulted along the surface of the pore cavities near the o.d. surface of the 3311 hour, PFBC/PCFBCexposed, Coors P-100A-1 alumina/mullite filter wall. 


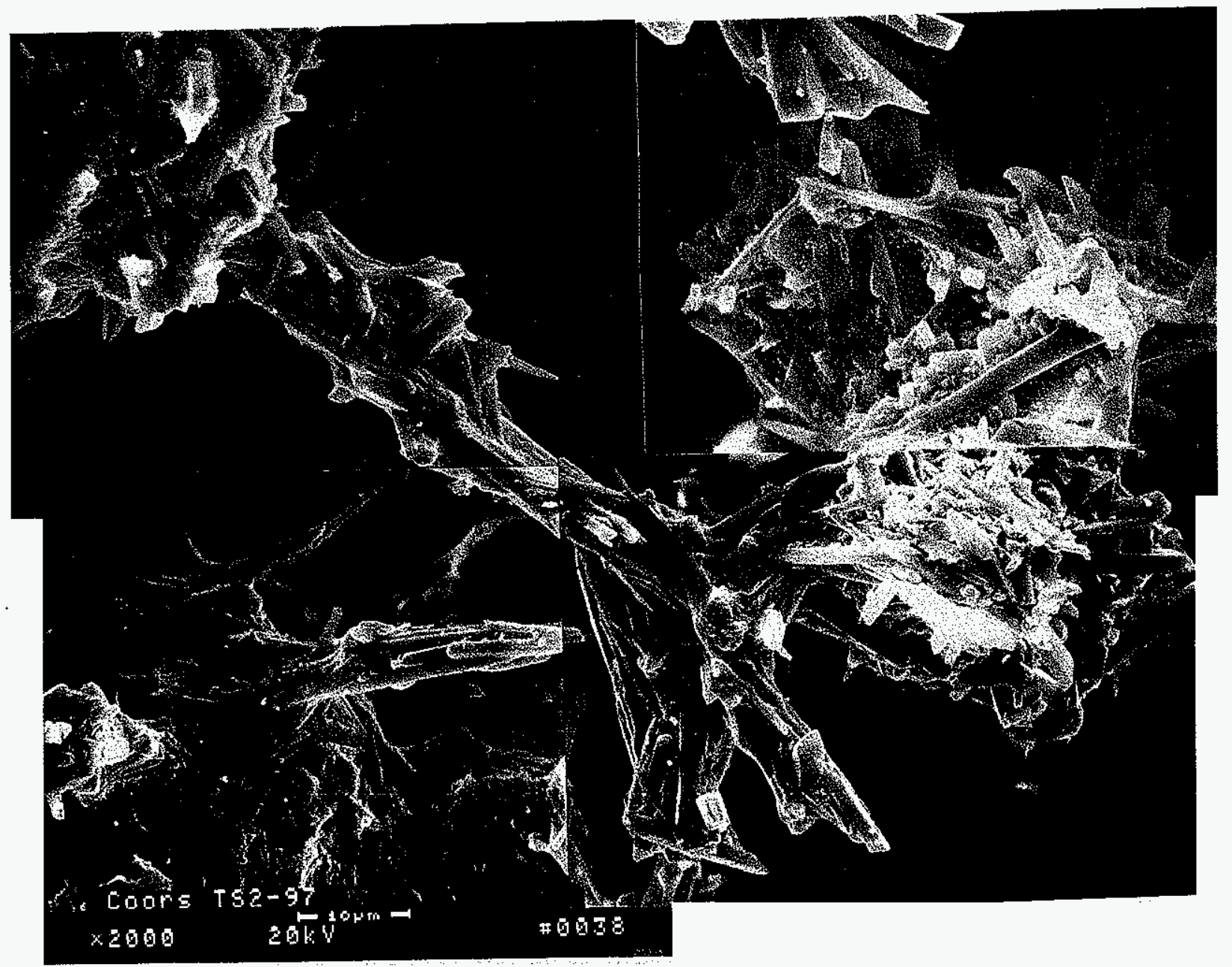

Figure 2-58 - Micrograph montage illustrating clustering and extension of the aluminosilicate rod-like formations across the pore cavities near the center of the 3311 hour, PFBC/PCFBC-exposed, Coors P-100A-1 alumina/mullite filter wall. 


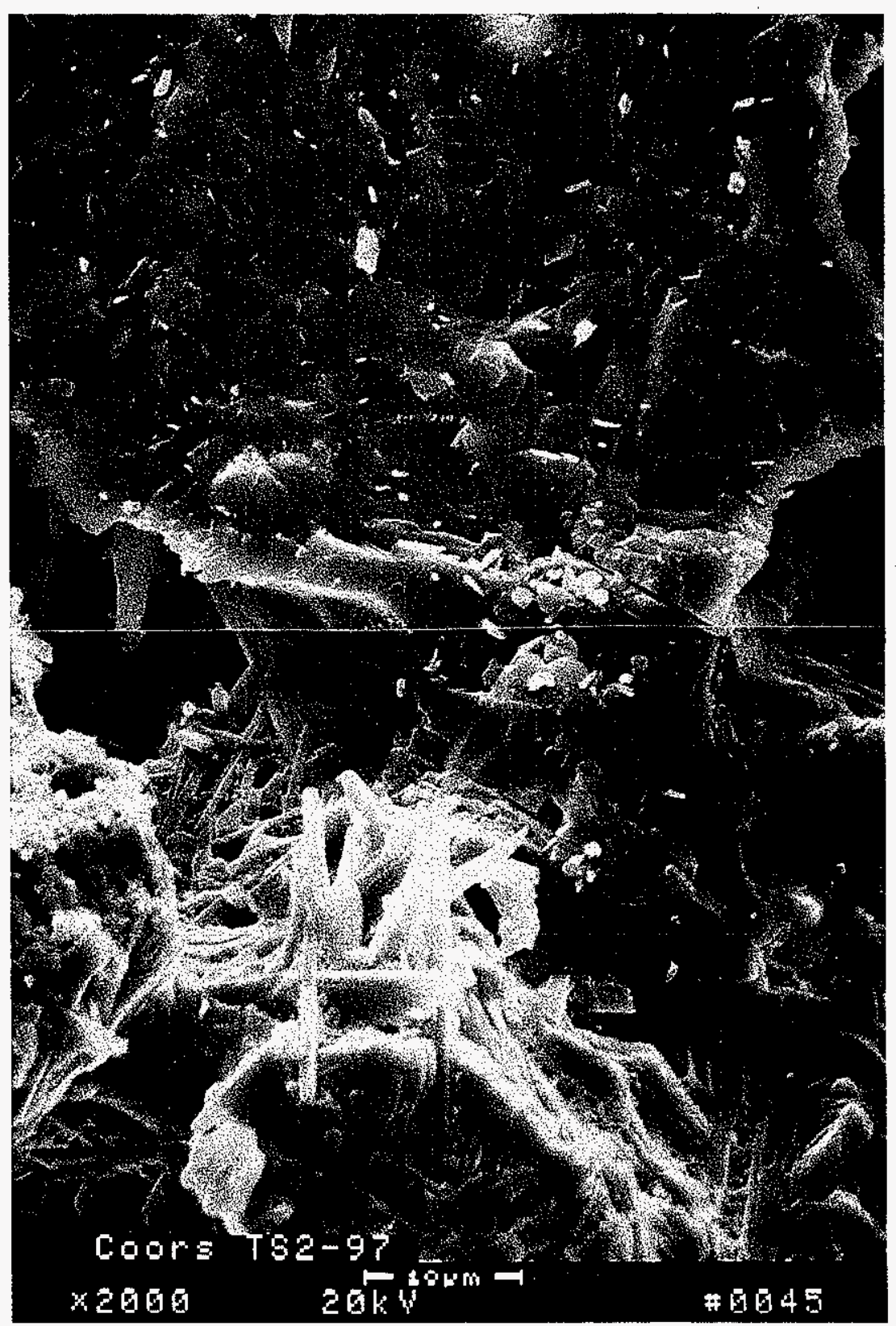

Figure 2-59 - Micrograph montage illustrating extensive crystallization that resulted within the ligaments and along the pore cavity walls near the center of the 3311 hour, PFBC/PCFBC-exposed, Coors P-100A-1 alumina/mullite filter wall. 

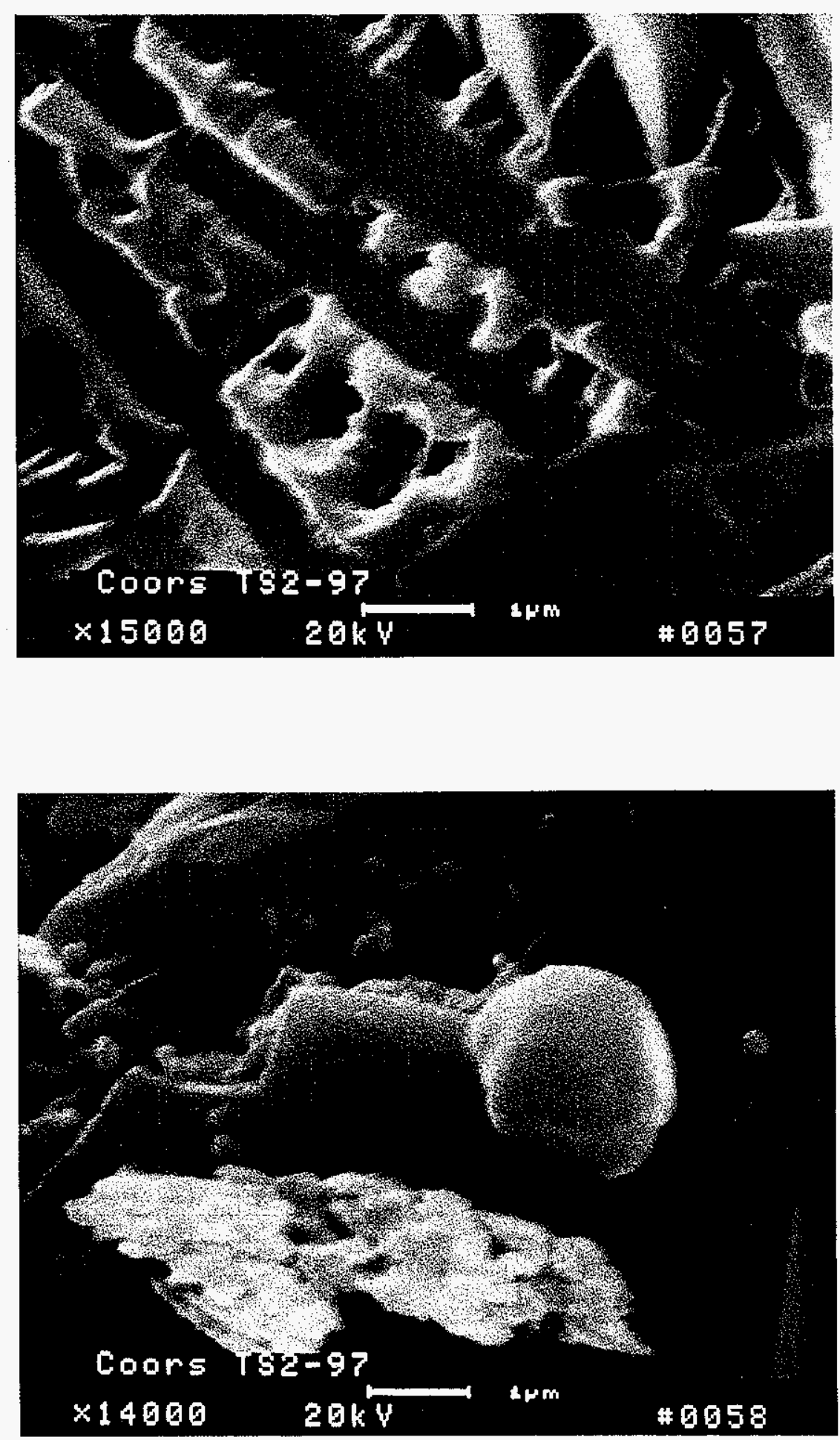

Figure 2-60 - Morphology of the submicron features that formed between the aluminosilicateenriched rods that were present along the pore cavity surfaces in the $\mathbf{3 3 1 1}$ hour, PFBC/PCFBC-exposed, Coors P-100A-1 alumina/mullite filter matrix. 


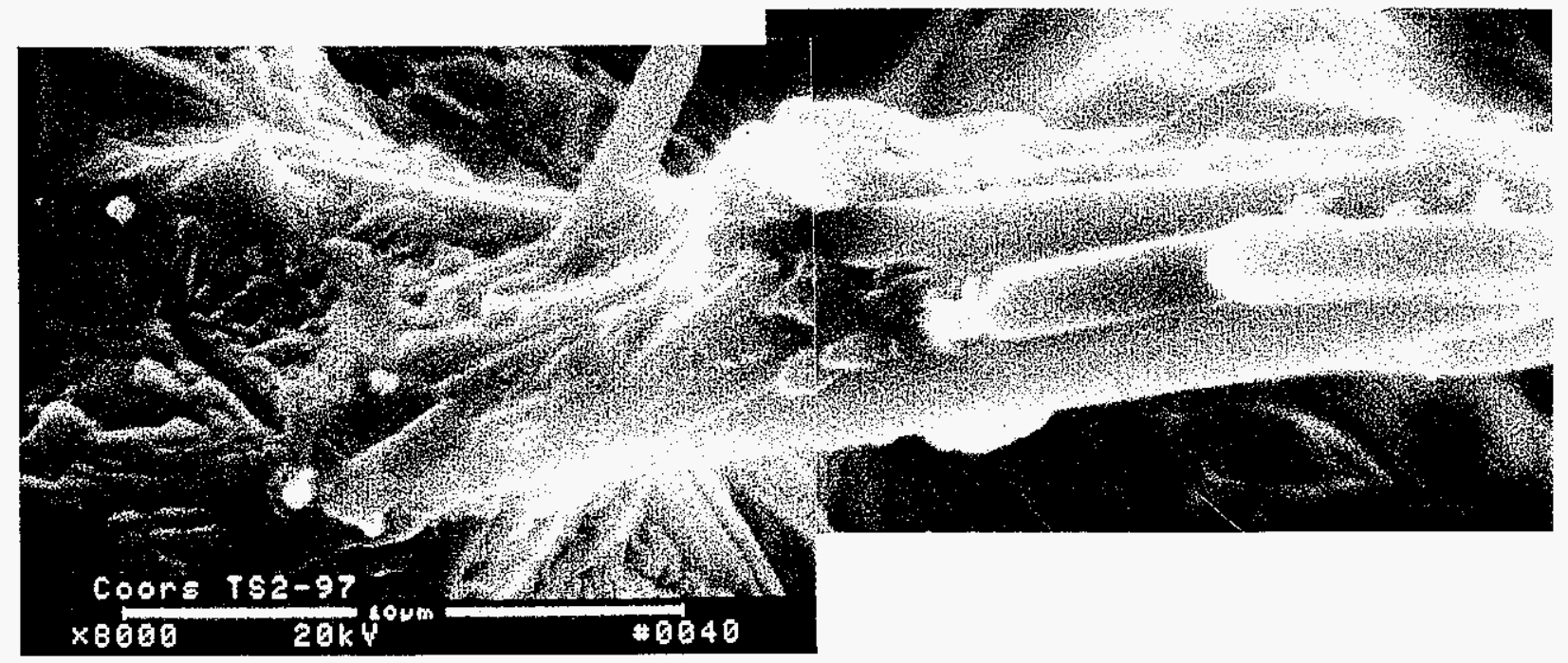

Figure 2-61 - Extension of the aluminosilicate rod-like formations across pore cavities within the 3311 hour, PFBC/PCFBC-exposed, Coors P-100A-1 alumina/mullite filter matrix. 

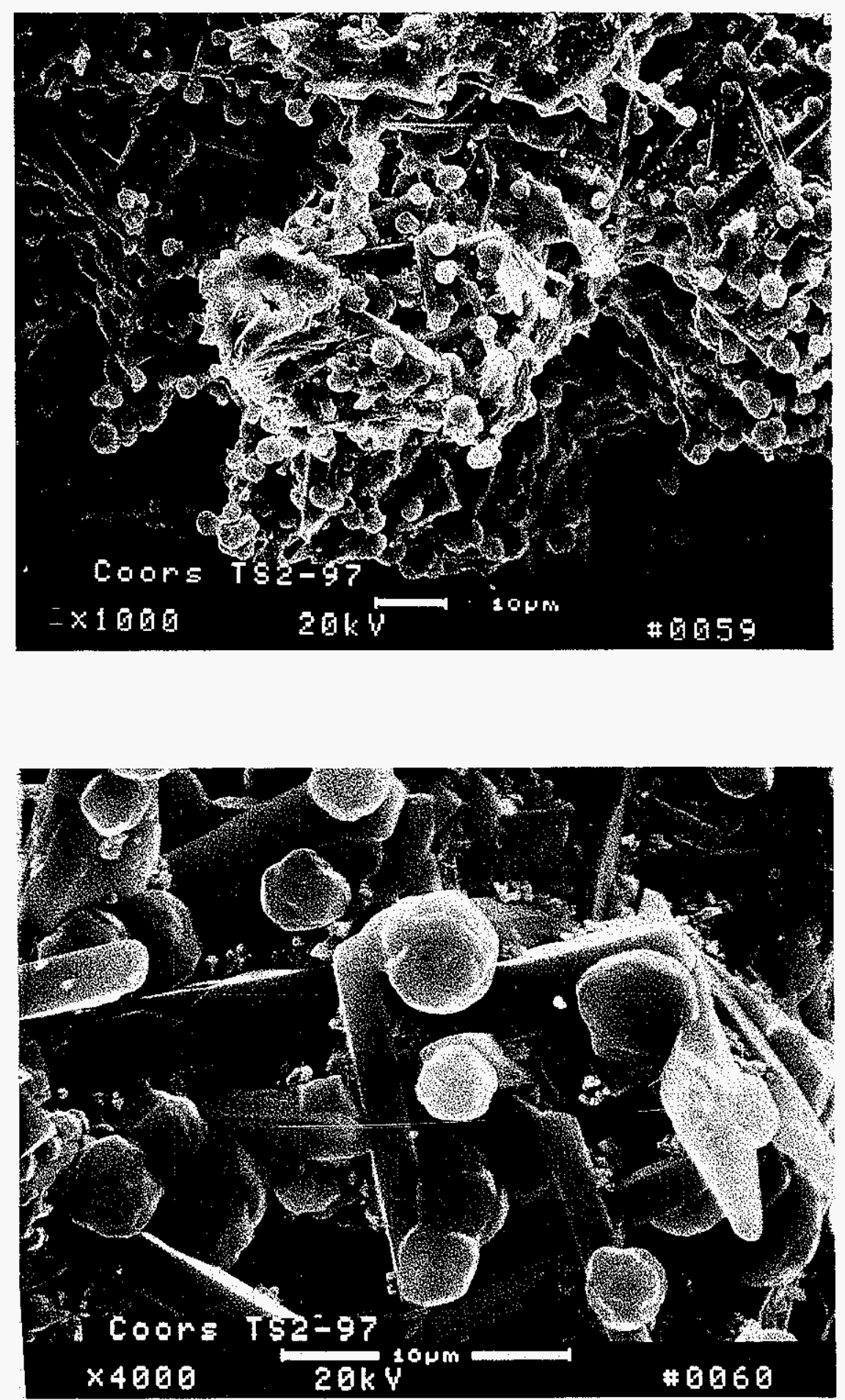

Figure 2-62 - Silica-enriched nodular formations resulting at the tip of the aluminosilicateenriched rods that were present along the pore cavity surfaces near the i.d. or pulse cycled surface of the 3311 hour, PFBC/PCFBC-exposed, Coors P-100A-1 alumina/mullite filter matrix. 

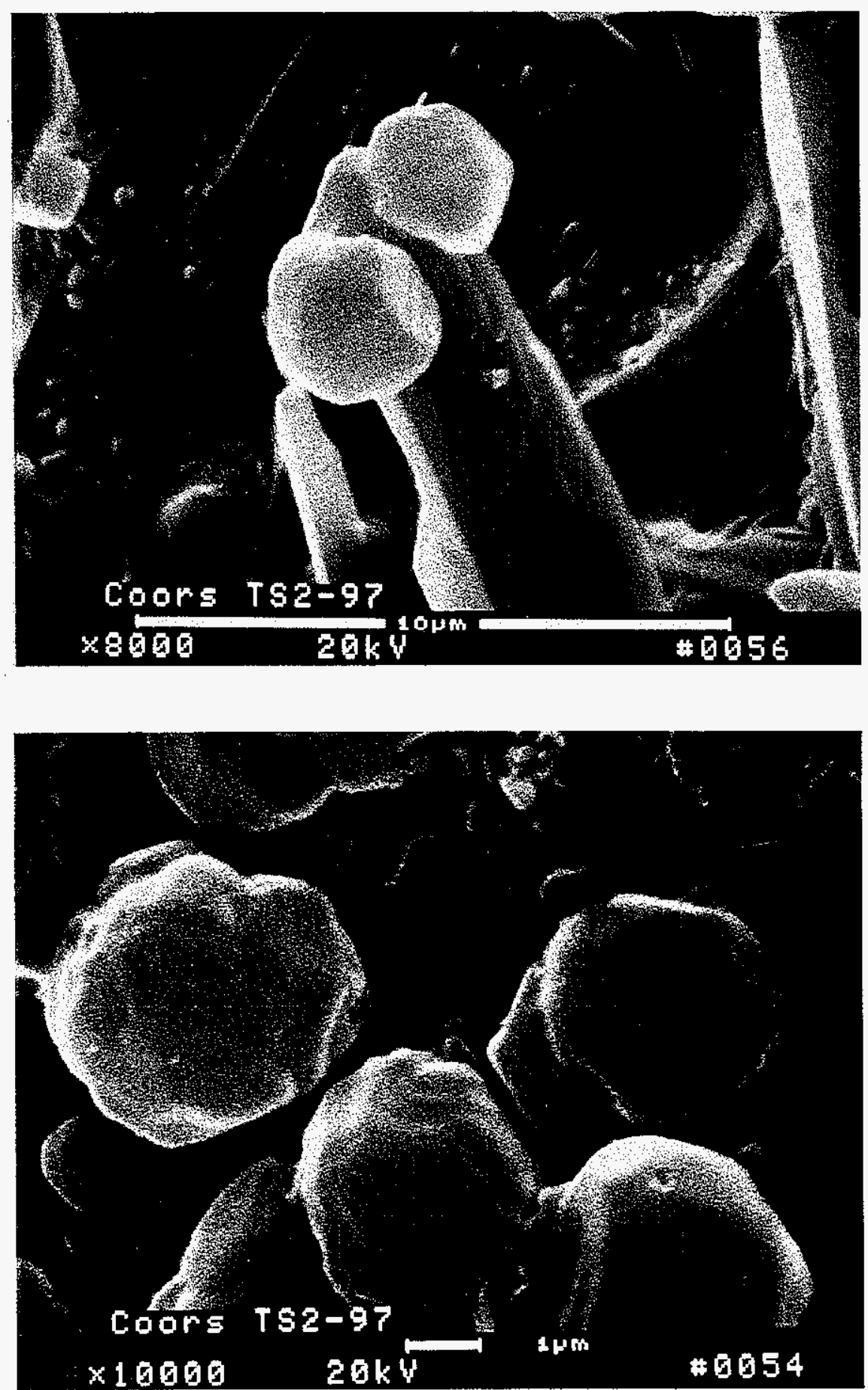

Figure 2-63 - Higher magnification micrographs illustrating the morphology of the angular, nearly round, nodular features that formed at the tip of the aluminosilicate rods that were present along the surface of the i.d or pulse cycled pore cavities in the 3311 hour, PFBCB/PCFBC-exposed, Coors P-100A-1 alumina/mullite filter matrix. 


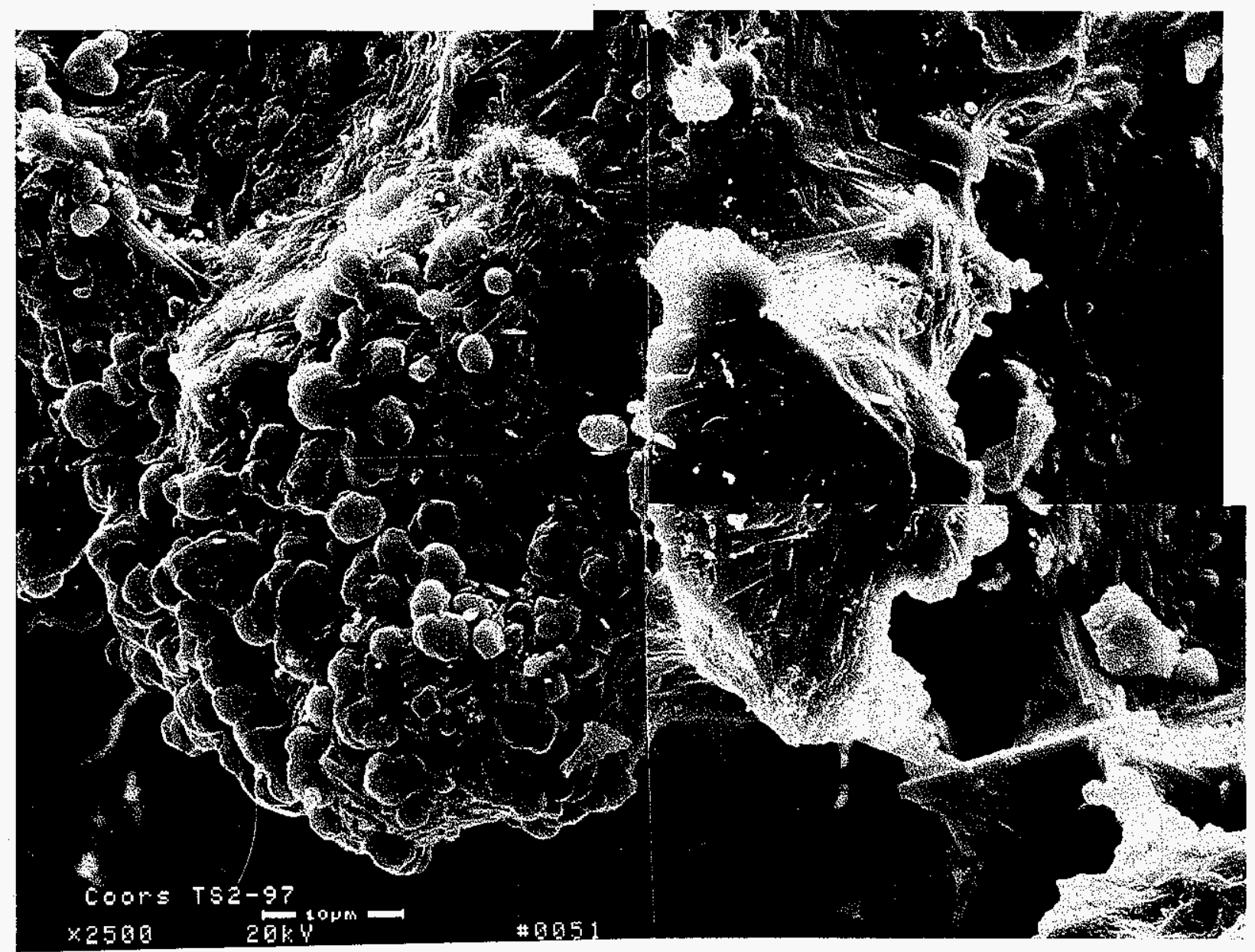

Figure 2-64 - Morphology of the i.d. or pulse cycled surface pore cavities in the 3311 hour, PFBC/PCFBC-exposed, Coors P-100A-1 alumina/mullite filter matrix. 


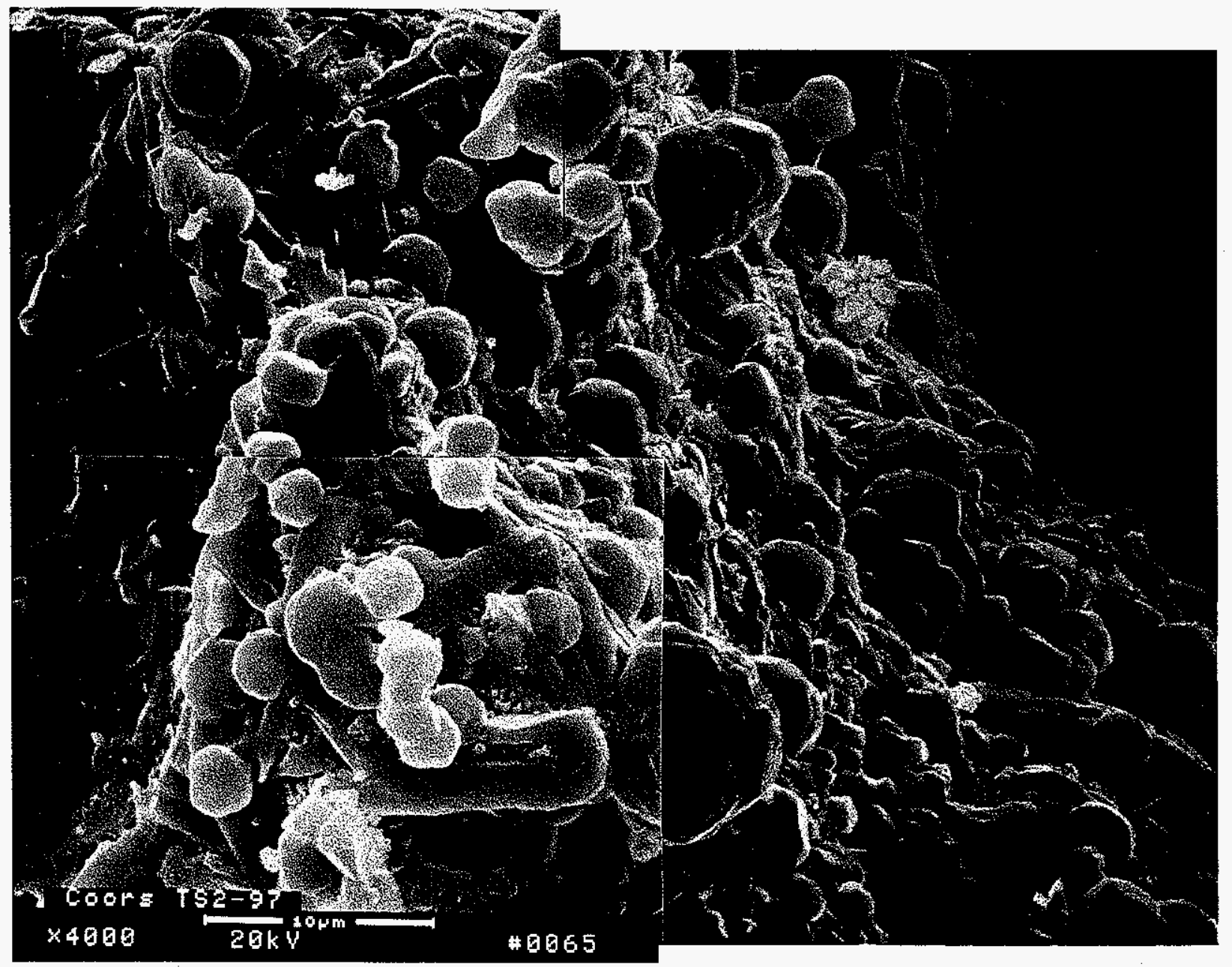

Figure 2-65 - Micrograph montage illustrating the formation of the angular, nearly round, nodular features that formed along the surface of the pore cavities in the 3311 hour, PFBCB/PCFBC-exposed, Coors P-100A-1 alumina/mullite filter matrix. 


\subsubsection{M CVI-SiC Composite Candle Filters}

3M CVI-SiC composite filter elements consist of three layers - an open mesh outer confinement layer, a middle filtration mat layer, and an inner structural support triaxial braided layer. ${ }^{4}$ Within the confinement and filtration mat layers, an $\sim 1-2 \mu \mathrm{m}$ layer of silicon carbide was chemically vapor infiltrated along the surface of Nextel ${ }^{\mathrm{TM}} 312$ or alumina-based fibers, while an $\sim 100 \mu \mathrm{m}$ layer of silicon carbide was deposited along the Nextel ${ }^{\mathrm{TM}} 312$ triaxial braid in the support matrix.

When removed from the filter array after 387 hours of operation at $850^{\circ} \mathrm{C}$ in the PCFBC environment (TS2-96), a color change was readily evident along the outer confinement and possibly filtration mat layers of the 3M CVI-SiC composite candle filters (Figure 2-66). The original dark black color of the CVI-SiC coating that encapsulated either the Nextel ${ }^{\mathrm{TM}} 312$ fibers in the outer confinement layer, or the alumina-based fibers in the filtration mat layer was not retained along the majority of the filter body. Instead after 387 hours of operation, the outer confinement layer appeared to be white (i.e., excluding the presence of ash fines), while the filtration mat layer was generally a light to medium grey. The initial consideration was that 'bare' fibers were present in the outer confinement layer as a result of removal of the CVI-SiC encapsulating shell during exposure of the 3M CVI-SiC composite filter elements to the high temperature oxidizing environment. Generally the triaxial support braid which consisted of an $\sim 100 \mu \mathrm{m}$ CVI-SiC layer that encapsulated twisted Nextel ${ }^{\mathrm{TM}} 312$ filaments or fiber bundles, retained its as-manufactured dark black appearance.

SEM/EDAX characterization of the PCFBC-exposed 3M CVI-SiC composite filter matrix confirmed that removal of the $\mathrm{SiC}$ layer which initially encapsulated the Nextel ${ }^{\mathrm{TM}} 312$ fibers in the outer confinement layer had occurred. Characterization of the lapped filtration mat indicated that oxidation of the $2 \mu \mathrm{m}$ CVI-SiC shell had also occurred. As a result, an $\sim 1 \mu \mathrm{m}$ oxygen-enriched layer formed along the outer surface of the as-manufactured CVI-SiC coating. An oxygen-enriched region also formed along the inner surface of the CVI-SiC shell, bonding the shell to the filtration mat fibers (Figure 2-67). Bonding of the oxygen-enriched CVI-SiC shell to the fibers ultimately reduced the fracture toughness and possibly increased the strength of this layer.

Characterization of the triaxial support braid identified oxidation and pitting along the outer surface of the CVI-SiC shell that encapsulated the underlying Nextel ${ }^{\mathrm{TM}} 312$ filaments (Figure 2-68). Within the interior of the filament or fiber bundles, a thin layer of CVI-SiC generally coated individual fibers. Frequently gaps were evident between the thin CVI-SiC layers and the fibers, as well as areas which clearly showed bonding of the shell to the surface of the contained fibers.

Microstructural characterization was not conducted on the $626 \mathrm{hr}$, PCFBC-exposed, 3M CVI-SiC filter matrix.

\subsubsection{DuPont PRD-66}

\subsubsection{As-Manufactured Filter Matrix}

DuPont PRD-66 candle filters consist of an $\sim 7 \mathrm{~mm}$ thick, structural support, filament wound, filter wall. An open filament winding process is typically utilized to form the diagonal weave, chevron patterns in the structural support filter matrix (Figure 2-69). Each polycrystalline, refractory,

\footnotetext{
${ }^{4}$ As a nonoxide filter matrix, the $3 \mathrm{M} \mathrm{CVI-SiC} \mathrm{matrix} \mathrm{is} \mathrm{no} \mathrm{longer} \mathrm{considered} \mathrm{as} \mathrm{a} \mathrm{viable} \mathrm{material} \mathrm{for} \mathrm{use} \mathrm{in}$ high temperature PFBC or PCFBC applications.
} 


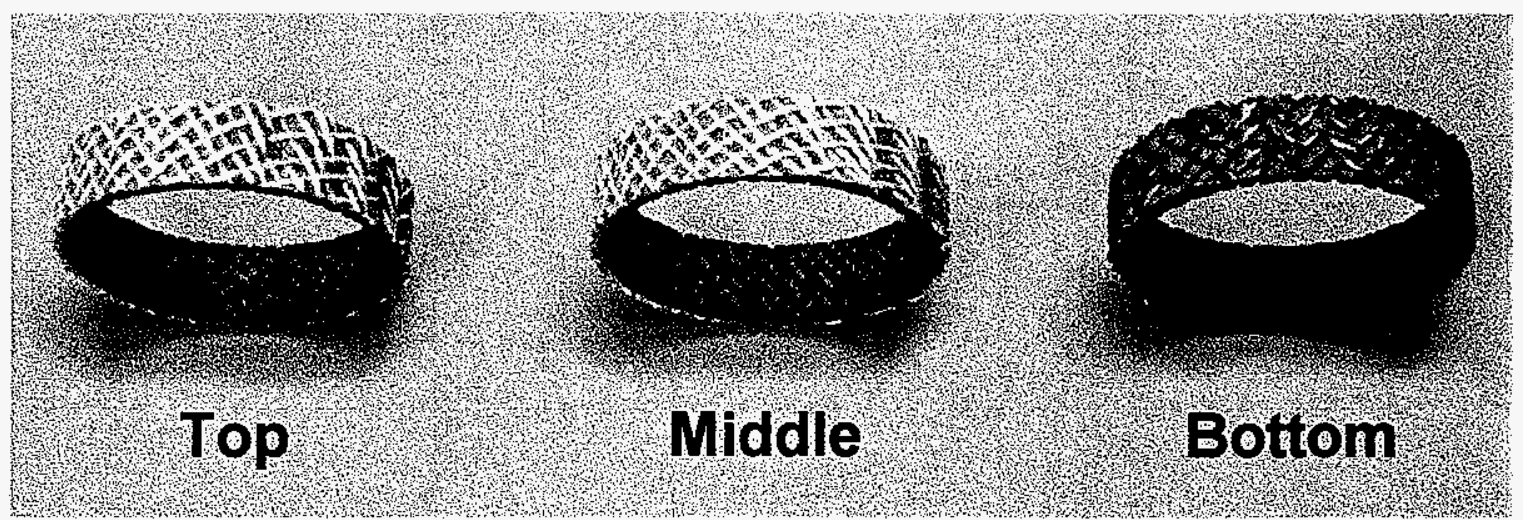

Figure 2-66 - Color gradient resulting along the length of the 3M CVI-SiC composite filters after operation in the PCFBC environment. 

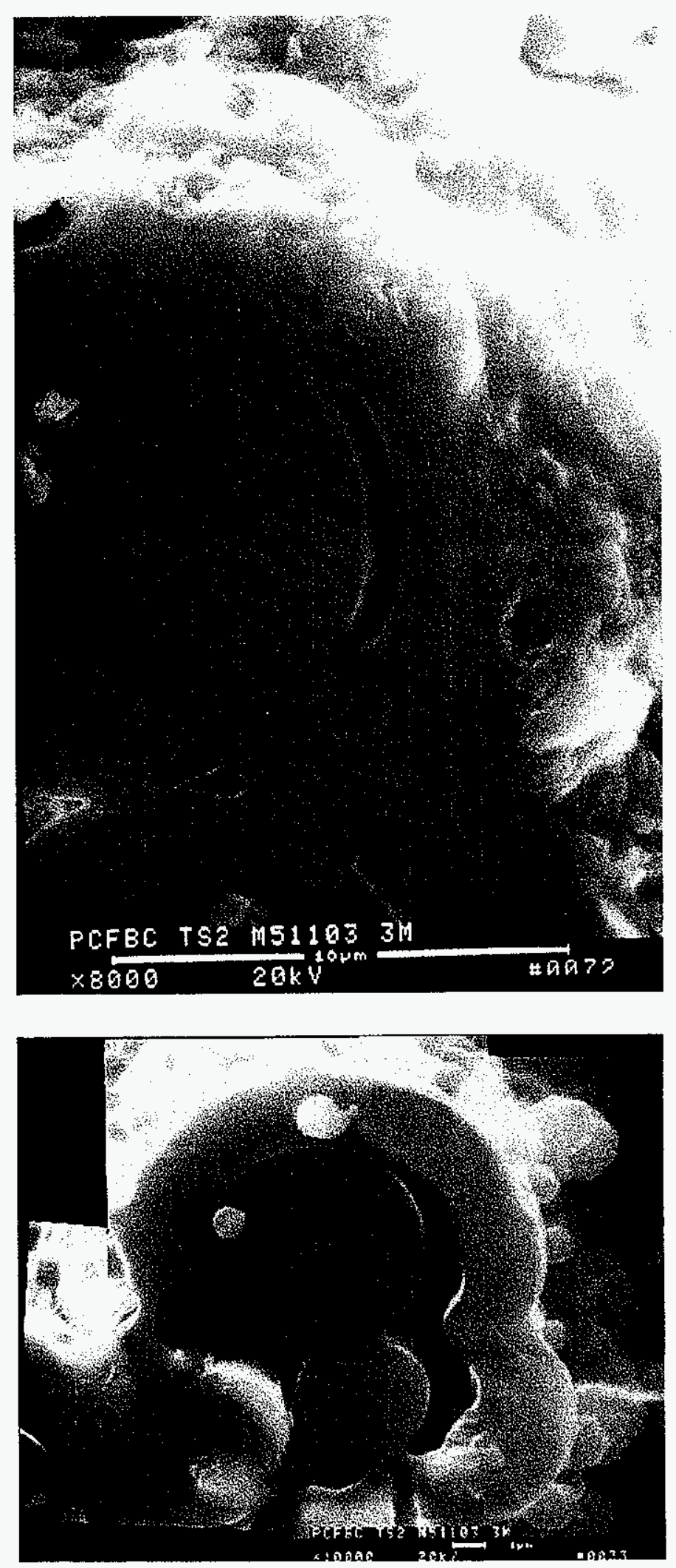

Figure 2-67 - Oxidation resulting along the outer and inner surfaces of the CVI-SiC encapsulating shell of the filtration mat fibers in the 387 hour, PCFBC-exposed, $3 \mathrm{M}$ composite filter matrix. 


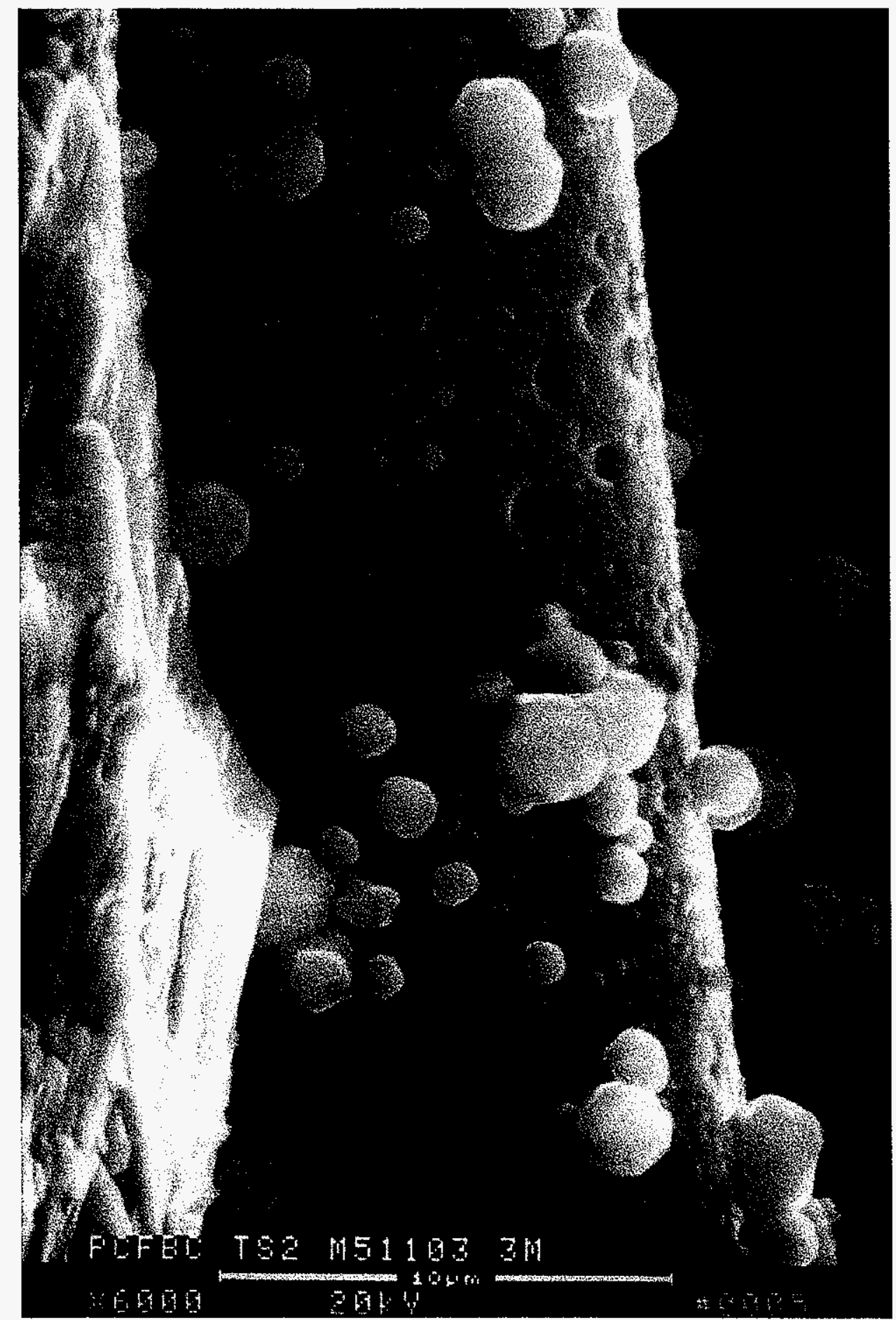

Figure 2-68 - Oxidation and pitting resulting along the outer surface of the CVI-SiC shell that encapsulated the Nexterm 312 filaments in the 387 hour, PCFBC-exposed, 3M composite filter matrix. 


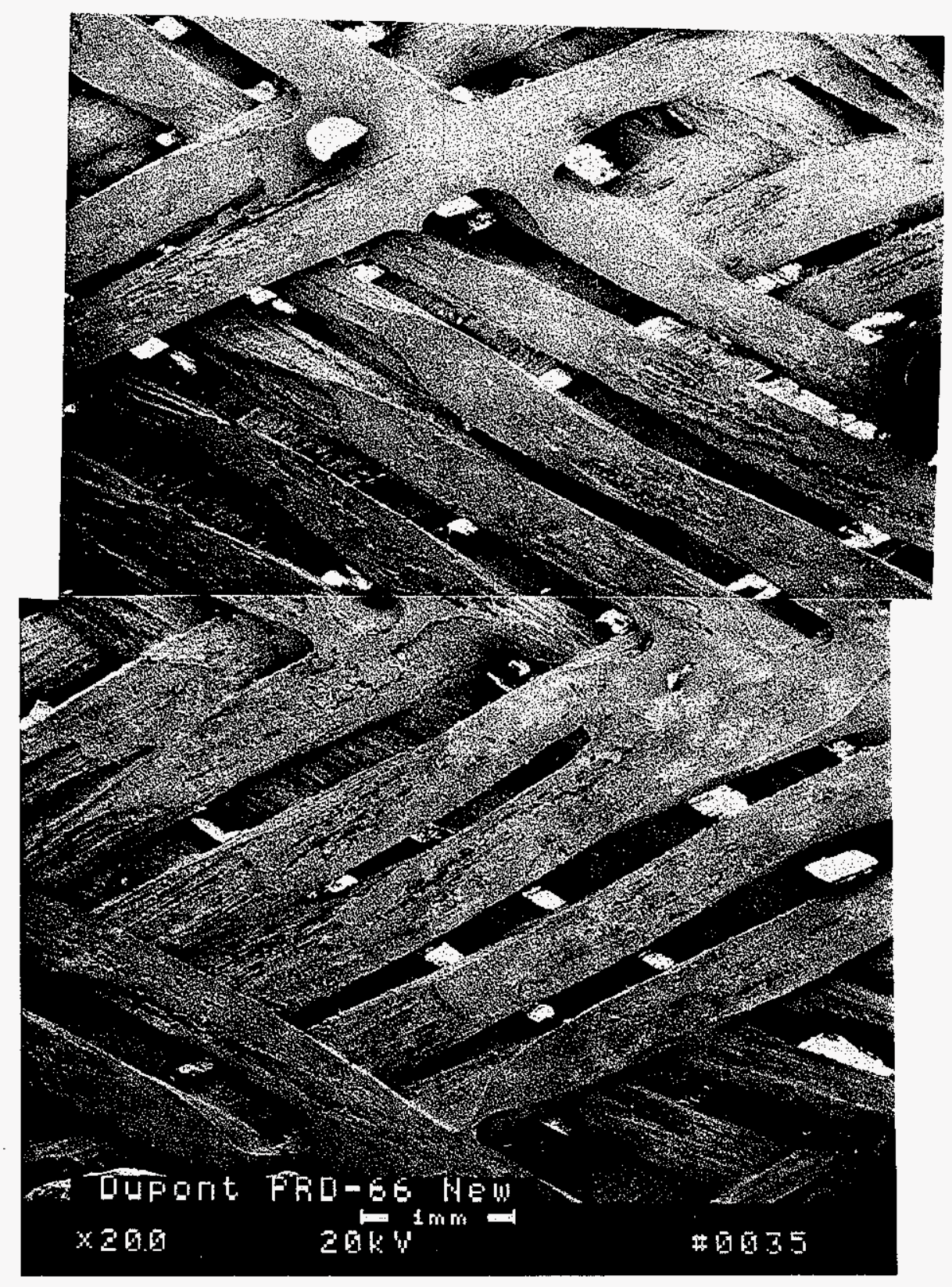

Figure 2-69 - Filament wound structural support matrix in the as-manufactured DuPont PRD-66 filter element. 
oxide-based, filament in the structural support filter wall is $200 \mu \mathrm{m}$ in diameter, and contains numerous $\sim 7-17 \mu \mathrm{m}$ diameter fiber replicas (Figures 2-70 and 2-71). ${ }^{5}$ A thin, single filament layer, membrane (Figure 2-72) is wrapped along the outer surface of the support matrix, producing a light weight, bulk or depth vs barrier filter element.

A coarse slurry of alumina-enriched grains (i.e., $\sim 75-100 \mu \mathrm{m}$ ) was used to sinter bond adjacent filament bundles together along the outer surface membrane of the as-manufactured DuPont PRD-66 filter elements that were supplied for use at Karhula (Figure 2-73). A finer slurry of alumina-enriched grains (i.e., $\leq 5-7 \mu \mathrm{m}$; Figure 2-74) was used in the structural support filament winding process to

- Coat and fill the voids along and between the outer surface of fibers replicas in the filament bundles (Figure 2-75)

- Sinter bond adjacent fiber replicas to each other

- Assist in bonding the external single filament layer to the underlying structural support filaments.

The intersecting wound filaments in the structural support filter wall were sinter bonded to each other via slurry matrix grains, thus providing strength to the filter matrix (Figure 2-76). As along the outer surface membrane, high temperature, sinter bonded slurry matrix grains generally filled the crevices between intersecting filaments, and infiltrated into the filament bundles, bonding adjacent fiber replicas to each other (Figures 2-77 and 2-78). A membrane was not applied to the i.d surface of the DuPont PRD-66 filter element.

When the as-manufactured DuPont PRD-66 filter wall was cross-sectioned, discrete and coalesced fiber replicas were seen to be present within the filament support matrix. Discrete fiber replicas tended to be surrounded by the infiltrated alumina-enriched slurry matrix (Figure 2-79). Where the infiltrated slurry matrix was absent, coalescence of the fiber replicas tended to result (Figures 2-80, 281 , and 2-82). Crystalline features were generally observed along the outer surface of the fiber replicas, as well as along their fresh fractured surfaces (Figure 2-83).

$\mathrm{X}$-ray diffraction analysis identified the composition of the as-manufactured DuPont PRD-66 filter matrix as $\sim 30 \%$ cordierite $\left(\mathrm{Mg}_{2} \mathrm{Al}_{4} \mathrm{Si}_{5} \mathrm{O}_{18}\right), \sim 50 \%$ corundum $\left(\mathrm{Al}_{2} \mathrm{O}_{3}\right)$, with secondary and minor concentrations of cristobalite $\left(\mathrm{SiO}_{2}\right)$, mullite $\left(3 \mathrm{Al}_{2} \mathrm{O}_{3} \cdot 2 \mathrm{SiO}_{2}\right)$, and an amorphous phase. Due to the differences in thermal expansion of corundum, cordierite, and mullite, a microcracked structure formed during high firing of the filter matrix.

The fiber replicas were identified to consist primarily of silicon-oxygen-aluminum, with minor concentrations of magnesium present. This composition was considered to reflect the presence of cordierite. Surrounding the filament bundles, fine grains of deposited slurry matrix were present which consisted of what was considered to be primarily alumina. Potential reactions between the deposited alumina slurry matrix grains and the cordierite fiber replicas, lead to the formation of an aluminosilicate phase which was considered to consist principally of alumina, with minor concentrations of mullite perhaps being present.

\footnotetext{
${ }^{5}$ When fresh fractured, the matrix broke as a brittle ceramic as opposed to a fracture toughened, fiber-containing filter matrix. Thus the matrix is referred to as containing fiber replicas as opposed to fibers.
} 


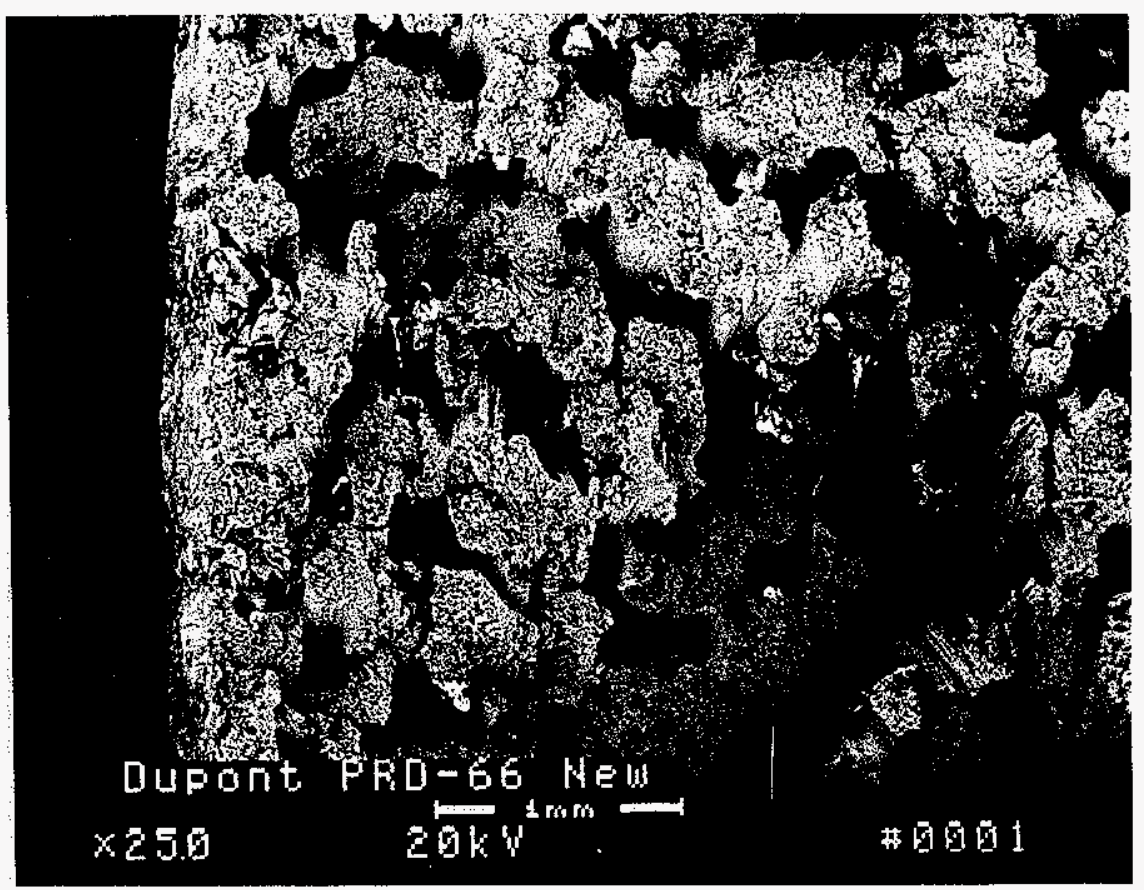

Figure 2-70 - Micrograph illustrating the morphology of the cross-sectioned DuPont PRD-66 filter wall. 


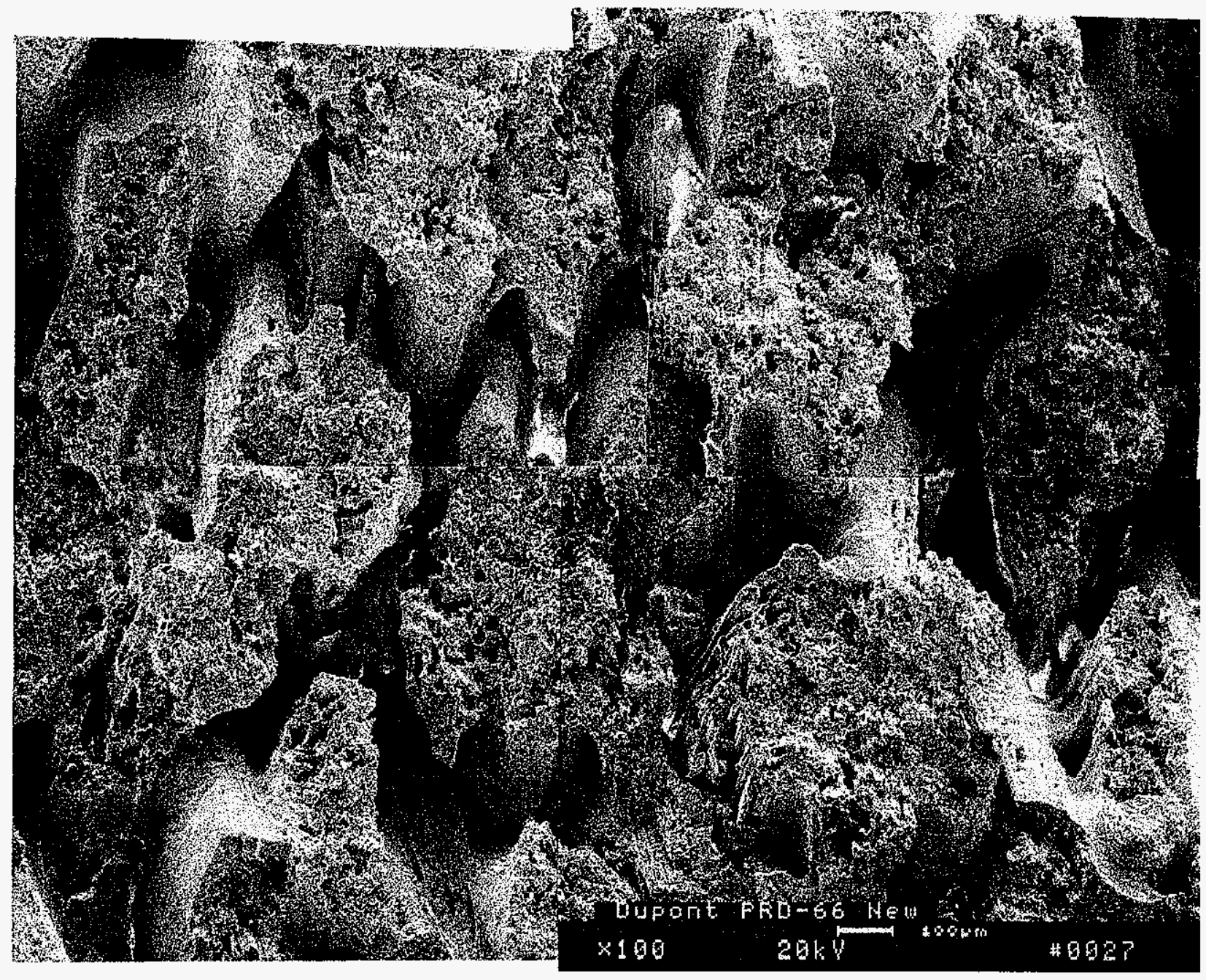

Figure 2-71 - Higher magnification micrograph montage illustrating the morphology of the fresh fractured filaments in the DuPont PRD-66 filter matrix. 


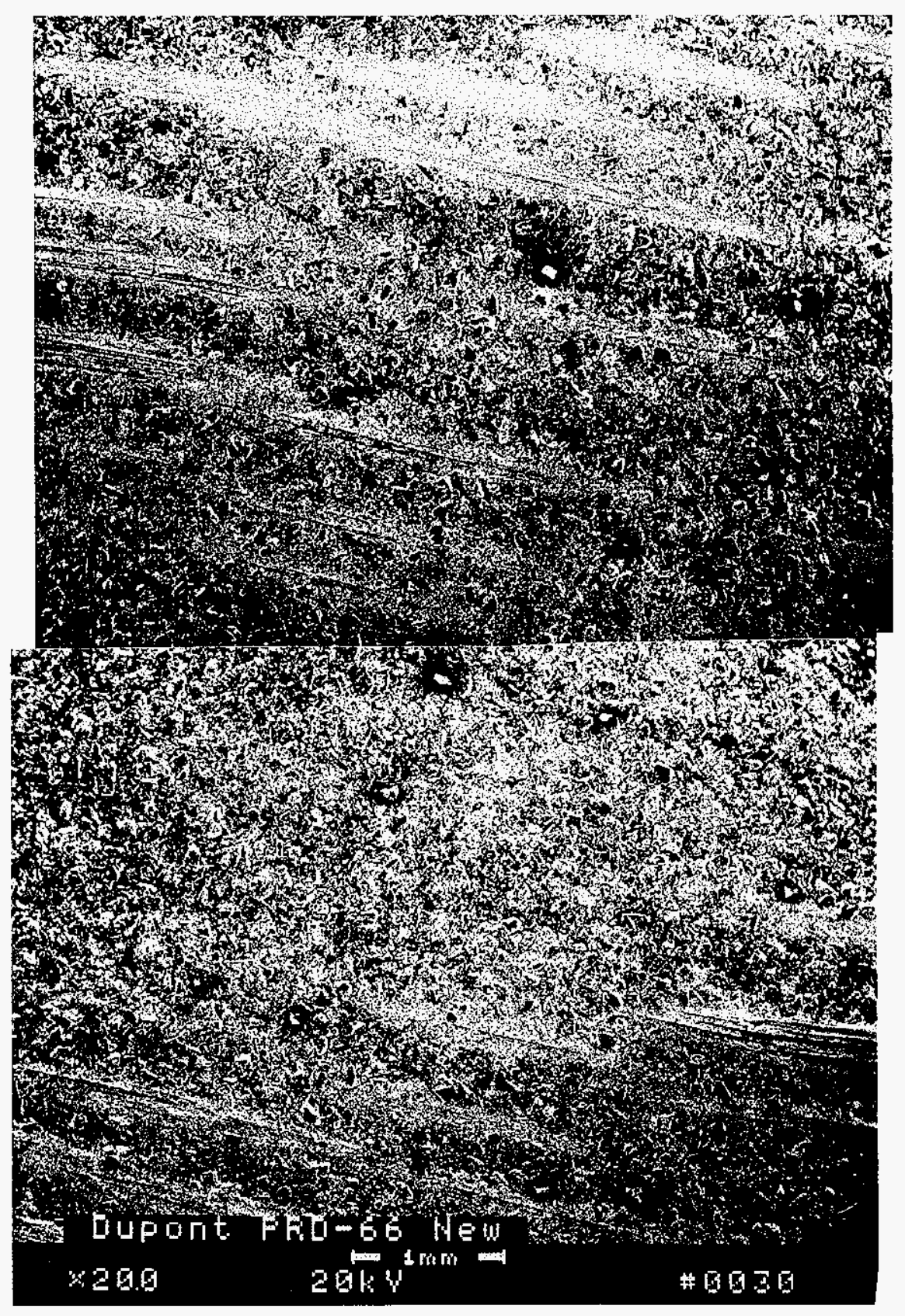

Figure 2-72 - Morphology of the outer surface membrane along the as-manufactured DuPont PRD-66 filter element. 


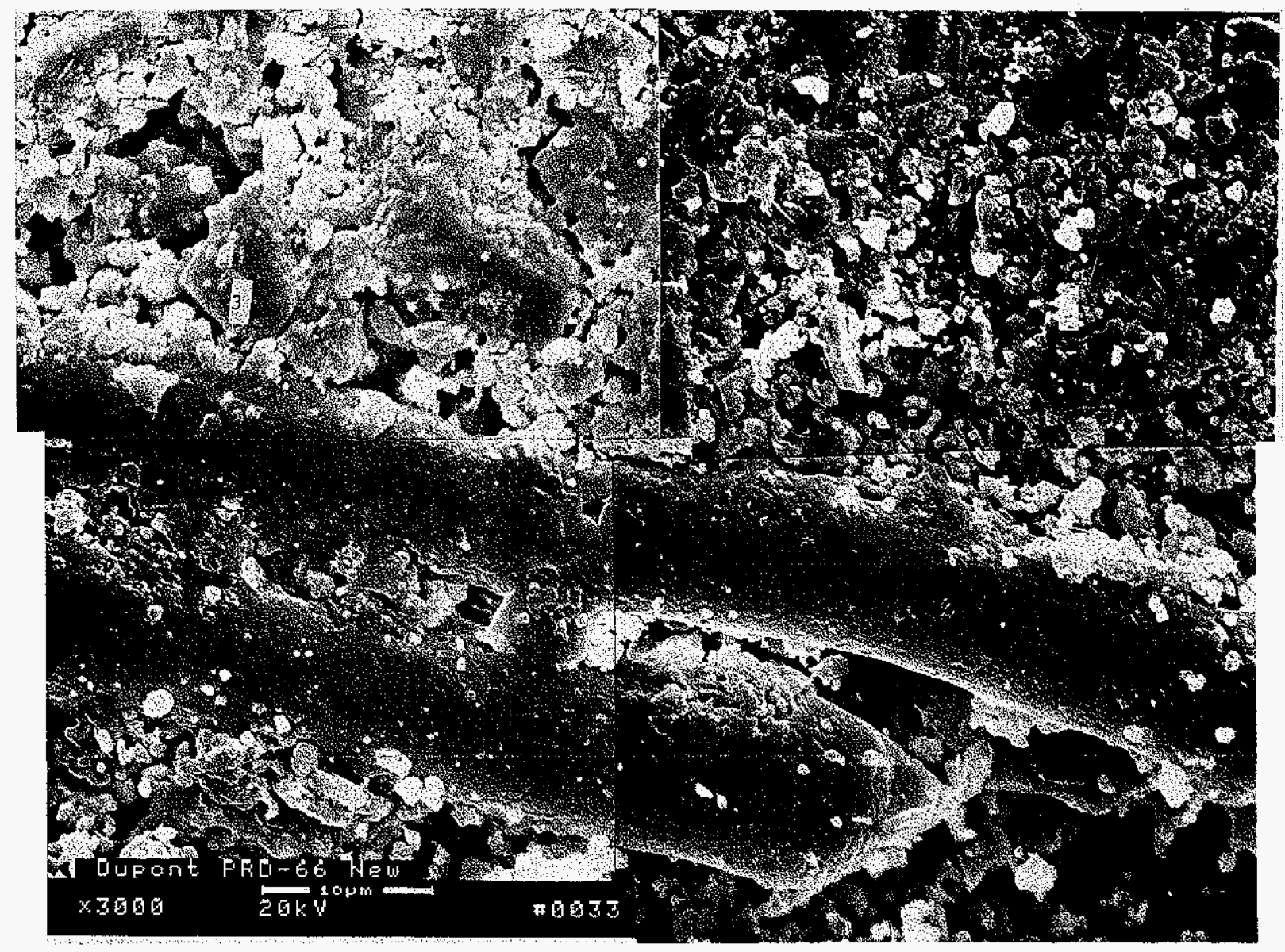

Figure 2-73 - Higher magnification micrograph montage illustrating the adherence of alumina grains along the cordierite fiber replicas in the thin filament layer that formed the outer surface membrane of the as-manufactured DuPont PRD-66 filter element. 

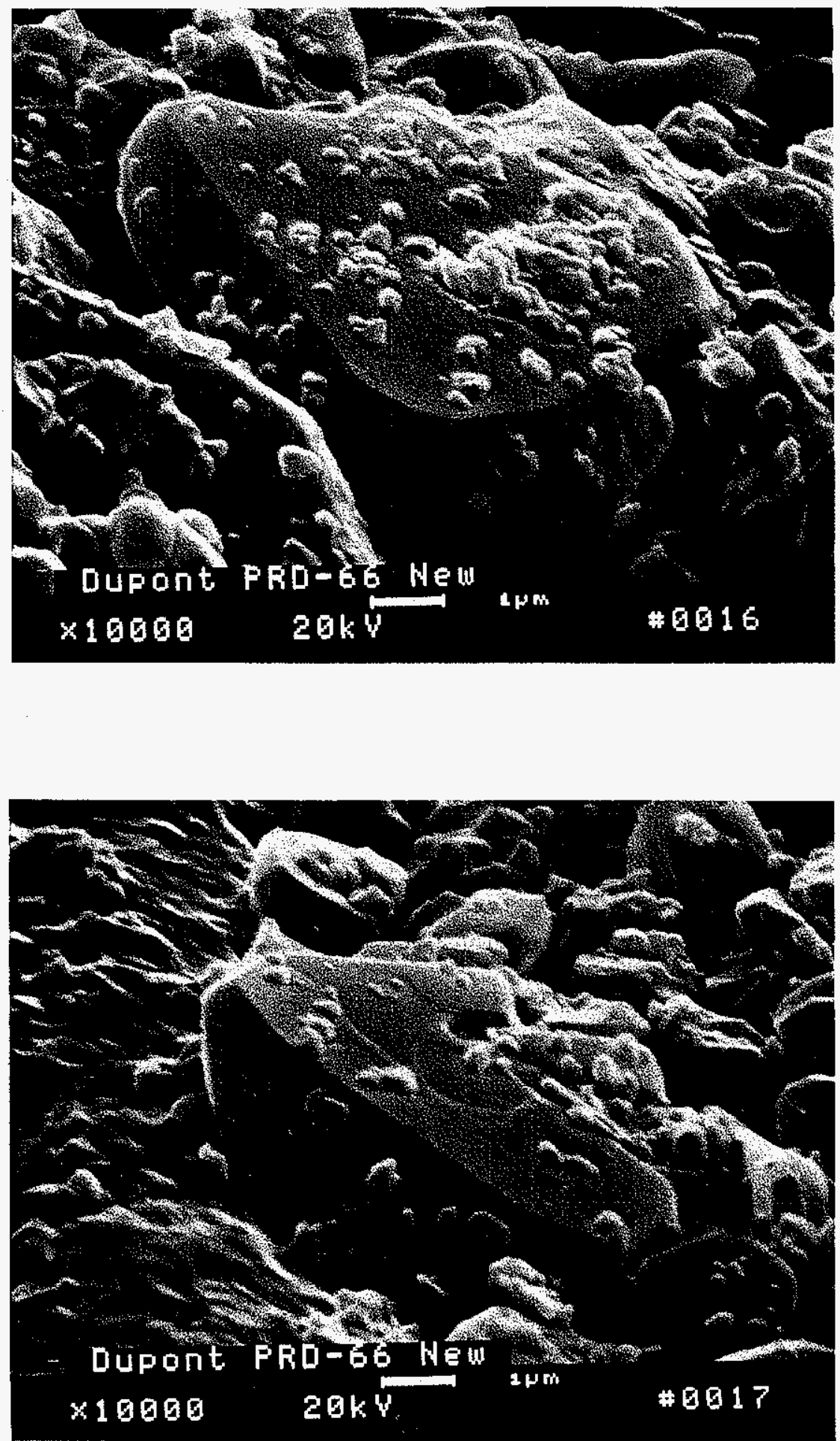

Figure 2-74 - Higher magnification micrographs illustrating the morphology of the slurry matrix grains that were present along the outer surface membrane of the as-manufactured DuPont PRD-66 filter matrix. 

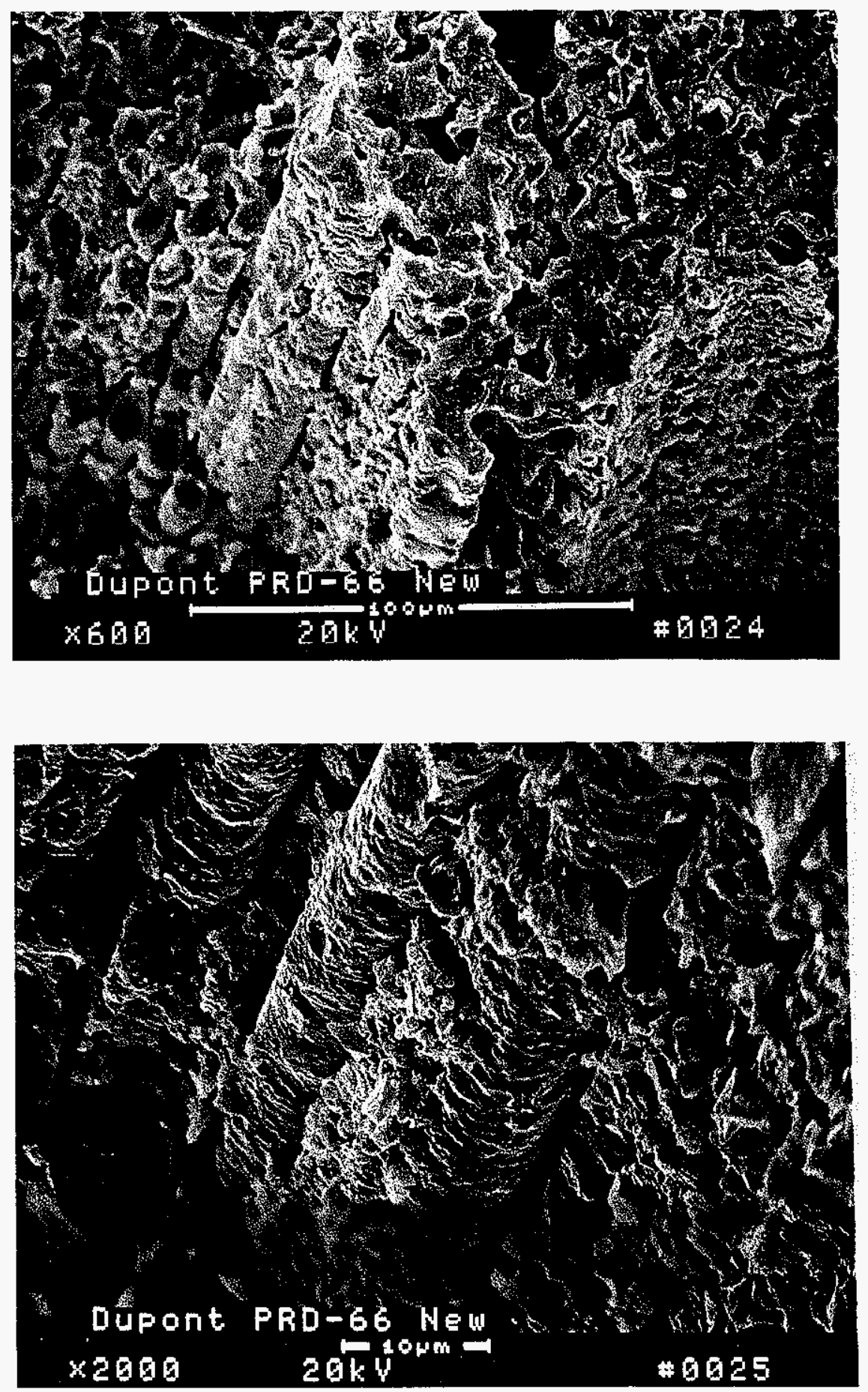

Figure 2-75 - Finer slurry alumina-enriched grains coating the outer surface of the fiber replicas in the filament bundles in the as-manufactured DuPont PRD-66 filter matrix. 


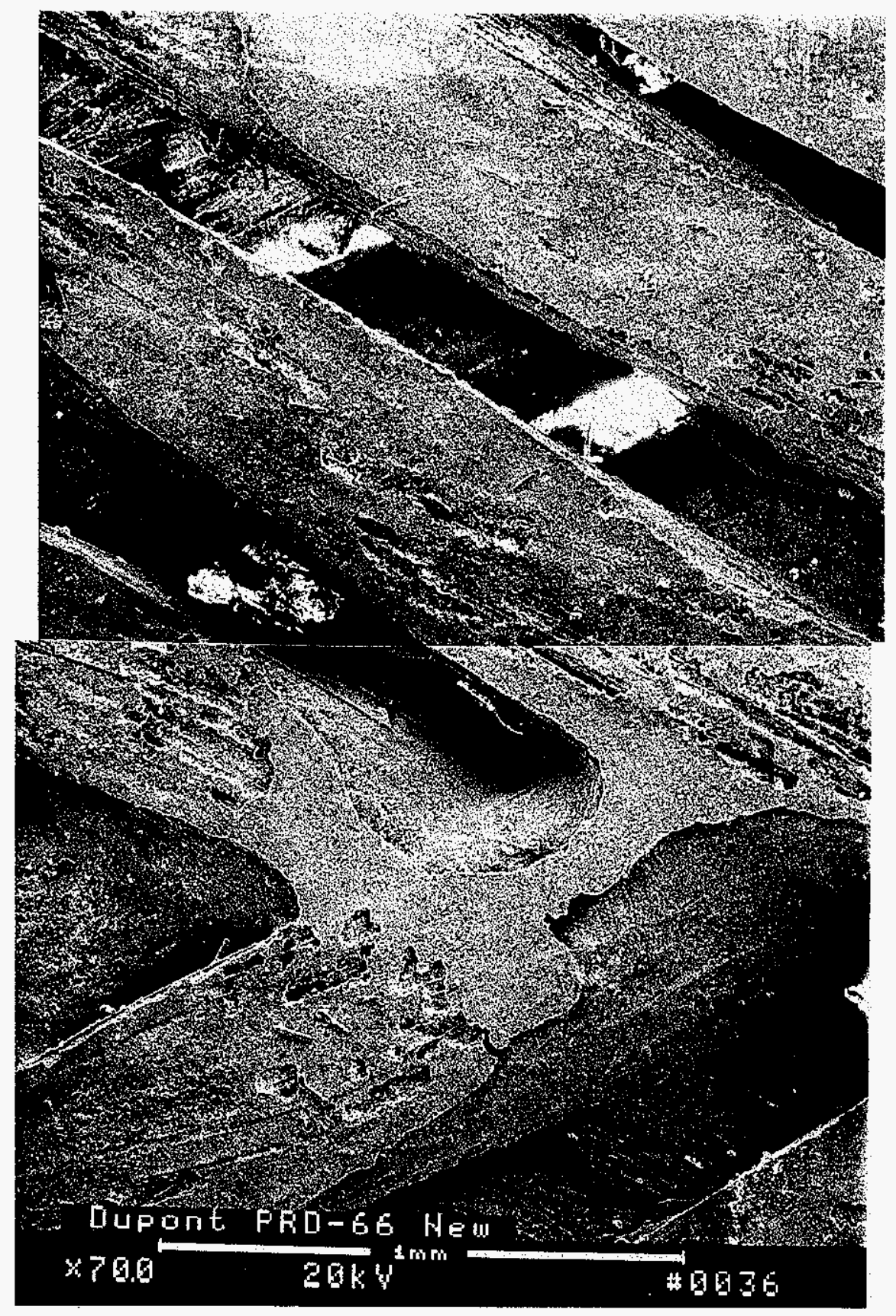

Figure 2-76 - Sinter bonding of the alumina-enriched, slurry-coated, adjacent filaments in the asmanufactured DuPont PRD-66 filter wall. 


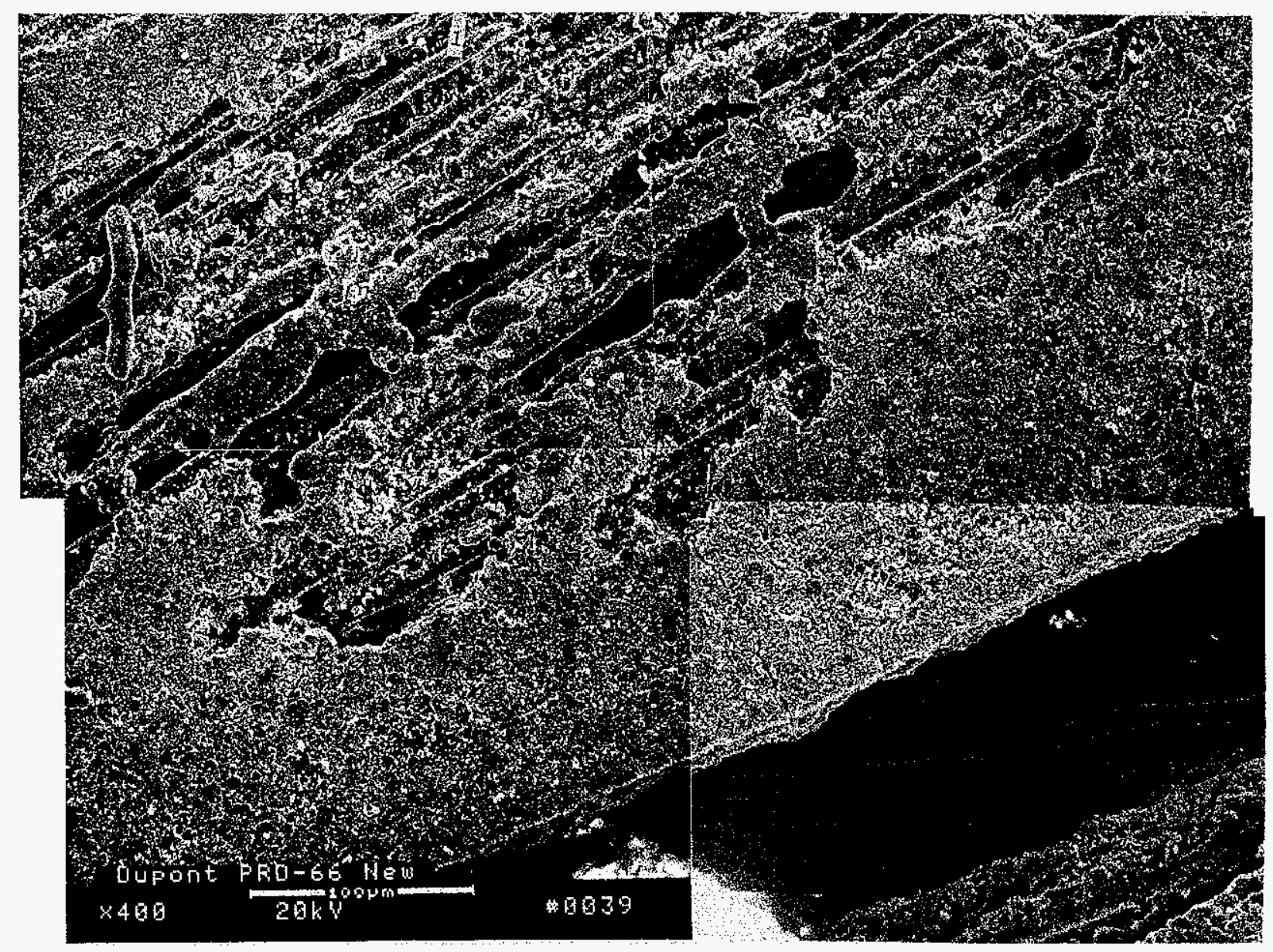

Figure 2-77 - Higher magnification micrograph montage illustrating the presence of the aluminaeuriched slurry coating along the outer surface of the filament bundles in the asmanufactured DuPont PRD-66 filter matrix. 


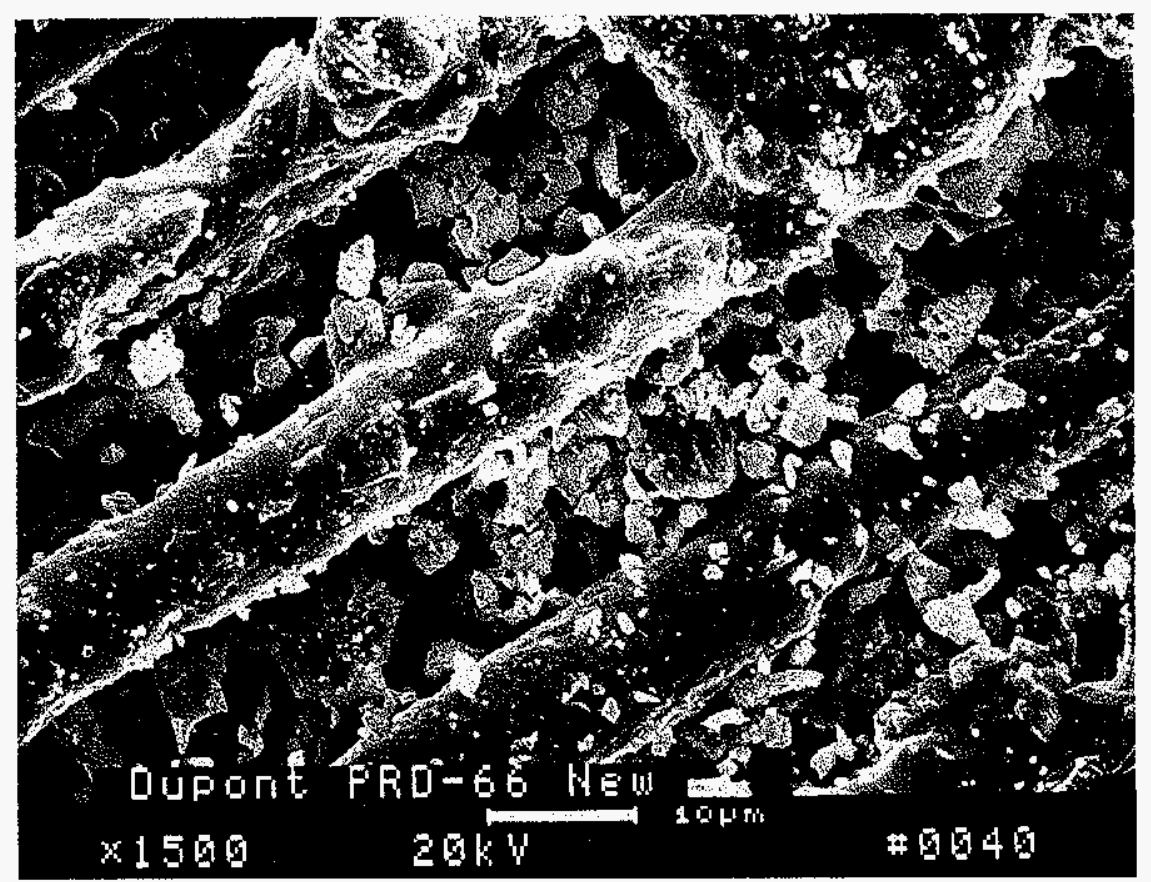

Figure 2-78 - Infiltration of the alumina-enriched grains and bonding between fiber replicas along the outer surface of the filament bundles in the as-manufactured DuPont PRD-66 filter matrix. 

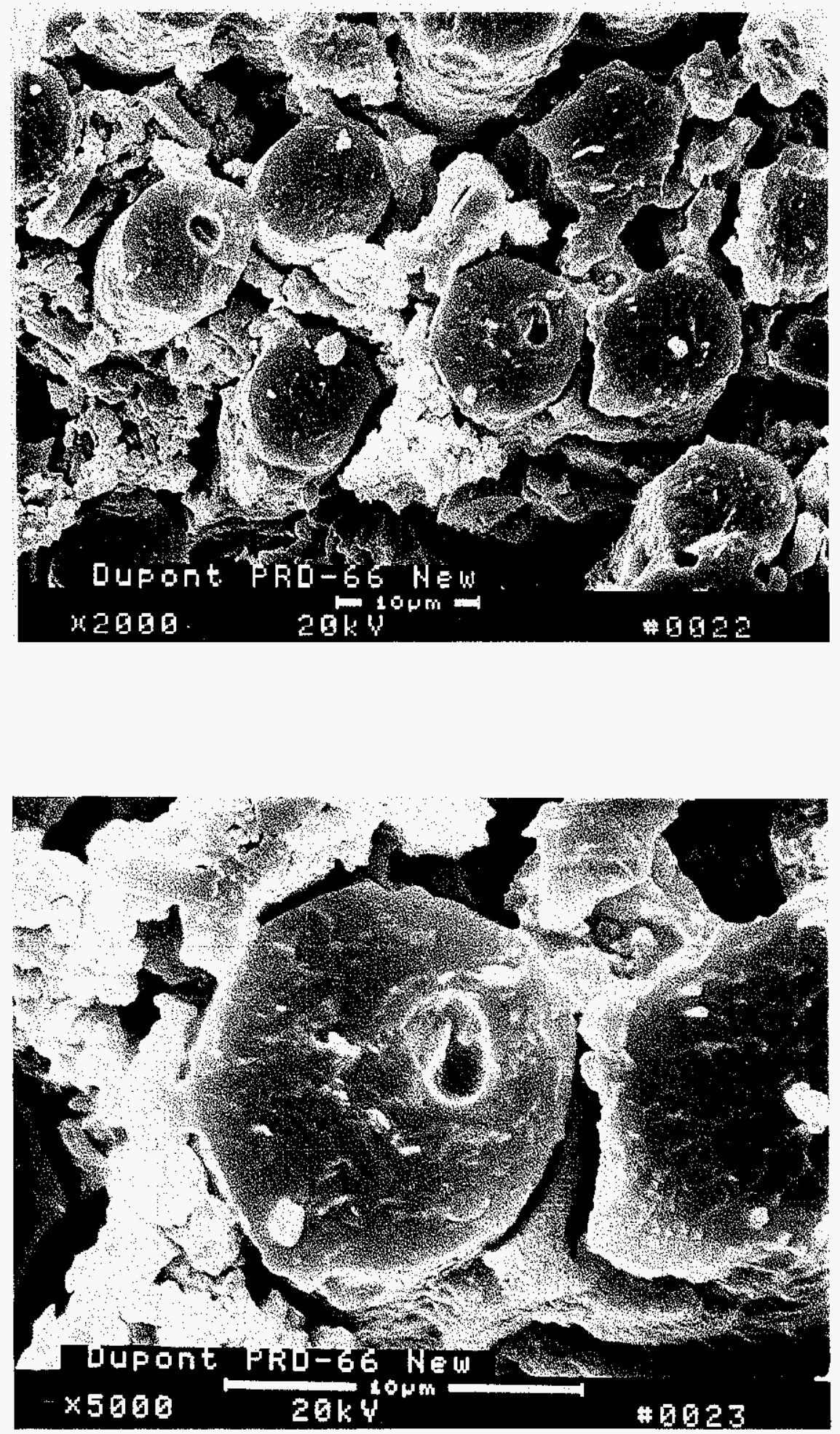

Figure 2-79 - Micrograph illustrating the formation of discrete fiber replicas in the filament bundles of the as-manufactured DuPont PRD-66 filter matrix. 


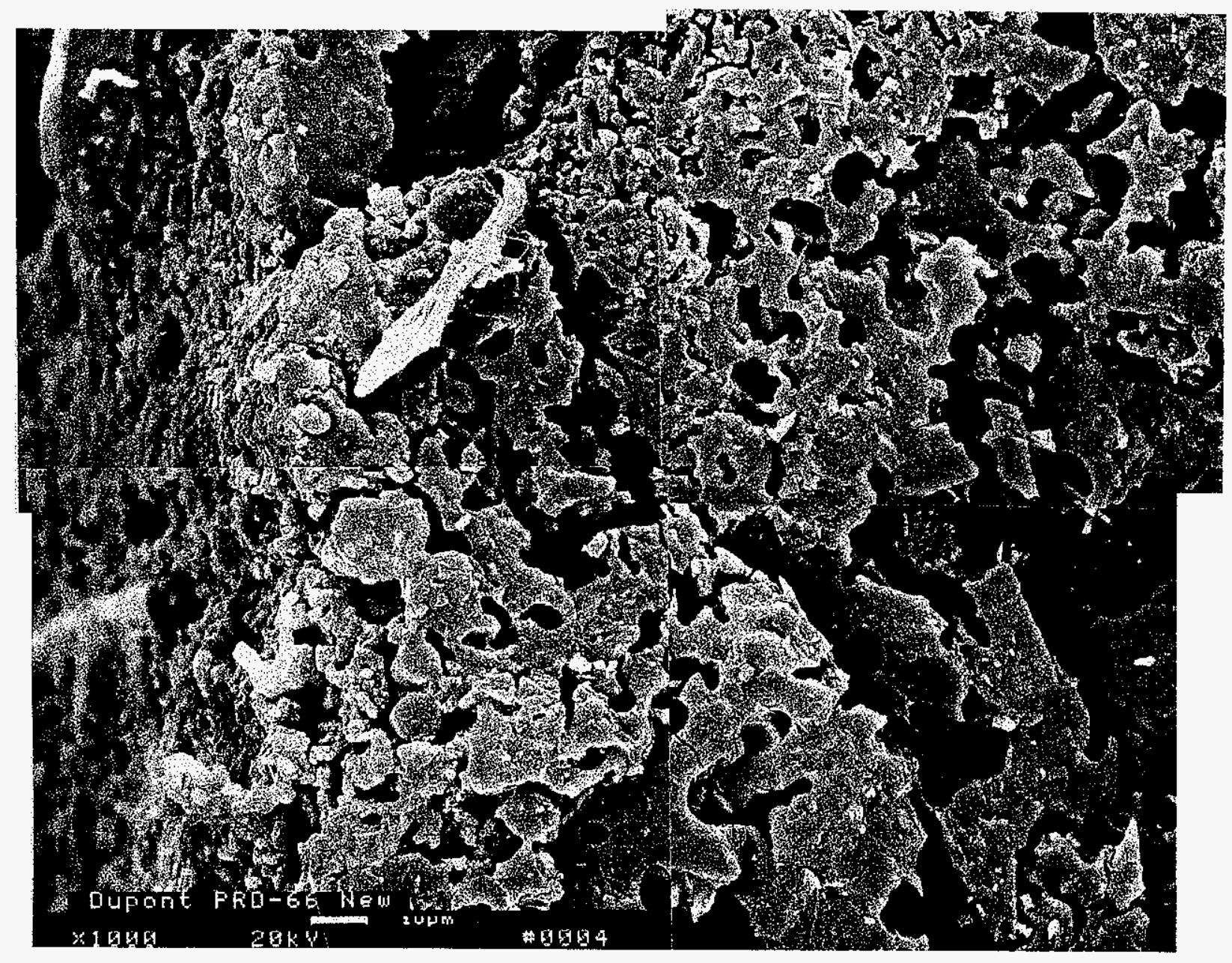

Figure 2-80 - Micrograph montage illustrating coalescence of the fiber replicas in the filament bundles of the as-manufactured DuPont PRD -66 filter matrix. 


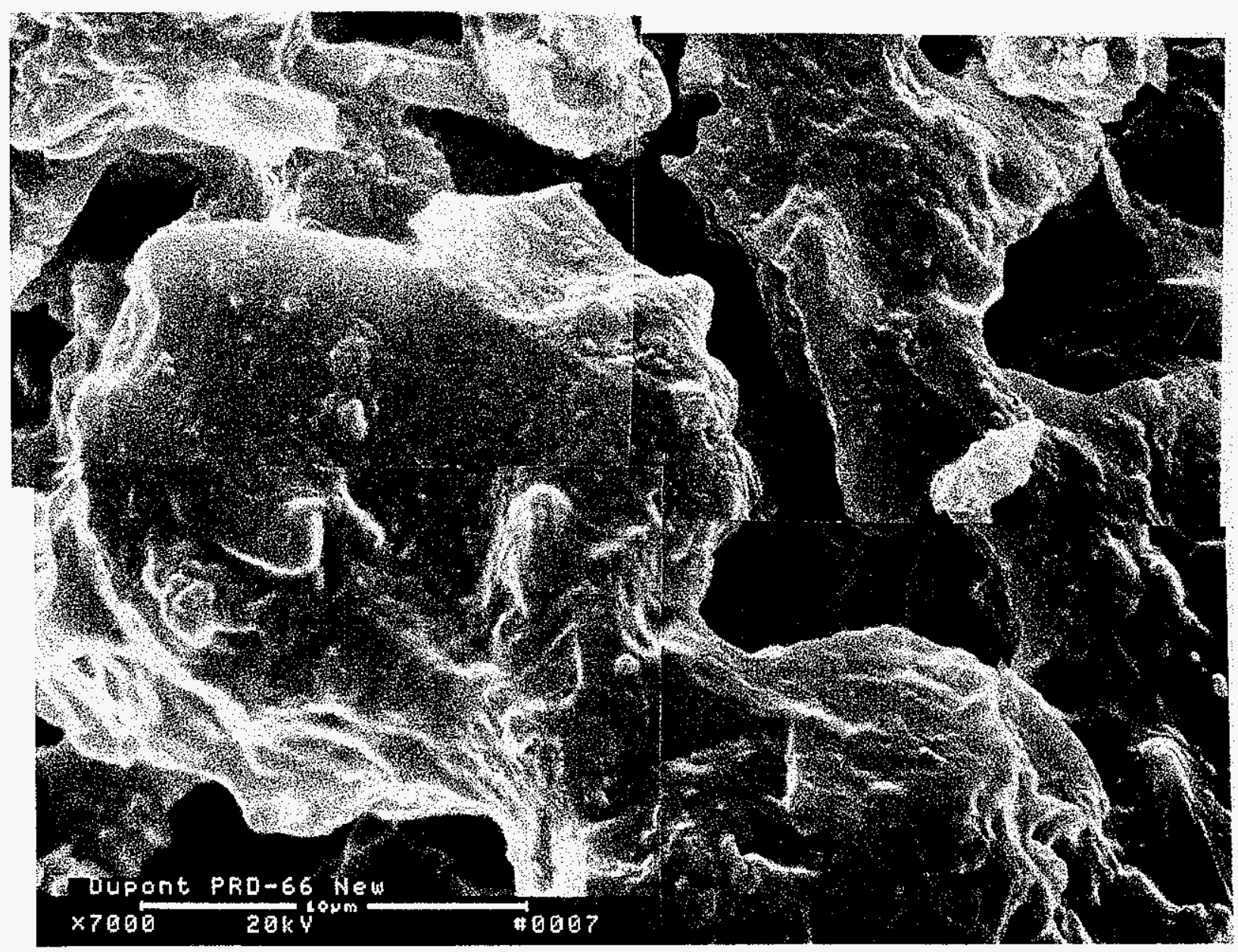

Figure 2-81 - Higher magnification micrograph montage illustrating bonding between adjacent fiber replicas in the filament bundles of the as-manufactured DuPont PRD-66 filter matrix. 


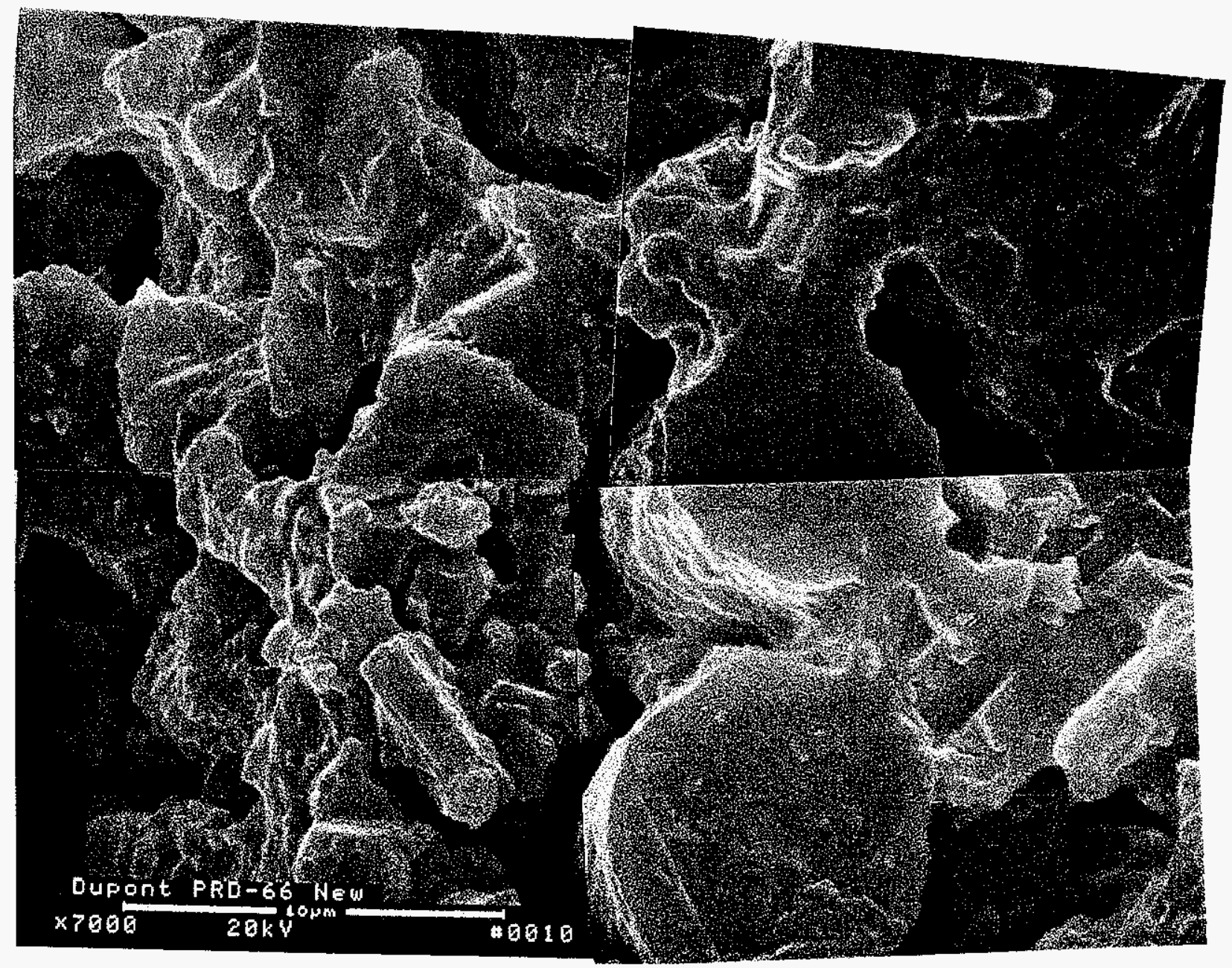

Figure 2-82 - Additional high magnification micrograph montage illustrating bonding between adjacent fiber replicas in the filament bundles of the as-manufactured DuPont PRD-66 filter matrix. 


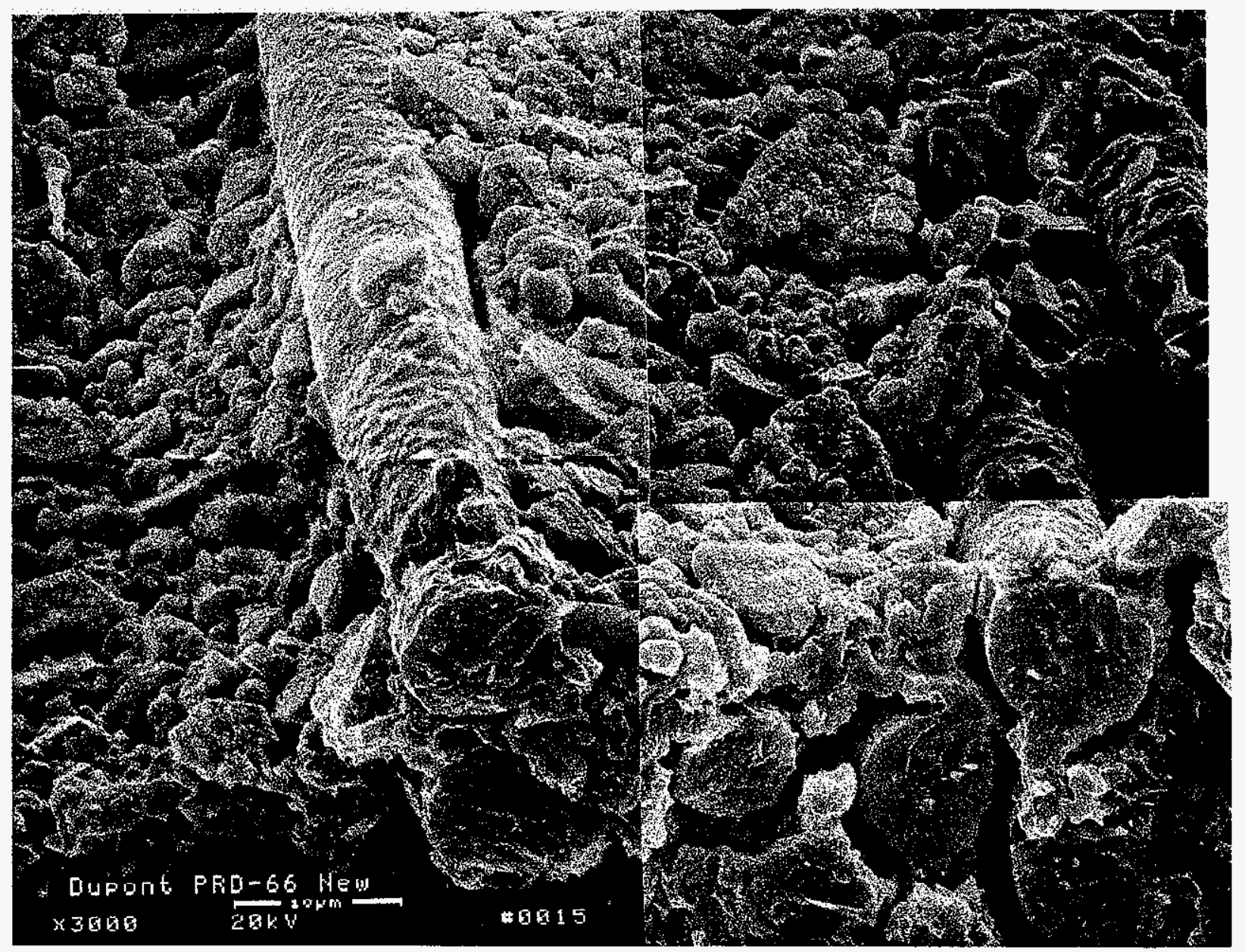

Figure 2-83 - Crystallization was evident along the outer surface and through the cross-sectioned fiber replicas in the filament bundles of the as-manufactured DuPont PRD-66 filter matrix. 


\subsubsection{PCFBC-Exposed Filter Matrix}

Seven $1.5 \mathrm{~m}$ DuPont PRD-66, oxide-based candle filters were installed in the bottom array of the W-APF filter at the Foster Wheeler PCFBC test facility in Karhula, Finland in the fall of 1997 (TS2-97). These elements were operated for a period of 342 to 581 hours at temperatures of $750^{\circ} \mathrm{C}$. Post-test characterization was conducted via SEM/EDAX analysis to determine the resulting microstructure and composition of the PCFBC-exposed DuPont PRD-66 filter matrix (i.e., candle filter D-587 (B50) - 581 hours).

Ash fines were identified along and within the pore cavities throughout the entire $\sim 7 \mathrm{~mm}$ thick structural support wall of the DuPont PRD-66 filter element after 581 hours of operation in the PCFBC environment at the Foster Wheeler test facility in Karhula, Finland. The retained ash fines consisted of irregularly shaped, flat and agglomerated particles which ranged in size from several microns to $\sim 20 \mu \mathrm{m}$. Retention of ash fines was expected to increased the gas flow resistance through the filter element. Deposition of fines within the pore cavities was considered to have resulted primarily from back pulsing of fines into the DuPont PRD-66 filament wound filter matrix after failure of an alternate candle(s) had occurred within the filter array during process operation.

Along the outer surface membrane of the 581 hour, PCFBC-exposed, DuPont PRD-66 filter element (Figures 2-84 and 2-85), 2-3.5 $\mu \mathrm{m}$ calcium aluminosilicate agglomerated crystalline features were observed to adhere directly to matrix grains, filament bundles, and fiber replicas (Figure 2-86). The calcium aluminosilicate crystalline fines were interspersed with submicron and micron ash particles which contained oxygen, silicon, aluminum, calcium, iron, and potassium.

Alternately, the morphology of the ash fines that were extensively deposited within the pore cavities along the i.d. or pulse cycled surface of the PCFBC-exposed DuPont PRD-66 filter is shown in Figure 2-87. The retained fines consisted of irregularly shaped, flat and agglomerated particles which ranged in size from several microns to $\sim 20 \mu \mathrm{m}$. EDAX analysis of the fines identified the presence of oxygen, silicon, aluminum, and calcium, with minor contributions of potassium, titanium, and sulfur.

The outer surface membrane of the DuPont PRD-66 filter element consisted of a single filament bundle that was uniformly wrapped around the outer surface of the $\sim 7 \mathrm{~mm}$ thick structural support filament wound matrix (Figure 2-88). The $\sim 240 \mu \mathrm{m}$ wide, outer surface membrane, filament bundle contained numerous discrete or coalesced fiber replicas. Spacing between the wrapped single filament bundle in the outer surface membrane was identified to be $\sim 100 \mu \mathrm{m}$. Approximately $100 \mu \mathrm{m}$ aluminaenriched matrix grains were sinter bonded to adjacent filament bundles in the outer surface membrane. Negligible change was identified in the complex microstructure of the DuPont PRD-66 filter matrix after 581 hours of operation in the PCFBC environment.

The cordierite-enriched fiber replicas that were contained within filament bundles of the PCFBCexposed DuPont PRD-66 filter matrix were seen to bond to each other (i.e., point contact; Figures 2-89 and 2-90). Fine grains surrounding the fiber replicas were considered to contain alumina, with minor concentrations of silicon and/or magnesium present. Typically coalescence of fiber replicas resulted within the interior of the filament bundle as opposed to along the outer surface of the filament where infiltrated matrix slurry surrounded the individual fiber replicas. Negligible change in the morphology of the fiber replicas resulted after 581 hours of operation of the DuPont PRD-66 filter matrix in the PCFBC environment. 


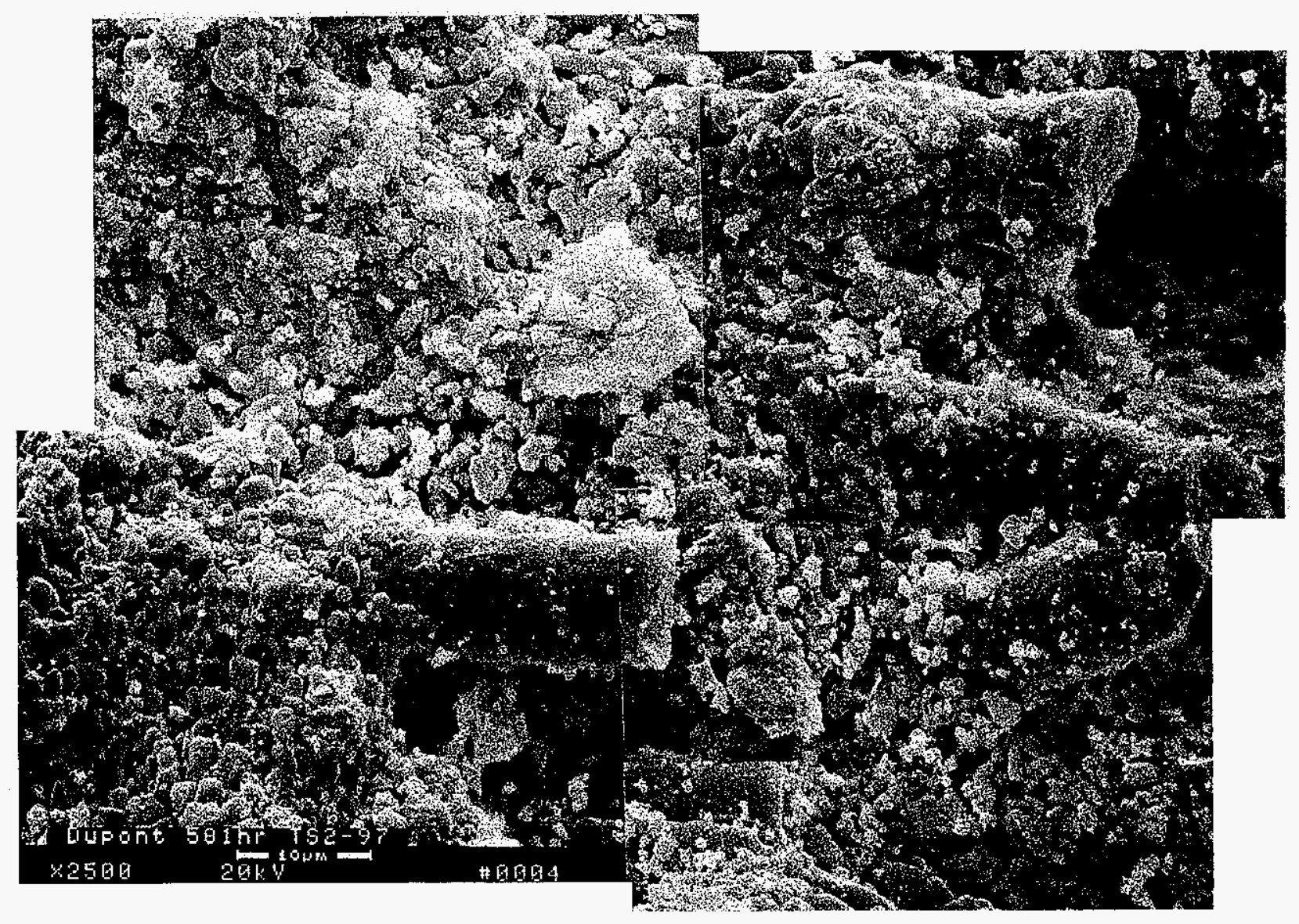

Figure 2-84 - High magnification micrograph montage illustrating the presence of crystalline calcium aluminosilicate and ash fines along the outer surface membrane fiber replicas and matrix grains in the PCFBC-exposed DuPont PRD-66 filter element. 


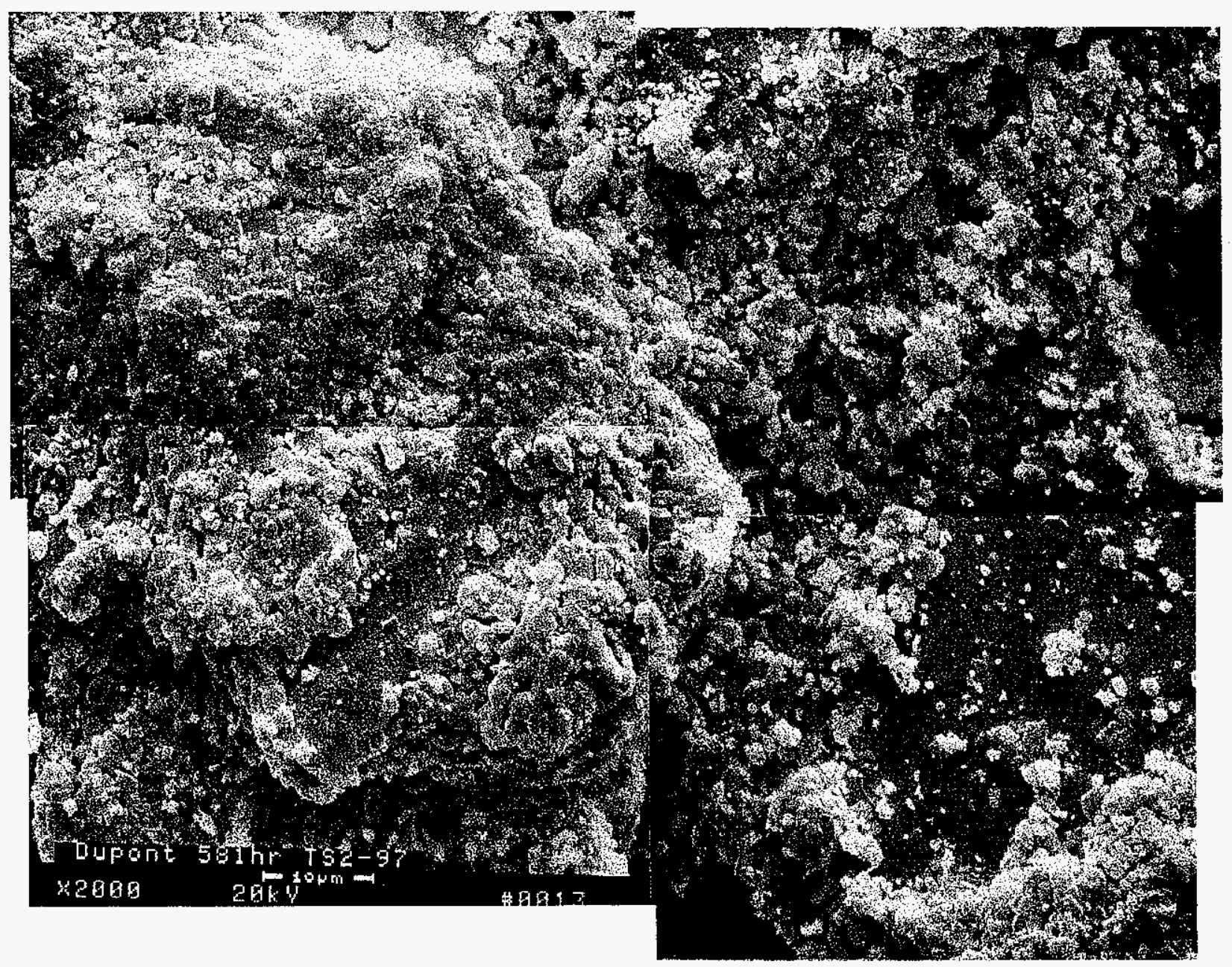

Figure 2-85 - Calcium aluminosilicate and ash fines were retained as agglomerates along the surface of the coarse alumina-enriched grains that were present along the outer surface membrane of the PCFBC-exposed DuPont PRD-66 filter element. 


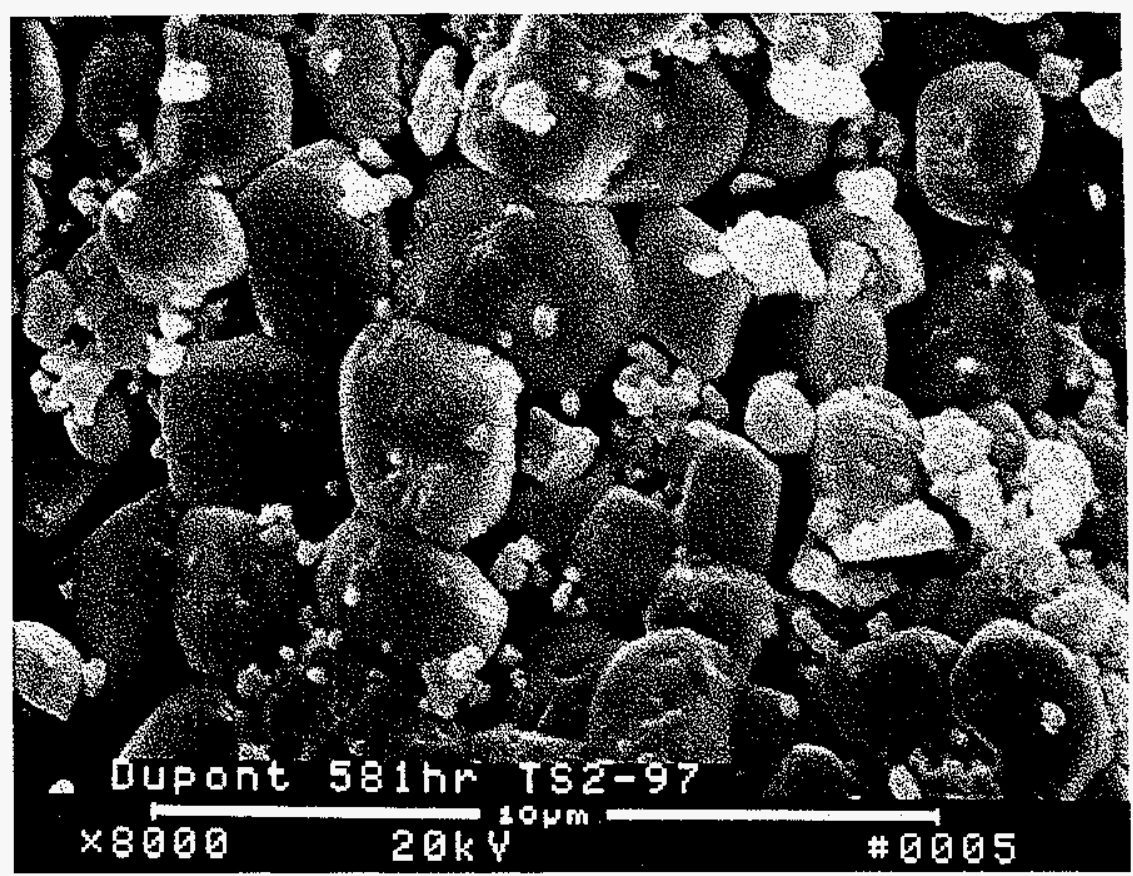

Figure 2-86 - Micrograph illustrating the crystalline morphology of the deposited calcium aluminosilicate particles. 


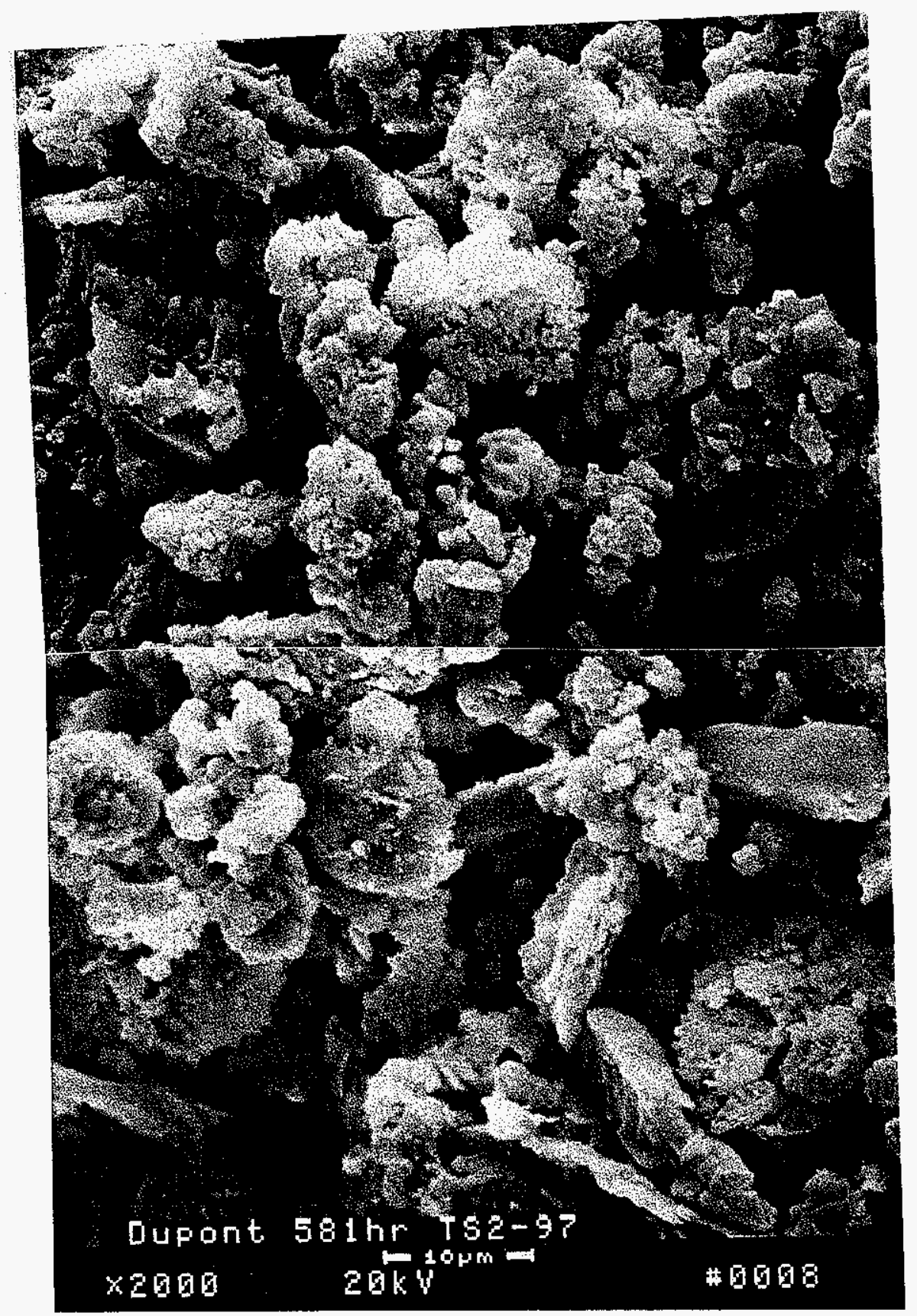

Figure 2-87 - Morphology of the ash fines that were retained within the pore cavities along the i.d. or pulse cycled surface of the PCFBC-exposed DuPont PRD-66 filter matrix. 


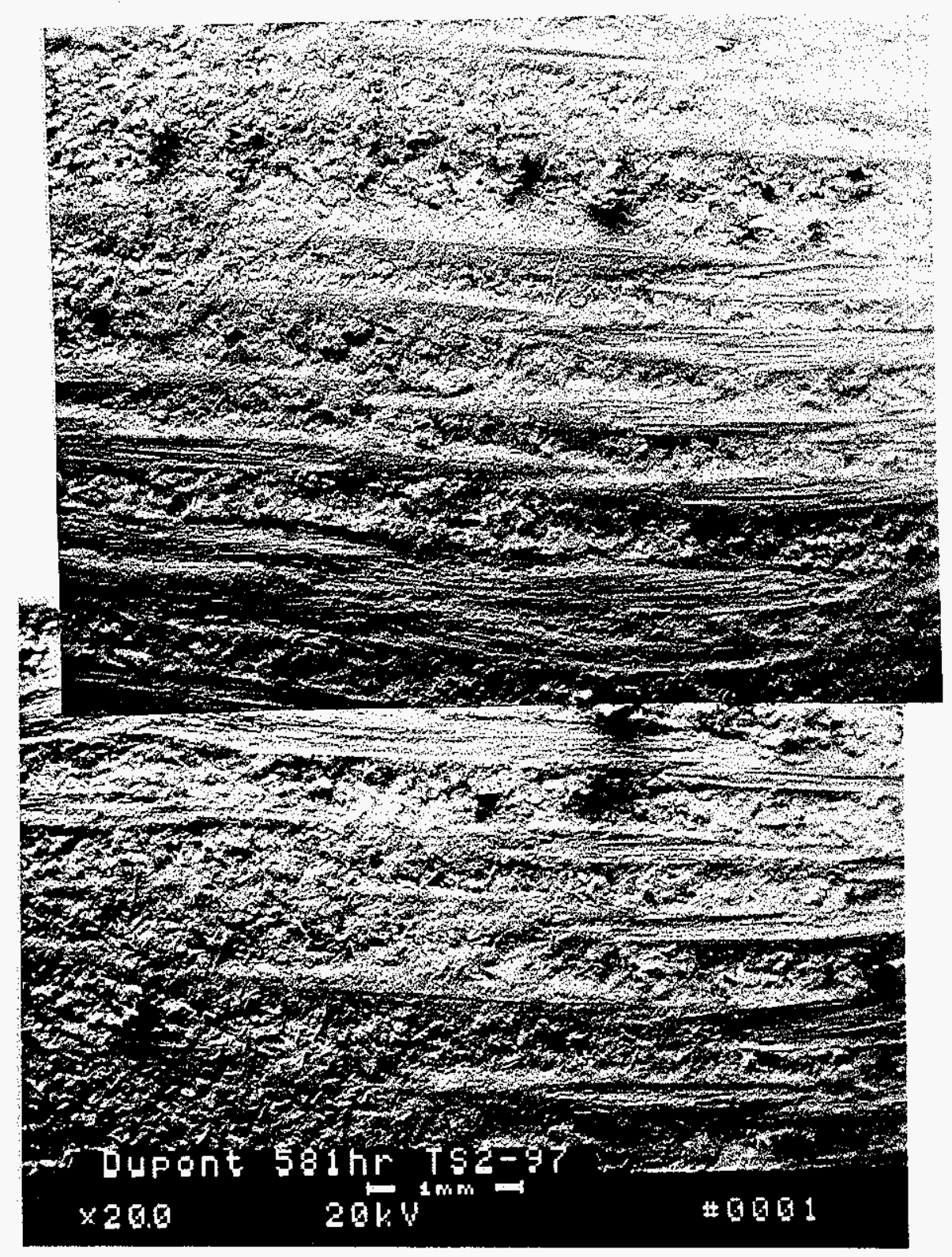

Figure 2-88 - Micrograph montage illustrating the morphology of the outer surface membrane of the 581 hour, PCFBC-exposed, DuPont PRD-66 filter element. 


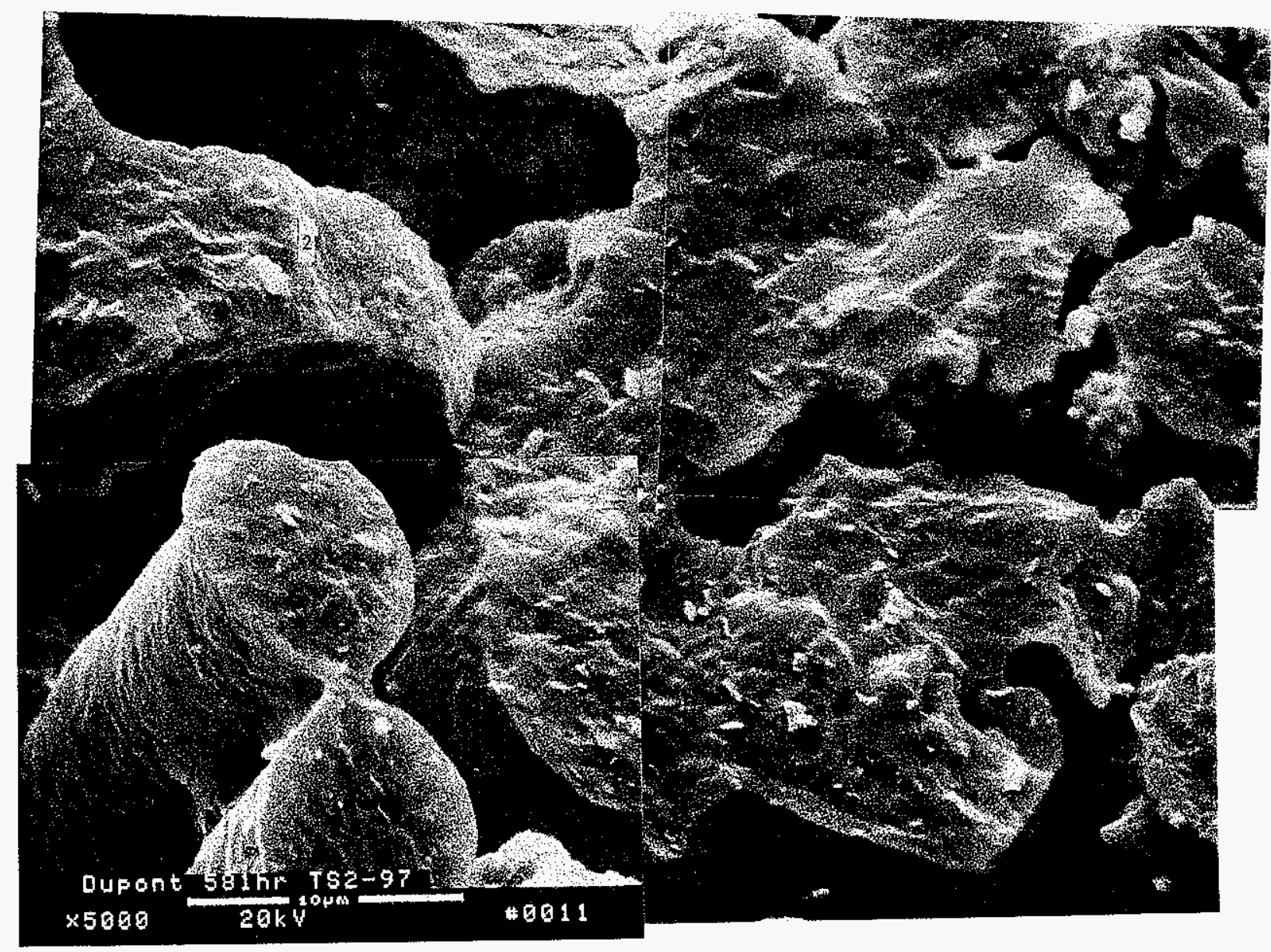

Figure 2-89 - Micrograph montage illustrating the morphology of the coalesced fiber replicas within the filament bundles in the PCFBC-exposed DuPont PRD-66 filter matrix. 


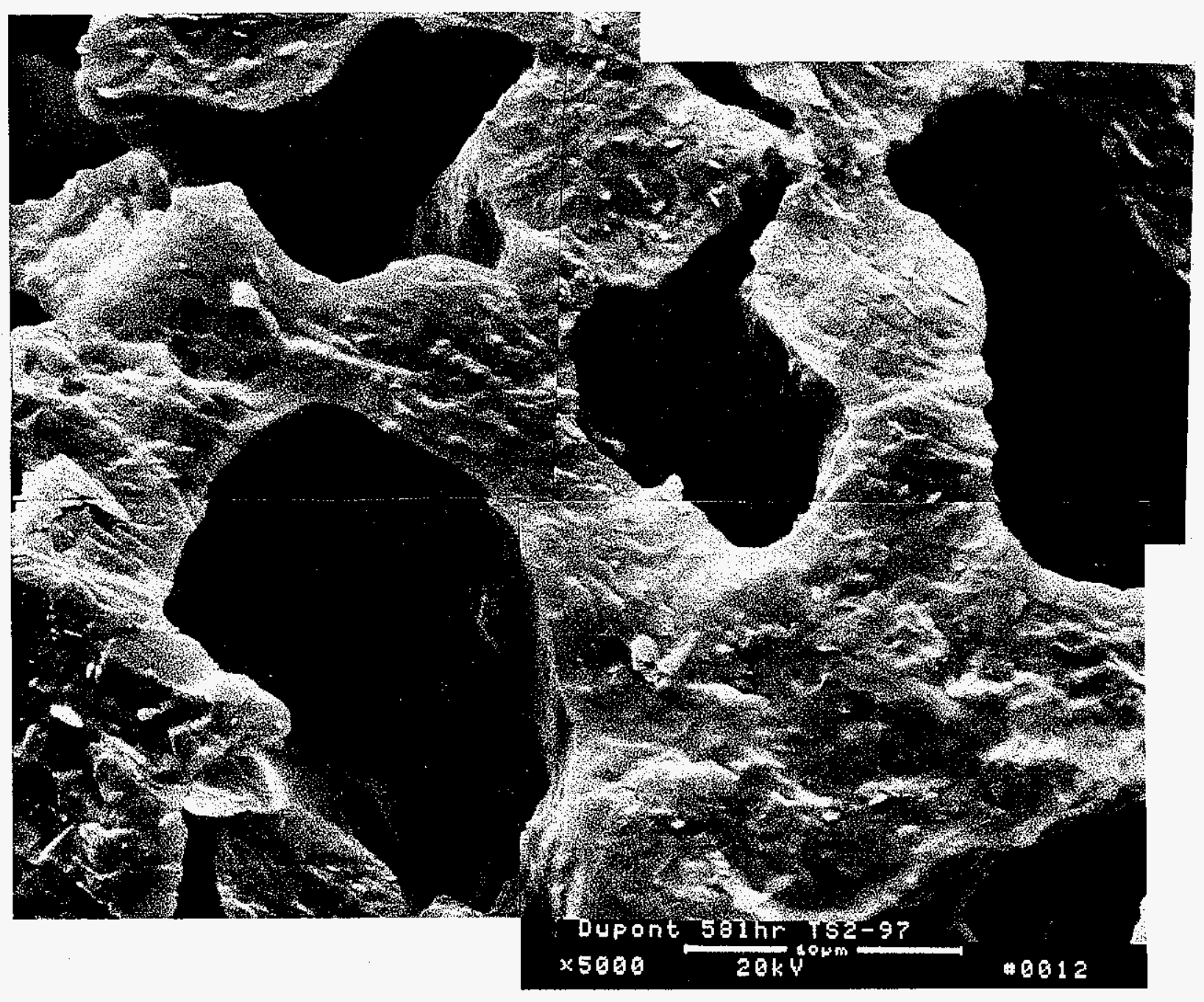

Figure 2-90 - Additional micrograph montage illustrating the morphology of the coalesced fiber replicas within the filament bundles in the PCFBC-exposed DuPont PRD-66 filter matrix. 


\subsubsection{McDermott CFCC}

\subsubsection{As-Manufactured Filter Matrix}

The McDermott continuous fiber ceramic composite (CFCC) filter elements are manufactured via a filament winding process utilizing Nextel ${ }^{\mathrm{TM}} 610$ fiber (i.e., alumina filament bundles), Saffil chopped fibers (i.e., 95-96\% alumina; silica), and an $\mathrm{Al}_{2} \mathrm{O}_{3}$ matrix. The diagonally wound, Nextel ${ }^{\mathrm{TM}} 610$ filament fiber bundles serve as the structural support matrix through the $\sim 5 \mathrm{~mm}$ thick McDermott CFCC filter wall. Interspersed throughout the filter wall are chopped fibers and a bonding matrix which provides the surface and bulk filtration characteristics of the filter element. As a result of the manufactured architecture of the chopped fiber and bonding matrix, a membrane is not directly applied to the outer surface of the McDermott CFCC filter element.

When characterized, the diagonally wound filament fiber bundles were generally seen to be embedded within a chopped fiber matrix along the outer surface of the as-manufactured McDermott CFCC candle filter (Figure 2-91). A mud cracked alumina matrix was also present along the outer surface of the Nextel ${ }^{\mathrm{TM}} 610$ and chopped Saffil fibers (Figure 2-92). Typically there appeared to be a higher concentration of the bonding matrix which formed mud cracked scales along the chopped fibers that were present along the o.d. surface of the McDermott CFCC filter element (Figure 2-93), in comparison to the limited quantity of bonding matrix that was present along the chopped fibers contained along the i.d. wall of the candle filter (Figures 2-94 and 2-95). The chopped fibers along the i.d. wall appeared to be randomly held together through packing and/or limited bonding via submicron particles and/or agglomerates. Along the i.d. wall of the candle filter, the chopped fibers were present as a feltlike layer which primarily covered the underlying wound filament fiber bundles. During pulse cleaning of the candle, the as-manufactured felt-like layer is expected to be removed, due to the limited bonding between adjacent fibers along the i.d. wall of the filter element.

The as-manufactured diagonally wound filament fiber bundles within the filter wall appeared to be continuous, and perhaps were twisted (Figure 2-96). The filament fiber bundles contained numerous $\sim 10 \mu \mathrm{m}$ diameter fibers (Figures 2-97 and 2-98).

\subsubsection{PCFBC-Exposed Filter Matrix}

Six $1.5 \mathrm{~m}$, McDermott oxide-based, CFCC candle filters were installed in the bottom array of the W-APF filter at the Foster Wheeler PCFBC test facility in Karhula, Finland in the fall of 1997 (TS2-97). The elements were operated for a period of 581 hours at temperatures of $750^{\circ} \mathrm{C}$. Post-test characterization of candle filter BW 7-5-30 (B33) was conducted via SEM/EDAX analysis to determine the resulting microstructure and composition of the PCFBC-exposed McDermott filter matrix.

Characterization of the PCFBC-exposed, McDermott, CFCC candle filter indicated that ash fines were present only along the o.d. and i.d. surfaces of the filter element. Deposition of fines along the i.d. surface was considered to have resulted primarily from back pulsing of particulates into the bore of the McDermott filters after failure of an alternate candle(s) had occurred within the filter array during process operation. Penetration of ash fines into the McDermott CFCC filter wall was not observed. 


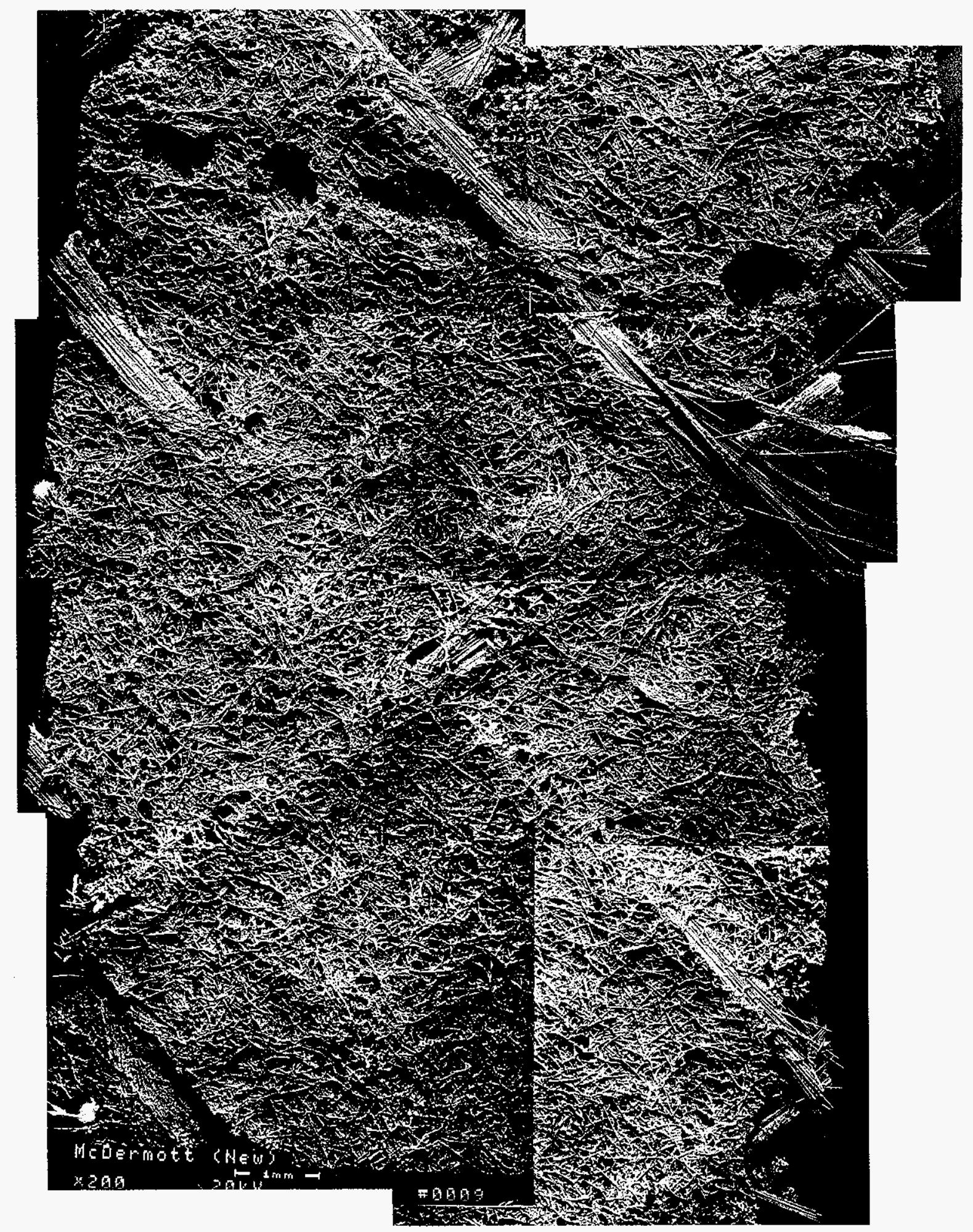

Figure 2-91 - Micrograph montage illustrating the morphology of the outer surface of the asmanufactured McDermott CFCC candle filter. 


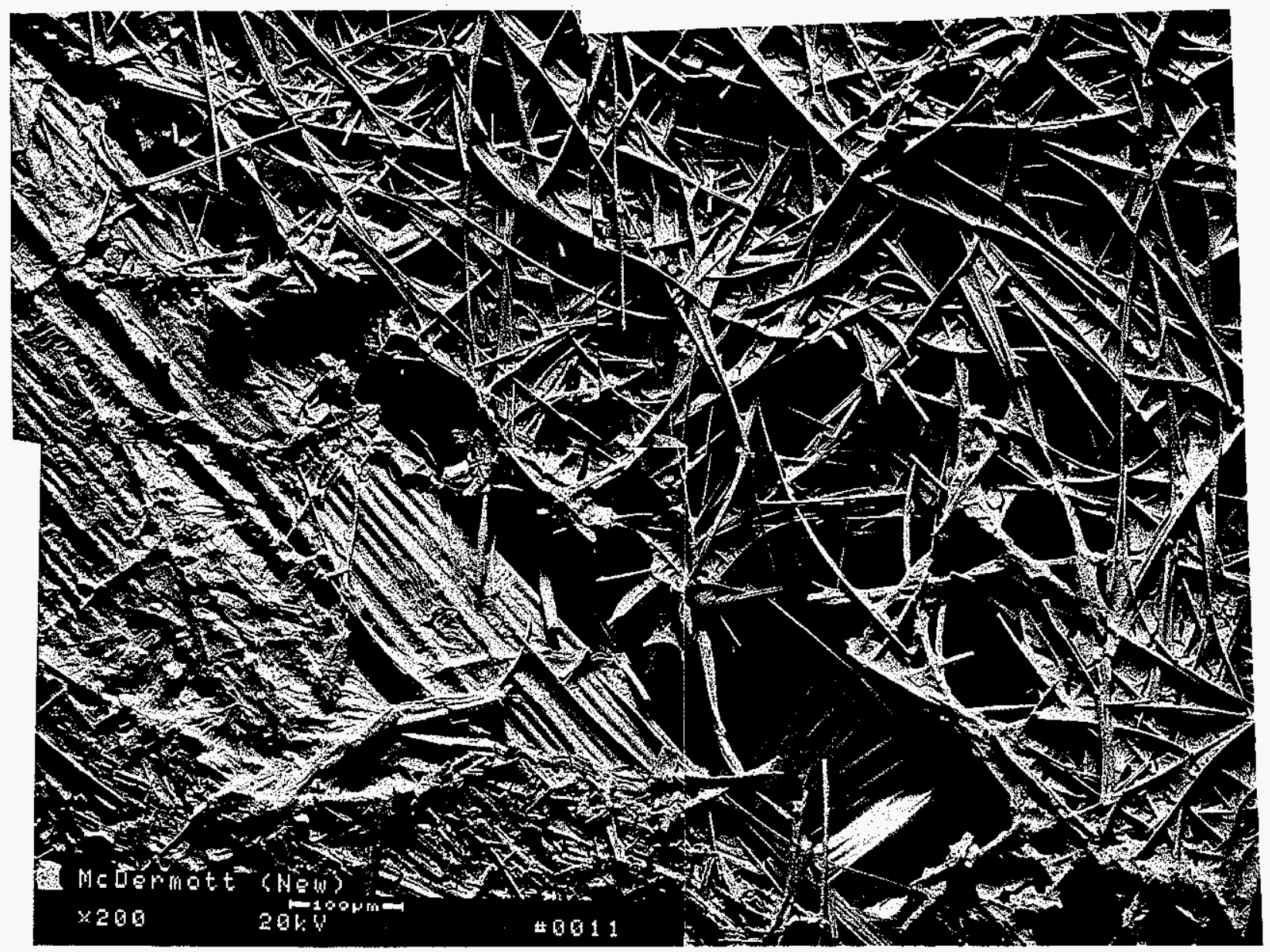

Figure 2-92 - Micrograph montage illustrating the morphology of the chopped fiber matrix and exposed filament fiber bundles that were present along the outer surface of the asmanufactured McDermott CFCC candle filter. 


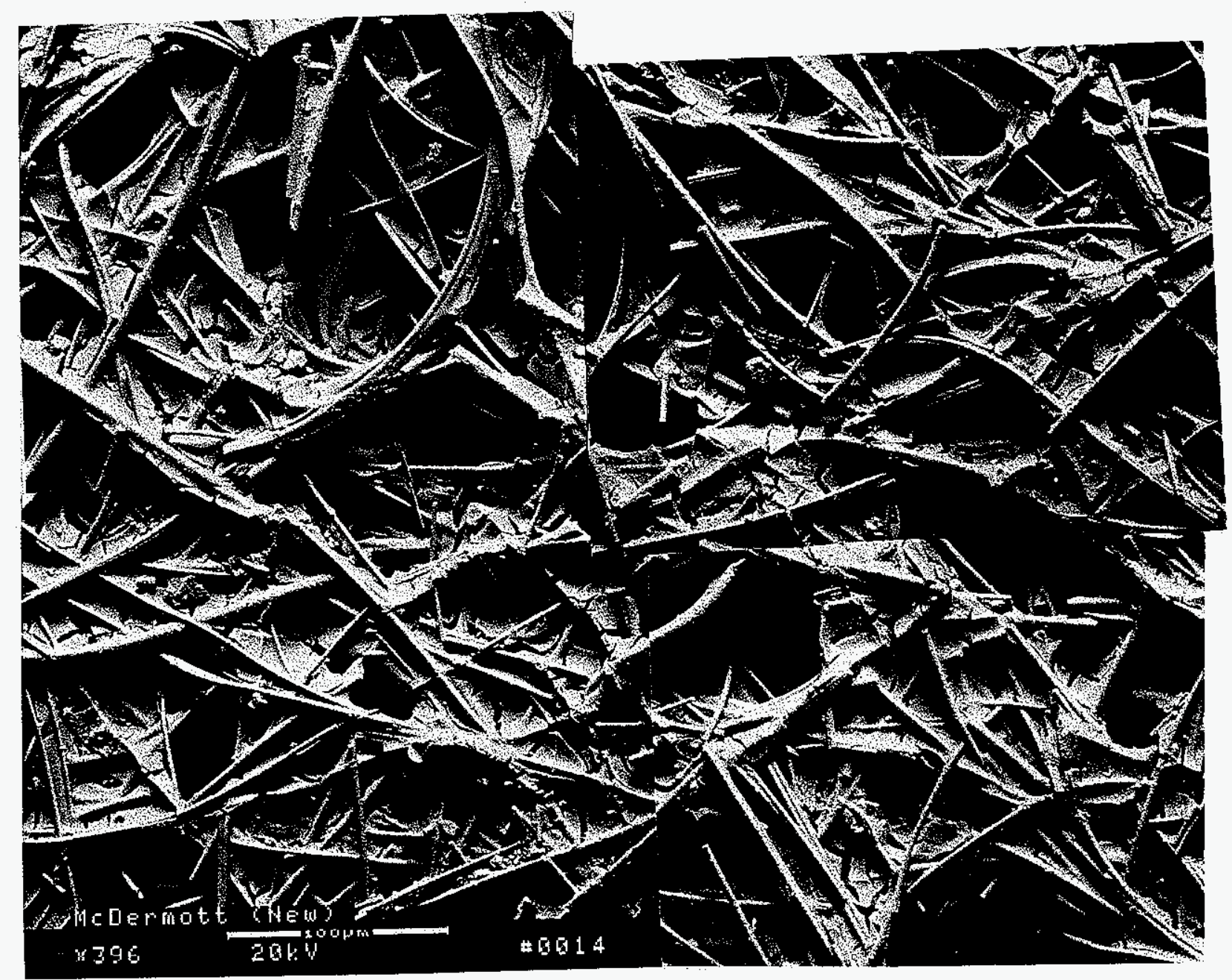

Figure 2-93 - Micrograph montage illustrating the morphology of the mud cracked bonding matrix and chopped fibers that were present along the outer surface of the asmanufactured McDermott CFCC filter element. 


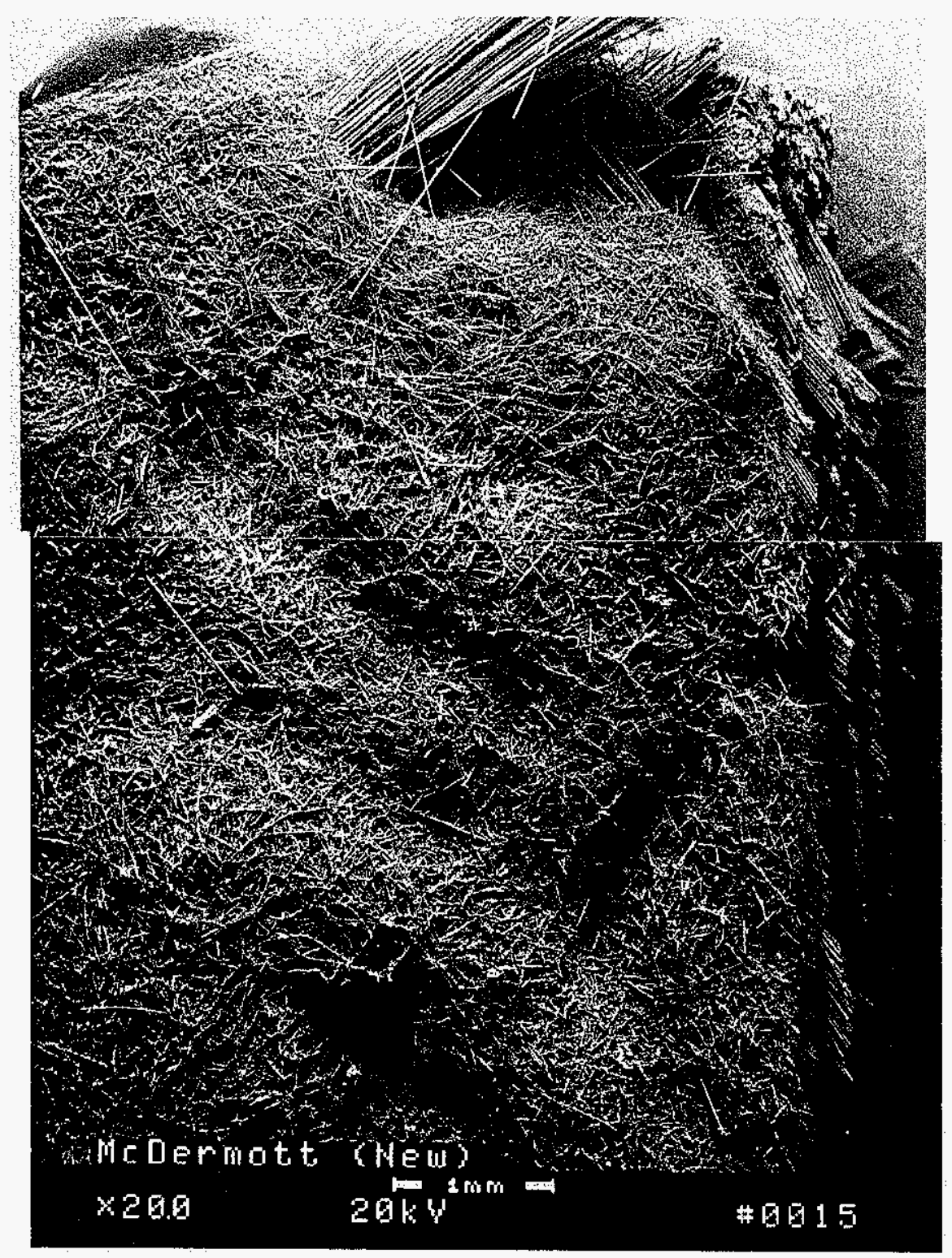

Figure 2-94 - Micrograph montage illustrating the morphology of the chopped fiber matrix that was present along the i.d. surface of the as-manufactured McDermott CFCC filter element. 


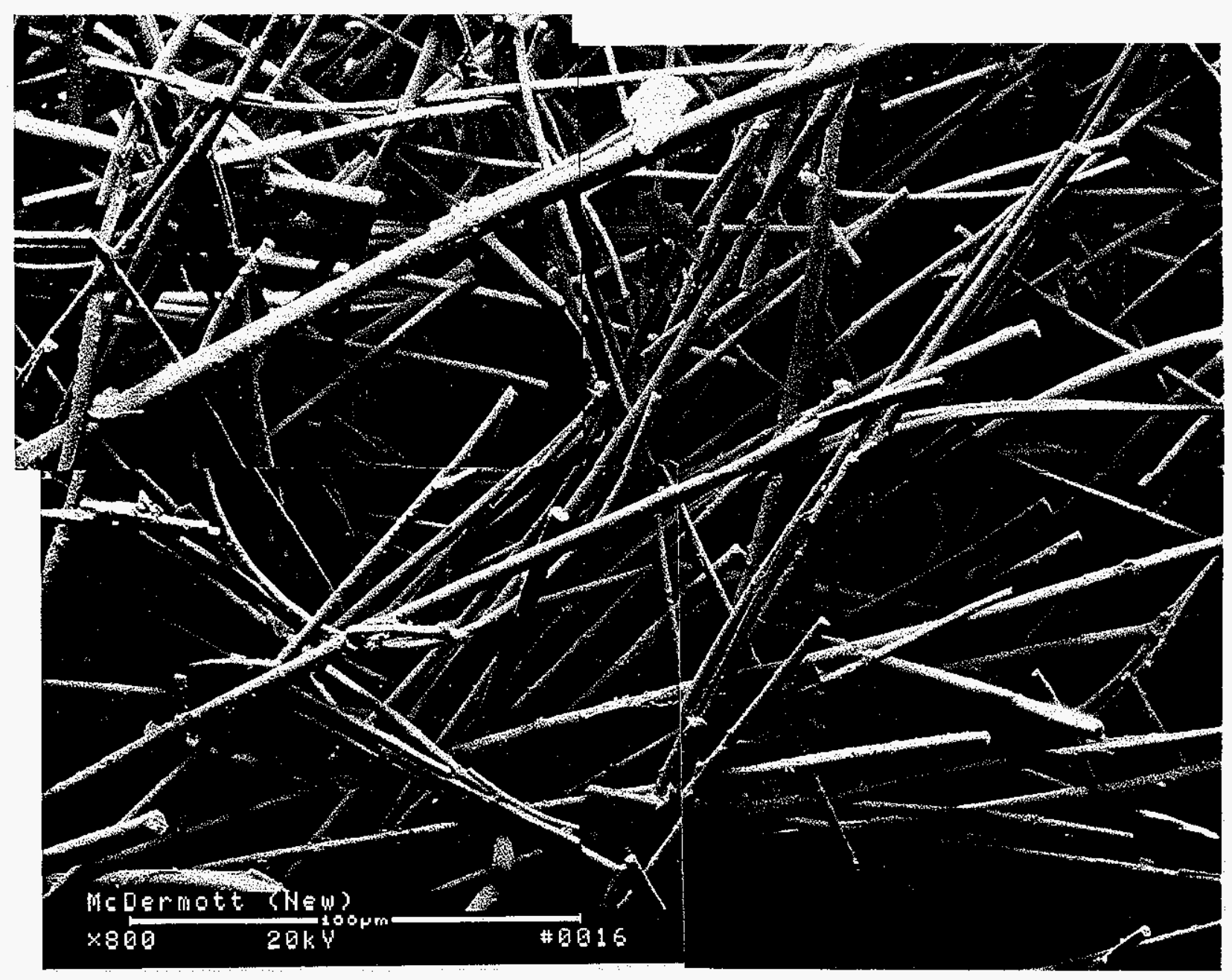

Figure 2-95 - Micrograph montage illustrating the morphology of the chopped fibers that were present along the i.d. surface of the as-manufactured McDermott CFCC filter element. 

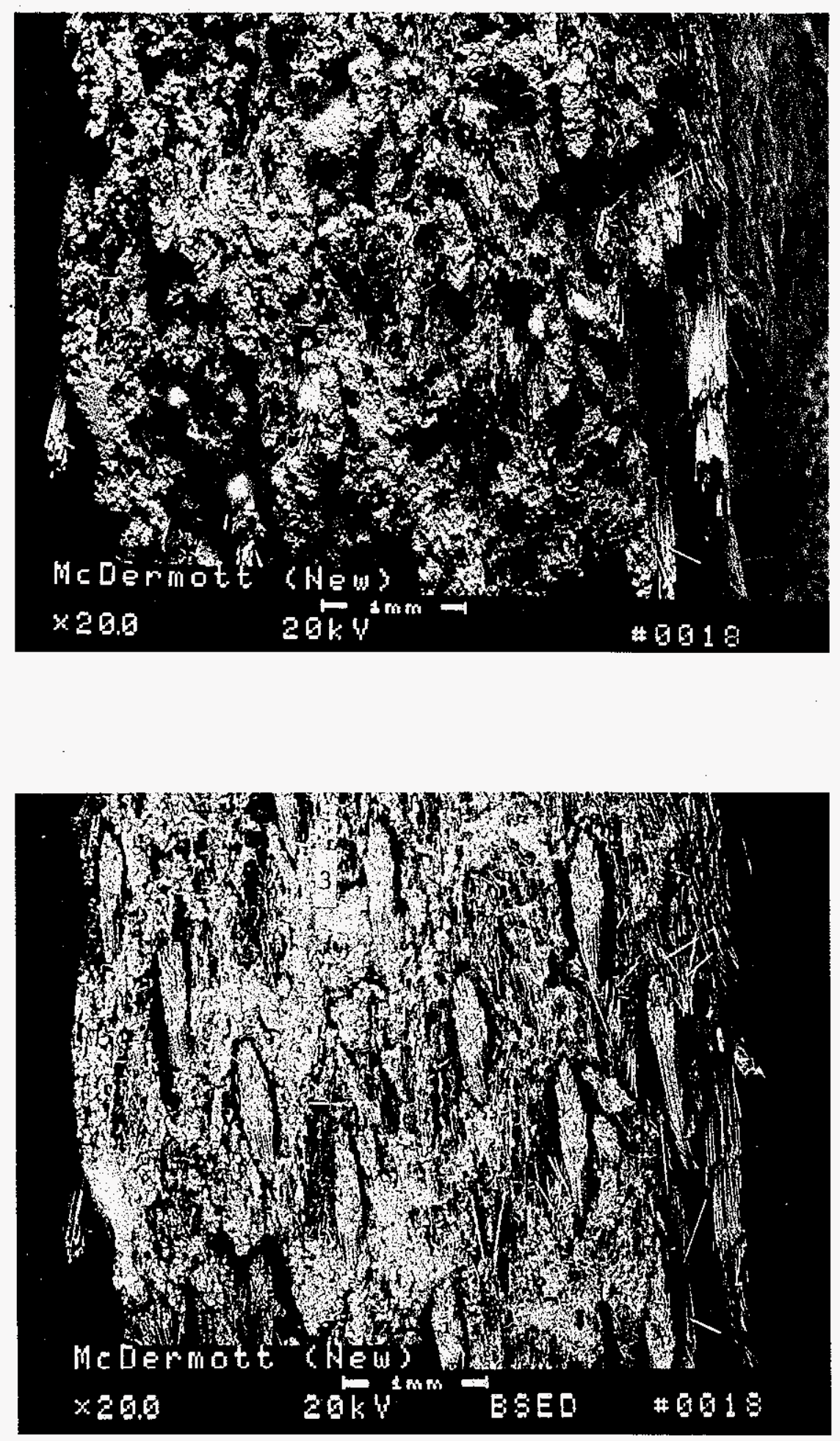

Figure 2-96 - Cross-sectioned surface of the as-manufactured McDermott CFCC filter wall. 


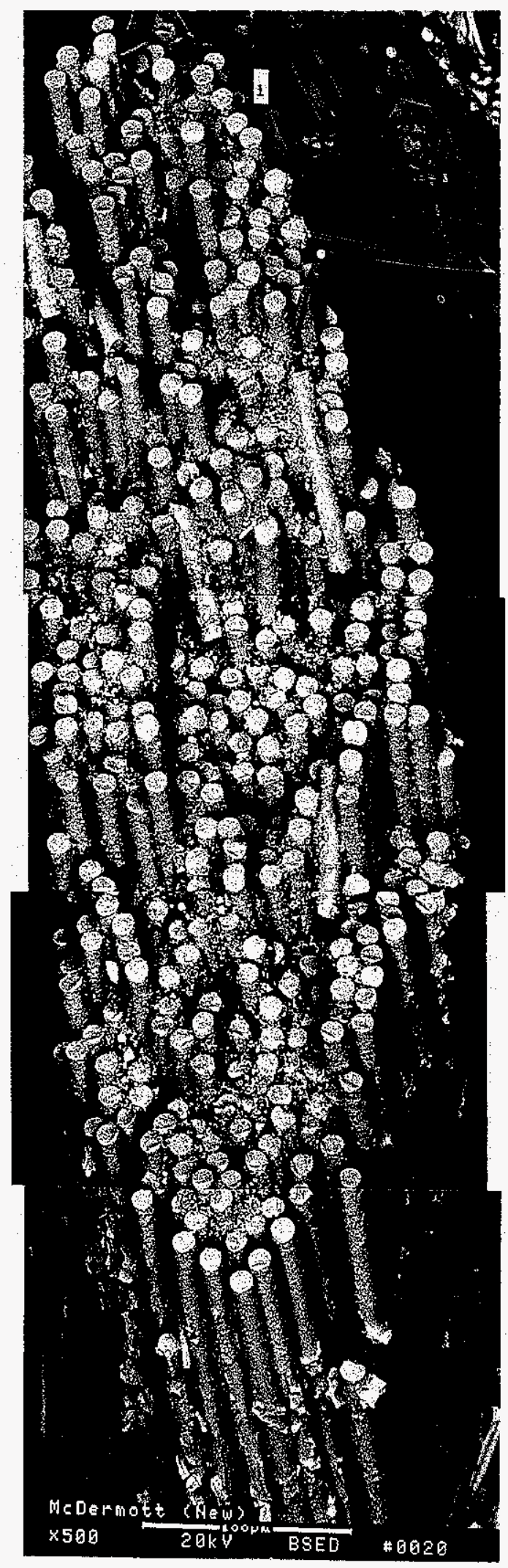

Figure 2-97 - High magnification micrograph montage illustrating the morphology of the crosssectioned filter fiber bundle within the filter wall of the as-manufactured McDermott CFCC filter element. 


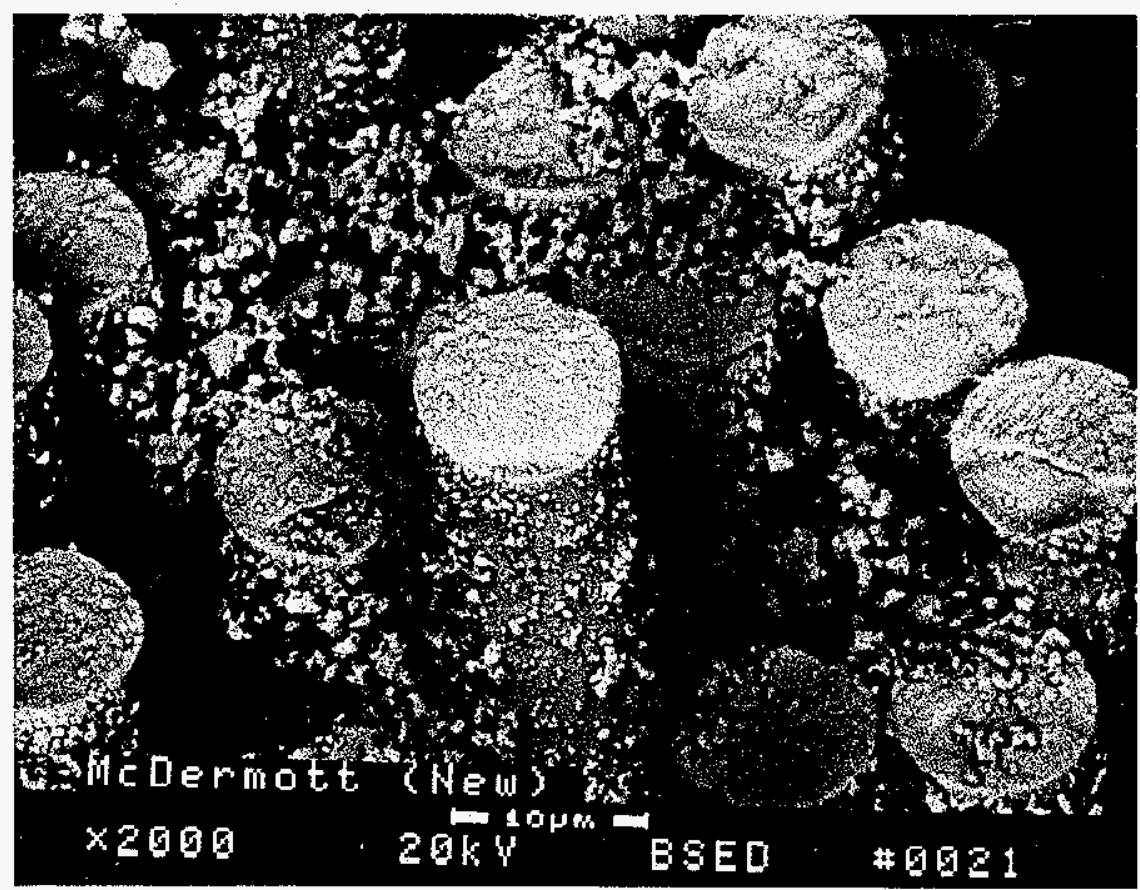

Figure 2-98 - Micrograph illustrating the morphology of the $\sim 10 \mu \mathrm{m}$ diameter alumina-enriched fibers and submicron agglomerated matrix particles that were present in the crosssectioned filament fiber bundle of the as-manufactured McDermott CFCC filter matrix. 
Along the o.d. surface of the PCFBC-exposed McDermott CFCC filter element, the wound filaments or fiber bundles were seen to be either exposed, or embedded below a layer of chopped fibers and bonding matrix (i.e., binder; Figure 2-99). Infrequently, the exposed filaments or fiber bundles were seen to be twisted. The chopped fibers and bonding matrix formed the external membrane layer along the outer surface of the PCFBC-exposed McDermott filter element (Figure 2100).

The chopped fibers that were present within the mat that encapsulated the wound filaments were identified by EDAX analysis to be enriched with aluminum and oxygen, with silicon also detected (i.e., Saffil). The length and cross-sectioned diameter of the chopped fibers were identified to be $<100-150$ $\mu \mathrm{m}$, and $<10 \mu \mathrm{m}$, respectively.

The bonding matrix present along the o.d. surface of the PCFBC-exposed McDermott filter element was identified to contain $\sim 10-30 \mu \mathrm{m}$ alumina-enriched grains. Mud-cracked areas were also evident along outer surfaces of the filament bundles that were present along the o.d. surface of the PCFBC-exposed McDermott filter element.

Growth of calcium-enriched, dendritic, rod-like crystalline formations was evident along the exposed surface of filament bundles that were present along the o.d. surface of the PCFBC-exposed McDermott filter element (Figures 2-101 and 2-102). The dendritic features were seen to radiate from a common nucleating point along the outer surface of the filament fiber bundle. The dendritic crystalline features appeared as relatively smooth surface, cubic, rectangular, or triangularly shaped rods. The central core of the rods had a characteristic textured or grain growth appearance. Previous effort at Siemens Westinghouse has shown that the characteristic calcium-enriched dendritic formations result from dissolution and recrystallization of sorbent particles that are present throughout the filter matrix. Typically dissolution and recrystallization is the result of sample preparation or element cleaning (i.e., water washing), and generally does not result during in-situ process operation.

A calcium-enriched, grain-like phase was deposited along the outer surface pore cavities of the PCFBC-exposed McDermott filter element (Figures 2-103 and 2-104). This phase was considered to be a precursor to the dendritic, rod-like, crystalline formations that typically resulted along the outer surface of the fibers that were present within the wound filaments.

Similar to the as-manufactured filter elements, the PCFBC-exposed McDermott CFCC filter matrix contained wound, alumina-enriched, Nextel ${ }^{\mathrm{TM}} 610$ filament fiber bundles throughout the $\sim 5 \mathrm{~mm}$ thick filter wall. The elliptically shaped filaments contained numerous $\sim 10 \mu \mathrm{m}$ diameter fibers (Figure 2105). Interspersed within the Nextel ${ }^{\mathrm{TM}} 610$ filaments were submicron agglomerated fines that were considered to have resulted from wetting and penetration of the slurry matrix throughout the fiber bundles during manufacturing of the filter element (Figures 2-106 and 2-107).

Throughout the cross-sectioned, PCFBC-exposed, McDermott filter wall, filament fiber bundles were seen to be embedded within the chopped fiber and bonding matrix (Figures 2-108 and 2-109). The chopped fiber and bonding matrix served as both an o.d. and i.d. surface membrane, as well as the substrate material separating wound filament fiber bundles. The chopped fibers and bonding matrix were considered to provide additional structural support to the filament wound, McDermott, CFCC construction. 


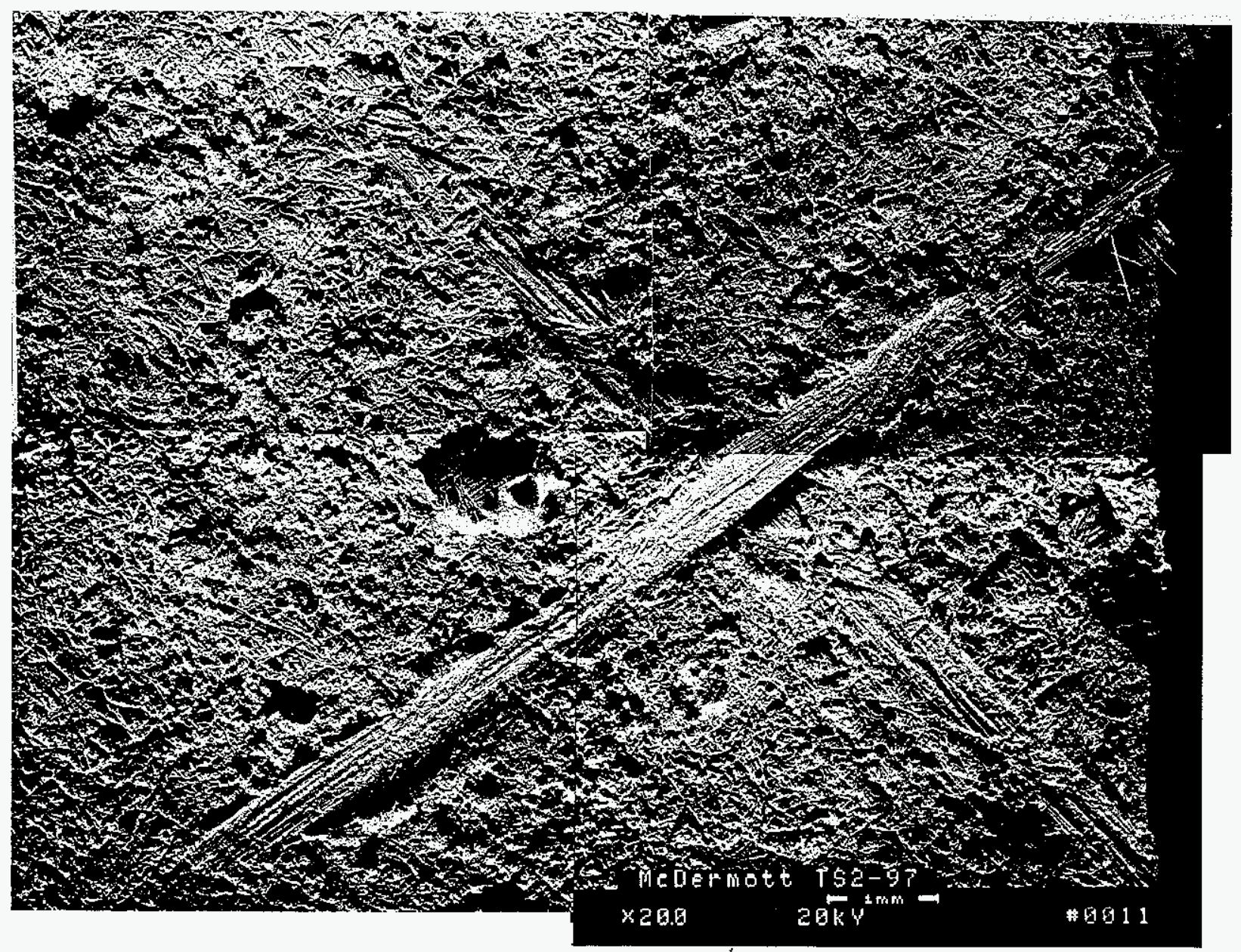

Figure 2-99 - Morphology of the PCFBC-exposed, filament wound, McDermott CFCC candle filter outer surface. 


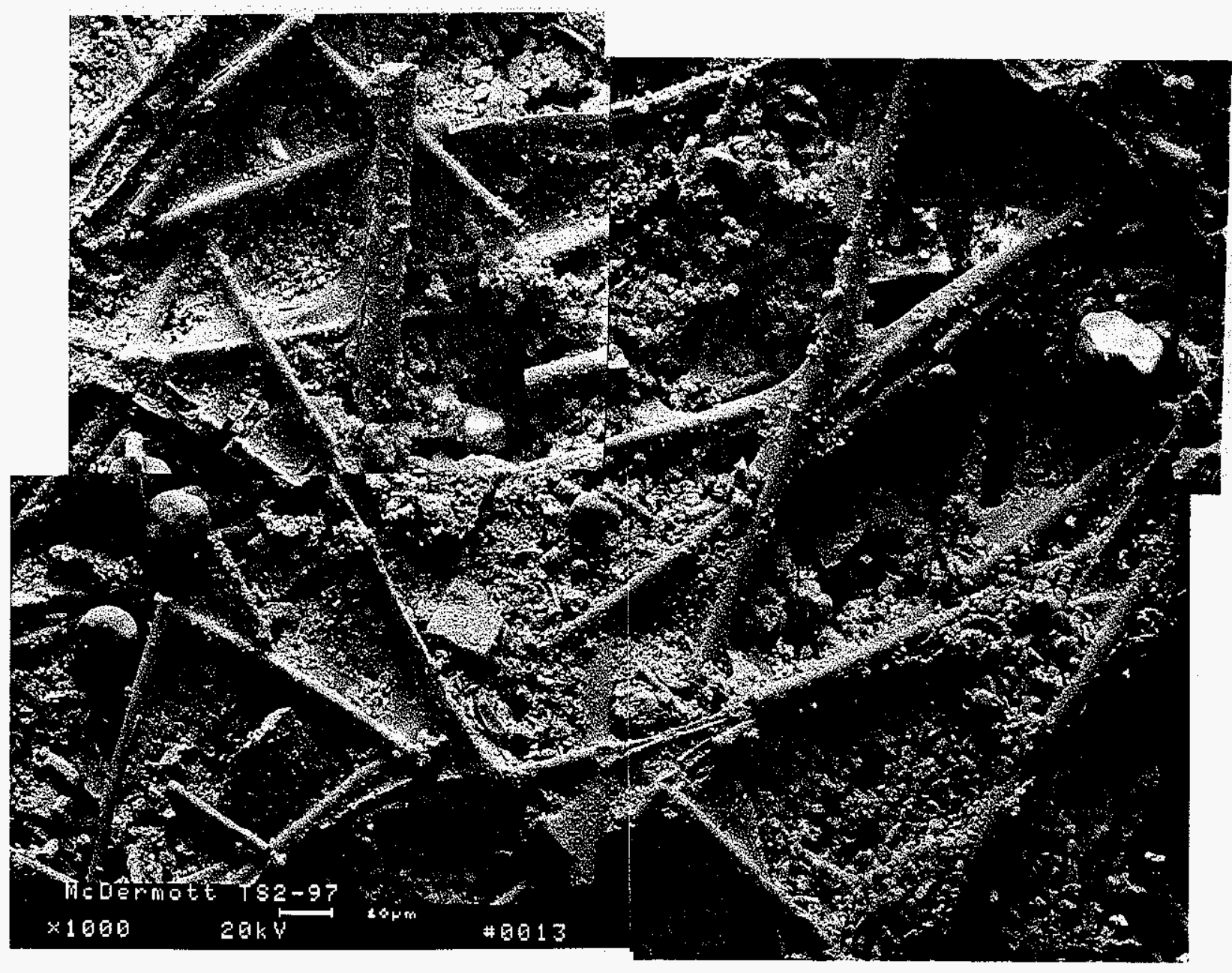

Figure 2-100 - Morphology of the chopped fibers and bonding matrix along the outer surface of the PCFBC-exposed, filament wound, McDermott CFCC candle filter. 


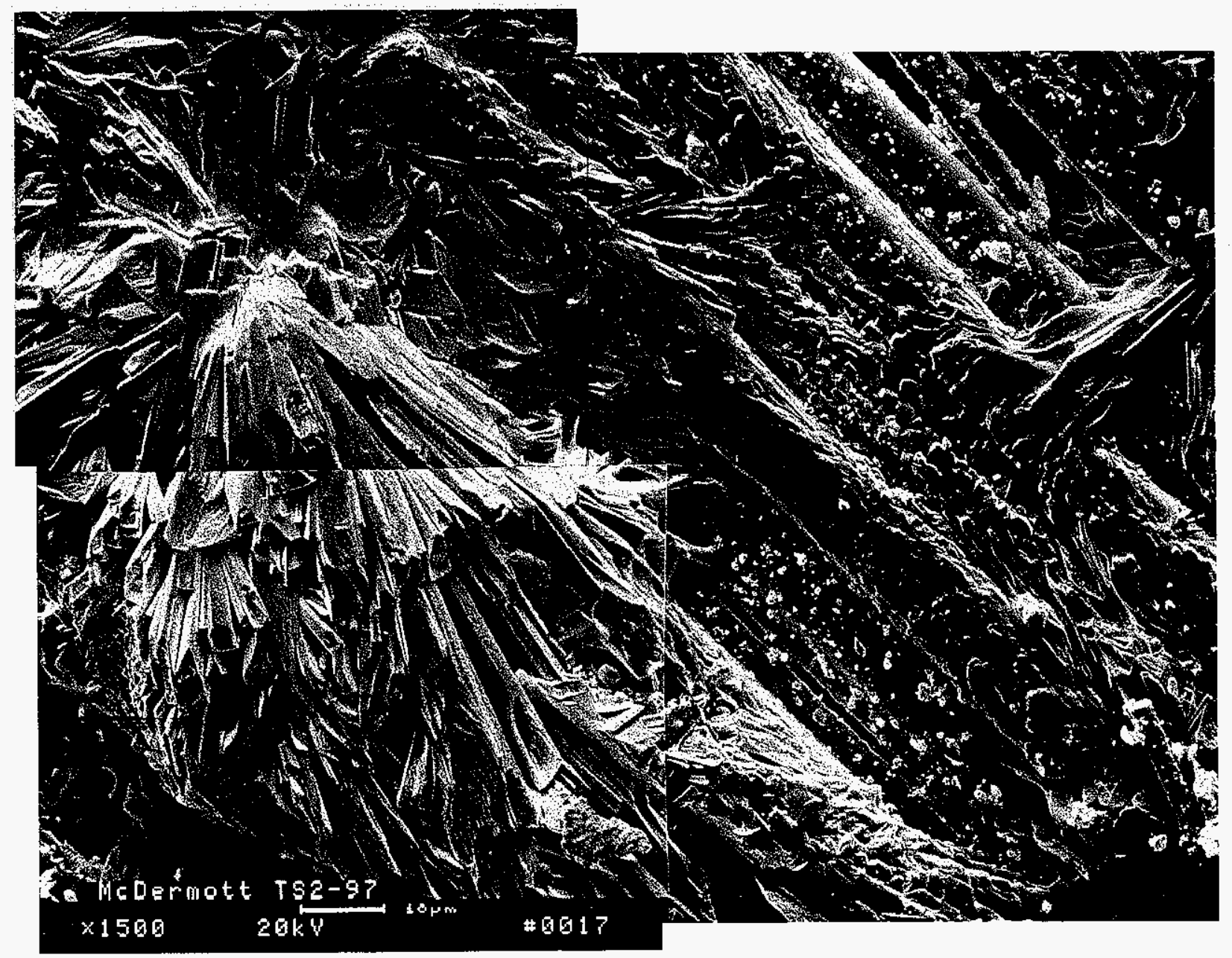

Figure 2-101 - Micrograph montage illustrating the morphology of the crystalline calciumenriched dendritic formations that resulted along the exposed fiber bundle filaments in the PCFBC-exposed McDermott CFCC candle filter. 


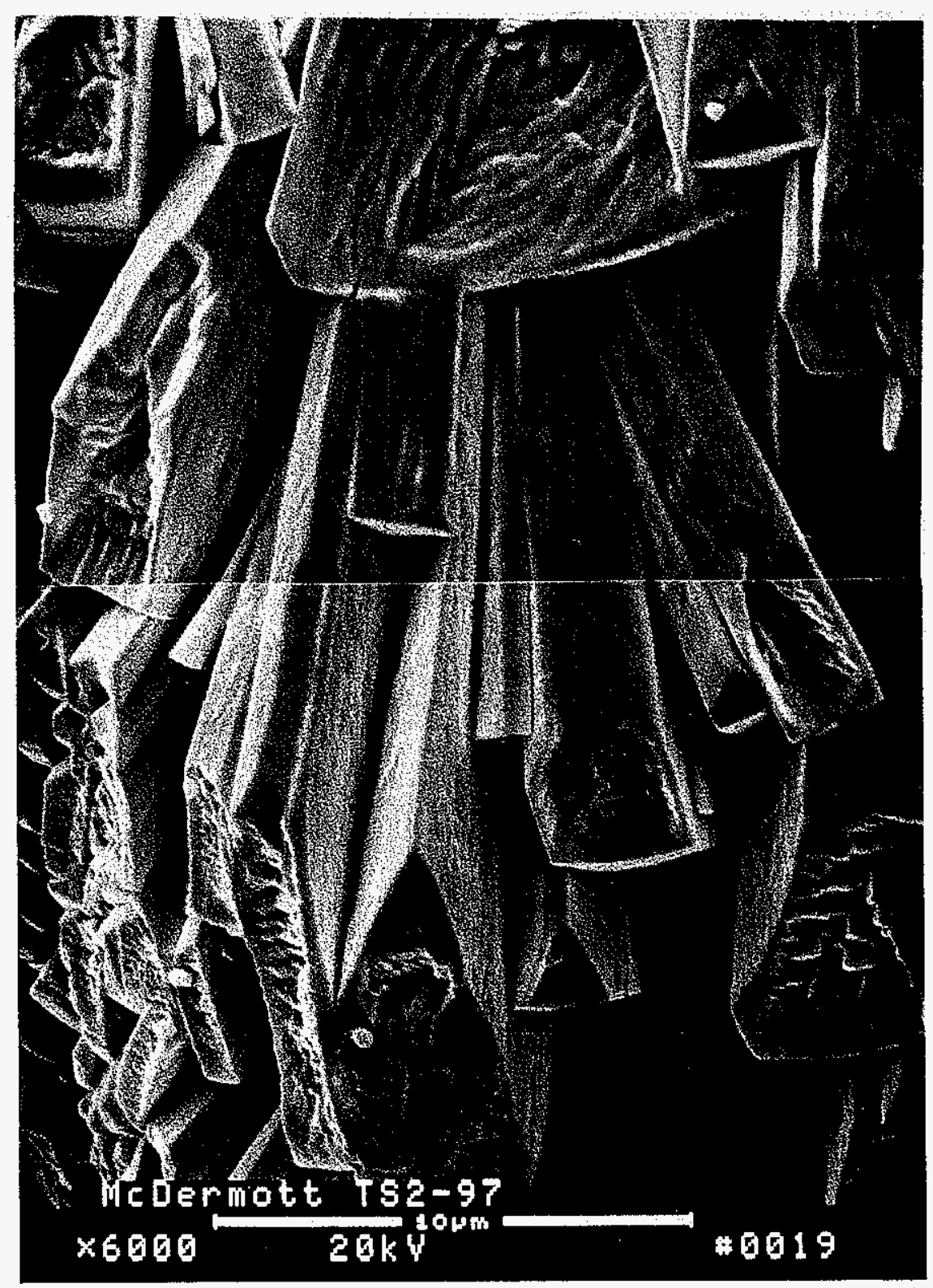

Figure 2-102 - Higher magnification micrograph montage illustrating the crystalline nature of the calcium-enriched dendritic formations that resulted within the PCFBCexposed McDermott CFCC candle filter. 


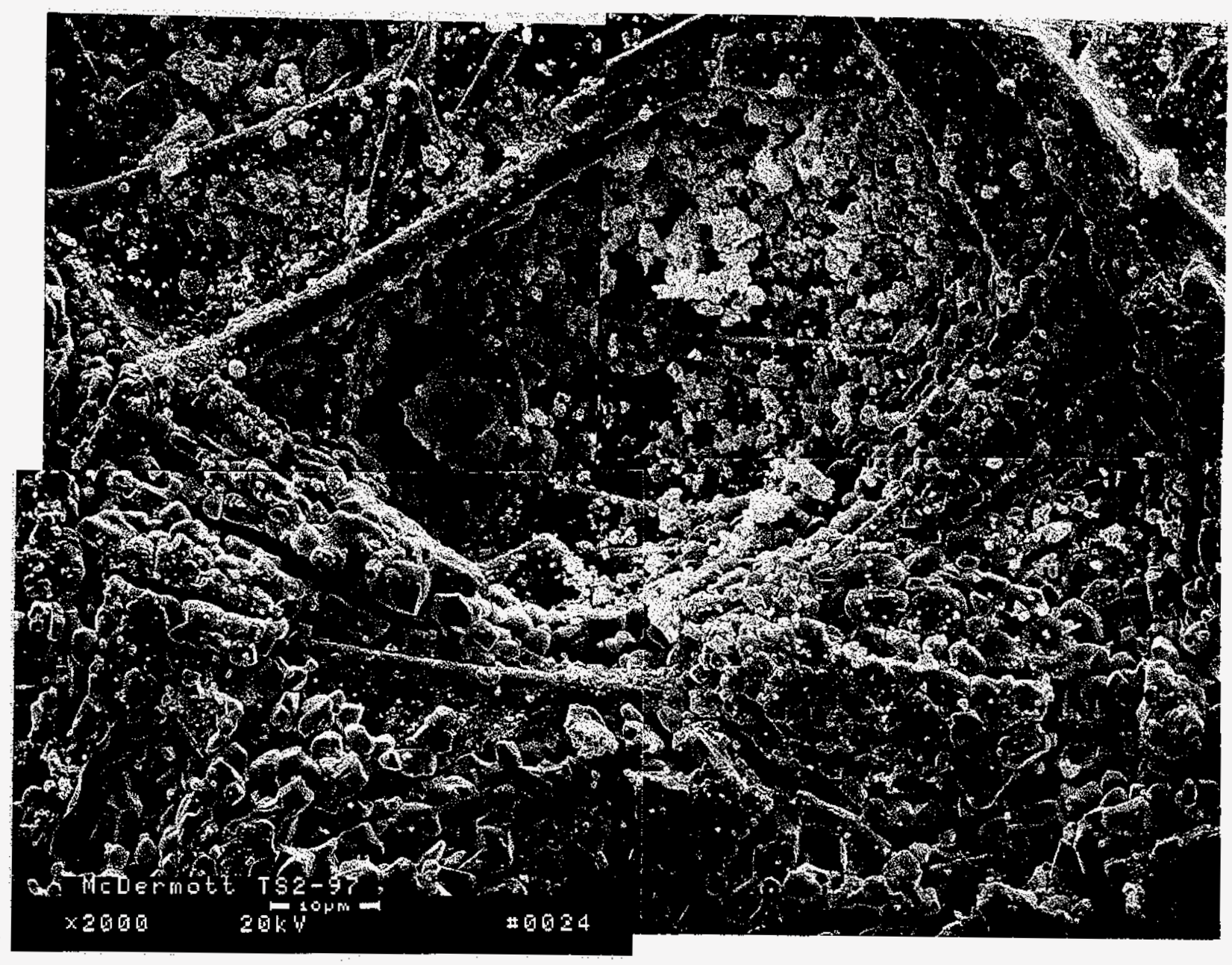

Figure 2-103 - Micrograph montage illustrating the presence of sorbent and ash fines along the outer surface pore cavities of the PCFBC-exposed McDermott CFCC candle filter. 

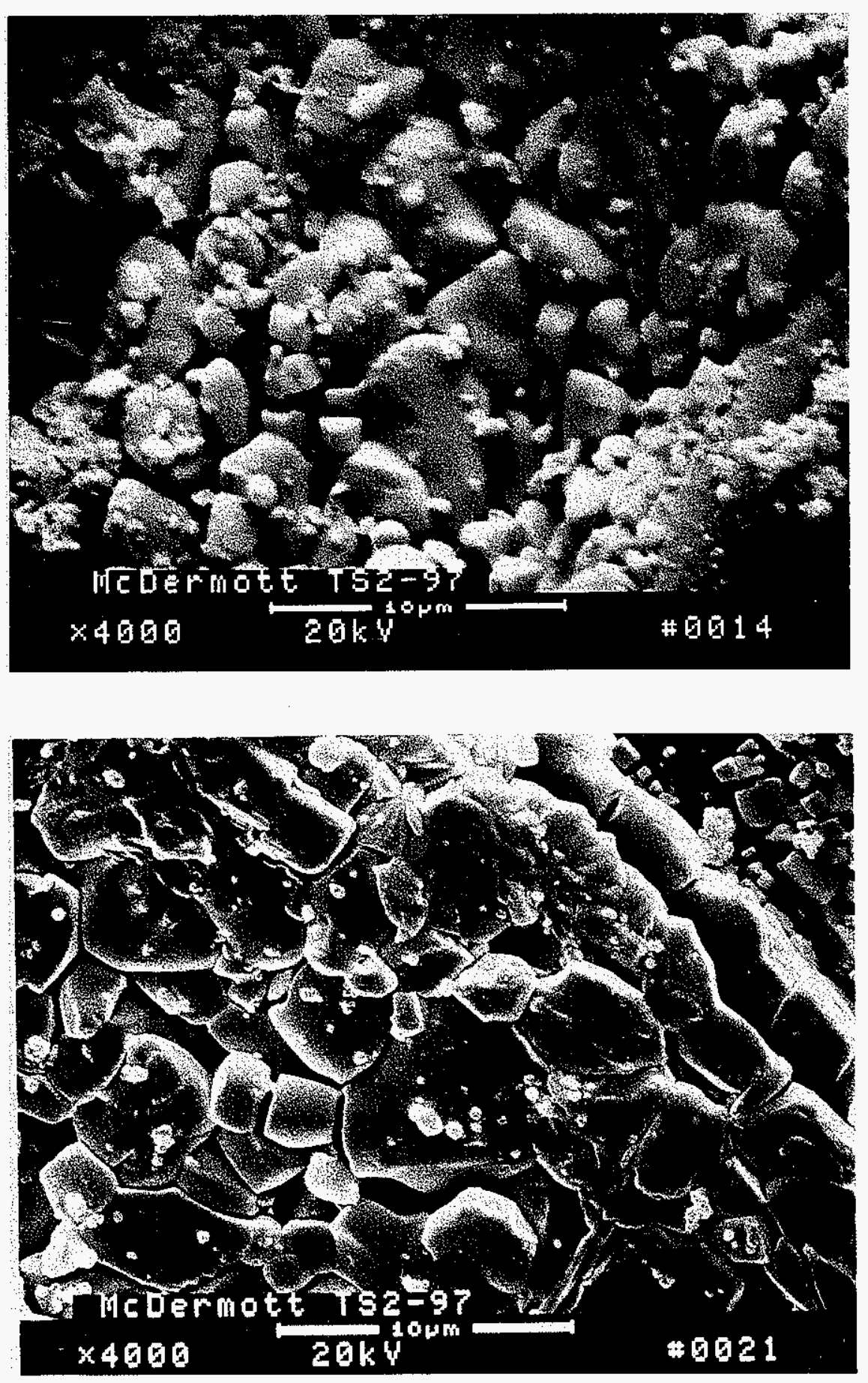

Figure 2-104 - Higher magnification micrographs illustrating the morphology of the sorbent and ash fines that were retained along the chopped fiber mat that was present along the outer surface of the PCFBC-exposed McDermott candle filter. 


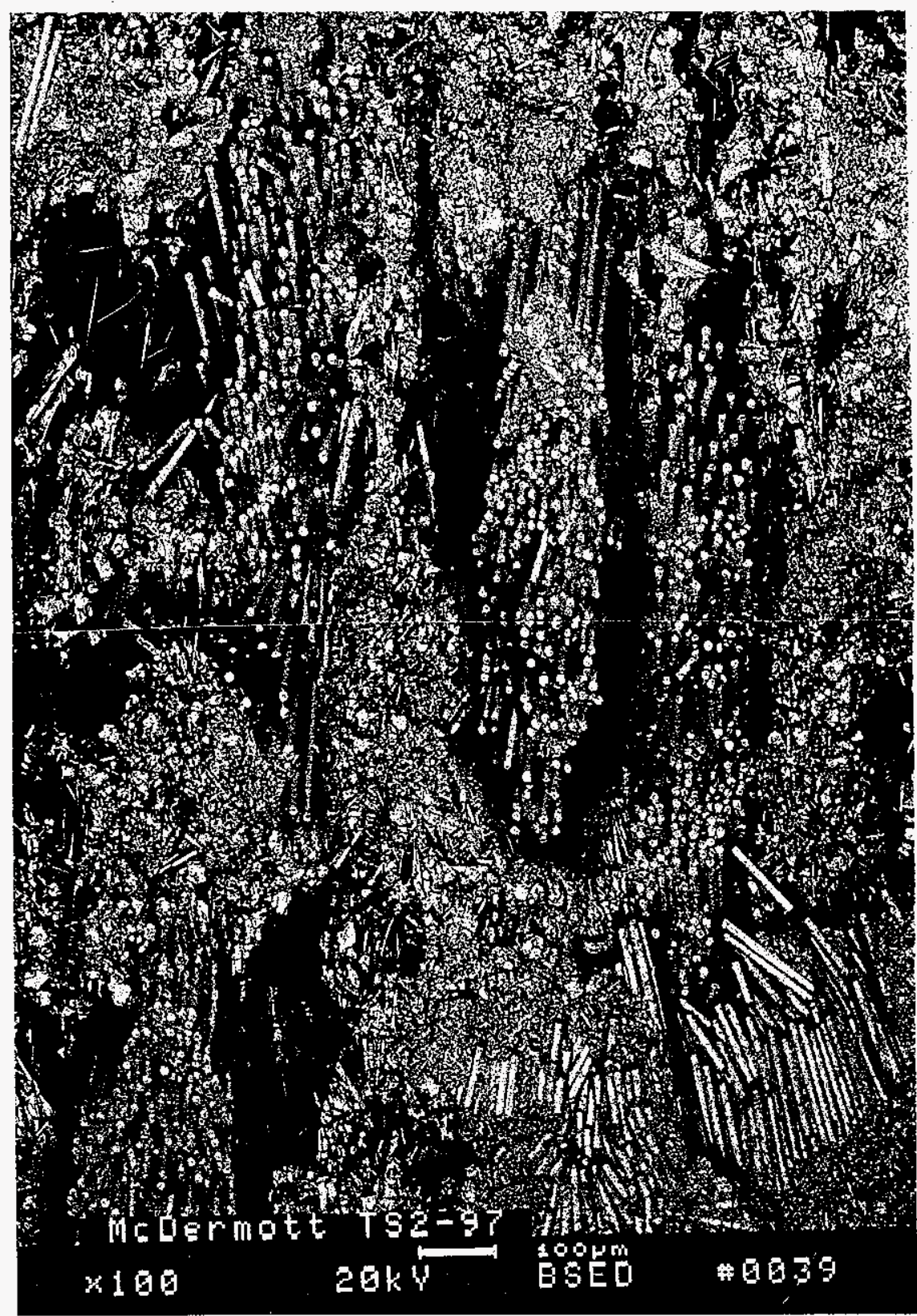

Figure 2-105 - Filament fiber bundles surrounded by chopped fibers and bonding matrix within the cross-sectioned, PCFBC-exposed, McDermott CFCC filter matrix. 


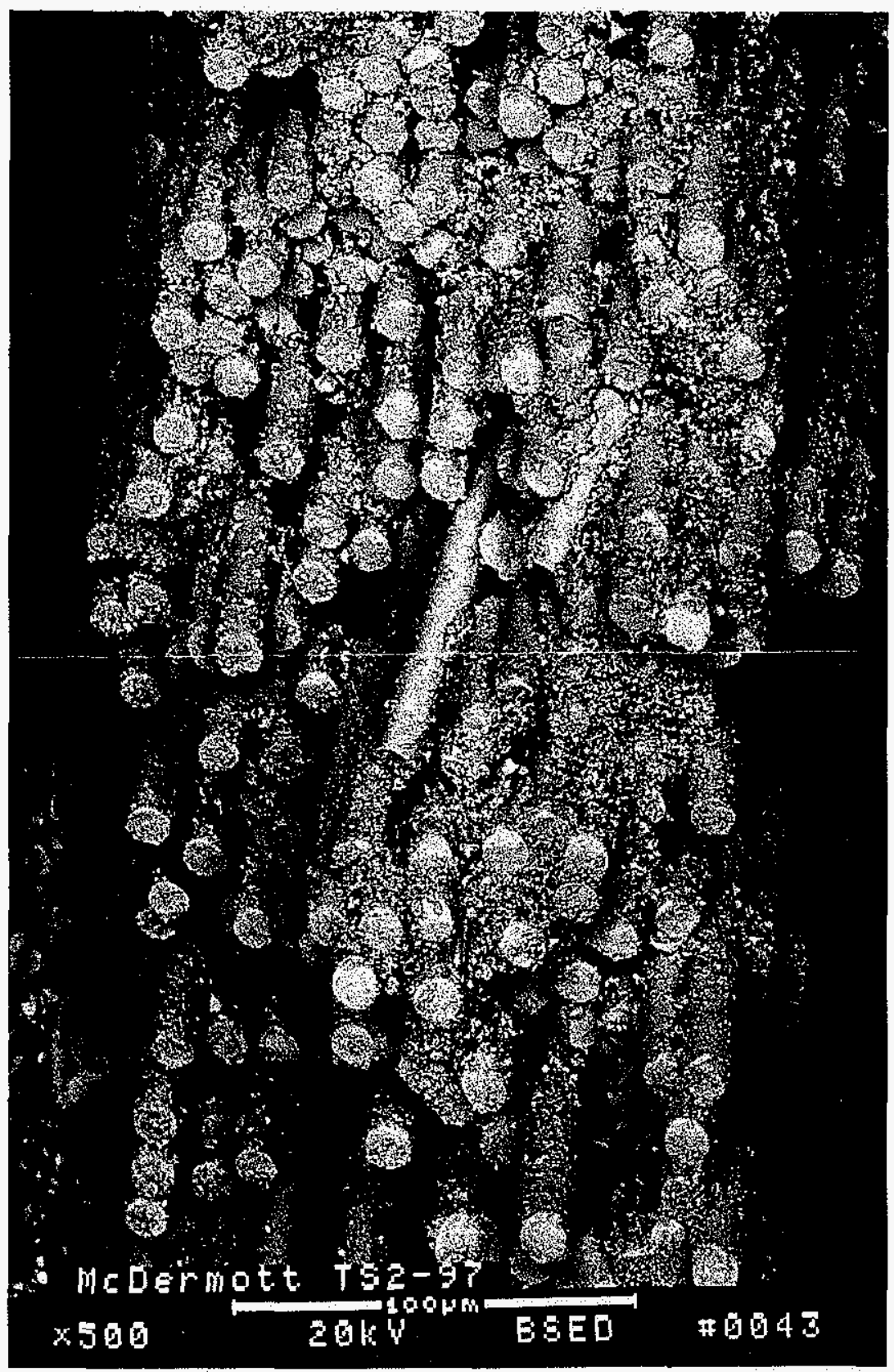

Figure 2-106 - Higher magnification micrograph montage illustrating the morphology of the cross-sectioned filament fiber bundles in the PCFBC-exposed McDermott CFCC candle filter. 


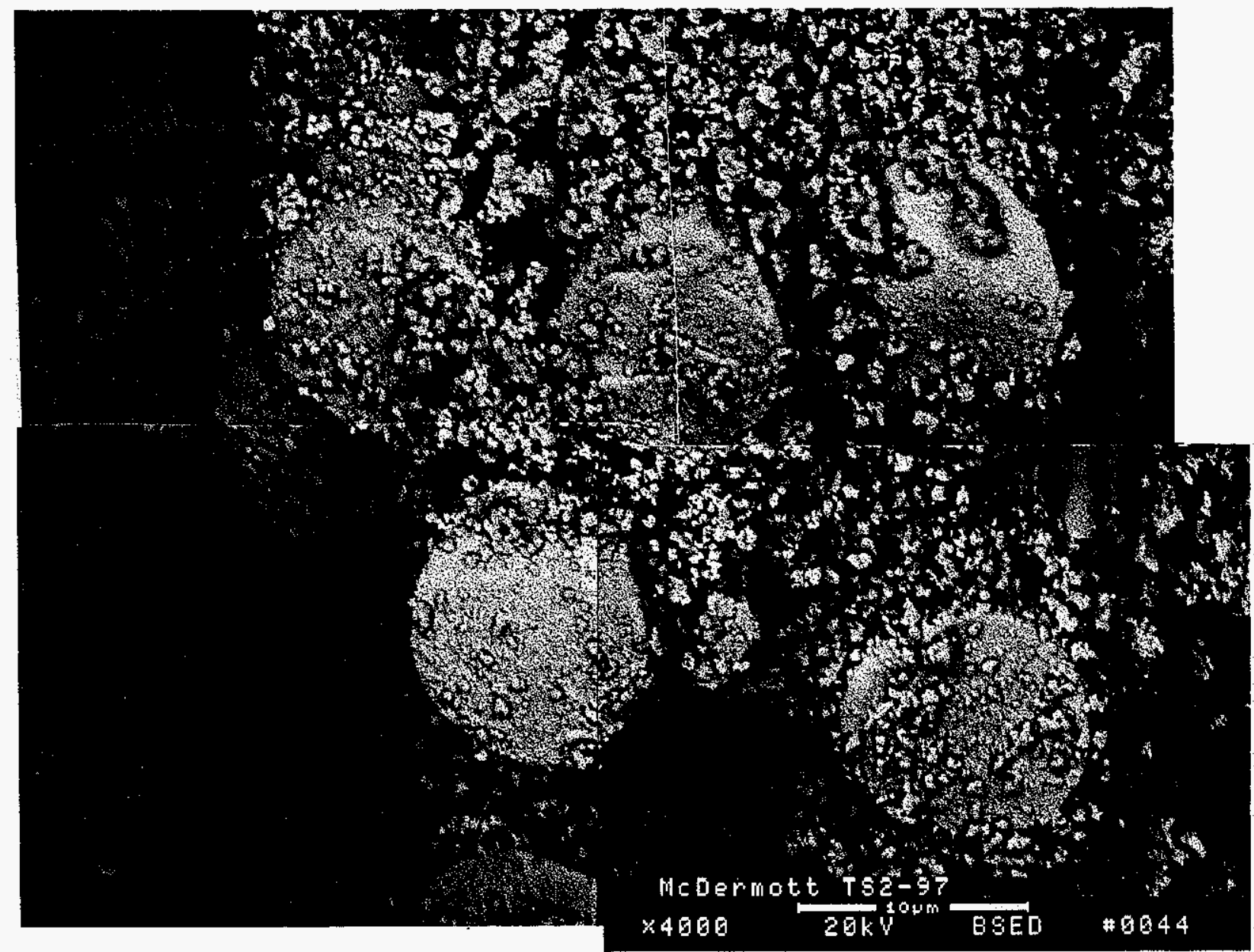

Figure 2-107 - Higher magnification micrograph montage illustrating the presence of the slurry bonding matrix media within the filament fiber bundle in the cross-sectioned, PCFBC-exposed, McDermott CFCC candle filter. 

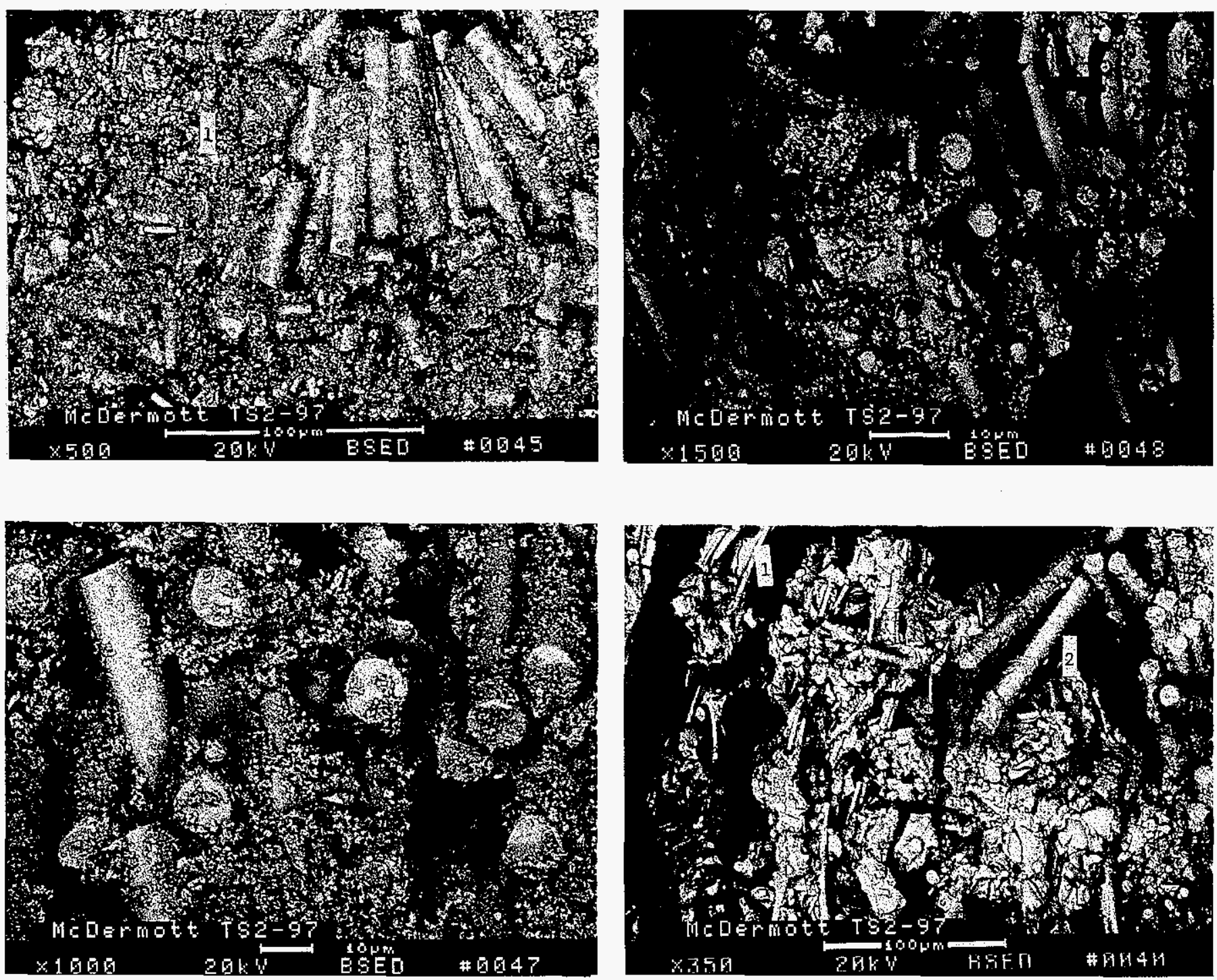

Figure 2-108 - Chopped fibers and bonding matrix which encapsulated the filament fiber bundles in the cross-sectioned, PCFBC-exposed, McDermott CFCC candle filter. 


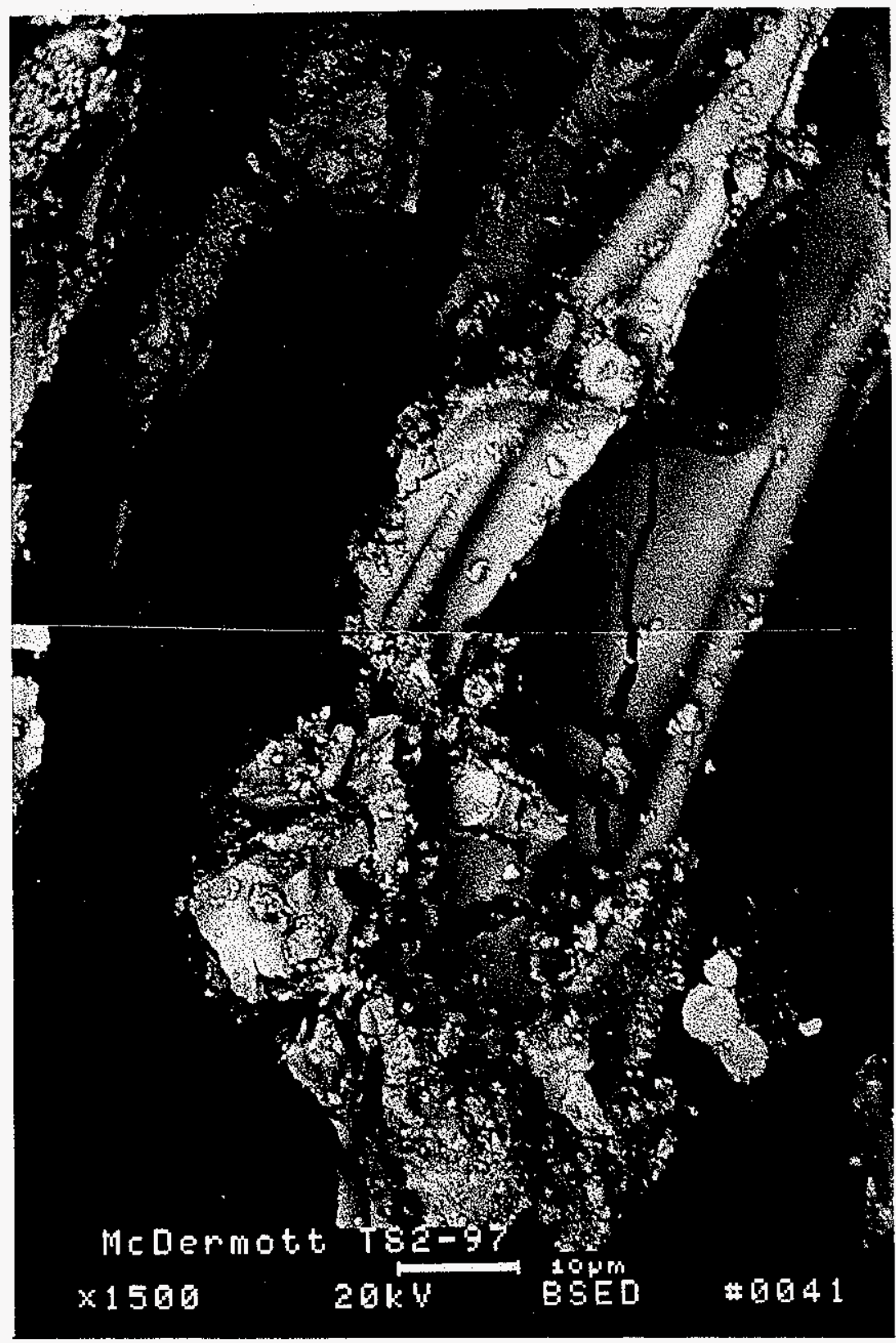

Figure 2-109 - Morphology of a fractured bonding matrix encapsulating shell that surrounded several chopped fibers in the cross-sectioned, PCFBC-exposed, McDermott CFCC candle filter. 
In comparison to the o.d. surface of the filter element, limited bonding matrix was evident along the chopped fibers that were present along i.d. surface of the PCFBC-exposed McDermott filter element (Figure 2-110). This was expected to have resulted from the manufacturing process used to fabricate the filter elements. Similar, however, to the o.d. surface of the PCFBC-exposed McDermott filter element, filament fiber bundles along the i.d. surface were either embedded below the chopped fiber mat, exposed and separated from the chopped mat, or were easily removed from the i.d. surface during sample preparation.

The microstructural analyses and performance characteristics during the initial 581 hours of PFCBC operation identified the potential viability and efficient surface particle removal capabilities of the oxide-based, filament wound McDermott CFCC filter element. Continued PCFBC exposure and additional microstructural analyses are, however, needed to address the potential issue of fiber crystallization and embrittlement within the McDermott CFCC filter matrix. Crystallization and/or embrittlement are expected to lead to a reduction in the fracture toughness of the McDermott CFCC matrix.

In addition, the issue of matrix pull-out particularly along the o.d. and i.d. surfaces of the McDermott CFCC filter element needs to be addressed during manufacturing, as well as monitored during continued field service operation of the elements. Indentation and separation of the chopped fiber layers along the top of the filter flange also need to be mitigated in order to provide and retain an adequate sealing surface during field service use of the McDermott CFCC filter elements.

\subsubsection{Blasch Mullite-Bonded Alumina}

\subsubsection{As-Manufactured Filter Matrix}

Blasch Precision Ceramics utilizes an injection molding technique to manufacture $1.5 \mathrm{~m}$, oxidebased, monolithic, candle filters. The wall thickness of the Blasch candle is $\sim 10 \mathrm{~mm}$ (Figure 2-111), and the filter element is typically fabricated without the inclusion of a finer porosity external membrane (Figure 2-112).

The as-manufactured, Blasch, oxide-based, monolithic filter matrix consists of alumina-enriched grains that are held together by striated, flat, plate-like, ligament features which contain a silica and an aluminosilicate or mullite phase. Directionality of the striated, flat, plate-like, mullite-containing ligaments was frequently observed within the cross-sectioned filter matrix, particularly near the center of the filter wall, as well as along the i.d. surface of the filter element (Figures 2-113 and 2-114).

In contrast to the relatively nondescript morphology of the outer surface of the as-manufactured, Blasch, oxide-based, monolithic filter matrix (Figure 2-115), flat, plate-like, striated features were observed to be present along the i.d. surface of the filter element (Figure 2-116). The striated bands formed bridging ligaments between grains, and channels within the pore cavities (Figure 2-117). Limited crystallization was evident along the o.d. surface grains of the as-manufactured Blasch filter matrix (Figure 2-118), through the fractured ligaments (Figure 2-119), as well as along the surface of the internal pore cavities (Figure 2-120). 


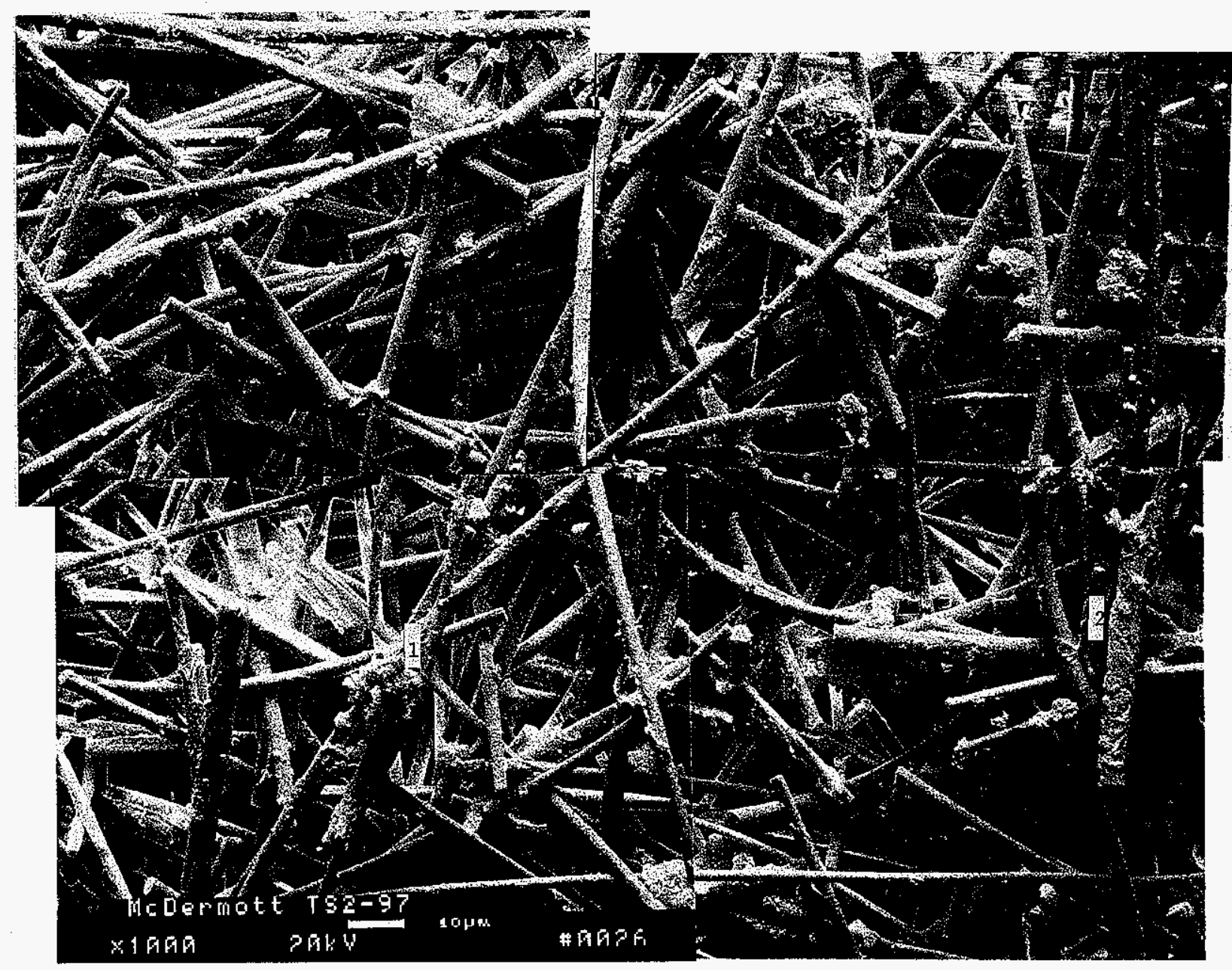

Figure 2-110 - Morphology of the chopped fibers that were present along the i.d. surface of the PCFBC-exposed McDermott candle filter. 


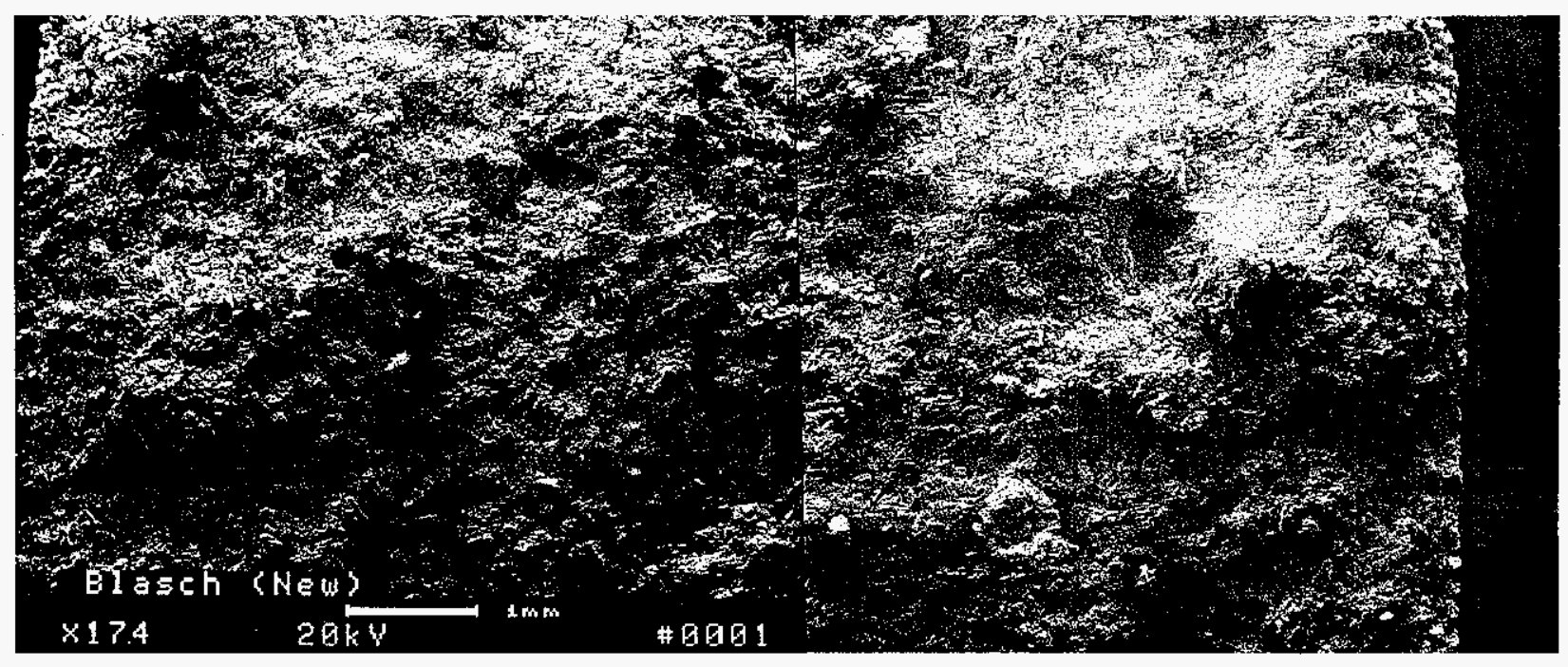

Figure 2-111 - Fresh fractured cross-sectioned surface of the as-manufactured monolithic oxidebased Blasch candle filter wall. 

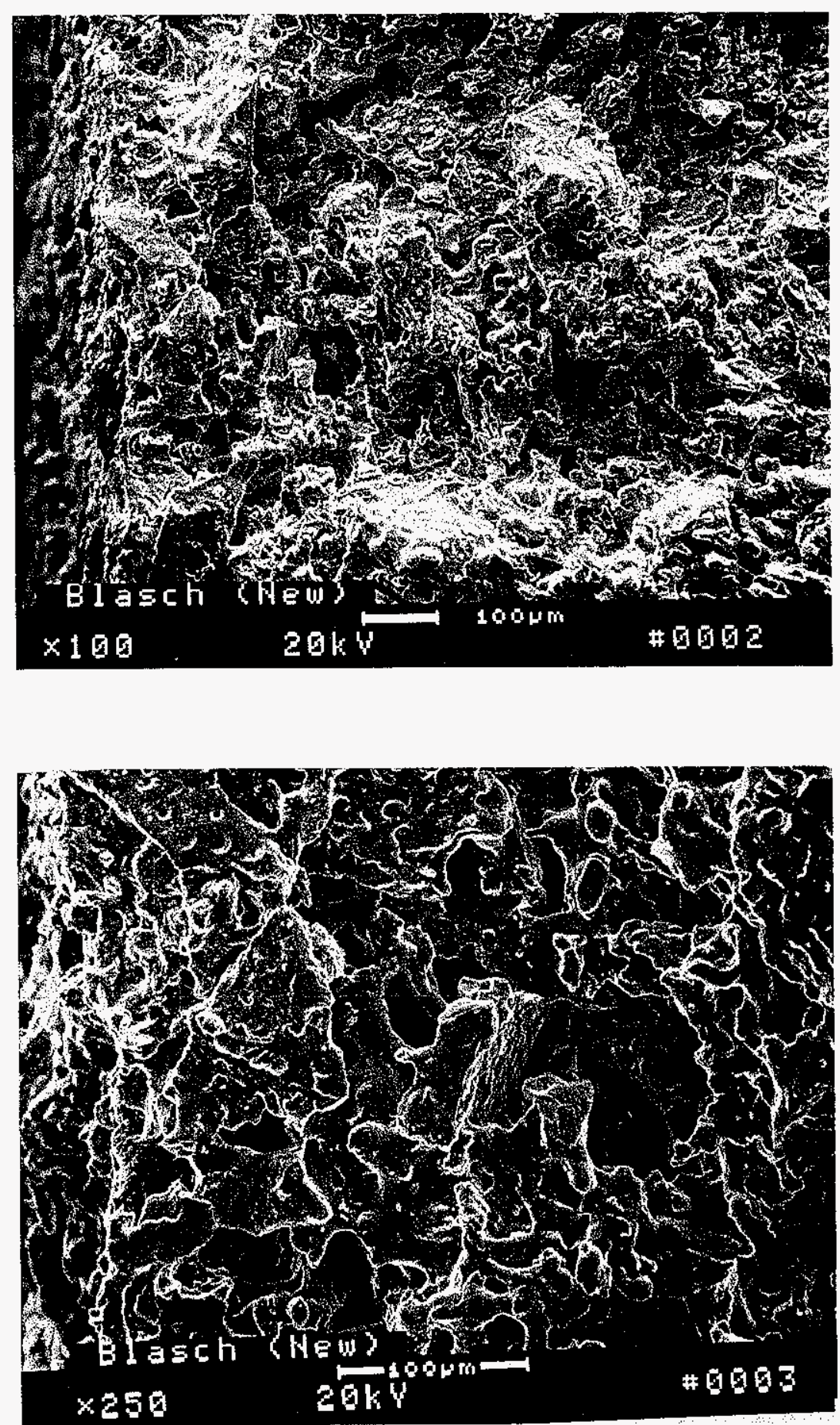

Figure 2-112 - Higher magnification micrographs illustrating the open porosity of the asmanufactured monolithic oxide-based Blasch candle filter matrix near the o.d. surface of the filter element. 

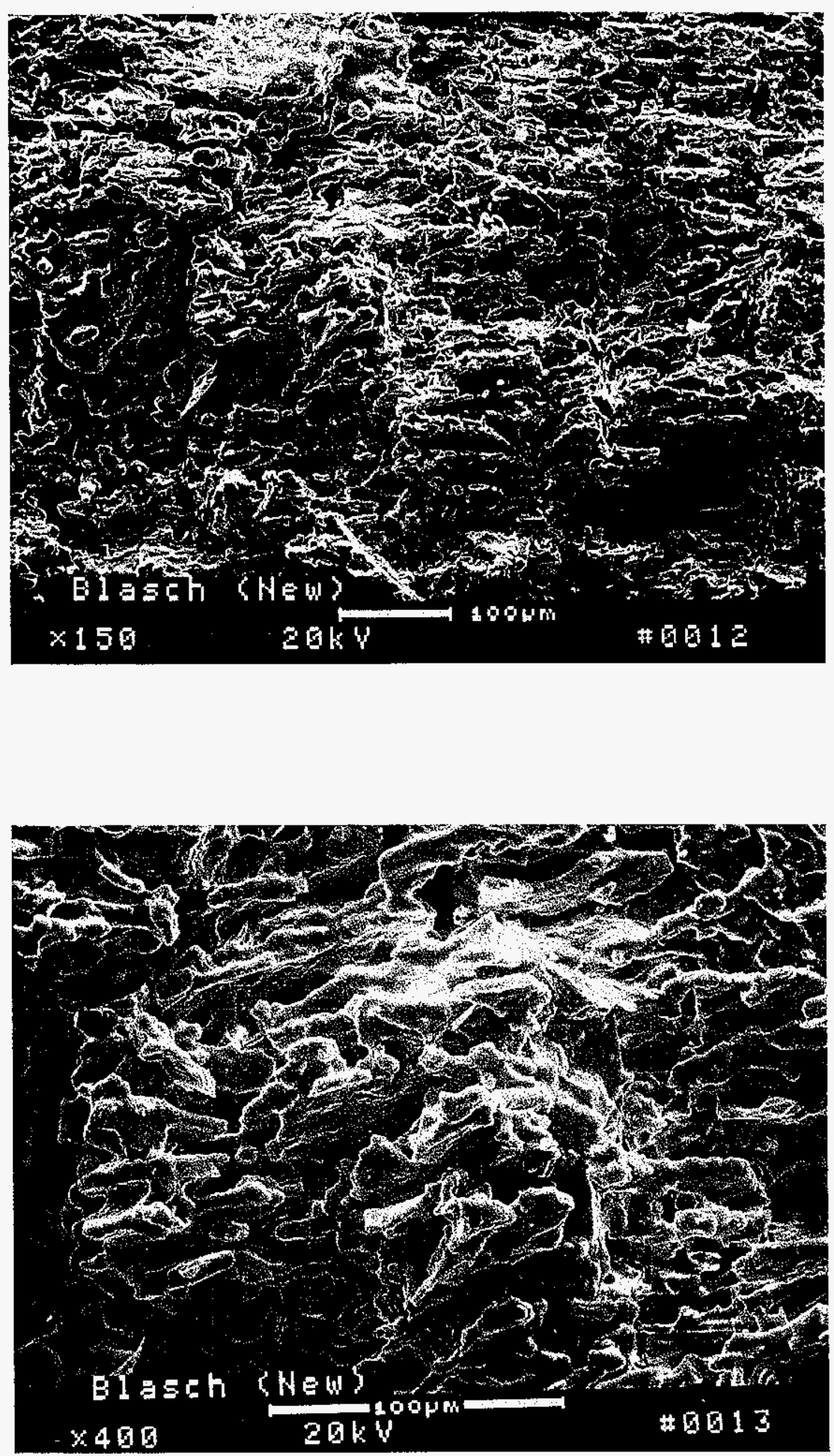

Figure 2-113 - Morphology of the as-manufactured monolithic oxide-based Blasch filter matrix near the center of the fresh fractured filter wall. 


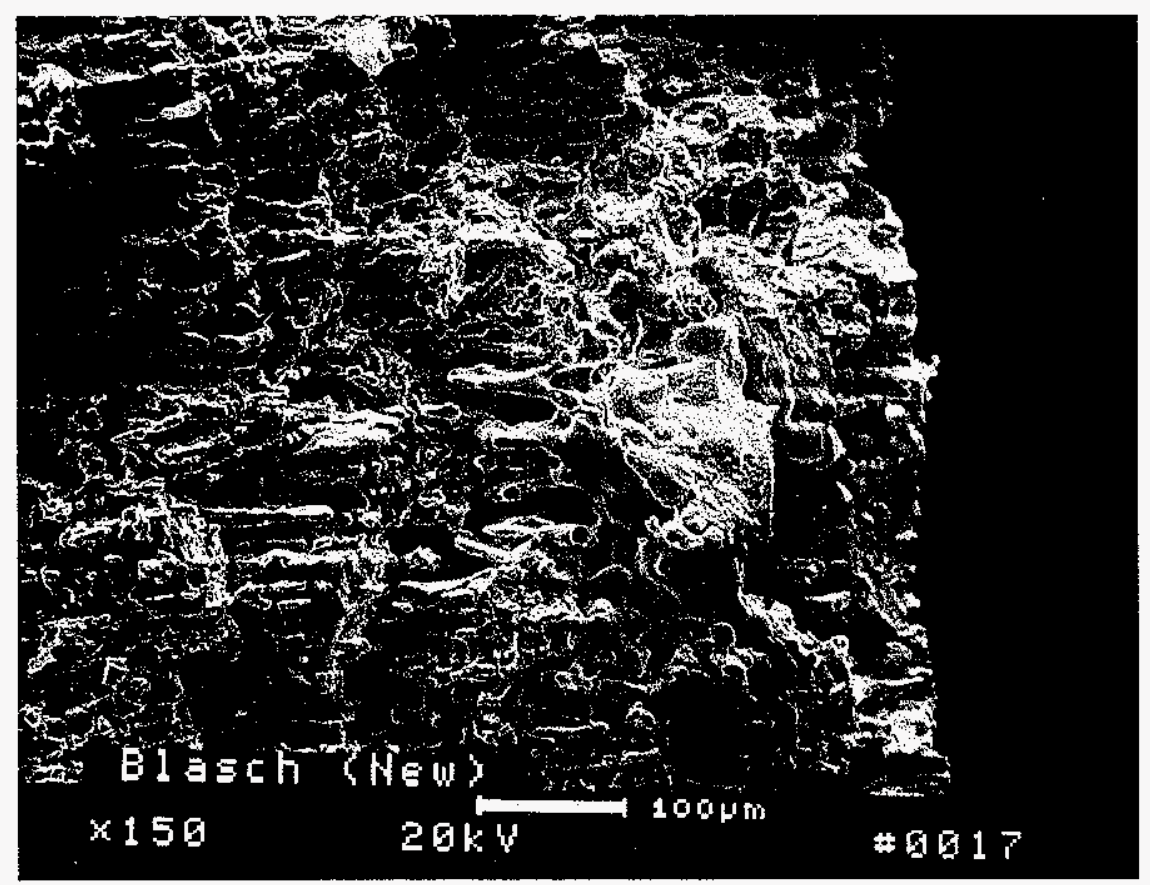

Figure 2-114 - Morphology of the fresh fractured Blasch oxide-based monolithic filter matrix near the i.d. surface of the filter element. 

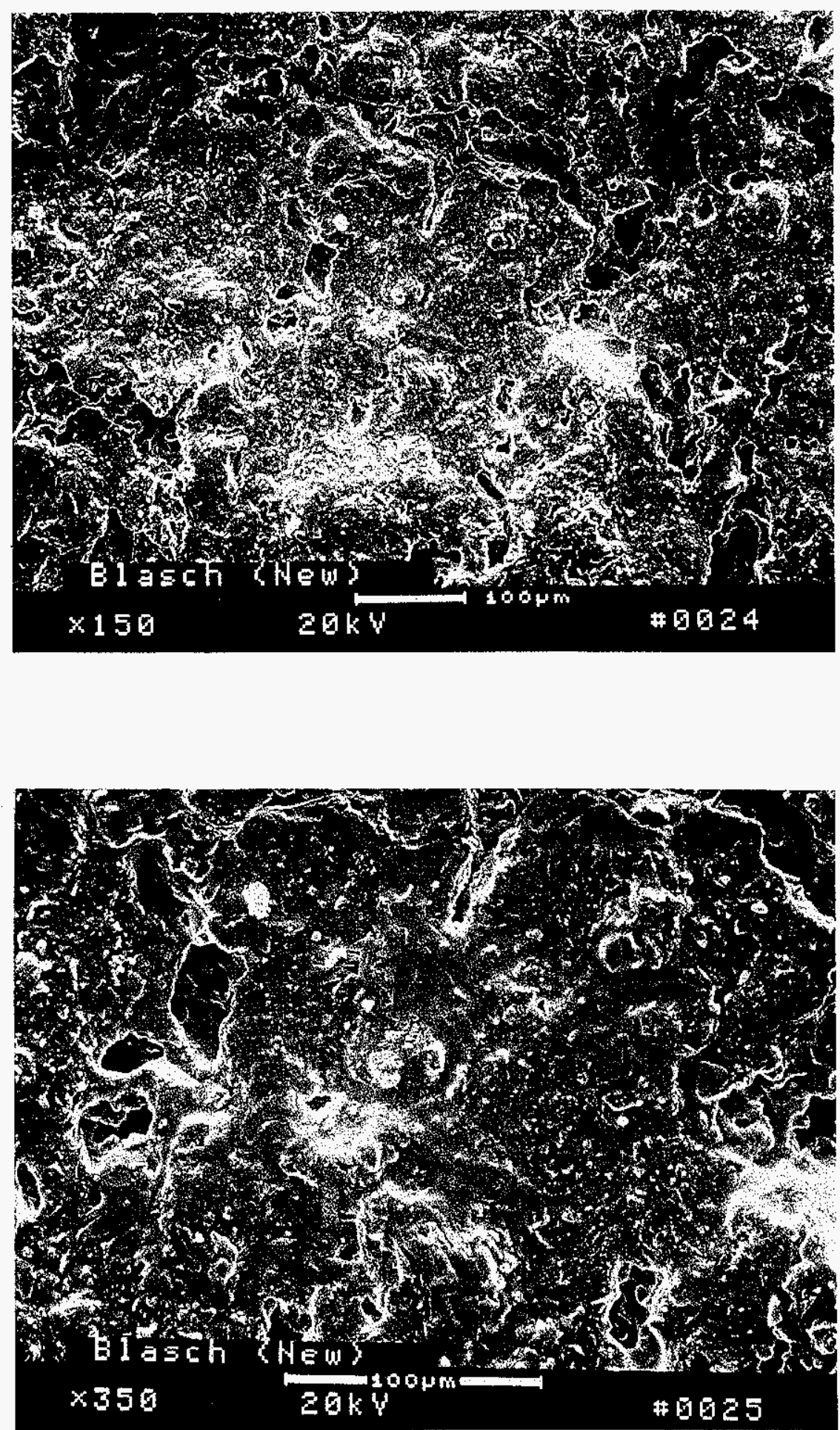

Figure 2-115 - Morphology of the outer surface of the as-manufactured monolithic oxide-based Blasch filter element. 

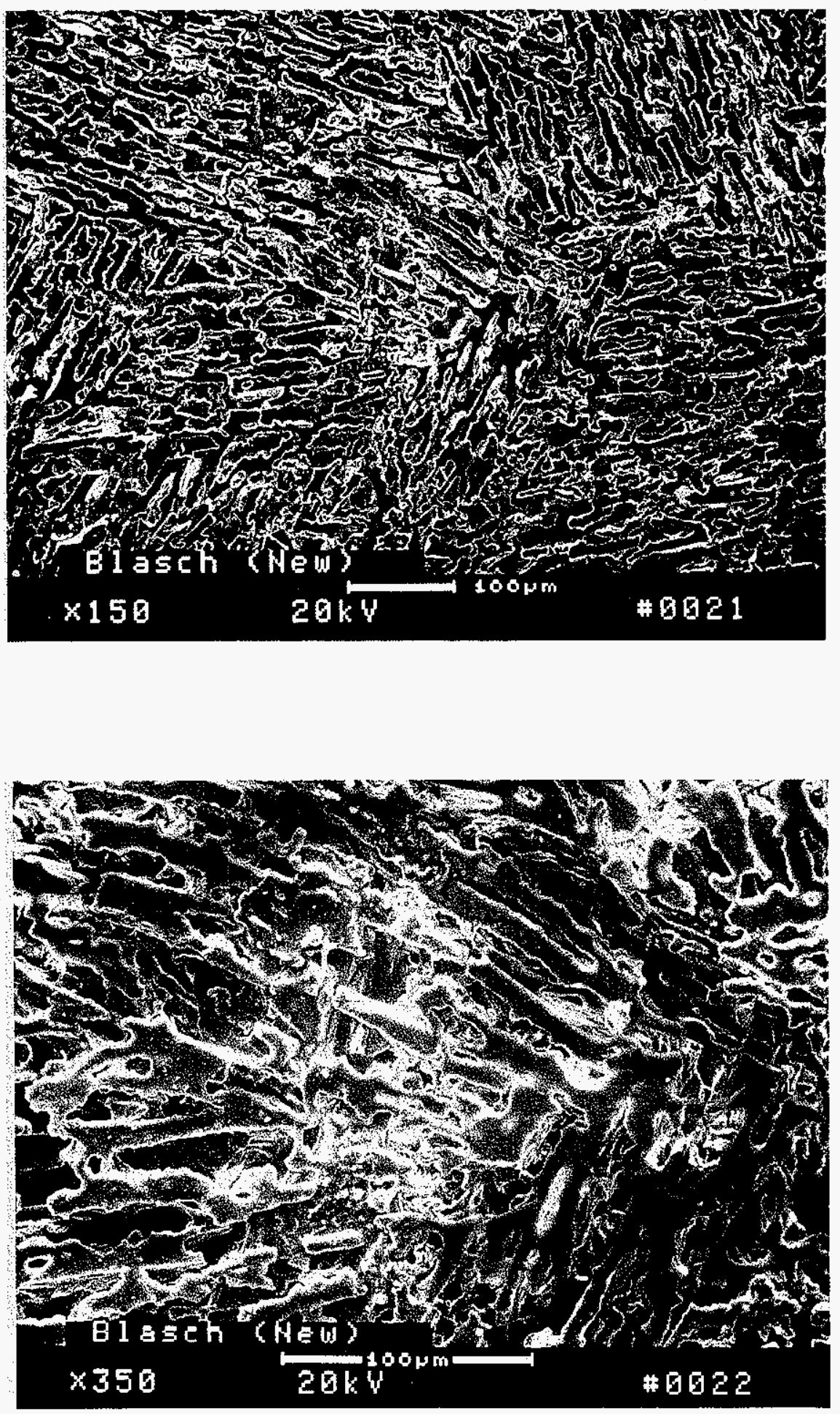

Figure 2-116 - Morphology of the as-manufactured monolithic oxide-based Blasch filter matrix along the i.d. surface of the filter element. 


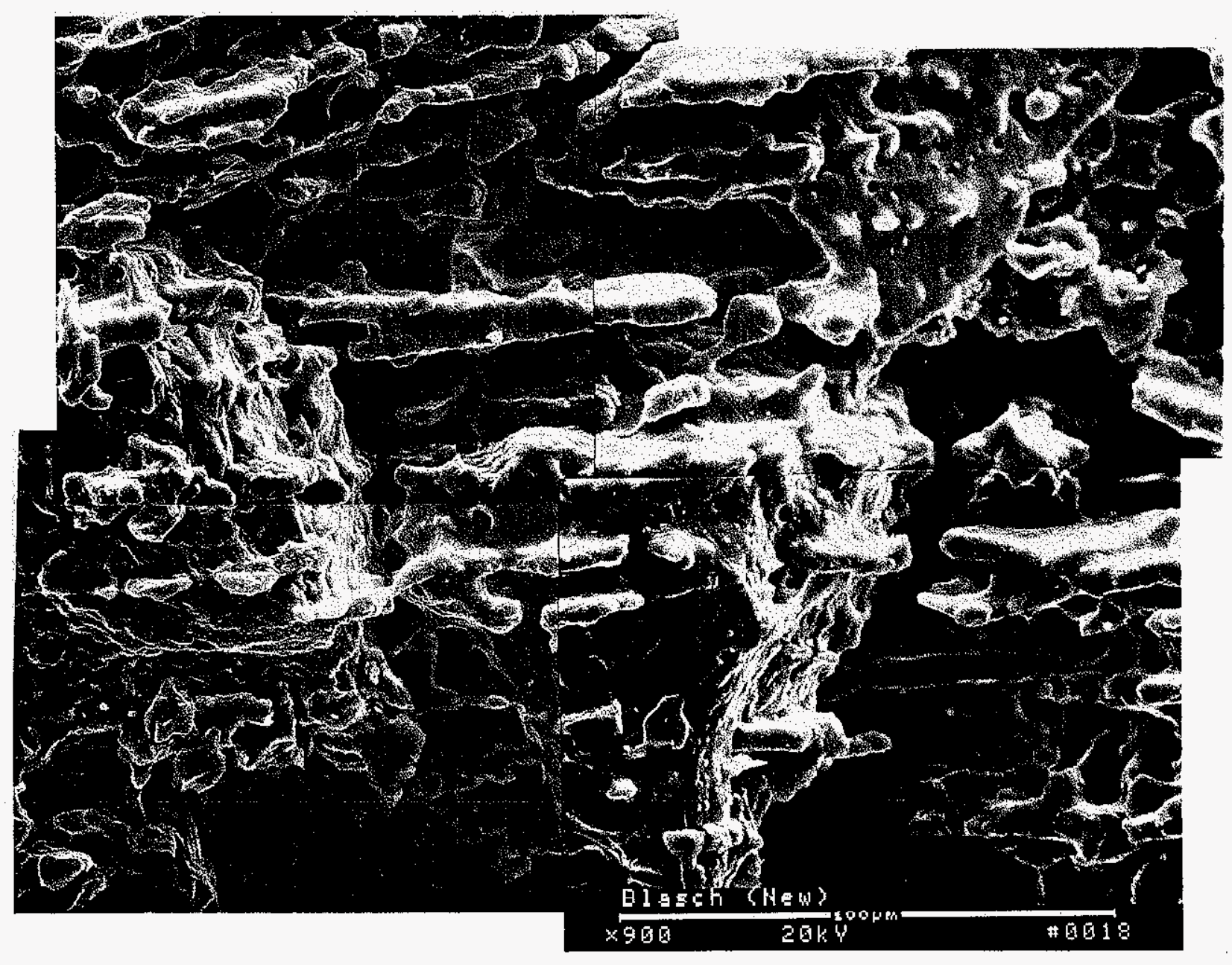

Figure 2-117 - Flat, plate-like, striated mullite bond posts or ligaments that resulted between adjacent alumina grains within the as-manufactured monolithic oxide-based Blasch filter matrix. 


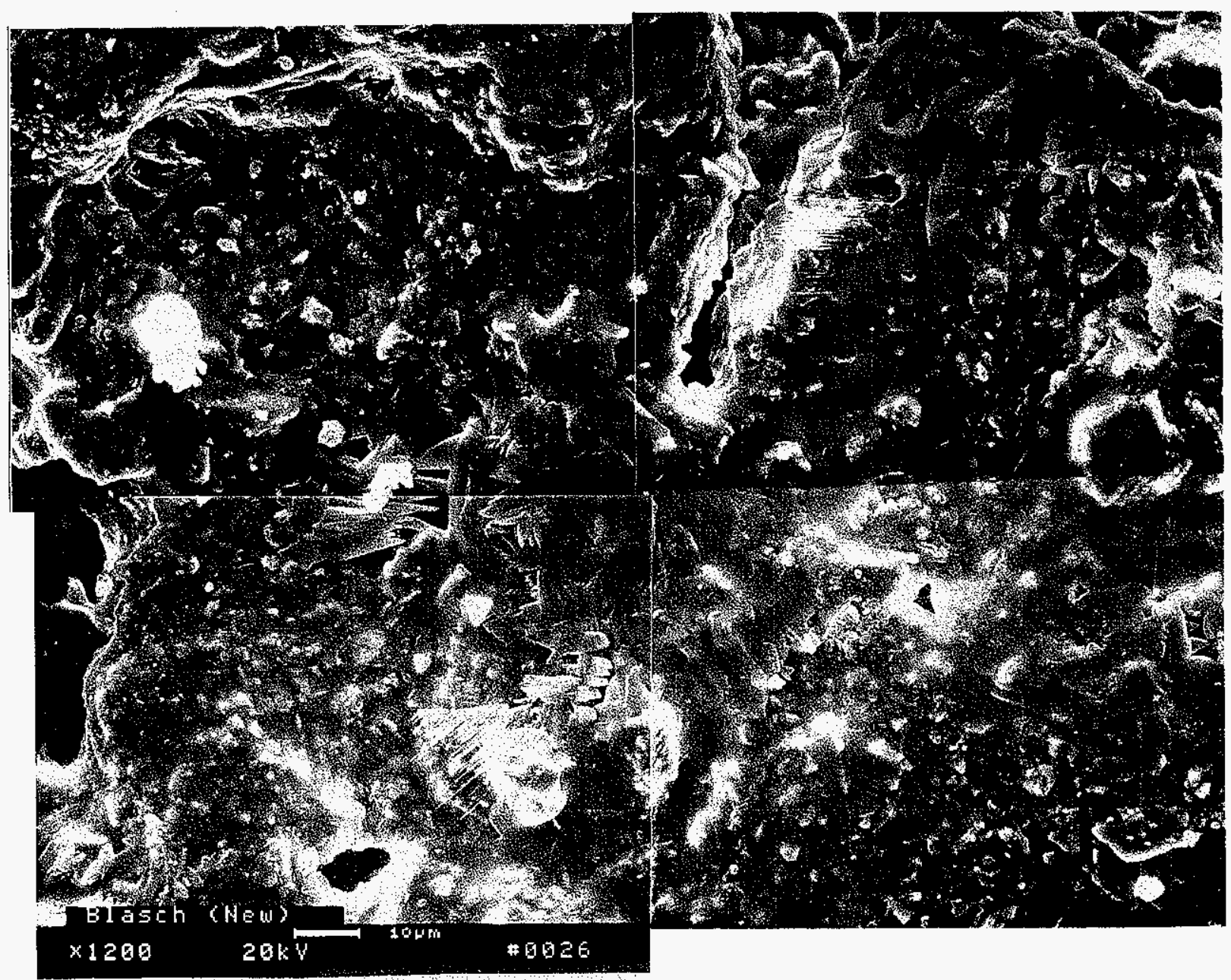

Figure 2-118 - High magnification micrograph montage illustrating the morphology of the asmanufactured monolithic oxide-based Blasch filter matrix along the o.d. surface of the filter element. 


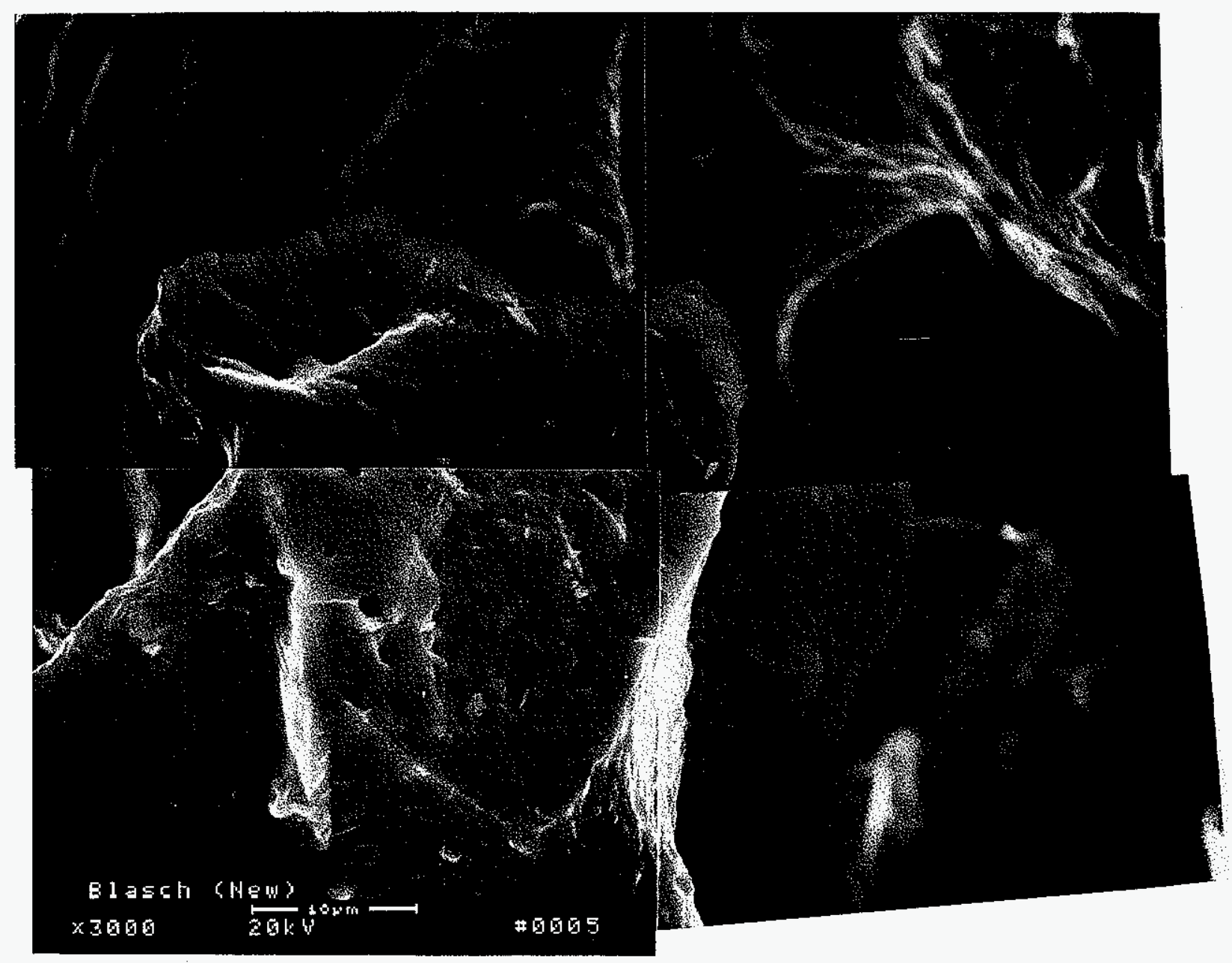

Figure 2-119 - Limited crystallization was evident throughout the ligaments within the asmanufactured monolithic oxide-based Blasch filter matrix. 


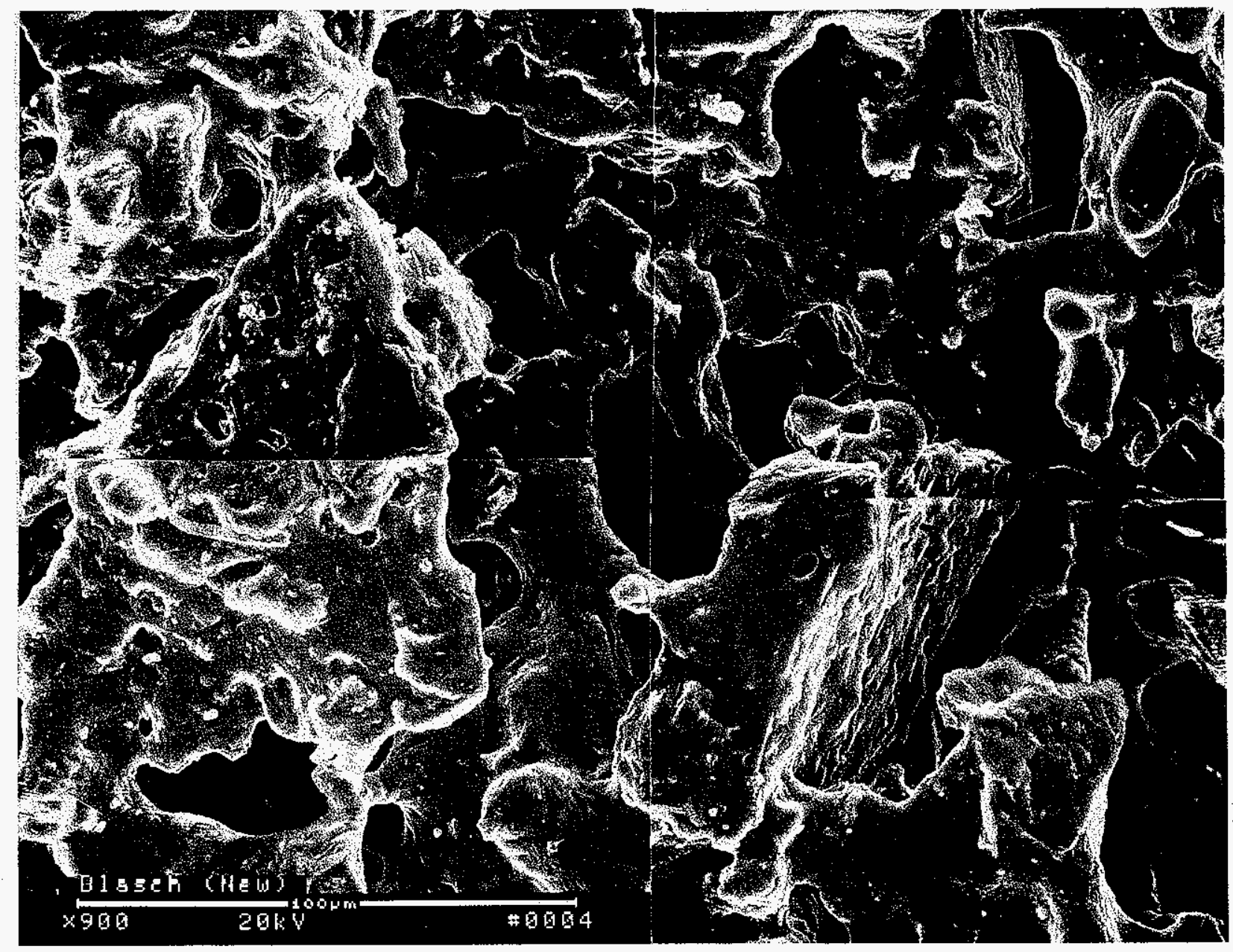

Figure 2-120 - Limited crystallization was evident along the surface of the mullite-enriched ligaments and alumina grains in the pore cavities of the as-manufactured monolithic oxide-based Blasch filter matrix. 


\subsubsection{PCFBC-Exposed Filter Matrix}

Initially four and subsequently six, $1.5 \mathrm{~m}$ Blasch oxide-based candle filters were installed in the bottom array of the W-APF filter at the Foster PCFBC test facility in Karhula, Finland in the fall of 1997 (TS2-97). The elements were operated for a period of 342 to 581 hours at temperatures of $750^{\circ} \mathrm{C}$. Posttest characterization was conducted on candle filter BP-4-270N7/97 (B40) which had been operated for 581 hours at Karhula. Characterization included SEM/EDAX analysis to determine the resulting microstructure and composition of the PCFBC-exposed Blasch filter matrix.

Although the Blasch oxide-based monolithic filter matrix is not fabricated with an external o.d. surface membrane, penetration of ash fines into the filter matrix was neither observed along the o.d. surface, nor along the pulse cycled or i.d. surface of the PCFBC-exposed filter element (Figure 2-121 and 2-122). Ash fines were, however, identified along the i.d. surface of the PCFBC-exposed Blasch candle filter (Figures 2-123 and 2-124). The presence of the i.d. surface fines was considered to have resulted primarily from back pulsing of particulates into the bore of the Blasch filters after failure of an alternate candle(s) had occurred within the filter array during process operation.

Throughout the PCFBC-exposed Blasch filter matrix, alumina-enriched grains were identified ranging in size from $\sim 100-150 \mu \mathrm{m}$ to $\sim 300-400 \mu \mathrm{m}$, serving as structural support grains in the oxidebased, monolithic filter matrix. Striated aluminosilicate or mullite-enriched ligaments or bond posts formed the network which held the structural support grains together within the Blasch oxide-based monolithic filter matrix. Along the surface of the fresh fractured, PCFBC-exposed, Blasch filter matrix, directionality of the ligaments or bond posts was observed, particularly along the center and i.d. surface of the filter element (Figures 2-125 and 2-126).

Extensive crystallization resulted along the o.d. surface grains of the PCFBC-exposed Blasch filter matrix (Figures 2-127 and 2-128). The cubic crystalline formations were identified to be enriched with oxygen and aluminum, with secondary contributions of silicon, while rod-like formations of mullite were also observed (Figure 2-129). Similarly after 581 hours of operation in the PCFBC environment, the outer surface of the alumina-enriched grains, as well as ligaments or bond posts were coated with a crystalline aluminosilicate or rod-like mullite phase (Figures 2-130, 2-131, and 2-132).

Extensive crystallization of the aluminosilicate or mullite-enriched surface phase was evident along the surface of the pore cavity walls throughout the entire PCFBC-exposed, Blasch, oxide-based, monolithic filter matrix (Figures 2-133 and 2-134). The concentration of silicon tended to be enriched along the surface of the pore cavity walls where the formation of crystalline aluminosilicate or mullite rods was limited. Crystallization of the aluminosilicate or mullite-enriched phase was also observed throughout the fractured ligaments (Figures 2-135 and 2-136).

\subsubsection{Ensto Mullite-Bonded Alumina}

In the as-manufactured Ensto filter matrix, $\sim 20-60 \mu \mathrm{m}$, irregularly shaped, alumina-enriched grains were used to form the porous outer surface membrane (Figures 2-137 and 2-138). The thickness of the outer surface membrane was determined to be $\sim 100 \mu \mathrm{m}$. Directly below the porous outer surface membrane was an $\sim 10 \mathrm{~mm}$ thick structural support layer which contained $\sim 400-600 \mu \mathrm{m}$ alumina-enriched grains. 


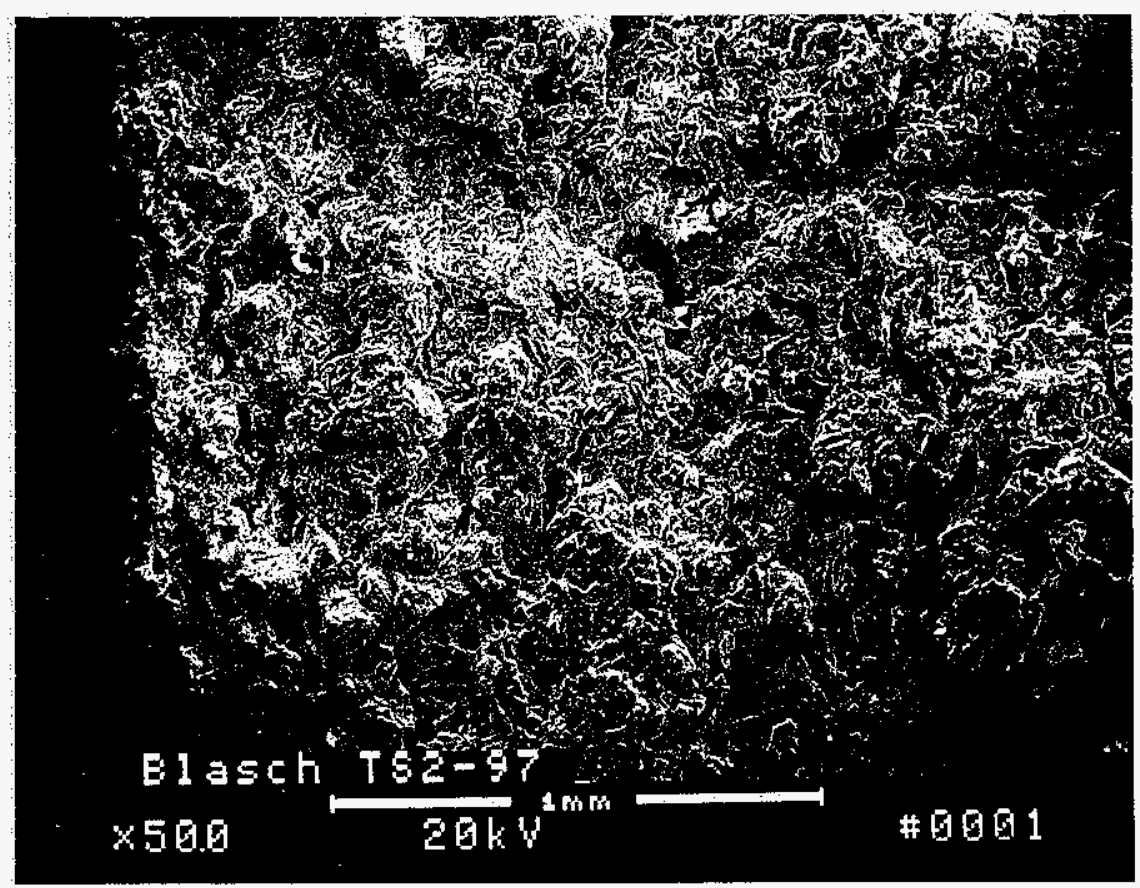

Figure 2-121 - Micrograph illustrating the morphology of the cross-sectioned Blasch filter matrix near the o.d. surface of the candle filter. 


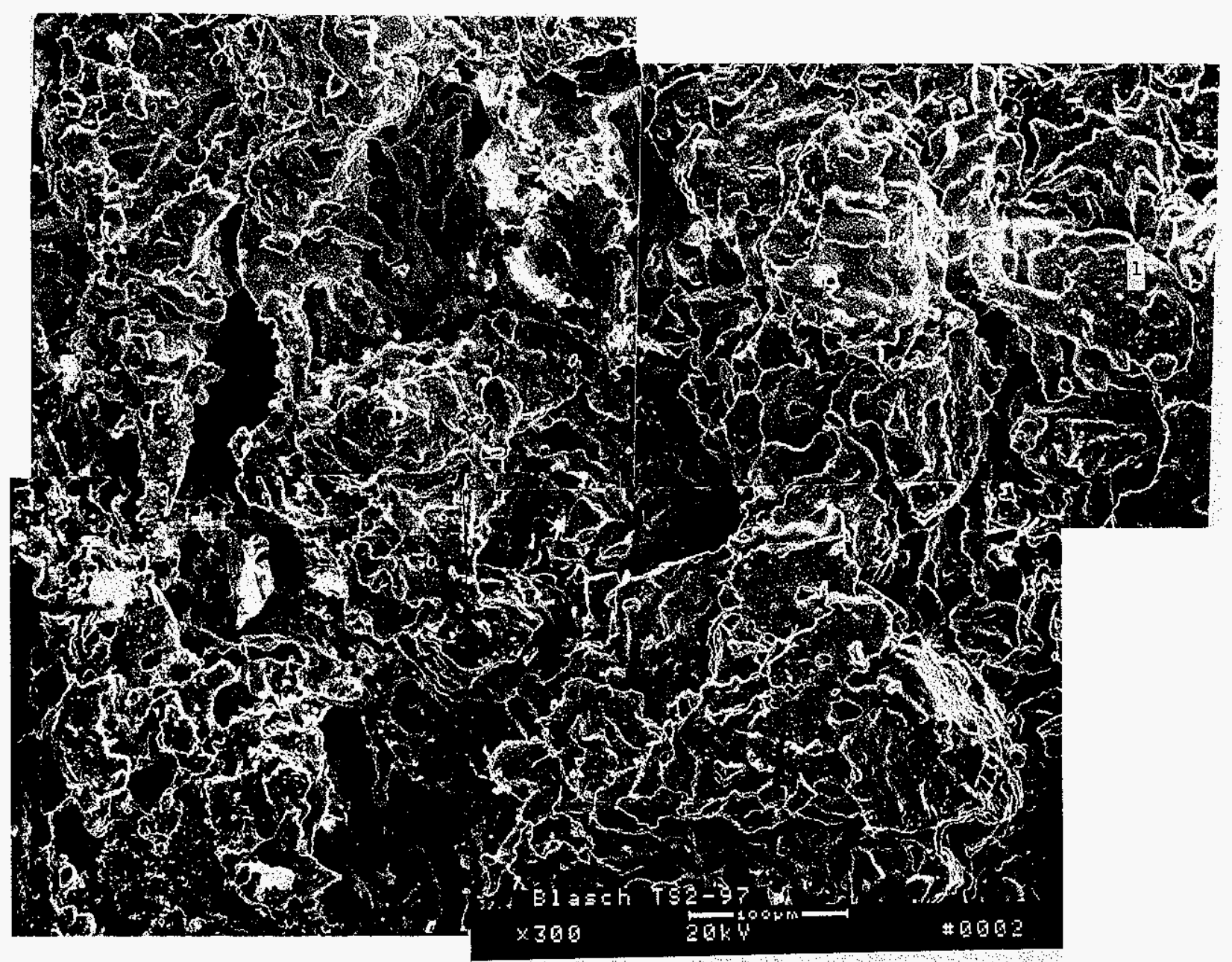

Figure 2-122 - Higher magnification micrograph montage illustrating the open porosity throughout the PCFBC-exposed Blasch candle filter. 

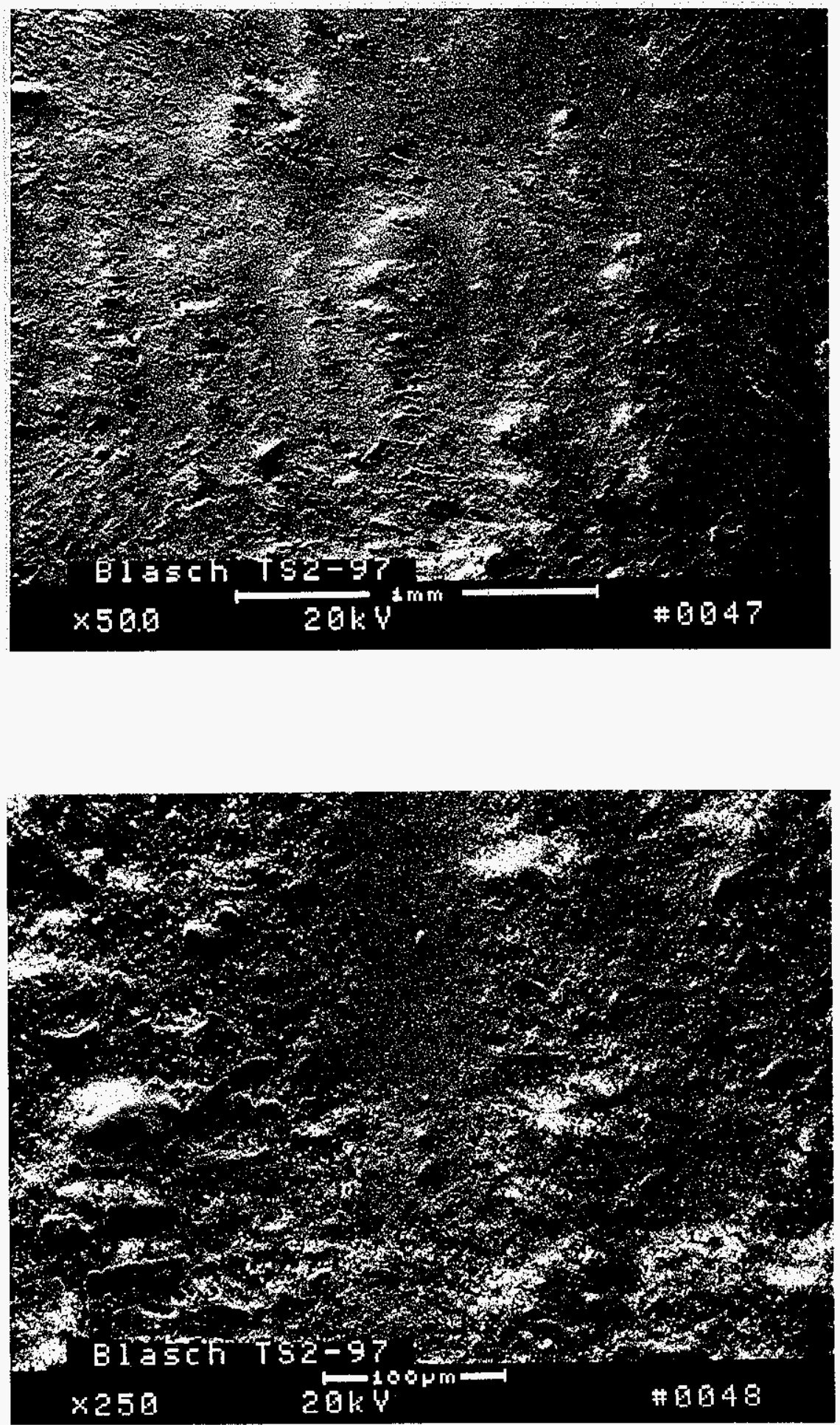

Figure 2-123 - Pulse cycled surface of the PCFBC-exposed Blasch candle filter. 


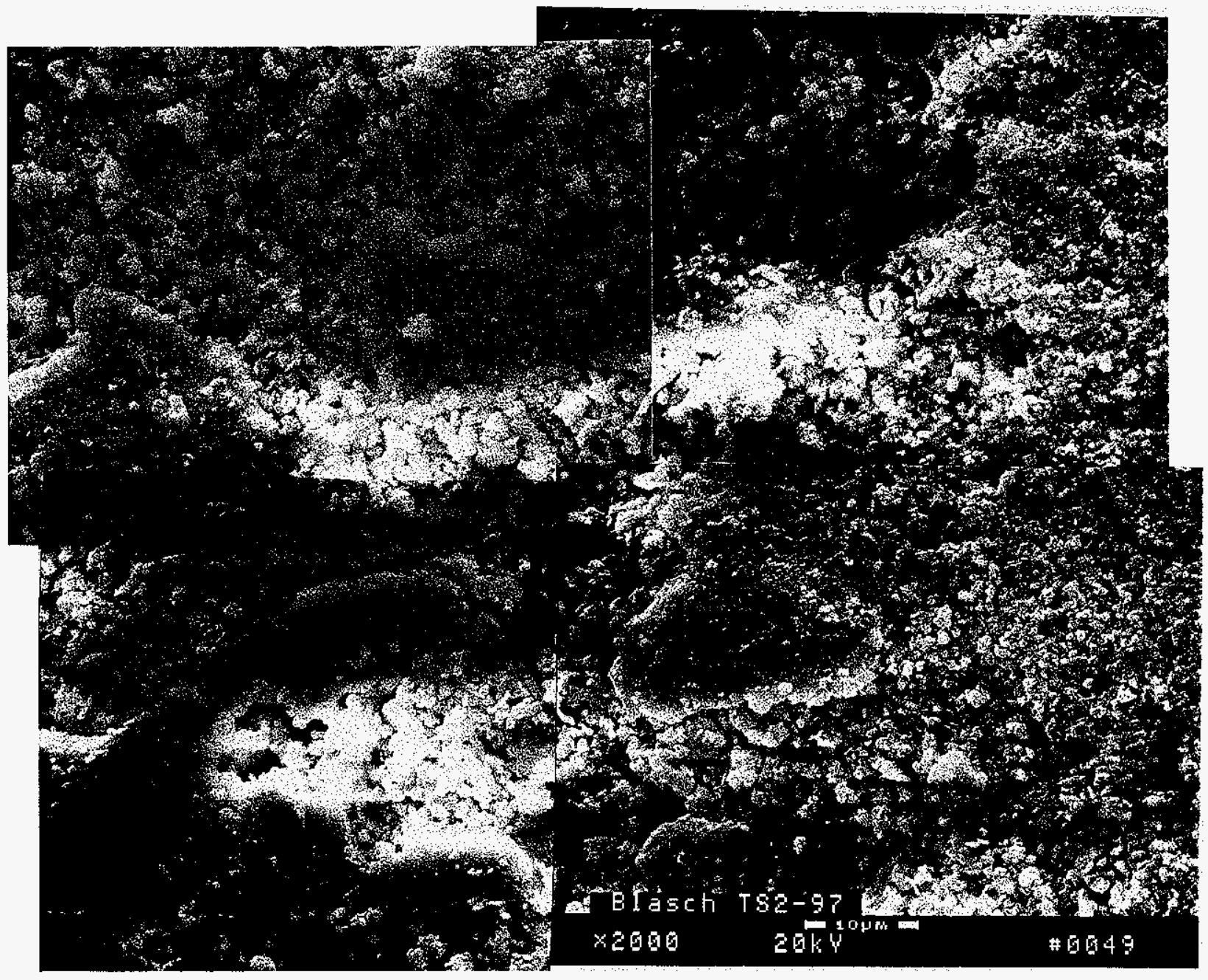

Figure 2-124 - Higher magnification micrograph montage illustrating retention of ash fines along the i.d. or pulse cycled surface of the PCFBC-exposed Blasch oxide-based candle filter. 


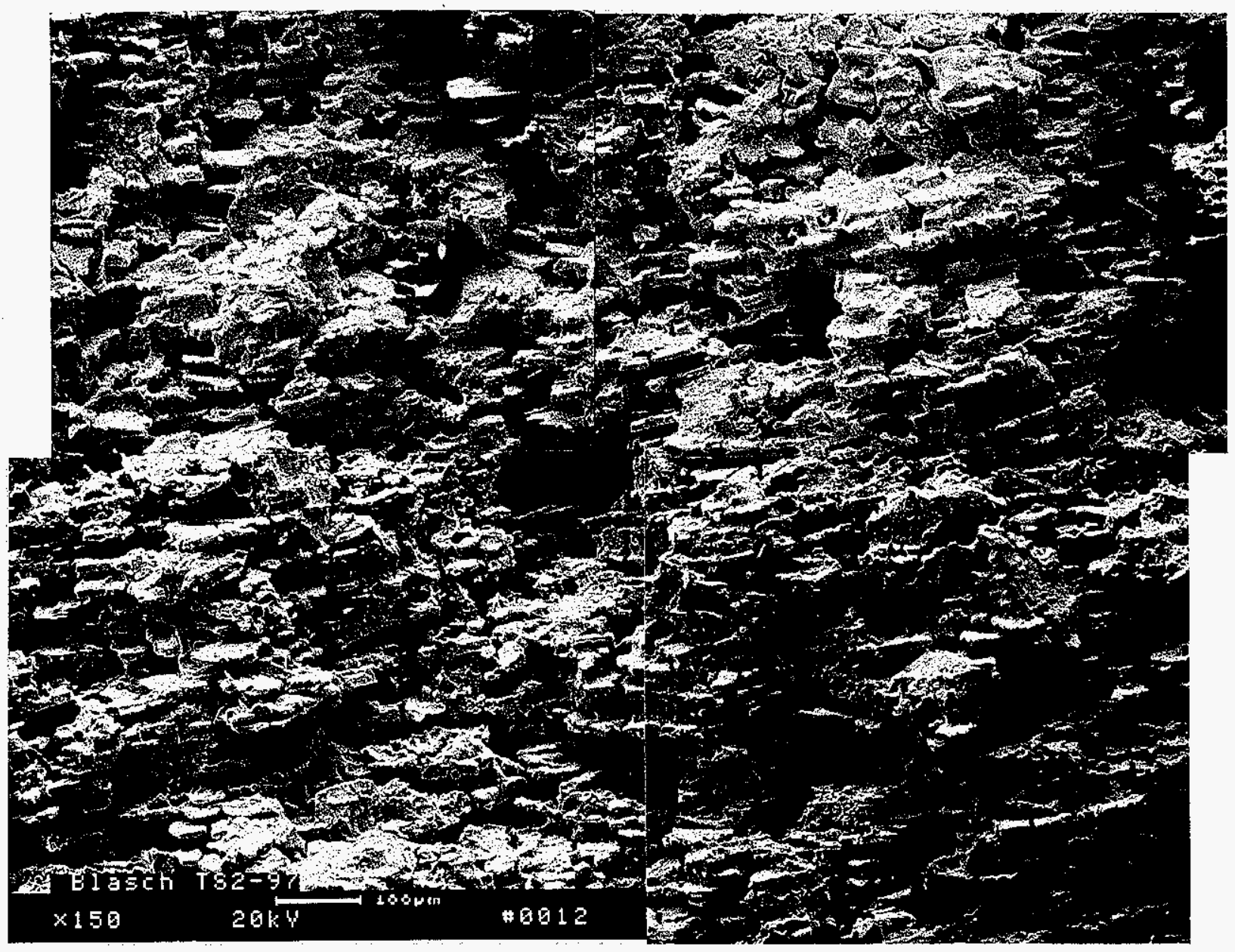

Figure 2-125 - Micrograph montage illustrating directionality of the ligaments or bond posts within the PCFBC-exposed Blasch filter matrix near the center of the fresh fractured filter wall. 


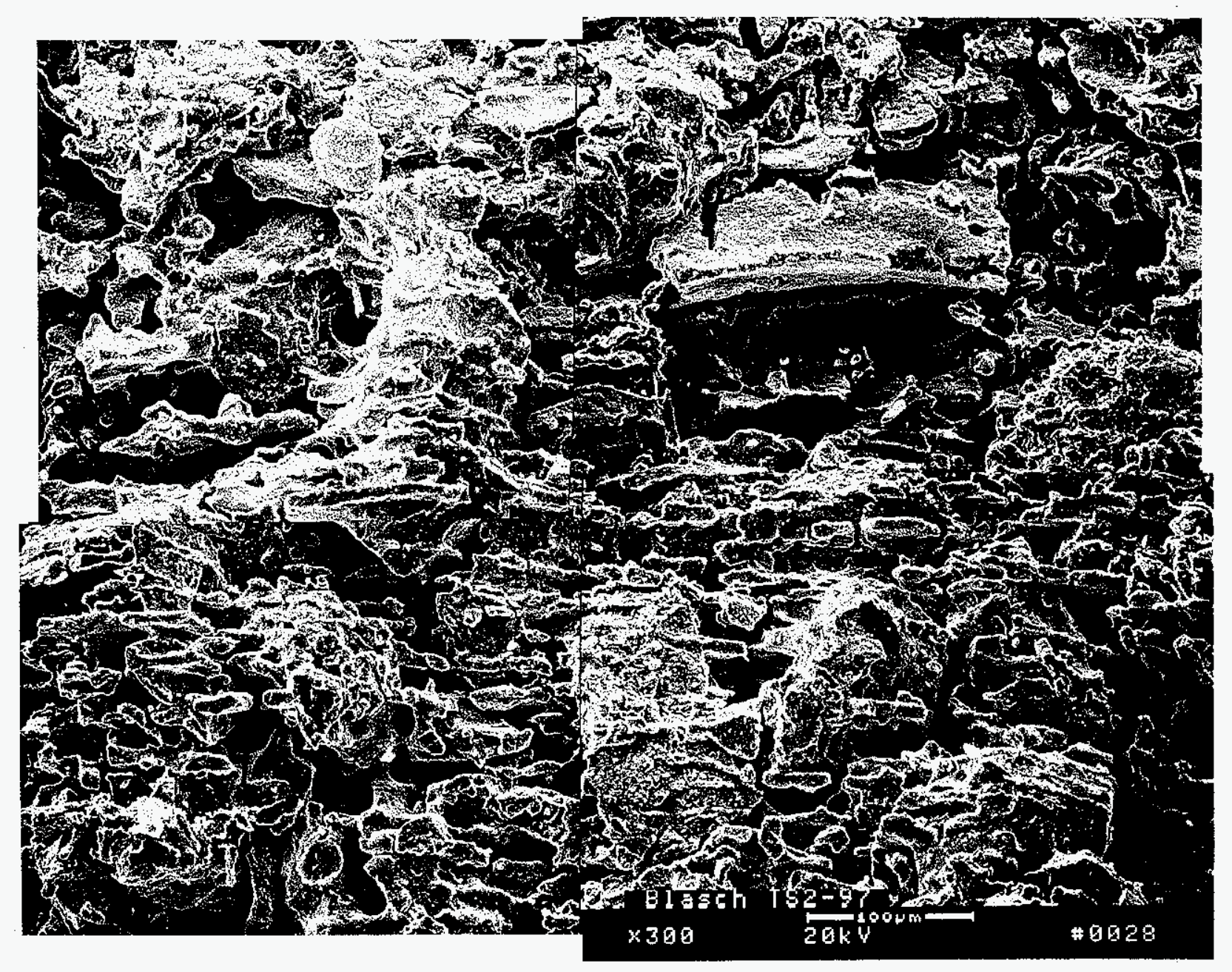

Figure 2-126 - Micrograph montage illustrating directionality of the ligaments or bond posts within the PCFBC-exposed Blasch filter matrix near the i.d. or pulse cycled surface of the filter element. 


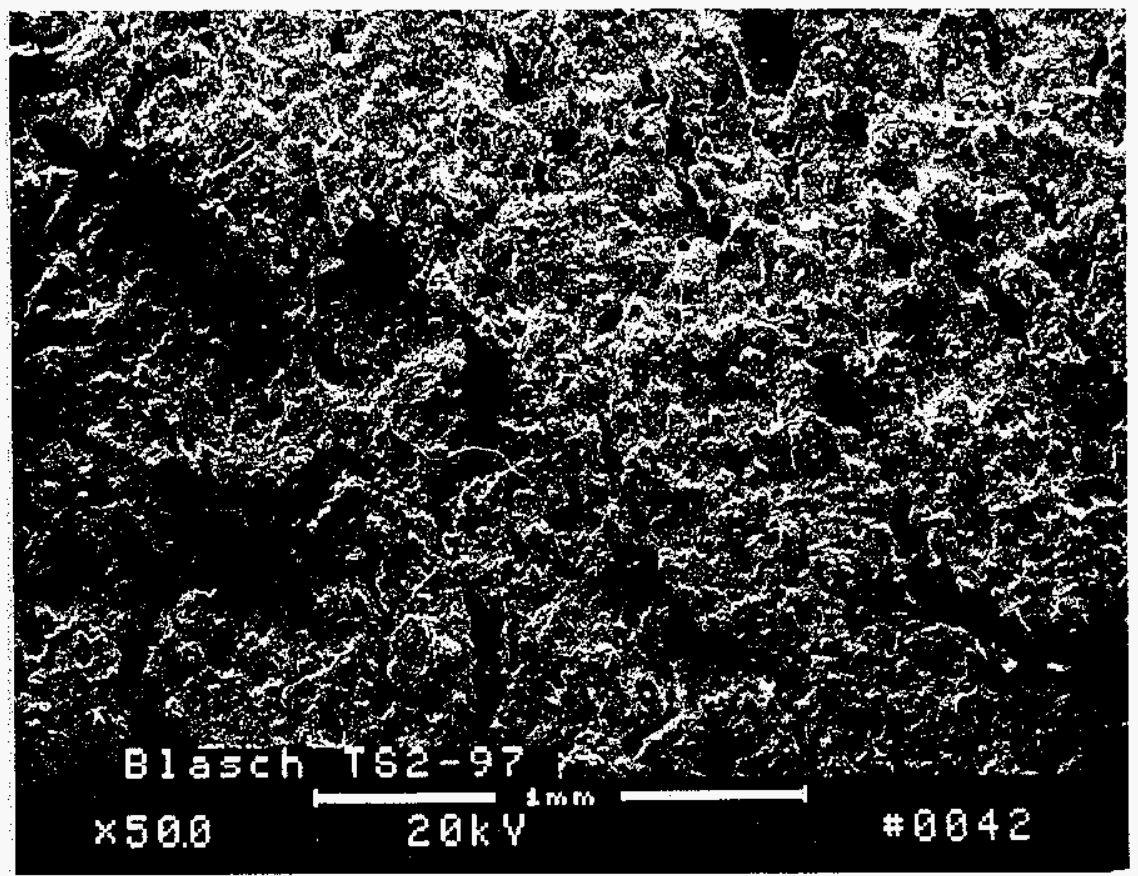

Figure 2-127 - Morphology of the o.d. surface of the PCFBC-exposed Blasch filter element. 


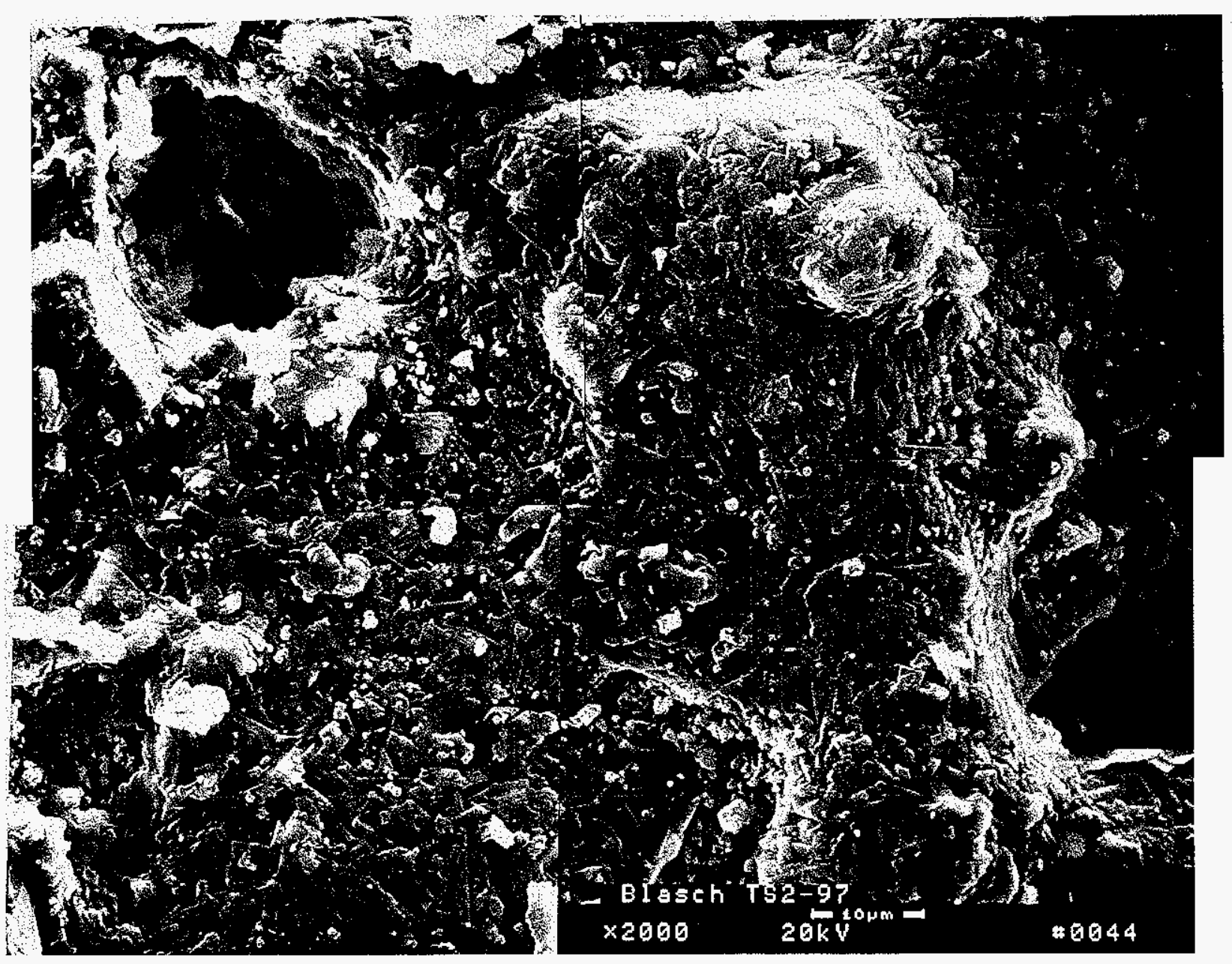

Figure 2-128 - Extensive crystallization resulted along the o.d. surface grains of the PCFBCexposed Blasch filter element. 

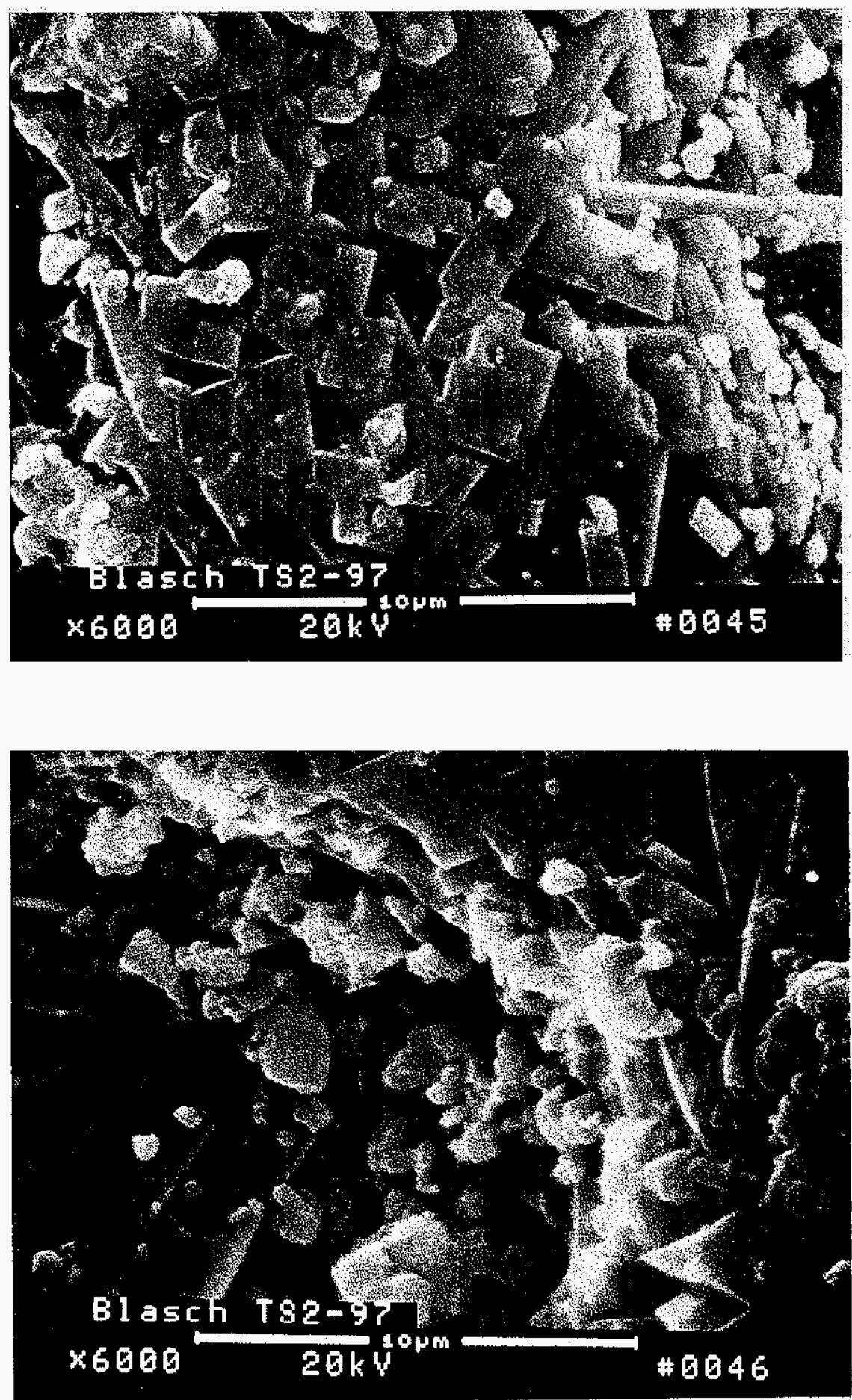

Figure 2-129 - Morphology of the crystalline formations that resulted along the o.d. surface grains of the PCFBC-exposed Blasch filter element. 


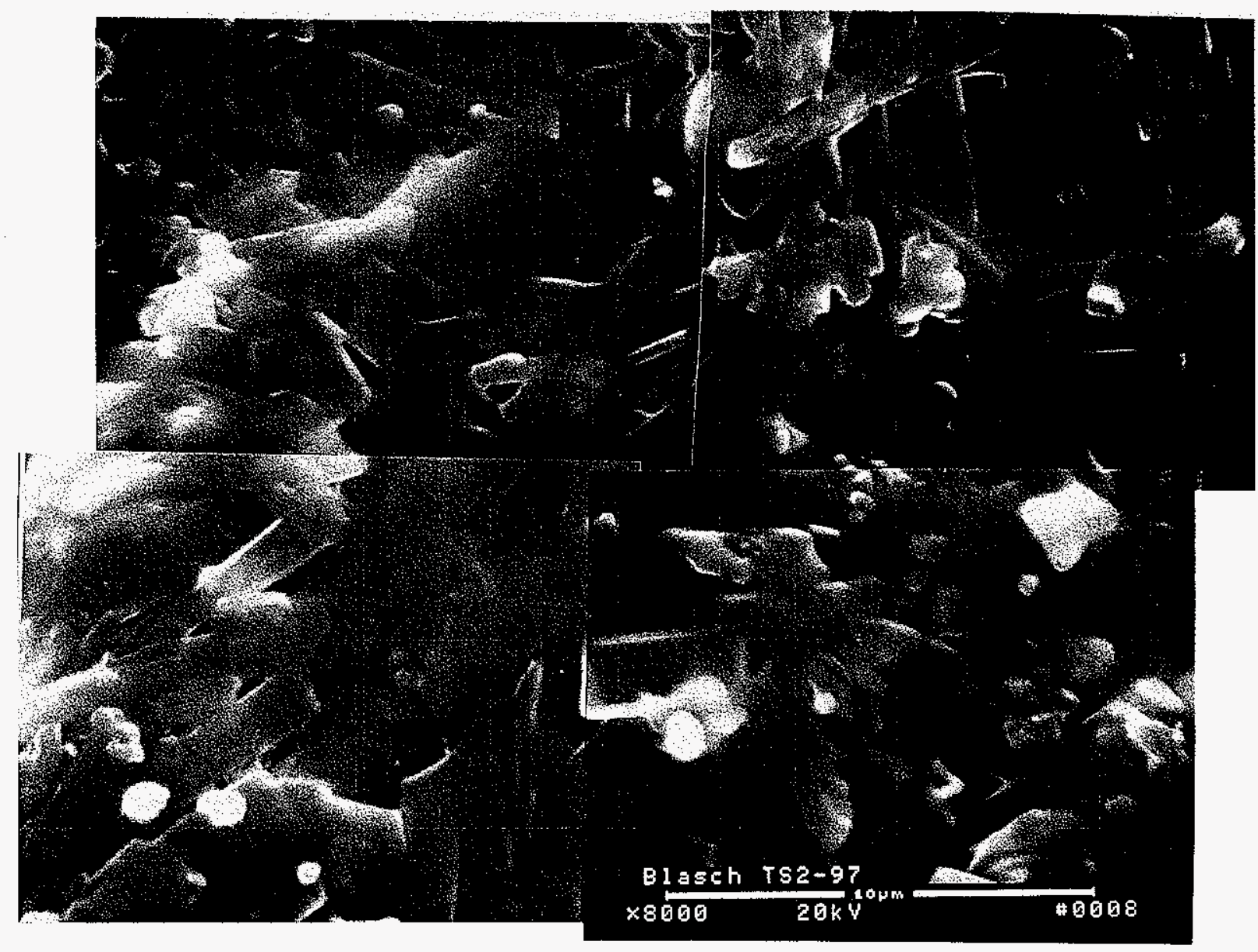

Figure 2-130 - High magnification micrograph montage illustrating extensive crystallization that resulted along the surface of the pore cavities near the o.d. surface of the PCFBCexposed Blasch filter matrix. 


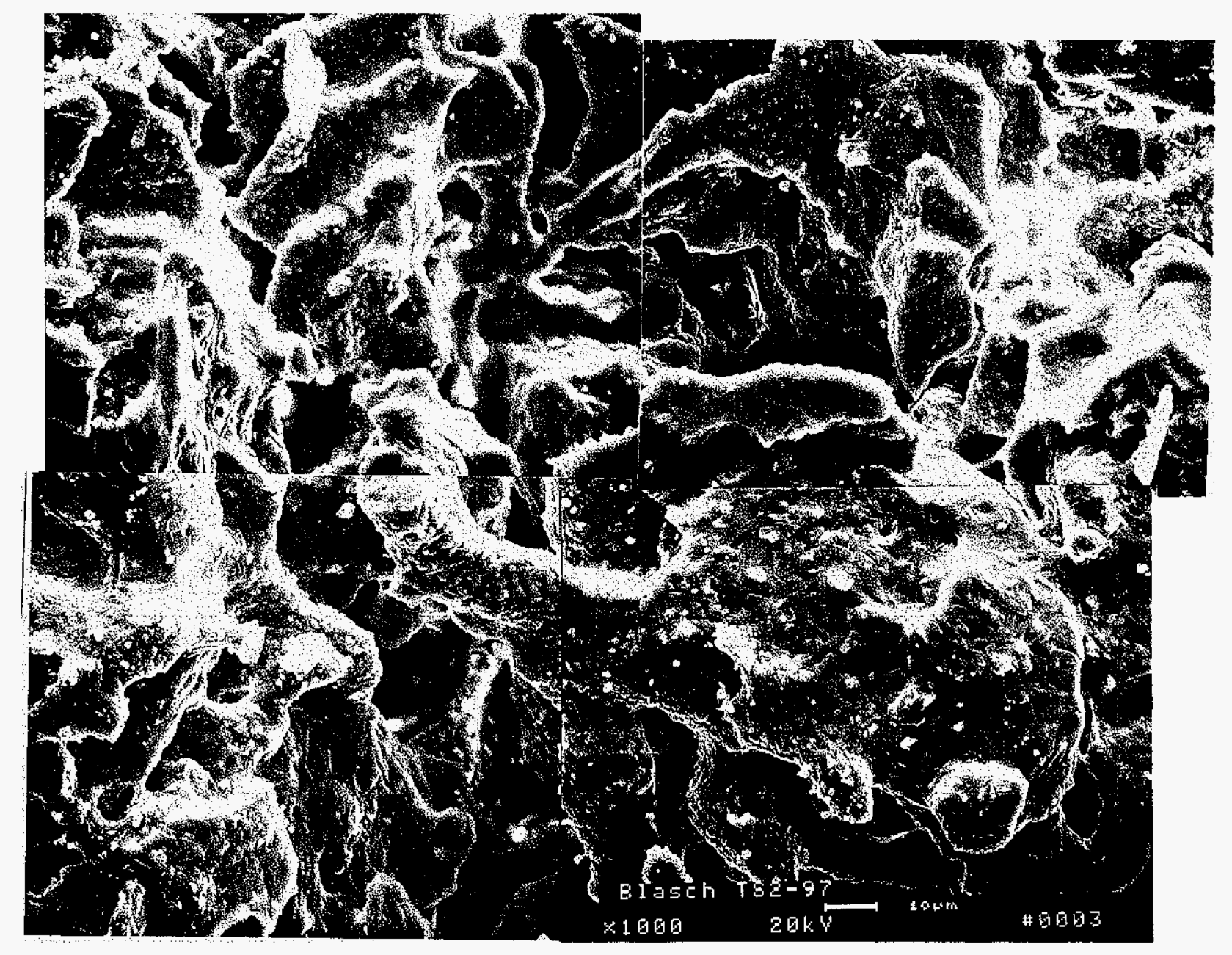

Figure 2-131 - Micrograph montage illustrating the extensive crystallization that resulted throughout the PCFBC-exposed Blasch filter matrix. 


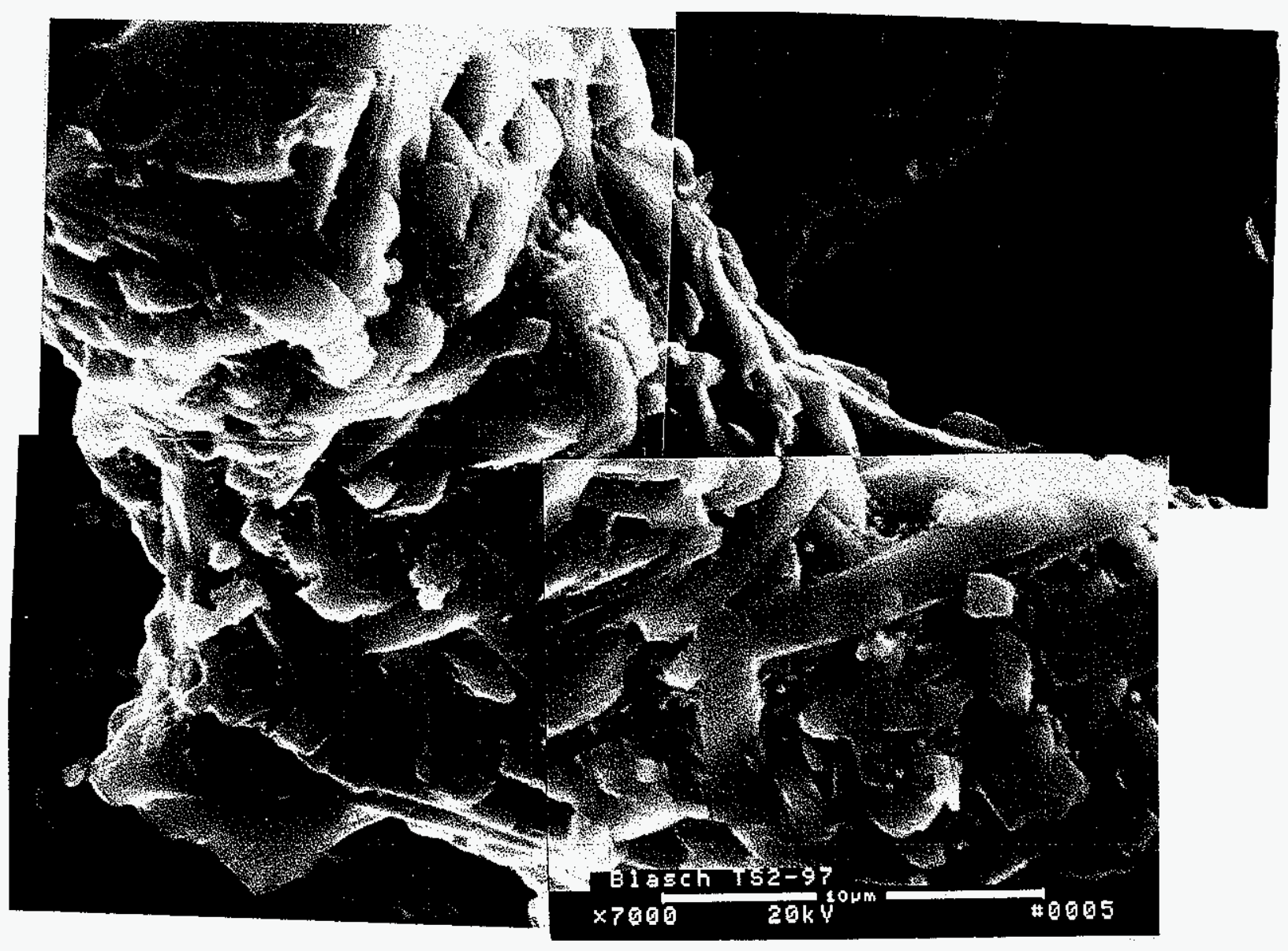

Figure 2-132 - Higher magnification micrograph montage illustrating the extensive crystallization that resulted along the surface of the bond posts or ligaments in the PCFBC-exposed Blasch filter matrix. 


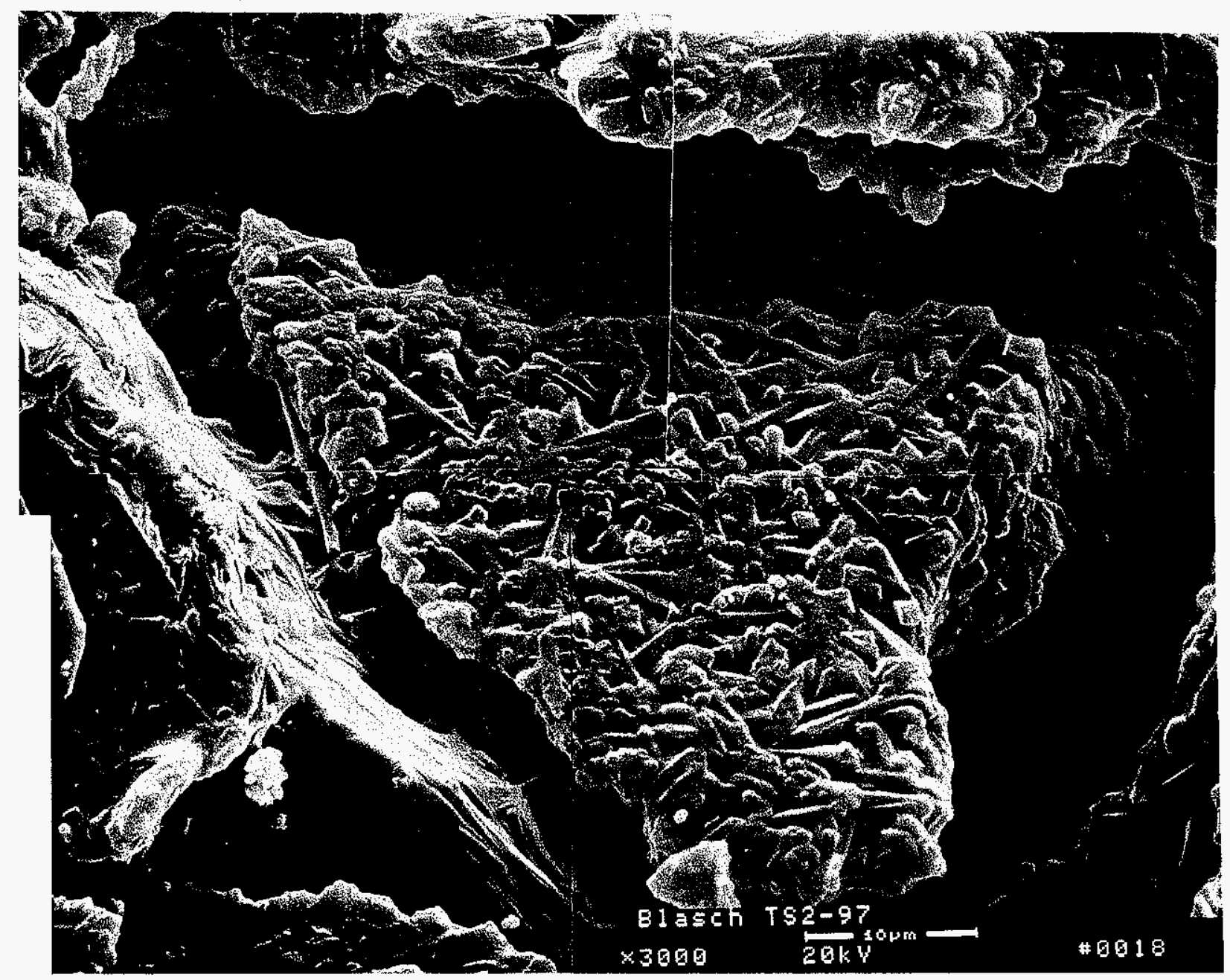

Figure 2-133 - Micrograph montage illustrating the extensive surface crystallization that resulted within the PCFBC-exposed Blasch filter matrix near the center of the fresh fractured filter wall. 


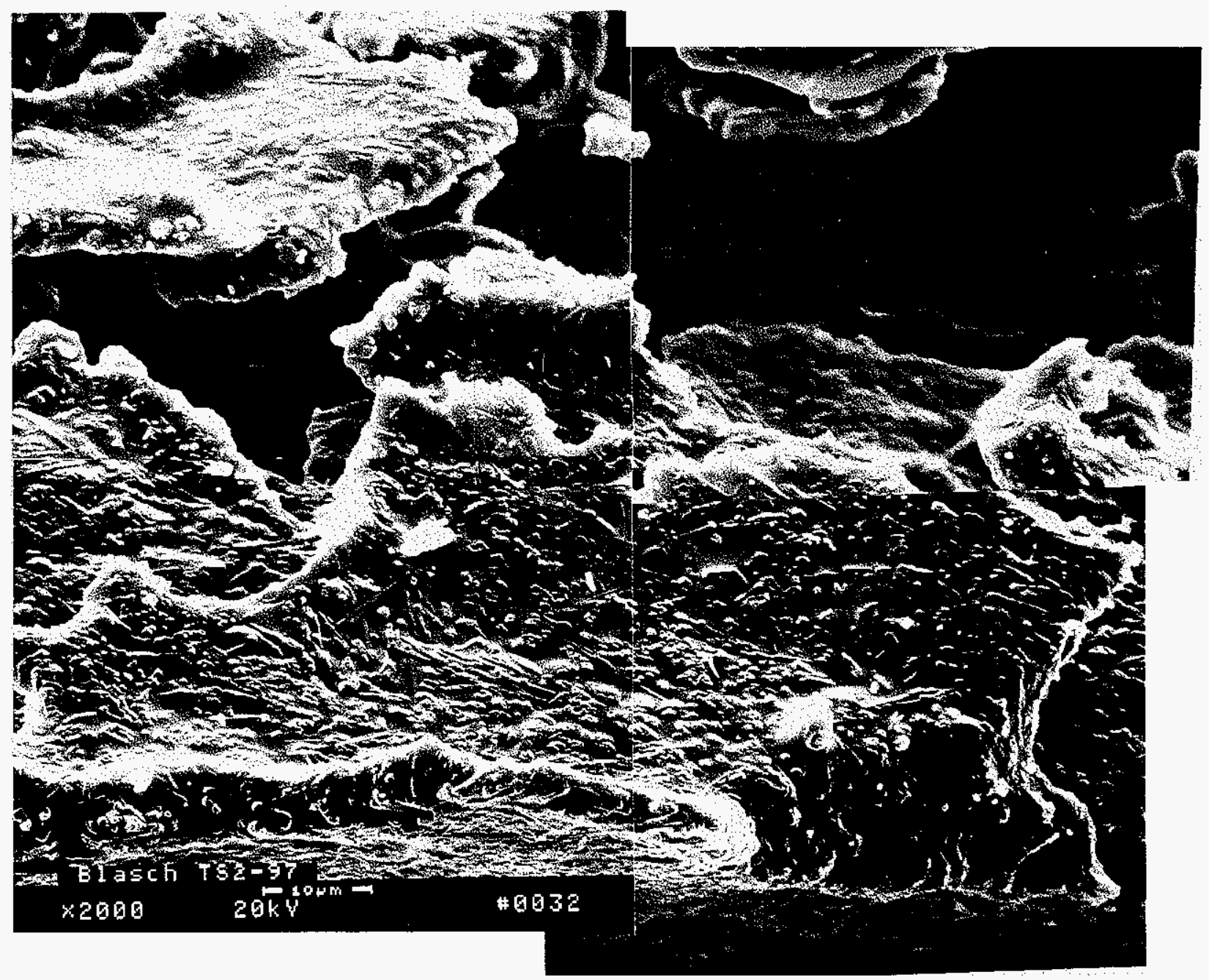

Figure 2-134 - Micrograph montage illustrating the extensive crystallization that resulted along the surface of ligaments and pore cavity walls in the PCFBC-exposed Blasch filter matrix near the i.d. or pulse cycled surface of the filter element. 


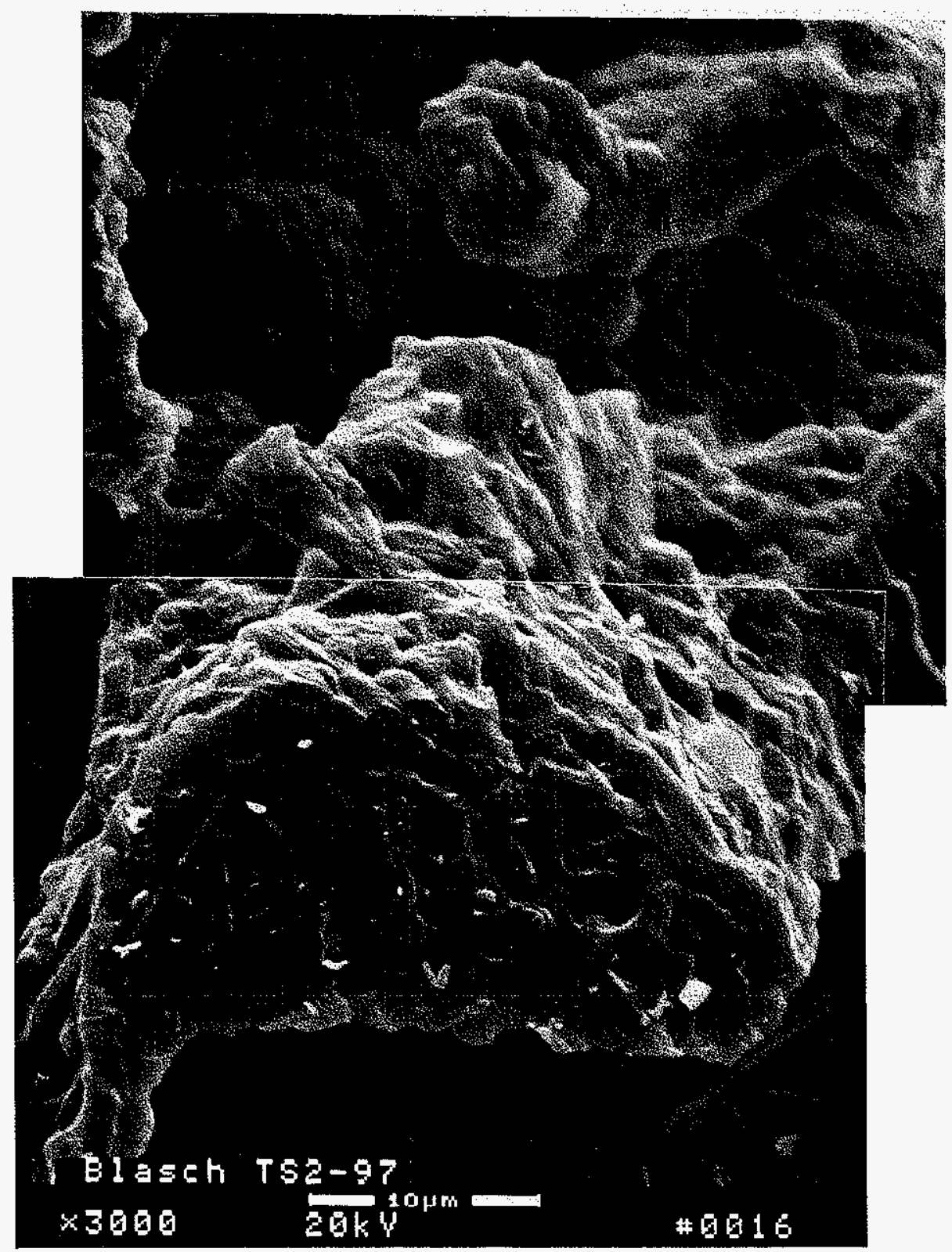

Figure 2-135 - Crystallization was evident along the outer surface, as well as throughout the fresh fractured mullite-containing ligaments in the PCFBC-exposed Blasch filter matrix. 


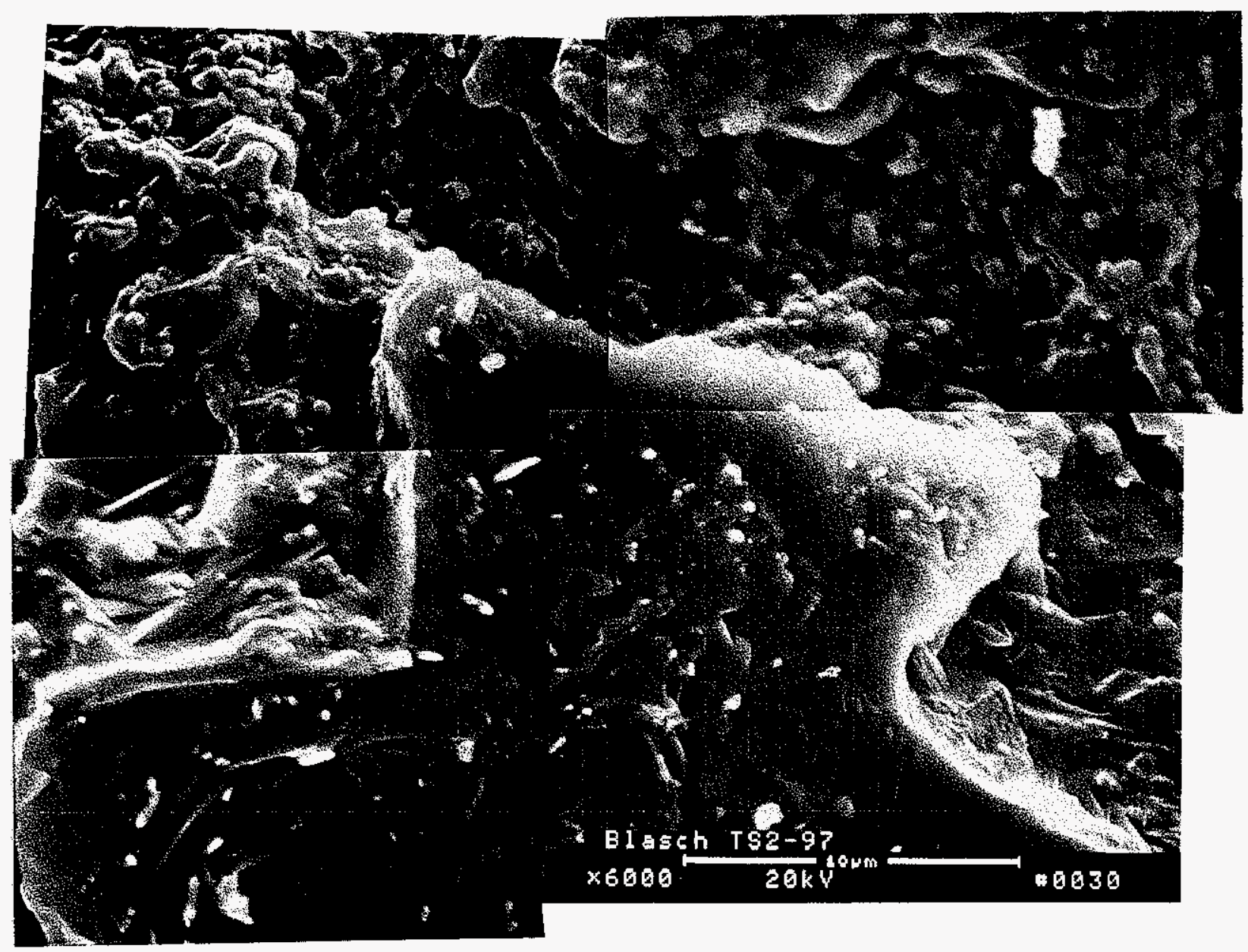

Figure 2-136 - Micrograph montage illustrating extensive crystallization throughout the fresh fractured ligaments and pore cavity surfaces in the PCFBC-exposed Blasch filter matrix. 


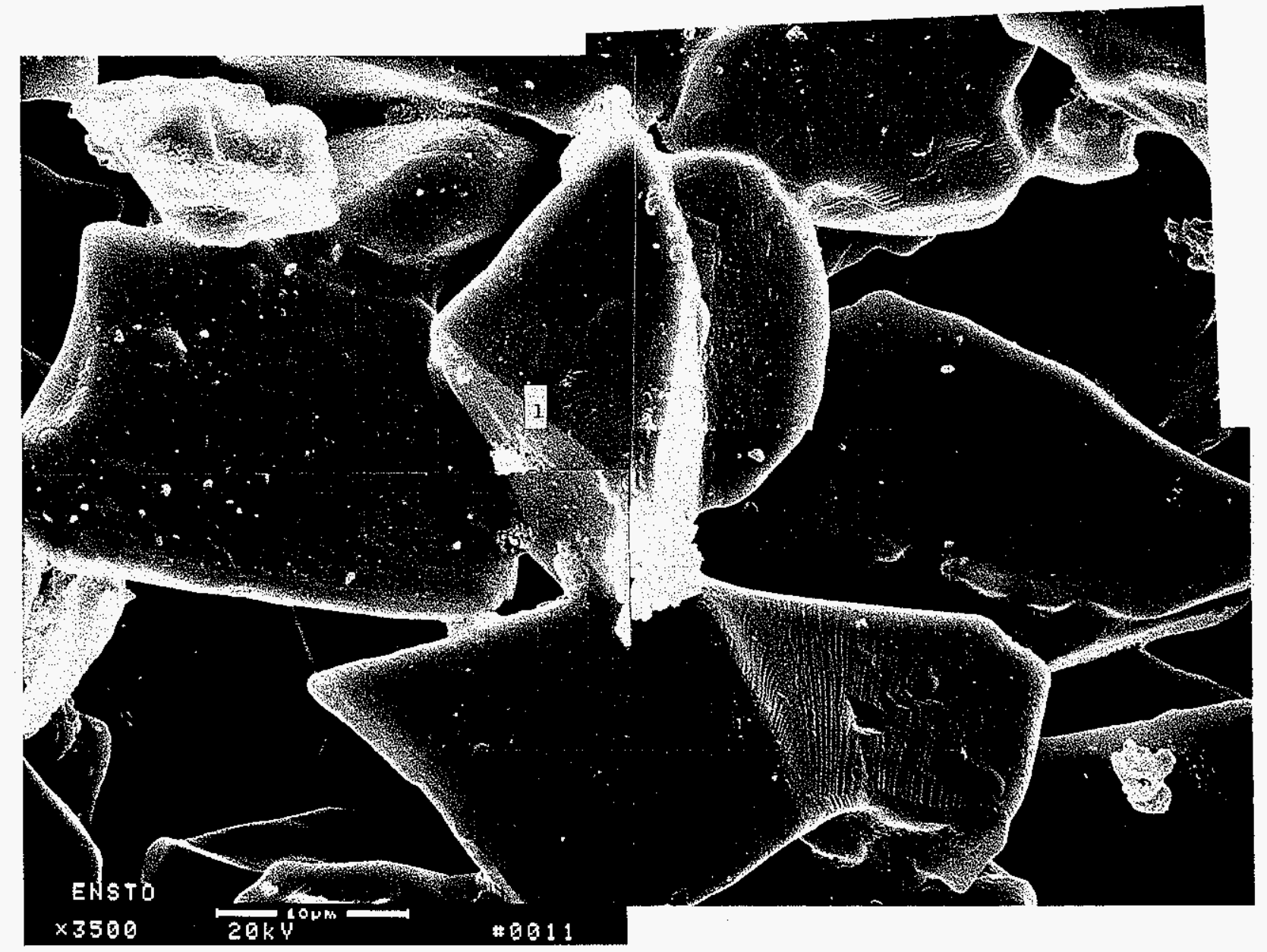

Figure 2-137 - Micrograph illustrating the morphology of the cross-sectioned as-manufactured Ensto filter matrix. 


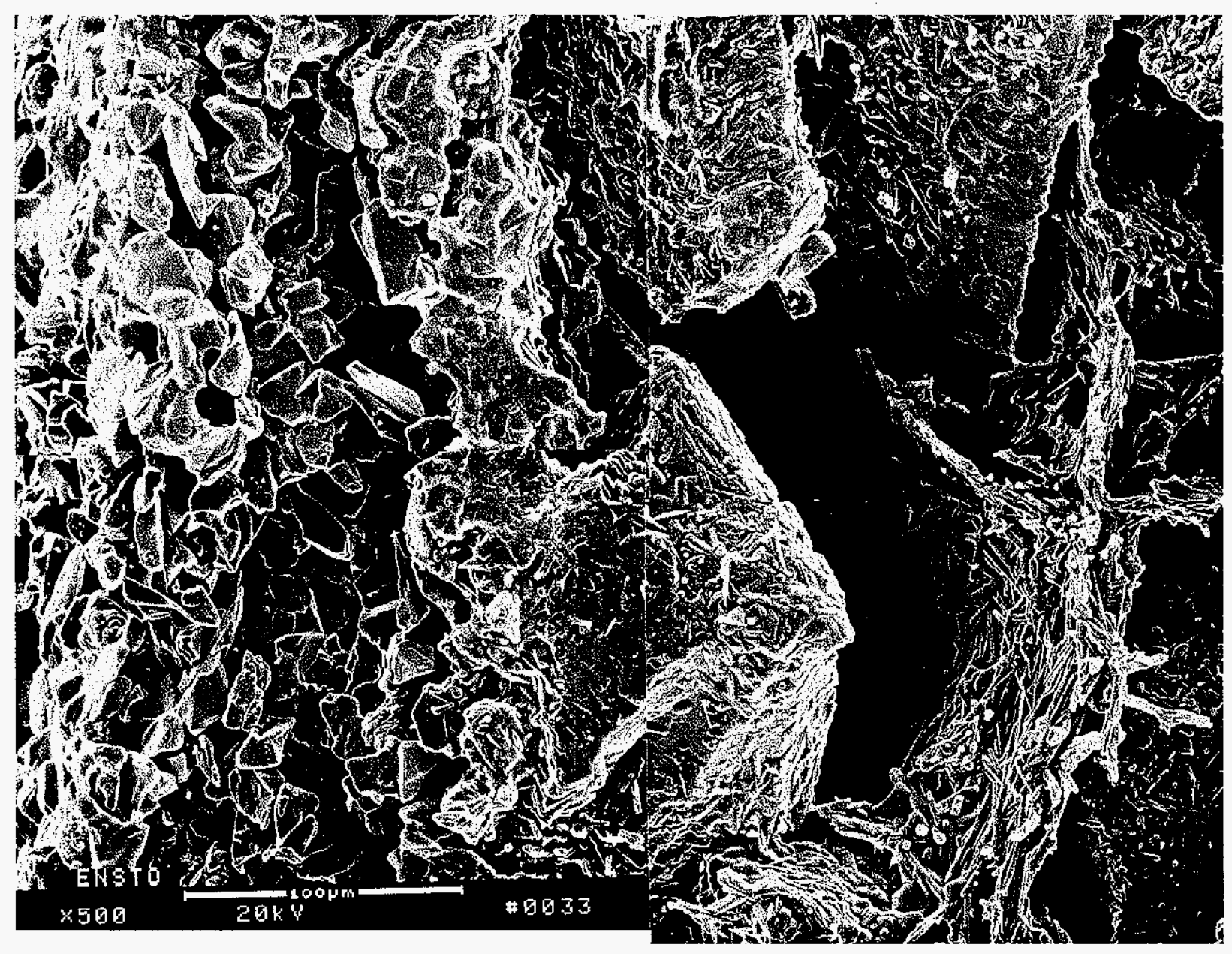

Figure 2-138 - Higher magnification micrograph montage illustrating the morphology of the membrane and underlying structural support grains in the as-manufactured Ensto mullite-bonded alumina filter matrix. 
Figure 2-139 identifies the relatively smooth surface of the alumina-enriched grains in the outer surface membrane. At higher magnification, submicron rounded nodular surface features were frequently seen along the edges of the alumina-enriched grains (Figures 2-140 and 2-141). These were identified to contain aluminum, oxygen, and calcium. Typically striated features were also present along the surface of the alumina-enriched grains (Figures 2-140 and 2-142) in the outer surface membrane. Minor concentrations of silicon and/or calcium were detected along the bonding surface of aluminaenriched ligaments that formed between adjacent grains in the as-manufactured outer surface membrane. In addition, sodium was detected as a trace constituent in association with silicon, while sulfur was present in trace concentrations in the conjunction with calcium.

Within the structural support wall, as well as along the i.d. surface of the as-manufactured Ensto filter element, flat, plate-like, alumina-enriched grains were seen to be encapsulated by a needle-like mullite phase (Figures 2-143 through 2-146). In one location, the thickness of the mullite encapsulating layer was determined to be $\sim 7 \mu \mathrm{m}$ (Figures 2-147 through 2-149). Frequently, the needle-like mullite formations bridged across the open pores in the as-manufactured Ensto filter matrix. Mullite was considered to serve as the bonding phase or ligament structure that held adjacent alumina-enriched grains together within the structural support wall of the Ensto filter matrix.

Although four Ensto mullite-bonded alumina candle filters had been installed and operated for a period of 581 hours in the PCFBC environment during conduct of TS2-97 in Karhula, and two additional Ensto candles experienced 342 hours of PCFBC operation, further microstructural characterization of the aged Ensto mullite-bonded alumina filter matrix was not performed by SWPC.

\subsection{Gravimetric Analysis}

In an attempt to demonstrate that oxidation of silicon carbide continues to occur with extended operation in the high temperature PCFBC environment, sections of the TS2-97, 2201 hour, PCFBCexposed, Schumacher Dia Schumalith FT20 and Pall 326 matrices were removed from the filter elements, and subjected to gravimetric analysis. Two competitive reactions are projected within the clay bonded silicon carbide matrices during operation in combustion gas environments. These include:

- Oxidation of silicon carbide to form silica $\left(\mathrm{SiO}_{2}\right)$ which decreases in rate with time

- Crystallization of $\mathrm{SiO}_{2}$ as tridymite, cristobalite or mullite (via reaction of $\mathrm{SiO}_{2}$ with $\mathrm{Al}_{2} \mathrm{O}_{3}$ ).

As shown in Table 2-6, the free (i.e., amorphous) silica concentrations were lower after 2201 hours of PCFBC operation in comparison to the amorphous silica concentrations identified for shorter periods of operation. Crystallization of the Schumacher Dia Schumalith FT20 oxide-containing phase was expected to have continued to occur, thus decreasing the solubility of the matrix in hydrofluoric acid (HF), resulting in a lower reported free silica content. In contrast, the concentration of free silica only slightly decreased in the Pall 326 filter matrix after 2201 hours of PCFBC operation. 

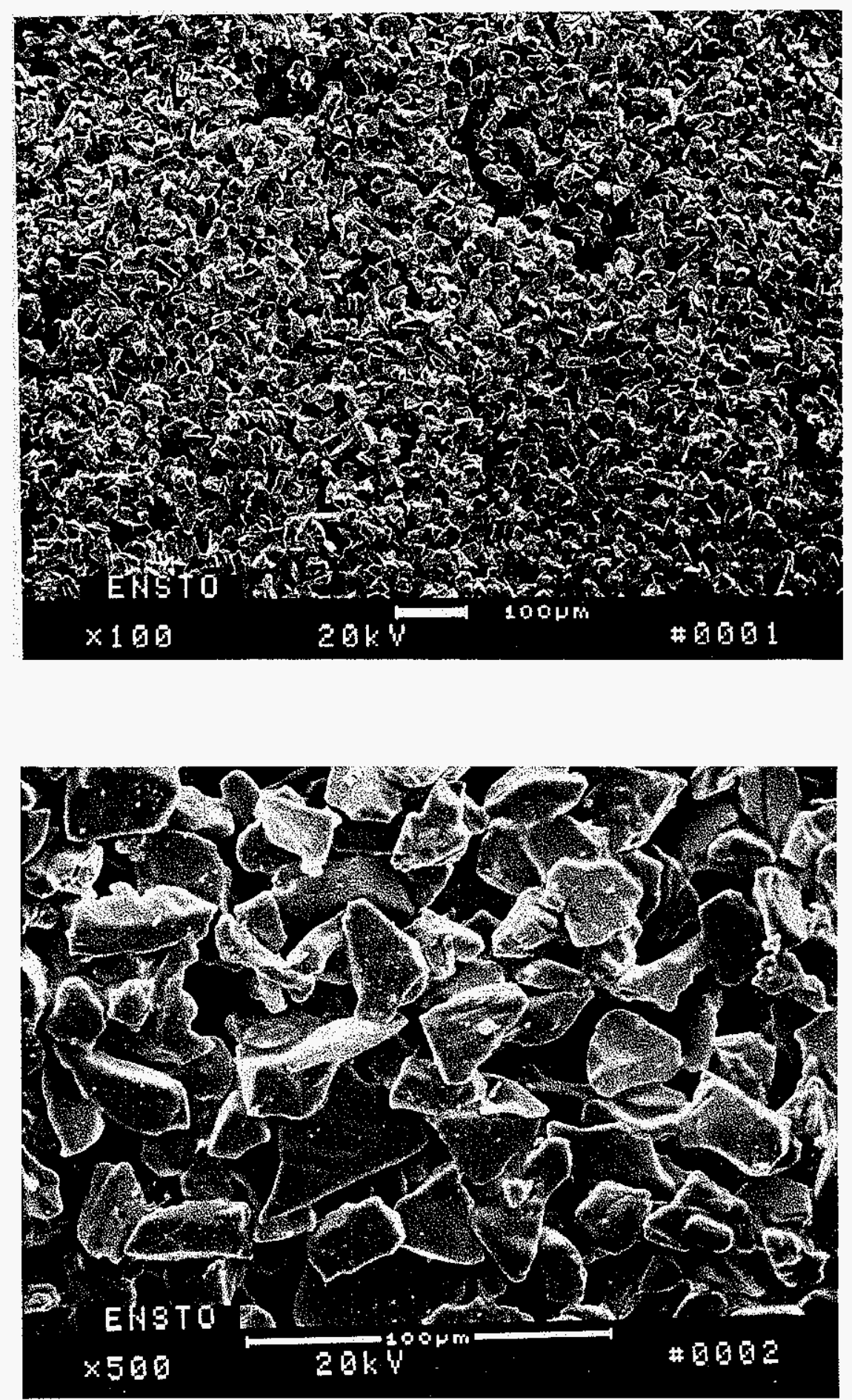

Figure 2-139 - Morphology of the outer surface membrane of the as-manufactured Ensto filter element. 


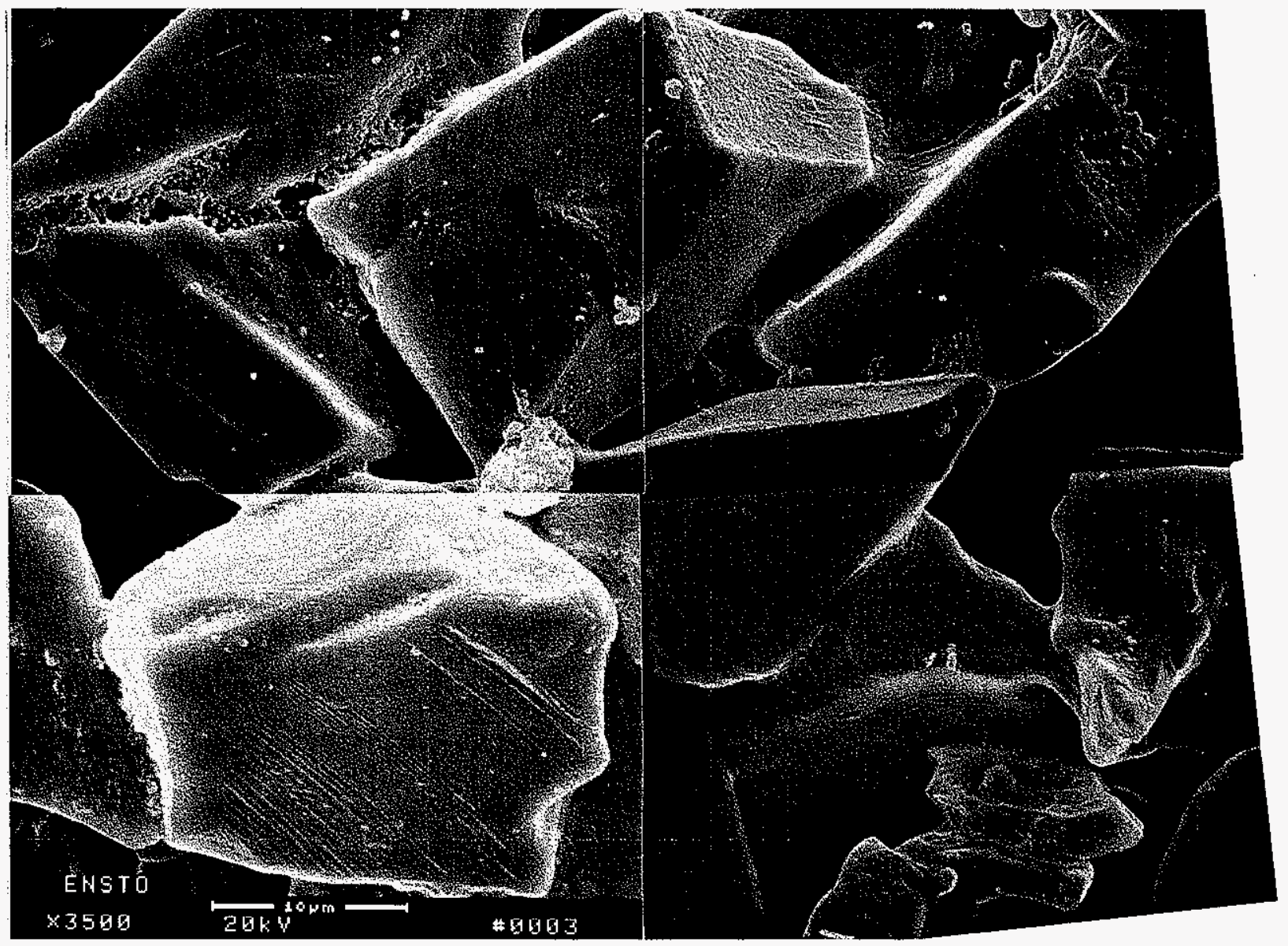

Figure 2-140 - Higher magnification micrograph montage illustrating the morphology of the alumina-enriched grains in the outer surface membrane of the as-manufactured Ensto filter element. 


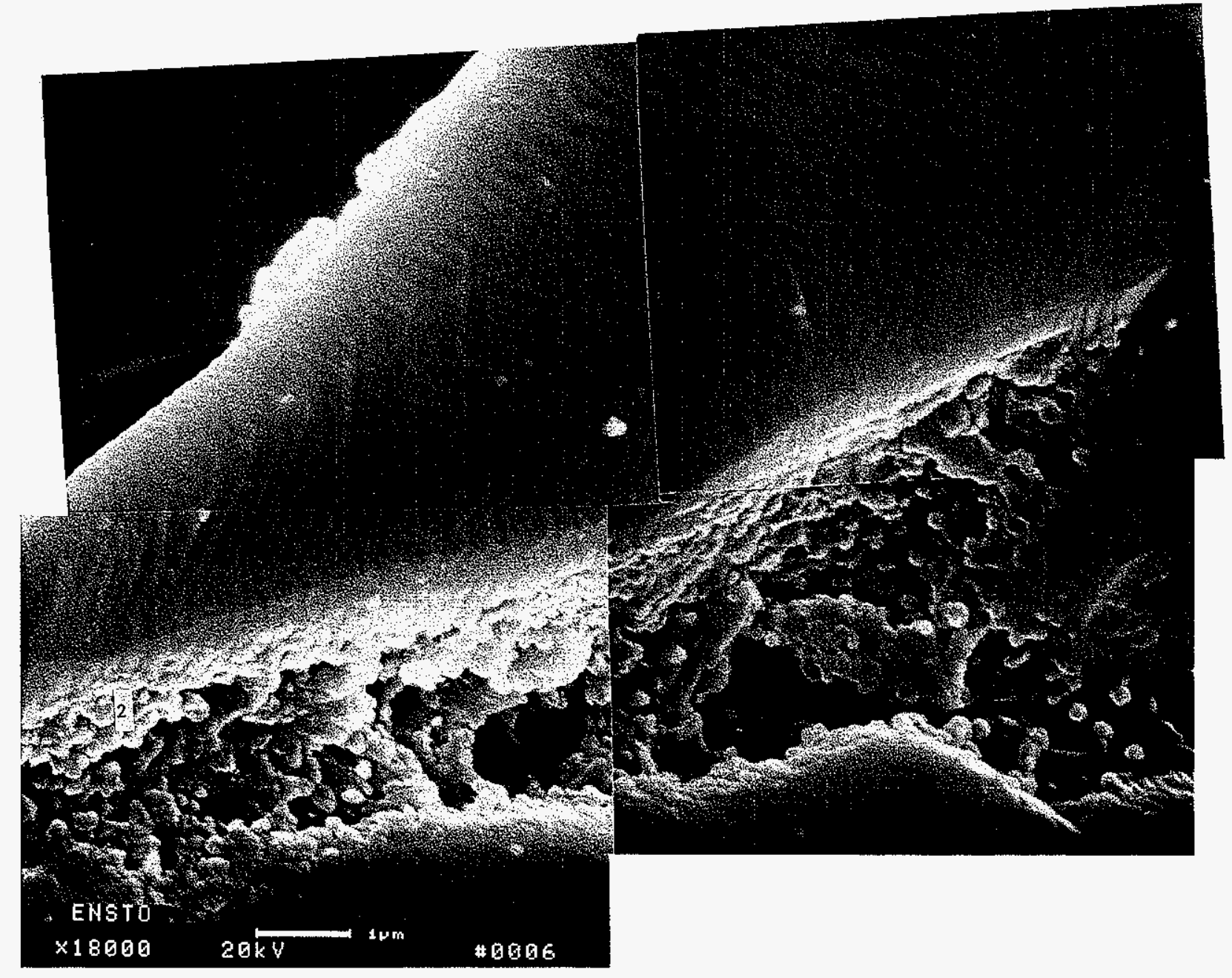

Figure 2-141 - Micrograph montage illustrating the submicron nodular features that resulted along the edges of the alumina-enriched grains in the outer surface membrane of the as-manufactured Ensto filter element. 


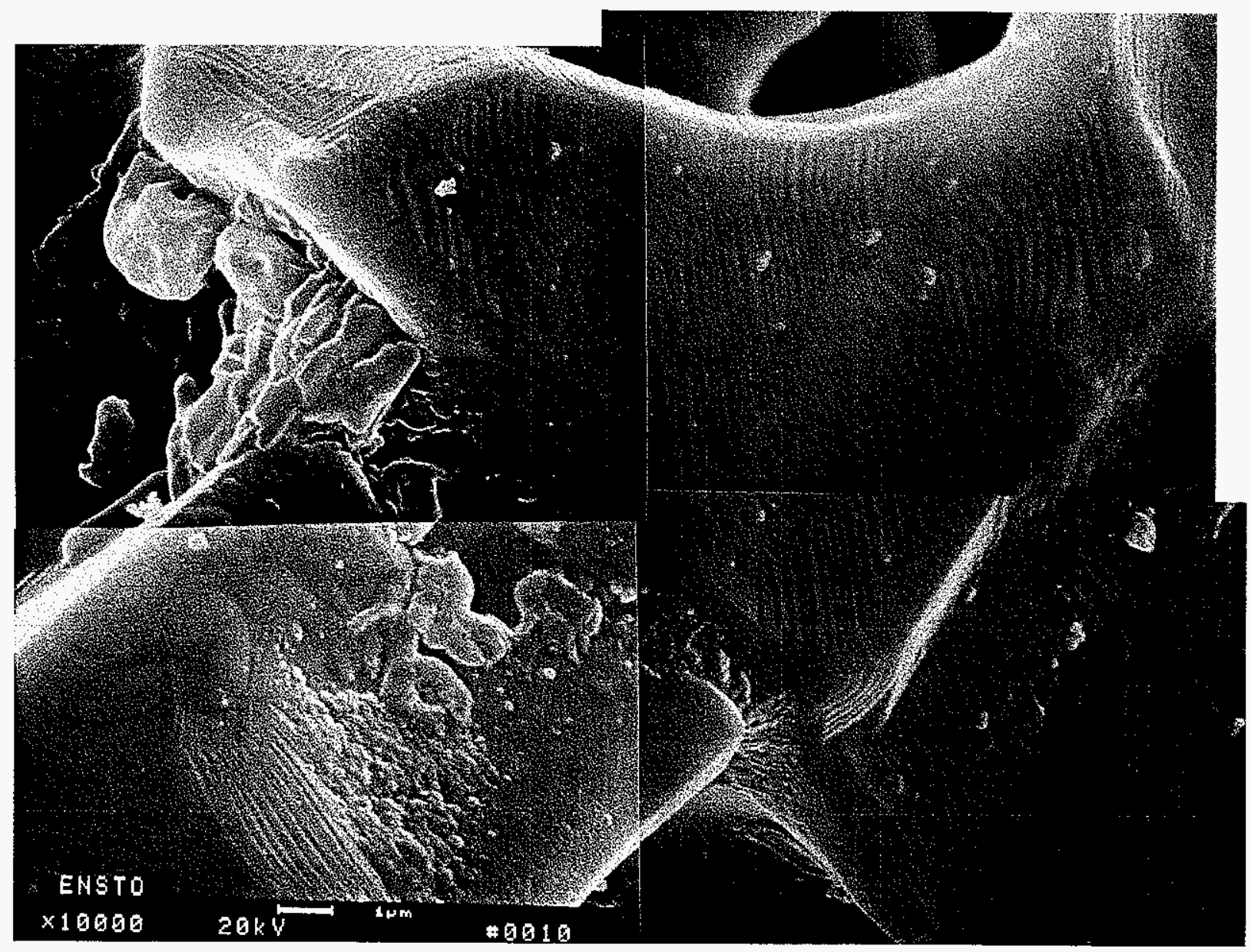

Figure 2-142 - Striated surface features of the alumina-enriched grains in the outer surface membrane of the as-manufactured Ensto filter element. Calcium, silicon, and sulfur were detected in the mottled material that appeared to bond adjacent alumina-enriched grains together within the outer surface membrane. 

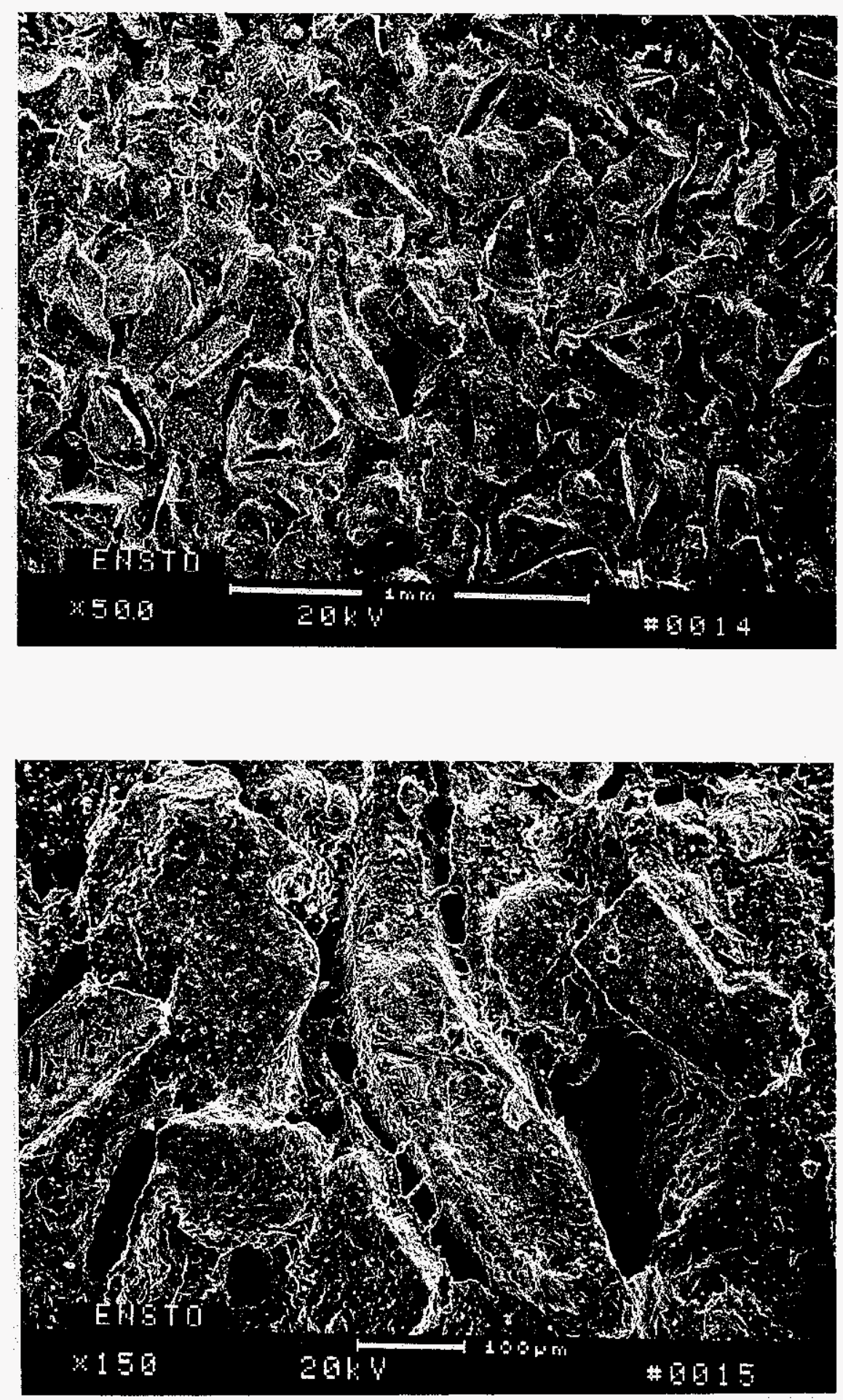

Figure 2-143 - Micrographs illustrating the morphology of the as-manufactured porous Ensto filter matrix along the i.d. surface of the candle filter. 


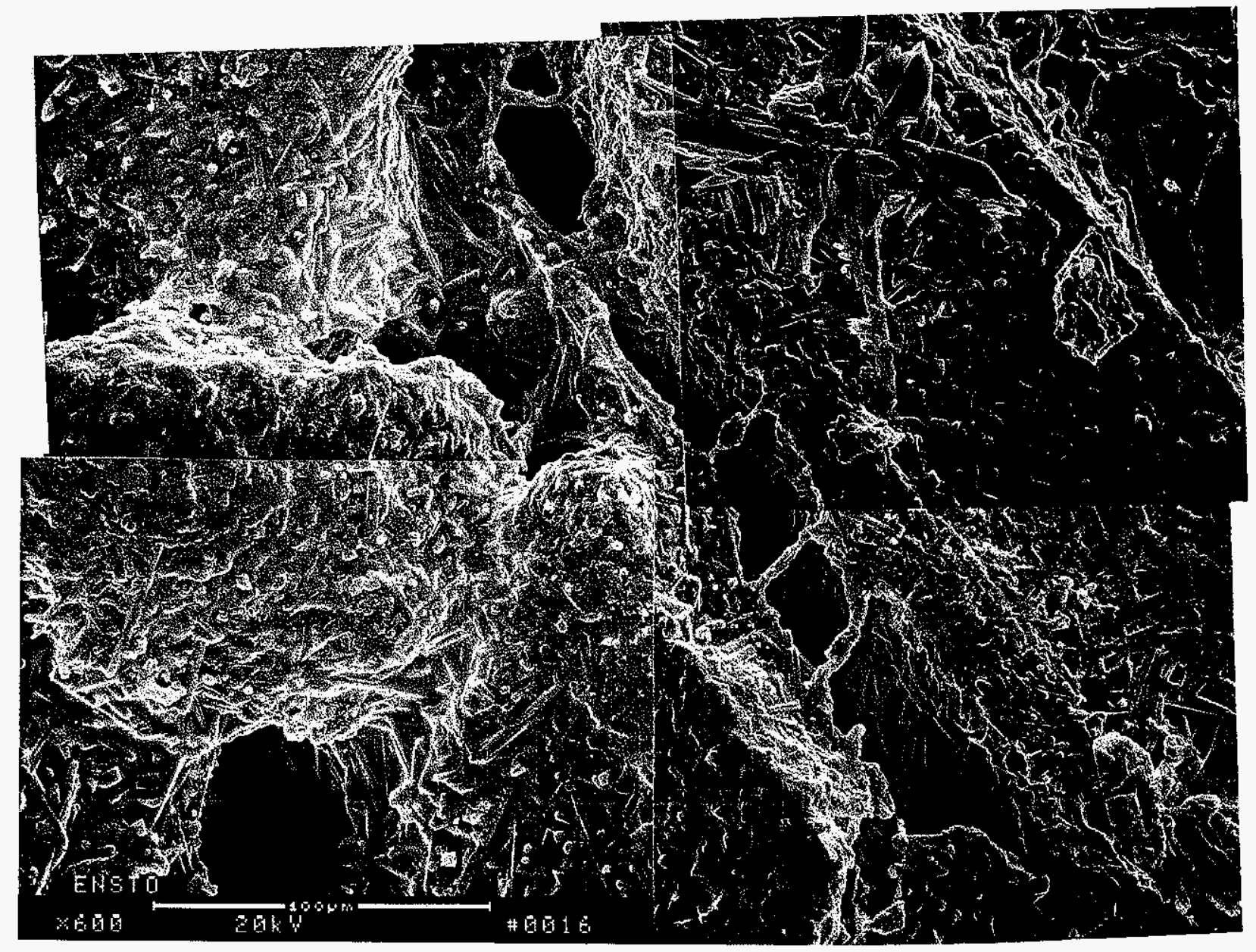

Figure 2-144 - Higher magnification micrograph montage illustrating the needle-like mullite phase formations that encapsulated the alumina-enriched structural support grains. Mullite needles tended to bridge across pores between adjacent grains within the as-manufactured Ensto filter matrix. 


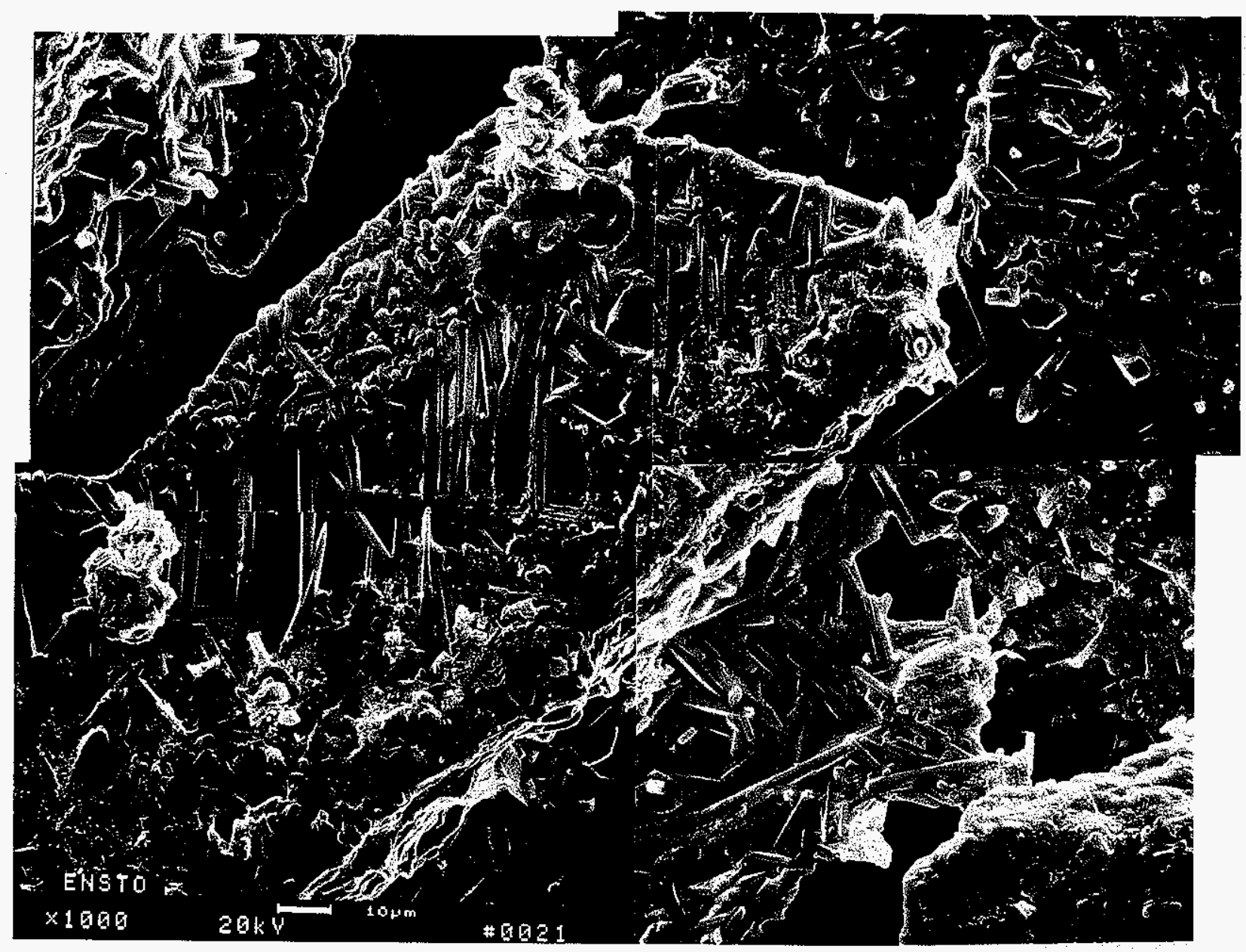

Figure 2-145 - Higher magnification micrograph montage illustrating the extensive mullite phase formation that resulted along the outer surface of the alumina-enriched grains in the as-manufactured Ensto filter matrix. 

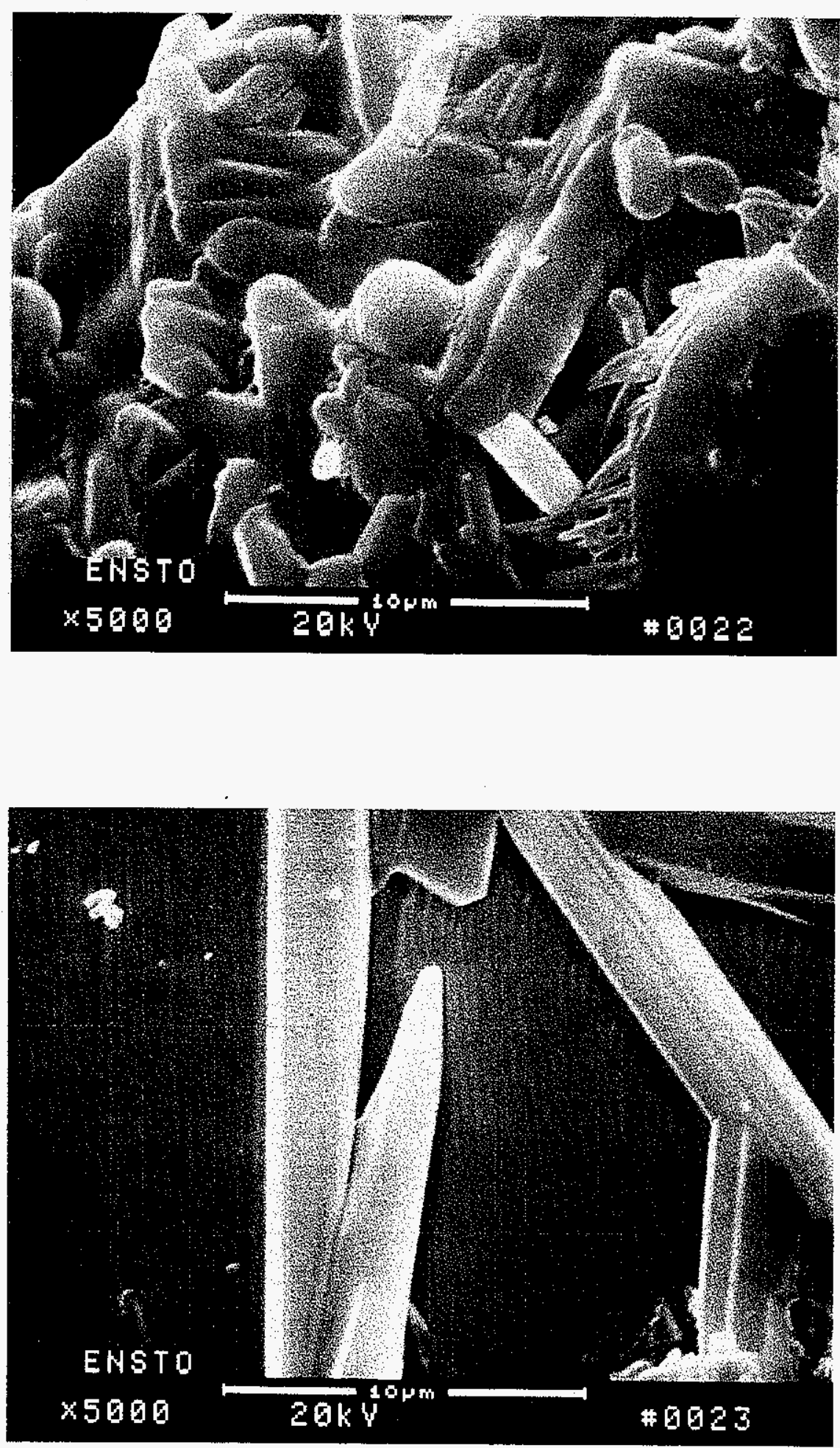

Figure 2-146 - Higher magnification micrographs illustrating the morphology of the mullite needle-like formations and precursor phase that formed along the outer surface of the alumina-enriched grains along the i.d. wall of the as-manufactured Ensto filter matrix. 


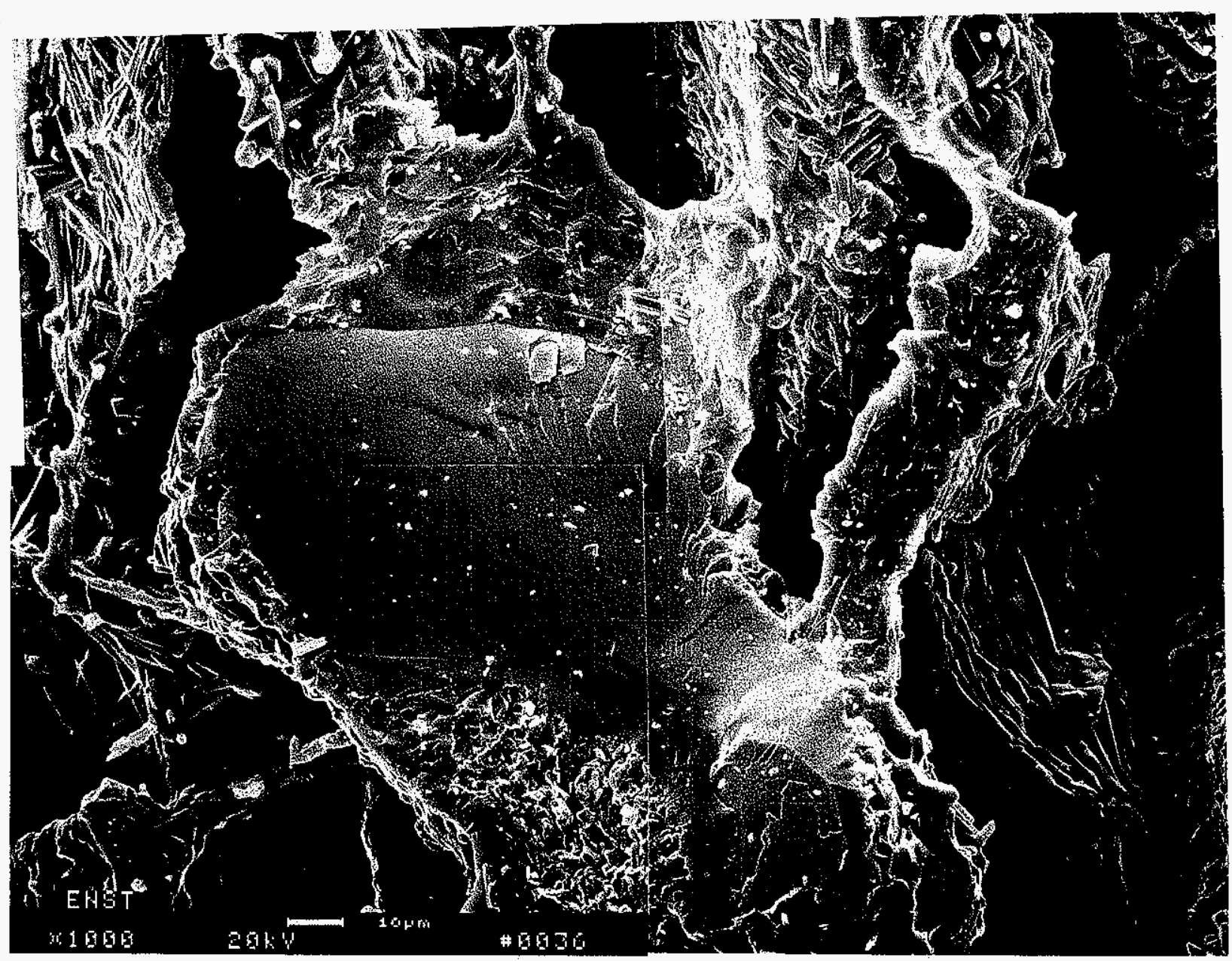

Figure 2-147 - Micrograph montage illustrating the crystalline mullite needle-like formation that encapsulated the alumina-enriched grains in the fresh fractured as-manufactured Ensto filter matrix. 


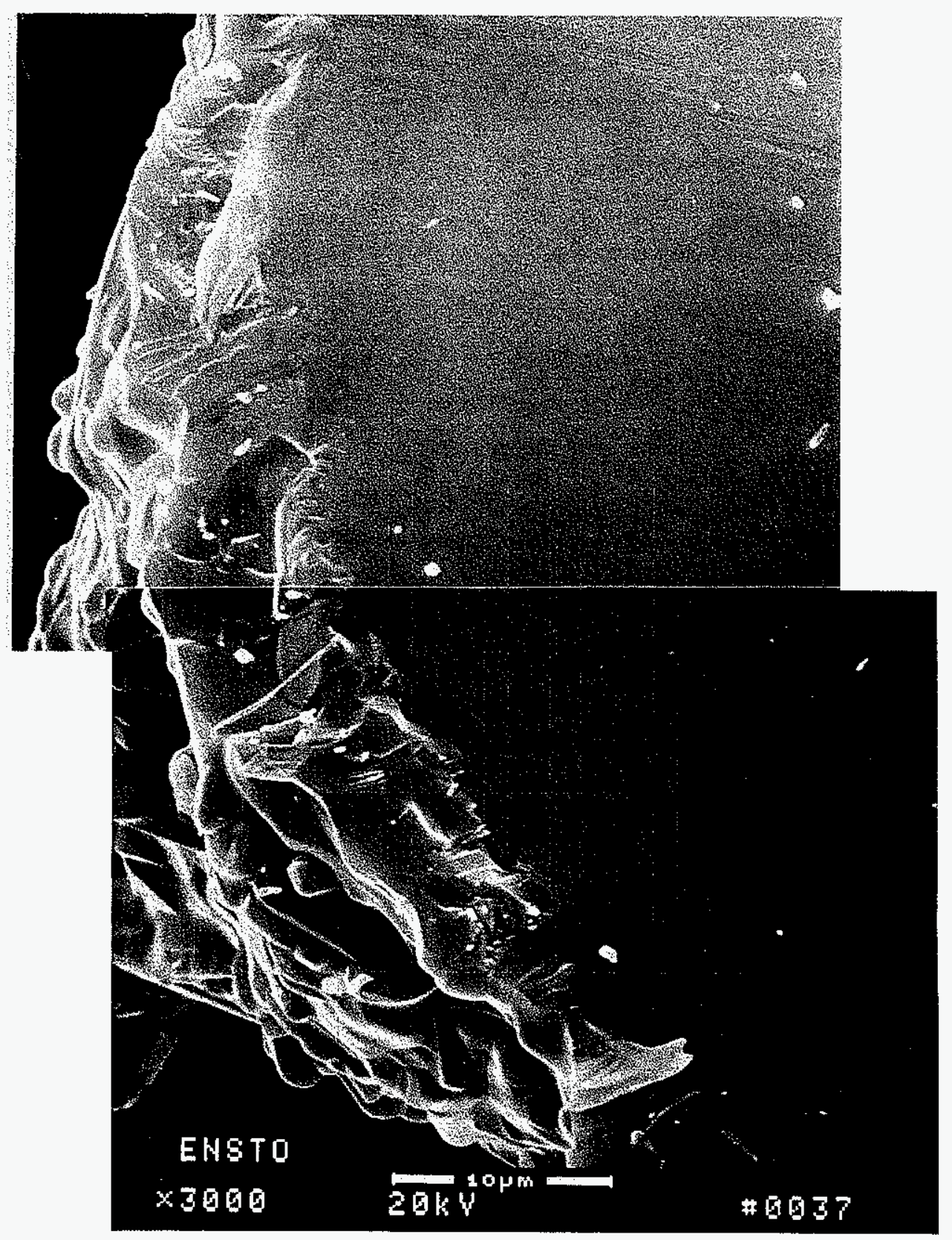

Figure 2-148 - Micrograph montage illustrating the morphology of the mullite phase that encapsulated the outer surface of the alumina-enriched grains near the center of the fresh fractured as-manufactured Ensto filter wall. 


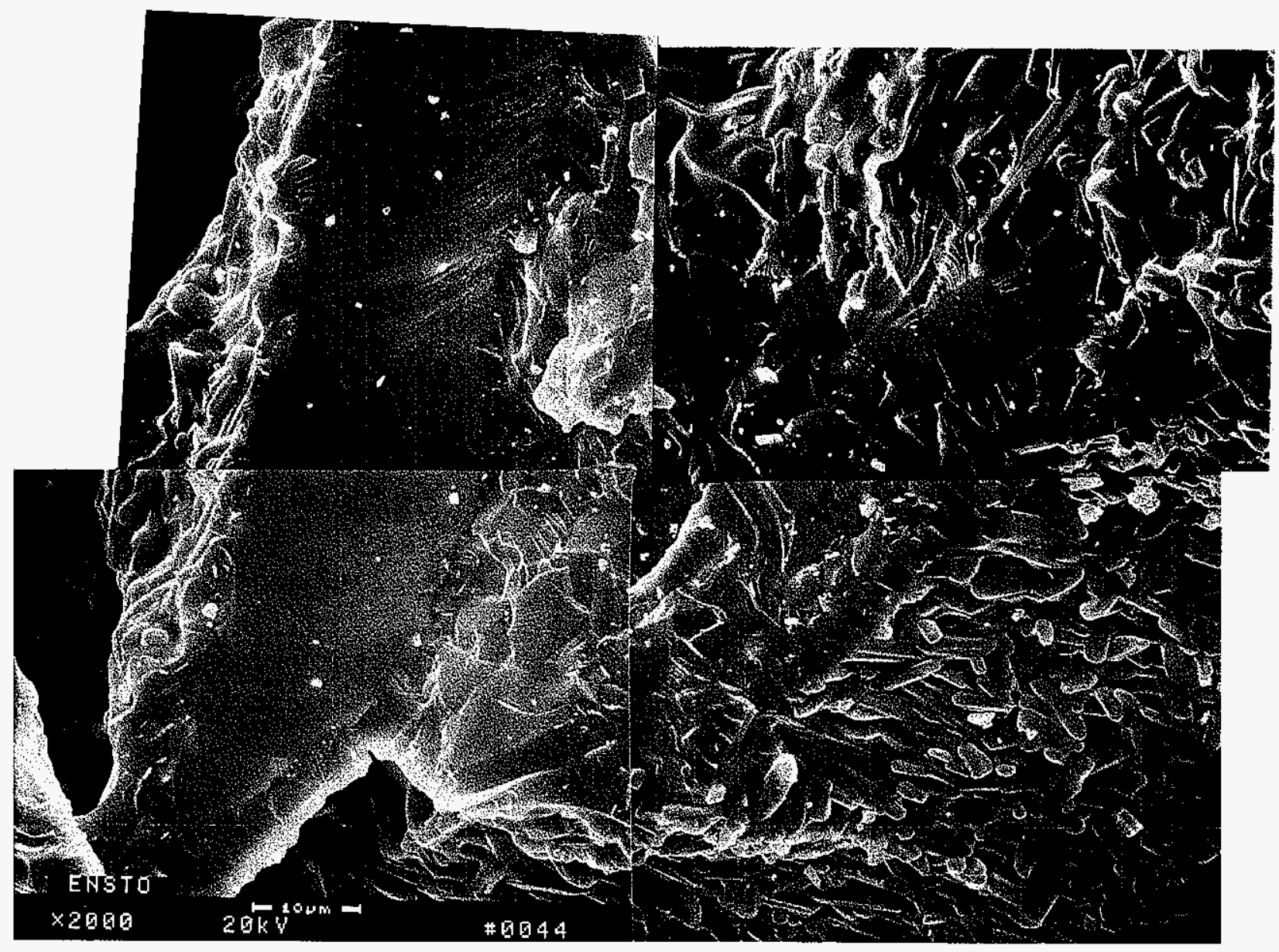

Figure 2-149 - Micrograph montage illustrating the morphology of the mullite needle-like phase formations that encapsulated the alumina-enriched grains in the structural support wall of the fresh fractured as-manufactured Ensto filter element. 


\subsection{High Temperature Oxidation vs Creep}

Based on the gravimetric analyses which identified an initial increase in the silica concentration in field-exposed filter materials, and the bench-scale, high temperature, flexural creep tests which identified negligible creep strain in the as-manufactured and field-exposed filter materials, oxidation of the silicon carbide matrix was considered to be the primary mechanism that was responsible for the 8-11 $\mathrm{mm}$ of elongation that was observed for the $1.5 \mathrm{~m}$ Schumacher Dia Schumalith FT20 and Pall 326 filter elements after 2201 hours of PCFBC operation. During oxidation of the silicon carbide grains, $\mathrm{SiO}_{2}$ formed resulting in a volume expansion of the matrix (Figure 2-150). Continued operation of the previously PCFBC-exposed Schumacher and Pall filter elements is recommended to determine the rate at which oxidation/elongation/creep occurs within the clay bonded silicon carbide materials as a function of extended plant operating time.

During PCFBC operation, consideration should also be given to competing volatilization mechanisms that release $\mathrm{Si}(\mathrm{OH})_{4}$ from the silicon carbide filter matrix during exposure to steam. In contrast to oxidation, volatilization would be expected to reduce the overall volume of the silicon carbide grains.
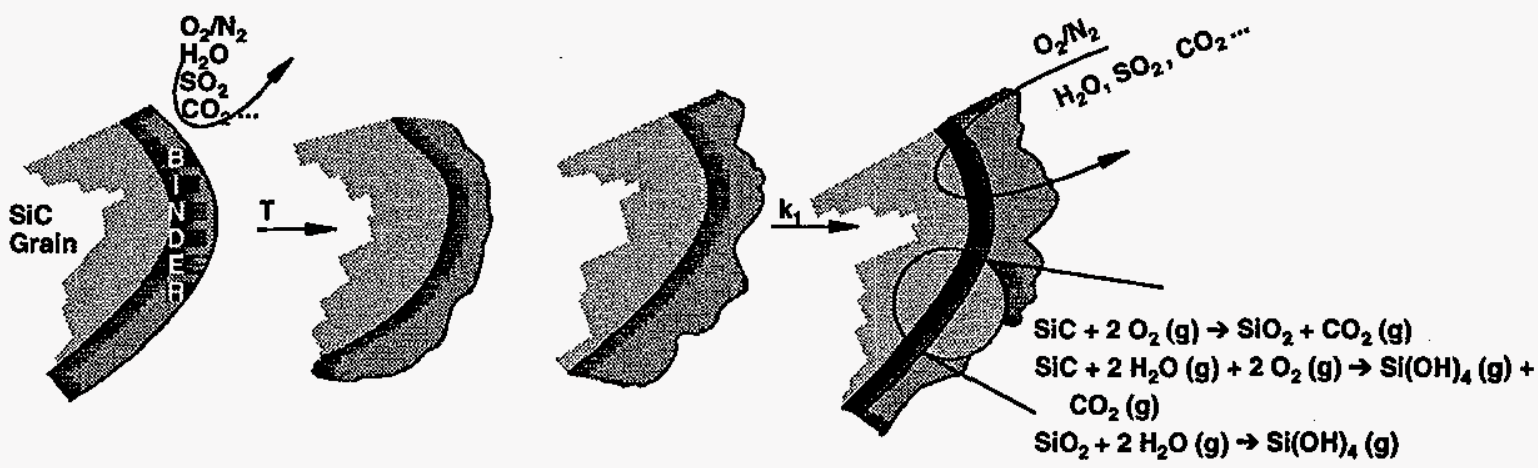

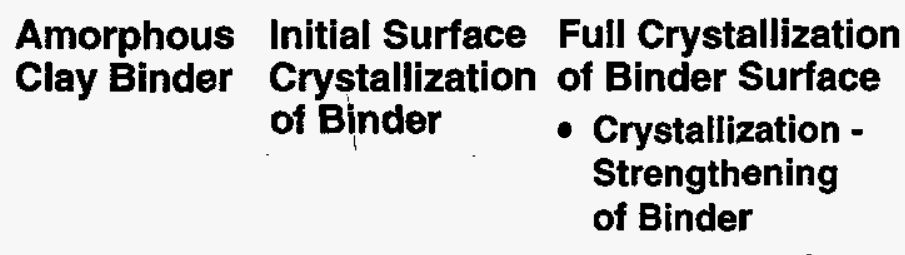

- Void Formations

- Potential Microcrack Locations

Oxidation of SiC Grain

- Volume Expansion

- Possible Enhanced HT Creep

Volatilization

- Volume Depletion

- Potential Enhanced Diffusion of Oxygen to SiC Grain Surface

Figure 2-150 - Microstructural changes within the clay bonded silicon carbide candle filters during extended operation in PFBC/PCFBC process gas environments. 


\subsection{Thermal Expansion}

Sections of the PCFBC-exposed Schumacher Dia Schumalith FT20 and Pall 326 filter materials were subjected to thermal expansion testing. As shown Figure 2-151, the thermal expansion of the PCFBC-exposed Schumacher and Pall filter materials is nearly identical. Similarly the thermal expansion of the PCFBC-exposed clay bonded silicon carbide filter materials is nearly identical to that of the as-manufactured Coors P-100A-1 alumina/mullite and Schumacher Dia Schumalith F40 filter matrices.

The thermal expansion of the porous ceramic filter materials is lower than the thermal expansion of the PCFBC or PFBC ash materials. The PCFBC ash sample that was used in the thermal expansion test was representative of the dust cake layer that remained along the outer surface of the candle filters at the conclusion of TS2-96. The PFBC ash sample was taken from a densely packed ash plug that formed within the inner bore of the filter elements during Test Segment No. 5 at AEP. The relatively wide range in the thermal expansion of the ash materials as a function of temperature is expected to reflect the difference in the density, as well as the variation in the composition of the ash deposits.

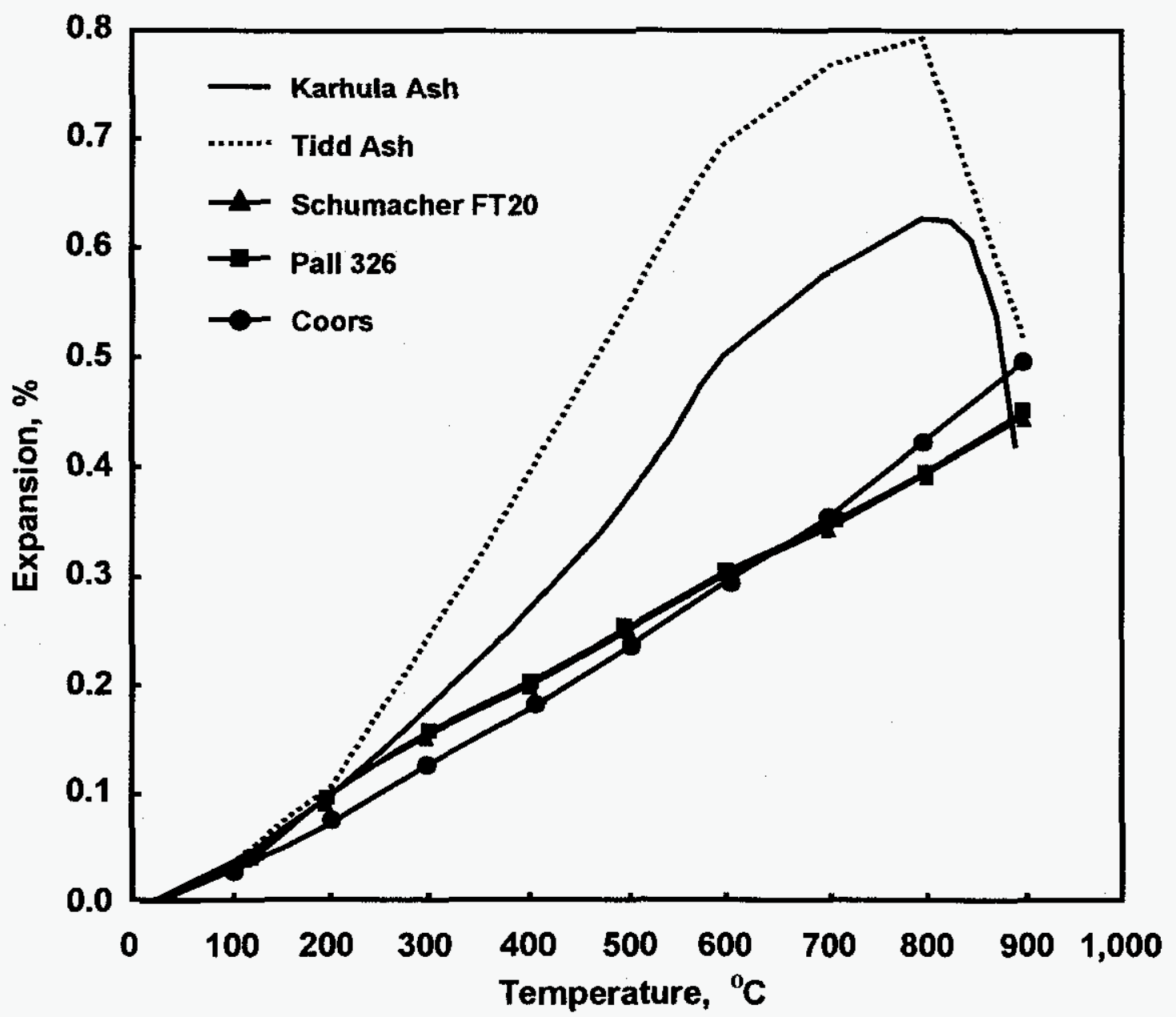

Figure 2-151 - Thermal expansion of the porous ceramic filter and ash materials. 


\subsection{PCFBC Ash Analysis}

Ash was removed from the outer surface of TS2-97-exposed candle filters which had been operated in the W-APF filter at the Foster Wheeler PCFBC test facility in Karhula, Finland. The feedstock materials used during the TS2-97 test campaign were Eastern Kentucky coal and Florida limestone. The filter operating temperatures ranged between 700 and $750^{\circ} \mathrm{C}$ during conduct of 581 hour TS2-97 filter test campaign.

A tan colored ash was removed from the outer surface of the filter elements (Figure 2-152). When characterized by SEM/EDAX analysis, the PCFBC ash that was collected along the outer surface of the filter elements was seen to consist of variably sized $<10 \mu \mathrm{m}$ particles (Figures 2-153 and 2-154). Area scan EDAX analysis of the ash identified the presence of $69.06 \% \mathrm{O}, 10.32 \% \mathrm{Si}, 7.05 \% \mathrm{Al}$, $6.00 \% \mathrm{Ca}, 3.88 \% \mathrm{~S}, 2.16 \% \mathrm{Fe}, 1.10 \% \mathrm{~K}, 0.28 \% \mathrm{Ti}$, and $0.15 \% \mathrm{Mg}$ (i.e., atomic percent basis). The $\sim 10 \mu \mathrm{m}$ amorphous fines present within the ash were identified by EDAX analysis to contain $60.48 \% \mathrm{O}$, $18.78 \% \mathrm{Si}, 11.39 \% \mathrm{Al}, 3.27 \% \mathrm{~K}, 2.07 \% \mathrm{Ca}, 1.58 \% \mathrm{Fe}, 1.22 \% \mathrm{~S}, 0.48 \% \mathrm{Na}, 0.36 \% \mathrm{Mg}$, and $0.36 \% \mathrm{Ti}$. Agglomerated fines which consisted of numerous $\sim 1 \mu \mathrm{m}$ particles were determined to contain $73.62 \% \mathrm{O}$, $10.68 \% \mathrm{Ca}, 9.71 \% \mathrm{~S}, 3.12 \% \mathrm{Si}, 1.96 \% \mathrm{Al}, 0.50 \% \mathrm{Fe}, 0.24 \% \mathrm{~K}$, and $0.16 \% \mathrm{Mg}$. Based on these analyses, the larger amorphous fines were considered to principally consist of ash fines, while the smaller agglomerated fines were considered to be primarily sorbent particles.

\subsection{Filter Flange Strength Measurements}

Filter elements are purchased to a specified flange, total length, and o.d. surface dimensional tolerance for use in SWPC's APF systems. However, as shown in Figure 2-155, the contour of the flange, and the wall thickness of the various monolithic and advanced composite candle filters vary, depending on the manufacturing process utilized to construct each filter element.

During installation, the candle flange is gasketed and fitted into a metal holder, and subsequently bolted to secure and position each element in the filter array. The applied loads are intended to be sufficient to seal and capture the candle flange within the metal holder mount.

For the McDermott composite candle during field operation, depressions and/or splitting of the as-manufactured bonded insert from the remainder of the flange were seen to have occurred. Alternately the thin walled 3M CVI-SiC composite filter flange tended to crack, if the spacer distance between the bolts was reduced to prevent movement of the candle within the holder mount. Similarly fine hairline cracks were observed along the outer surface of the DuPont PRD-66 filament wound flange after 581 hours of PCFBC operation. In contrast during field operation, crack formations along the monolithic filter element flanges were not observed using the same mounting arrangement.

In an attempt to assess the ultimate radial load that can be applied to the flange of the monolithic and advanced composite filter elements, flange sections (i.e., $40 \mathrm{~mm}$ sections from the top of the flange)

were cut from the various filter elements. Each section was subjected to diametral testing at either $750^{\circ} \mathrm{C}$ 


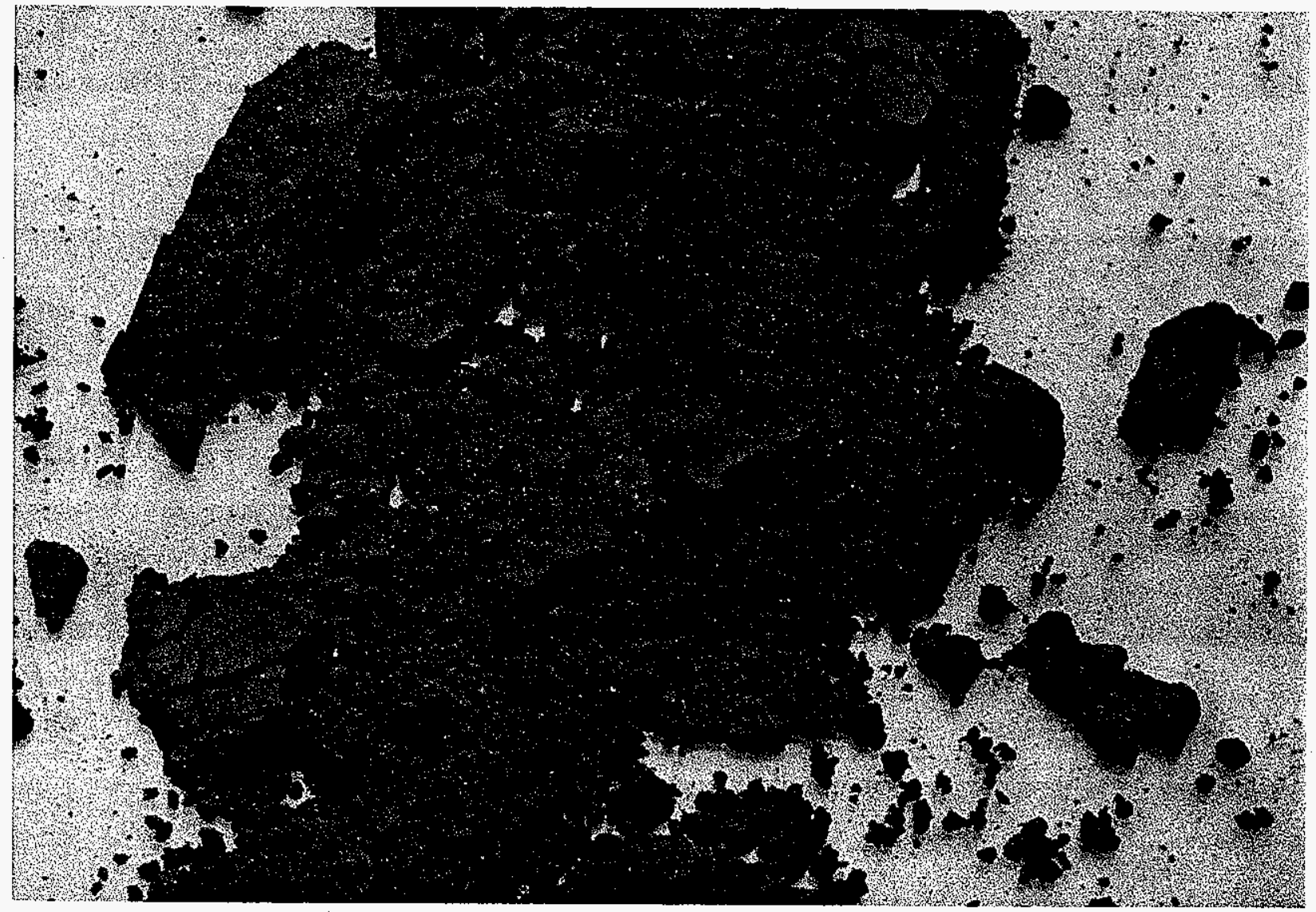

Figure 2-152 - PCFBC ash fines collected along the outer surface of the filter elements at the conclusion of TS2-97. 

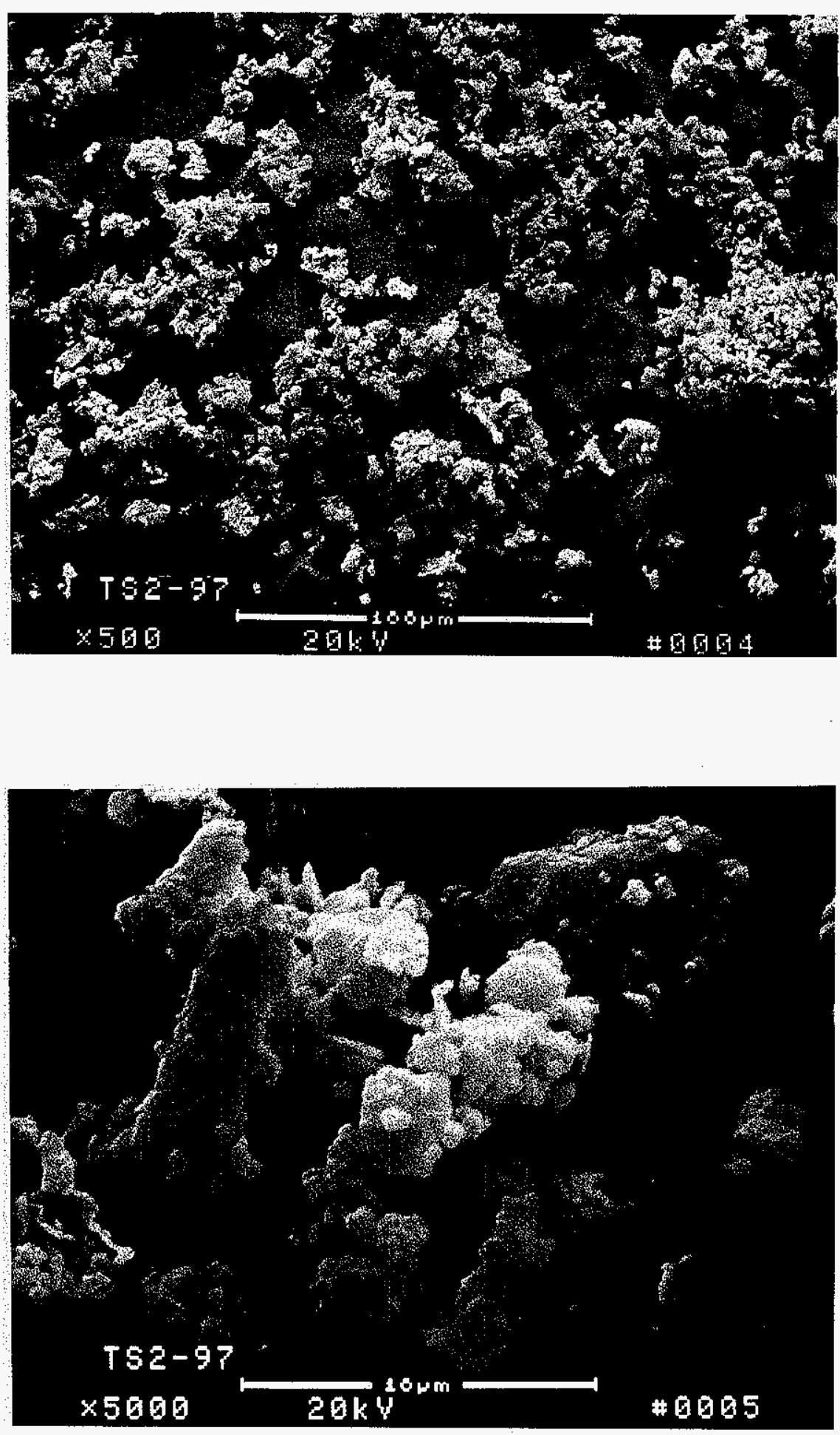

Figure 2-153 - Micrographs illustrating the morphology of the PCFBC ash fines that remained along the outer surface of the filter elements at the conclusion of TS2-97. 

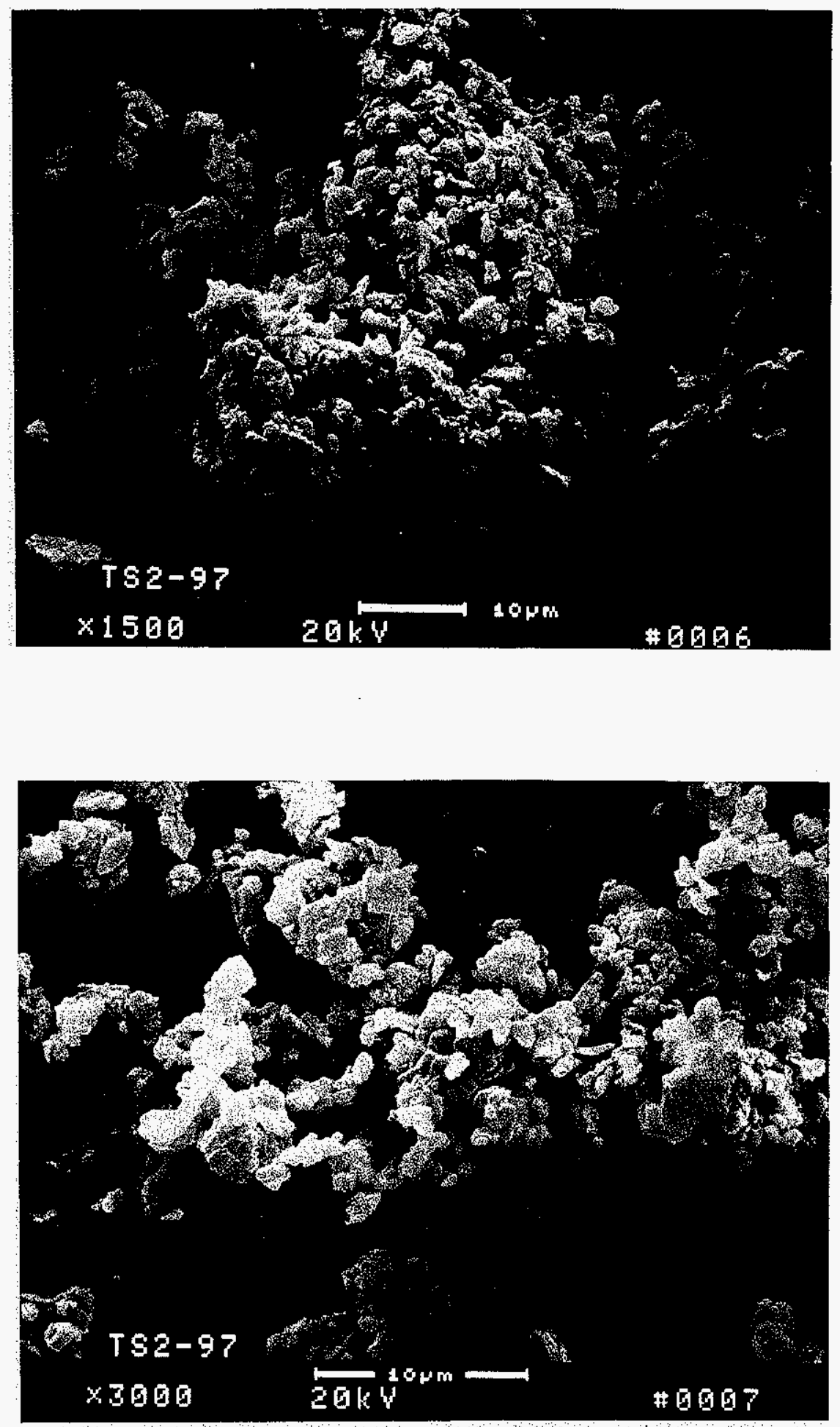

Figure 2-154 - Additional micrographs illustrating the morphology of the PCFBC ash fines that remained along the outer surface of the filter elements at the conclusion of TS2-97. 


\section{POROUS CERAMIC FILTER ELEMENTS}

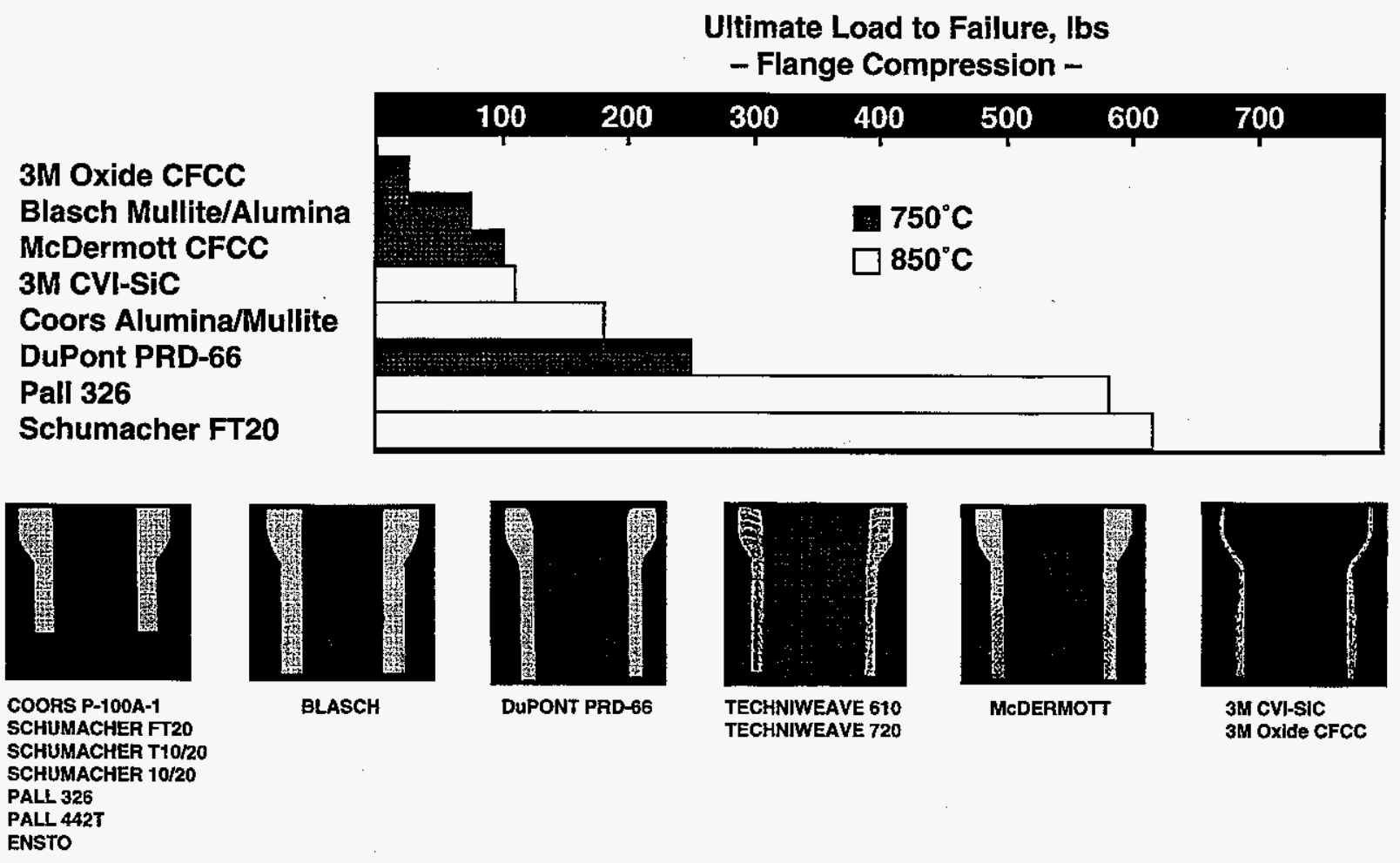

Figure 2-155 - Cross-sectioned wall thickness and strength of the commercially available monolithic and advanced second generation candle filter flanges.

or $850^{\circ} \mathrm{C}^{6}$ Diametral testing reflected a load imparted by the presence of ash between the gasketed flange and the inner surface of the metal holder.

The compressive load to failure for the continuous fiber reinforced ceramic composite filter flanges ranged between 26.2 and 102.6 pounds, while the compressive load to failure for the monolithic flanges ranged between 76.5 and 610.5 pounds. The ultimate load to failure for the filament wound flange was 247.6 pounds.

Similar flange crush strength testing is recommended to be conducted utilizing the Siemens Westinghouse filter gasketing and mounting configuration.

\footnotetext{
${ }^{6}$ The process operating temperature that each candle filter had been subjected to during PCFBC testing in Karhula, Finland, during the 1995-1997 test campaigns was used in this effort. For example, the Coors, Pall, Schumacher, and $3 \mathrm{M}$ candles were subjected primarily to $850^{\circ} \mathrm{C}$ process temperatures, while the DuPont PRD$66, \mathrm{McDermott}$, and Blasch candles experienced operating temperatures of $750^{\circ} \mathrm{C}$.
} 


\section{ACCELERATED LIFE TESTING OF PCFBC-EXPOSED FILTER ELEMENTS}

\subsection{Program Overview}

In March 1998, SWPC STC initiated an extended accelerated filter life test program in which PCFBC and/or PFBC-aged candle filters were subjected to simulated high temperature, high pressure, combustion gas operating conditions in order to demonstrate the feasibility of matrix-conditioned elements to achieve extended service operation. The field-tested monolithic filter elements used in this effort had previously experienced 1035-3311 hours of service life, while the composite and advanced monolithic candles experienced 581 hours of service life (Table 3-1).

A maximum of sixteen candles were installed in the filter array (Figure 3-1) which then underwent 40.5 hours of steady state PFBC operation at $1550^{\circ} \mathrm{F}$ and 68 psig. $^{7}$ Subsequently the filter array was subjected to 20,089 accelerated pulse cleaning cycles, representing 10,045 hours or $>1$ year of equivalent field service life. During this test segment, the array experienced 707 hours of operation at $1550^{\circ} \mathrm{F}$, and underwent 22 cold starts and 57 warm starts, where the array was heated at a rate of $400^{\circ}$ $500^{\circ} \mathrm{F} / \mathrm{min}$ from either room temperature or $\sim 750^{\circ} \mathrm{F}$, respectively, to $1550^{\circ} \mathrm{F} .^{8}$ Twelve filter elements, which included monolithic oxides and nonoxides, and oxide-based filament wound and CFCC matrices, successfully demonstrated their ability to achieve $>1$ year of equivalent PCFBC/PFBC operating life (Figure 3-2). Three failures resulted during conduct of accelerated pulse cycling in the extended filter life test program. These included thermal fatigue failure of an aged Coors P-100A-1 alumina/mullite candle (3761 equivalent operating hours), failure at the base of the flange of an aged DuPont PRD-66 candle (3108 equivalent operating hours), and delamination of the layered configuration and failure at the base of the flange of an aged 3M CVI-SiC candle (2373 equivalent operating hours). Due to the absence of the filter vessel shroud during the initial stages of testing, a 'thermally worn area' resulted which removed the outer surface membrane of the Pall 326 filter element (2453 equivalent operating hours), and failure of a second Pall 326 filter element ( 2453 equivalent operating hours) occurred at a similar location. Thermal fatigue, as well as removal of the Pall 326 outer surface membrane were considered to have resulted from direct impingement of the simulated PFBC gas stream along the outer surface of both filter elements.

In order to simulate a sequence of projected commercial turbine trip events during the course of plant life, the filter array was then subjected to thirty thermal transients in which an initial temperature drop of $180^{\circ} \mathrm{F} / \mathrm{min}$ was experienced, with cooling continuing until temperatures of $660^{\circ} \mathrm{F}$ were achieved during a 11-13 minute period. Subsequently the array was reheated to $1550^{\circ} \mathrm{F}$ within a $25-30$ minute period. Testing was completed in December 1998. After final disassembly of the filter array, thirteen of the fifteen candles remained intact, surviving both the accelerated pulse cycle and thermal transient test campaigns, while a newly manufactured Coors P-100A-1 alumina/mullite, and PCFBC-aged/accelerated pulse cycled Blasch candle experienced thermal fatigue failure or crack formation, respectively. The newly manufactured Coors filter element had been fabricated with the originally designed square vs radiused end cap. The square end cap had previously been identified to introduce stress risers and failure within the Coors elements. ${ }^{(6)}$ A detailed description of the extended accelerated life test program is presented in the following sections. Subsequently a description of the candle post-test inspection and material characterization results are presented.

\footnotetext{
${ }^{7}$ Fail-safe/regenerator units were positioned above each filter element. These units were comparable to fail-safe/regenerators used during PCFBC testing at the Foster Wheeler test facility in Karhula, Finland. ${ }^{8}$ The heating rate used during accelerated life testing exceeded the $180^{\circ} \mathrm{F} / \mathrm{hr}\left(100^{\circ} \mathrm{C} / \mathrm{hr}\right)$ heating rate used at the Foster Wheeler test facility in Karhula, Finland.
} 


\section{TABLE 3-1. SUMMARY OF THE EXTENDED FILTER LIFE TEST PROGRAM}

\begin{tabular}{|c|c|c|c|c|c|c|}
\hline \multirow[b]{2}{*}{$\begin{array}{l}\text { Array } \\
\text { Location/ } \\
\text { Supplier }\end{array}$} & \multirow[b]{2}{*}{$\begin{array}{c}\text { Steady State } \\
3 / 23 / 98- \\
3 / 26 / 98 \\
\end{array}$} & \multicolumn{5}{|c|}{ Accelerated Pulse Cycling } \\
\hline & & $\begin{array}{l}3 / 26 / 98-4 / 3 / 98 \\
\text { (2836 Pulses) }\end{array}$ & \begin{tabular}{|c|}
$5 / 21 / 98-$ \\
$5 / 28 / 98$ \\
(284 Pulses)
\end{tabular} & $\begin{array}{c}\text { 6/2/98- } \\
6 / 10 / 98 \\
\text { (1935 Pulses) }\end{array}$ & $\begin{array}{c}\text { 6/16/98- } \\
7 / 24 / 98 \\
\text { (4974 Pulses) }\end{array}$ & $\begin{array}{c}\text { 8/4/98- } \\
\text { 8/21/98 } \\
\text { (3494 Pulses) }\end{array}$ \\
\hline \multicolumn{2}{|c|}{$\begin{array}{l}\text { Total Cumulative Number of } \\
\text { Pulses }\end{array}$} & 2836 * & 3120 & 5055 & 10029 & 13523 \\
\hline 1 & - & - & -- & - & - & - \\
\hline $\begin{array}{c}2 \\
\text { Coors }\end{array}$ & $\begin{array}{c}\mathrm{FC}-044(\mathrm{M} 12) \\
2166 \mathrm{Hrs}\end{array}$ & $\begin{array}{c}\mathrm{FC}-044(\mathrm{M} 12) \\
2166 \mathrm{Hrs}\end{array}$ & $\begin{array}{c}\text { FC-044(M12) } \\
2166 \mathrm{Hrs}\end{array}$ & $\begin{array}{c}\text { FC-044(M12) } \\
2166 \text { Hrs }\end{array}$ & $\begin{array}{c}\text { FC-044 (M12) } \\
2166 \mathrm{Hrs}\end{array}$ & $\begin{array}{c}\text { FC-044(M12) } \\
2166 \mathrm{Hrs}\end{array}$ \\
\hline $\begin{array}{c}3 \\
\text { Coors } \\
\end{array}$ & $\begin{array}{c}\mathrm{FC}-065(\mathrm{M} 10) \\
2166 \mathrm{Hrs} \\
\end{array}$ & $\begin{array}{c}\text { FC-065 (M10) } \\
2166 \mathrm{Hrs} \\
\end{array}$ & $\begin{array}{c}\text { FC-065 (M10) } \\
2166 \mathrm{Hrs} \\
\end{array}$ & $\begin{array}{c}\text { FC.065 (M10) } \\
2166 \mathrm{Hrs}\end{array}$ & $\begin{array}{c}\mathrm{FC}-065(\mathrm{M} 10) \\
2166 \mathrm{Hrs}\end{array}$ & $\begin{array}{c}\mathrm{FC}-065(\mathrm{M} 10) \\
2166 \mathrm{Hrs}\end{array}$ \\
\hline $\begin{array}{c}4 \\
\text { Coors } \\
\end{array}$ & $\begin{array}{c}\mathrm{AB33}(\mathrm{T} 14) \\
3311 \mathrm{Hrs} \\
\end{array}$ & $\begin{array}{c}\text { AB33 (T14) } \\
3311 \mathrm{Hrs}\end{array}$ & $\begin{array}{c}\mathrm{AB} 33(\mathrm{~T} 14) \\
3311 \mathrm{Hrs}\end{array}$ & $\begin{array}{c}\text { AB33 (T14) } \\
3311 \text { Hrs }\end{array}$ & $\begin{array}{c}\text { AB33 (T14) } \\
3311 \text { Hrs } \\
\end{array}$ & $\begin{array}{c}\text { AB33 (T14) } \\
3311 \mathrm{Hrs} \\
\end{array}$ \\
\hline $\begin{array}{c}5 \\
\text { Coors } \\
\end{array}$ & $\begin{array}{c}\text { FC-001 (M14) } \\
2201 \mathrm{Hrs} \\
\end{array}$ & $\begin{array}{c}\text { FC-001 (Ml4) } \\
2201 \mathrm{Hrs}\end{array}$ & $\begin{array}{c}\mathrm{FC} \cdot 001(\mathrm{M} 14) \\
2201 \mathrm{Hrs}^{4}\end{array}$ & P $100 \mathrm{~A}$ - & $\begin{array}{c}\text { P-100A-1 } \\
\text { (New) }\end{array}$ & $\begin{array}{l}\text { P-100A-1 } \\
\text { (New) }\end{array}$ \\
\hline $\begin{array}{c}6 \\
\text { Coors/ } \\
\text { Ensto } \\
\end{array}$ & $\begin{array}{c}\text { FC-023 (T15) } \\
2201 \mathrm{Hrs}\end{array}$ & $\begin{array}{c}\mathrm{FC}-023(\mathrm{~T} 15) \\
2201 \mathrm{Hrs}^{1}\end{array}$ & $40058(126)$ & $\begin{array}{c}\text { FC-058 (M26) } \\
2166 \mathrm{Hrs}\end{array}$ & $\begin{array}{c}\mathrm{FC}-058(\mathrm{M} 26)^{6} \\
2166 \mathrm{Hrs}\end{array}$ & E \\
\hline $\begin{array}{c}7 \\
\text { Pall 326/ } \\
\text { 3M CVI-SiC }\end{array}$ & $\begin{array}{c}\text { R1-656 (M2) } \\
1035 \mathrm{Hrs}\end{array}$ & $\begin{array}{c}\mathrm{R} 1-656(\mathrm{M} 2) \\
1035 \mathrm{Hrs}^{2}\end{array}$ & 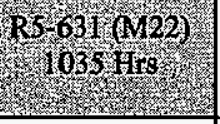 & $\begin{array}{c}\text { R5-631 (M22) } \\
1035 \text { Hrs }\end{array}$ & $\begin{array}{c}\text { R5-63! (M22) } \\
1035 \mathrm{Hrs}\end{array}$ & 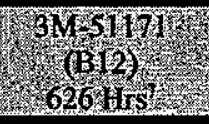 \\
\hline $\begin{array}{c}8 \\
\text { Schumacher } \\
\text { FT20/IF\&P } \\
\text { REECER } \\
\end{array}$ & $\begin{array}{c}\mathrm{S} 350 \mathrm{~F} / 16(\mathrm{~T} 2) \\
1035 \mathrm{Hrs}\end{array}$ & $\begin{array}{c}\mathrm{S} 350 \mathrm{~F} / 16(\mathrm{~T} 2) \\
1035 \mathrm{Hrs}\end{array}$ & $\begin{array}{c}\mathrm{S} 350 \mathrm{~F} / 16(\mathrm{~T} 2) \\
1035 \mathrm{Hrs}\end{array}$ & $\begin{array}{c}\mathrm{S} 350 \mathrm{~F} / 16(\mathrm{~T} 2) \\
1035 \mathrm{Hrs}\end{array}$ & $\begin{array}{c}\mathrm{S} 350 \mathrm{~F} / 16(\mathrm{~T} 2)^{6} \\
1035 \mathrm{Hrs}\end{array}$ & Tox \\
\hline $\begin{array}{c}9 \\
\begin{array}{c}\text { Schumacher } \\
\text { FT20 }\end{array} \\
\end{array}$ & $\begin{array}{c}\mathrm{S} 350 \mathrm{~F} / 32(\mathrm{~T} 3) \\
1035 \mathrm{Hrs}\end{array}$ & $\begin{array}{c}\mathrm{S} 350 \mathrm{~F} / 32(\mathrm{~T} 3) \\
1035 \mathrm{Hrs}\end{array}$ & $\begin{array}{c}\mathrm{S} 350 \mathrm{~F} / 32(\mathrm{~T} 3) \\
1035 \mathrm{Hrs}\end{array}$ & $\begin{array}{c}\mathrm{S} 350 \mathrm{~F} / 32(\mathrm{~T} 3) \\
1035 \mathrm{Hrs}\end{array}$ & $\begin{array}{c}\mathrm{S} 350 \mathrm{~F} / 32(\mathrm{~T} 3) \\
1035 \mathrm{Hrs}\end{array}$ & $\begin{array}{c}\mathrm{S} 350 \mathrm{~F} / 32(\mathrm{~T} 3) \\
1035 \mathrm{Hrs}\end{array}$ \\
\hline $\begin{array}{c}10 \\
\text { Pall } 326\end{array}$ & $\begin{array}{c}\mathrm{R} 1-658(\mathrm{M} 3) \\
1035 \mathrm{Hrs}\end{array}$ & $\begin{array}{c}\text { R1-658 (M3) } \\
1035 \text { Hrs }\end{array}$ & $\begin{array}{c}\mathrm{R} 1-658(\mathrm{M} 3) \\
1035 \mathrm{Hrs}\end{array}$ & $\begin{array}{c}\text { R1-658 (M3) } \\
1035 \text { Hrs }\end{array}$ & $\begin{array}{c}\mathrm{R} 1-658(\mathrm{M} 3) \\
1035 \mathrm{Hrs} \\
\end{array}$ & $\begin{array}{c}\mathrm{R} 1-658(\mathrm{M} 3) \\
1035 \mathrm{Hrs} \\
\end{array}$ \\
\hline $\begin{array}{c}11 \\
\text { Schumacher } \\
\text { FT20 }\end{array}$ & $\begin{array}{c}\text { S350F/60 (T5) } \\
1035 \mathrm{Hrs}\end{array}$ & $\begin{array}{c}\mathrm{S} 350 \mathrm{~F} / 60(\mathrm{~T} 5) \\
1035 \mathrm{Hrs}\end{array}$ & $\begin{array}{c}\mathrm{S} 350 \mathrm{~F} / 60(\mathrm{~T} 5) \\
1035 \mathrm{Hrs}\end{array}$ & $\begin{array}{c}\text { S350F/60 (T5) } \\
1035 \mathrm{Hrs}\end{array}$ & $\begin{array}{c}\mathrm{S} 350 \mathrm{~F} / 60(\mathrm{~T} 5) \\
1035 \mathrm{Hrs}\end{array}$ & $\begin{array}{c}\mathrm{S} 350 \mathrm{~F} / 60(\mathrm{~T} 5) \\
1035 \mathrm{Hrs}\end{array}$ \\
\hline $\begin{array}{c}12 \\
\text { Pall } 326\end{array}$ & $\begin{array}{c}\text { R1-659(M17) } \\
1035 \mathrm{Hrs}\end{array}$ & $\begin{array}{c}\text { R1-659(M17) } \\
1035 \mathrm{Hrs}\end{array}$ & $\begin{array}{c}\mathrm{R} 1-659(\mathrm{M} 17) \\
1035 \mathrm{Hrs}\end{array}$ & $\begin{array}{c}\text { R1-659(M17) } \\
1035 \mathrm{Hrs}\end{array}$ & $\begin{array}{c}\text { R1-659(M17) } \\
1035 \mathrm{Hrs}\end{array}$ & $\begin{array}{c}\text { R1-659 (M17) } \\
1035 \mathrm{Hrs}\end{array}$ \\
\hline 13 & - & - & - & - & - & - \\
\hline $\begin{array}{c}14 \\
\text { DuPont PRD- } \\
66 \\
\end{array}$ & $\begin{array}{c}\text { D581 (B42) } \\
581 \mathrm{Hrs}\end{array}$ & $\begin{array}{c}\text { D581 (B42) } \\
581 \mathrm{Hrs}\end{array}$ & $\begin{array}{c}\text { D581 (B42) } \\
581 \mathrm{Hrs}\end{array}$ & $\begin{array}{c}\text { D581 (B42) } \\
581 \mathrm{Hrs}^{5}\end{array}$ & H & $\begin{array}{c}\text { D571C } \\
\text { (New) }\end{array}$ \\
\hline $\begin{array}{c}15 \\
\text { McDermott }\end{array}$ & $\begin{array}{l}\text { B\&W 7-5-29 } \\
\text { (B32) 581 Hrs }\end{array}$ & $\begin{array}{l}\text { B\&W 7-5-29 } \\
\text { (B32) } 581 \mathrm{Hrs}\end{array}$ & $\begin{array}{l}\text { B\&W 7-5-29 } \\
\text { (B32) 581 Hrs }\end{array}$ & $\begin{array}{l}\text { B\&W 7-5-29 } \\
\text { (B32) 581 Hrs }\end{array}$ & $\begin{array}{l}\text { B\&W 7-5-29 } \\
\text { (B32) 581 Hrs }\end{array}$ & $\begin{array}{c}\text { B\&W 7-5-29 } \\
\text { (B32) 581 Hrs }\end{array}$ \\
\hline $\begin{array}{c}16 \\
\text { Pall } 326 \\
\end{array}$ & $\begin{array}{c}\text { Rl-667 (M4) } \\
1035 \text { Hrs } \\
\end{array}$ & $\begin{array}{c}\mathrm{R} 1-667(\mathrm{M} 4) \\
1035 \mathrm{Hrs}^{3}\end{array}$ & 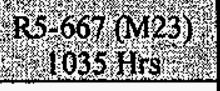 & $\begin{array}{c}\text { R5-667 (M23) } \\
1035 \text { Hrs }\end{array}$ & $\begin{array}{c}\mathrm{R} 5-667(\mathrm{M} 23) \\
1035 \mathrm{Hrs} \\
\end{array}$ & $\begin{array}{c}\mathrm{R} 5-667(\mathrm{M} 23) \\
1035 \mathrm{Hrs}\end{array}$ \\
\hline $\begin{array}{c}17 \\
\text { Schumacher } \\
\text { FT20 } \\
\end{array}$ & $\begin{array}{c}\mathrm{S} 350 \mathrm{~F} / 43(\mathrm{~T} 4) \\
1035 \mathrm{Hrs}\end{array}$ & $\begin{array}{c}\mathrm{S} 350 \mathrm{~F} / 43(\mathrm{~T} 4) \\
1035 \mathrm{Hrs}\end{array}$ & $\begin{array}{c}\mathrm{S} 350 \mathrm{~F} / 43(\mathrm{~T} 4) \\
1035 \mathrm{Hrs}\end{array}$ & $\begin{array}{c}\mathrm{S} 350 \mathrm{~F} / 43(\mathrm{~T} 4) \\
1035 \mathrm{Hrs}\end{array}$ & $\begin{array}{c}\mathrm{S} 350 \mathrm{~F} / 43(\mathrm{~T} 4) \\
1035 \mathrm{Hrs}\end{array}$ & $\begin{array}{c}\mathrm{S} 350 \mathrm{~F} / 43(\mathrm{~T} 4) \\
1035 \mathrm{Hrs}\end{array}$ \\
\hline $\begin{array}{c}18 \\
\text { Blasch } \\
\end{array}$ & $\begin{array}{l}\text { BP4-270P7/97 } \\
\text { (B41) 581 Hrs }\end{array}$ & $\begin{array}{l}\text { BP4-270P7/97 } \\
\text { (B41) 581 Hrs }\end{array}$ & $\begin{array}{l}\text { BP4-270P7/97 } \\
\text { (B41) 581 Hrs }\end{array}$ & $\begin{array}{l}\text { BP4-270P7/97 } \\
\text { (B41) 581 Hrs }\end{array}$ & $\begin{array}{l}\text { BP4-270P7/97 } \\
\text { (B41) 581 Hrs }\end{array}$ & $\begin{array}{l}\text { BP4-270P7/97 } \\
\text { (B41) 581 Hrs }\end{array}$ \\
\hline 19 & - & - & - & - & - & - \\
\hline & & & & & & \\
\hline
\end{tabular}




\section{TABLE 3-1 (Cont'd). SUMMARY OF THE EXTENDED FILTER LIFE TEST PROGRAM}

\begin{tabular}{|c|c|c|c|}
\hline $\begin{array}{l}\text { Array } \\
\text { Location/ } \\
\text { Supplier }\end{array}$ & $\begin{array}{c}\text { Accelerated } \\
\text { Pulse Cycling } \\
8 / 27 / 98 \\
10 / 5 / 98\end{array}$ & $\begin{array}{l}\text { Thermal } \\
\text { Transients } \\
11 / 11 / 98- \\
12 / 10 / 98\end{array}$ & Comments \\
\hline $\begin{array}{l}\text { Total Cumulative } \\
\text { Number of Pulses }\end{array}$ & 20089 & $\begin{array}{l}30 \text { Thermal } \\
\text { Transients }\end{array}$ & \\
\hline 1 & 二 & - & \\
\hline $\begin{array}{c}2 \\
\text { Coors } \\
\end{array}$ & $\begin{array}{c}\mathrm{FC}-044(\mathrm{M} 12) \\
2166 \mathrm{Hrs}^{8}\end{array}$ & 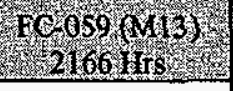 & FC-059 (M13) Intact - Continued Life Testing Planned \\
\hline $\begin{array}{c}3 \\
\text { Coors } \\
\end{array}$ & $\begin{array}{c}\mathrm{FC}-065(\mathrm{Ml0}) \\
2166 \mathrm{Hrs}\end{array}$ & $\begin{array}{c}\mathrm{FC}-065(\mathrm{M} 10) \\
2166 \mathrm{Hrs} \\
\end{array}$ & FC-065 (M10) Intact - Continued Life Testing Planned \\
\hline $\begin{array}{c}4 \\
\text { Coors } \\
\end{array}$ & $\begin{array}{c}\text { AB33 (T14) } \\
3311 \mathrm{Hrs}\end{array}$ & HOLD & - \\
\hline $\begin{array}{c}5 \\
\text { Coors }\end{array}$ & $\begin{array}{l}\text { P-100A-1 } \\
\text { (New) }\end{array}$ & $\begin{array}{l}\text { P-100A-1 } \\
\text { (New) }\end{array}$ & P-100A-1 Intact - Continued Life Testing Planned \\
\hline $\begin{array}{c}6 \\
\text { Ensto } \\
\end{array}$ & $\begin{array}{c}\text { E-141-97(B25) } \\
581 \mathrm{Hrs}\end{array}$ & $\begin{array}{l}\text { E-141-97(B25) } \\
581 \mathrm{Hrs} \\
\end{array}$ & E-141-97 (B25) Intact - Continued Life Testing Planned \\
\hline 7 & 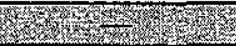 & - & $-\infty$ \\
\hline $\begin{array}{c}8 \\
\text { IF\&P REECER } \\
\end{array}$ & $\begin{array}{l}\text { IF\&P } \\
\text { 0 Hrs } \\
\end{array}$ & $\begin{array}{l}\text { IF\&P } \\
\text { O Hrs }\end{array}$ & IF\&P REECER Intact - Continued Life Testing Planned \\
\hline $\begin{array}{c}9 \\
\text { Schumacher FT20 }\end{array}$ & $\begin{array}{c}\mathrm{S} 350 \mathrm{~F} / 32(\mathrm{~T} 3) \\
1035 \mathrm{Hrs}\end{array}$ & $\begin{array}{c}\mathrm{S} 350 \mathrm{~F} / 32(\mathrm{~T} 3) \\
1035 \mathrm{Hrs}\end{array}$ & S350F/32 (T3) Intact - Continued Life Testing Planned \\
\hline $\begin{array}{c}10 \\
\text { Pall } 326 \\
\end{array}$ & $\begin{array}{c}\mathrm{R} 1-658(\mathrm{M} 3) \\
1035 \mathrm{Hrs}\end{array}$ & $\begin{array}{c}\mathrm{R} 1.658(\mathrm{M} 3) \\
1035 \mathrm{Hrs}\end{array}$ & R1-658 (M3) Intact - Continued Life Testing Planned \\
\hline $\begin{array}{c}11 \\
\text { Schumacher FT20 }\end{array}$ & $\begin{array}{c}\mathrm{S} 350 \mathrm{~F} / 60(\mathrm{~T} 5) \\
1035 \mathrm{Hrs}^{\mathrm{B}}\end{array}$ & 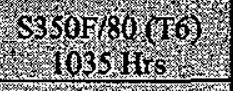 & $\mathrm{S} 350 \mathrm{~F} / 80$ (T6) Intact - Continued Life Testing Planned \\
\hline $\begin{array}{c}12 \\
\text { Pall } 326 \\
\end{array}$ & $\begin{array}{c}\mathrm{R} 1-659(\mathrm{M} 17) \\
1035 \mathrm{Hrs}^{8}\end{array}$ & 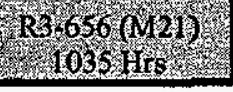 & R3-656 (M21) Intact - Continued Life Testing Planned \\
\hline $\begin{array}{c}13 \\
\text { Coors } \\
\end{array}$ & - & $100 \mathrm{~d}$ & $\begin{array}{l}\text { Circumferential failure at } \sim 24 \text { inches from the bottom closed end } \\
\text { cap. Failure occurred between thermal transient } \# 19 \text { and } \# 20 \text {. }\end{array}$ \\
\hline $\begin{array}{c}14 \\
\text { DuPont PRD-66 } \\
\end{array}$ & $\begin{array}{l}\text { DS71C } \\
\text { (New) }\end{array}$ & $\begin{array}{l}\text { D571C } \\
(\text { New })^{9} \\
\end{array}$ & D571C Intact - Continued Life Testing Planned \\
\hline $\begin{array}{l}15 \\
\text { McDermott }\end{array}$ & $\begin{array}{l}\text { B\&W 7-5-29 } \\
\text { (B32) } 581 \mathrm{Hrs}\end{array}$ & $\begin{array}{c}\text { B\&W 7-5-29 } \\
\text { (B32) } \\
581 \mathrm{Hrs}^{9} \\
\end{array}$ & $\begin{array}{l}\text { Depressions, debonding, and separation of areas visible along the } \\
\text { flange i.d.; Removal of chopped fiber material in localized areas } \\
\text { along o.d. surface exposing subsurface filament fiber bundles. }\end{array}$ \\
\hline $\begin{array}{c}16 \\
\text { Pall } 326 \\
\end{array}$ & $\begin{array}{c}\text { R5-667 (M23) } \\
1035 \mathrm{Hrs} \\
\end{array}$ & $\begin{array}{c}\mathrm{R} 5-667(\mathrm{M} 23) \\
1035 \mathrm{Hrs}^{9}\end{array}$ & R5-667 (M23) Intact - Continued Life Testing Planned \\
\hline $\begin{array}{c}17 \\
\text { Schumacher FT20 }\end{array}$ & $\begin{array}{c}\mathrm{S} 350 \mathrm{~F} / 43(\mathrm{~T} 4) \\
1035 \mathrm{Hrs} \\
\end{array}$ & $\begin{array}{c}\mathrm{S} 350 \mathrm{~F} / 43(\mathrm{~T} 4) \\
1035 \mathrm{Hrs}^{9}\end{array}$ & S350F/43 (T4) Intact - Continued Life Testing Planned \\
\hline $\begin{array}{c}18 \\
\text { Blasch }\end{array}$ & $\begin{array}{l}\text { BP4-270P7/97 } \\
\text { (B41) } 581 \mathrm{Hrs}\end{array}$ & $\begin{array}{c}\mathrm{BP} 4-270 \mathrm{P} 7 / 97 \\
(\mathrm{~B} 41) \\
581 \mathrm{Hrs}^{9} \\
\end{array}$ & $\begin{array}{l}\text { Longitudinal crack formation extending } \sim 2 \text { inches from the } \\
\text { bottom end cap to } \sim 20 \text { inches along the length of the candle filter. }\end{array}$ \\
\hline 19 & - & - & 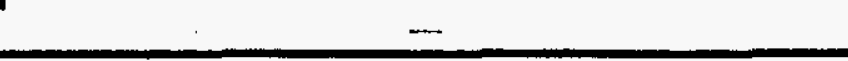 \\
\hline & Renlacement ele & Alracticizat & Elements removed as a result of in-situ or maintenance failure. \\
\hline
\end{tabular}




\section{TABLE 3-1 (Cont'd). SUMMARY OF THE EXTENDED FILTER LIFE TEST PROGRAM}

* Modification to the filter vessel shroud.

1. Originally intact, but broken during handling and removal from the filter array.

2. Failed after 2836 pulse cycles. Candle located adjacent to the shroud. Location was in direct line with the inlet combustion gas.

3. Thermally worn outer membrane section location was in direct line with the inlet combustion gas.

4. Failed after 3120 pulse cycles. Initially 5 pulse cycles were delivered on restart to acquire high speed thermocouple data, followed by $5-1 / 2$ hours of steady state testing, with pulse cleaning prior to shutdown. Subsequently 278 additional pulse cycles were delivered to the array prior to identifying a slight decrease in the pressure drop across the array. Effective cumulative operating life of 3761 hours (2201 PCFBC hours; 1560 accelerated pulse cycling hours).

5. Failure of the PRD-66 filter element at the base of the flange after 581 hours of PCFBC operation and subsequently 5055 accelerated pulse cleaning cycles. Effective cumulative operating life of 3108 hours (581 PCFBC hours; 2527 accelerated pulse cycling hours).

6. Elements removed for material characterization.

7. Failure of 3M CVI-SiC composite element: $626 \mathrm{hrs} \mathrm{PCFBC} \mathrm{operation;} 3494$ accelerated pulse cleaning cycles.

8. Elements removed for material characterization at the completion of 20,089 accelerated pulse cleaning cycles.

9. Elements instrumented with an outside/inside thermocouple ( 2 total; at the base of the flange).

10. New Coors P-100A-1 alumina/mullite element (out-of-spec) instrumented with 5 thermocouples; Three (3) along outside (top; middle; bottom) and two (2) thermocouples along i.d. bore (top/bottom) at nearly equivalent positions as along the outside wall.

\begin{tabular}{|c|c|}
\hline \multicolumn{2}{|c|}{ INTIAL TEST ARRAY } \\
- Steady State - \\
\hline Element & Location \\
\hline Coors P-100A-1 & $2,3,4,5,6$ \\
\hline Pall 326 & $7,10,12,16$ \\
\hline Schumacher FT20 & $8,9,11,17$ \\
\hline DuPont PRD-66 & 14 \\
\hline McDermott CFCC & 15 \\
\hline Blasch & 18 \\
\hline Other & $1,13,19$ \\
\hline
\end{tabular}

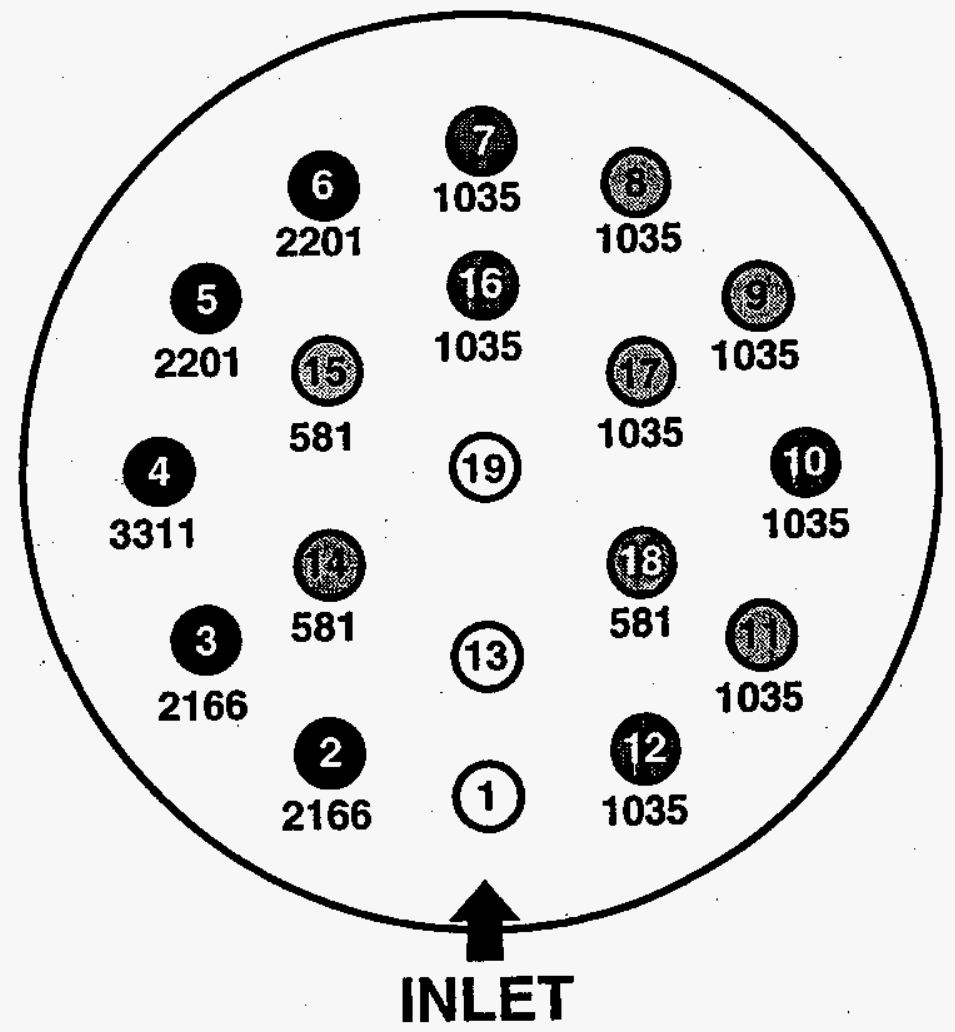

Figure 3-1 - Extended filter life test program array. Location of the elements are designated within each circle. The age of the PCFBC-exposed elements are identified below each filter position. 


\subsubsection{Steady State Testing}

Steady state testing was initiated on March 23, 1998 and continued through March 26, 1998 in the PFBC simulator test facility in Pittsburgh, PA (Figure 3-3). Initially sixteen candle filters (Table 3-1) were installed in a tubesheet array which was then lowered into the filter vessel. The test facility was closed, pressurized and heated to operating temperatures of $1550^{\circ} \mathrm{F}$ within 2 hours. During testing, the operating pressure of the unit was maintained at $68 \mathrm{psig.}$

In order to simulate the PFBC gas environment, natural gas was combusted, producing a $6 \% \mathrm{O}_{2}$, $7 \% \mathrm{CO}_{2}, 14 \%$ steam, and $73 \% \mathrm{~N}_{2}$ gas stream which then passed through the porous candle filter array at typical velocities of $5.5 \mathrm{ft} / \mathrm{min}$. Once at temperature and pressure, $\sim 1100 \mathrm{ppm}$ re-entrained PFBC ash was delivered to the filter array, forming the dust cake layer along the outer surface of the filter elements. The pressure differential across the filter array was permitted to increase to $\sim 65 \mathrm{in}-\mathrm{wg}$, prior to pulse cleaning. During conditioning of the filter elements, a pulse cleaning cycle was delivered to the filter array every 8 hours, returning the pressure differential to near baseline conditions. The duration of the pulse cleaning cycle was $0.3 \mathrm{sec}$. The thermal intensity ${ }^{9}$ of the pulse cleaning cycle was $\sim 50 \mathrm{BTU} / \mathrm{hr}^{\circ} \mathrm{ft}^{2}$, comparable to back pulse conditions used in pilot plant operations.

Steady state testing of the sixteen filter element array was conducted for a maximum of 12 hours during each of the four days. The combustor flame was extinguished each evening, and the unit was depressurized and slow cooled. By morning, the filter array temperature had decreased to $750-800^{\circ} \mathrm{F}$. In order to resume testing, the filter array temperature was increased to $1550^{\circ} \mathrm{F}$ within a one to two hour period. Steady state testing continued in this manner for a period of 40.5 hours. Isokinetic dust sampling was conducted at the end of each day in order to assure that the filter array was functionally intact (i.e., absence of failed filter elements and/or gasketing). Successful conduct of the 40.5 hour steady state operating period identified the initial viability of the PCFBC-aged filter elements for use in the extended filter life test program.

\subsubsection{Accelerated Pulse Cycling}

After completion of 40.5 hours of steady state testing on March 26, 1998, accelerated pulse cycling was initiated, subjecting the $1550^{\circ} \mathrm{F}, 68 \mathrm{psig}$, sixteen element filter array to pulse cleaning cycles every 2 minutes. In this manner, the effects of long-term thermal fatigue could be identified on the stability of the various ceramic filter matrices. On April 3, 1998, after 2836 accelerated pulse cycles had been achieved, an increase in the outlet dust load was observed, and the system was shutdown. Once cooled and the vessel opened, inspection identified that one Pall candle filter had failed (Location 7, R1656 (M2)). Upon lifting the array, and beginning dismantling, a second Pall element (Location 16, R1667 (M4)) which was directly in-line with the combustor gas flow inlet, was seen to be intact, but had a 'thermally worn area' which removed an $\sim 1-2$ inch elliptical section of the membrane and perhaps the underlying subsurface matrix (Figure 3-4). The failure location of R1-656 (M2) was at the same location as the 'thermally worn area' of R1-667 (M4). The failure and 'thermally worn area' of both elements were attributed, to direct impingement of the combustor inlet gas stream, since a shroud had not been installed in the PFBC simulator test facility. Alternate secondary or minor effects may have included

\footnotetext{
${ }^{9}$ Thermal intensity (TI) is defined as the heat rate of the pulse gas (air) delivered per filter surface area:$$
\mathrm{TI}=\left(\mathrm{m} \times \mathrm{c}_{\mathrm{p}} \times \Delta \mathrm{T}\right) / \mathrm{A} \text {. }
$$ 


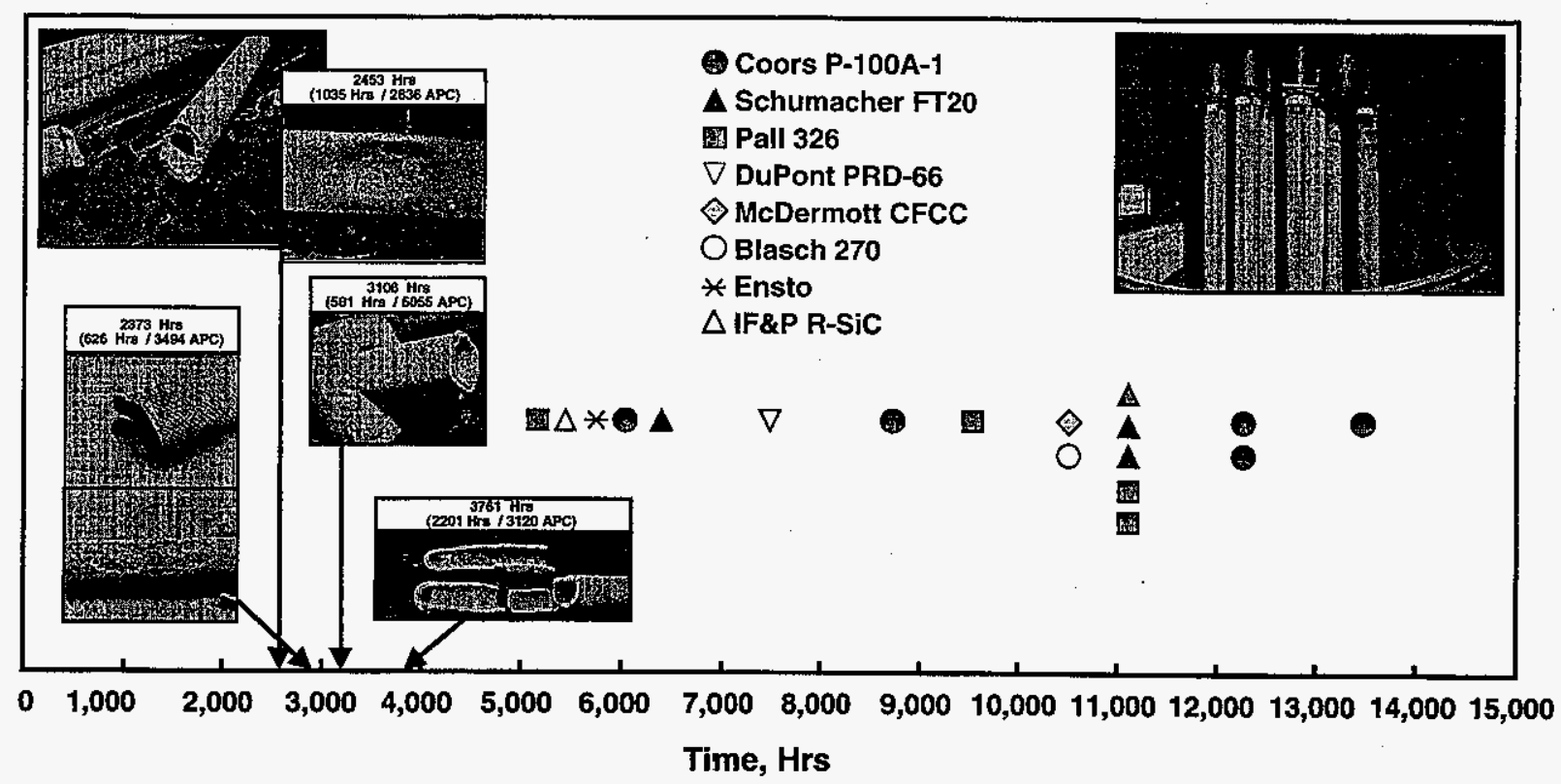

Figure 3-2 - Viability of the PCFBC/PFBC-exposed filter elements expressed in equivalent exposure hours achieved to date.

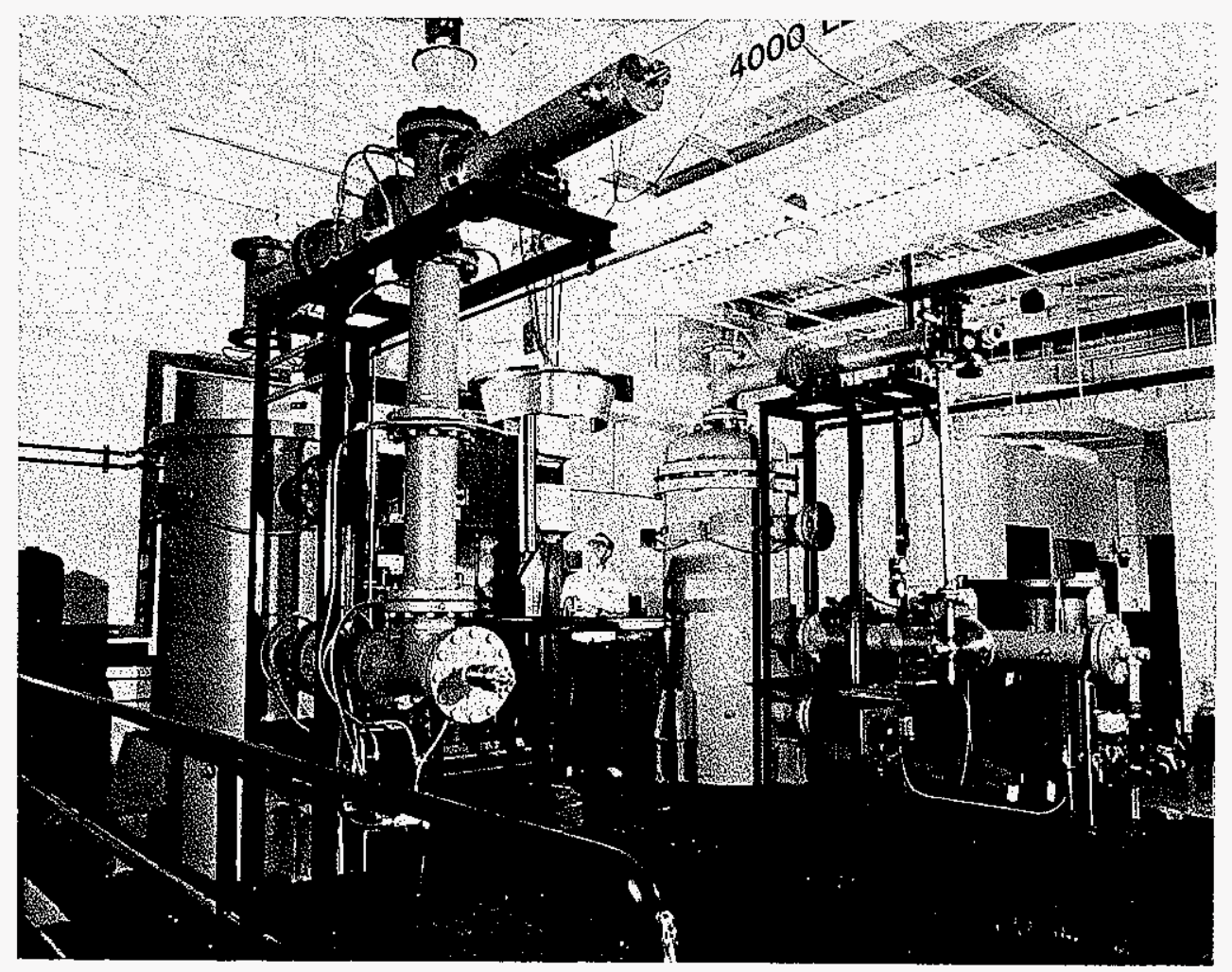

Figure 3-3 - SWPC STC PFBC simulator test facility. 


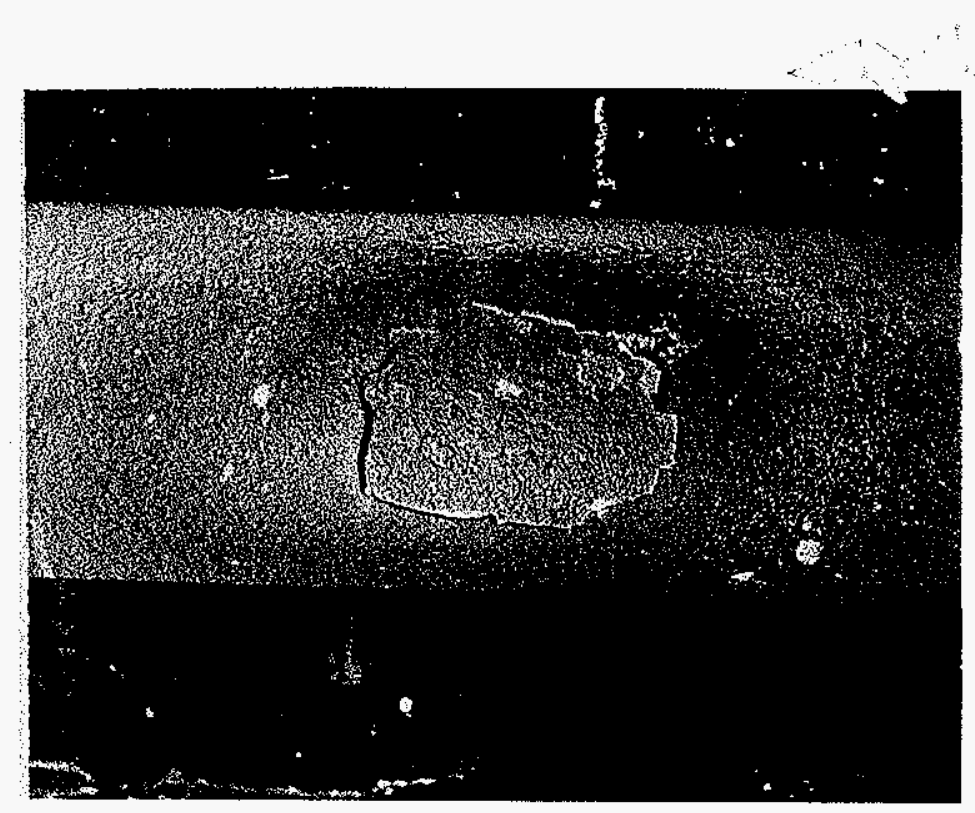

Figure 3-4 - Thermally worn area along the PCFBC-exposed Pall 326 candle filter.

thermal radiation from the combustion chamber that was $\sim 6 \mathrm{ft}$ from the "thermally worn area" and/or failure location of the Pall 326 filter elements. As a result, disassembly of the unit was undertaken, and a metal shroud was installed. Upon disassembly of the array, one of the Coors elements was inadvertently broken (Location 6, FC023 (T15)).

Characterization of a section of the filter membrane from around the periphery of the "thermally worn area' of the PCFBC-exposed Pall 326 filter element was conducted in an attempted to identify whether additional uptake of alkali into the clay bonded silicon carbide filter matrix had occurred, or alternately if microstructural analysis (SEM) could discern whether molten ash particles fused to the ceramic filter matrix. EDAX analysis of the section of the membrane that had been exposed to the PFBC simulator process gas stream identified the presence of $62.78 \% \mathrm{O}, 18.04 \% \mathrm{Ca}, 9.79 \% \mathrm{Mg}, 3.60 \% \mathrm{Si}$, $2.85 \% \mathrm{~S}, 1.66 \% \mathrm{Al}$, and $1.28 \% \mathrm{Fe}$ (i.e., atomic percent basis). Along a second section of the filter membrane that had been directly exposed to the PFBC simulator process gas stream, EDAX analysis identified the presence of $62.85 \% \mathrm{O}, 17.02 \% \mathrm{Ca}, 9.06 \% \mathrm{Mg}, 4.61 \% \mathrm{Si}, 2.94 \% \mathrm{~S}, 2.02 \% \mathrm{Al}$, and $1.53 \% \mathrm{Fe}$. These analyses reflected the presence of calcined dolomitic sorbent and ash fines. Notably, the sorbent contained a low concentration of sulfur.

Along the opposite surface of the removed membrane material (i.e., surface that was in contact with the underlying filter matrix), EDAX analyses identified the presence of $60.27 \% \mathrm{O}, 28.24 \% \mathrm{Si}$, $3.82 \% \mathrm{Ca}, 3.22 \% \mathrm{Al}, 2.08 \% \mathrm{Mg}, 1.14 \% \mathrm{Fe}$, and $0.66 \% \mathrm{~S}$. A second location of the material was characterized, and was identified to contain $60.85 \% \mathrm{O}, 31.22 \% \mathrm{Si}, 2.33 \% \mathrm{Al}, 2.22 \% \mathrm{Ca}, 1.54 \% \mathrm{Mg}$, $0.89 \% \mathrm{Fe}, 0.50 \% \mathrm{~K}$, and $0.46 \% \mathrm{~S}$. Although fines were identified to be present in this area, the quantity was negligible in comparison the presence of a silica-enriched phase. Sorption of gas phase alkali released from passage of the reentrained process fines had not occurred, and was not considered to enhance fluxing of the matrix, leading to spalling and ultimately the observed 'thermally worn area' along the outer surface of the PCFBC-exposed Pall 326 filter element. What was considered to have occurred was that the area of the Pall 326 filter element that was in direct line with the inlet combustion gas passage flow stream, experienced accelerated oxidation, leading to a localized area enriched with silica. 
Due the differences in thermal expansion of the localized silica-enriched area and the silicon carbide filter matrix, spalling occurred during vessel start-up and cool-down cycles. Alternate scenarios were proposed which attempted to explain the existence of the 'thermally worn area' as the result of thermal erosion of the filter matrix resulting from contact of the matrix for extended periods of time to the $\sim 6 \mathrm{ft} / \mathrm{min}$ combustion gas stream. Thus in order to avoid the formation of 'thermally worn areas' and/or failure of the filter elements during field operation, direct gas impingement with the filter surface must be avoided.

The temperature ramp utilized to heat the filter vessel from cold start (i.e., $\sim 500^{\circ} \mathrm{F} / \mathrm{hr}$; Figure 35), and the somewhat less severe thermal ramp rate utilized to heat the array after cool-down over night (i.e., $\sim 300-350^{\circ} \mathrm{F} / \mathrm{hr}$; Figure 3-6) were evaluated in view of commercial operation, as well as to the potential to induce high stress, ultimately causing failure of the various porous filter matrices. A $1 / 4$-inch sheathed thermocouple positioned within the filter array was utilized to control and monitor the vessel temperature. Similarly, a $1 / 4$-inch sheathed thermocouple was positioned within the combustion passage. As shown in Figure 3-7, the combustion passage temperature was higher than the internal vessel temperature. Since thermocouples were not positioned along the 'thermally worn area' of the Pall 326 filter element, the actual temperature experienced at this location, was considered to fall between the identified combustion passage inlet temperature and vessel temperature shown on Figure 3-7.

In order to continue to conduct extended life testing, three additional PCFBC-exposed filter elements were requested to be shipped from Karhula, Finland, to be used as replacements for the failed filter elements. The following Pall 326 and Coors P-100A-1 alumina/mullite elements were received during the first week of May 1998:

- Coors FC-058 (M26) - 2166 hrs PCFBC operation

- Pall R5-631 (M22) - 1035 hrs PCFBC operation

- Pall R5-667 (M23) - 1035 hrs PCFBC operation.

Modification of the liner and installation of the shroud within the PFBC simulator was accomplished by May 15, 1998. Candles were reinstalled into their original positions, with FC- 058 being positioned in Location 5 replacing FC-023, R5-631 in Location 7 replacing R1-656, and R5-667 in Location 16 replacing R1-667 (Table 3-1). In addition, each fail-safe/regenerator unit was wrapped with a gasket sleeving material to prevent racheting of the units during continued pulse cleaning. One failsafe/regenerator that had initially been manufactured for use in the SWPC mini-filter vessel at Piñon Pine was installed within the array.

High speed Type $\mathrm{K}$ exposed junction ( 20 mil sheath; 4 mil wire) thermocouples were installed through the fail-safe/regenerators and into the i.d. bore of the hemispherical flange of candles located in Locations 16 and 17 (R5-667 and S350F/43, respectively). Testing resumed on May 21, 1998. Five pulse cycles were delivered to the array, and the temperature drop within the elements was monitored. An $\sim 100^{\circ} \mathrm{F}$ and $\sim 45^{\circ} \mathrm{F}$ temperature drop inside the top of each element was repeatedly measured during delivery of each pulse cleaning cycle. The variation in temperature was considered to have resulted from the variability in the condition of the fail-safe/regenerator units that were used since many had previously experienced significant hours of prior operation in the W-APF system at the AEP Tidd Demonstration Plant in Brilliant, Ohio, and to the gas flow resistance of the attached candle.

After delivery of the 5 pulse cleaning cycles, the filter array was subjected to $\sim 5-1 / 2$ hours of steady state testing, and an additional pulse cleaning cycle. A dust outlet measurement was taken to assure complete sealing and barrier filtration performance of the filter array. This segment of testing was completed prior to shutdown for the May 25, 1998, Memorial Day holiday weekend. 


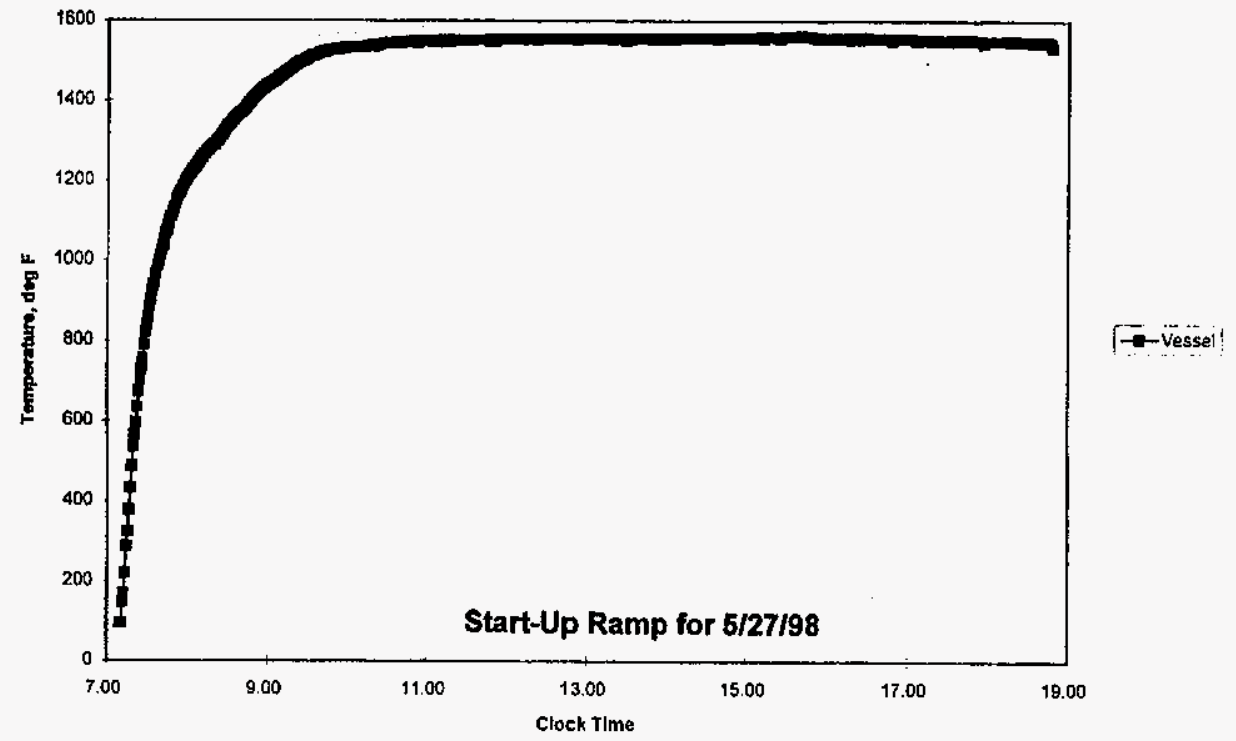

Figure 3-5 - Temperature profile of the filter array during heat-up from a cold start.

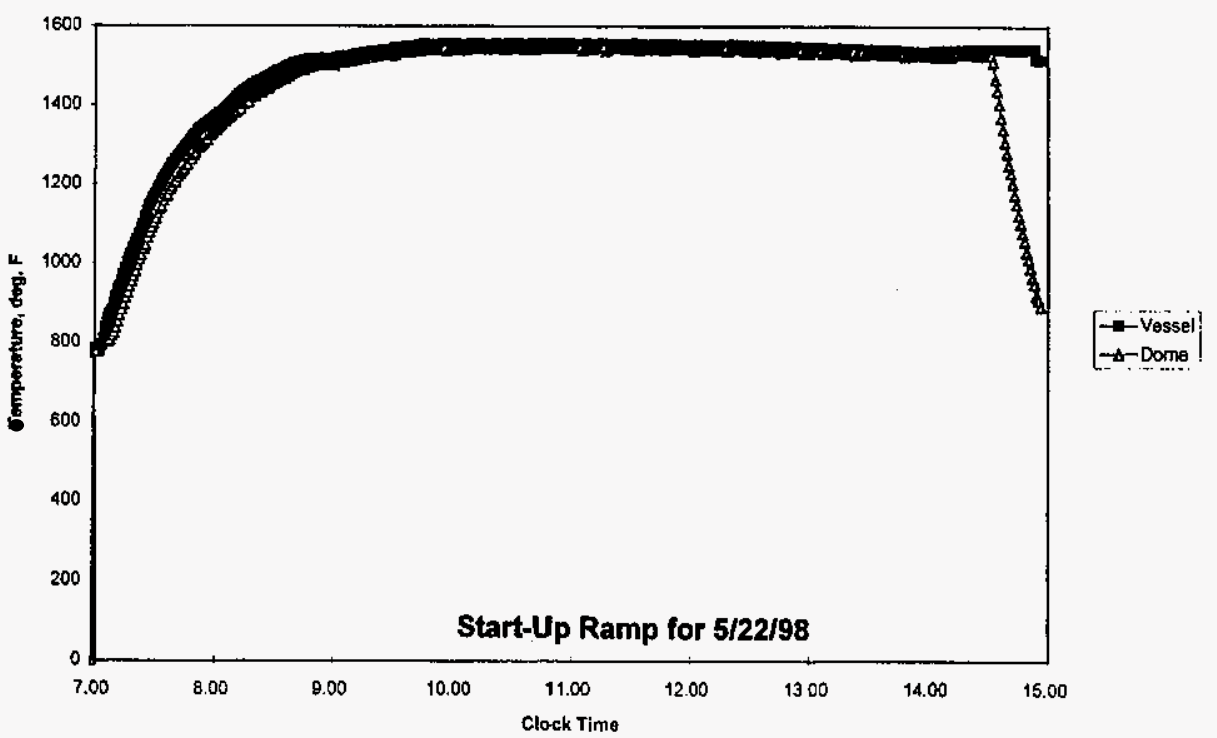

Figure 3-6 - Temperature profile of the filter array during heat-up from a warm restart. 


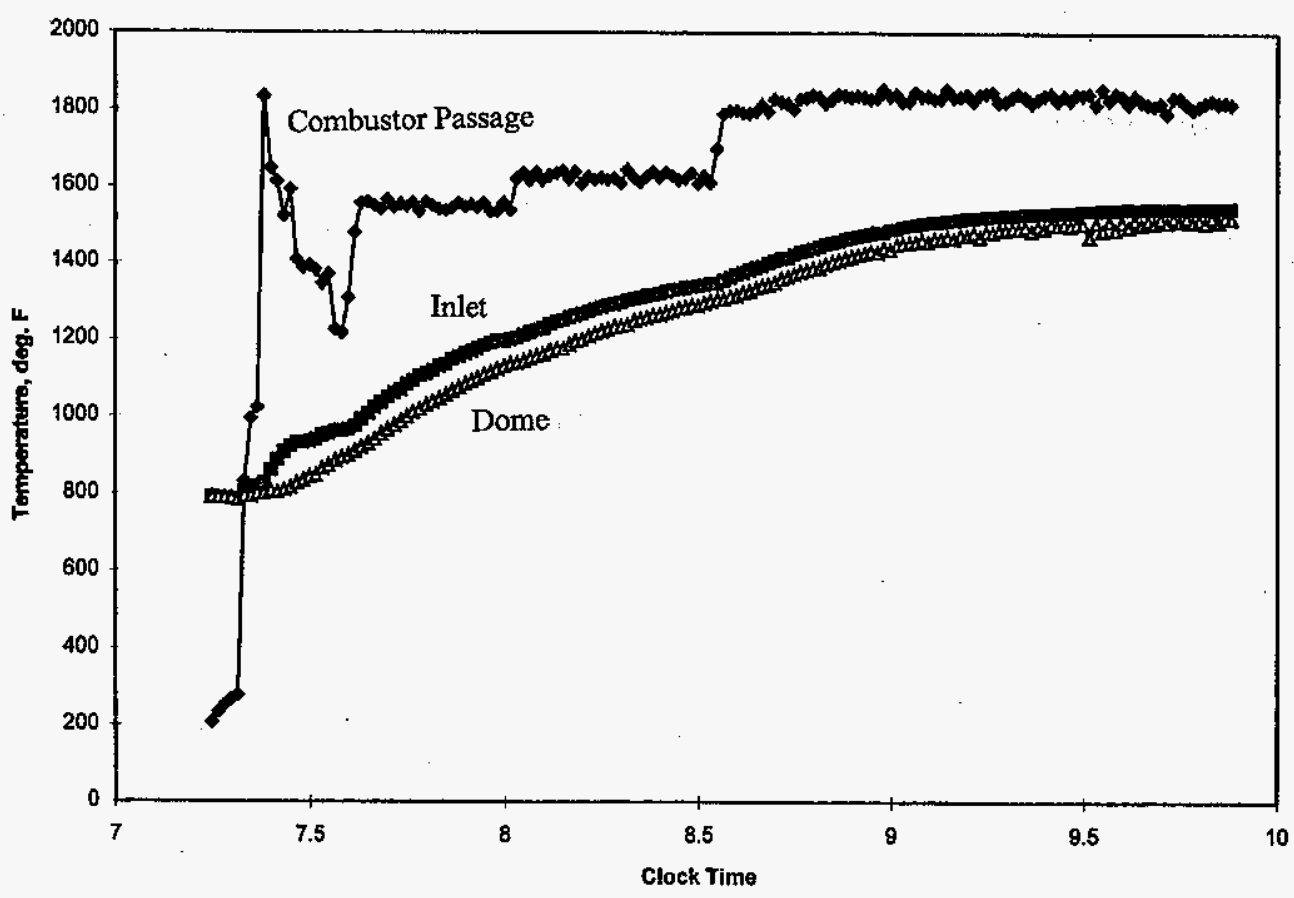

Figure 3-7 - Filter array and combustion passage temperature profiles during initiation of testing.

Testing resumed on May 27, 1998, and an additional 278 pulse cleaning cycles were delivered to the filter array. A drop in system pressure was identified at $\sim 4: 15 \mathrm{pm}$, and pieces of an filter end cap were found in the ash hopper. Testing was terminated, and the system was slow cooled. Disassembly of the unit on May 29, 1998 indicated that the Coors filter element located in Location 5 (FC-001 (M14; 2201 hrs PCFBC operation) had failed after delivery of 3120 pulse cleaning cycles. Figure 3-8 provides a photograph of the $\sim 9$ inch failed Coors filter end cap region that was removed from the ash hopper. As shown in Figure 3-8, the failure was nearly circumferential, with longitudinal splitting and Hackel lines that typically result due to thermal fatigue of the Coors P-100A-1 alumina/mullite filter matrix. The remainder of the candle appeared to be intact.

After removal of FC-001 from the array, a newly manufactured Coors P-100A-1 alumina/mullite filter element was installed in Location 5. This element was identified to be dimensionally out-of-spec, and was not targeted for field service operation. No other filter elements were removed from the array, and the unit was reassembled for continued operation.

Testing was reinitiated on June 2, 1998, and continued through June 10, 1998, prior to detection of dust in the outlet gas stream. During this time, the filter array had acquired an additional 1935 pulse cleaning cycles. Inspection of the filter array after cool-down identified that failure at the base of the flange of the 581 hour, PCFBC-exposed, DuPont PRD-66 candle had occurred (Location 14; Figure 3-9). During extended life testing, this element experienced a total of 5055 accelerated pulse cleaning cycles. A newly manufactured DuPont PRD-66 filter element was installed in the failed DuPont PRD-66 filter location.

Testing was reinitiated on June 16,1998 . On June 22,1998 , failure of an o-ring in the compressor solenoid occurred, and testing was terminated. Maintenance on the compressor was completed, and testing resumed on June 23, 1998. At the end of June, the PCFBC-exposed filter array 


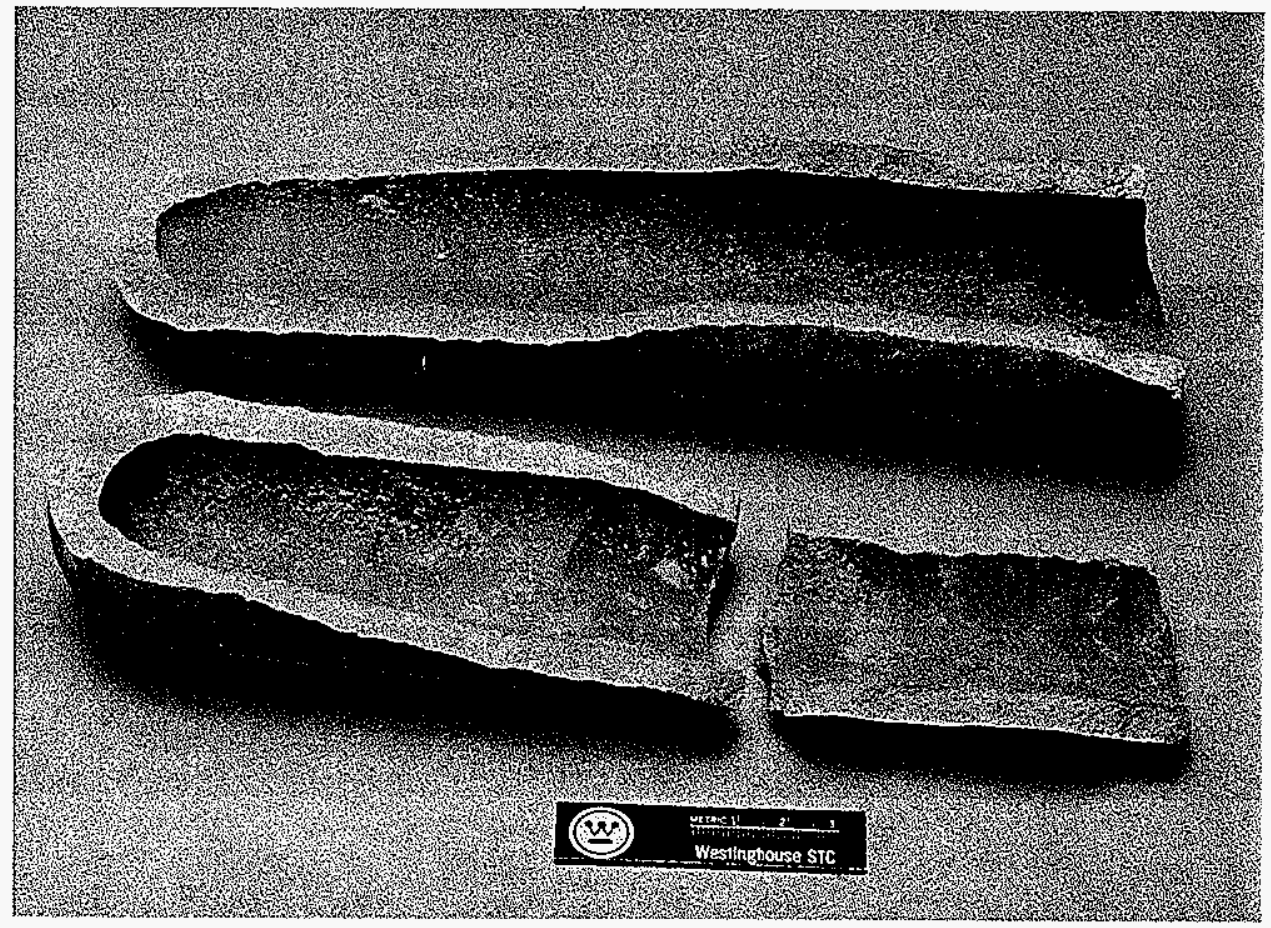

Figure 3-8 - Fractured PCFBC-exposed Coors P-100A-1 alumina/mullite candle filter.

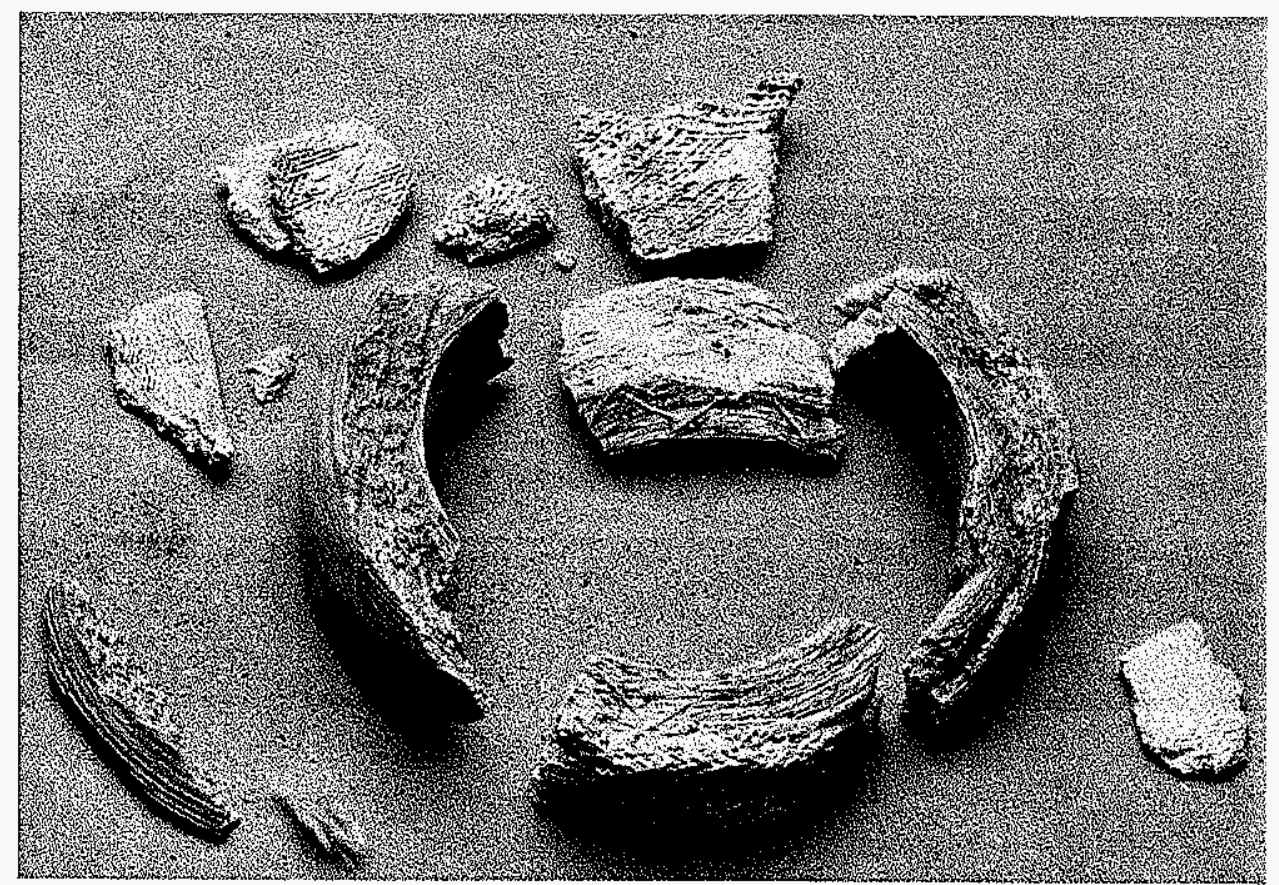

Figure 3-9 - Fractured flange of the DuPont PRD-66 candle filter. Initially failure had occurred at the base of the flange, leaving the flange wedged in the filter holder mount. During removal, additional cracking of the flange resulted. 
had been subjected to $>6425$ accelerated pulse cleaning cycles in the PFBC simulator test facility in Pittsburgh, PA. Figure 3-10 illustrates the variation in the candle filter failure location that resulted during extended life cycle testing in the PFBC simulator test facility.

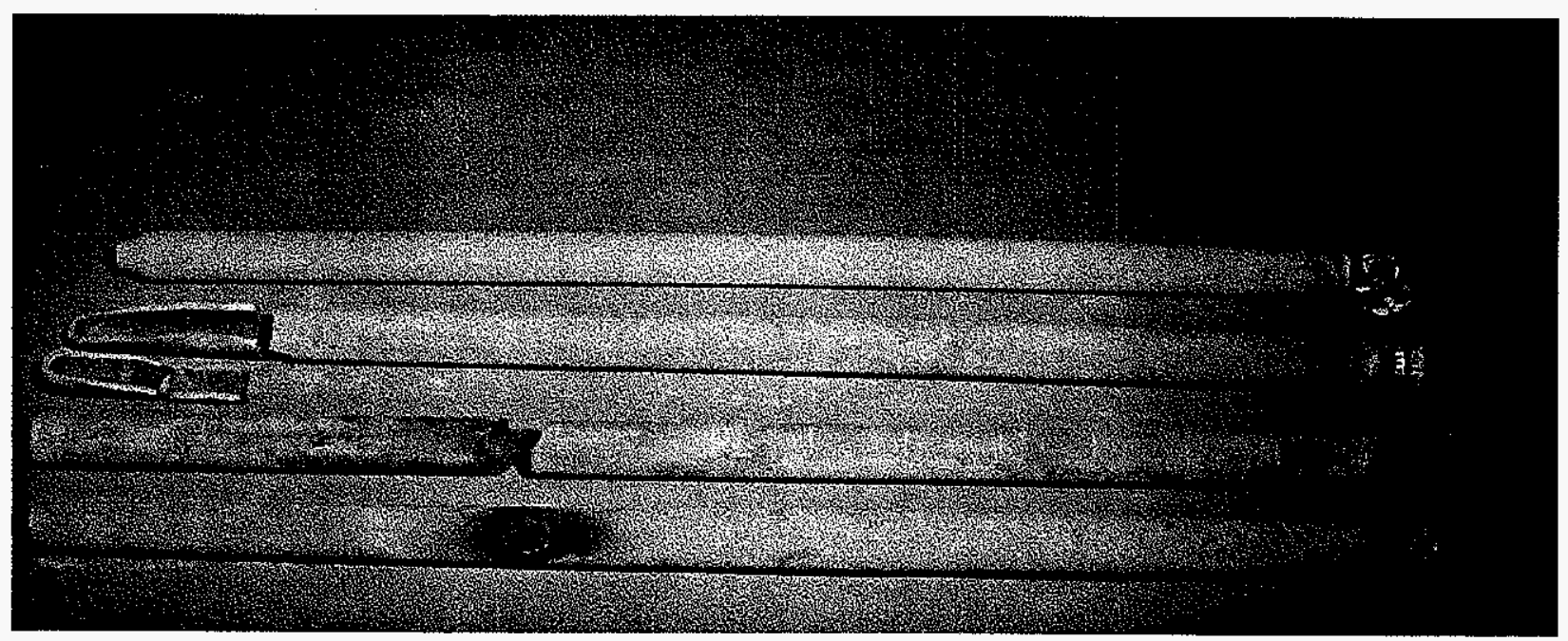

Figure 3-10 - Candle filter failure locations. Candles include DuPont PRD-66 (Top), Coors P-100A-1 Alumina/Mullite, Pall 326, and Pall 326 (Bottom)

Extended life testing of the PCFBC-aged candle filter continued through July 24, 1998, whereupon 10,029 accelerated pulse cleaning cycles (i.e., 5015 hours of equivalent process operation assuming delivery of a pulse cleaning cycle every 30 minutes) had been delivered to the filter array. At this time, testing was terminated in order to remove the following three candle filter for material characterization:

- 2166 hr PCFBC-aged Coors P-100A-1 candle FC-058 (M26) (Location 6) with 7193 accelerated pulse cleaning cycles. Equivalent exposure hours: $5762.5 \mathrm{hrs}$.

- 1035 hr PCFBC-aged Pall 326 candle R5-631 (M22) (Location 7) with 7193 accelerated pulse cleaning cycles. Equivalent exposure hours: 4631.5 hrs.

- $1035 \mathrm{hr}$ PCFBC-aged Schumacher Dia Schumalith FT20 candle S350F/16 (T2) (Location 8) with 10,029 accelerated pulse cleaning cycles. Equivalent exposure hours: $6049.5 \mathrm{hrs}$.

As shown in Table 3-1, the positions of the removed filter elements were filled with:

- $581 \mathrm{hr}$ PCFBC-aged Ensto candle E-141-97 (B25) (Location 6)

- $626 \mathrm{hr}$ PCFBC-aged 3M CVI-SiC candle 3M-51171 (B12) (Location 7)

- As-manufactured IF\&P REECER (Recrystallized SiC) candle (Location 8). 
For the Coors P-100A-1 alumina/mullite candle filter which had acquired a total of 3311 hours of testing (i.e., 1110 hours at the AEP PFBC Tidd Demonstration Plant in Brilliant, Ohio, and 2201 hours at the Foster Wheeler PCFBC test facility in Karhula, Finland), exposure to 10,029 simulated pulse cleaning cycles represented $8326 \mathrm{hrs}$ of operation or an equivalent of $>1$ year of service operating life (i.e., $>8000$ hrs).

Extended filter life testing of the PCFBC-aged candle filters resumed on August 4, 1998 (Table 31). A decrease in system $\Delta \mathrm{p}$ was identified on Friday, August 21, 1998. Characterization of the coarse PFBC ash outlet loading indicated a $24 \mathrm{mg}$ increase over the baseline dust outlet loading early in the morning of August 21,1998, and subsequently a $159 \mathrm{mg}$ increase over baseline during mid-morning/early afternoon of August 21, 1998. The system was cooled, opened, and inspected on Monday, August 24, 1998.

Failure of the 3M CVI-SiC composite candle filter 3M-51171 (B12) in Location 7 was identified during post-test inspection (Figure 3-11). All other filter elements remained intact. The 3M CVI-SiC element had previously been exposed at Karhula for 626 hours prior to failure at STC after being subjected to 3494 pulse cleaning cycles. The equivalent exposure hours or cumulative operating life of this element was therefore 2373 hours.

Further inspection indicated that failure of the 3M CVI-SiC element resulted from

- Descaling of the outer confinement layer and filtration mat at $\sim 37-52 \mathrm{~cm}(\sim 14.5-20.5$ inches) from the base of the flange. The descaled area was $150 \mathrm{~mm}$ long $\times 30-40 \mathrm{~mm}$ wide.

- The triaxial braid weave was exposed in many areas, permitting dust to penetrate into the i.d. bore of the candle.

- Embrittlement of Nextel ${ }^{\mathrm{TM}} 312$ fibers was evident. Debonding and removal of tie-fibers at base of the flange was observed.

- Failure at the base of the flange.

- A $3.8 \mathrm{~cm}(\sim 1-1 / 2$ inch) section of the contoured flange base remained attached to the filter body.

- Three bolts/nuts were removed from the ash hopper. The lower cast nut was held onto the filter holder mount via the fourth double lock bolt/nut.

- The metal insert/fail-safe-regenerator unit appeared to have dropped, and was held within the metal holder via the bottom cast nut.

- The inner or primary gasket seal was intact and retrieved from the ash hopper.

- The secondary gasket seal was frayed, but remained along the filter body.

With the exception of failure at the flange and descaling of the outer layers, the remainder of the 3M CVI$\mathrm{SiC}$ filter body was intact. Thus the proposed failure mechanisms for the $3 \mathrm{M} \mathrm{CVI-SiC} \mathrm{composite} \mathrm{candle}$ filter during extended accelerated life testing at SWPC include

- Matrix Failure

- Debonding of the outer confinement and filtration mat layers due to reduced bonding to the underlying triaxial support braid.

- Element Failure

- Loosening of the filter holder fixturing due to repeated pulse cycling

- Failure of the bolts due to higher impact loading and fatigue

- Failure of the filter flange. 
The same metal insert hardware had been utilized to install the 3M CVI-SiC candles within the filter array at SWPC STC as at AEP and Karhula. Unlike AEP and Karhula, ash had not wedged between the candle and filter holder during testing at SWPC STC to prevent movement and/or loosening of the bolts/nuts. Due to extended use in the actual process gas environment, oxidation of the metal bolts/nuts was expected to have resulted to a greater extent at AEP and at Karhula preventing loosening and/or movement of the bolts/nuts, in comparison to the extent of oxidation which resulted at SWPC STC. In order to prevent loosening of bolts/nuts during continued extended accelerated life testing at SWPC STC, the filter holder nuts were wired similar to standard practices used on rotating equipment in the aerospace and turbine industry.
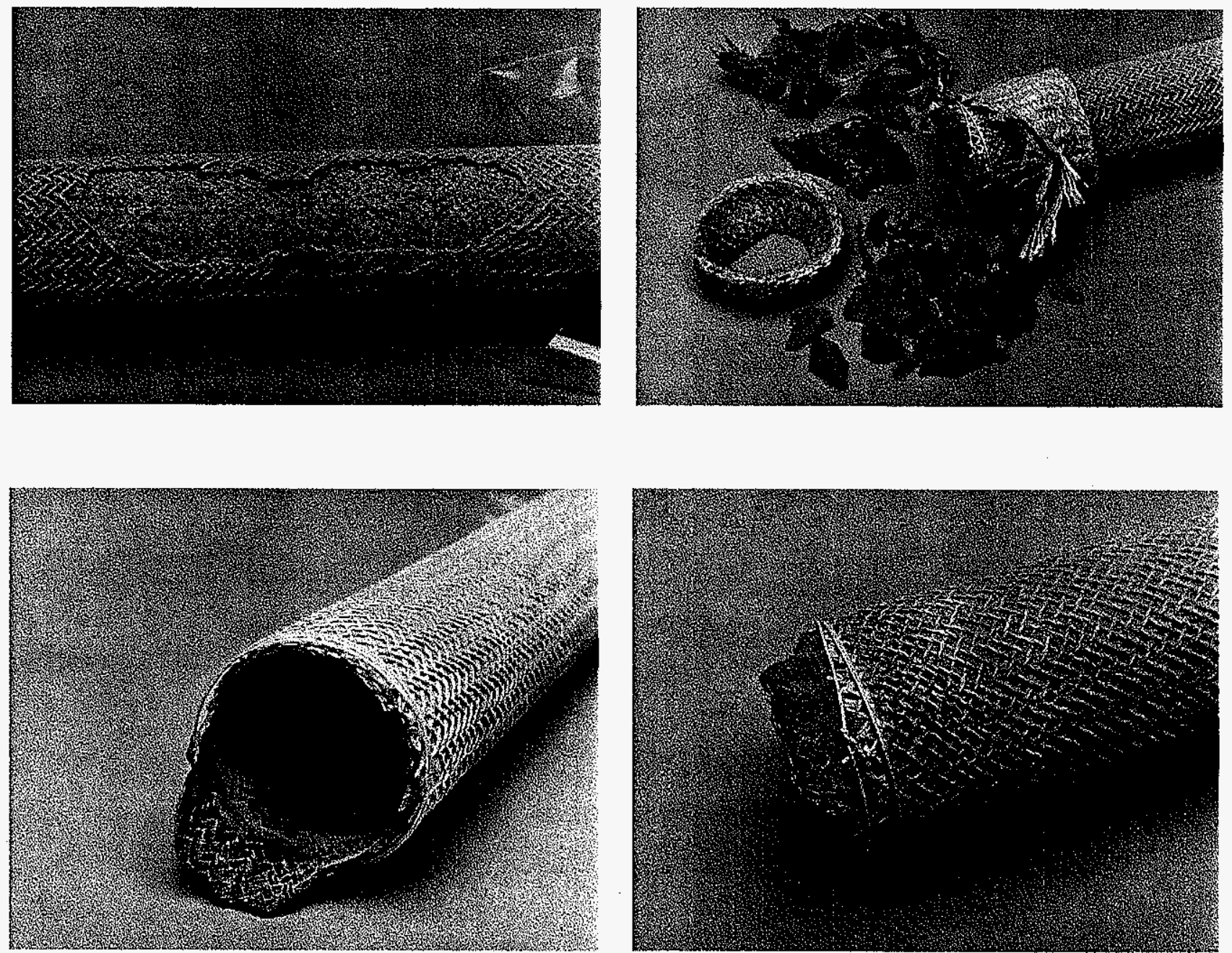

Figure 3-11 - Debonding of the outer confinement layer and filtration mat, and failure of the flange of the PCFBC-exposed/extended life-tested 3M CVI-SiC composite candle filter. 
After removal of the failed 3M CVI-SiC filter element from the array, Location 7 was blankedoff, and the system was reassembled. Testing resumed on August 27, 1998. With the exception of experiencing a leak in the filter system exhaust line on September 16, 1998 which caused testing to be terminated for one day, no issues were encountered during September 1998. Testing continued until October 5, 1998, whereupon 20,089 accelerated pulse cleaning cycles had been delivered to the filter array (i.e., 10,045 equivalent operating hours), representing $>1$ year of equivalent exposure operating hours. Twelve filter elements remained intact during conduct of the entire accelerated pulse cycle test program. Although this effort simulated $>1$ year of equivalent process operating life, the 581-2201 hour, PCFBC-exposed, filter elements experienced $\sim 707$ hours of operation in the PFBC simulator test facility, undergoing 22 cold and 57 warm starts.

After removal of the elements from the filter array at the conclusion of the accelerated pulse cycle test segment, each element was inspected and gas flow permeability tested. With the exception of minor surface abrasions on the McDermott candle filters, all elements were identified to be intact. The resulting room temperature gas flow resistance measurements for the extended filter life-tested elements are presented in Figures 3-12 through 3-15. Ash was removed from the outer surface of each element via vacuuming prior to testing.

During conduct of the final segment of the accelerated pulse cycle test program, temperature profiles generated throughout the vessel and filter array (Figure 3-16) were identified via the following thermocouples:

- Combustor: $1 / 8$ inch Type $\mathrm{K}$

- Inlet: $1 / 8$ inch Type $\mathrm{K}$

- Vessel (Passage): $1 / 4$ inch Type K

- Outside Candle: 0.020 inch Type K (Exposed Bead)

- Inside Candle: 0.020 inch Type K (Exposed Bead)

- Outlet: $1 / 8$ inch Type $\mathrm{K}$.

A maximum temperature difference of $180^{\circ} \mathrm{F}$ was recorded during the first hour of heating from cold start $\left(70^{\circ} \mathrm{F}\right)$ between the o.d. surface and i.d. bore of the candle (Figure 3-17). Both the outer and inner wall temperatures were nearly identical once temperatures of $1000^{\circ} \mathrm{F}$ were achieved.

\subsubsection{Thermal Transient Testing}

In order to identify the potential viability and life of each filter element during commercial operation, the ceramic candle filter array was subjected to a series of simulated thermal transient excursions, typical of what may be experienced during field operation. Testing included

- Initial operation of the filter array at PCFBC process temperatures (i.e., $1550^{\circ} \mathrm{F}$ ).

- Reduction in process temperature at a rate of $-180^{\circ} \mathrm{F} / \mathrm{min}\left(-100^{\circ} \mathrm{C} / \mathrm{min}\right)$ until temperatures of $660^{\circ} \mathrm{F}\left(350^{\circ} \mathrm{C}\right)$ were achieved.

- Rapid reheating of the array, with subsequent repetition of the thermal transient event, achieving 30 thermal transient cycles to reflect commercial service life.

- Conduct of the thermal transient event with simultaneous pulse cycling. 


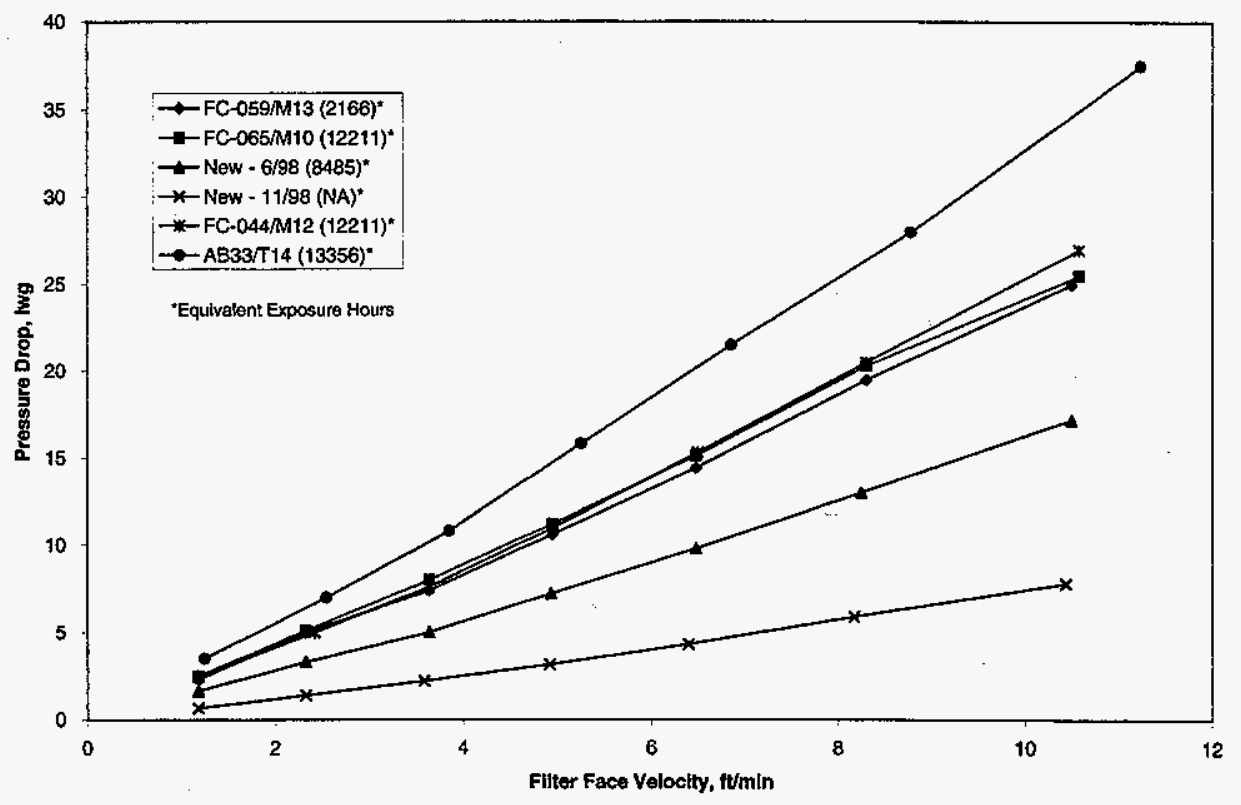

Figure 3-12 - Gas flow resistance of the Coors P-100A-1 alumina/mullite extended life-tested filter elements.

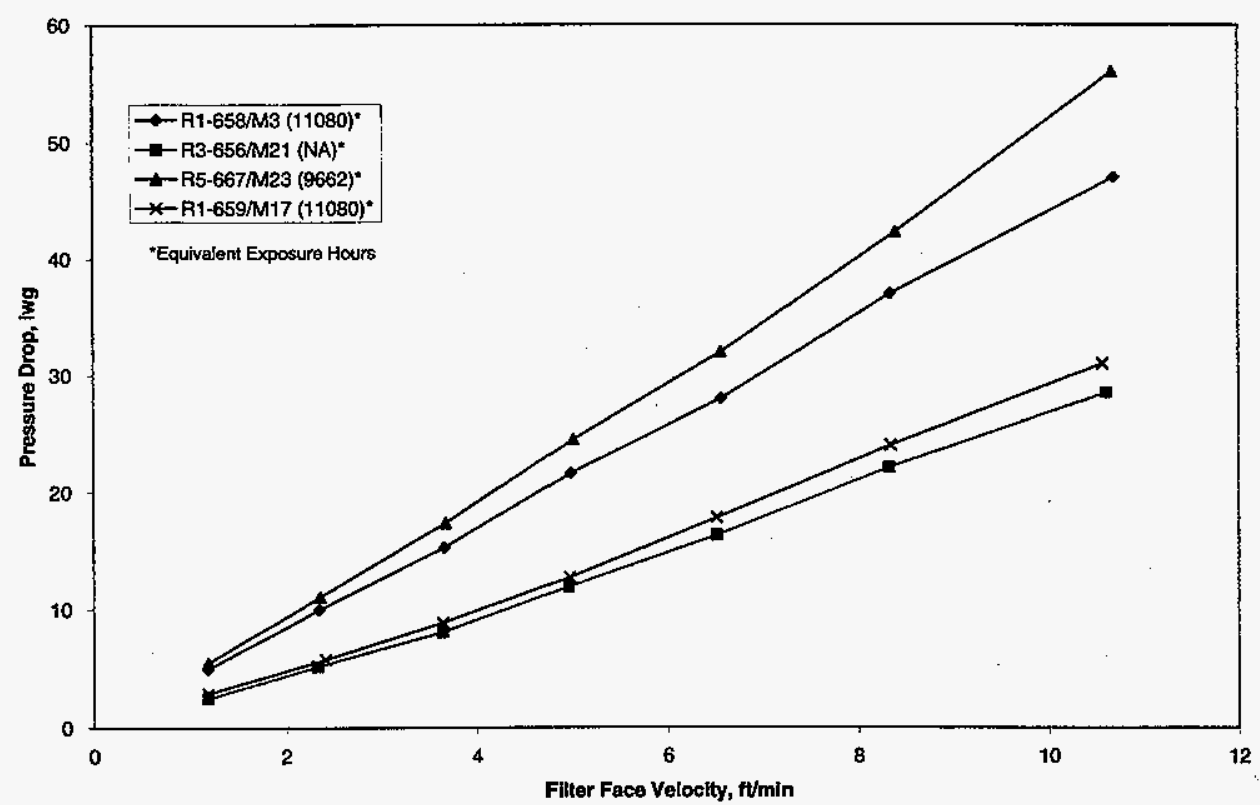

Figure 3-13 - Gas flow resistance measurements of the Pall 326 extended life-tested filter elements. 


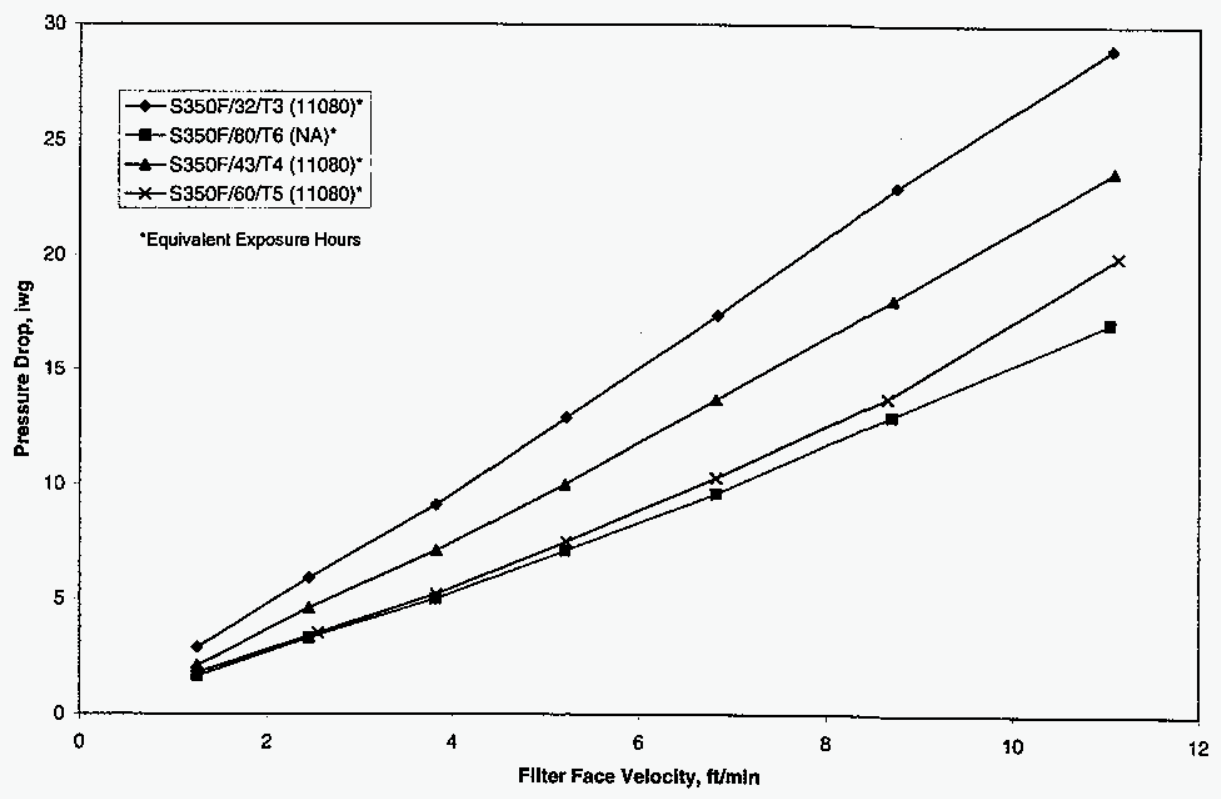

Figure 3-14 - Gas flow resistance measurements of the Schumacher Dia Schumalith FT20 extended life-tested filter elements.

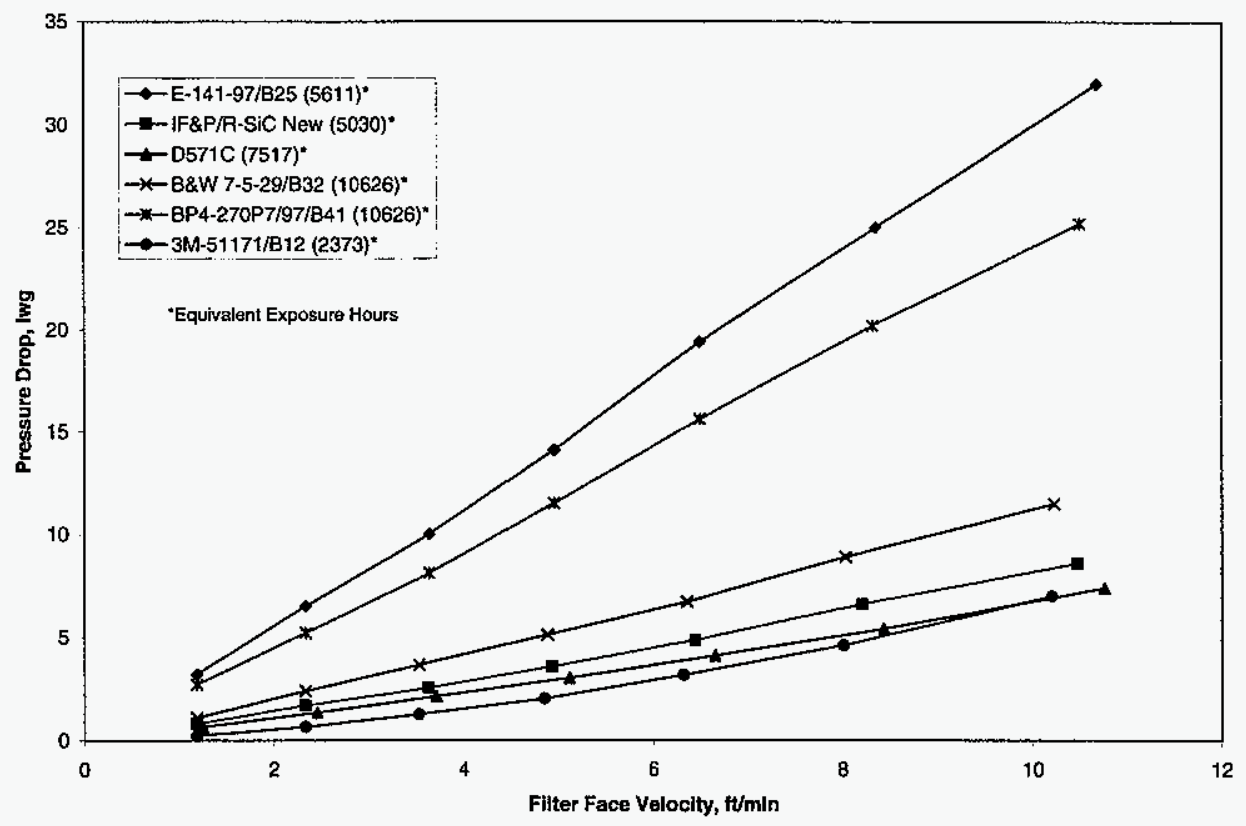

Figure 3-15 - Gas flow resistance of the advanced monolithic, filament wound, and composite extended life-tested filter elements. 


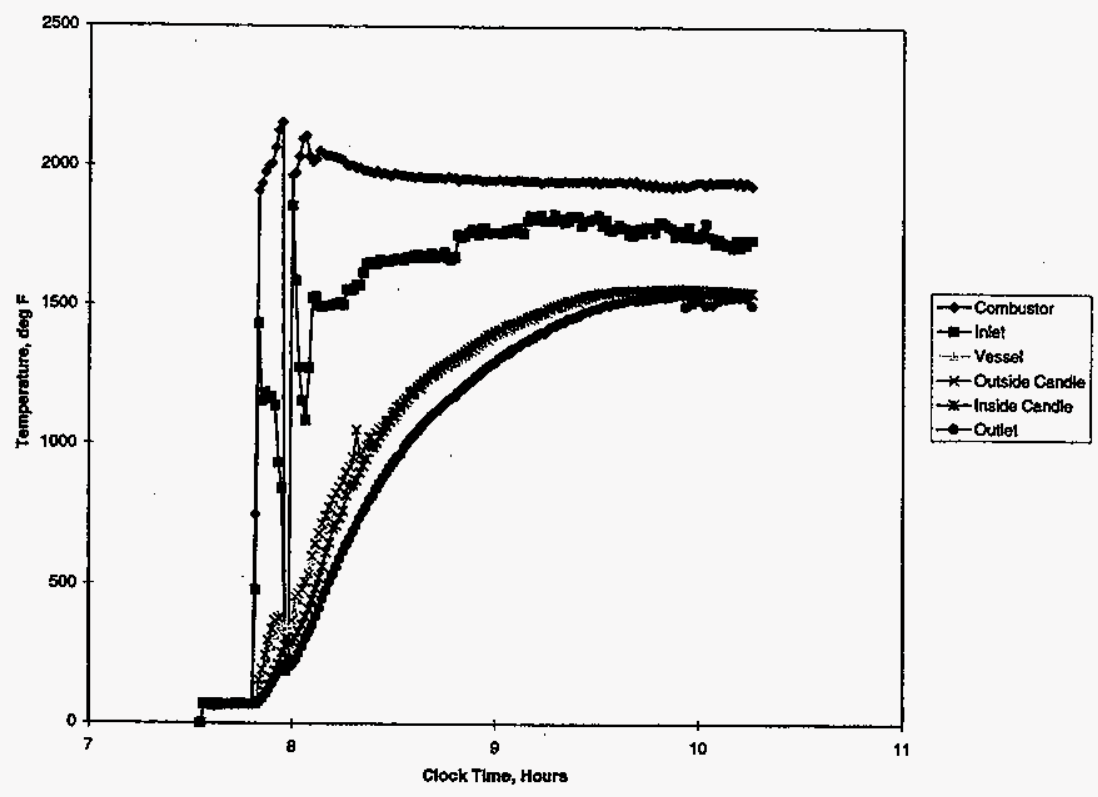

Figure 3-16 - Temperature profile throughout the filter array during heating from cold start conditions.

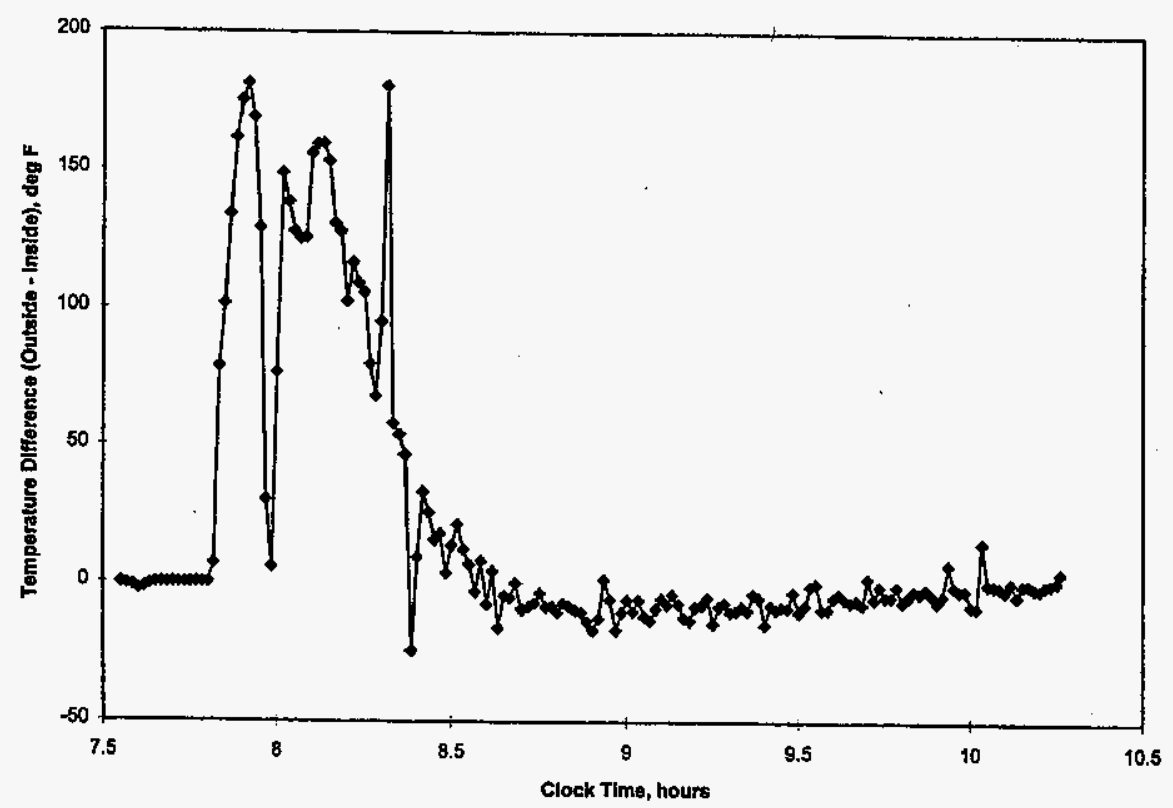

Figure 3-17 - Temperature difference between the outer surface and i.d. bore of the candle during heating of the filter array from cold start conditions. 
Prior to initiating the thermal transient segment of the extended filter life test program, temperature excursions projected at the AEP PFBC Tidd Demonstration Plant in Brilliant, Ohio, were assessed in view of what had previously been conducted in the PFBC simulator test facility at SWPC STC. In preparation for conduct of the final segment of testing, maintenance of the filter system was required to repair a leak in the exhaust line that was identified after system shutdown on October 5, 1998.

During the final segment of testing, an additional as-manufactured but out-of-spec Coors P-100A1 alumina/mullite candle filter was installed in the filter array. This element was positioned in Location 13 (i.e., the inner row of candles), and was instrumented with three thermocouples along its outer surface (i.e., top; middle ( $\sim 500 \mathrm{~mm}$ from the flange); bottom $(\sim 1000 \mathrm{~mm}$ from the flange)), and two thermocouples along its inner wall (i.e., top; bottom $(\sim 1000 \mathrm{~mm}$ from the flange)). The outer surface thermocouples were held in position by stainless steel wire ties, while the inner surface thermocouples were inserted through the center of the fail-safe/regenerator units, and subsequently threaded into the i.d. bore of the filter elements. Previously exposed DuPont PRD-66 (D571C, Location 14), McDermott oxide-based CFCC (B\&W 7-5-29 (B32), Location 15), Pall 326 (R5-667 (M23), Location 16), Schumacher Dia Schumalith FT20 clay bonded silicon carbide (S350F/43 (T4), Location 14), and Blasch 270 mullite-bonded alumina (BP4-270P7/97 (B41), Location 18) elements also positioned in the inner row of candles in the filter array, were instrumented with thermocouples along both outer and inner surfaces, below each filter flange (Figure 3-18). The temperatures at the various locations along the outer and inner surfaces of the filter elements were monitored during conduct of several pulse cleaning cycles, prior to initiating the thermal transient segment of testing. Continued temperature monitoring was attempted during subsequent heat-up and cool-down transients. In this manner, the following information was generated:

- Temperature variations throughout the filter array.

- Temperature variations along the outer surface of the filter element (i.e., top/middle/bottom of the filter element).

- Temperature variations through the filter wall during heat-up and cool-down of the array.

- Temperature variations through the monolithic, composite, and filament wound filter matrices during exposure to simulated process transients.

- Impact of retained ash fines within the various matrices (i.e., reduced gas flow permeability) on the resulting temperature profile through the porous ceramic filter walls.

Thermal transient testing was initiated on November 11, 1998, and continued through December 10,1998 . During this phase of the program, the filter array was heated to temperatures of $1550^{\circ} \mathrm{F}$, from either a cold or warm start, as previously conducted during the accelerated pulse cycle campaign. The filter array was held at temperature for a period of 10-20 minutes, prior to extinguishing the combustor flame, and varying the air flow rates into the filter vessel (i.e., 200-1750 lb/hr). Testing included

Series 1

- Thermal trip at $200 \mathrm{lb} / \mathrm{hr}$-air

Series 2

- Thermal trip at $800 \mathrm{lb} / \mathrm{hr}$-air

Series 3

- Thermal trip at $1575 \mathrm{lb} / \mathrm{hr}$-air

- Thermal trip at $1575 \mathrm{lb} / \mathrm{hr}$-air (Repeated to show reproducibility) 


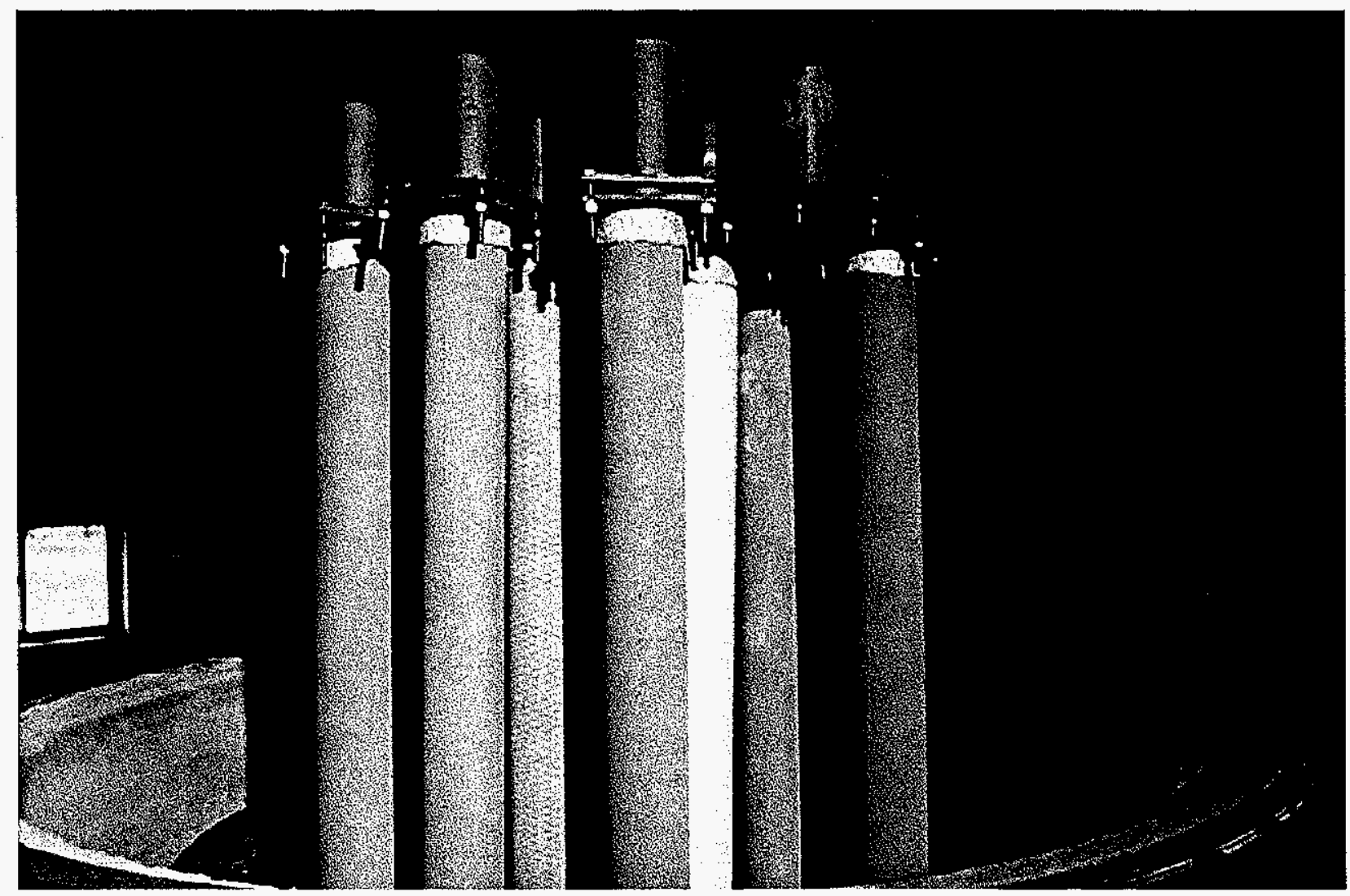

Figure 3-18 - Filter array prior to initiating thermal transient testing. 
Series 4

- Thermal trip at $1750 \mathrm{lb} / \mathrm{hr}$-air

Series 5

- Two pulse cleaning cycles

Series 6

- Thermal trip at $1750 \mathrm{lb} / \mathrm{hr}$-air (Repeated to show reproducibility)

- $1400 \mathrm{ppm}$ dust was fed for a period of $4.8 \mathrm{hrs;} \Delta \mathrm{P}$ of $11 \mathrm{in}$-wg over baseline was established

- Thermal trip at $1750 \mathrm{lb} / \mathrm{hr}$-air

- Additional $1400 \mathrm{ppm}$ dust was fed for a period of $5.7 \mathrm{hrs} ; \Delta \mathrm{P}$ of $21 \mathrm{in}$-wg over baseline was established

- Three (3) thermal trips at $1750 \mathrm{lb} / \mathrm{hr}$-air (Repeated to show reproducibility)

- Nineteen (19) additional $1750 \mathrm{lb} / \mathrm{hr}$-air thermal transients to complete a series of twentyfive events.

\section{Series 7}

- A pulse cleaning cycle was delivered to the filter array during the first minute of thermal transient cycle 26 . The dust cake was removed from the outer surface of the filter elements.

- A pulse cleaning cycle was delivered to the filter array during the first minute of thermal transient cycle 27. The outer surface of the candles was expected to have been cleaned after delivery of the pulse cleaning cycle during conduct of thermal transient cycle 26.

- A pulse cleaning cycle was delivered to the filter array during the second minute of thermal transient cycle 28 .

- A pulse cleaning cycle was delivered to the filter array during the first minute of thermal transient cycle 29 (i.e., comparable to thermal transient cycle 27).

- A pulse cleaning cycle was delivered to the filter array during the second minute of thermal transient cycle 30 (i.e., comparable to thermal transient cycle 28).

\subsubsection{Turbine Trip Simulation}

Figures 3-19 through 3-23 illustrate the temperature profiles that resulted during approximately the first ten minutes of the increasing thermal transient intensity series (i.e., Series 1 - $200 \mathrm{lb} / \mathrm{hr}$; Series 2 $800 \mathrm{lb} / \mathrm{hr}$; Series $3-1575 \mathrm{lb} / \mathrm{hr}$; Series $4-1750 \mathrm{lb} / \mathrm{hr}$ ), along both inner and outer surfaces, directly below the flange of the Coors P-100A-1 alumina/mullite, Blasch, Pall 326, Schumacher Dia Schumalith FT20, DuPont PRD-66, and McDermott CFCC filter elements. Figure 3-24 illustrates the temperature profile at all five thermocouple locations along the Coors P-100A-1 alumina/mullite filter element during thermal transient Series 3 (i.e., $1575 \mathrm{lb} / \mathrm{hr}$ ). Based on the information generated during conduct of thermal transient Series 1 through 4 , for an array of fifteen candles,

- The targeted thermal transient temperature ramp rate of $-180^{\circ} \mathrm{F} / \mathrm{min}\left(-100^{\circ} \mathrm{C} / \mathrm{min}\right)$ for commercial operations was achieved under $1575 \mathrm{lb} / \mathrm{hr}$ and $1750 \mathrm{lb} / \mathrm{hr}$-air conditions along the o.d. surface of the Coors P-100A-1 alumina/mullite filter element, as identified by the bottom thermocouple that was positioned $\sim 1000 \mathrm{~mm}$ from the flange. 
Outside TC's - $200 \mathrm{lb} / \mathrm{hr}$ Trip

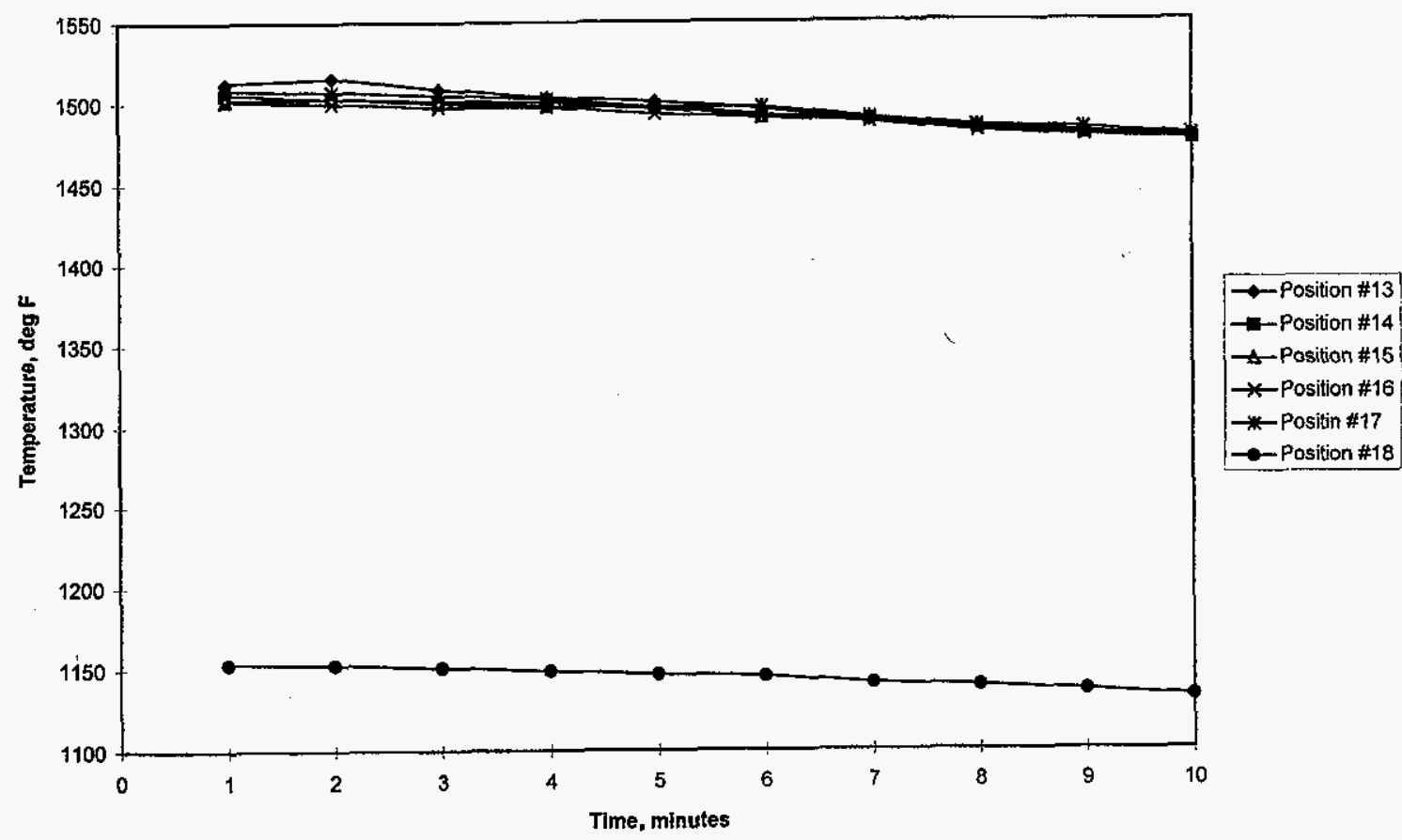

Inside TC's - $200 \mathrm{lb} / \mathrm{hr}$ Trip

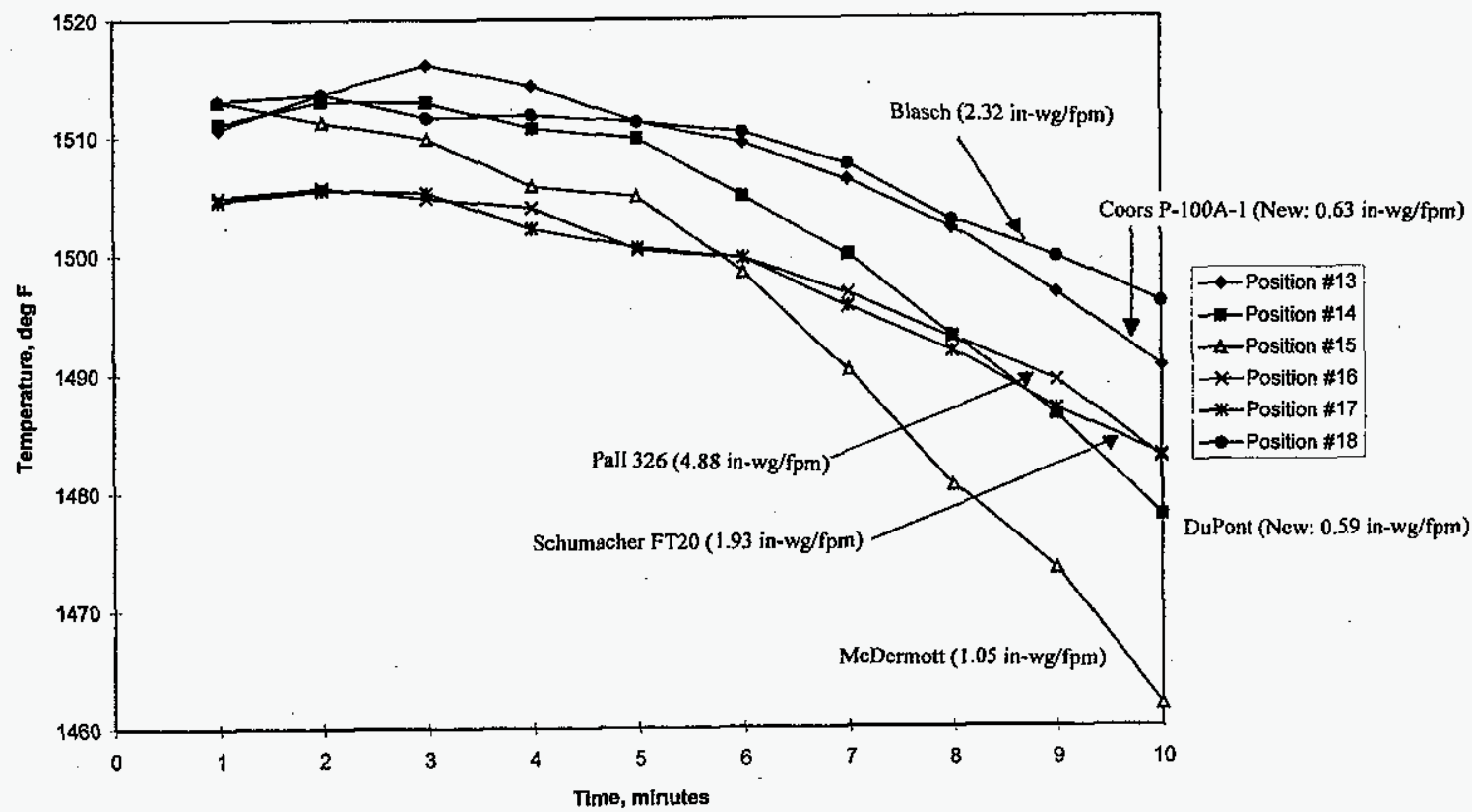

Figure 3-19 - Temperature profiles generated directly below the flange of the inner row filter elements during conduct of the $200 \mathrm{lb} / \mathrm{hr}$-air thermal transient (Series 1). 


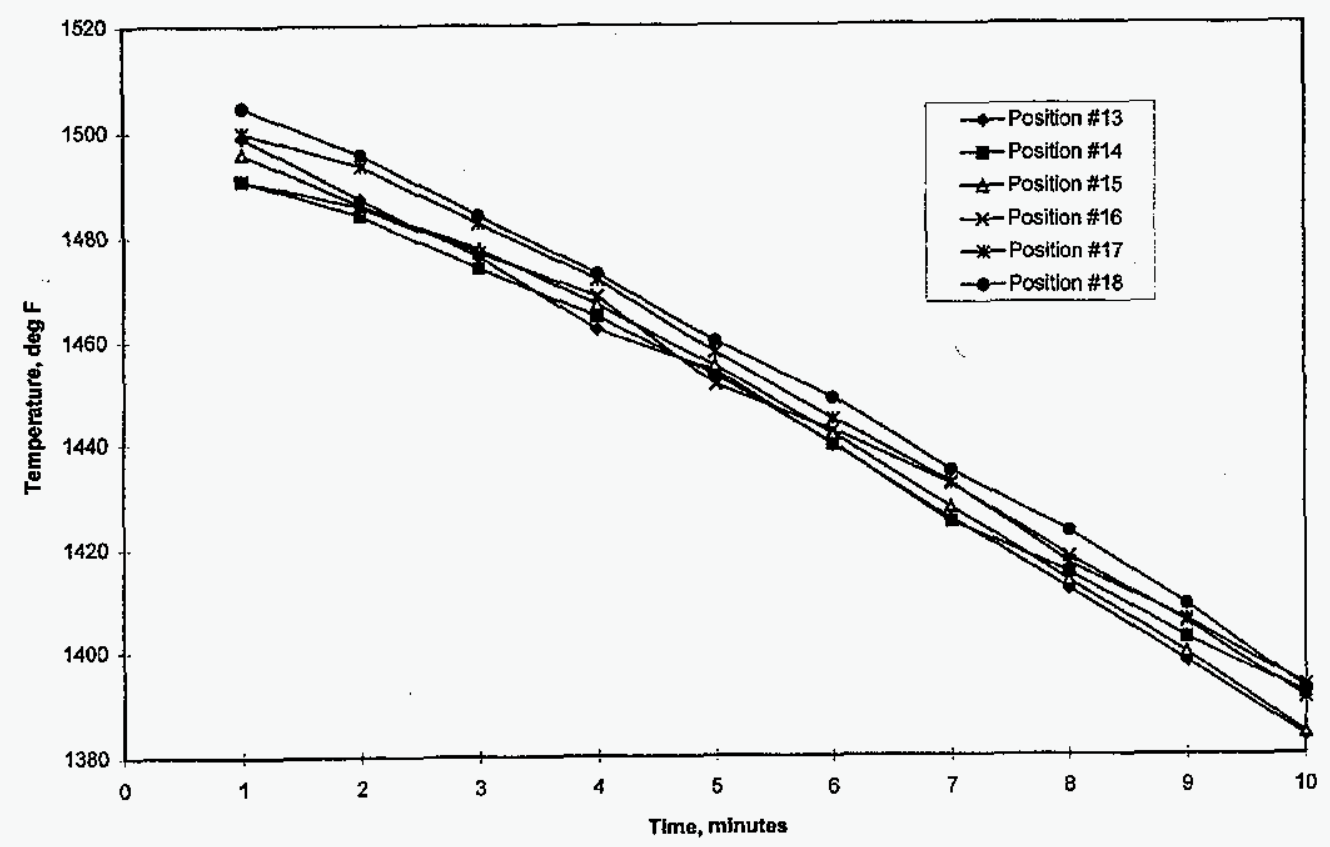

Inside Top TC's - 800 lb/hr Trip

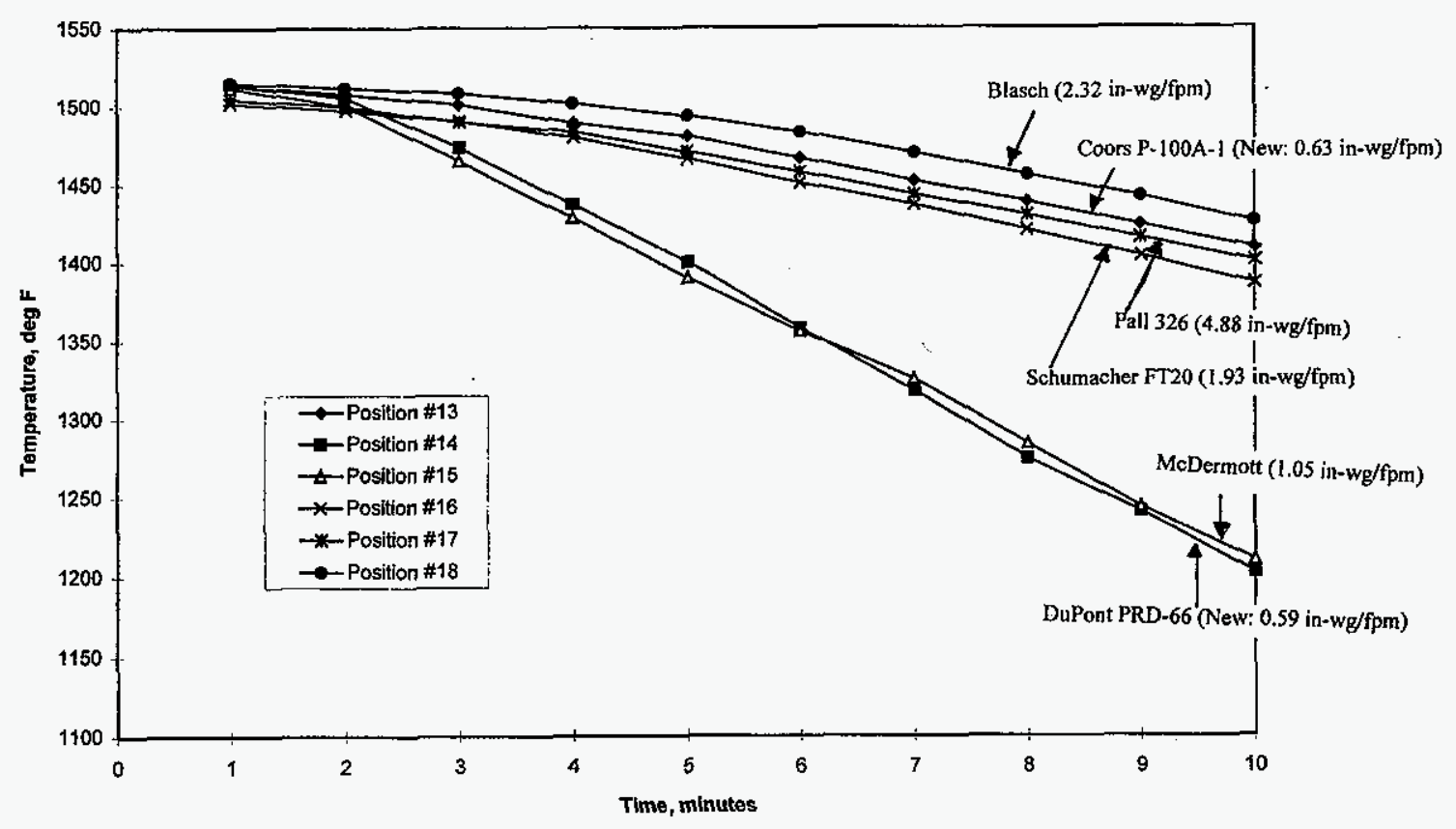

Figure 3-20 - Temperature profiles generated directly below the flange of the inner row filter elements during conduct of the $800 \mathrm{lb} / \mathrm{hr}$-air thermal transient (Series 2). 
Outside Top TC'c - 1575 lb/hr Trip \#1

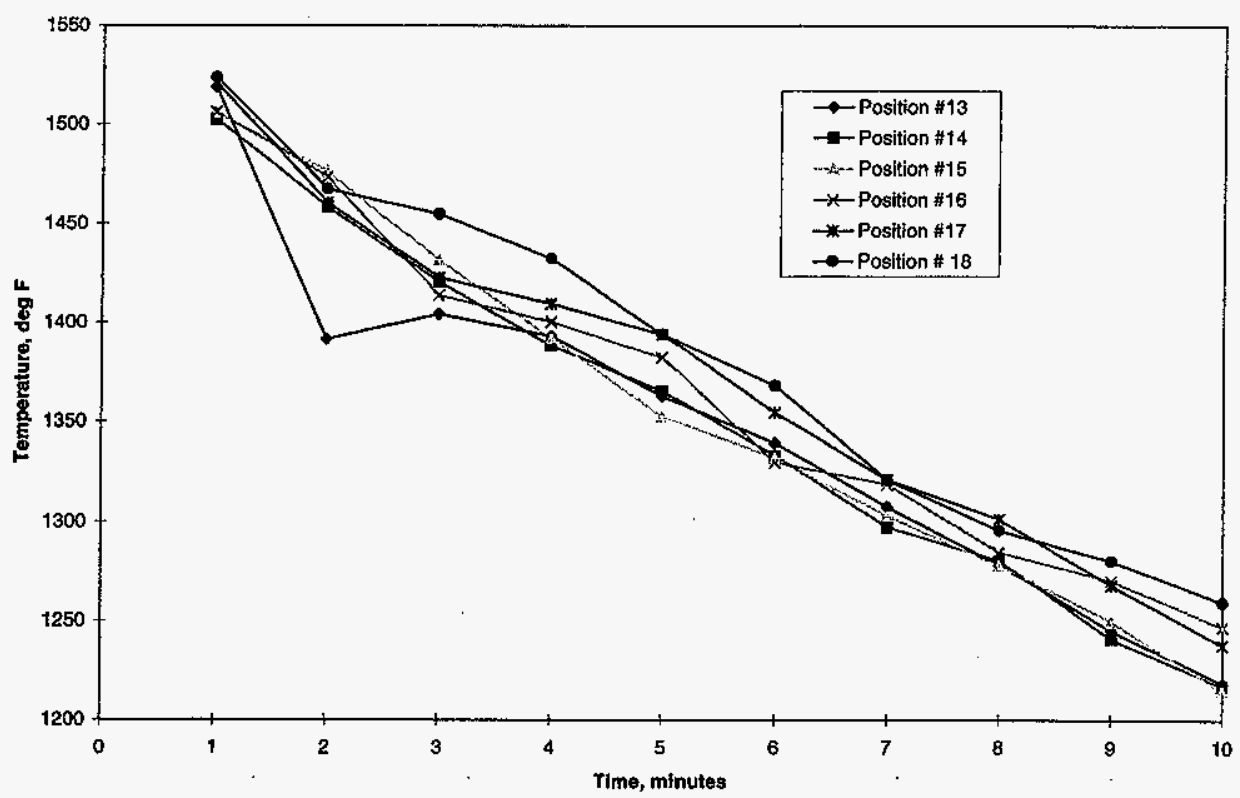

Inside Top TC's - $1575 \mathrm{lb} / \mathrm{hr}$ Trip \#1

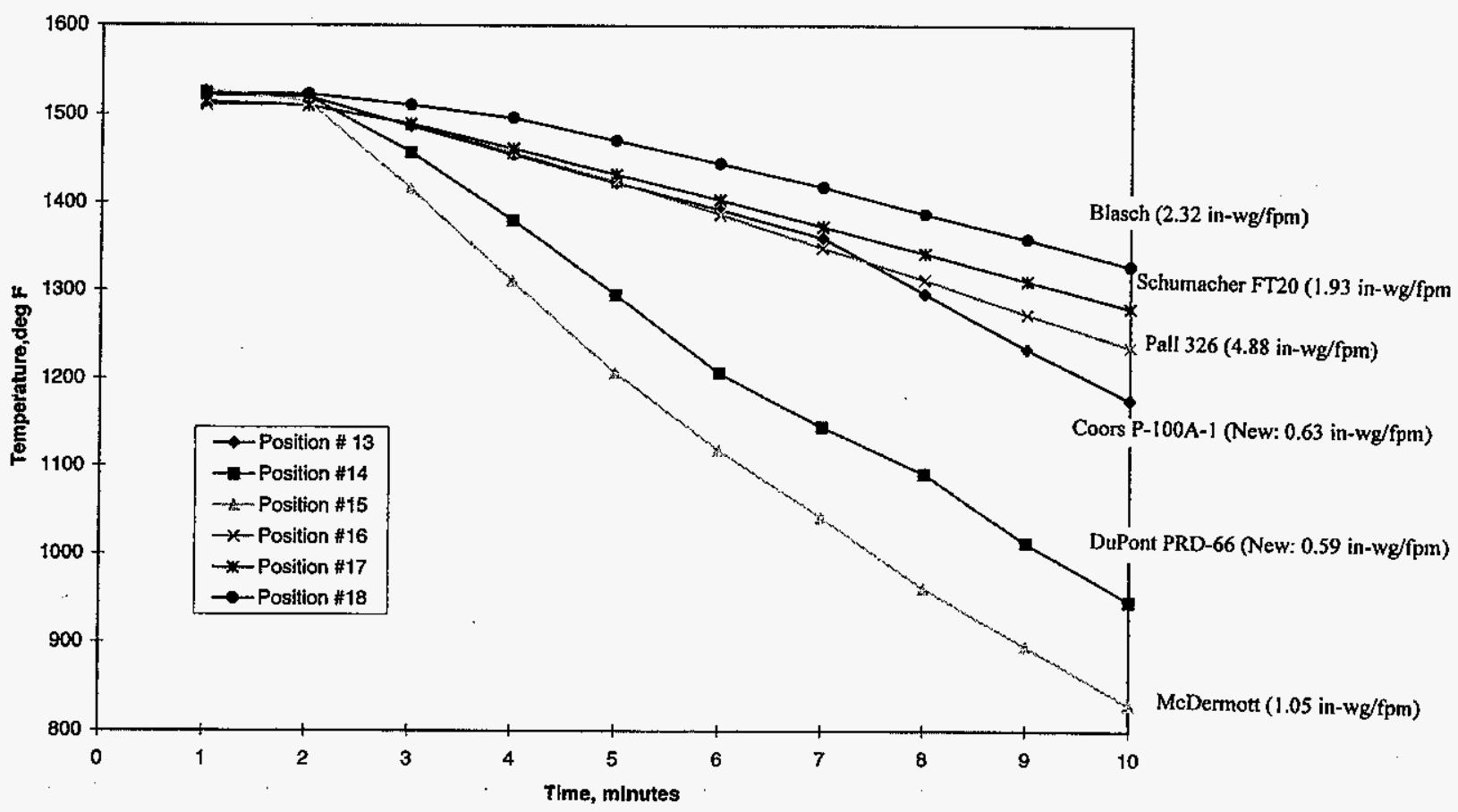

Figure 3-21 - Temperature profiles generated directly below the flange of the inner row filter elements during conduct of the $1575 \mathrm{lb} / \mathrm{hr}$-air thermal transient (Series 3). 
Outside Top TC's - 1575 lb/hr Trip \#2

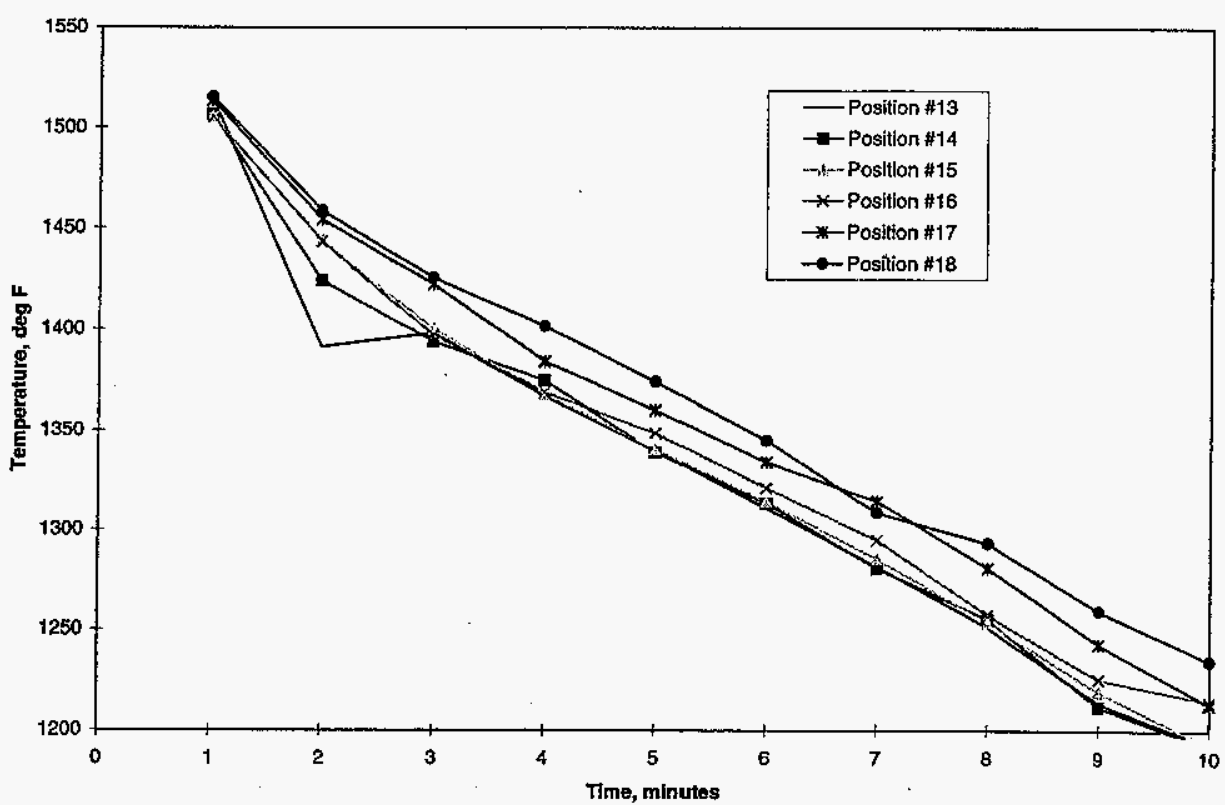

Inside Top TC's - $1575 \mathrm{lb} / \mathrm{hr}$ Trip \#2

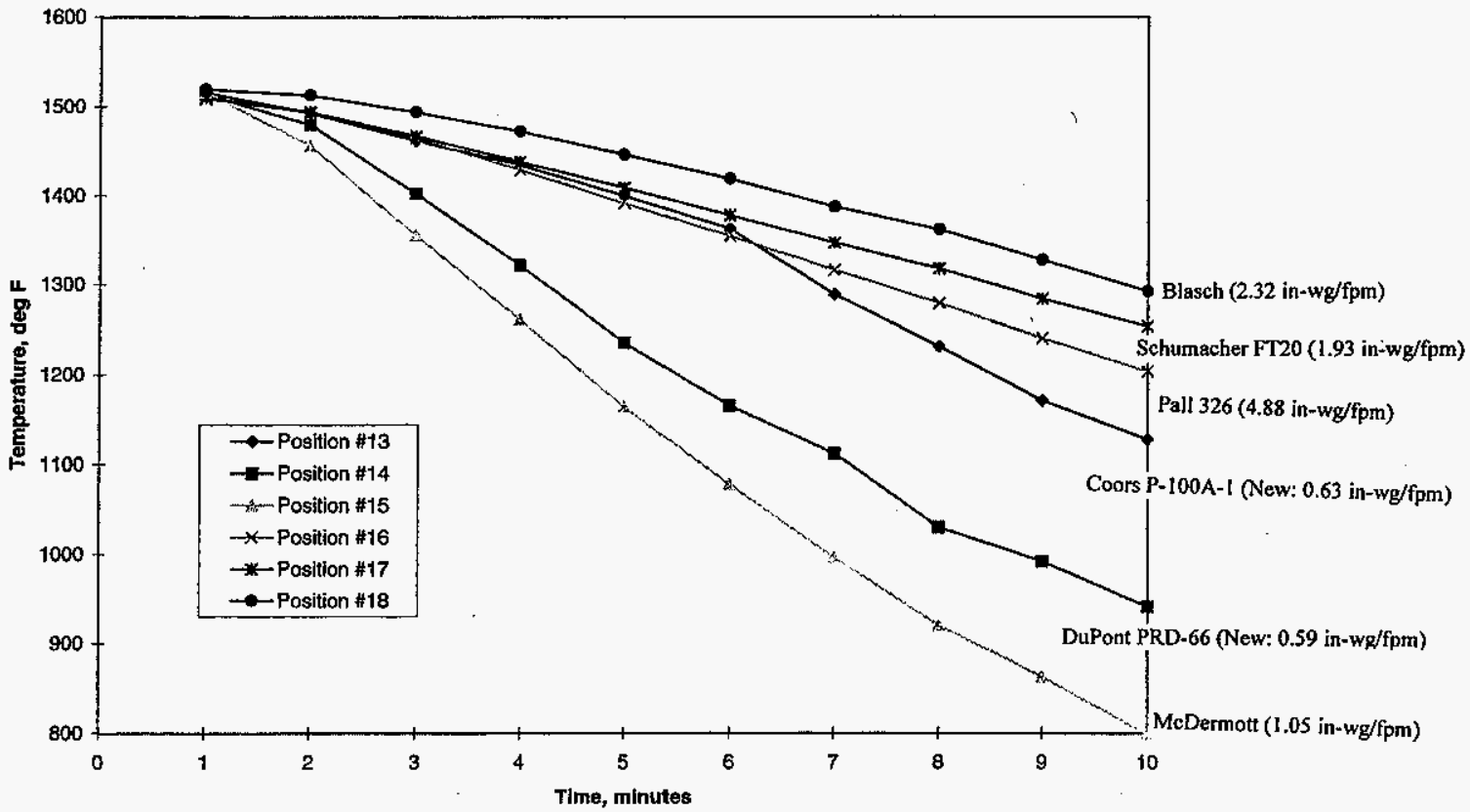

Figure 3-22 - Temperature profiles generated directly below the flange of the inner row filter elements during conduct of the $1575 \mathrm{lb} / \mathrm{hr}$-air thermal transient (Repeat of Series 3). 
Outside Top TC's - $1750 \mathrm{lb} / \mathrm{hr}$ Trip

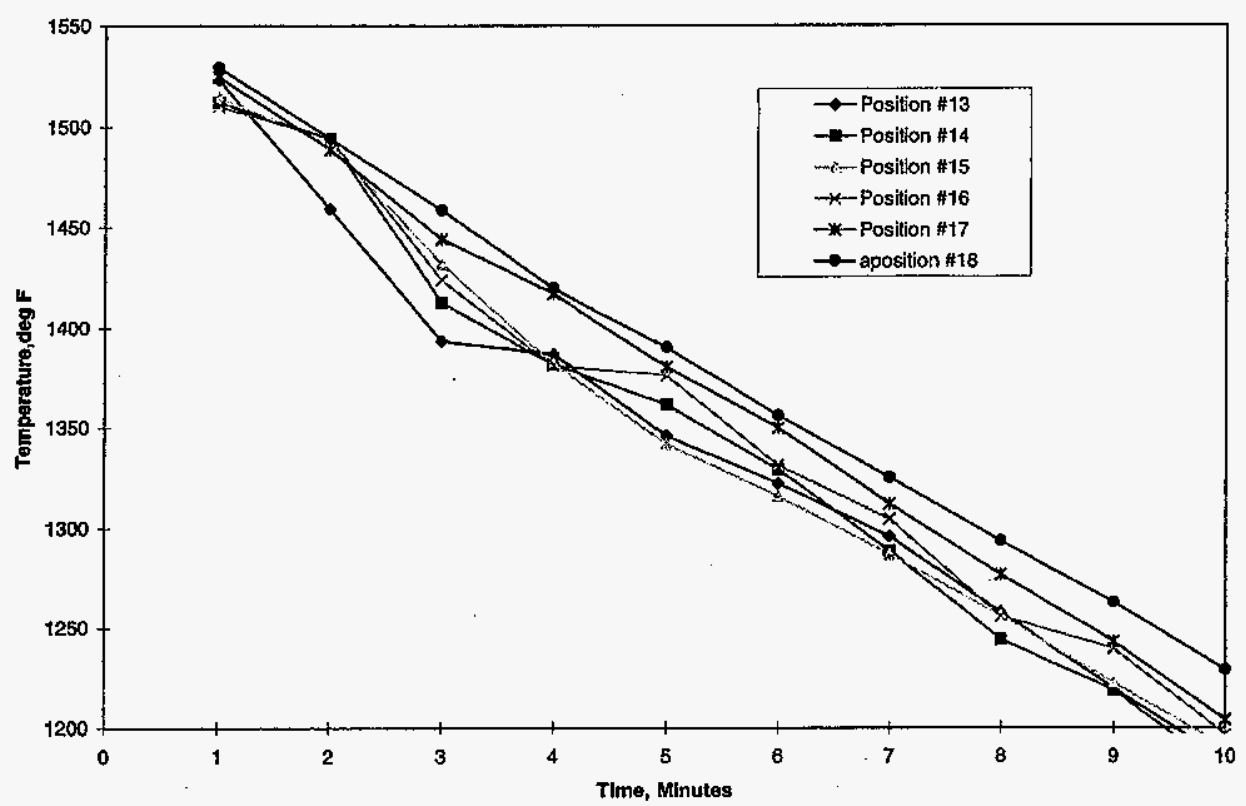

Inside Top TC's - $1750 \mathrm{lb} / \mathrm{hr}$ Trip

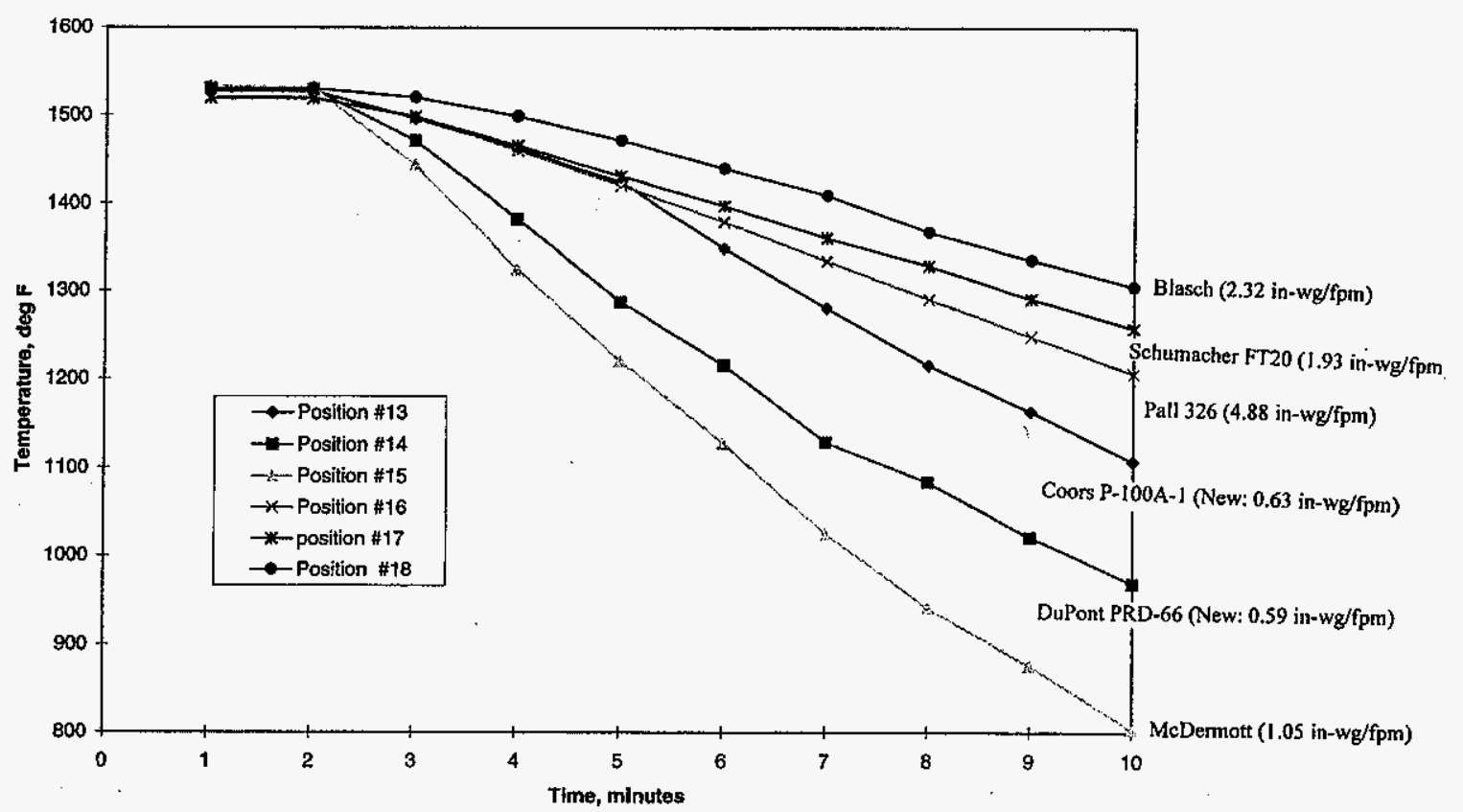

Figure 3-23- Temperature profiles generated directly below the flange of the inner row filter elements during conduct of the $1750 \mathrm{lb} / \mathrm{hr}$-air thermal transient (Series 4). 


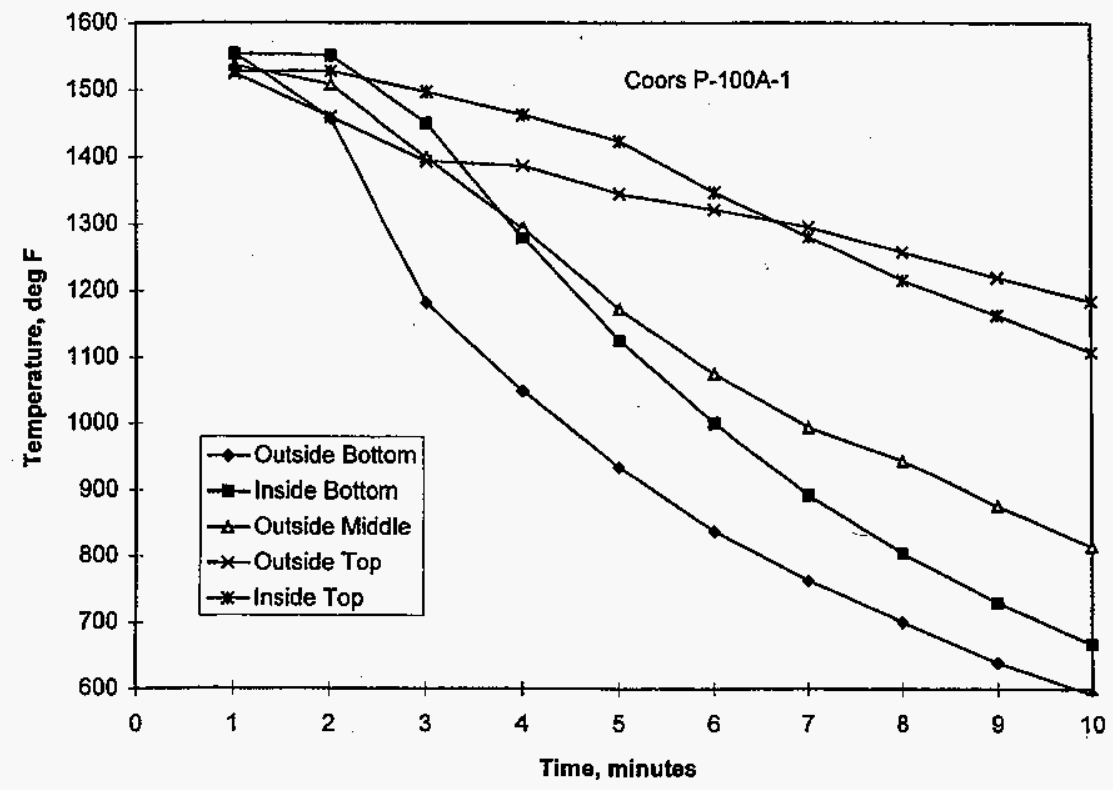

Figure 3-24 - Radial and axial temperature profile of the Coors P-100A-1 alumina/mullite filter element during conduct of the $1575 \mathrm{lb} / \mathrm{hr}$-air thermal transient.

- After a thermal transient had been conducted, reheating of the array was initiated when the middle thermocouple positioned along the outer surface of the Coors P$100 \mathrm{~A}-1$ alumina/mullite filter element achieved $660^{\circ} \mathrm{F}\left(350^{\circ} \mathrm{C}\right)$.

- An axial thermal gradient resulted along the outer surface of the Coors P-100A-1 alumina/mullite filter element (Table 3-2).

- A slight variation in temperature was identified by the thermocouples positioned along the outer surface of all inner row elements. A radial gradient at this location within the vessel was considered to be minimal, if present.

- Differences were evident between the outer and inner thermocouple temperatures at each location during a thermal transient.

- A greater drop in temperature was seen across the wall of the advanced second generation PCFBC-aged McDermott and non-PCFBC-aged, accelerated life-tested, DuPont PRD-66 filter elements in comparison to the monolithic as-manufactured Coors P-100A-1 alumina/mullite, and PCFBC-aged Pall 326, Schumacher Dia Schumalith FT20, and Blasch filter elements.

- After conducting two pulse cycles, the temperature measurements along the i.d. wall directly below the flange of the Pall 326 and McDermott CFCC filter elements were reversed.

- Table 3-3 identifies the relative reproducibility of the temperature measurement at the top of the various candle filters during the first $9-10$ minutes of the $1750 \mathrm{lb} / \mathrm{hr}$-air thermal transients conducted in Series 4. 


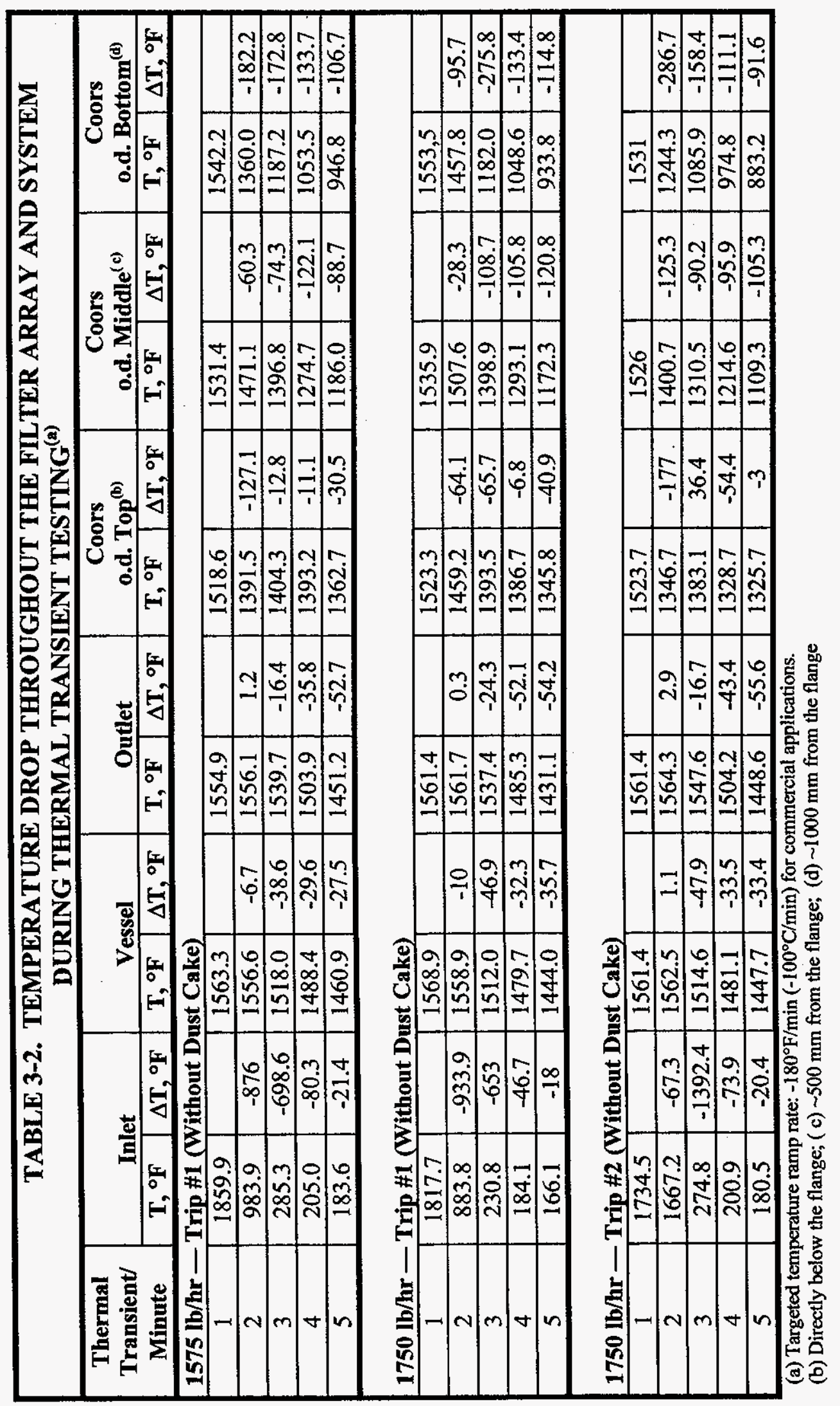


TABLE 3-2 (Cont'd). TEMPERATURE DROP THROUGHOUT THE FILTER ARRAY AND SYSTEM DURING THERMAL TRANSIENT TESTING

\begin{tabular}{|c|c|c|c|c|}
\hline \multirow{2}{*}{$\begin{array}{c}\text { Thermal Transient/ } \\
\text { Minute }\end{array}$} & \multicolumn{2}{|c|}{ Coors - i.d. Top ${ }^{(2)}$} & \multicolumn{2}{|c|}{ Coors - i.d. Bottom ${ }^{(b)}$} \\
\hline & $\mathbf{T},{ }^{\circ} \mathbf{F}$ & $\Delta \mathbf{T},{ }^{\circ} \mathbf{F}$ & $\mathbf{T},{ }^{\circ} \mathbf{F}$ & $\Delta \mathrm{T},{ }^{\circ} \mathbf{F}$ \\
\hline \multicolumn{5}{|c|}{$1575 \mathrm{lb} / \mathrm{hr}$ - Trip \#1 (Without Dust Cake) } \\
\hline 1 & 1522.2 & & 1543.3 & \\
\hline 2 & 1519.9 & -2.3 & 1538.1 & -5.2 \\
\hline 3 & 1486.8 & -33.1 & 1422.9 & -115.2 \\
\hline 4 & 1454.5 & -32.3 & 1272 & -150.9 \\
\hline 5 & 1422.5 & -32 & 1133.6 & -138.4 \\
\hline \multicolumn{5}{|c|}{$1750 \mathrm{lb} / \mathrm{hr}$ - Trip \#1 (Without Dust Cake) } \\
\hline 1 & 1527.3 & & 1553.5 & \\
\hline 2 & 1527.4 & 0.1 & 1551.4 & -2.1 \\
\hline 3 & 1496.7 & -30.7 & 1450.2 & -101.2 \\
\hline 4 & 1462.6 & -34.1 & 1279.2 & -171 \\
\hline 5 & 1423.9 & -38.7 & 1125.7 & -153.5 \\
\hline \multicolumn{5}{|c|}{$1750 \mathrm{lb} / \mathrm{hr}$ - Trip \#2 (Without Dust Cake) } \\
\hline 1 & 1521.3 & & 1533.2 & \\
\hline 2 & 1503.9 & -17.4 & 1489.8 & -43.4 \\
\hline 3 & 1463.2 & -40.7 & 1338.3 & -151.5 \\
\hline 4 & 1430.4 & -32.8 & 1184 & -154.3 \\
\hline 5 & 1397.5 & -32.9 & 1056.9 & -127.1 \\
\hline
\end{tabular}

(a) $\sim 500 \mathrm{~mm}$ from the flange; (b) $\sim 1000 \mathrm{~mm}$ from the flange 


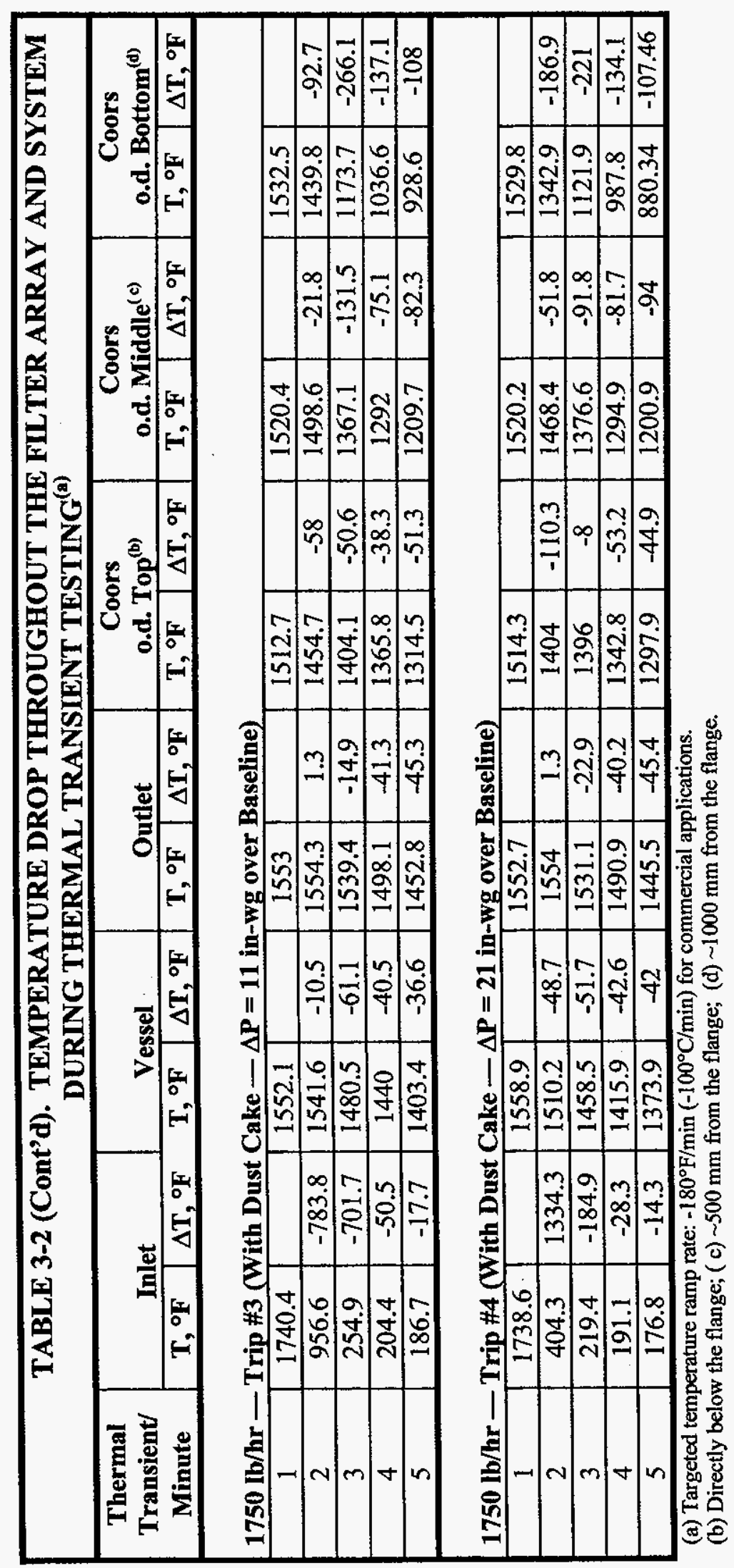


TABLE 3-2 (Cont'd). TEMPERATURE DROP THROUGHOUT THE FILTER ARRAY AND SYSTEM DURING THERMAL TRANSIENT TESTING

\begin{tabular}{|c|c|c|c|c|}
\hline \multirow{2}{*}{$\begin{array}{c}\text { Thermal Transient } / \\
\text { Minute }\end{array}$} & \multicolumn{2}{|c|}{ Coors - i.d. Top ${ }^{(a)}$} & \multicolumn{2}{|c|}{ Coors - i.d. Bottom ${ }^{(\mathbf{b})}$} \\
\hline & $\mathbf{T},{ }^{\circ} \mathbf{F}$ & $\Delta \mathbf{T},{ }^{\circ} \mathbf{F}$ & $\mathbf{T},{ }^{\circ} \mathbf{F}$ & $\Delta \mathbf{T},{ }^{\circ} \mathbf{F}$ \\
\hline \multicolumn{5}{|c|}{$1750 \mathrm{lb} / \mathrm{hr}$ - Trip \#3 (With Dust Cake $-\Delta \mathrm{P}=11$ in-wg over Baseline) } \\
\hline 1 & 1510.2 & & 1522.9 & \\
\hline 2 & 1511.1 & 0.9 & 1524.9 & 2 \\
\hline 3 & 1490.9 & -20.2 & 1482.6 & -42.3 \\
\hline 4 & 1460.7 & -30.2 & 1368.9 & -113.7 \\
\hline 5 & 1429.5 & -31.2 & 1234.4 & -134.5 \\
\hline \multicolumn{5}{|c|}{$1750 \mathrm{lb} / \mathrm{hr}-$ Trip $\# 4$ (With Dust Cake $-\Delta \mathrm{P}=21$ in-wg over Baseline) } \\
\hline 1 & 1514.8 & & 1527.3 & \\
\hline 2 & 1517.5 & 2.7 & 1527.4 & 0.2 \\
\hline 3 & 1494.3 & -23.2 & 1472.2 & -55.2 \\
\hline 4 & 1467 & -27.3 & 1363.5 & -108.7 \\
\hline 5 & 1438.2 & -28.8 & 1238.4 & -125.1 \\
\hline
\end{tabular}

(a) $\sim 500 \mathrm{~mm}$ from the flange; (b) $\sim 1000 \mathrm{~mm}$ from the flange. 
TABLE 3-3. TEMPERATURE DIFFERENTIAL ALONG THE O.D. AND I.D. SURFACES OF THE VARIOUS CANDLE FILTERS DURING THERMAL TRANSIENT TESTING

- $1750 \mathrm{lb} / \mathrm{hr}$ Air Flow -

- First 10 minutes of exposure to the $1750 \mathrm{lb} / \mathrm{hr}$-air thermal transient -

\begin{tabular}{|c|c|c|c|}
\hline \multicolumn{2}{|c|}{ Filter Element } & \multicolumn{2}{|c|}{$\Delta T$ i.d. Surface - Top } \\
\hline \multicolumn{2}{|c|}{ Coors P-100A-1 } & \multicolumn{2}{|c|}{$400^{\circ} \mathrm{F}$} \\
\hline \multicolumn{2}{|c|}{ Schumacher FT20 } & \multicolumn{2}{|c|}{$240^{\circ} \mathrm{F}$} \\
\hline \multicolumn{2}{|c|}{ Pall 326} & \multicolumn{2}{|c|}{$310^{\circ} \mathrm{F}$} \\
\hline \multicolumn{2}{|c|}{ Blasch 270} & \multicolumn{2}{|c|}{$190^{\circ} \mathrm{F}$} \\
\hline \multicolumn{2}{|c|}{ DuPont PRD-66 } & \multicolumn{2}{|c|}{$545^{\circ} \mathrm{F}$} \\
\hline \multicolumn{2}{|c|}{ McDermott } & \multicolumn{2}{|c|}{$720^{\circ} \mathrm{F}$} \\
\hline \multicolumn{4}{|c|}{$\begin{array}{r}-1750 \mathrm{lb} / \mathrm{hr} \text { Air Flow (Repeat) - } \\
- \text { First } 9 \text { minutes of exposure to the } 1750 \mathrm{lb} / \mathrm{hr} \text {-air thermal transient - }\end{array}$} \\
\hline Filter Element & $\begin{array}{l}\Delta \mathbf{T} \text { o.d. Surface - } \\
\text { Top }\end{array}$ & $\begin{array}{l}\Delta \text { T i.d. Surface - } \\
\text { Top }\end{array}$ & $\begin{array}{l}\Delta \text { T Through The } \\
\text { Wall - Top }\end{array}$ \\
\hline Coors P-100A-1 & $\sim 330^{\circ} \mathrm{F}$ & $\sim 410^{\circ} \mathrm{F}$ & $\sim 80^{\circ} \mathrm{F}$ \\
\hline Schumacher FT20 & $\sim 315^{\circ} \mathrm{F}$ & $\sim 260^{\circ} \mathrm{F}$ & $\sim 55^{\circ} \mathrm{F}$ \\
\hline Pall 326 & $\sim 325^{\circ} \mathrm{F}$ & $\sim 315^{\circ} \mathrm{F}$ & $\sim 10^{\circ} \mathrm{F}$ \\
\hline Blasch 270 & $\sim 300^{\circ} \mathrm{F}$ & $\sim 205^{\circ} \mathrm{F}$ & $\sim 95^{\circ} \mathrm{F}$ \\
\hline DuPont PRD-66 & $\sim 325^{\circ} \mathrm{F}$ & $\sim 545^{\circ} \mathrm{F}$ & $\sim 220^{\circ} \mathrm{F}$ \\
\hline McDermott CFCC & $\sim 300^{\circ} \mathrm{F}$ & $\sim 720^{\circ} \mathrm{F}$ & $\sim 420^{\circ} \mathrm{F}$ \\
\hline Filter Element & $\begin{array}{l}\Delta T \text { o.d. Surface - } \\
\text { Bottom }\end{array}$ & $\begin{array}{l}\Delta \text { T i.d. Surface - } \\
\text { Bottom }\end{array}$ & $\begin{array}{l}\Delta \text { T Through The } \\
\text { Wall - Bottom }\end{array}$ \\
\hline Coors P-100A-1 & $\sim 930^{\circ} \mathrm{F}$ & $\sim 845^{\circ} \mathrm{F}$ & $\sim 85^{\circ} \mathrm{F}$ \\
\hline
\end{tabular}

\subsubsection{Characterization of Temperature Transients during Pulse Cycling}

Prior to delivery of dust into the filter vessel, two pulse cleaning cycles were delivered to the filter array, and temperatures were monitored along the various locations of the inner row filter elements as a function of time in Series 5 . The results of this effort indicated that

- An axial gradient existed along the i.d. wall of the Coors P-100A-1 alumina/mullite filter element.

- Virtually no change in temperature resulted along the o.d. surface of the filter elements as a result of pulse cycling.

- As shown in Table 3-4, the maximum drop in temperature directly below the flange of each filter element appeared to be directly related to the gas flow resistance of the filter matrix.

- Excellent reproducibility of the temperature measurements resulted during conduct of both pulse cleaning cycles (Figure 3-25 and 3-26). 
TABLE 3-4. MAXIMUM TEMPERATURE DIFFERENTIAL ALONG THE I.D. SURFACE OF THE CERAMIC CANDLE FILTERS DURING PULSE CYCLING

\begin{tabular}{|c|c|c|c|}
\hline Filter Element & $\begin{array}{c}\text { Gas Flow } \\
\text { Permeability, } \\
\text { in-wg/fpm }\end{array}$ & $\begin{array}{c}\text { i.d Top } \\
\text { Max } \Delta \text { T, } \\
\text { Pulse Cycle \#1 }\end{array}$ & $\begin{array}{c}\text { i.d. Top } \\
\text { Max } \Delta \text { T, } \\
\text { Pulse Cycle \#2 }\end{array}$ \\
\hline Coors P-100A-1 & 0.63 & -240.1 & -231.6 \\
\hline DuPont PRD-66 & 0.59 & -220.7 & -201.8 \\
\hline McDermott CFCC & 1.05 & -224.7 & -179.3 \\
\hline Schumacher FT20 & 1.93 & - & - \\
\hline Blasch 270 & 2.32 & -108.4 & -100.2 \\
\hline Pall 326 & 4.88 & -92.5 & -90.0 \\
\hline
\end{tabular}

\subsubsection{Continuation of Turbine Trip Simulations}

During Series 6, a $1750 \mathrm{lb} / \mathrm{hr}$-air thermal transient was delivered to the filter array to demonstrate reproducibility of the thermocouple measurements with previously recorded temperatures that were generated prior to pulse cycling. Dust was then fed to the filter array $(1400 \mathrm{ppm})$ for a period of 4.8 hours. The pressure drop across the array increased by $11 \mathrm{in}$-wg over baseline. Virtually no significant change was identified in the recorded temperatures after 10 minutes of exposure to the $1750 \mathrm{lb} / \mathrm{hr}$-air thermal transient along the o.d. top/middle/bottom sections (i.e., directly below the flange; $500 \mathrm{~mm}$ from the flange; $\sim 1000 \mathrm{~mm}$ from the flange) of the Coors P-100A-1 alumina/mullite filter element, in the presence or absence of the dust cake. Along the i.d. surface of the Coors P-100A-1 alumina/mullite candle, the presence of o.d. surface dust tended to suppress the temperature drop along the i.d. surface of the filter element during the first 10 minutes of the $1750 \mathrm{lb} / \mathrm{hr}$-air thermal transient exposure (Table 3-5; Figure 3-27). Once again, an axial gradient existed along the o.d. and i.d. surfaces of the Coors P-100A-1 alumina/mullite filter element.

TABLE 3-5. INFLUENCE OF THE CONDITIONED ASH CAKE LAYER ON TEMPERATURE DROP ALONG THE I.D. SURFACE OF THE COORS P-100A-1 ALUMINA/MULLITE FILTER ELEMENT DURING THERMAL TRANSIENT TESTING

\begin{tabular}{|c|c|c|}
\hline Location & $\begin{array}{c}\Delta \text { T Without Dust } \\
- \text { After Pulse Cycling }\end{array}$ & $\begin{array}{c}\Delta \text { T With Dust } \\
\text { - After Pulse Cycling - }\end{array}$ \\
\hline i.d. Top & $370^{\circ} \mathrm{F}$ & $250^{\circ} \mathrm{F}$ \\
\hline i.d. Bottom & $870^{\circ} \mathrm{F}$ & $800^{\circ} \mathrm{F}$ \\
\hline
\end{tabular}

During conduct of thermal transient Series 6 , virtually no significant temperature difference was identified along the o.d. surface directly below the flange of clean or dust-laden inner row filter elements during the first 10 minutes of exposure to the $1750 \mathrm{lb} / \mathrm{hr}$-air thermal transient. While conducting the 1750 


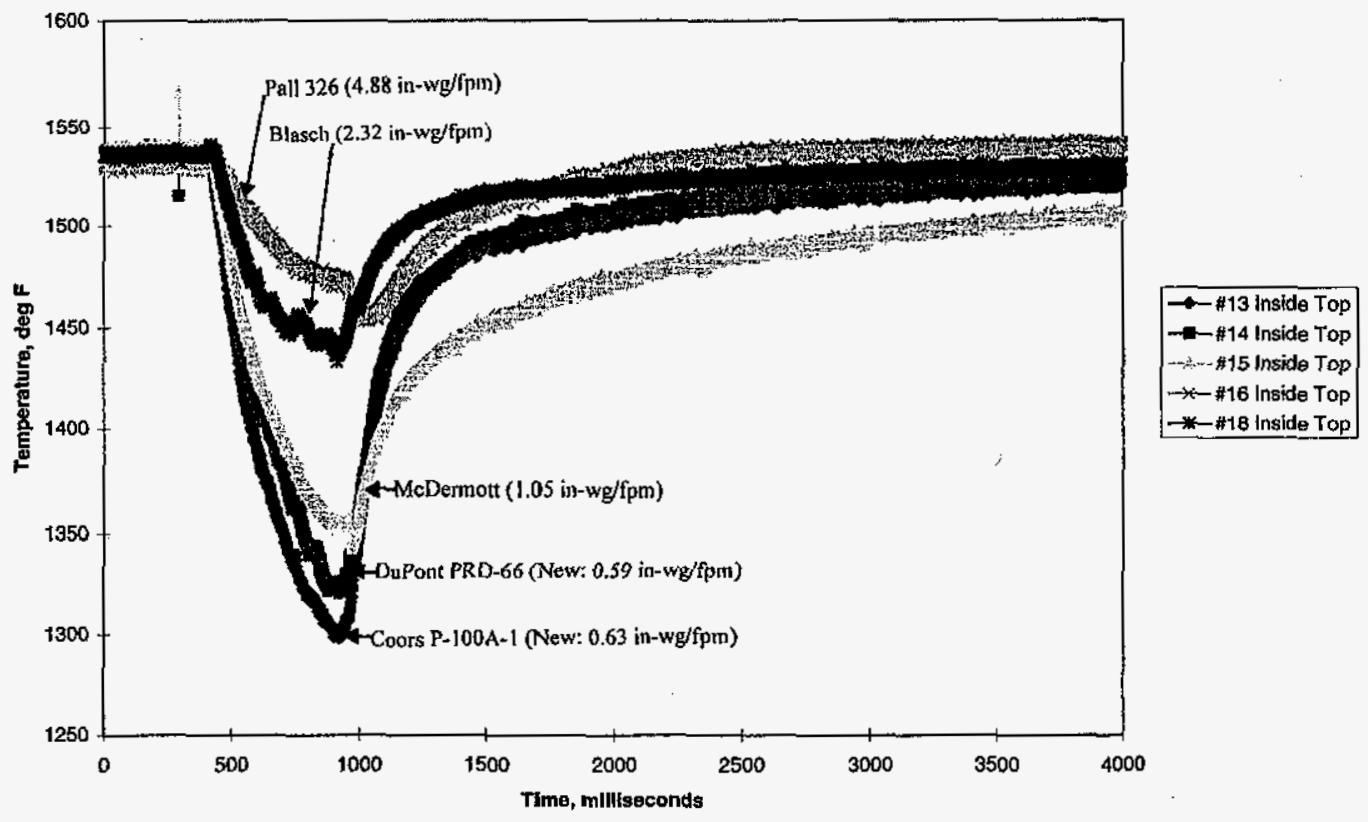

Figure 3-25 - Temperature profiles that resulted along the i.d. surface at the base of the flange of the porous ceramic filter elements during pulse cleaning.

Second Puise - 11/13/98

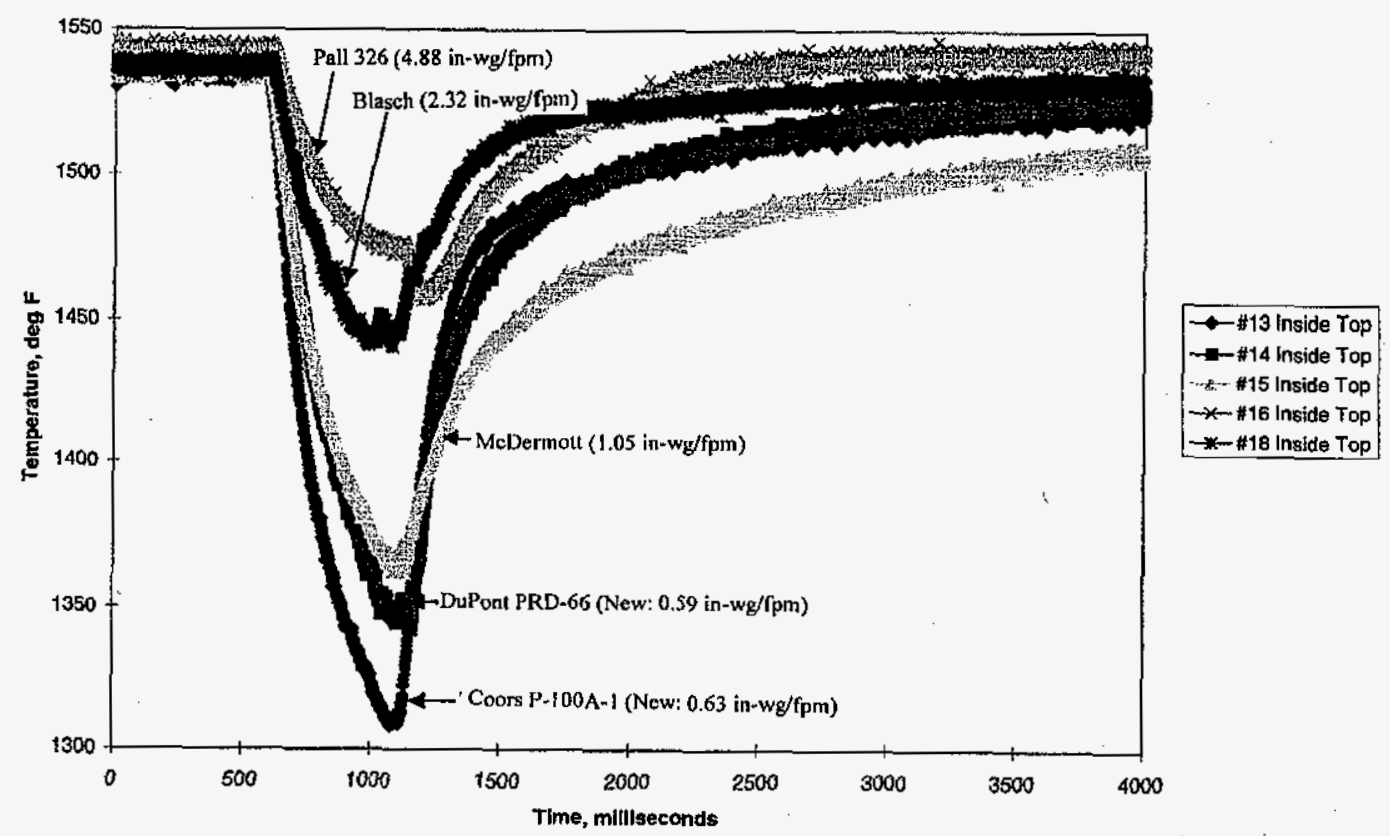

Figure 3-26 - Temperature profiles that resulted along the i.d. surface at the base of the flange of the porous ceramic filter elements during the second pulse cleaning cycle. 


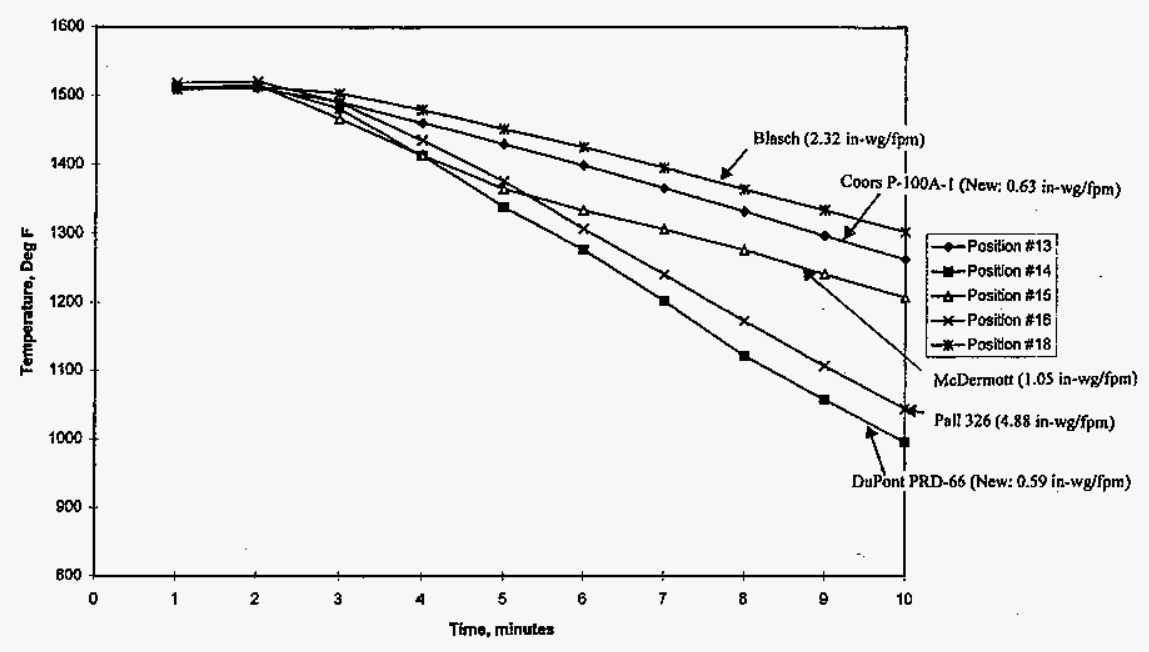

Outside TC's - $1750 \mathrm{lb} / \mathrm{hr}$ Trip With Dust Cake

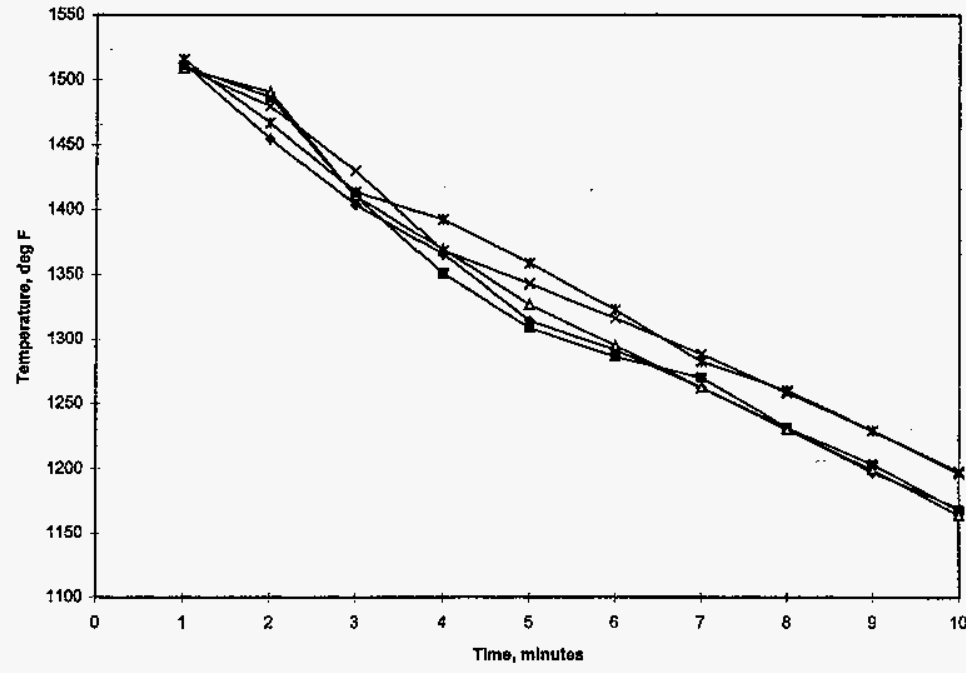

Inside TC's - $1750 \mathrm{lb} / \mathrm{hr}$ Trip Without Dust Cake

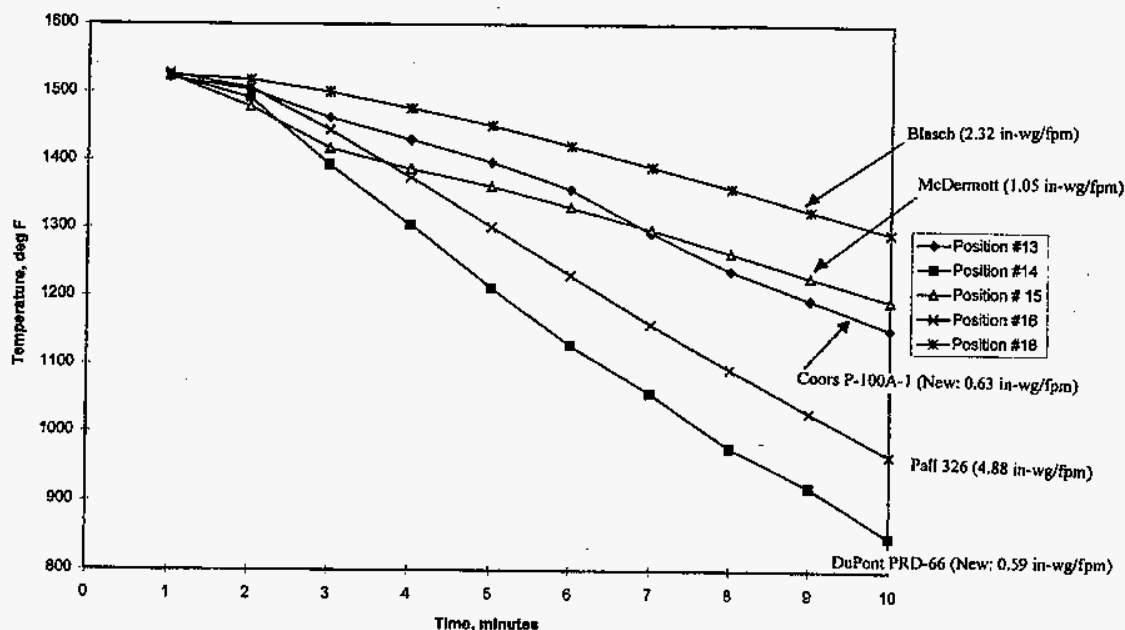

Figure 3-27 - Temperature profiles generated directly below the flange of the inner row filter elements during conduct of the $1750 \mathrm{lb} / \mathrm{hr}$-air thermal transient (With and without the o.d. surface dust cake layer). 
$\mathrm{lb} / \mathrm{hr}$-air thermal transient after delivery of two pulse cleaning cycles to the filter array, thermocouple \#17 failed (Schumacher Dia Schumalith FT20).

As shown in the Table 3-6, the presence of the initial dust cake layer along the outer surface of the filter elements after 8 minutes of exposure to the $1750 \mathrm{lb} / \mathrm{hr}$-air thermal transient caused what appeared to be a less severe temperature drop along the i.d. surface, directly below the flange of the Coors P-100A-1 alumina/mullite and DuPont PRD-66 filter elements, but a more severe temperature drop along the i.d. surface, directly below the flange of the Blasch and McDermott filter elements.

Comparison of the temperatures recorded during this sequence vs the initial series of $1750 \mathrm{lb} / \mathrm{hr}$ air thermal transients indicated that a change in the thermocouple measurements had occurred after delivery of two pulse cleaning cycles. The most significant change in temperature occurred along the Pall 326 and DuPont PRD-66 filter elements (greater temperature drop), and the Coors P-100A-1 and McDermott CFCC filter elements (smaller temperature drop). This may have resulted from changes in the location of the thermocouples along the i.d. bore of the filter elements, and/or alternately, malfunctioning of the thermocouples (i.e., failure of thermocouple \#17 - Schumacher Dia Schumalith FT20 candle), after pulse cycling.

\section{TABLE 3-6. INFLUENCE OF THE CONDITIONED ASH CAKE LAYER ON TEMPERATURE DROP ALONG THE I.D. SURFACE OF THE VARIOUS CERAMIC FILTER ELEMENTS DURING THERMAL TRANSIENT TESTING}

\begin{tabular}{|c|c|c|}
\hline Filter Element & $\begin{array}{c}\Delta \text { T i.d. Surface - Top } \\
- \text { Without Dust } \\
- \text { After Pulse Cycling }\end{array}$ & $\begin{array}{c}\Delta \text { T i.d. Surface - Top } \\
- \text { With Dust }- \text { After Pulse Cycling }\end{array}$ \\
\hline Coors P-100A-1 & $320^{\circ} \mathrm{F}$ & $245^{\circ} \mathrm{F}$ \\
\hline Schumacher FT20 & - & - \\
\hline Pall 326 & $490^{\circ} \mathrm{F}$ & $490^{\circ} \mathrm{F}$ \\
\hline Blasch 270 & $180^{\circ} \mathrm{F}$ & $220^{\circ} \mathrm{F}$ \\
\hline DuPont PRD-66 & $610^{\circ} \mathrm{F}$ & $520^{\circ} \mathrm{F}$ \\
\hline McDermott CFCC & $280^{\circ} \mathrm{F}$ & $315^{\circ} \mathrm{F}$ \\
\hline Filter Element & $\Delta$ T i.d. Surface - Top & $\Delta$ T i.d. Surface - Top \\
(Without Dust) & - After Pulse Cycling \\
\hline Coors P-100A-1 & - Prior to Pulse Cycling & $320^{\circ} \mathrm{F}$ \\
\hline Schumacher FT20 & $400^{\circ} \mathrm{F}$ & - \\
\hline Pall 326 & $245^{\circ} \mathrm{F}$ & $490^{\circ} \mathrm{F}$ \\
\hline Blasch 270 & $300^{\circ} \mathrm{F}$ & $180^{\circ} \mathrm{F}$ \\
\hline DuPont PRD-66 & $195^{\circ} \mathrm{F}$ & $610^{\circ} \mathrm{F}$ \\
\hline McDermott CFCC & $545^{\circ} \mathrm{F}$ & $280^{\circ} \mathrm{F}$ \\
\hline
\end{tabular}

Additional dust was fed for a period of 5.7 hours, and a pressure drop across the filter array of 21 in-wg over baseline was established. Three $1750 \mathrm{lb} / \mathrm{hr}$-air thermal transients were delivered to the array to demonstrate reproducibility of the recorded temperatures at various locations along the filter elements. 
The temperature drop during the first 10 minutes of the $1750 \mathrm{lb} / \mathrm{hr}$-air thermal transient is shown in Table 3-7. Excellent reproducibility was shown for the various temperatures identified at all locations along the Coors P-100A-1 alumina/mullite candle filter during the first 10 minutes of exposure to the $1750 \mathrm{lb} / \mathrm{hr}$-air thermal transient event.

\begin{tabular}{|c|c|c|c|}
\hline \multicolumn{4}{|c|}{$\begin{array}{l}\text { TABLE 3-7. TEMPERATURE DROP ALONG THE O.D AND I.D. SURFA } \\
\text { OF THE COORS P-100A-1 ALUMINAMMLLITE CANDLE FILTER } \\
\text { DURING THERMAL TRANSIENT TESTING } \\
- \text { Dust Cake: } \Delta P=21 \text { in-wg over baseline - } \\
-1750 \mathrm{lb} / \mathrm{hr} \text { Air Flow }-\end{array}$} \\
\hline Coors P-100A-1 & Transient \#1 & Transient \#2 & Transient \#3 \\
\hline o.d. Top & $480^{\circ} \mathrm{F}$ & $510^{\circ} \mathrm{F}$ & $500^{\circ} \mathrm{F}$ \\
\hline o.d. Middle & $860^{\circ} \mathrm{F}$ & $870^{\circ} \mathrm{F}$ & $870^{\circ} \mathrm{F}$ \\
\hline o.d. Bottom & $1070^{\circ} \mathrm{F}$ & $1070^{\circ} \mathrm{F}$ & $1070^{\circ} \mathrm{F}$ \\
\hline i.d. Top & $370^{\circ} \mathrm{F}$ & $370^{\circ} \mathrm{F}$ & $370^{\circ} \mathrm{F}$ \\
\hline i.d. Bottom & $970^{\circ} \mathrm{F}$ & $960^{\circ} \mathrm{F}$ & $970^{\circ} \mathrm{F}$ \\
\hline
\end{tabular}

An $\sim 440-505^{\circ} \mathrm{F}$ temperature drop was experienced along the o.d. surface, directly below the flange of the dust-laden inner row filter elements during the first 10 minutes of exposure to the 1750 $\mathrm{lb} / \mathrm{hr}$-air thermal transient (Table 3-8). Table 3-8 similarly identifies the temperature along the i.d. surface directly below the flange of the inner row candles. Excellent reproducibility was shown for the recorded $\Delta T$ 's along the i.d. surface, directly below the flange of the various filter elements, during exposure to the three $1750 \mathrm{lb} / \mathrm{hr}$-air thermal transient events.

A comparison of the $\Delta T$ 's along the i.d. surface, directly below the flange of the various filter elements as a function of pressure drop across the array due to the collection of ash along the o.d. surface of the filter elements is shown in the Table 3-9. A thicker dust cake (i.e., greater $\Delta \mathrm{P}$ across the array over baseline) tended to increase the $\Delta \mathrm{T}$ along the i.d. surface, directly below the flange of the various filter elements during thermal transient testing. The presence of ash may have slightly reduced the temperature difference between the various candles along the top i.d. surface.

\subsubsection{Combined Pulse Cycle and Thermal Transient Testing}

During conduct of Series 7, a greater drop in temperature was experienced along the top i.d. wall of the Coors P-100A-1 filter element than along the bottom i.d. wall of the candle during pulse cycling

- Thermal Transient $26:-284^{\circ} \mathrm{F}$ vs $-165^{\circ} \mathrm{F}$, respectively (Figure $3-28$ )

- Thermal Transient $27:-281^{\circ} \mathrm{F}$ vs $-82^{\circ} \mathrm{F}$, respectively (Figure 3-29).

During pulse cleaning, a slight temperature rise was experienced along the o.d. surface of each filter element. 
TABLE 3-8. TEMPERATURE DROP ALONG THE O.D. AND I.D. SURFACES OF THE VARIOUS CERAMIC CANDLE FILTERS

\section{DURING THERMAL TRANSIENT TESTING}

- Dust Cake: $\Delta P=21$ in-wg over baseline - $1750 \mathrm{lb} / \mathrm{hr}$ Air Flow -

\begin{tabular}{|c|c|c|c|}
\hline Location & Transient \#1 & Transient \#2 & Transient \#3 \\
\hline o.d. Surface - Top & $440-495^{\circ} \mathrm{F}$ & $440-500^{\circ} \mathrm{F}$ & $440-505^{\circ} \mathrm{F}$ \\
\hline $\begin{array}{c}\text { Filter Element } \\
\text { i.d. Surface - Top }\end{array}$ & Transient \#1 & Transient \#2 & Transient \#3 \\
\hline Coors P-100A-1 & $360^{\circ} \mathrm{F}$ & $365^{\circ} \mathrm{F}$ & $370^{\circ} \mathrm{F}$ \\
\hline Schumacher FT20 & - & - & - \\
\hline Pall 326 & $670^{\circ} \mathrm{F}$ & $670^{\circ} \mathrm{F}$ & $675^{\circ} \mathrm{F}$ \\
\hline Blasch 270 & $320^{\circ} \mathrm{F}$ & $335^{\circ} \mathrm{F}$ & $340^{\circ} \mathrm{F}$ \\
\hline DuPont PRD-66 & $670^{\circ} \mathrm{F}$ & $670^{\circ} \mathrm{F}$ & $670^{\circ} \mathrm{F}$ \\
\hline McDermott CFCC & $435^{\circ} \mathrm{F}$ & $440^{\circ} \mathrm{F}$ & $440^{\circ} \mathrm{F}$ \\
\hline
\end{tabular}

\section{TABLE 3-9. INFLUENCE OF ASH ON THE TEMPERATURE DROP ALONG THE I.D. SURFACES OF THE VARIOUS CERAMIC CANDLE FILTERS DURING THERMAL TRANSIENT TESTING \\ - $1750 \mathrm{lb} / \mathrm{hr}$ Air Flow -}

\begin{tabular}{|c|c|c|c|}
\hline Filter Element & $\begin{array}{c}\Delta \mathrm{T} \text { i.d. Surface - Top } \\
\text { - Without Dust } \\
\text {-After Pulse Cycling- }\end{array}$ & $\begin{array}{c}\Delta \mathrm{T} \text { i.d. Surface - Top } \\
\text { - With Dust - } \\
\Delta \mathrm{P}=11 \text { in-wg over baseline }\end{array}$ & $\begin{array}{c}\Delta \mathrm{T} \text { i.d. Surface - Top } \\
\text { - With Dust - } \\
\Delta \mathrm{P}=21 \text { in-wg over baseline }\end{array}$ \\
\hline Coors P-100A-1 & $320^{\circ} \mathrm{F}$ & $245^{\circ} \mathrm{F}$ & $360-370^{\circ} \mathrm{F}$ \\
\hline Schumacher FT20 & - & - & - \\
\hline Pall 326 & $490^{\circ} \mathrm{F}$ & $490^{\circ} \mathrm{F}$ & $670-675^{\circ} \mathrm{F}$ \\
\hline Blasch 270 & $180^{\circ} \mathrm{F}$ & $220^{\circ} \mathrm{F}$ & $320-340^{\circ} \mathrm{F}$ \\
\hline DuPont PRD-66 & $610^{\circ} \mathrm{F}$ & $520^{\circ} \mathrm{F}$ & $670^{\circ} \mathrm{F}$ \\
\hline McDermott CFCC & $280^{\circ} \mathrm{F}$ & $315^{\circ} \mathrm{F}$ & $435-440^{\circ} \mathrm{F}$ \\
\hline$\Delta \mathrm{T}$ Range & $430^{\circ} \mathrm{F}$ & $300^{\circ} \mathrm{F}$ & $350-330^{\circ} \mathrm{F}$ \\
\hline
\end{tabular}

The maximum drop in temperature along the top i.d. surface of the various inner row filter elements is shown in Table 3-10. A greater drop in temperature was experienced along the top i.d. wall of filter elements which had lower gas flow resistance (i.e., new Coors and DuPont filters) in comparison to filter elements which had higher gas flow resistance (i.e., PCFBC-aged elements which had ash retained within the filter matrices). During conduct of thermal transient \#27, failure of the o.d. bottom thermocouple along the Coors P-100A-1 alumina/mullite filter occurred, and subsequently during conduct of thermal transient \#28, failure of both Pall 326 and Coors P-100A-1 alumina/mullite i.d. top thermocouples occurred. Table 3-11 illustrates the temperature throughout the filter array as a function of time. 
Inside Top TC's - $1750 \mathrm{lb} / \mathrm{hr}$ Trip With Dust Cake and Pulse, \#26 12/9/98

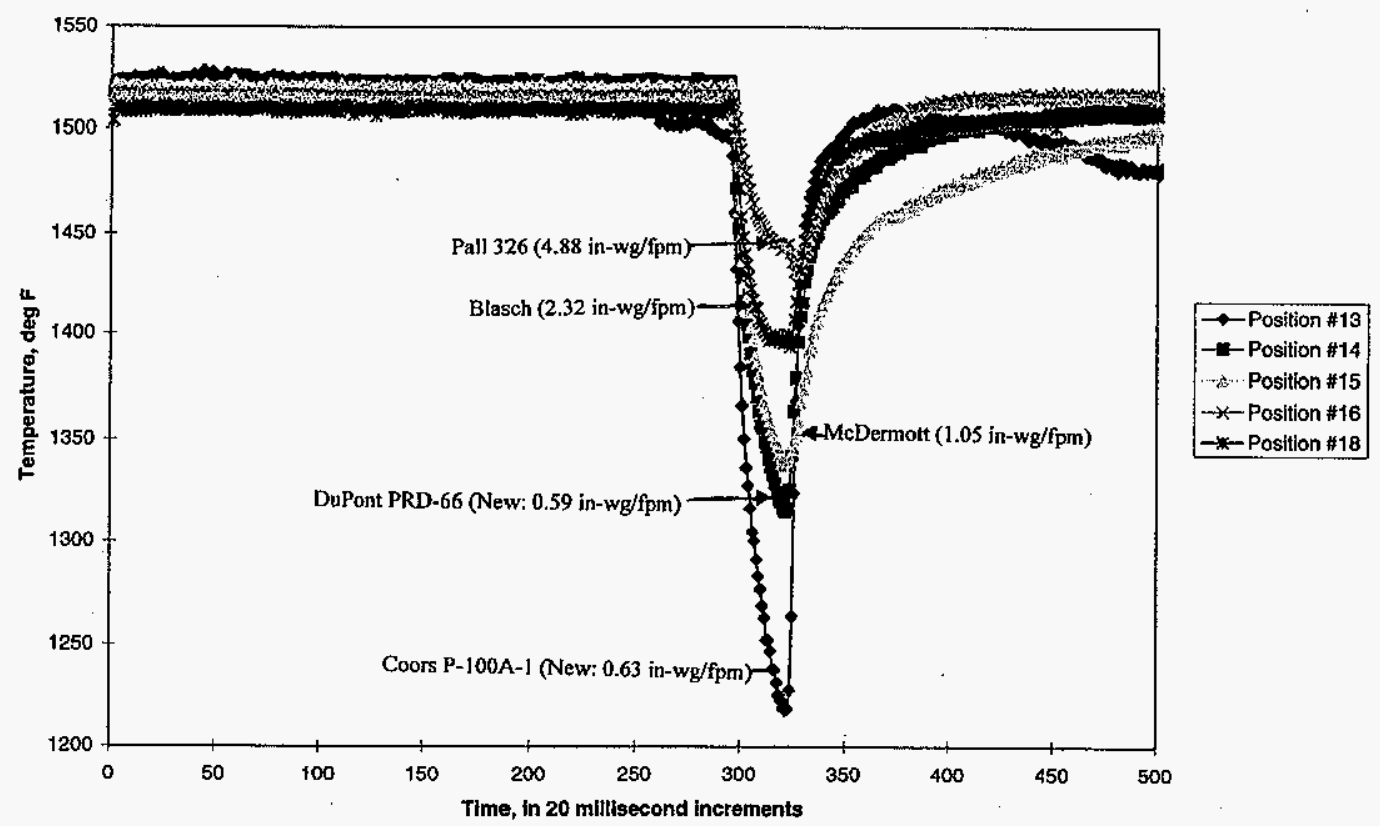

Figure 3-28 - Temperature profiles that resulted along the i.d. surface at the base of the flange of the porous ceramic filter elements during delivery of the pulse cleaning cycle after the first minute of thermal transient $\$ 26$.

Inside Top TC's - $1750 \mathrm{lb} / \mathrm{hr}$ Trip With Pulse, \#27 12/9/98

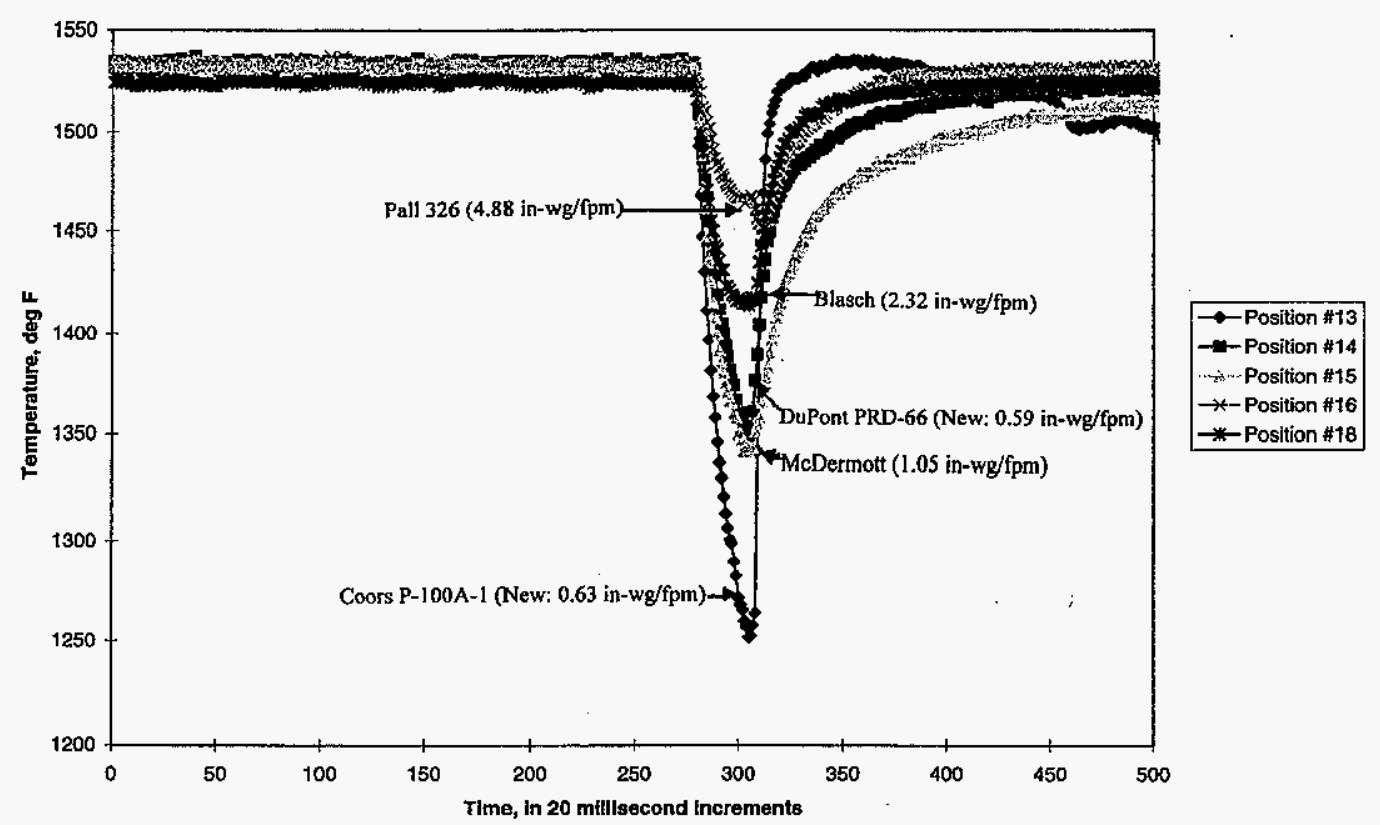

Figure 3-29 - Temperature profiles that resulted along the i.d. surface at the base of the flange of the porous ceramic filter elements during delivery of the pulse cleaning cycle after the second minute of thermal transient $\$ 27$. 
TABLE 3-10. MAXIMUM TEMPERATURE DROP EXPERIENCED ALONG THE TOP I.D. SURFACE OF THE POROUS CERAMIC FILTER ELEMENTS DURING THERMAL TRANSIENT TESTING WITH SIMULTANEOUS PULSE CYCLING - $1750 \mathrm{lb} / \mathrm{hr}$ Air Flow -

\begin{tabular}{|c|c|c|c|c|c|c|c|c|c|}
\hline \multirow{2}{*}{$\begin{array}{c}\text { Pulse Cycle } \\
\text { Time/ } \\
\text { Thermal } \\
\text { Transient } \\
\text { Filter Element }\end{array}$} & \multicolumn{3}{|c|}{$\begin{array}{c}\text { First Minute of the } \\
\text { Thermal Transient \#26 } \\
\text { (Dust Cake) }\end{array}$} & \multicolumn{3}{|c|}{$\begin{array}{l}\text { First Minute of the } \\
\text { Thermal Transient \#27 } \\
\text { (No Dust Cake) }\end{array}$} & \multicolumn{3}{|c|}{$\begin{array}{l}\text { Second Minute of the } \\
\text { Thermal Transient \#28 } \\
\text { (No Dust Cake) }\end{array}$} \\
\hline & $\begin{array}{c}\text { Initial T, } \\
{ }^{\circ} \mathbf{F}\end{array}$ & $\begin{array}{c}\text { Min } \mathbf{T}, \\
{ }^{\circ} \mathbf{F}\end{array}$ & $\begin{array}{c}\operatorname{Max} \\
\Delta T\end{array}$ & $\begin{array}{c}\text { Initial } T \text {, } \\
{ }^{\circ} \mathbf{F}\end{array}$ & $\begin{array}{c}\text { Min T, } \\
{ }^{\circ} \mathbf{F}\end{array}$ & $\begin{array}{c}\text { Max } \\
\Delta \mathbf{T}\end{array}$ & $\begin{array}{c}\text { Initial } \mathbf{T}, \\
{ }^{\circ} \mathbf{F}\end{array}$ & $\begin{array}{c}\text { Min } T \text {, } \\
{ }^{\circ} \mathbf{F}\end{array}$ & $\begin{array}{c}\operatorname{Max} \\
\Delta \mathrm{T}\end{array}$ \\
\hline & 1502.4 & 1218.2 & -284.2 & 1532.7 & 251.7 & & - & - & - \\
\hline DuP & & & & & & & 1483.9 & 1315.8 & -168.1 \\
\hline McDermott & & & & 1534.8 & & & 1460.7 & 1283.4 & -177.3 \\
\hline Pall 326 & & & & & 1451.7 & & - & - & - \\
\hline Blasch & 1509.1 & 1393.9 & -115.2 & 1524.9 & 1414.2 & -110.7 & 1513.4 & 1400.7 & -112. \\
\hline
\end{tabular}

TABLE 3-11. TEMPERATURE DROP THROUGHOUT THE FILTER ARRAY AS A FUNCTION OF TIME DURING THERMAL TRANSIENT TESTING WITH SIMULTANEOUS PULSE CYCLING

\begin{tabular}{|c|c|c|c|c|c|c|c|c|}
\hline \multirow[t]{2}{*}{$\begin{array}{c}\text { Time, } \\
\text { min }\end{array}$} & \multicolumn{2}{|c|}{$\begin{array}{c}\text { Coors P-100A-1 } \\
\text { (Position 13) } \\
\text { o.d. Top } \\
\end{array}$} & \multicolumn{2}{|c|}{$\begin{array}{c}\begin{array}{c}\text { Coors P-100A-1 } \\
\text { (Position 13) } \\
\text { i.d. Top }\end{array} \\
\end{array}$} & \multicolumn{2}{|c|}{$\begin{array}{c}\text { DuPont PRD-66 } \\
\text { (Position 14) } \\
\text { o.d. Top } \\
\end{array}$} & \multicolumn{2}{|c|}{$\begin{array}{c}\text { DuPont PRD-66 } \\
\text { (Position 14) } \\
\text { i.d. Top }\end{array}$} \\
\hline & Temp., ${ }^{\circ} \mathrm{F}$ & $\Delta \mathrm{T}$ & Temp., ${ }^{\circ} \mathrm{F}$ & $\Delta T$ & Temp., ${ }^{\circ} \mathbf{F}$ & $\Delta \mathrm{T}$ & Temp., ${ }^{\circ} \mathbf{F}$ & $\Delta \mathbf{T}$ \\
\hline \multicolumn{9}{|c|}{ Thermal Transient \#26 } \\
\hline 0 & 1514.7 & & 1518.3 & & 1519.0 & & 1517.5 & \\
\hline 0.5 & 1364.5 & -150.2 & 1371.4 & -146.9 & 1449.1 & -69.9 & 1510.2 & -7.3 \\
\hline 1.0 & 1300.8 & -63.7 & 1287.7 & -83.7 & 1409.5 & -39.6 & 1473.1 & -37.1 \\
\hline 1.5 & 1292.0 & -8.8 & 1230.8 & -56.9 & 1371.6 & -37.9 & 1434.7 & -38.4 \\
\hline \multicolumn{9}{|c|}{ Thermal Transient \#27 } \\
\hline 0 & 1528.9 & & 1530.7 & & 1536.8 & & 1535.2 & \\
\hline 0.5 & 1375.9 & -153.0 & 1358.8 & -171.9 & 1470.0 & -66.8 & 1522.6 & -12.6 \\
\hline 1.0 & 1333.4 & -42.5 & 1259.4 & -99.4 & 1443.7 & -26.3 & 1495.2 & -27.4 \\
\hline 1.5 & 1341.1 & 7.7 & 1196.2 & -63.2 & 1393.5 & -50.2 & 1458.9 & -36.3 \\
\hline \multicolumn{9}{|c|}{ Thermal Transient \#28 } \\
\hline 0 & 1527.8 & & 1529.8 & & 1531.4 & & 1537.3 & \\
\hline 0.5 & 1388.7 & -139.1 & 1354.5 & -175.3 & 1457.6 & -73.8 & 1523.7 & -13.6 \\
\hline 1.0 & 1363.6 & -25.1 & 1254.6 & -99.9 & 1419.1 & -38.5 & 1488.2 & -35.5 \\
\hline 1.5 & 1344.2 & -19.4 & - & - & 1378.8 & -40.3 & 1447.7 & -40.5 \\
\hline
\end{tabular}




\section{TABLE 3-11 (COnt'd). TEMPERATURE DROP THROUGHOUT THE FILTER ARRAY AS A FUNCTION OF TIME DURING THERMAL TRANSIENT TESTING WITH SIMULTANEOUS PULSE CYCLING}

\begin{tabular}{|c|c|c|c|c|c|c|c|c|}
\hline \multirow{2}{*}{$\begin{array}{l}\text { Time, } \\
\min \end{array}$} & \multicolumn{2}{|c|}{$\begin{array}{l}\text { McDermott } \\
\text { (Position 15) } \\
\text { 0.d. Top }\end{array}$} & \multicolumn{2}{|c|}{$\begin{array}{l}\text { MeDermott } \\
\text { (Position 15) } \\
\text { i.d. Top }\end{array}$} & \multicolumn{2}{|c|}{$\begin{array}{c}\text { Pall 326 } \\
\text { (Position 16) } \\
\text { o.d. Top }\end{array}$} & \multicolumn{2}{|c|}{$\begin{array}{c}\text { Pall 326 } \\
\text { (Position 16) } \\
\text { idd. Top }\end{array}$} \\
\hline & Temp., ${ }^{\circ} \mathrm{F}$ & $\Delta T$ & Temp., ${ }^{\circ} \mathbf{F}$ & $\Delta \mathbf{T}$ & Temp., ${ }^{\circ} \mathrm{F}$ & $\Delta \mathrm{T}$ & Temp., ${ }^{\circ} \mathrm{F}$ & $\Delta T$ \\
\hline \multicolumn{9}{|c|}{ Thermal Transient \#26 } \\
\hline 0 & 1512.3 & & 1514.8 & & 1499.2 & & 1510.3 & \\
\hline 0.5 & 1455.1 & -57.2 & 1495.9 & -18.9 & 1455.6 & -43.6 & 1511.6 & 1.3 \\
\hline 1.0 & 1416.9 & -38.2 & 1456.0 & -39.9 & 1430.2 & -25.4 & 1492.5 & -19.1 \\
\hline 1.5 & 1399.5 & -17.4 & 1424.7 & -31.3 & 1418.0 & -12.2 & 1469.7 & -22.8 \\
\hline \multicolumn{9}{|c|}{ Thermal Transient \#27 } \\
\hline 0 & 1530.0 & & 1535.0 & & 1518.8 & & 1531.8 & \\
\hline 0.5 & 1468.9 & -61.1 & 1516.6 & -18.4 & 1472.5 & -46.3 & 1530.7 & -1.1 \\
\hline 1.0 & 1449.0 & -19.9 & 1479.7 & -36.9 & 1452.0 & -20.5 & 1513.4 & -17.3 \\
\hline 1.5 & 1424.1 & -24.9 & 1444.3 & -35.4 & 1436.2 & -15.8 & 1492.3 & -21.1 \\
\hline \multicolumn{9}{|c|}{ Thermal Transient \#28 } \\
\hline 0 & 1525.8 & & 1529.8 & & 1509.6 & & - & \\
\hline 0.5 & 1446.6 & -79.2 & 1505.1 & -24.7 & 1461.7 & -47.9 & $\overline{-}$ & - \\
\hline 1.0 & 1436.7 & -9.9 & 1466.1 & -39.0 & 1442.3 & -19.4 & - & $=$ \\
\hline 1.5 & 1410.3 & -26.4 & 1428.1 & -38.0 & 1417.8 & -24.5 & - & - \\
\hline \multirow[t]{2}{*}{$\begin{array}{l}\text { Time, } \\
\text { min }\end{array}$} & \multicolumn{2}{|c|}{$\begin{array}{c}\text { Schumacher FT20 } \\
\text { (Position 17) } \\
\text { o.d. Top }\end{array}$} & \multicolumn{2}{|c|}{$\begin{array}{l}\text { Schumacher FT20 } \\
\text { (Position 17) } \\
\text { i.d. Top }\end{array}$} & \multicolumn{2}{|c|}{$\begin{array}{c}\text { Blasch 270 } \\
\text { (Position 18) } \\
\text { o.d. Top }\end{array}$} & \multicolumn{2}{|c|}{$\begin{array}{c}\text { Blasch 270 } \\
\text { (Position 18) } \\
\text { i.d. Top }\end{array}$} \\
\hline & Temp., ${ }^{\circ} \mathrm{F}$ & $\Delta \mathbf{T}$ & Temp., ${ }^{\circ} \mathbf{F}$ & $\Delta \mathbf{T}$ & Temp., ${ }^{\circ} \mathrm{F}$ & $\Delta \mathbf{T}$ & Temp., ${ }^{\circ} \mathbf{F}$ & $\Delta \mathbf{T}$ \\
\hline \multicolumn{9}{|c|}{ Thermal Transient \#26 } \\
\hline 0 & 1500.6 & & - & - & 1512.5 & & 1503.7 & \\
\hline 0.5 & 1423.9 & -76.7 & - & $=$ & 1412.8 & -99.7 & 1510.7 & 7.0 \\
\hline 1.0 & 1405.8 & -18.1 & $\overline{-}$ & $=$ & 1391.9 & -20.9 & 1501.5 & -9.2 \\
\hline 1.5 & 1377.1 & -28.7 & - & $=$ & 1371.9 & -20.0 & 1487.1 & -14.4 \\
\hline \multicolumn{9}{|c|}{ Thermal Transient \#27 } \\
\hline 0 & 1522.4 & & - & $=$ & 1519.5 & & 1524.9 & \\
\hline 0.5 & 1446.6 & -75.8 & $=$ & $=$ & 1429.5 & -90.0 & 1528.5 & 3.6 \\
\hline 1.0 & 1429.5 & -17.1 & - & - & 1423.6 & -5.9 & 1520.8 & -7.7 \\
\hline 1.5 & 1400.2 & -29.3 & - & $=$ & 1409.4 & -14.2 & 1505.3 & -15.5 \\
\hline \multicolumn{9}{|c|}{ Thermal Transient \#28 } \\
\hline 0 & 1511.6 & & $=$ & $=$ & 1512.3 & & 1520.2 & \\
\hline 0.5 & 1447.9 & -63.7 & - & - & 1435.3 & -77.0 & 1520.1 & -0.1 \\
\hline 1.0 & 1407.6 & -40.3 & $=$ & $=$ & 1420.9 & -14.4 & 1511.1 & -9.0 \\
\hline 1.5 & 1402.9 & -4.7 & - & - & 1403.4 & -17.5 & 1496.8 & -14.3 \\
\hline
\end{tabular}




\subsubsection{Post-Test Inspection}

After completion of the thermal transient test campaign at STC on December 10, 1998, disassembly of the filter array was initiated on January 5, 1999. As shown in Figure 3-30, all elements initially appeared to be intact. Further inspection of the array indicated that failure of the newly installed, thermocouple instrumented, Coors P-100A-1 alumina/mullite filter element had occurred circumferentially at $\sim 24$ inches from the bottom closed end cap (Figure 3-31). The newly installed Coors P-100A-1 candle had previously been identified as dimensionally 'out-of-spec', and thus had been rejected from field service. Based on a review of the temperature measurements generated during the thermal transient test campaign, failure of the thermocouple along the bottom o.d. surface of the Coors P$100 \mathrm{~A}-1$ alumina/mullite filter element was considered to have occurred between thermal transient \#19 and $\# 20$. Further post-test inspection of the Coors P-100A-1 alumina/mullite filter element indicated that the internal i.d. bore of the failed candle was relatively clean. The lower section of the Coors P-100A-1 alumina/mullite filter element was seen to have fractured into several pieces, perhaps as a result of impact in the ash hopper.

In addition to the failed, newly installed, Coors P-100A-1 alumina/mullite candle filter, a longitudinal crack was visible along the outer surface of the 581 hour, PCFBC-exposed/extended filter life-tested, Blasch candle filter (Figure 3-32). The longitudinal crack extended $\sim 2$ inches $(\sim 5 \mathrm{~cm})$ from the bottom end cap to $\sim 20$ inches $(\sim 51 \mathrm{~cm})$ along the lower body of the Blasch filter element.
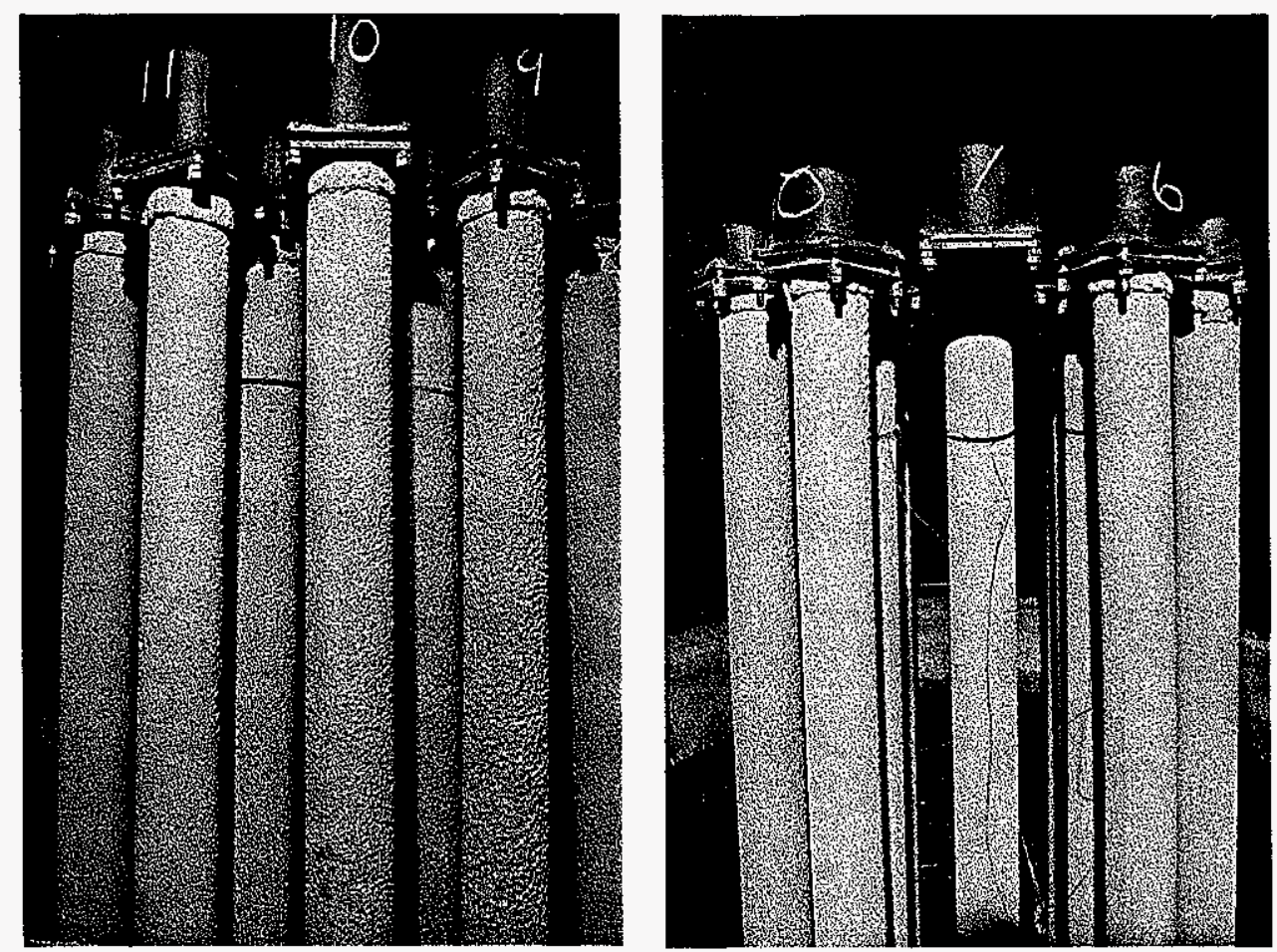

Figure 3-30 - Photographs of the filter array at the conclusion of the thermal transient test program. 

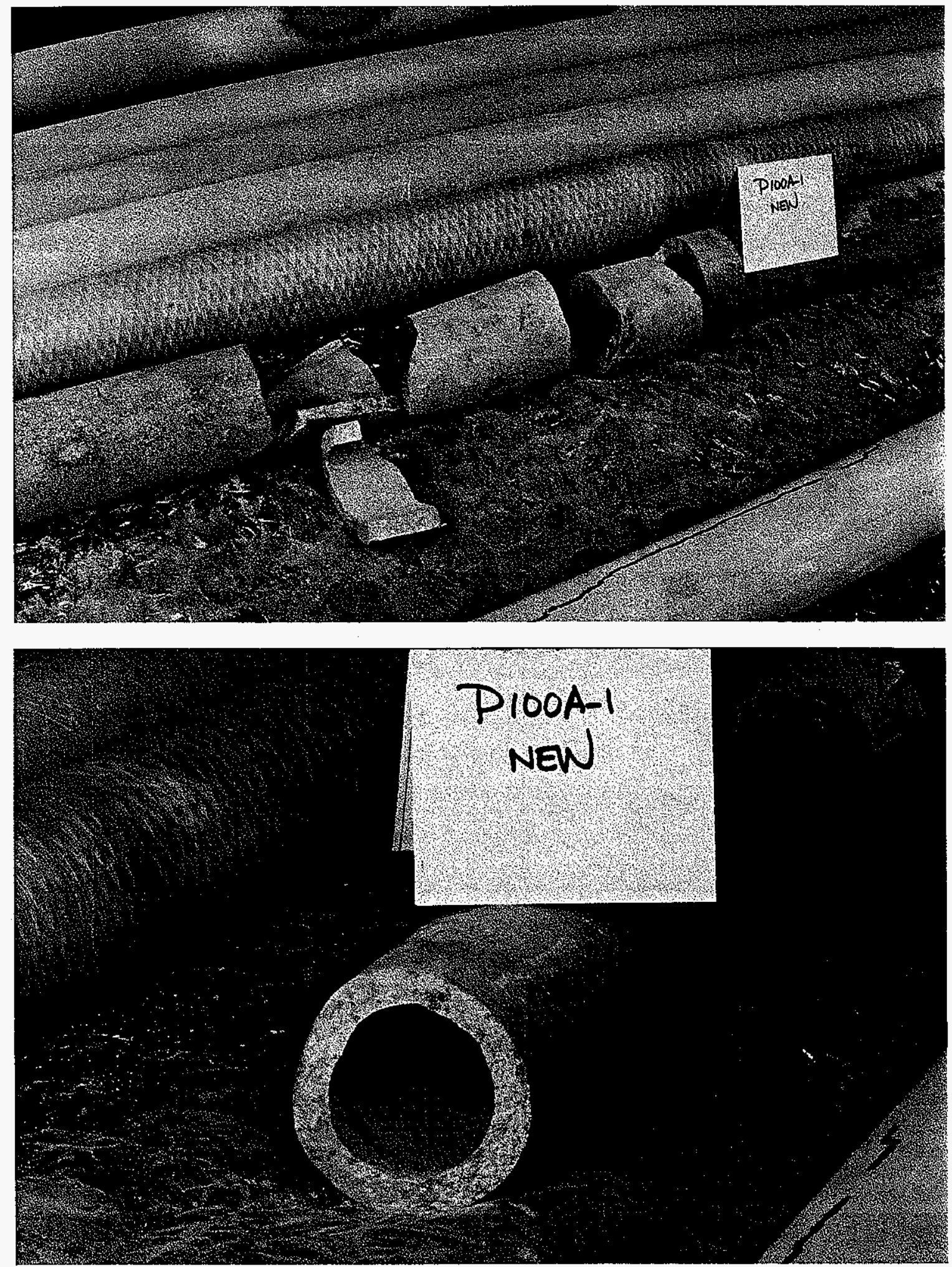

Figure 3-31 - Coors P-100A-1 alumina/mullite candle filter failure. Failure was identified to have occurred between thermal transient \#19 and \#20. 


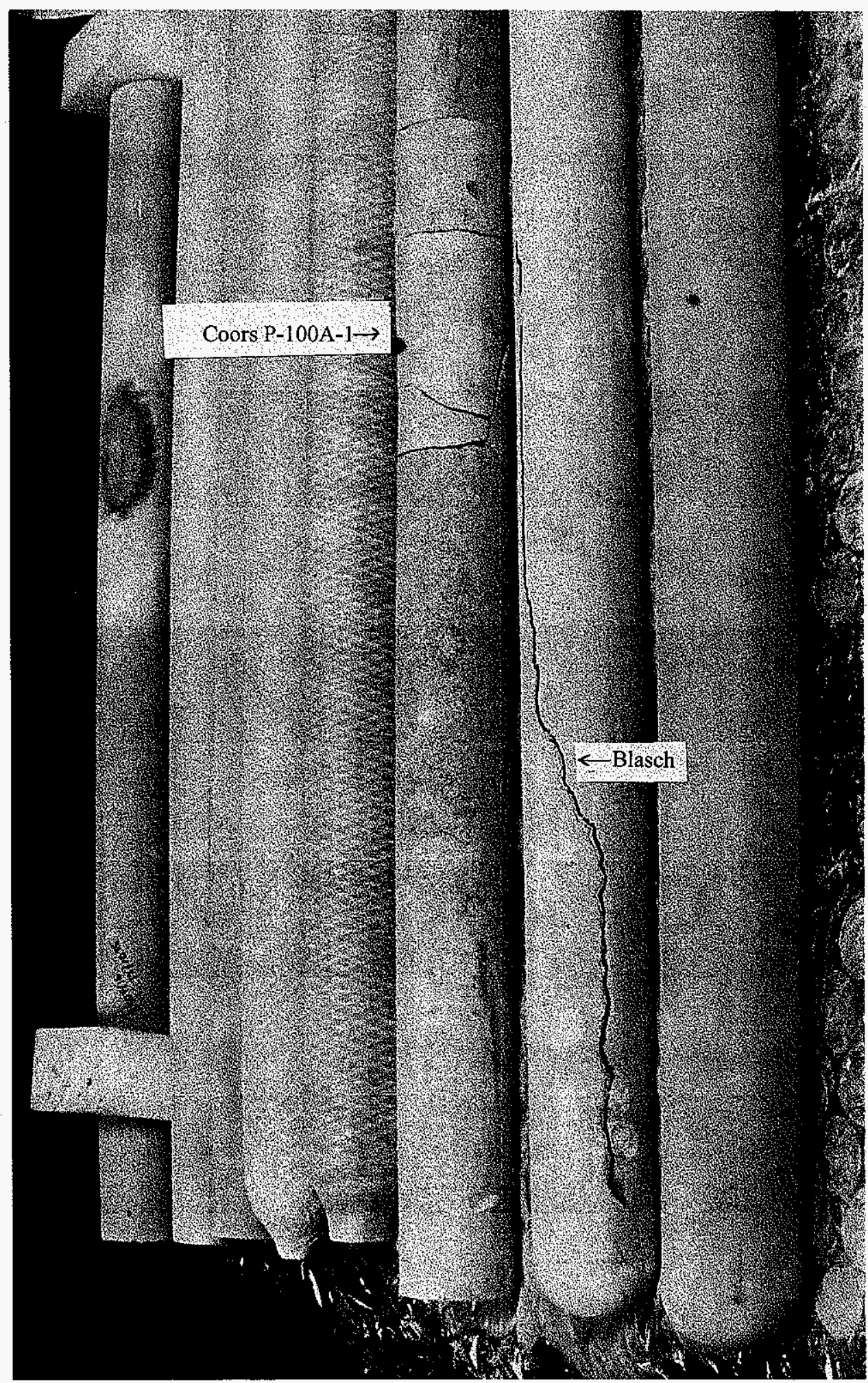

Figure 3-31 (Cont'd.) - Coors P-100A-1 alumina/mullite candle filter failure. Failure was identified to have occurred between thermal transient \#19 and \#20. 


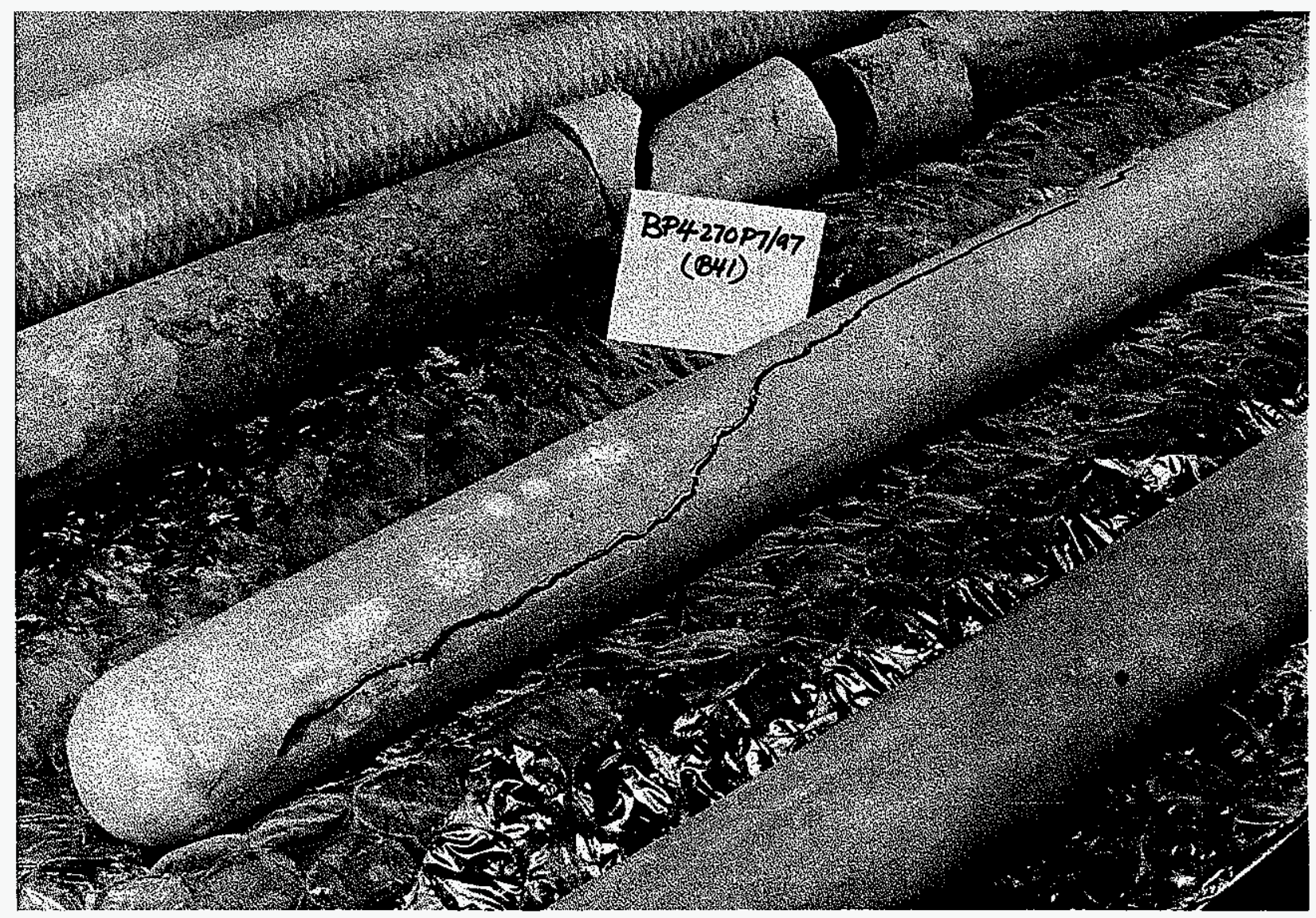

Figure 3-32 - Longitudinal crack formation along the lower section of the Blasch filter element identified at the conclusion of the thermal transient test program. 
The McDermott element which had experienced $581 \mathrm{hr}$ of PCFBC-exposure, and which had been subjected to the extended filter life program, had what appeared to be debonding or delamination crack formations along the top surface of the flange, with slight separation of the interior plug from the external filament wound flange wall (Figure 3-33). SWPC's redesigned top metal holders which had been used at Karhula and at STC were designed to specifically mitigate this issue. Areas of chopped fibers and bonding matrix were removed along the outer surface of the McDermott filter element, exposing the underlying fiber wound filaments and chopped fibers (Figure 3-34).

Post-test inspection of the IF\&P REECER (recrystallized silicon carbide) filter element identified the excellent condition of the oxide-based insert along the flange i.d. wall (Figure 3-35). The insert was added to provide an adequate flange sealing surface during mounting and operation of the element in SWPC's filter array. Minor depressions along the i.d. of the flange were seen which can be compensated for during manufacturing of the filter element and/or with modification to SWPC's mounting and holder assembly.

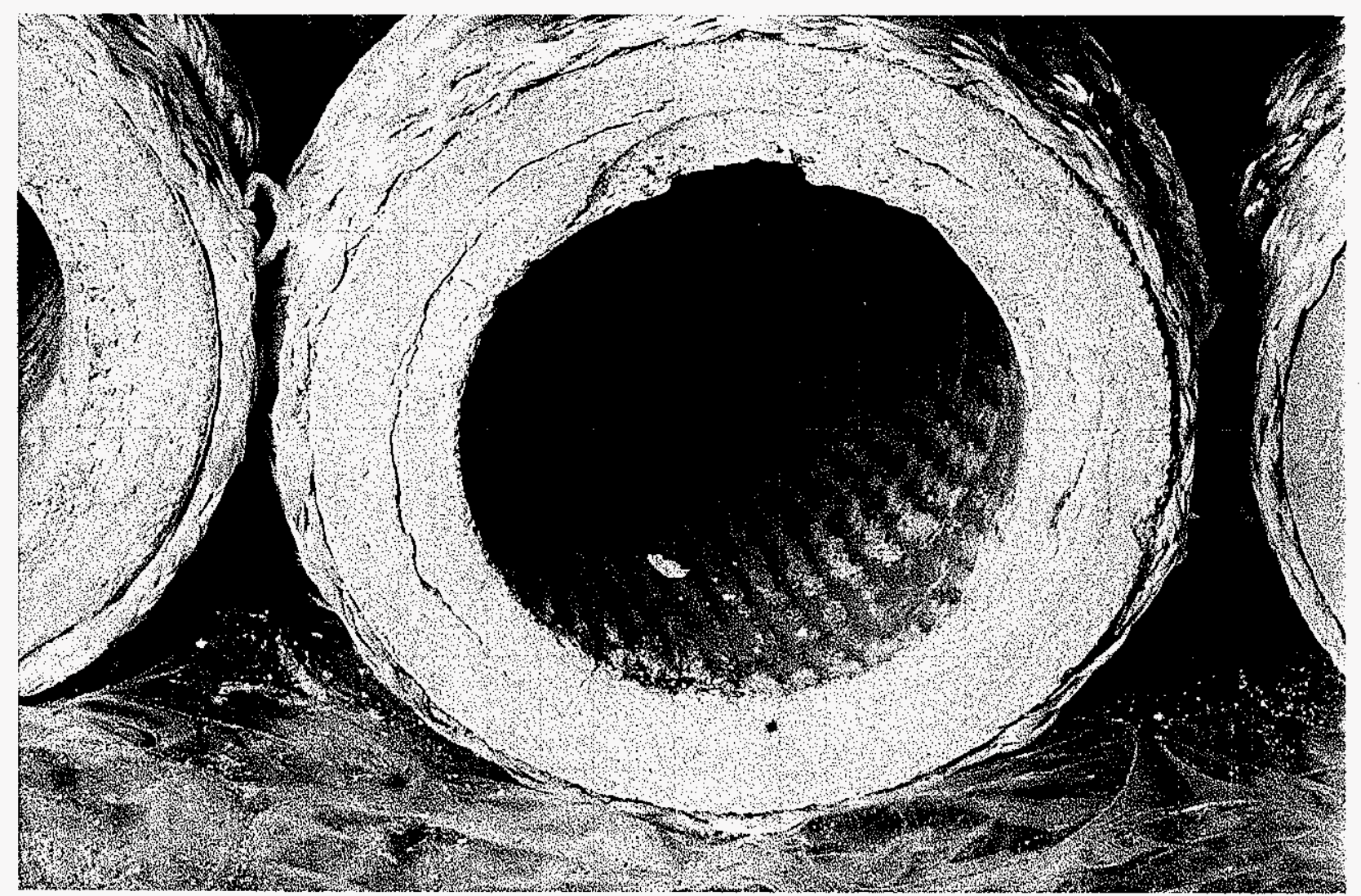

Figure 3-33 - Separation along the flange of the McDermott CFCC filter element at the conclusion of thermal transient testing. 

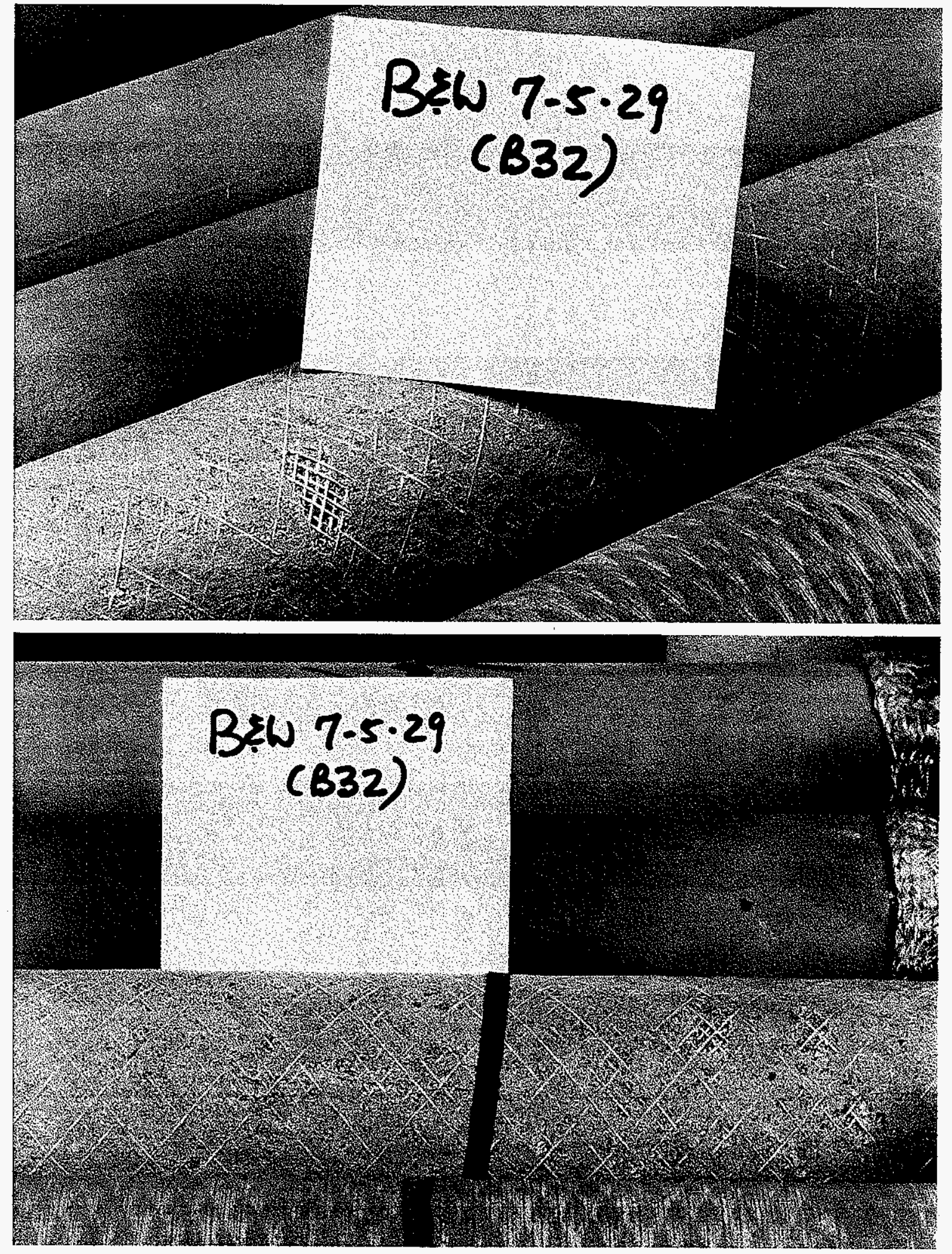

Figure 3-34 - Removal of the chopped fiber and bonding matrix in localized areas along the outer surface of the McDermott CFCC filter element at the conclusion of the thermal transient test program. 


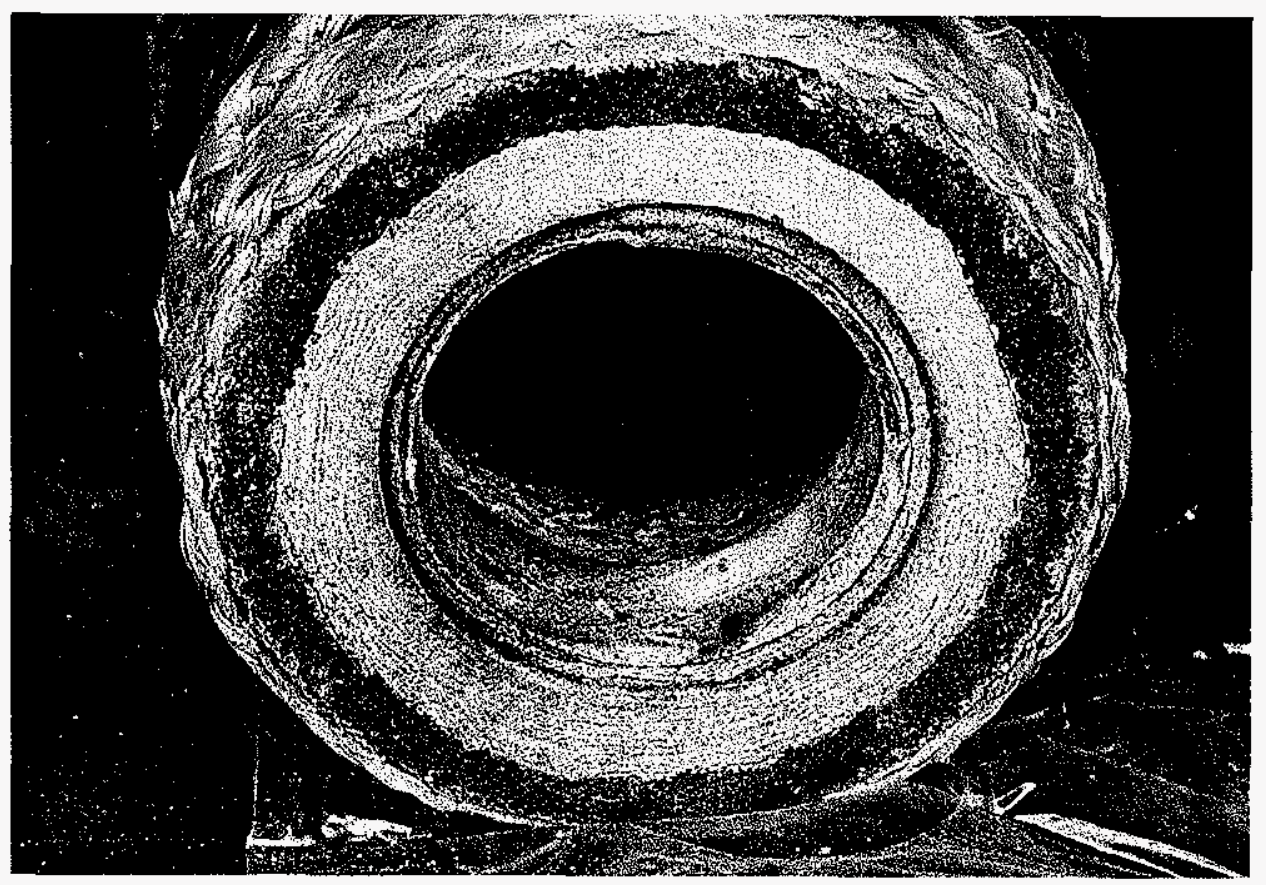

Figure 3-35 - Oxide-based insert bonded to the i.d. surface of the flange of the IF\&P REECER candle filter at the conclusion of the thermal transient test program.

After cleaning, an oval-shaped discoloration mark was detected on the surface of the Schumacher Dia Schumalith FT20 candle filter (Figure 3-36). This mark generally coincided with the failure location identified for the Coors P-100A-1 and Blasch 270 filters at the conclusion of the thermal transient test campaign. A similar oval-shaped discolored area was observed along the Pall 326 candle that had been removed prior to installation of the metal shroud in the filter vessel. Once again, the oval-shaped discolored area along the Pall 326 candle was located at approximately the same area as the fracture site identified for an adjacent Pall 326 filter element.

After removal and cleaning of all elements from the filter array, the room temperature gas flow resistance of each thermal transient-tested candle filter was determined. Table 3-12 provides a summary of the post-test gas flow resistance measurements, and compares each value with gas flow resistance measurements for comparable as-manufactured filter elements. 


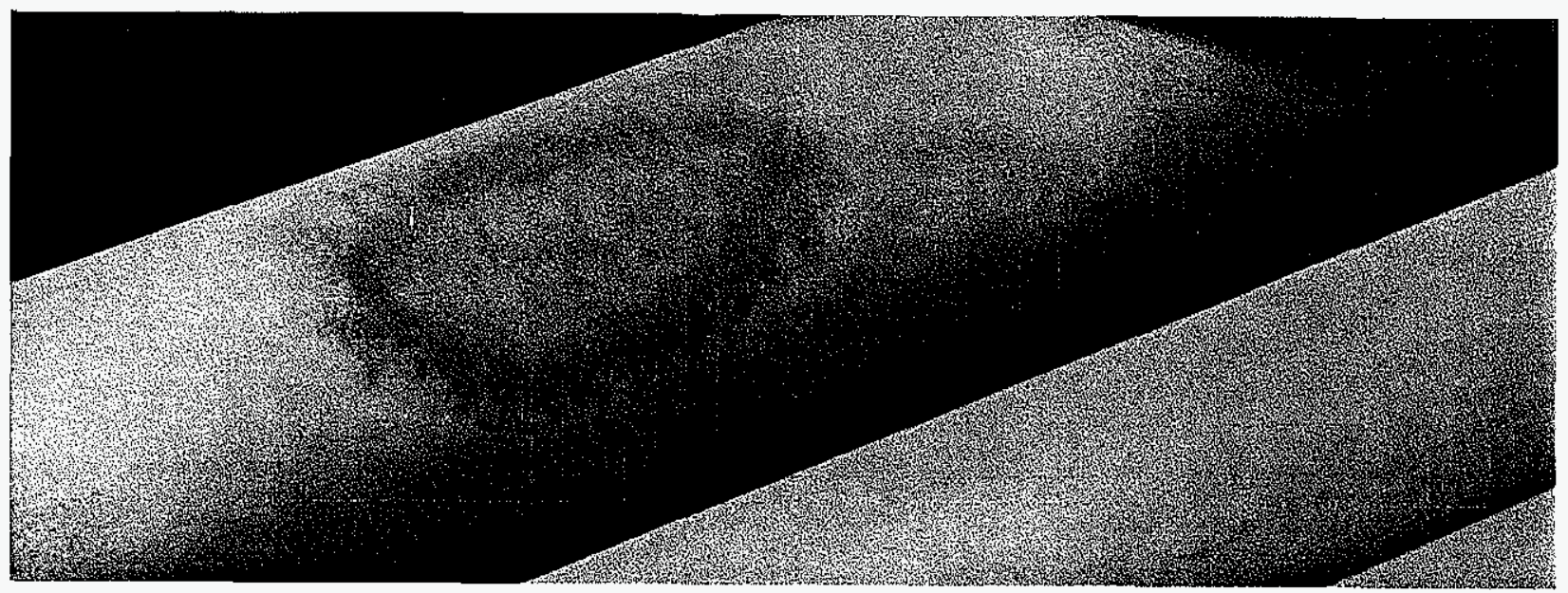

Figure 3-36 - Discoloration area along the outer surface of the Schumacher Dia Schumalith FT20 candle filter.

Although the $581 \mathrm{hr}$, PCFBC-exposed, Blasch candle filter was intact at the end of the extended life thermal transient test program, a longitudinal crack was visible along the outer surface of the filter element, extending $\sim 5 \mathrm{~cm}$ from the bottom end cap for $\sim 50 \mathrm{~cm}$ along the lower body of the filter element (Figure 3-37). When sectioned at $\sim 5 \mathrm{~cm}$ below the end of the crack shown in Area 1, Figure 3-37, the crack was seen to have propagated through the filter wall (Figure 3-38), and extend intermittently for $\sim 3 \mathrm{~cm}$ vs $\sim 5 \mathrm{~cm}$ along the i.d. bore of the element (Figure 3-39). Along this cross-sectioned plane, the crack appeared to be somewhat more open along the o.d. surface of the element. As shown in Figure 338 , the crack resulted through the thicker section of the nonconcentric filter wall (i.e., larger thermal stress resulting through the thicker nonconcentric section of the filter matrix). Additional cracks were not identified along this cross-sectioned plane of the filter wall (i.e., at $180^{\circ}$ from the previously discussed crack).

When sectioned at $\sim 6 \mathrm{~cm}$ above the end of the crack shown in Area 2, Figure 3-37, the longitudinal crack which was visible along the outer surface of the filter element (Figure 3-40), was seen once again to propagate through the filter wall, and extend for $\sim 0.5 \mathrm{~cm}$ along the i.d. wall (Figure 3-41). As previously discussed, the longitudinal crack was located along the thicker section of the nonconcentric filter wall, and additional cracks were not identified. 
TABLE 3-12. GAS FLOW RESISTANCE OF THE

EXTENDED LIFE-TESTED FILTER ELEMENTS

\begin{tabular}{|c|c|c|}
\hline $\begin{array}{c}\text { Array } \\
\text { Location }\end{array}$ & $\begin{array}{c}\text { Filter Element Identification Number } \\
\text { (PCFBC Operating Hrs/Equivalent Extended Hrs) }\end{array}$ & $\begin{array}{l}\text { Resistance, in-wg/fpm } \\
\text { @ } 5 \mathrm{ft} / \mathrm{min}^{*}\end{array}$ \\
\hline 1 & - & - \\
\hline 2 & $\mathrm{FC} 059(\mathrm{M} 13)-(2166 \mathrm{Hrs} / 10,045 \mathrm{Hrs})$ & $2.14(2.12)$ \\
\hline 3 & FC065 (M10)-(2166 Hrs/10,045 Hrs $)$ & $2.26(2.32)$ \\
\hline 4 & - & - \\
\hline 5 & P-100A-1 (New) $-(0 \mathrm{Hrs} / 8485 \mathrm{Hrs})$ & $1.46(1.56)$ \\
\hline 6 & E-141-97(B25)-(581 Hrs/5030 Hrs $)$ & $2.85(2.62)$ \\
\hline 7 & - & - \\
\hline 8 & IF \&P - (0 Hrs $/ 5030 \mathrm{Hrs})$ & $0.73(1.01)$ \\
\hline 9 & $\mathrm{~S} 350 \mathrm{~F} / 32(\mathrm{~T} 3)-(1035 \mathrm{Hrs} / 10,045 \mathrm{Hrs})$ & $2.48(2.34)$ \\
\hline 10 & $\mathrm{R} 1-658(\mathrm{M} 3)-(1035 \mathrm{Hrs} / 10,045 \mathrm{Hrs})$ & $4.33(4.38)$ \\
\hline 11 & $\mathrm{~S} 350 \mathrm{~F} / 80(\mathrm{~T} 6)-(1035 \mathrm{Hrs} / 0 \mathrm{Hrs})$ & $1.37(1.25)$ \\
\hline 12 & $\mathrm{R} 3-656(\mathrm{M} 21)-(1035 \mathrm{Hrs} / 0 \mathrm{Hrs})$ & $2.4(2.20)$ \\
\hline 13 & $\mathrm{P}-100 \mathrm{~A}-1 \mathrm{New}-(0 \mathrm{Hrs} / 0 \mathrm{Hrs})$ & $0.63(-)^{* *}$ \\
\hline 14 & D571C $(\mathrm{New})-(0 \mathrm{Hrs} / 7517 \mathrm{Hrs})$ & $0.59(0.79)$ \\
\hline 15 & $\mathrm{~B} \& W 7-5-29(\mathrm{~B} 32)-(581 \mathrm{Hrs} / 10,045 \mathrm{Hrs})$ & $1.05(1.12)$ \\
\hline 16 & R5-667 (M23)- $(1035 \mathrm{Hrs} / 8627 \mathrm{Hrs})$ & $4.88(4.84)$ \\
\hline 17 & $\mathrm{~S} 350 \mathrm{~F} / 43(\mathrm{~T} 4)-(1035 \mathrm{Hrs} / 10,045 \mathrm{Hrs})$ & $1.93(1.92)$ \\
\hline 18 & BP4-270P7/97 (B41) - $(581 \mathrm{Hrs} / 10,045 \mathrm{Hrs})$ & $2.32(2.02)^{* * *}$ \\
\hline 19 & - & - \\
\hline
\end{tabular}

* Prior to conduct of thermal transient testing (After conduct of thermal transient testing).

** The Coors P-100A-1 alumina/mullite filter element failed between thermal transient \#19 and \#20.

*** After completion of the thermal transient test campaign, a longitudinal crack was observed at $\sim 5 \mathrm{~cm}$ and extended to $\sim 51 \mathrm{~cm}$ from the end cap of the filter element.

NOTE: At $5 \mathrm{ft} / \mathrm{min}$, the gas flow resistance through all fail-safe/regenerators that were positioned above each candle filter ranged between $0.24-0.36 \mathrm{in}-\mathrm{wg} / \mathrm{ft} / \mathrm{min}(\mathrm{Mean} \pm 1 \sigma: 0.30 \pm 0.037)$.

Along neither of the crack termination areas was there evidence of crack formations along alternate areas of the filter wall. However, when o-ring sections were cut from the filter body along areas that contained the longitudinal crack, and notches subsequently cut spanning the longitudinal crack, several c-rings were identified to contain cracks along their i.d. surface and across the filter wall thickness (Figure 3-42). While attempting to photograph such a c-ring, the c-ring failed along the crack formation (Figure 3-43; the marker shows the position of the original crack along the i.d. wall and across the wall thickness). Notably the crack appeared to be more open along the i.d. surface of the Blasch filter element. Along the fractured filter wall, dust was seen to penetrate $\sim 0.4 \mathrm{~mm}$ into the filter matrix along either the o.d. or i.d. surfaces (Figure 3-43).

Similar to the Blasch filter element, nonconcentricity of the PCFBC-exposed/extended life-tested Coors filter element was identified along the lower section of the candle (i.e., closest to the end cap; Figure 3-44). During plant operation, perhaps a larger stress gradient was established through the thicker area of the nonconcentric Coors P-100A-1 filter wall, leading to failure of elements, particularly at the mid-section and along the lower $\sim 1 / 3$ of the filter element. Manufacturing modifications are needed to resolve the production of nonconcentric filter elements. 


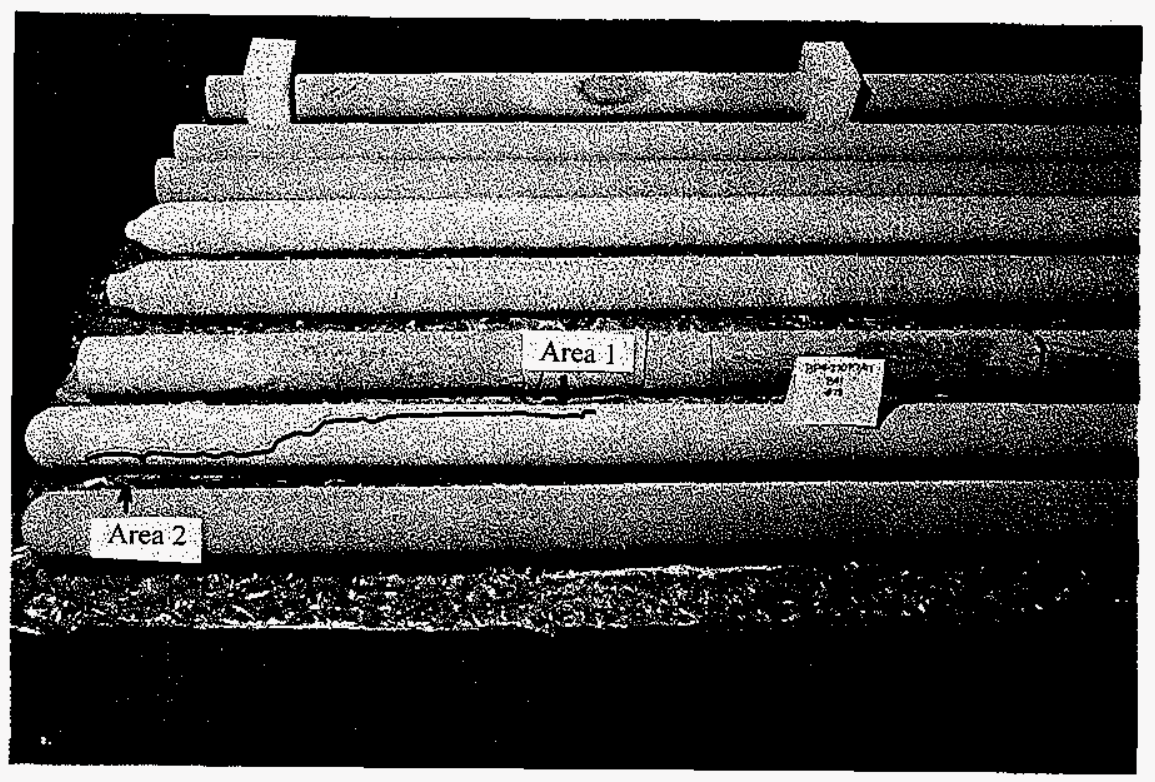

Figure 3-37 - Longitudinal crack identified along the lower section of the Blasch mullite-bonded alumina candle filter at the conclusion of the thermal transient test program.

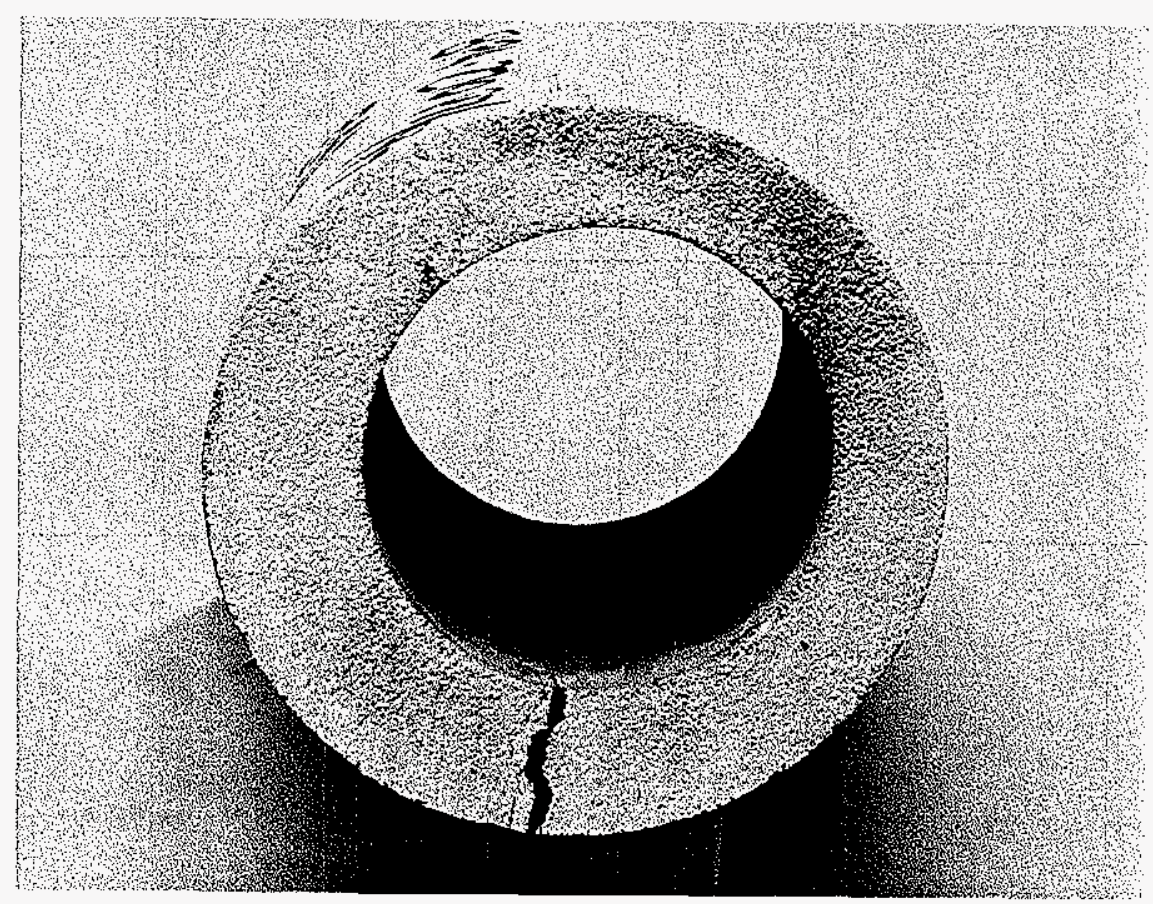

Figure 3-38 - Crack formation across the Blasch mullite-bonded alumina filter wall. 


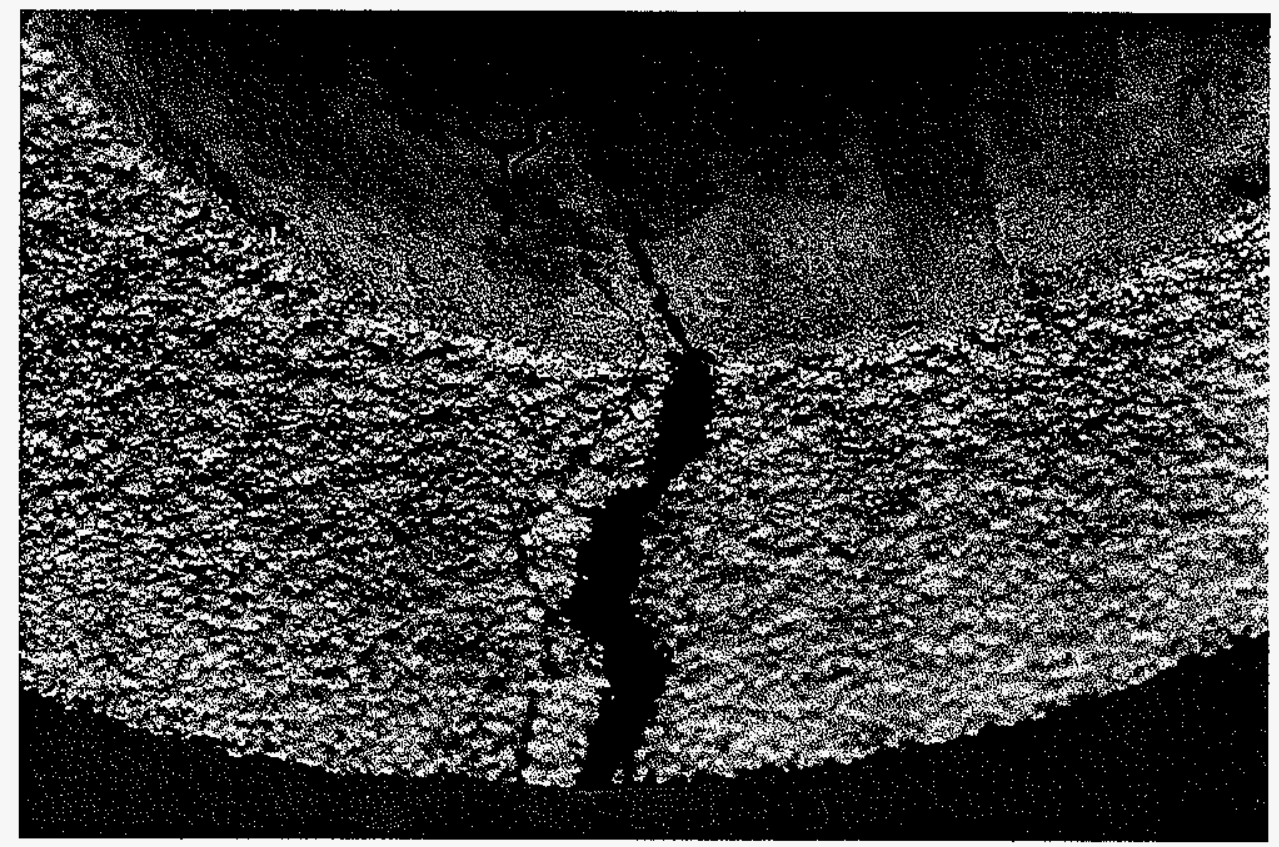

Figure 3-39 - Intermittent extension of the externally visible longitudinal crack along the i.d. surface of the Blasch mullite-bonded alumina filter element.

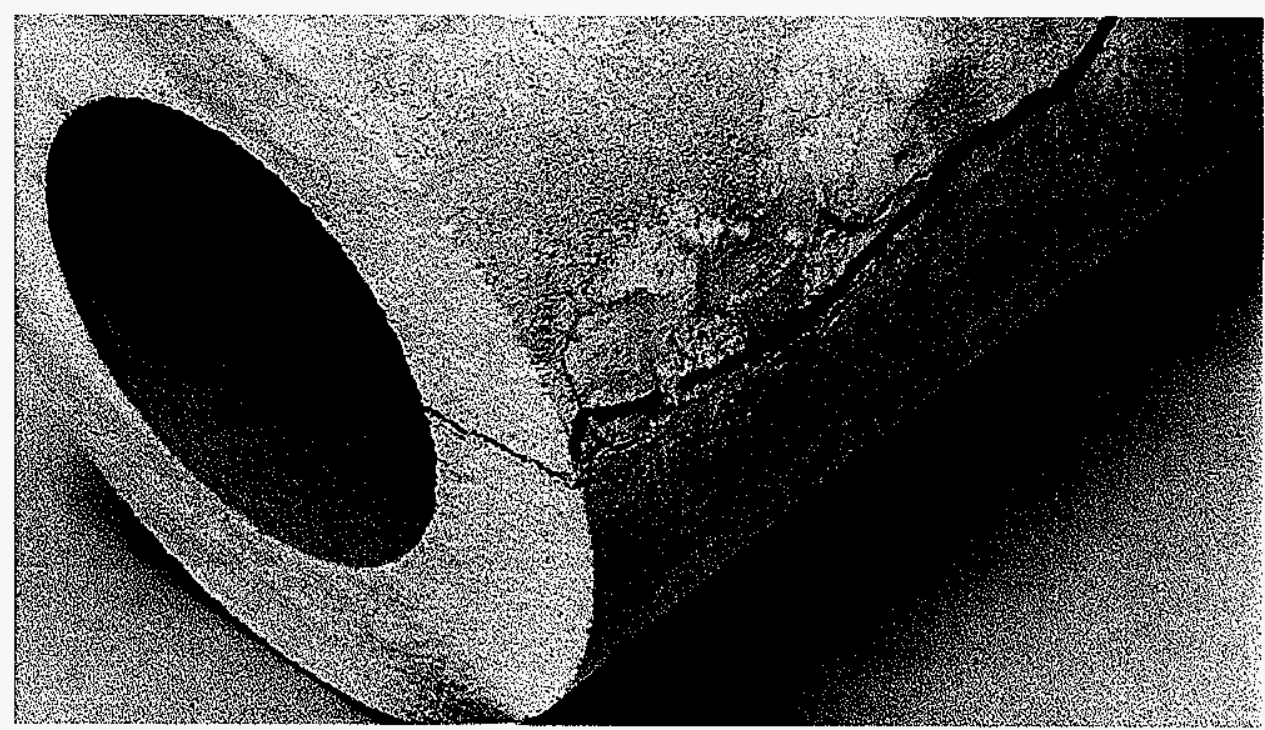

Figure 3-40 - Longitudinal crack formation near the end cap of the Blasch mullite-bonded alumina filter element which propagated through the filter wall thickness. 


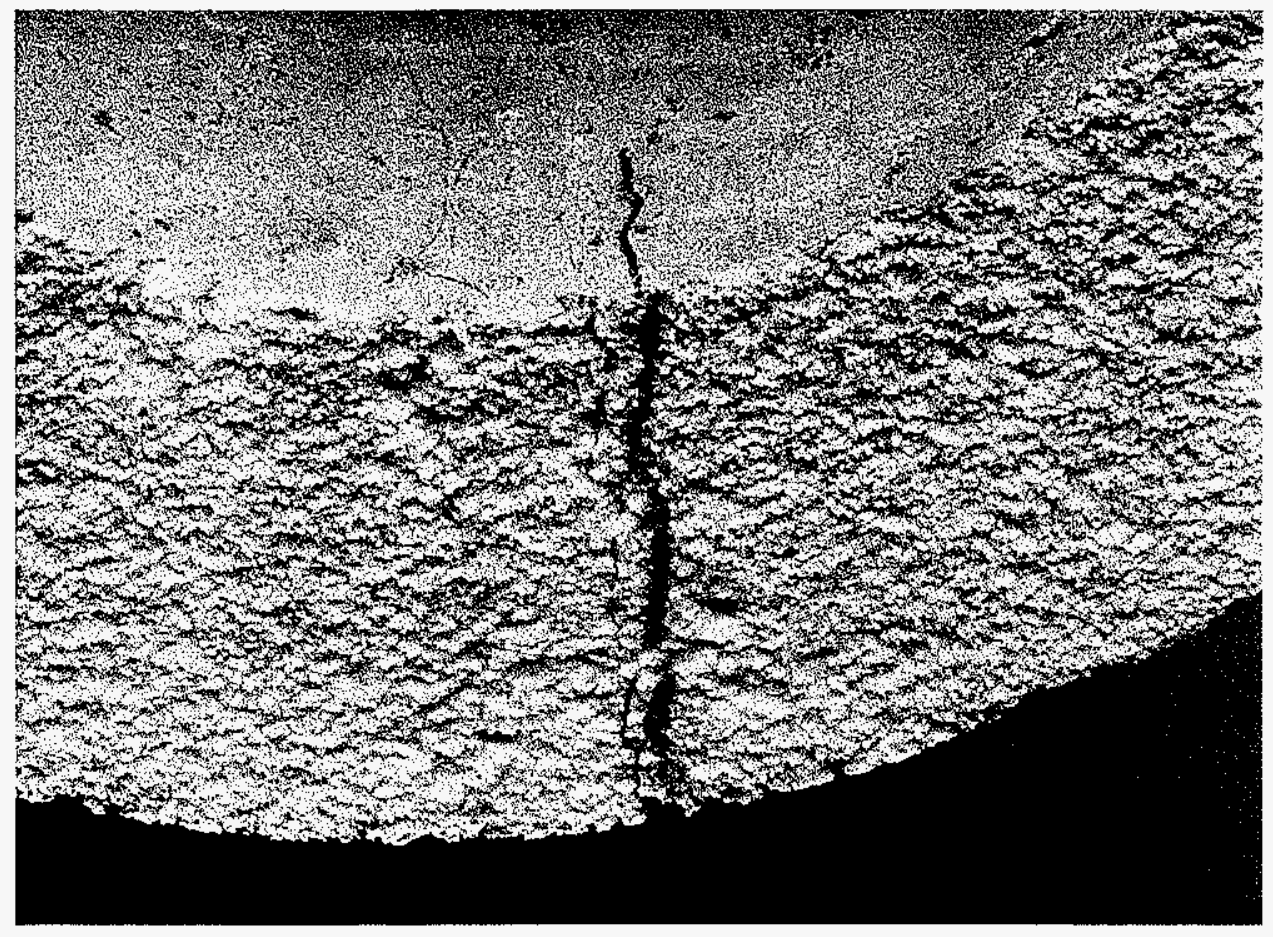

Figure 3-41 - Longitudinal crack formation near the end cap of the Blasch mullite-bonded alumina filter element which propagated through the filter wall thickness, and extended for $\sim \mathbf{5} \mathbf{~ m m}$ along the i.d. surface of the filter element.

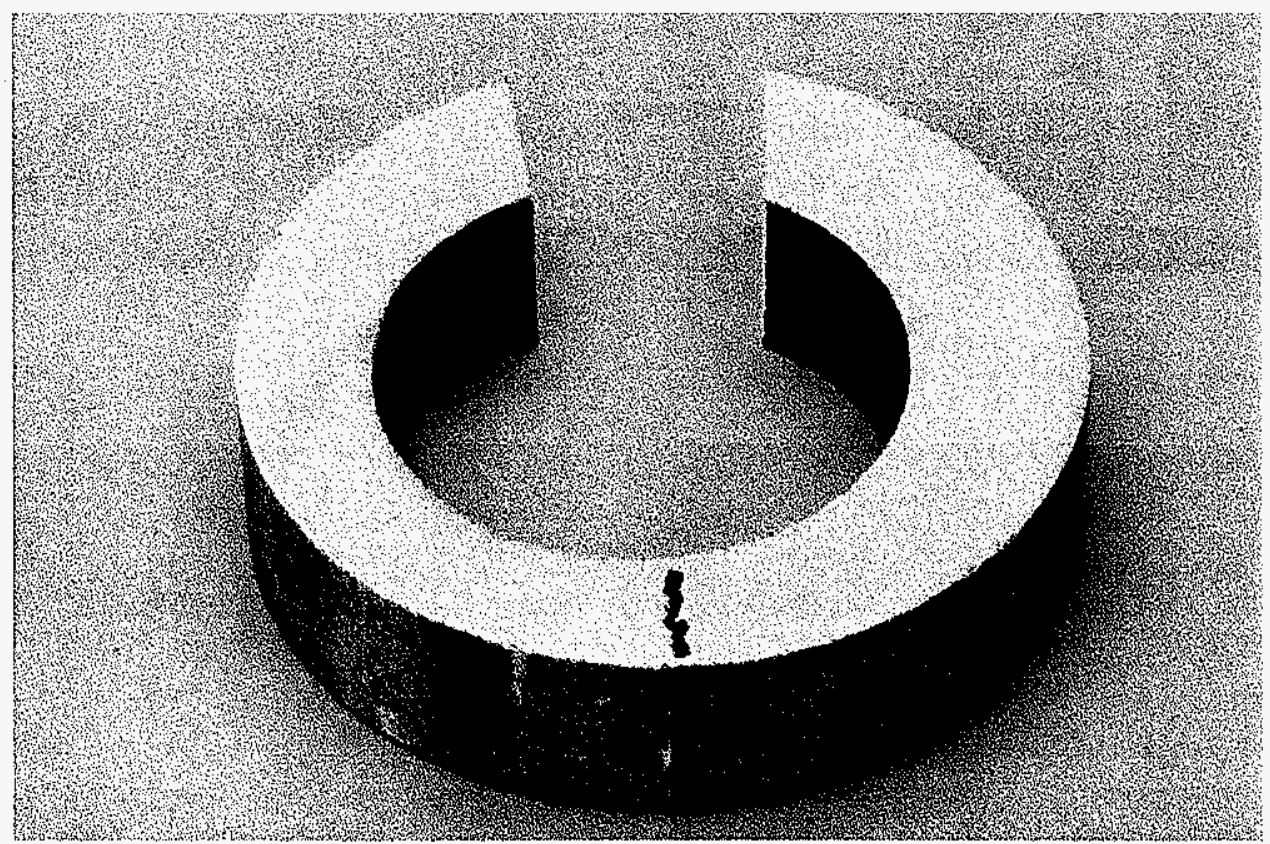

Figure 3-42 - C-ring section removed from the area of the filter body which contained the longitudinal crack formation. The longitudinal crack was removed by notching. At $180^{\circ}$ from the longitudinal crack, a hairline crack was visible along the i.d. surface of the filter element. The hairline crack propagated through the filter wall, but was not evident along the o.d. surface. 


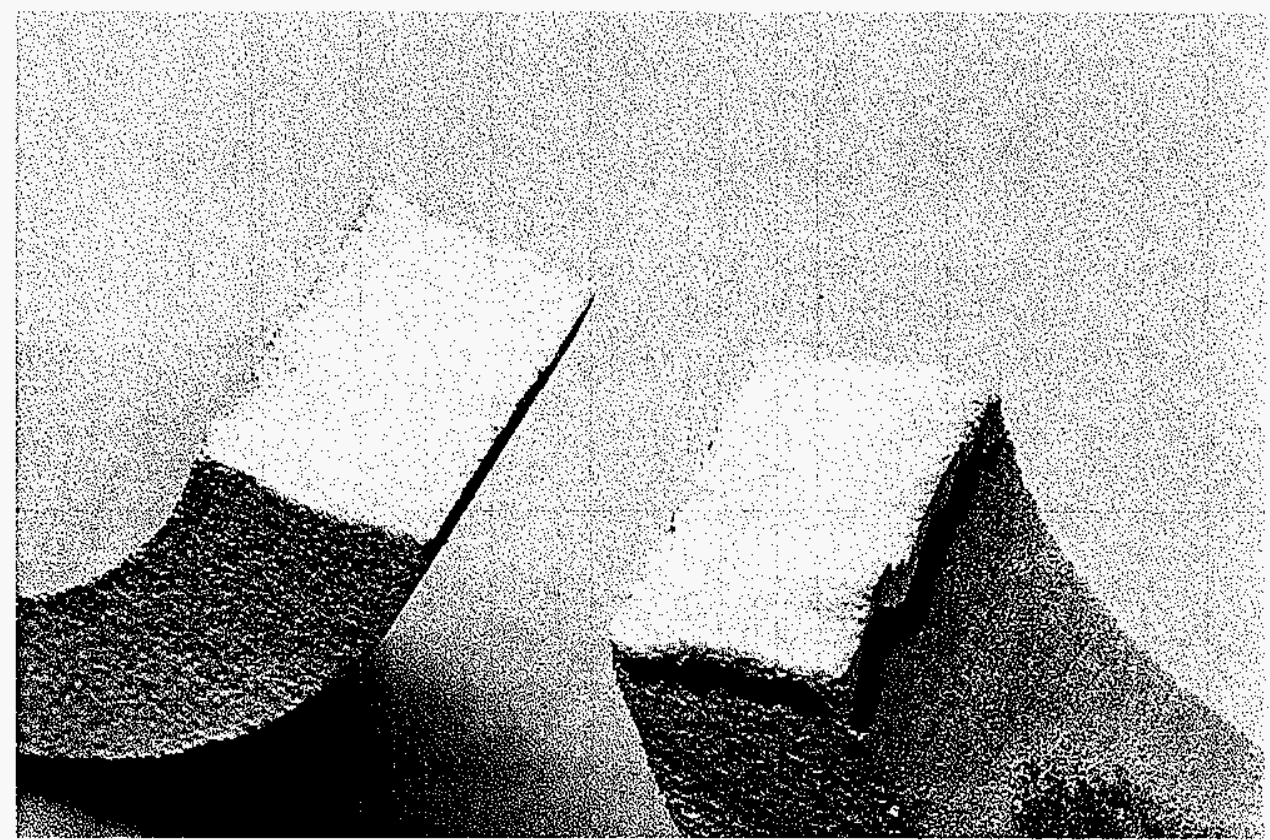

Figure 3-43 - Fractured filter wall along the hairline crack formation that was $\sim 180^{\circ}$ from the externally visible longitudinal crack.

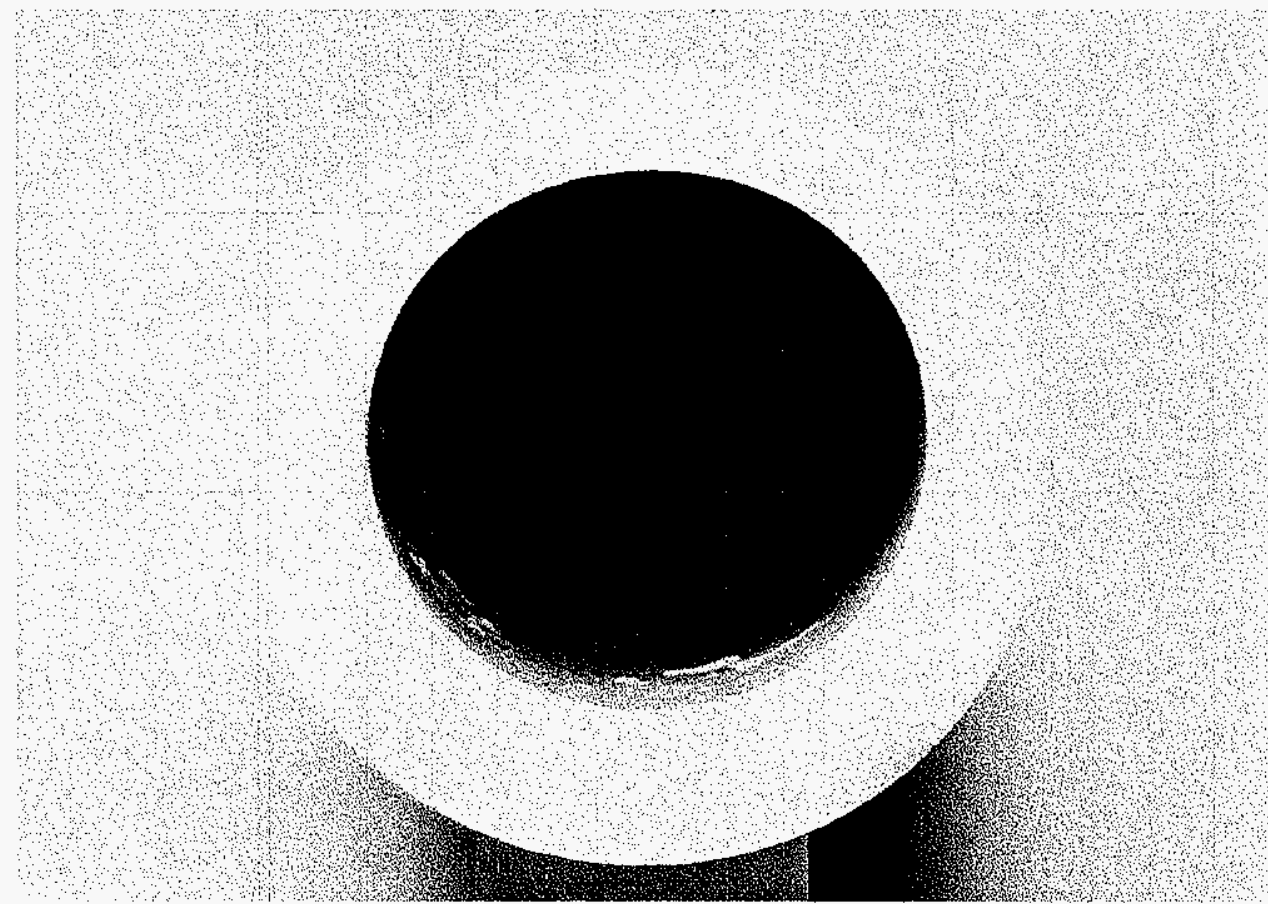

Figure 3-44 - Sectioned Coors P-100A-1 alumina/mullite filter illustrating the lack of concentricity of the element along the lower section of the candle. 
The outer surface of the end cap of the extended life-tested McDermott CFCC filter element is shown in Figure 3-45. Nextel ${ }^{\mathrm{TM}} 610$ fibers were seen to be wound around the tip of the filter element with limited infiltrated Saffil and/or matrix remaining in this area. Along the i.d. surface (Figure 3-46), individually wound fibers were intermittently evident. The black debris at the tip of the end cap was expected to have resulted from pulse cleaning which carried oxide metal particles from downstream hardware into the i.d. bore of the filter element.

When cross-sectioned (Figure 3-47), the tip of the McDermott candle was seen to contain a plug. Ash fines were evident between the inserted densified plug and the filament wound fiber matrix. The difference in thermal expansion of the ash, candle matrix, and plug needs to be addressed to assure retention of the plug within the filter body during extended service operation. Similarly production of the McDermott CFCC filter element needs to be modified in order to manufacture an integral filter body. SWPC has frequently indicated to all filter suppliers, the preference for manufacturing elements which eliminates the inclusion of plugs, inserts, seams, etc., along and/or within a filter body.

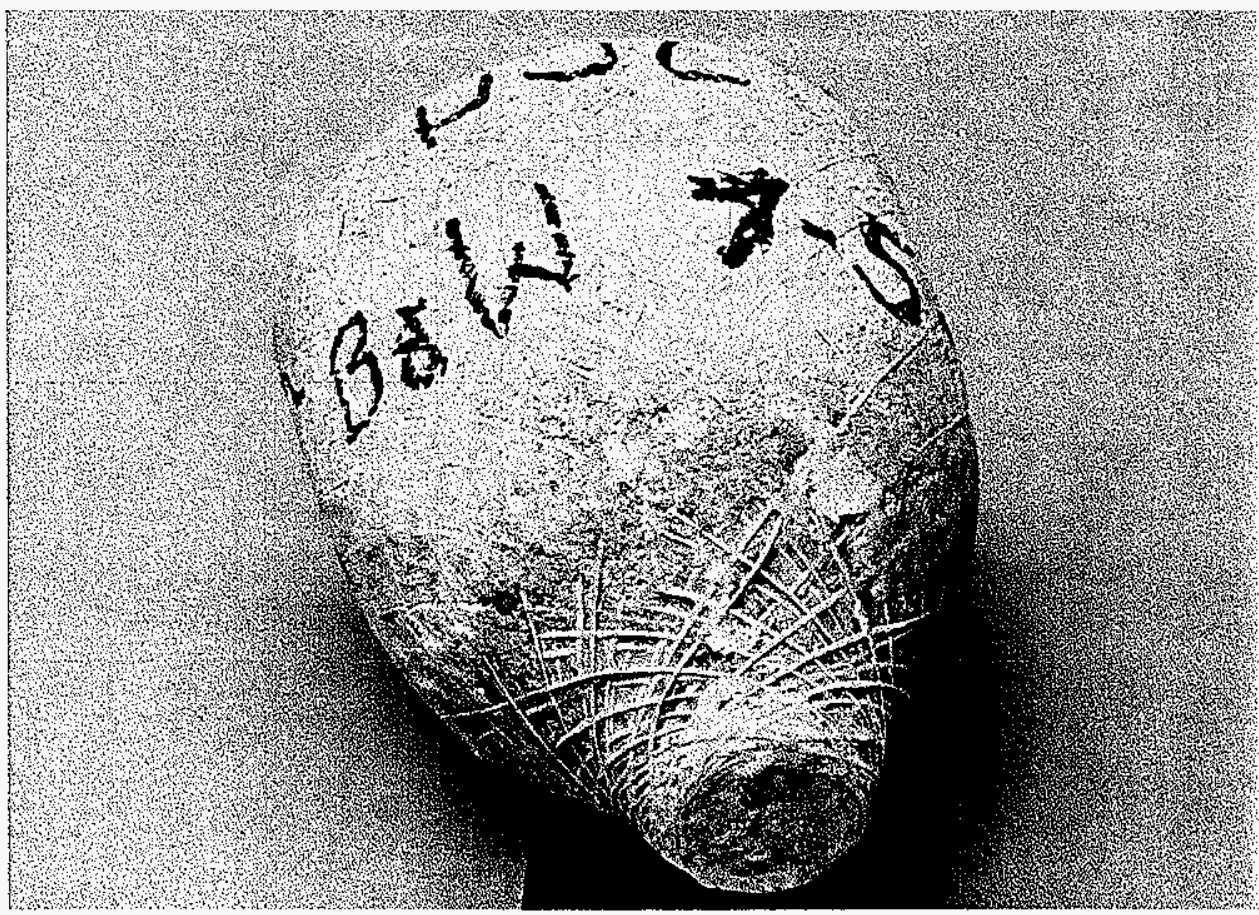

Figure 3-45 - Outer surface of the end cap of the thermal transient-tested McDermott CFCC filter element. 


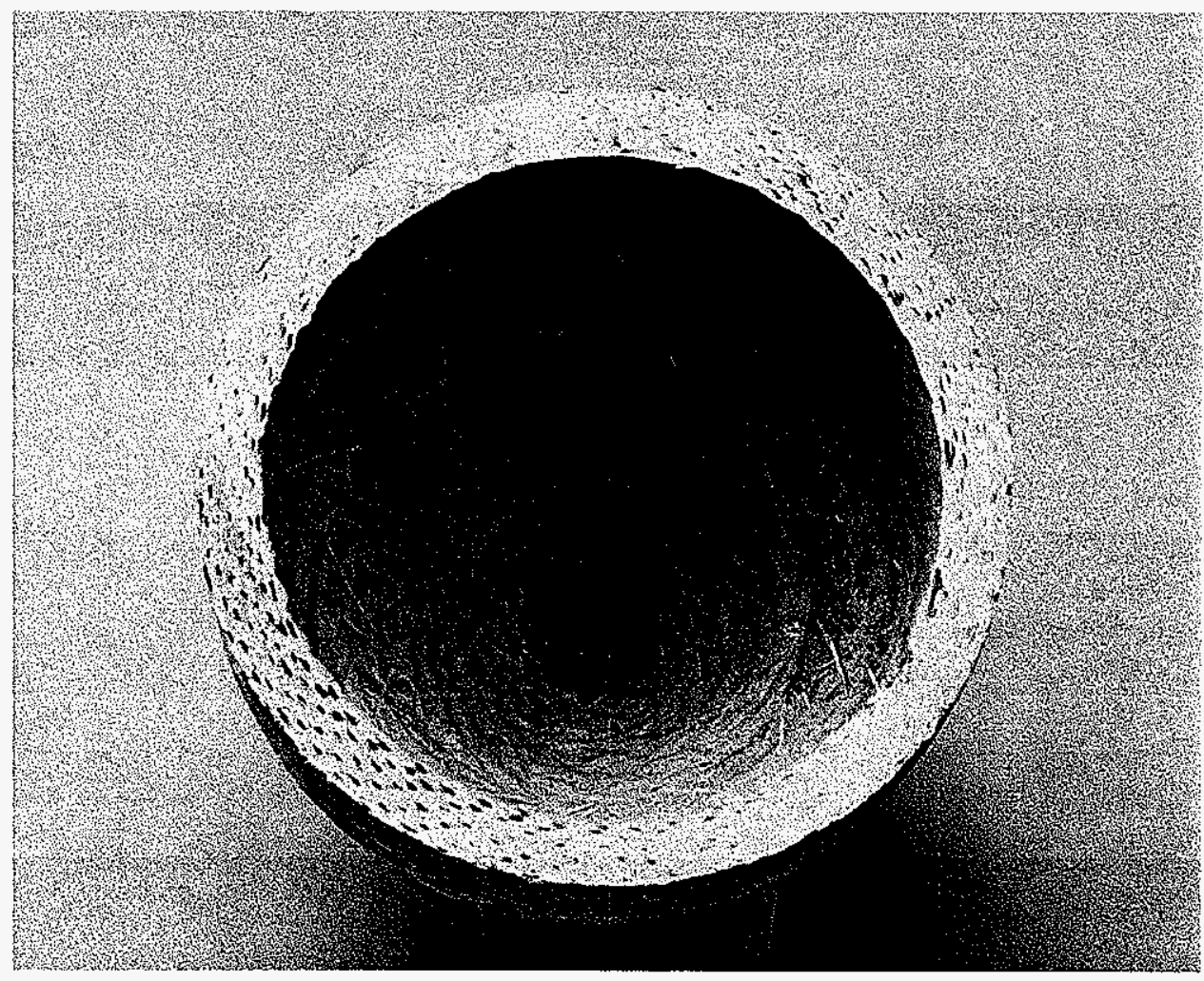

Figure 3-46 - Internal surface of the end cap of the thermal transient-tested McDermott CFC candle filter.

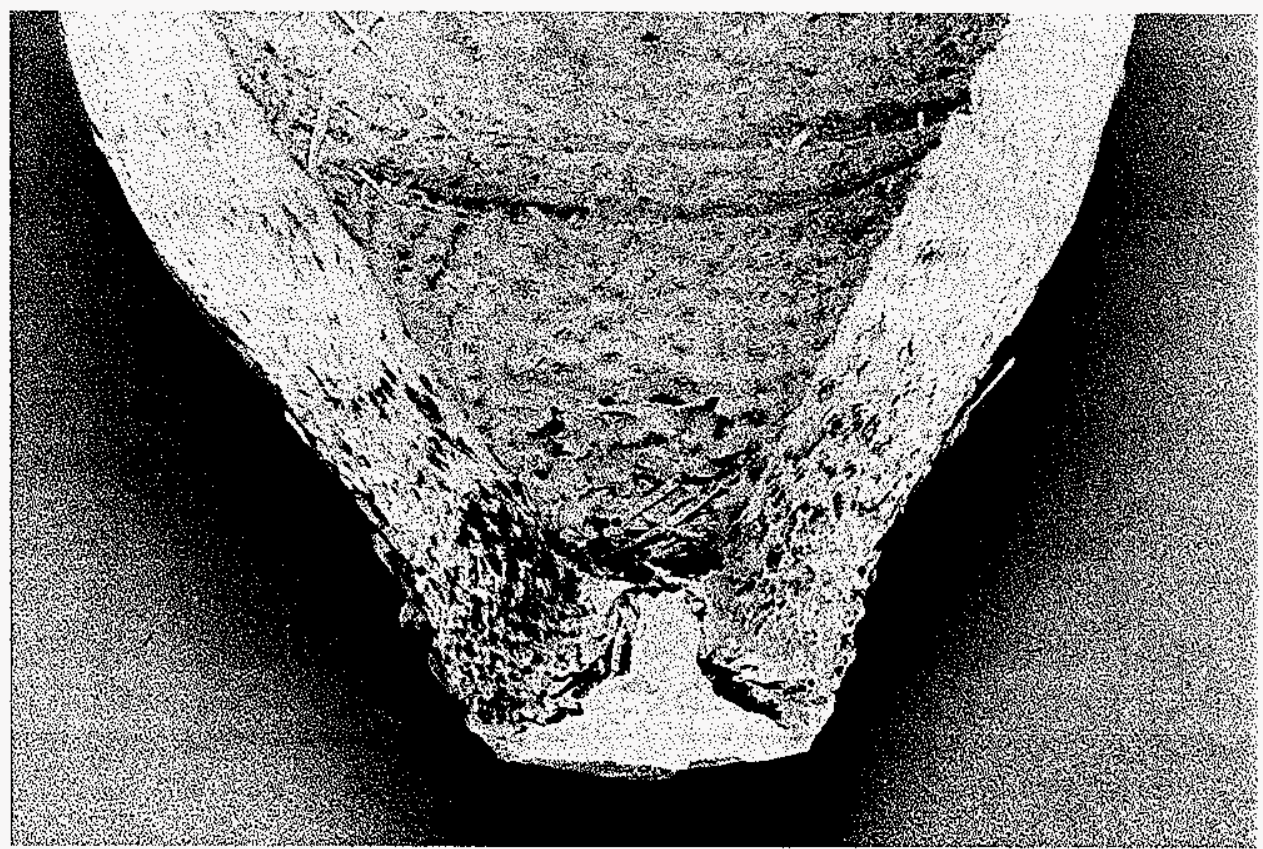

Figure 3-47 - Plug insert at the tip of the McDermott CFCC filter element. Ash fines were detected between the plug inset and the filament wound filter matrix. 


\subsection{Compressive and Tensile Strength}

Characterization of the residual process temperature strength of the PCFBC-exposed/ extended life-tested monolithic and advanced second generation candle filters was undertaken to determine the impact of long-term thermal fatigue and/or thermal transient conditions on the stability of the various porous ceramic filter matrices. As shown in Figure 3-48 and Table 3-13,

- A continued slight decrease in the o.d. tensile strength of the PCFBC-exposed Schumacher Dia Schumalith FT20 and Pall 326 matrices resulted after 12,111 equivalent hours of service operation.

- Stabilization or a slight increase in the o.d. tensile strength of the PCFBC-exposed Coors P$100 \mathrm{~A}-1$ alumina/mullite filter matrix resulted after 12,111 equivalent hours of service operation.

- After exposure to thirty thermal transients, the o.d. tensile strength of the PCFBC-exposed Pall 326 filter matrix was reduced, while virtually no change in the o.d. tensile strength of the PCFBC-exposed Coors P-100A-1 alumina/mullite matrix was apparent.

Table 3-14 identifies the ultimate load-to-failure for each material tested.

High temperature strength data that were generated by testing c-rings in compression and tension at SWPC STC were provided to Dr. J. P. Singh at the Argonne National Laboratory (ANL). At ANL, these data were utilized to generate Weibull modulus values for the various ceramic filter materials. At SWPC STC, the resulting Weibull modulus values were correlated with process operating time, and are presented in Figures 3-49 through 3-55 for the PCFBC-exposed Schumacher Dia Schumalith FT20, Pall 326, Coors P-100A-1 alumina/mullite, 3M CVI-SiC, Blasch, McDermott CFCC, and DuPont PRD-66 matrices, respectively. Where applicable, extended life test data are presented by a circled open diamond.

Typically after extended life testing of the PCFBC-exposed, porous ceramic filter materials, the Weibull modulus was reduced, sometimes significantly. The reduction in the modulus values indicated a wider distribution in strength for the materials, as well as higher probability for failure of the ceramic materials under a certain stress.

Table 3-15 summarizes the range and average Weibull values for the PCFBC-exposed monolithic, filament wound, and CFCC ceramic filter materials. In general, an average Weibull modulus of $>10$ resulted for the monolithic oxide and nonoxide-based filter matrices when tested at high temperature in either compression or tension. Alternately, the CFCC and lower strength Blasch materials typically had a Weibull modulus of $<10$ when tested at high temperature in either compression or tension. The filament wound DuPont PRD-66, had characteristics of the monolithic filter matrices when tested at high temperature in compression, but was similar to the CFCC matrices when tested at high temperature in tension. 

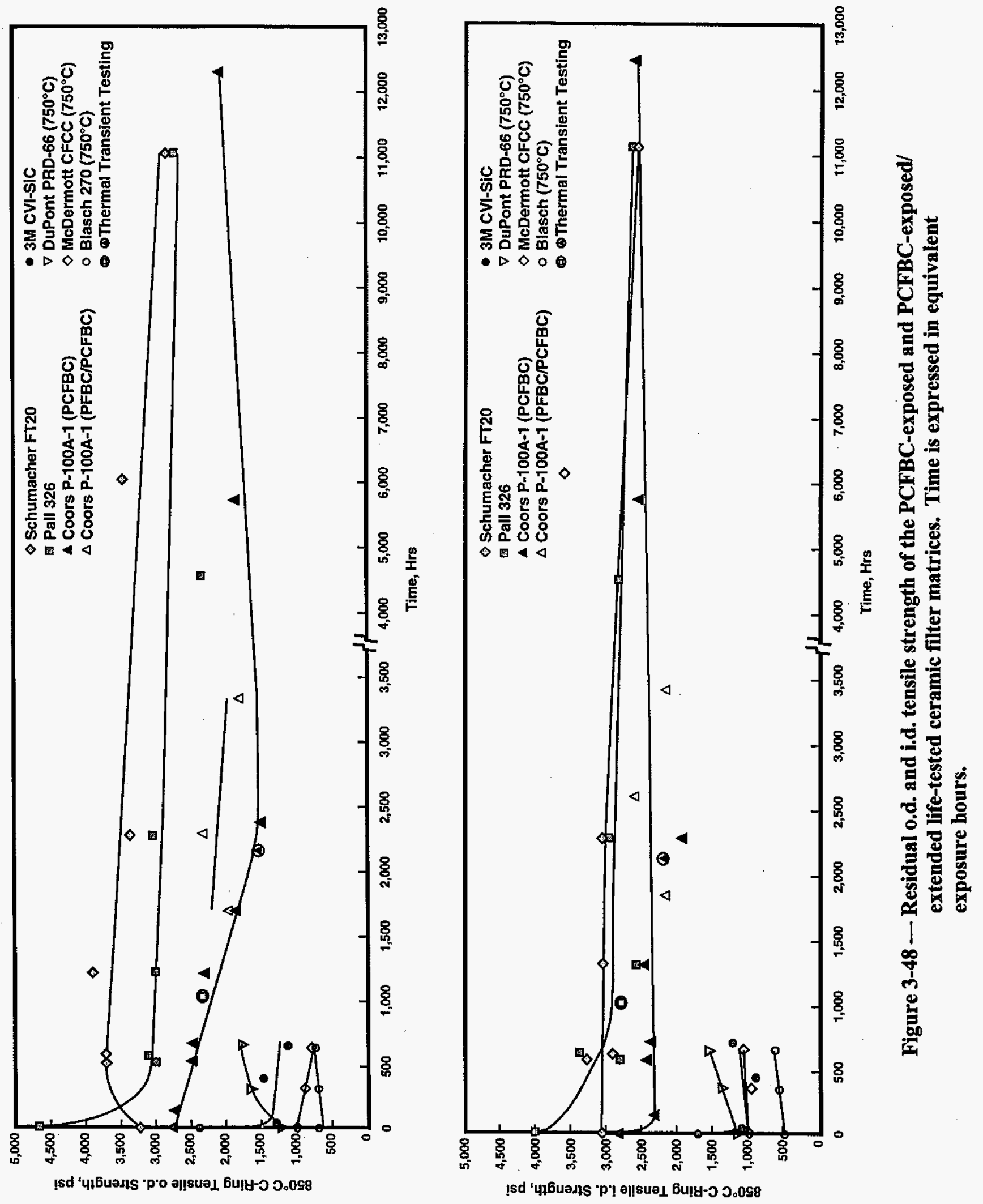


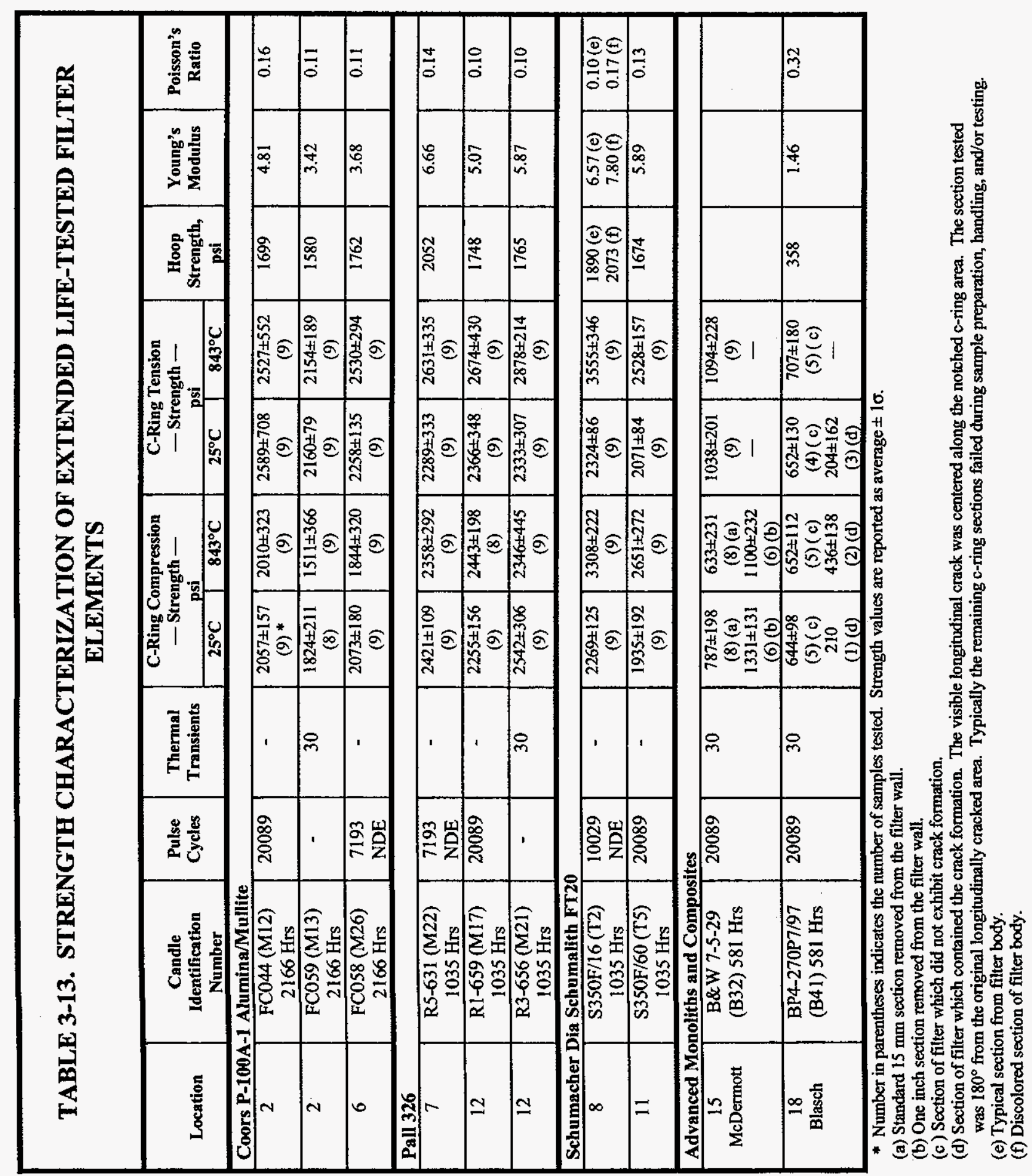




\section{TABLE 3-14. ULTIMATE LOAD-TO-FAILURE FOR THE EXTENDED LIFE-TESTED FILTER ELEMENTS}

\begin{tabular}{|c|c|c|c|c|c|c|c|}
\hline \multirow[t]{2}{*}{ Location } & \multirow[t]{2}{*}{$\begin{array}{c}\text { Candle } \\
\text { Identification }\end{array}$} & \multirow[t]{2}{*}{$\begin{array}{l}\text { Pulse } \\
\text { Cycles }\end{array}$} & \multirow[t]{2}{*}{$\begin{array}{l}\text { Thermal } \\
\text { Transients }\end{array}$} & \multicolumn{2}{|c|}{$\begin{array}{c}\text { C-Ring Compression - } \\
\text { Load - } \\
\text { lbs }\end{array}$} & \multicolumn{2}{|c|}{$\begin{array}{c}\text { C-Ring Tension } \\
\text { - Load - } \\
\text { lbs }\end{array}$} \\
\hline & & & & $25^{\circ} \mathrm{C}$ & $843^{\circ} \mathrm{C}$ & $25^{\circ} \mathrm{C}$ & $843^{\circ} \mathrm{C}$ \\
\hline \multicolumn{8}{|c|}{ Coors P-100A-1 Alumina/Mullite } \\
\hline 2 & 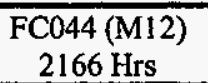 & 20089 & - & $\begin{array}{l}34.98 \pm 7.08 \\
(9)^{*}\end{array}$ & $\begin{array}{l}35.01 \pm 8.36 \\
\text { (9) }\end{array}$ & $\begin{array}{c}28.79 \pm 3.19 \\
(9)\end{array}$ & $\begin{array}{c}29.30 \pm 6.04 \\
\text { (9) }\end{array}$ \\
\hline 2 & $\begin{array}{c}\text { FC059(M13) } \\
2166 \mathrm{Hrs}\end{array}$ & - & 30 & $\begin{array}{c}32.53 \pm 4.21 \\
(8)\end{array}$ & $\begin{array}{c}26.67 \pm 7.13 \\
(9)\end{array}$ & $\begin{array}{l}23.84 \pm 3.70 \\
(9)\end{array}$ & $\begin{array}{c}25.86 \pm 1.79 \\
\text { (9) }\end{array}$ \\
\hline 6 & $\begin{array}{c}\text { FC058 (M26) } \\
2166 \mathrm{Hrs}\end{array}$ & $\begin{array}{l}7193 \\
\text { NDE }\end{array}$ & - & $\begin{array}{c}38.16 \pm 6.41 \\
(9)\end{array}$ & $\begin{array}{c}31.56 \pm 5.82 \\
(9)\end{array}$ & $\begin{array}{c}26.90 \pm 3.34 \\
(9)\end{array}$ & $\begin{array}{c}30.14 \pm 5.67 \\
(9)\end{array}$ \\
\hline \multicolumn{8}{|l|}{ Pall 326} \\
\hline 7 & $\begin{array}{c}\text { R5-631 (M22) } \\
1035 \mathrm{Hrs}\end{array}$ & $\begin{array}{l}7193 \\
\text { NDE }\end{array}$ & - & $\begin{array}{l}51.67 \pm 2.91 \\
(9)\end{array}$ & $\begin{array}{l}49.78 \pm 7.12 \\
(9)\end{array}$ & $\begin{array}{l}31.68 \pm 4.21 \\
(9)\end{array}$ & $\begin{array}{c}36.68 \pm 5.26 \\
(9)\end{array}$ \\
\hline 12 & $\begin{array}{c}\text { R1-659 (M17) } \\
1035 \text { Hrs }\end{array}$ & 20089 & - & $\begin{array}{l}46.84 \pm 5.00 \\
(9)\end{array}$ & $\begin{array}{c}50.05 \pm 6.63 \\
(8) \\
\end{array}$ & $\begin{array}{c}31.79 \pm 5.35 \\
(9)\end{array}$ & $\begin{array}{c}35.99 \pm 5.70 \\
(9) \\
\end{array}$ \\
\hline 12 & $\begin{array}{c}\text { R3-656 (M21) } \\
1035 \mathrm{Hrs} \\
\end{array}$ & - & 30 & $\begin{array}{c}51.43 \pm 8.77 \\
(9)\end{array}$ & $\begin{array}{c}46.44 \pm 10.17 \\
(9)\end{array}$ & $\begin{array}{c}30.84 \pm 5.07 \\
(9)\end{array}$ & $\begin{array}{c}37.27 \pm 1.97 \\
\text { (9) }\end{array}$ \\
\hline \multicolumn{8}{|c|}{ Schumacher Dia Schumalith FT20 } \\
\hline 8 & $\begin{array}{c}\mathrm{S} 350 \mathrm{~F} / 16(\mathrm{~T} 2) \\
1035 \mathrm{Hrs}\end{array}$ & $\begin{array}{l}10029 \\
\mathrm{NDE}\end{array}$ & - & $\begin{array}{c}41.80 \pm 2.64 \\
(9)\end{array}$ & $\begin{array}{l}59.12 \pm 4.58 \\
(9)\end{array}$ & $\begin{array}{c}27.99 \pm 1.82 \\
(9)\end{array}$ & $\begin{array}{c}42.50 \pm 4.58 \\
(9)\end{array}$ \\
\hline 11 & $\begin{array}{c}\text { S350F/60 (T5) } \\
1035 \mathrm{Hrs}\end{array}$ & 20089 & - & $\begin{array}{l}35.38 \pm 3.30 \\
(9)\end{array}$ & $\begin{array}{c}48.06 \pm 3.14 \\
(9)\end{array}$ & $\begin{array}{l}25.21 \pm 1.45 \\
(9)\end{array}$ & $\begin{array}{c}31.03 \pm 2.43 \\
(9)\end{array}$ \\
\hline \multicolumn{8}{|c|}{ Advanced Monoliths and Composites } \\
\hline $\begin{array}{c}15 \\
\text { McDermott }\end{array}$ & $\begin{array}{l}\text { B\&W 7-5-29 } \\
\text { (B32) 581 Hrs }\end{array}$ & 20089 & 30 & $\begin{array}{c}2.64 \pm 0.46 \\
(8)(a) \\
20.52 \pm 2.07 \\
\text { (6) (b) }\end{array}$ & $\begin{array}{c}2.15 \pm 0.68 \\
\text { (8) (a) } \\
17.58 \pm 3.19 \\
\text { (6) (b) }\end{array}$ & $\begin{array}{l}2.93 \pm 0.41 \\
(9) \\
-\end{array}$ & $\begin{array}{c}2.98 \pm 0.34 \\
(9) \\
-\end{array}$ \\
\hline $\begin{array}{c}18 \\
\text { Blasch }\end{array}$ & $\begin{array}{l}\text { BP4-270P7/97 } \\
\text { (B41) } 581 \mathrm{Hrs}\end{array}$ & 20089 & 30 & $\begin{array}{c}14.44 \pm 3.79 \\
(5)(\mathrm{c}) \\
3.7 \\
\text { (1) (d) }\end{array}$ & $\begin{array}{c}11.78 \pm 1.22 \\
(5)(\mathrm{c}) \\
11.10 \pm 8.06 \\
\text { (2)(d) }\end{array}$ & $\begin{array}{c}9.33 \pm 3.27 \\
(4)(\mathrm{c}) \\
2.30 \pm 1.76 \\
\text { (3) (d) }\end{array}$ & $\begin{array}{c}10.76 \pm 3.07 \\
(5)(\mathrm{c}) \\
-\end{array}$ \\
\hline
\end{tabular}

* Number in parentheses indicates the number of samples tested. Load-to-failure values are reported as average $1 \sigma$.

(a) Standard $15 \mathrm{~mm}$ section removed from the filter wall.

(b) One inch section removed from the filter wall.

(c) Section of filter which did not exhibit crack formation.

(d) Section of filter which contained the crack formation. The visible longitudinal crack was centered along the notched c-ring area The section tested was $180^{\circ}$ from the original longitudinally cracked area. Typically the remaining c-ring sections failed during sample preparation, handling, and/or testing. 

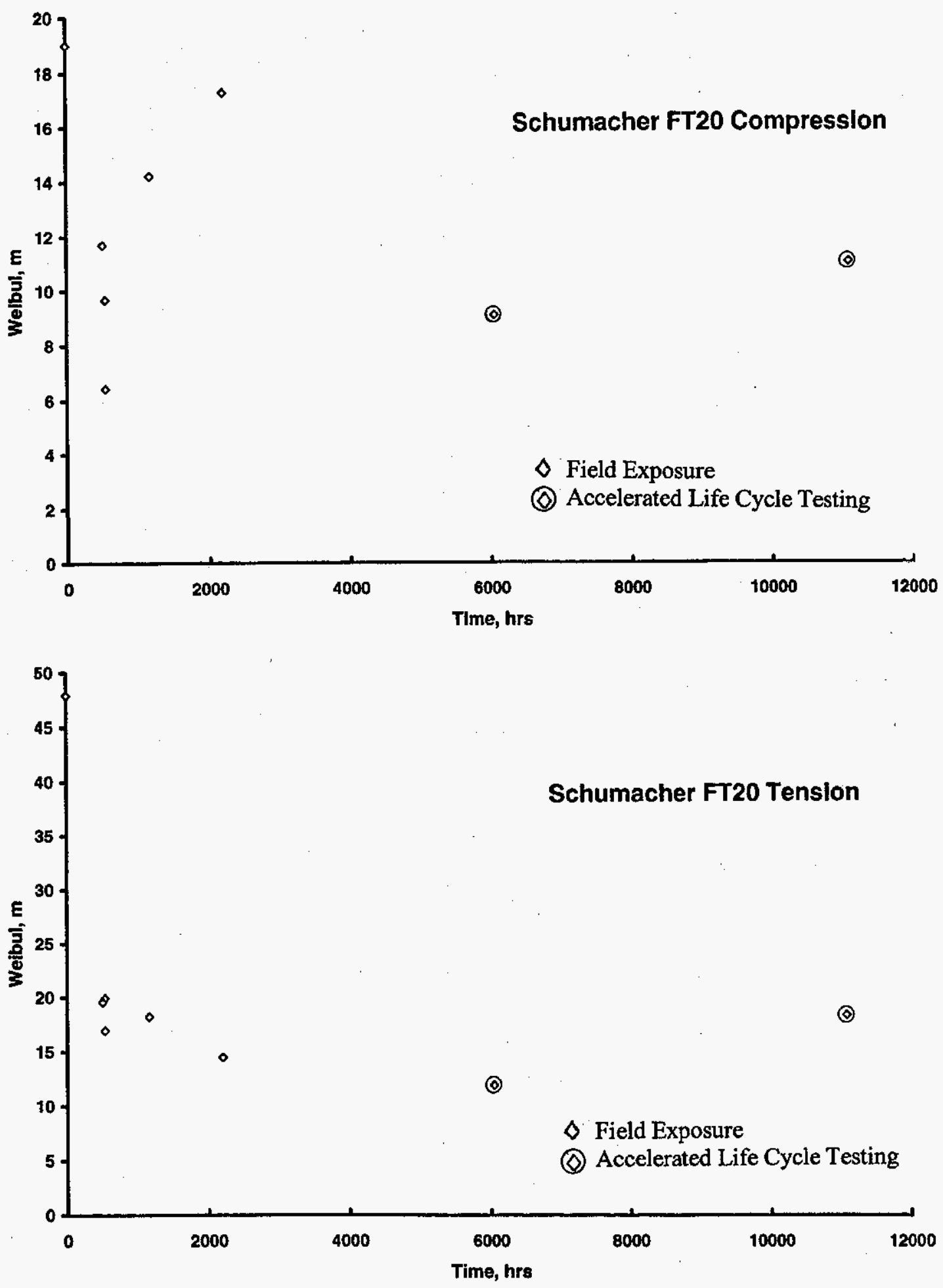

Figure 3-49 - Weibull modulus of the Schumacher Dia Schumalith FT20 filter material as a function of equivalent exposure hours. 

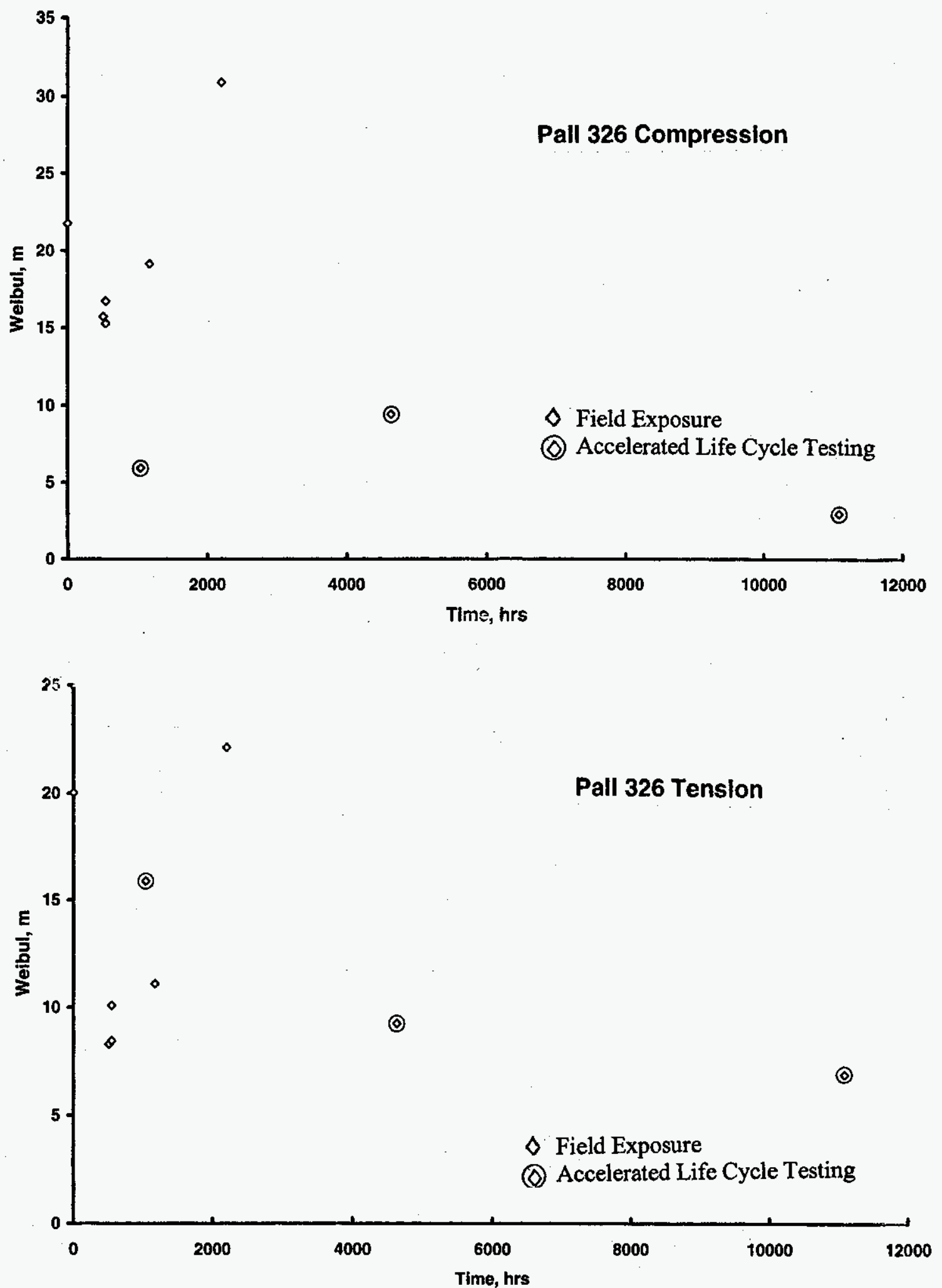

Figure 3-50 - Weibull modulus of the Pall 326 filter material as a function of equivalent exposure hours. 

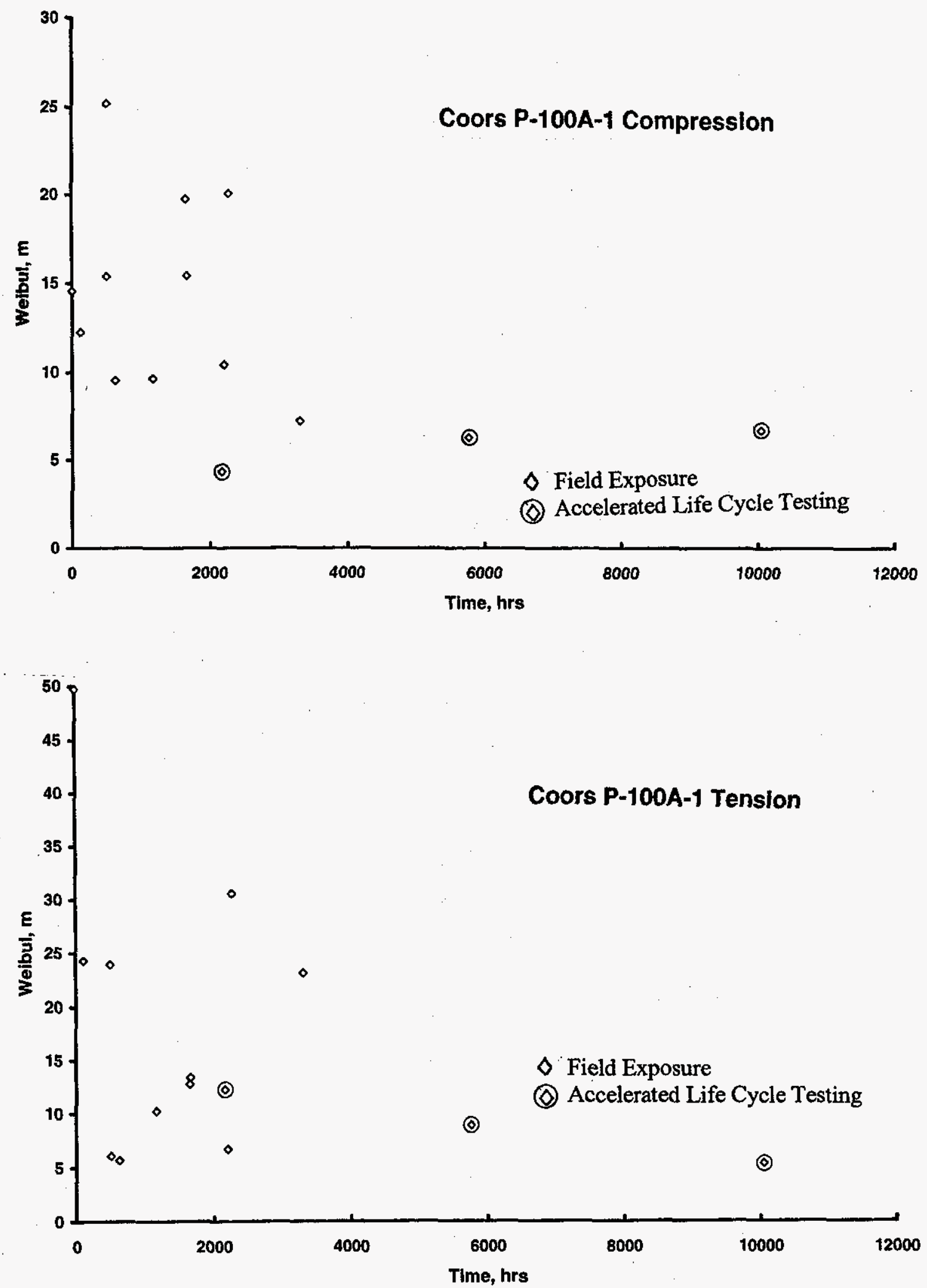

Figure 3-51 - Weibull modulus of the Coors P-100A-1 alumina/mullite filter material as a function of equivalent exposure hours. 

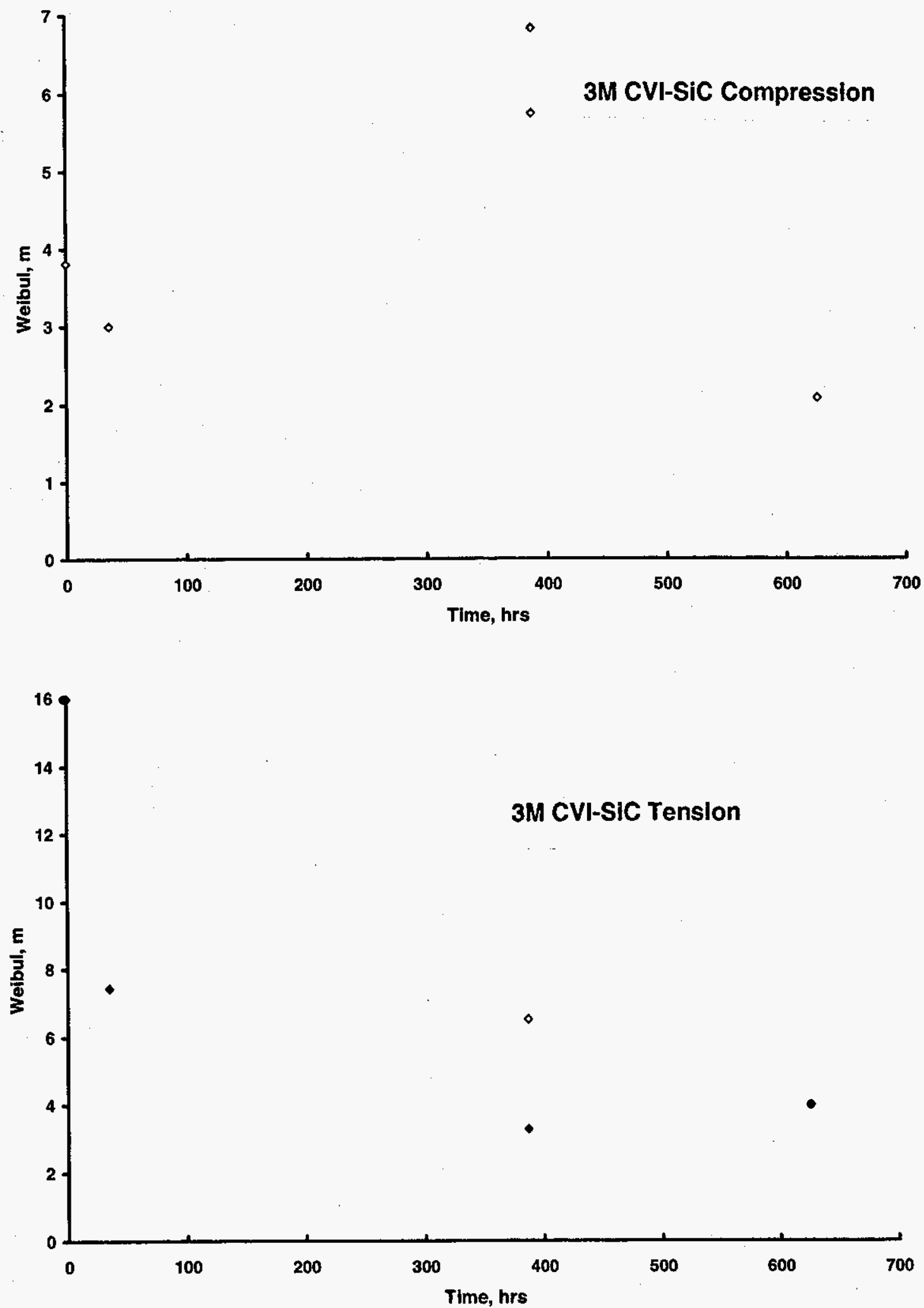

Figure 3-52 - Weibull modulus of the 3M CVI-SiC filter material as a function of equivalent exposure hours. 

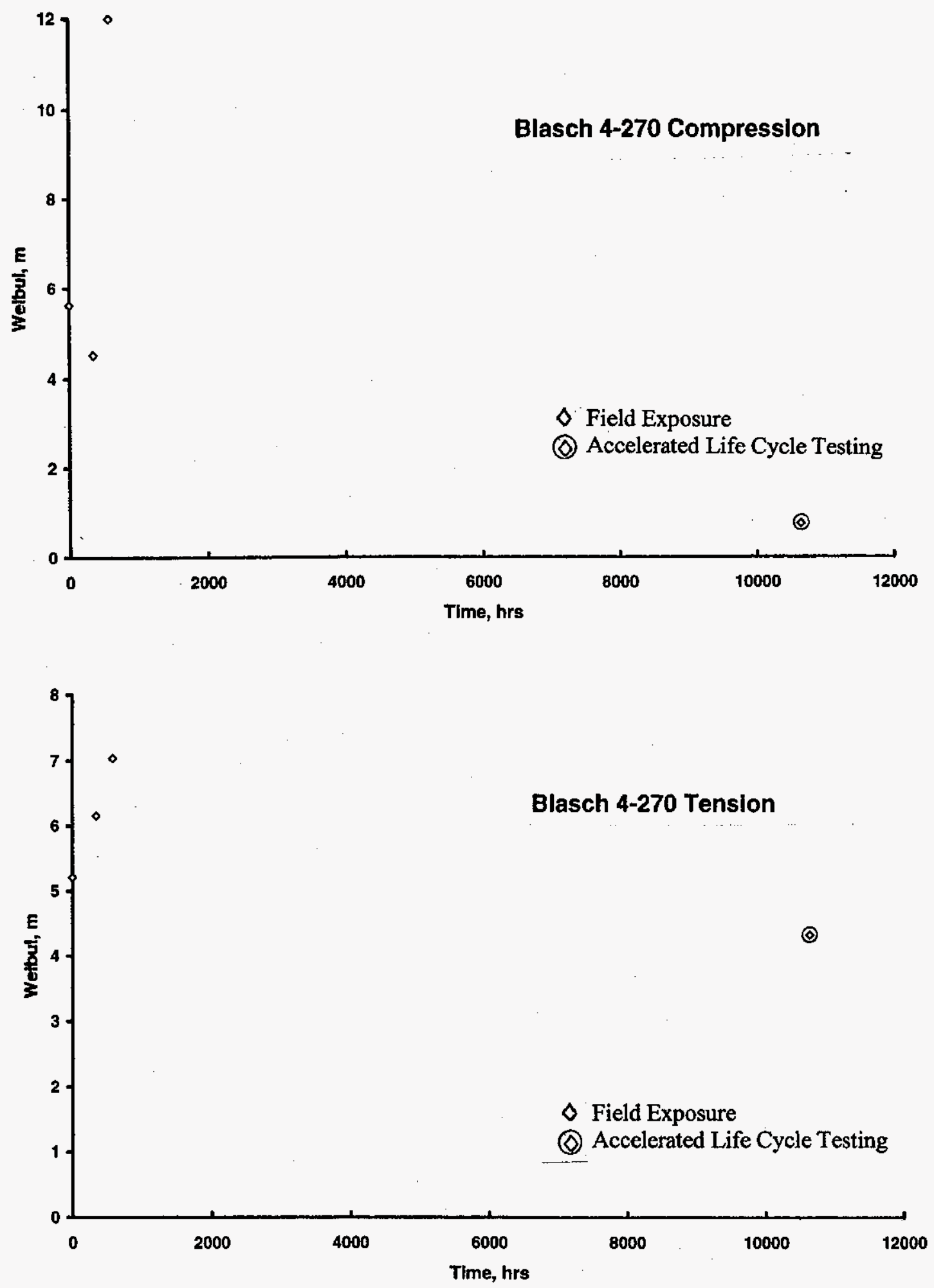

Figure 3-53 - Weibull modulus of the Blasch mullite-bonded alumina filter material as a function of equivalent exposure hours. 

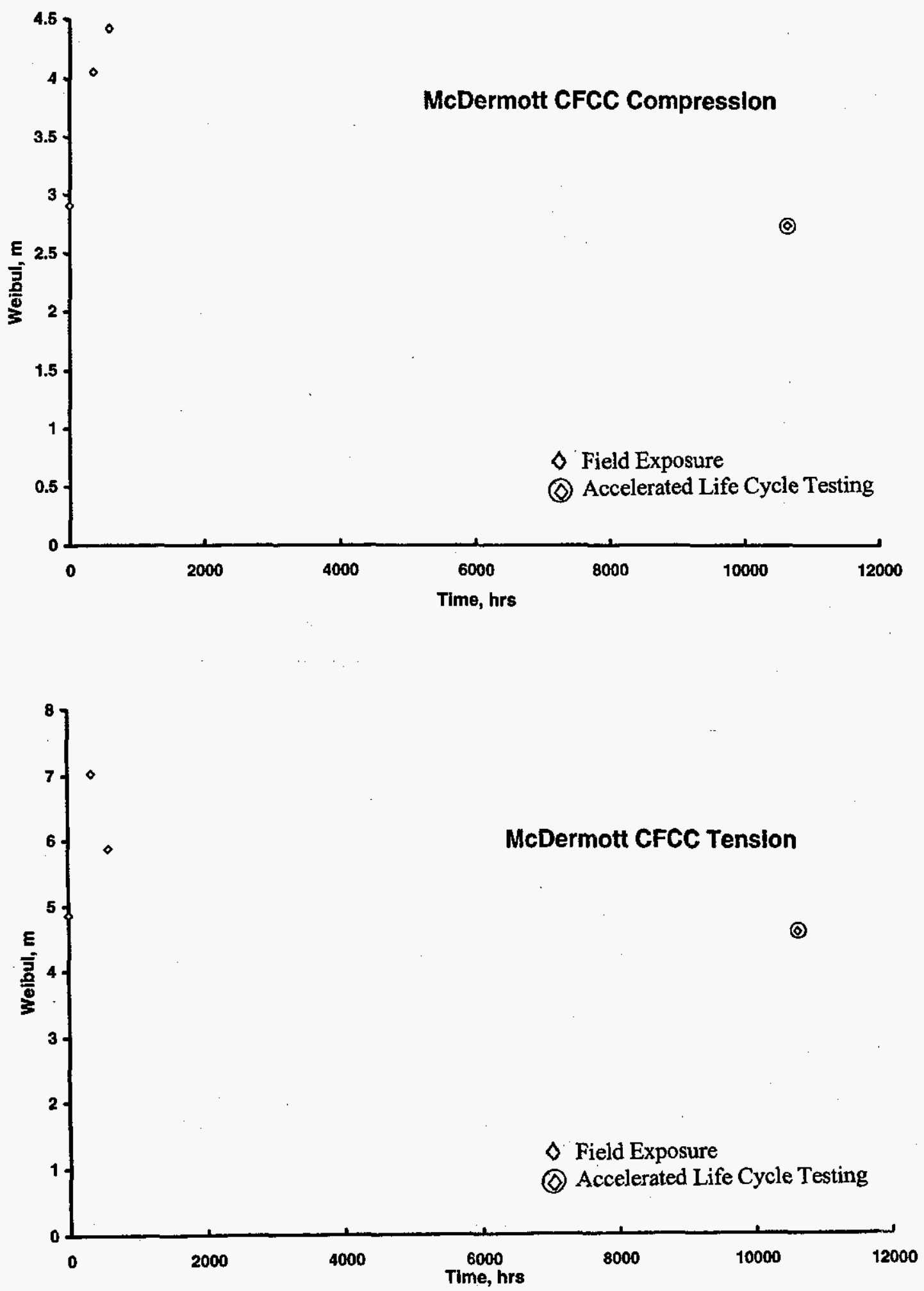

Figure 3-54 - Weibull modulus of the McDermott CFCC filter material as a function of equivalent exposure hours. 

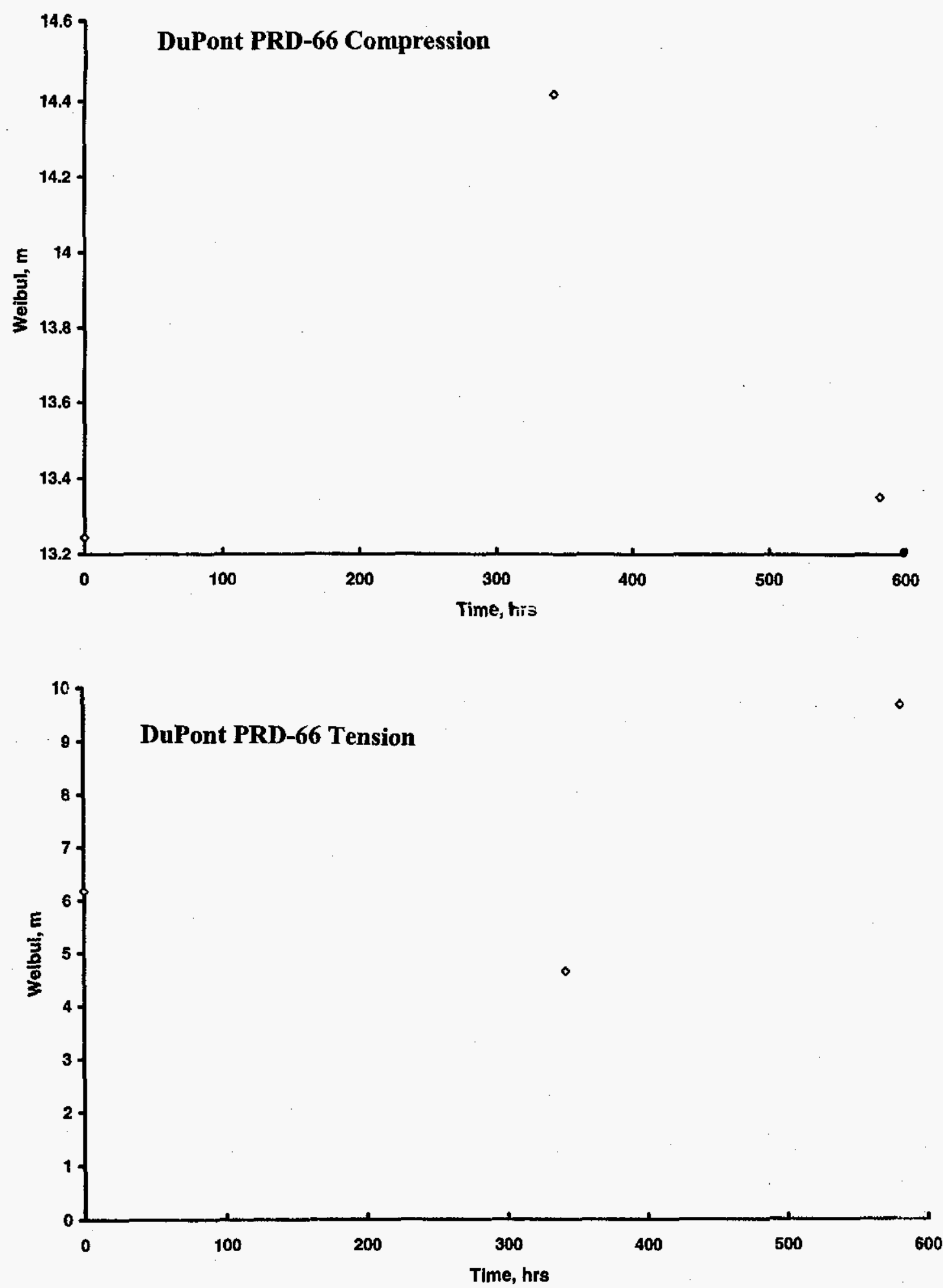

Figure 3-55 - Weibull modulus of the DuPont PRD-66 filter material as a function of equivalent exposure hours. 


\section{TABLE 3-15. WEIBULL MODULUS FOR THE PCFBC-EXPOSED AND EXTENDED LIFE-TESTED POROUS CERAMIC FILTERS}

\begin{tabular}{|c|c|c|}
\hline $\begin{array}{c}\text { Filter } \\
\text { Matrix }\end{array}$ & $\begin{array}{c}\text { High Temperature } \\
\text { Compression }\end{array}$ & $\begin{array}{c}\text { High Temperature } \\
\text { Tension }\end{array}$ \\
\hline Schumacher FT20 & $\sim 6-19(\sim 13)^{*}$ & $\sim 14-48(\sim 23)$ \\
\hline Pall 326 & $\sim 15-31(\sim 20)$ & $\sim 8-22(\sim 13)$ \\
\hline Coors P-100A-1 & $\sim 7-25(\sim 15)$ & $\sim 6-50(\sim 19)$ \\
\hline 3M CVI-SiC & $\sim 2-7(\sim 4)$ & $\sim 3-16(\sim 7)$ \\
\hline Blasch 4-270 & $\sim 5-12(\sim 7)$ & $\sim 5-7(\sim 6)$ \\
\hline McDermott CFCC & $\sim 3-4(\sim 4)$ & $\sim 5-7 \sim 6)$ \\
\hline DuPont PRD-66 & $\sim 13-14(\sim 14)$ & $\sim 5-10(\sim 7)$ \\
\hline
\end{tabular}

* Average shown in parentheses.

\subsection{Hoop Stress, Elastic Modulus, and Poisson's Ratio}

A $254 \mathrm{~mm}$ section of material was removed from each of the PCFBC-exposed/extended lifetested candle filters. Two $90^{\circ}$ strain gage rosettes were installed along both inside and outside surfaces of the filter sections, at approximately the center of each test sample. A water-filled bladder was inserted into the i.d. bore of each filter section, and was subsequently pressurized to determine the ultimate hoop strength of the filter material.

The burst pressure needed to fail each Schumacher Dia Schumalith FT20, Pall 326, and Coors P-100A-1 alumina/mullite, PCFBC-exposed and PCFBC-exposed/extended life-tested filter section, as well as the ultimate hoop stress, elastic modulus, and Poisson's ratio established for each filter section are presented in Table 3-16. When plotted as a function of time (Figures 3-56, 3-57, and 3-58),

- A significant decrease in Young's Modulus appeared to result for the PCFBC-exposed Schumacher Dia Schumalith FT20 filter matrix.

- A slight decrease in Young's Modulus appeared to result for the PCFBC-exposed Pall 326 filter matrix.

- Although significantly scattered, a decrease in Young's Modulus appeared to result for the PCFBC-exposed Coors P-100A-1 alumina/mullite filter matrix.

When the PCFBC-exposed/extended life-tested Young's Modulus data were added to Figures 356, 3-57, and 3-58, and projected back to the original PCFBC-exposed candle life, the Pall 326 and Schumacher Dia Schumalith FT20 data generally fell above the data generated for both PCFBC-exposed matrices. This may have resulted from the continued phase and microstructural changes which occurred during extended filter life testing of both clay bonded silicon carbide filter materials.

In contrast, when the PCFBC-exposed/extended life-tested Young's Modulus data for the Coors P-100A-1 alumina/mullite filter matrix were projected back to the PCFBC-exposed life, the data fell within the scatter band obtained for the PCFBC-exposed monolithic, oxide-based, filter material. This may have resulted since continued phase and microstructural changes within the Coors P-100A-1 alumina/mullite filter matrix were limited during extended life testing of the element. 
TABLE 3-16. SUMMARY OF HOOP STRENGTH, YOUNG'S MODULUS, AND POISSON'S RATIO FOR THE MONOLITHIC FILTER ELEMENTS AS A FUNCTION OF EXPOSURE TIME/CONDITIONS

\begin{tabular}{|c|c|c|c|c|c|}
\hline $\begin{array}{c}\text { Candle } \\
\text { Identification } \\
\text { Number }\end{array}$ & $\begin{array}{l}\text { Operating } \\
\text { Time, Hrs }\end{array}$ & $\begin{array}{c}\text { Burst Pressure, } \\
\text { psi }\end{array}$ & $\begin{array}{l}\text { Ultimate Hoop } \\
\text { Stress, psi }\end{array}$ & $\begin{array}{l}\text { Young's } \\
\text { Modulus, } \\
\text { psi x 10 }\end{array}$ & $\begin{array}{l}\text { Poisson's } \\
\text { Ratio }\end{array}$ \\
\hline \multicolumn{6}{|c|}{ Schumacher Dia Schumalith FT20 } \\
\hline $\begin{array}{c}\text { As-Manufactured } \\
\text { S350F/108 (T12) } \\
\text { S350F/42 (B15) } \\
\text { S350F/30 (T26) } \\
\text { S350F/7 (T18) } \\
\text { S350F/16 (T2) } \\
\\
\text { S350F/60 (T5) }\end{array}$ & $\begin{array}{c}- \\
540 \\
505 \\
1166 \\
2201 \\
1035 / 10029 \\
1035 / 20089 \\
\end{array}$ & $\begin{array}{l}665 \\
555 \\
590 \\
720 \\
585 \\
720 \\
790 \\
625 \\
\end{array}$ & $\begin{array}{l}1703 \\
1496 \\
1584 \\
1942 \\
1025 \\
1890 \\
2073 \\
1674 \\
\end{array}$ & \begin{tabular}{c|}
7.3 \\
7.44 \\
7.39 \\
5.77 \\
2.82 \\
6.57 \\
7.80 \\
5.89 \\
\end{tabular} & $\begin{array}{l}0.17 \\
0.21 \\
0.15 \\
0.11 \\
0.13 \\
0.10 \\
0.17 \\
0.13 \\
\end{array}$ \\
\hline \multicolumn{6}{|l|}{ Pall 326} \\
\hline $\begin{array}{c}\text { As-Manufactured } \\
\text { R5-655 (M21) } \\
\text { R5-654 (B21) } \\
\text { R6-674 (M26) } \\
\text { R2-669 (M18) } \\
\text { R5-631 (M22) } \\
\text { R1-659 (M17) } \\
\text { R3-656 (M21) } \\
\end{array}$ & $\begin{array}{c}- \\
540 \\
505 \\
1166 \\
2201 \\
1035 / 7193 \\
1035 / 20089 \\
1035 / 30 \mathrm{~T} \\
\end{array}$ & $\begin{array}{l}\mathrm{NE} \\
525 \\
520 \\
650 \\
690 \\
815 \\
690 \\
600 \\
\end{array}$ & \begin{tabular}{c|}
$\mathrm{NE}$ \\
1369 \\
1344 \\
1641 \\
1764 \\
2052 \\
1748 \\
1765 \\
\end{tabular} & $\begin{array}{l}\text { NE } \\
5.00 \\
5.15 \\
4.83 \\
4.83 \\
6.66 \\
5.07 \\
5.87 \\
\end{array}$ & \begin{tabular}{l|}
$\mathrm{NE}$ \\
0.16 \\
0.16 \\
0.13 \\
0.11 \\
0.14 \\
0.10 \\
0.10 \\
\end{tabular} \\
\hline \multicolumn{6}{|c|}{ Coors P-100A-1 Alumina/Mullite } \\
\hline $\begin{array}{c}\text { As-Manufactured } \\
\text { FC-070 (B22) } \\
\text { DC-051 (B1) } \\
\text { FC-035 (B16) } \\
\text { FC-007 (B29) } \\
\text { EC-014 (B28) } \\
\text { FC-040 (M6) } \\
\text { FC-018 (M16) } \\
\text { AB-13 (M15) } \\
\text { FC044 (M12) } \\
\text { FC059 (M13) } \\
\text { FC058 (M26) }\end{array}$ & $\begin{array}{c}\overline{505} \\
1650(\mathrm{a}) \\
626(\mathrm{TS} 3) \\
1166 \\
2276(\mathrm{a}) \\
1661 \\
2201 \\
3311(\mathrm{a}) \\
2166 / 20089 \\
2166 / 30 \mathrm{~T} \\
2166 / 7193\end{array}$ & $\begin{array}{l}860 \\
540 \\
505 \\
520 \\
565 \\
505 \\
588 \\
545 \\
520 \\
618 \\
600 \\
670\end{array}$ & $\begin{array}{l}2317 \\
1503 \\
1373 \\
1425 \\
1402 \\
1380 \\
1599 \\
1473 \\
1441 \\
1699 \\
1580 \\
1762\end{array}$ & \begin{tabular}{l|l}
5.7 \\
4.84 \\
5.18 \\
3.90 \\
3.44 \\
4.37 \\
4.36 \\
5.79 \\
3.99 \\
4.81 \\
3.42 \\
3.68
\end{tabular} & $\begin{array}{l}0.23 \\
0.21 \\
0.20 \\
0.18 \\
0.25 \\
0.24 \\
0.12 \\
0.18 \\
0.15 \\
0.16 \\
0.11 \\
0.11\end{array}$ \\
\hline
\end{tabular}

(a) PFBC/PCFBC-exposed candle filter. 
Schumacher Dia Schumalith FT20

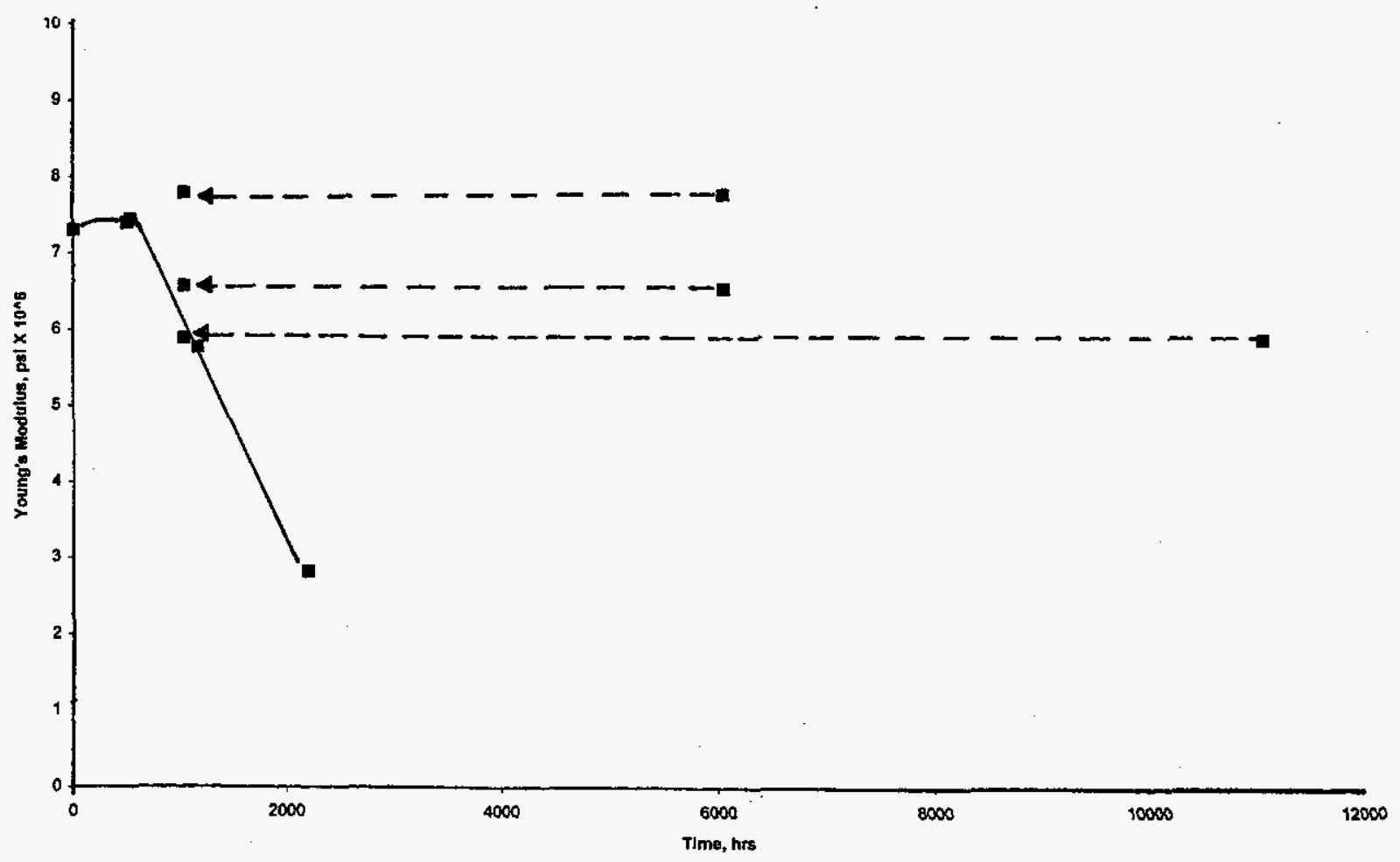

Figure 3-56 - Young's Modulus as a function of time for the Schumacher Dia Schumalith FT20 filter matrix. 


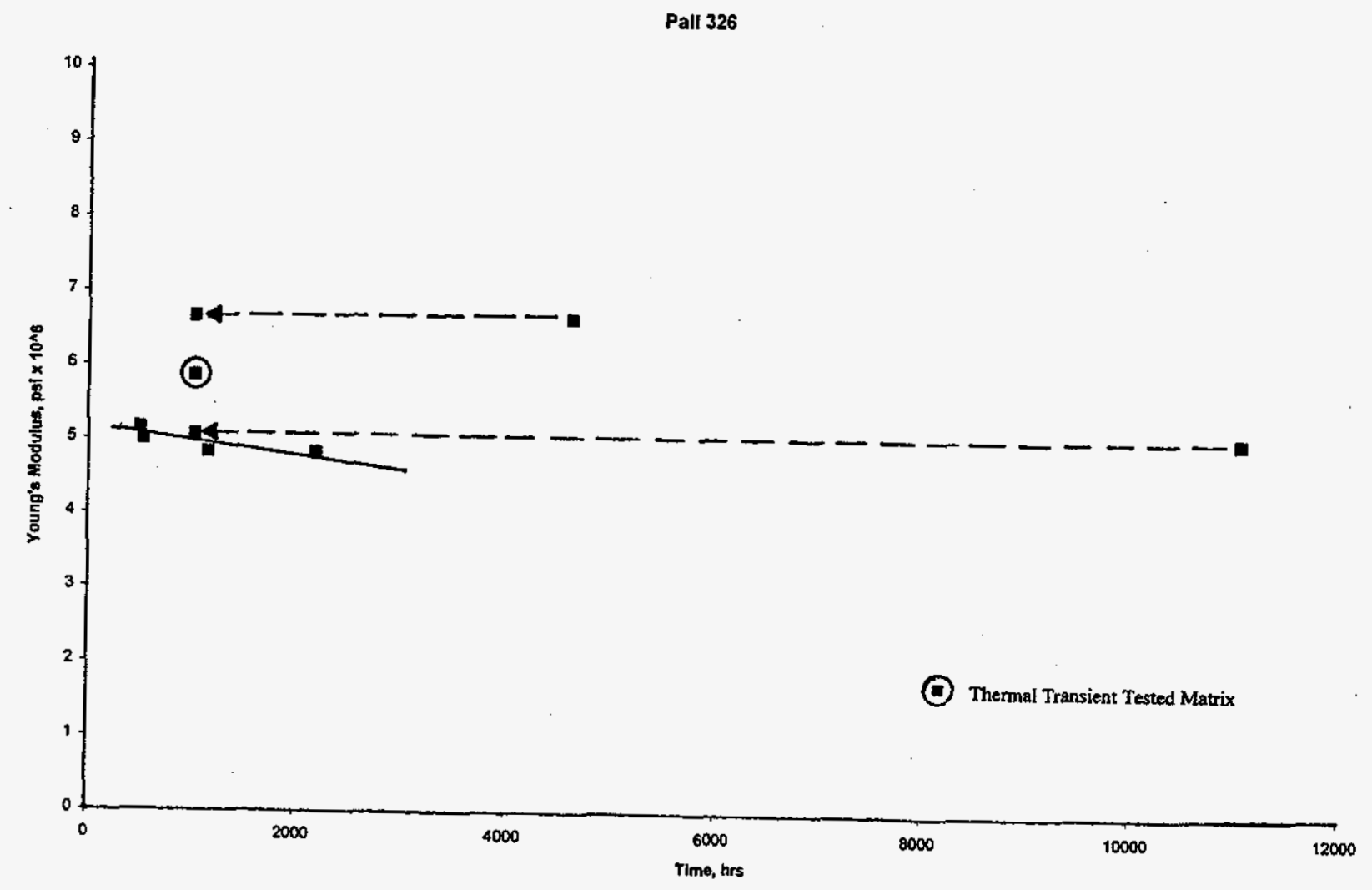

Figure 3-57 - Young's Modulus as a function of time for the Pall 326 filter matrix. 


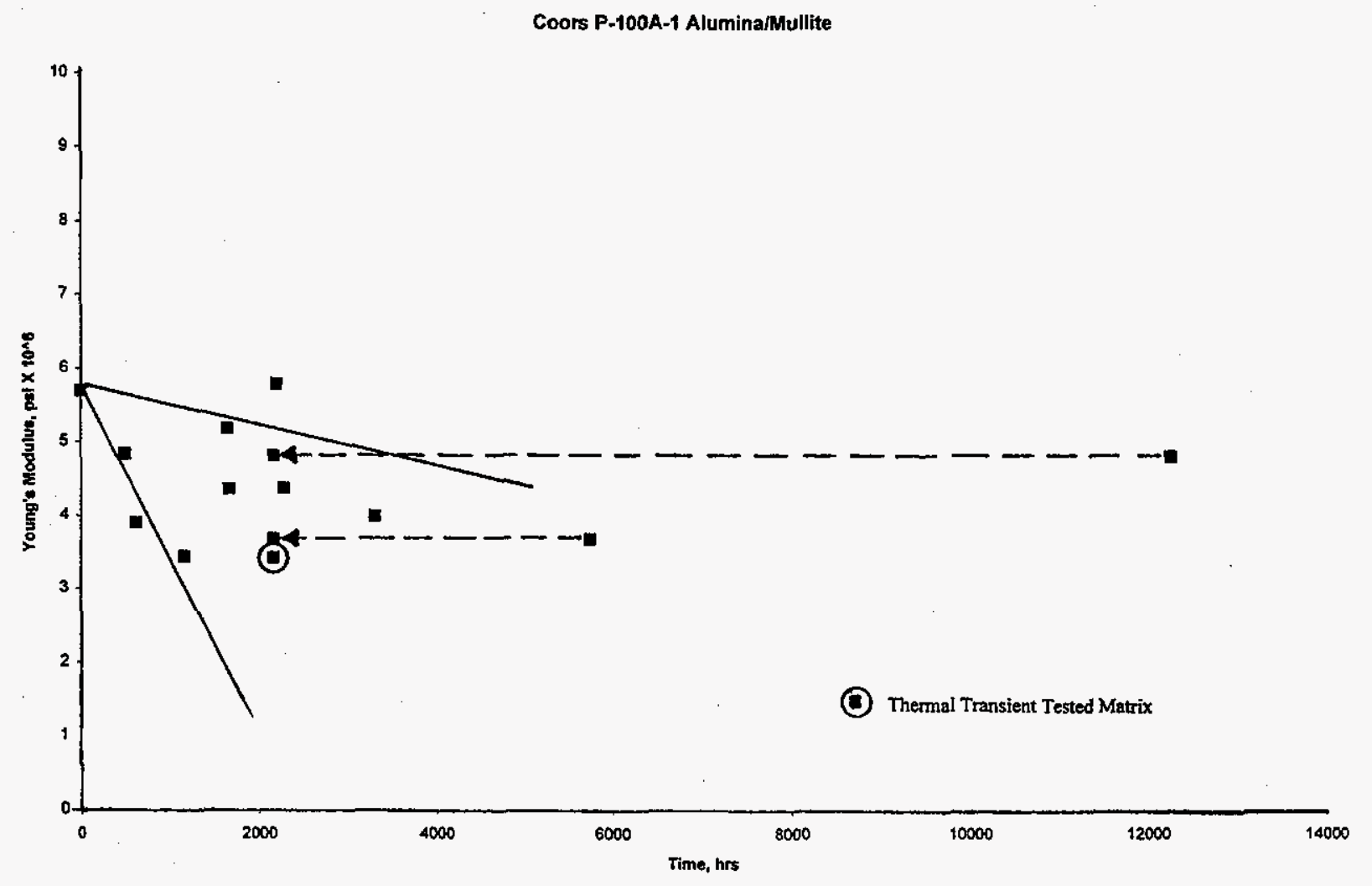

Figure 3-58 - Young's Modulus as a function of time for the Coors P-100A-1 alumina/mullite filter matrix. 
Table 3-17 identifies the burst pressure needed to fail the Blasch mullite-bonded alumina, McDermott CFCC, DuPont PRD-66, Ensto mullite-bonded alumina, and 3M CVI-SiC, PCFBC-exposed and/or PCFBC-exposed/extended life-tested filter sections, as well as the ultimate hoop stress, elastic modulus, and Poisson's ratio established for each filter section.

\section{TABLE 3-17. SUMMARY OF HOOP STRENGTH, YOUNG'S MODULUS, AND POISSON'S RATIO FOR THE ADVANCED FILTER ELEMENTS AS A FUNCTION OF EXPOSURE TIME/CONDITIONS}

\begin{tabular}{|c|c|c|c|c|c|}
\hline $\begin{array}{c}\text { Candle } \\
\text { Identification } \\
\text { Number }\end{array}$ & $\begin{array}{l}\text { Operating } \\
\text { Time, Hrs }\end{array}$ & $\begin{array}{c}\text { Burst Pressure, } \\
\text { psi }\end{array}$ & $\begin{array}{l}\text { Ultimate Hoop } \\
\text { Stress, psi }\end{array}$ & $\begin{array}{l}\text { Young's } \\
\text { Modulus, } \\
\text { psi x } 10^{6}\end{array}$ & $\begin{array}{l}\text { Poisson's } \\
\text { Ratio }\end{array}$ \\
\hline \multicolumn{6}{|c|}{ Blasch Mullite-Bonded Alumina } \\
\hline BP4-270C-7/97 & - & 150 & 363 & 2.35 & 0.18 \\
\hline BP-4-270J 7/97 (B39) & 342 & 175 & 410 & 1.92 & 0.09 \\
\hline BP-4-270N7/97 (B40) & 581 & 205 & 485 & 1.26 & 0.10 \\
\hline $\begin{array}{c}\mathrm{BP} 4-270 \mathrm{P} 7 / 97 \\
\text { (B41) }\end{array}$ & $581 / 20089 / 30 \mathrm{~T}$ & 140 & 358 & 1.46 & 0.32 \\
\hline \multicolumn{6}{|c|}{ McDermott Oxide-Based CFCC } \\
\hline $7-6-3$ & - & 220 & 1256 & 1.61 & 0.99 \\
\hline BW 7-5-15 (B14) & 342 & 140 & 845 & 1.80 & 1.04 \\
\hline BW 7-5-30 (B33) & 581 & 185 & 1077 & 1.61 & 1.13 \\
\hline BW 7-5-29 (B32) & $581 / 20089 / 30 \mathrm{~T}$ & ND & ND & ND & ND \\
\hline \multicolumn{6}{|l|}{ DuPont PRD-66 } \\
\hline D-583 & - & 195 & 731 & 7.85 & 1.09 \\
\hline D-580 (B51) & 342 & 190 & 735 & 8.19 & 0.71 \\
\hline D-587 (B50) & 581 & 210 & 792 & 6.57 & 0.71 \\
\hline \multicolumn{6}{|l|}{ Ensto } \\
\hline $129-97$ & 581 & 505 & 1073 & 5.19 & 0.61 \\
\hline \multicolumn{6}{|c|}{ 3M CVI-SiC Composite } \\
\hline As-Manufactured & - & ND & $1.01 \mathrm{ksi}$ & $2.96-3.38$ & $0.14-0.27$ \\
\hline M-51103 (B36) & 387 & 133 & 1179 & 3.35 & 0.22 \\
\hline $\mathrm{M}-51153$ (B31) & 626 & 105 & 946 & 5.59 & 0.34 \\
\hline
\end{tabular}

ND: Not determined.

Three full length PCFBC-exposed/extended life-tested candle filters were supplied by SWPC STC to Dr. Roger Chen at West Virginia University (WVU) for NDE evaluation. These included:

- Coors FC058 (M26) - 7193 hrs of equivalent service life

- Pall 326 (R5-631 M22) - 7193 hours of equivalent service life

- Schumacher Dia Schumalith FT20 (S350F/16 T2) - 10,029 hours of equivalent service life.

The NDE technique that was developed at WVU to detect cracks and/or flaws utilized a modular experimental system whereby each candle filter element was freely suspended at the flange using elastic tubes tied to the top of a rectangular metallic structural frame, simulating a free-free boundary condition (Appendix B). The filter was then subjected to impact hammer excitation, and the response was 
monitored by an accelerometer. The accelerometer was placed perpendicular to the filter surface, with the impact performed as normal to the filter surface as possible. The time domain waveform from both the impact and the acceleration response were stored in a digital oscilloscope, and then processed by using signal processing software.

Fourier transform analysis was performed on the signals to obtain the Frequency Response Function (FRF). The FRF was defined as the ratio between the measured response and the excitation force in the frequency domain. The FRF defined peaks that corresponded to the modal frequencies at

each mode of vibration. The first eight flexural vibration modes, covering a frequency range up to $\sim 400$ $\mathrm{Hz}$, were clearly defined. From the FRFs, the frequency and amplitude values were noted, and the vibration mode shapes of each mode were constructed.

Finite element models were constructed using 8-node, 3-dimensional brick elements, and were used to calculate the Young's modulus and Poisson's ratio assumption. The experimental frequency values were compared to the calculated frequency at each vibration mode for refinement of the Young's modulus and the Poisson's ratio assumption. Ultimately change, as well as the extent of change, in Young's Modulus with operating time will be considered as basis for defining residual filter life.

The three full filter elements provided by SWPC STC were initially tested in their as-received state with ash present along the outer surface of each filter element. All elements were washed, dried, and retested. The results of the NDE evaluation indicated that

- A small difference in the natural frequency values at each mode was identified for the Coors P-100A-1, Pall 326, and Schumacher Dia Schumalith FT20 candles when the elements were tested in either their as-received or washed state. The general conclusion was that the presence of ash along the surface or contained within the accelerated life-tested elements did not impact the vibrational modes or subsequent material properties of the monolithic filter materials.

- Assuming a Poison's Ratio of 0.25 for all filters, three-dimensional finite element analysis for the Coors, Pall, and Schumacher elements generated a Young's Modulus of $4.20 \times 10^{6} \mathrm{psi}$, $7.00 \times 10^{6} \mathrm{psi}$, and $6.30 \times 10^{6} \mathrm{psi}$, respectively, with a weight density of $0.066 \mathrm{lb} / \mathrm{in}^{3}, 0.071$ $\mathrm{lb} / \mathrm{in}^{3}$, and $0.073 \mathrm{lb} / \mathrm{in}^{3}$, respectively.

- Based on the resulting vibrational frequency mode shapes (i.e., frequency response function vs distance along the length of the element) generated during nondestructive characterization, bulk matrix damage was not identified to have occurred in the accelerated pulse cycled Coors P-100A-1, Pall 326, and Schumacher Dia Schumalith FT20 filter elements.

- The Young's Modulus identified via NDE at WVU and the destructive characterization performed at SWPC are shown in Table 3-18. Variation existed between the destructive and nondestructive results.

- The largest difference between two characterization techniques was identified for the Young's Modulus for the Coors filter matrix. Localized variations along the length of the element were averaged by NDE, while the destructive results reflect bulk matrix properties within a $254 \mathrm{~mm}$ section of material that was consistently taken from a defined location along the length of the filter element. Localized damage may be more pronounced within the Coors alumina/mullite filter matrix as a response to thermal 
fatigue at the location selected for destructive burst strength testing, thus the lower Young's Modulus value.

- The $4-5 \%$ variation in the destructively vs nondestructively generated Young's Modulus for the Pall and Schumacher filter elements was generally considered to only reflect differences between the experimental techniques and/or calculation methodology used for the two analysis procedures.

TABLE 3-18. COMPARISION OF YOUNG'S MODULUS DATA GENERATED VIA DESTRUCTIVE AND NONDESTRUCTIVE TECHNIQUES

\begin{tabular}{|c|c|c|c|c|c|}
\hline \multirow[b]{2}{*}{ Supplier } & \multirow[b]{2}{*}{$\begin{array}{c}\text { Element } \\
\text { Identification }\end{array}$} & \multirow[b]{2}{*}{$\begin{array}{l}\text { Extended } \\
\text { Life, Hrs }\end{array}$} & \multicolumn{3}{|c|}{ Young's Modulus, psi x $10^{6}$} \\
\hline & & & Destructive* & $\begin{array}{c}\text { Non- } \\
\text { Destructive }\end{array}$ & $|\Delta \%|$ \\
\hline Coors & $\begin{array}{c}\text { FC058 (M26) } \\
2166 \mathrm{Hrs}\end{array}$ & 7193 & $\begin{array}{c}3.68 \\
(5.7)^{* *}\end{array}$ & 4.20 & 14 \\
\hline Pall 326 & $\begin{array}{c}\mathrm{R} 5-631(\mathrm{M} 22) \\
1035 \mathrm{Hrs} \\
\end{array}$ & 7193 & 6.66 & 7.00 & 5.1 \\
\hline $\begin{array}{l}\text { Schumacher } \\
\text { FT20 }\end{array}$ & $\begin{array}{c}\mathrm{S} 350 \mathrm{~F} / 16(\mathrm{~T} 2) \\
1035 \mathrm{Hrs}\end{array}$ & 10029 & $\begin{array}{c}6.57 \\
(7.3)^{* *}\end{array}$ & 6.30 & 4.1 \\
\hline
\end{tabular}

* Single $254 \mathrm{~mm}$ section removed from each element which was subjected to room temperature burst strength testing.

** As-manufactured but untested filter element.

\subsection{High Temperature Creep}

High temperature creep testing was conducted on $115 \mathrm{~mm} \times 8.5 \mathrm{~mm} \times 12 \mathrm{~mm}$ bars that were removed from the PCFBC-exposed, Schumacher Dia Schumalith FT20 (S350F/60 (T5)) and Pall 326 (R1659 (M17)) candle filters. Both filter elements had experienced 1035 hours of PCFBC operation at Karhula, and were subsequently subjected to 20,089 accelerated pulse cleaning cycles in the SWPC STC extended filter life test program. The total equivalent operating life for both porous ceramic filter materials was therefore 11,080 hours. A maximum creep strain of $0.11 \%$ and $0.12 \%$ was identified for the Schumacher Dia Schumalith FT20 S350F/60 and Pall 326 R1-659 filter matrices, respectively, after exposure in static air for a period of $500 \mathrm{hrs}$ at temperatures of $843^{\circ} \mathrm{C}\left(1550^{\circ} \mathrm{F}\right)$, with an applied load of 500 psi (Figure 3-59). Based on these results, the PCFBC-exposed/extended life-tested clay bonded silicon carbide filter matrices were not considered to exhibit high temperature creep strain during process operation. 
Outer Surface Membrane

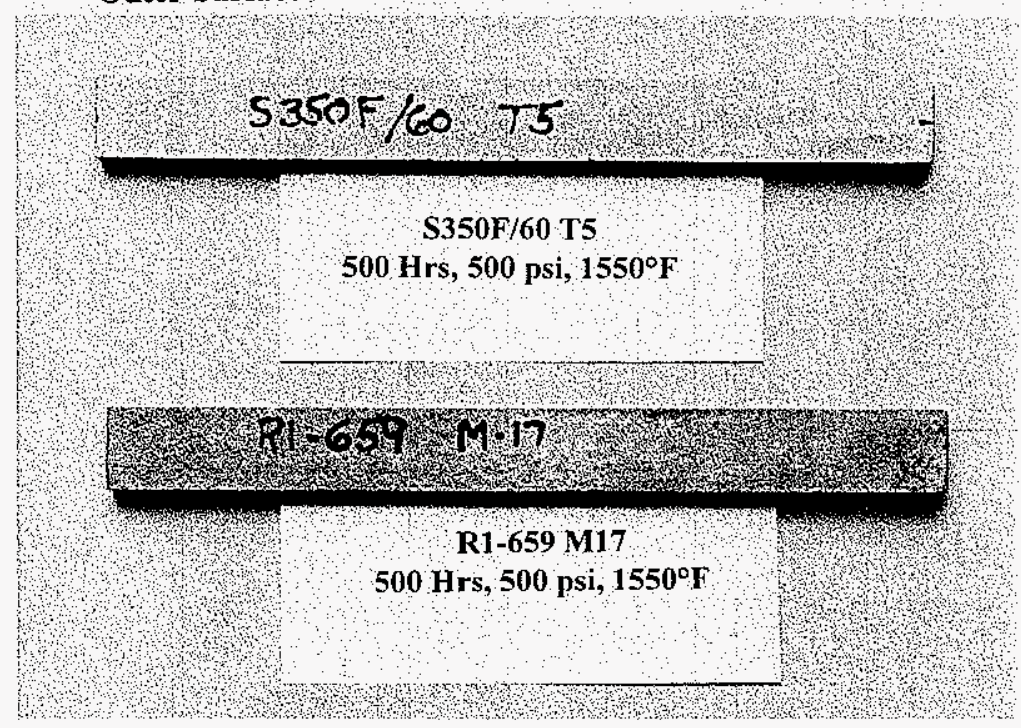

\section{Cross-Sectioned Wall}

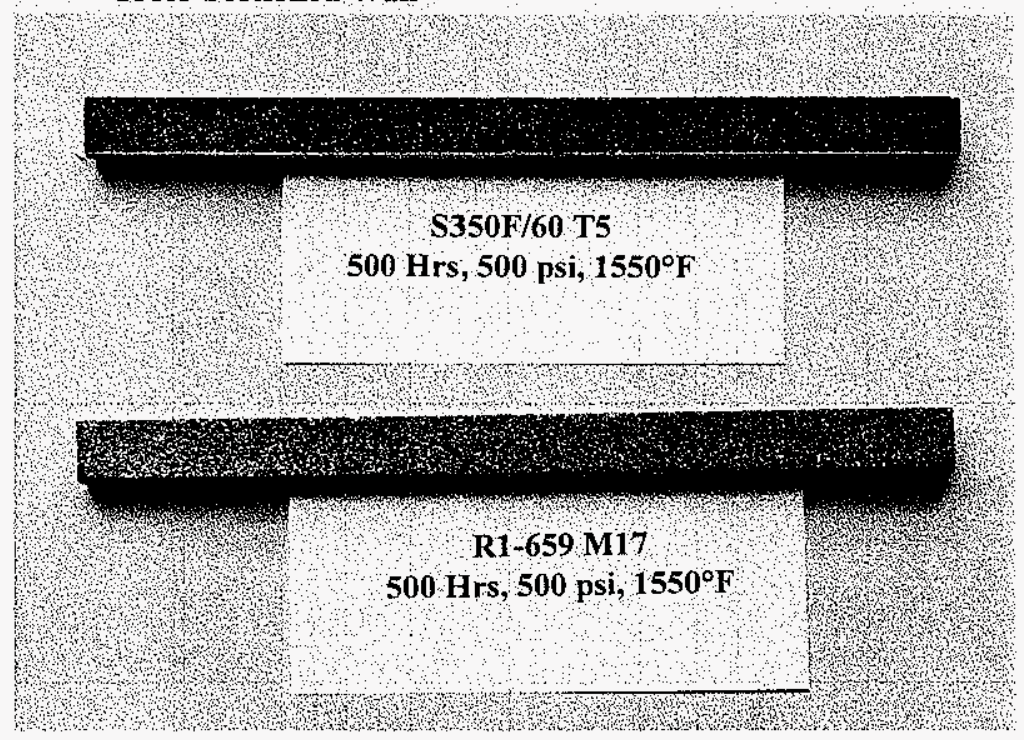

Figure 3-59 - Photographs illustrating the PCFBC-exposed/extended life-tested Schumacher Dia Schumalith FT20 and Pall 326 filter matrices after exposure in static air for a period of $500 \mathrm{hrs}$ at temperatures of $1550^{\circ} \mathrm{F}$ to an applied load of $500 \mathrm{psi}$. 


\subsection{Microstructural Analysis}

Characterization of five PCFBC-exposed/extended life-tested filter elements was conducted in order to discern whether additional microstructural changes had occurred within the porous ceramic filter materials. The impact of extended aging on the

- Schumacher Dia Schumalith FT20 (S350F/60 (T5) - 11,080 equivalent operating hours)

- Pall 326 (R1-659 (M17) - 11,080 equivalent operating hours)

- Coors P-100A-1 alumina/mullite (FC044 (M12) - 12,211 equivalent operating hours)

- McDermott CFCC (BW 7-5-29 (B32) - 10,626 equivalent operating hours/30 thermal transients)

- Blasch mullite-bonded alumina (BP4-270P7/97 (B41) - 10,626 equivalent operating hours/30 thermal transients)

filter matrices is presented in the following sections of this report. Alternate candle filters which remained intact at the conclusion of the extended accelerated life test program (i.e., Table 3-1; Coors P100A-1, Schumacher F20, Pall 326, Ensto, IF\&P REECER, and DuPont PRD-66) will undergo additional extended life testing under DOE/NETL Contract No. DE-AC21-94MC31147.

\subsubsection{Schumacher Dia Schumalith FT20}

Microstructural characterization was conducted on the Schumacher Dia Schumalith FT20 filter element identified as $\mathrm{S} 350 \mathrm{~F} / 60$ (T5) which had been exposed for 1035 hours at the Foster Wheeler PCFBC test facility in Karhula, Finland, and which subsequently experienced 10,045 hours of equivalent operating life in the PFBC simulator test facility in Pittsburgh, PA. Post-test characterization of the aged element's microstructure was conducted via SEM/EDAX analysis.

During extended filter life testing, microstructural and phase changes continued to occur within the 1035 hour, PCFBC-exposed, Schumacher Dia Schumalith FT20 filter matrix. The formation of $\sim 6 \mu \mathrm{m}$, hexagonally shaped, silica-enriched grains at the base of the binder bond posts or ligaments and the silicon carbide structural support grains was evident (Figures 3-60 and 3-61). Remnants of the oxideenriched grains were identified along the outer surface of the residual structural support silicon carbide grains (Figures 3-62, 3-63, and 3-64), in the fresh fractured, PCFBC-exposed/extended life-tested, Schumacher Dia Schumalith FT20 filter matrix. The thickness of the residual crystallized bindercontaining/oxide-enriched encapsulating layer that surrounded the structural support silicon carbide grains is shown in Figures 3-65 and 3-66. The morphology of the outer surface binder containing/oxideenriched encapsulating layer is shown in Figure 3-67. The mottled, coalesced, textured surface phase frequently contained crack formations.

Segregated areas (Figure 3-68) enriched with amorphous features (Figure 3-69; area enriched with oxygen and silicon, with minor contributions of aluminum and potassium, and trace concentrations of sodium), crystallized features (Figure 3-69; area enriched with oxygen and silicon, with minor concentrations of aluminum; Figures 3-70 and 3-71), and crystalline aluminosilicate rod-like features (i.e., mullite; Figures 3-72 and 3-73) were observed along the binder-containing/oxide-enriched layer that encapsulated the structural support silicon carbide grains. Nearly spherical, angularly-shaped features (Figure 3-74) were also observed at the tips of the aluminosilicate rods that were present within the oxideenriched encapsulating shell that surrounded the silicon carbide grains along the i.d. or pulse cycled surface of the PCFBC-exposed/extended life-tested Schumacher Dia Schumalith FT20 filter element. 


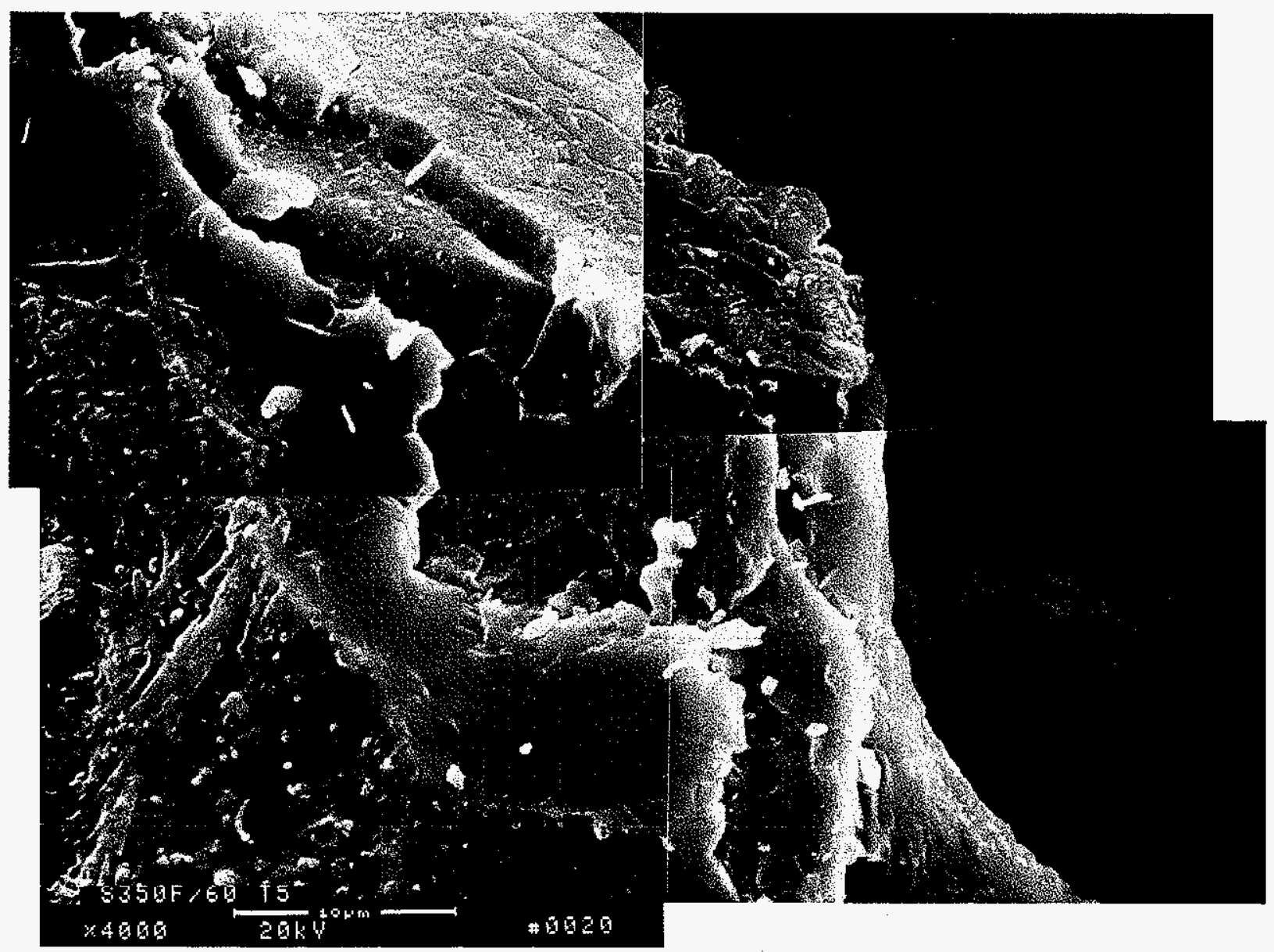

Figure 3-60 - Micrograph montage illustrating the formation of silica-enriched grains at the base of the binder bond posts or ligaments and the structural support silicon carbide grains in the PCFBC-exposed/extended life-tested Schumacher Dia Schumalith FT20 filter matrix. 


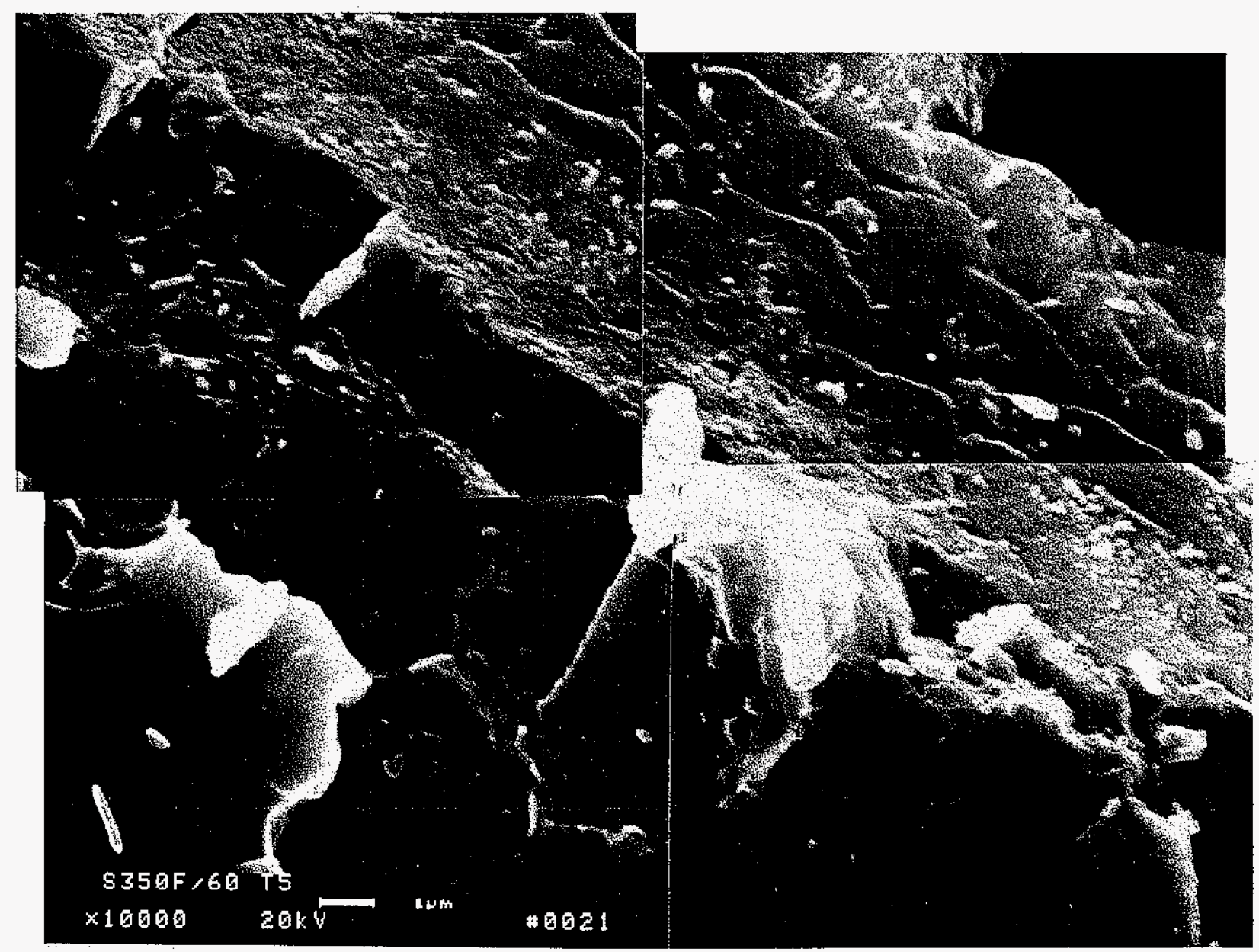

Figure 3-61 - Higher magnification micrograph montage illustrating the morphology of silicaenriched grains at the base of the binder bond posts or ligaments and the structural support silicon carbide grains in the PCFBC-exposed/extended life-tested Schumacher Dia Schumalith FT20 filter matrix. 


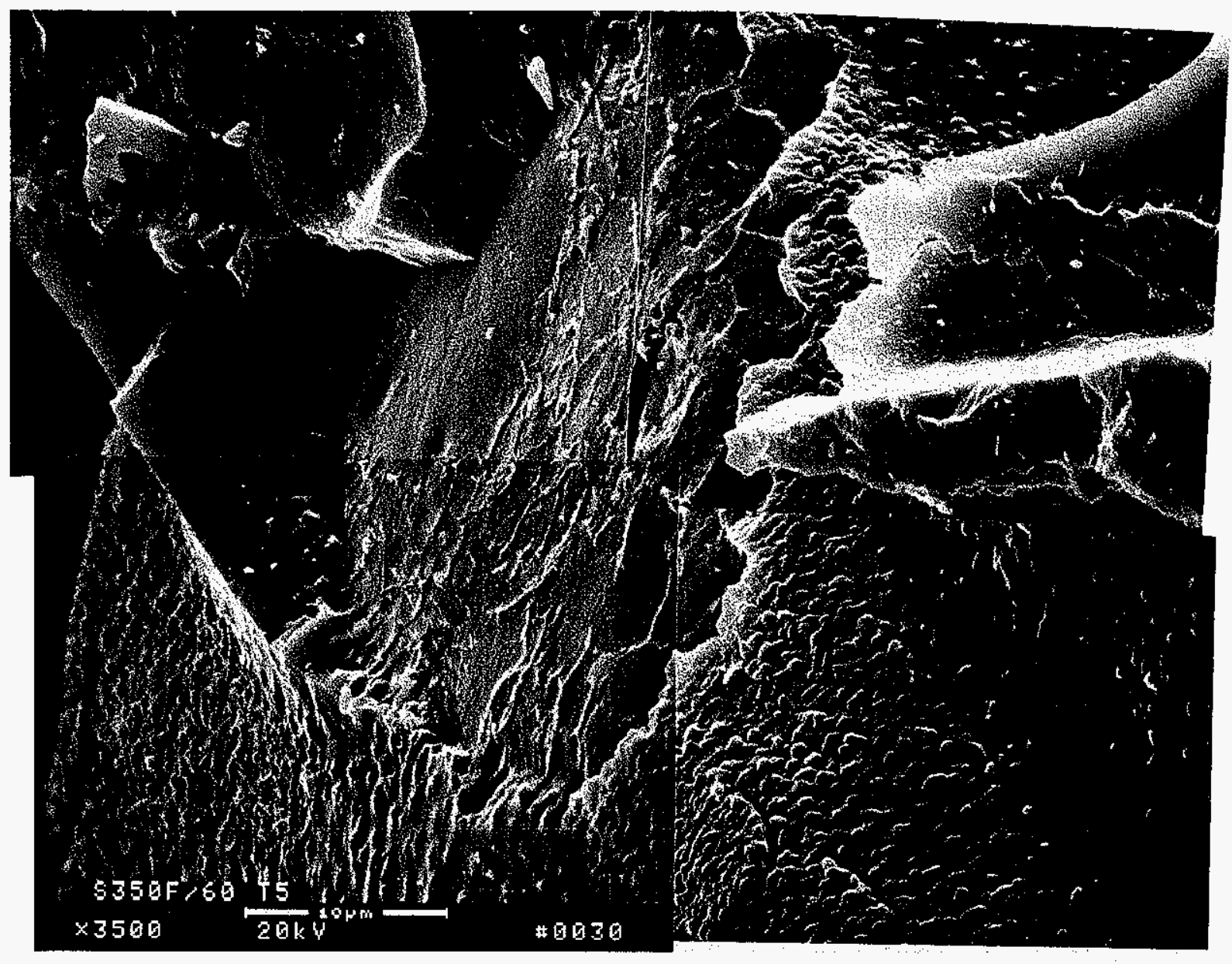

Figure 3-62 - High magnification micrograph montage illustrating the morphology of the exposed silicon carbide grain, and associated crystallized binder-containing oxide-enriched encapsulating coating, and fractured bond post or ligament. 


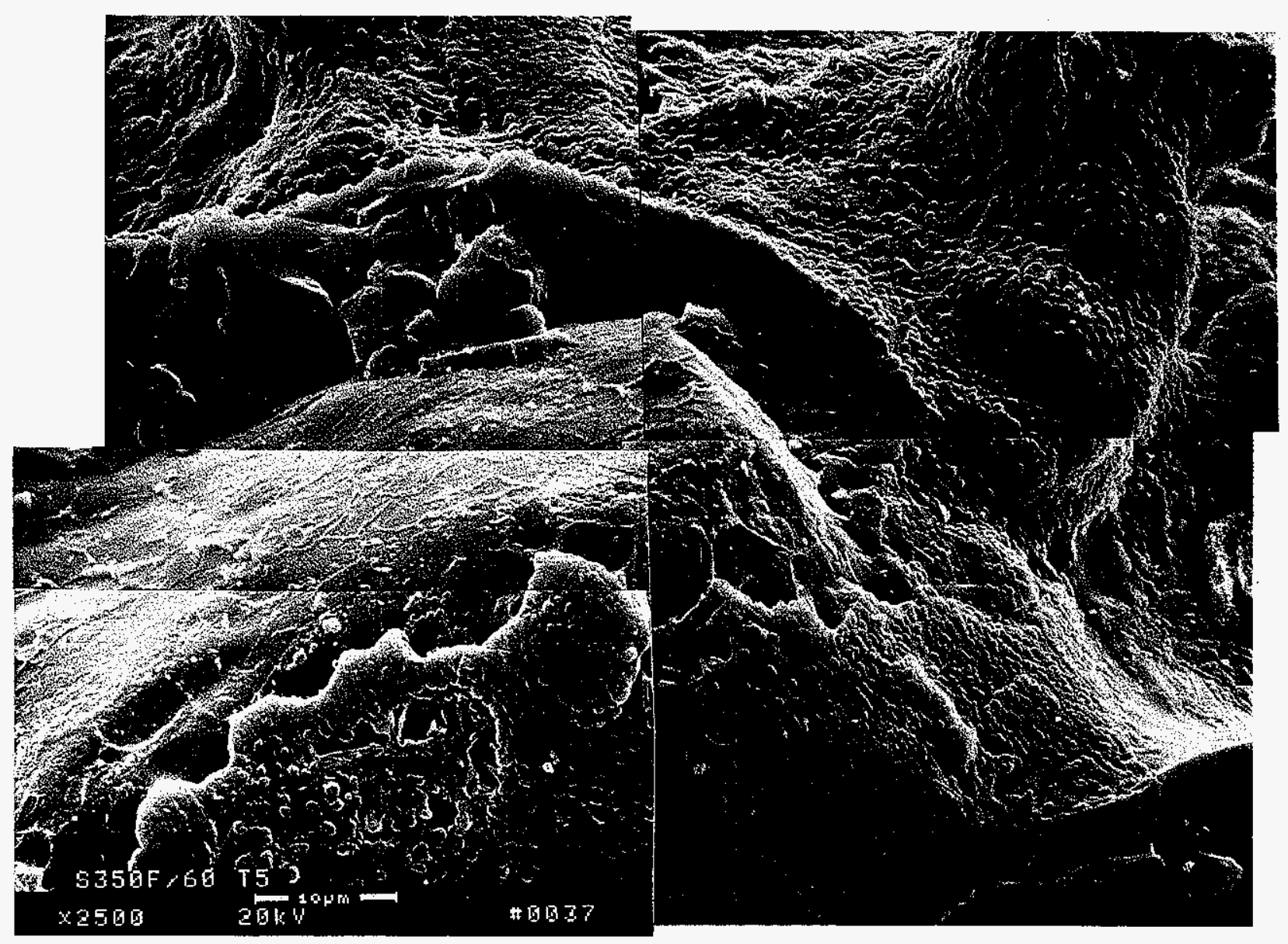

Figure 3-63 - Micrograph montage illustrating the residual oxide-enriched grain formation that remained along the surface of the structural support silicon carbide grains in the fresh fractured, PCFBC-exposed/extended life-tested, Schumacher Dia Schumalith FT20 filter matrix. 

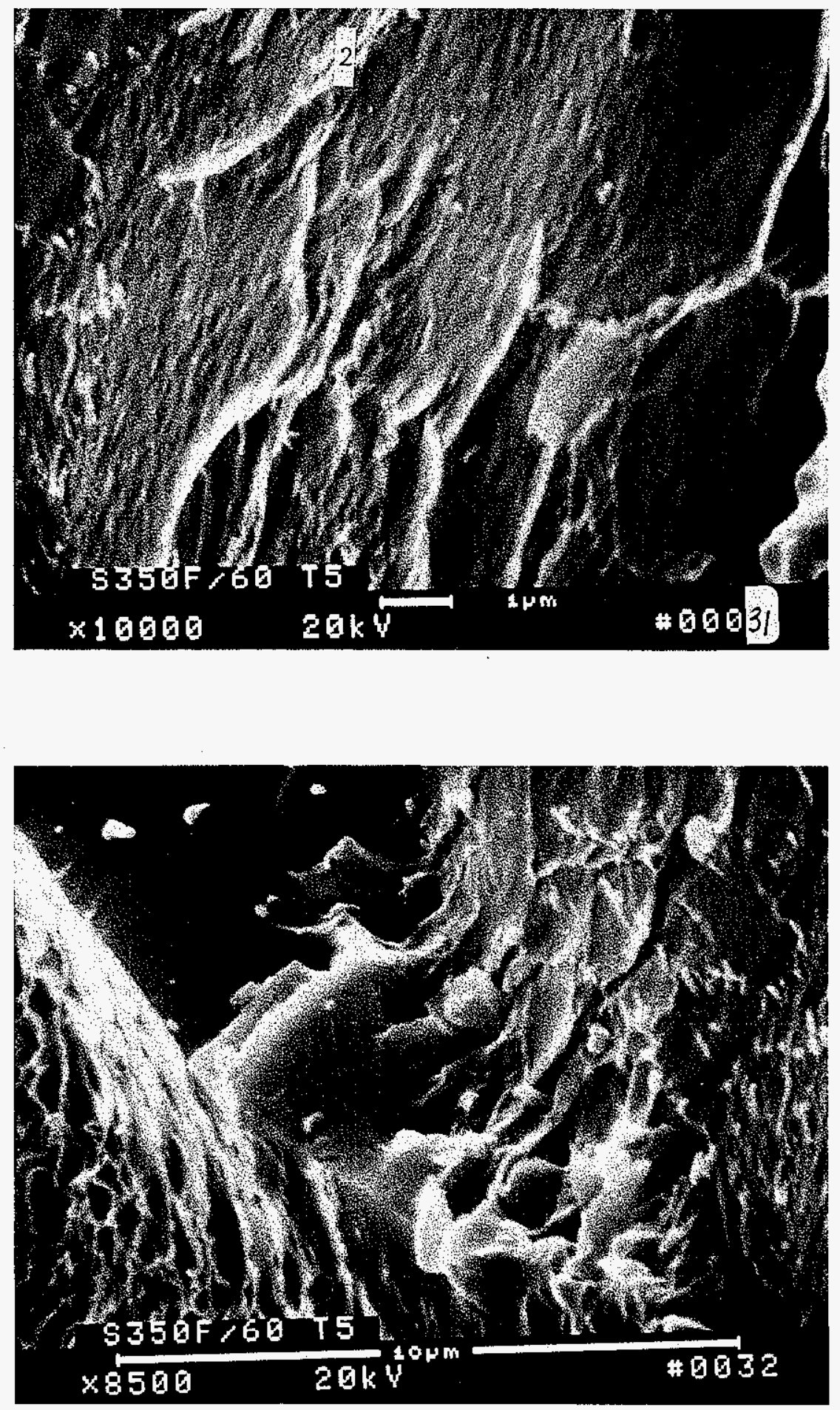

Figure 3-64 - Additional micrographs illustrating the residual binder-containing ridges that remained along the surface of the silicon carbide grain after debonding of the binder ligaments or bond posts, as well as crystalline features of the binder-enriched oxide-containing encapsulating shell. 


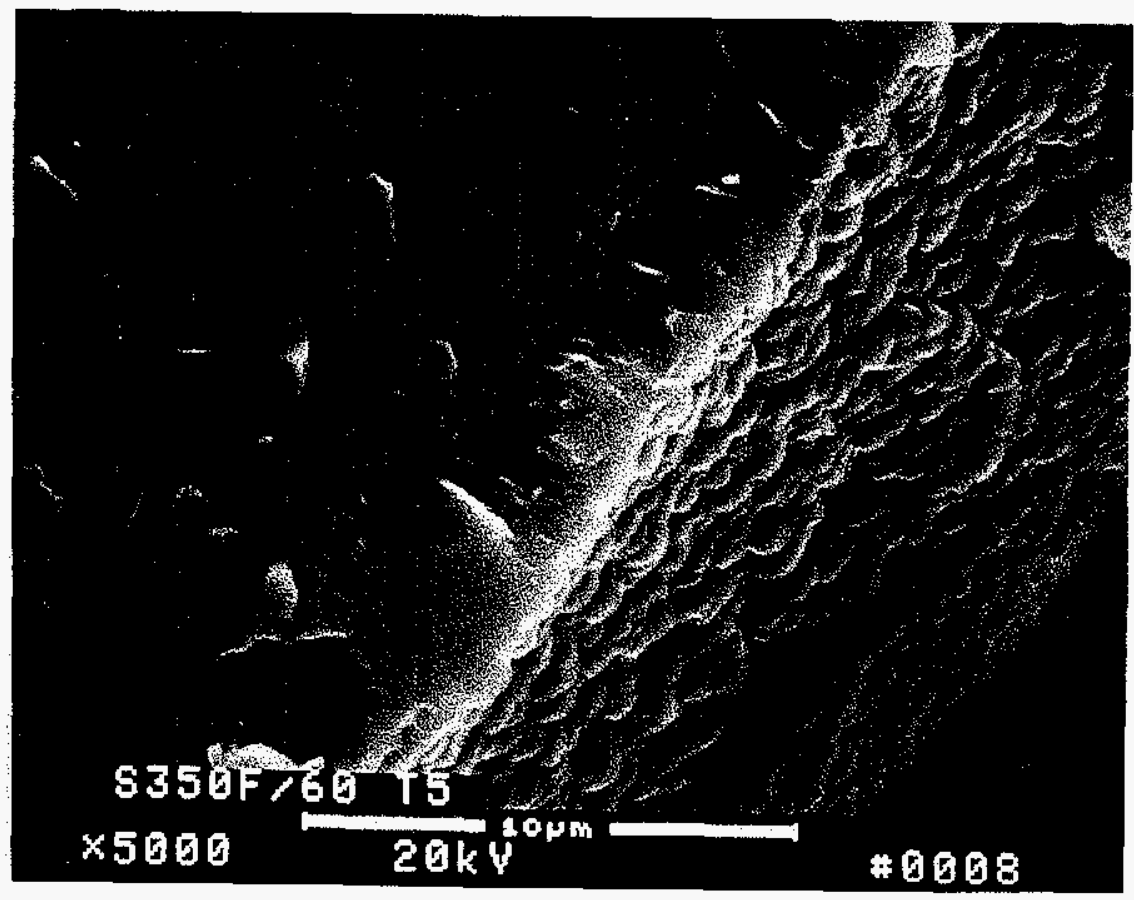

Figure 3-65 - Micrograph illustrating the thickness of the crystalline binder-containing/oxideenriched encapsulating layer that remained along the outer surface of the PCFBCexposed/extended life-tested Schumacher Dia Schumalith FT20 filter matrix. 


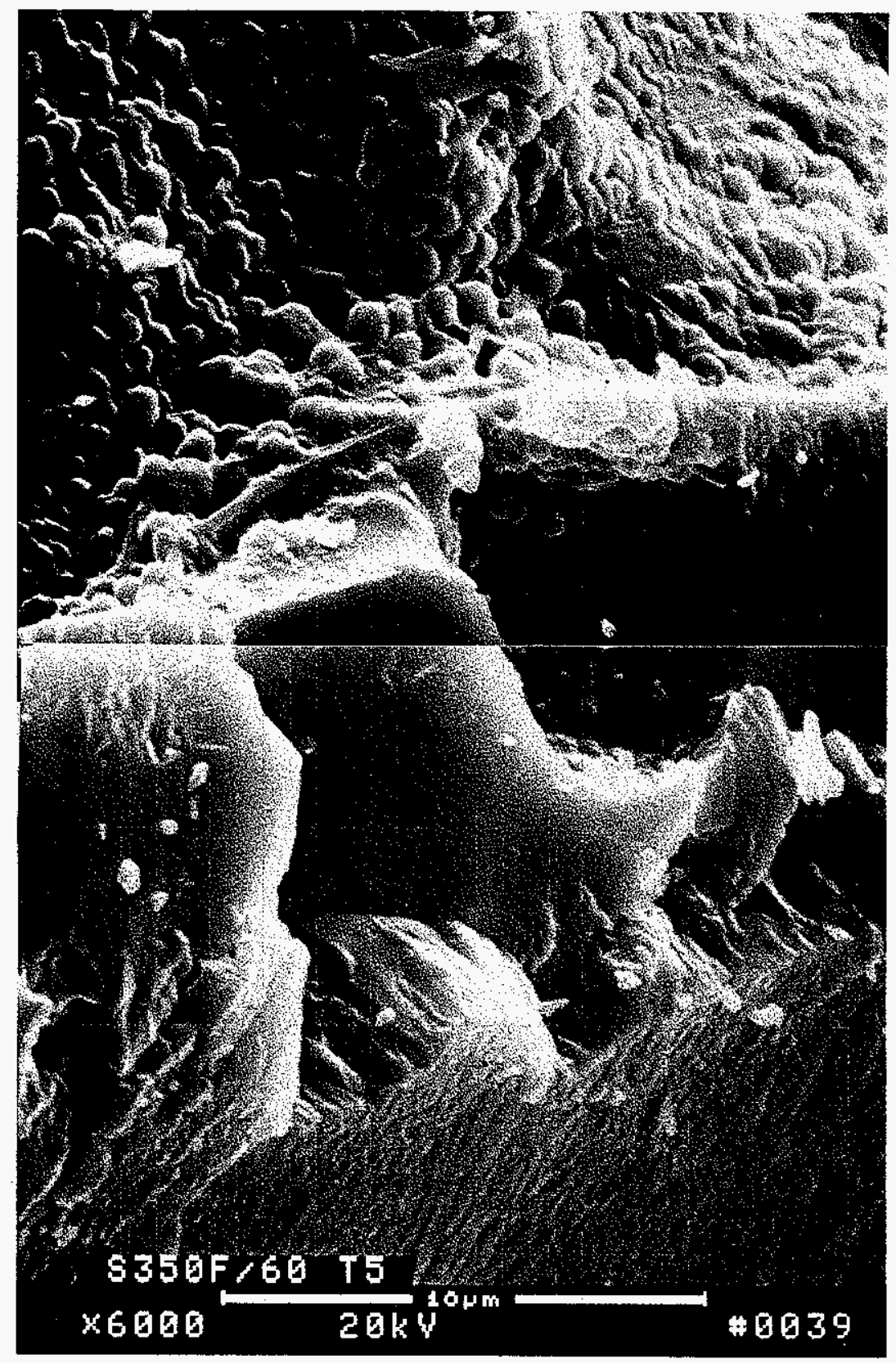

Figure 3-66 - High magnification micrograph montage illustrating the thickness and morphology of the outer crystallized surface of the binder/oxide-enriched layer that encapsulated the PCFBC-exposed/extended life-tested Schumacher Dia Schumalith FT20 filter matrix, as well as the crystalline binder-containing phase at the grain-ligament interface. 

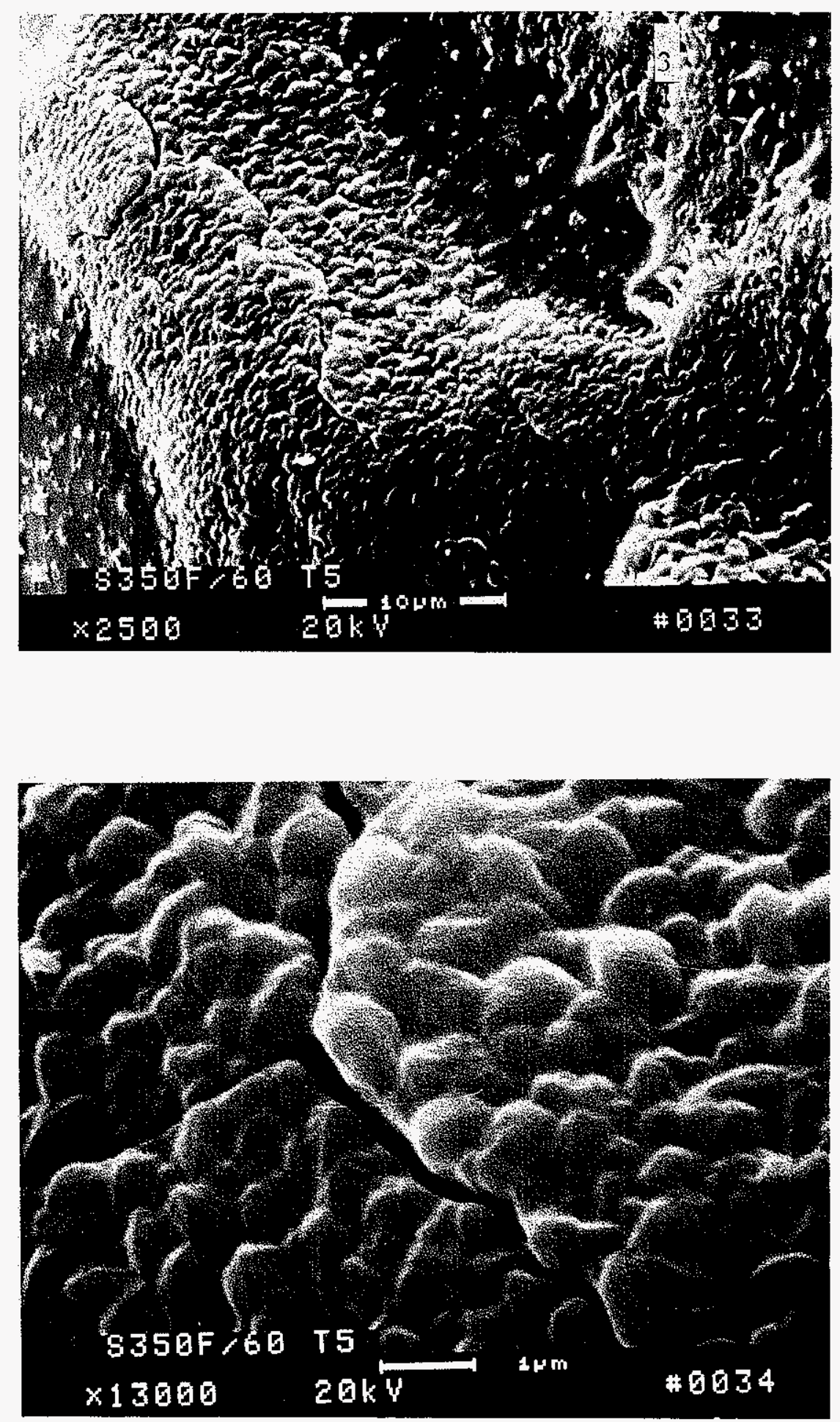

Figure 3-67 - Morphology of the crystallized, binder-containing, oxide-enriched coating that encapsulated the silicon carbide grains in the PCFBC-exposed/extended life-tested Schumacher Dia Schumalith FT20 filter matrix. 


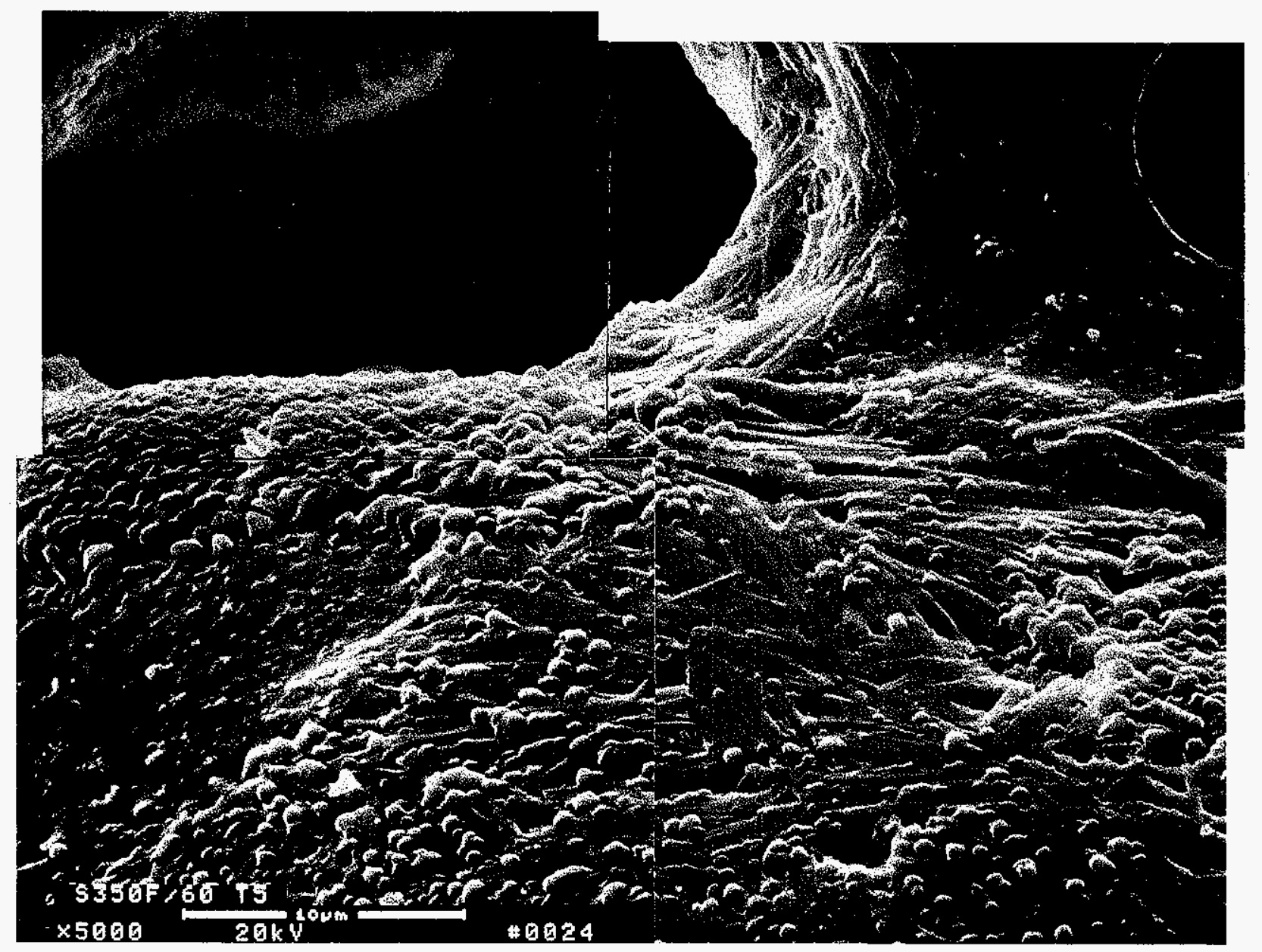

Figure 3-68 - High magnification micrograph montage illustrating the various crystalline features that resulted within the binder/oxide-enriched layer that encapsulated the surface of the silicon carbide grains in the PCFBC-exposed/extended life-tested Schumacher Dia Schumalith FT20 filter matrix near the center of the fresh fractured filter wall. 


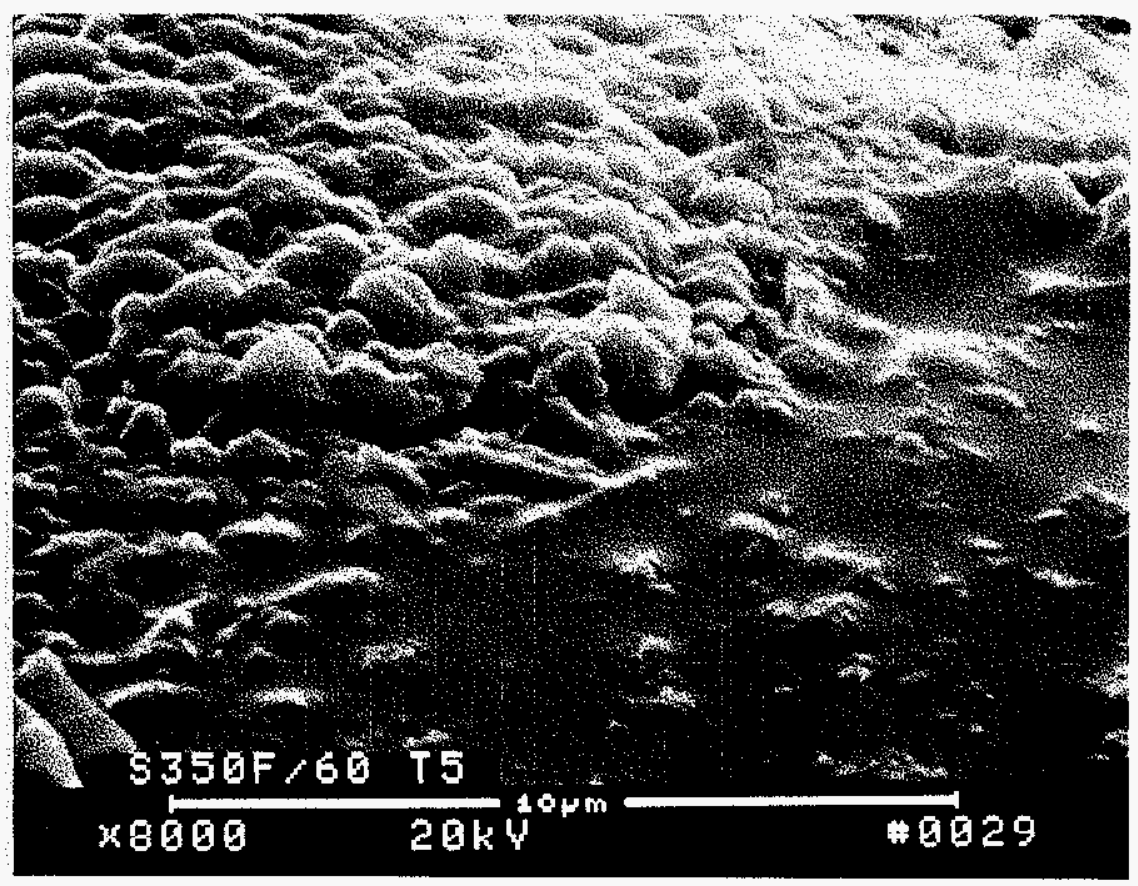

Figure 3-69 - Micrograph illustrating the crystalline and amorphous characteristics of the oxideenriched coating that encapsulated the silicon carbide grains in the PCFBCexposed/extended life-tested Schumacher Dia Schumalith FT20 filter matrix near the center of the fresh fractured filter wall. 


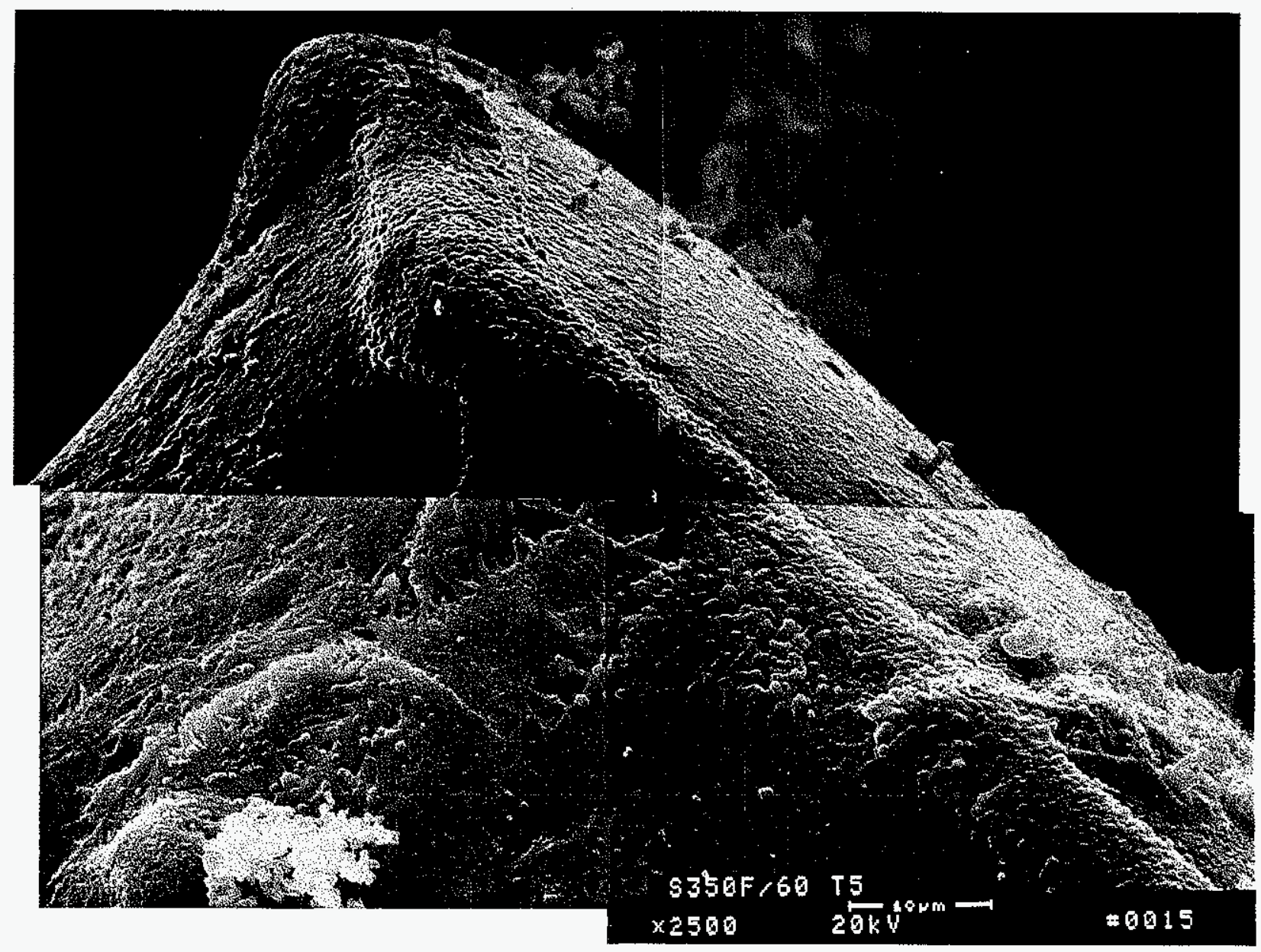

Figure 3-70 - Micrograph montage illustrating the extensive crystallization that resulted along the external surface of the silicon carbide grains in the PCFBC-exposed/extended lifetested Schumacher Dia Schumalith FT20 filter matrix along the i.d. or pulse cycled surface of the filter element. 

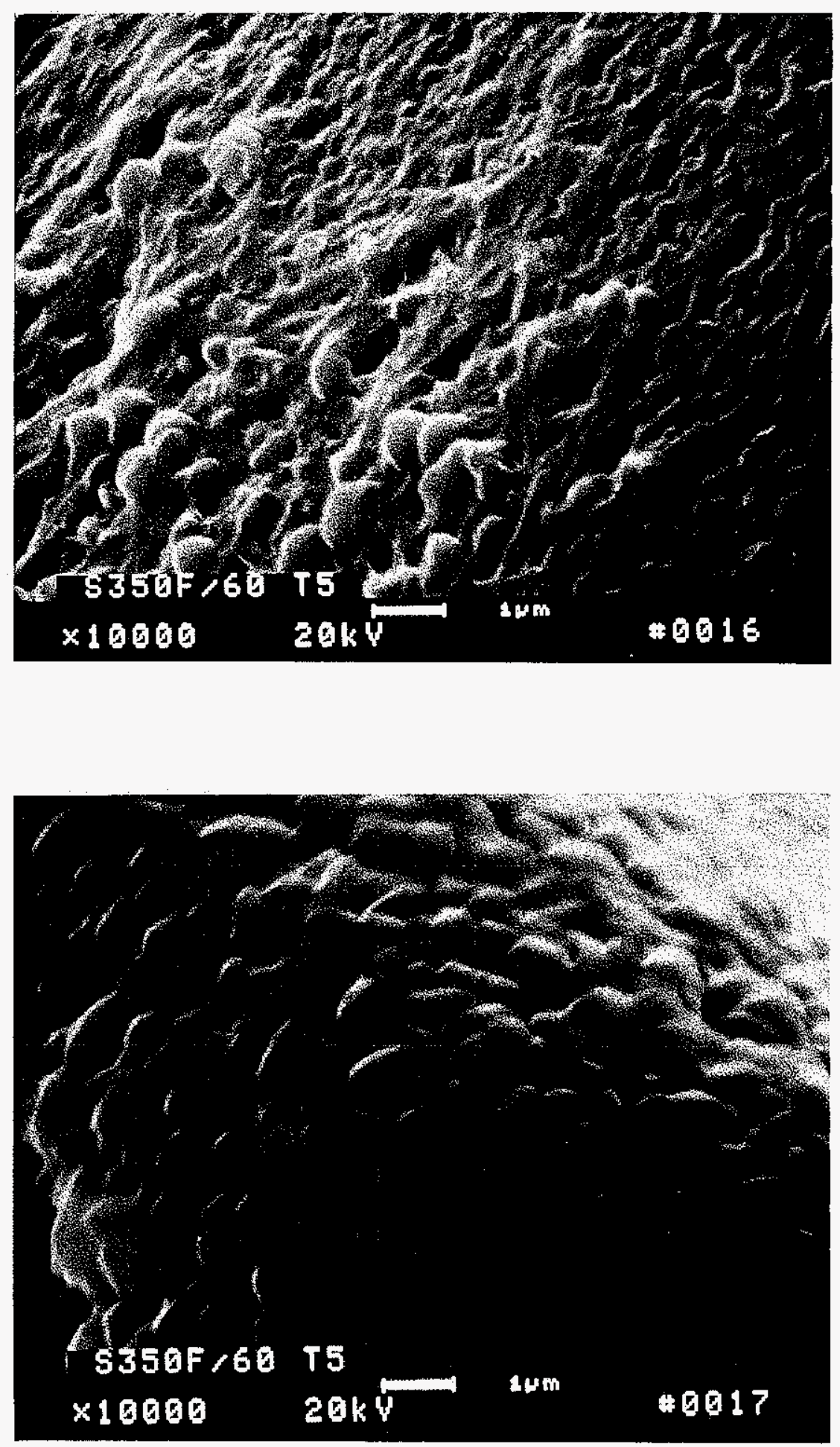

Figure 3-71 - Higher magnification micrographs illustrating the morphology of the crystallized binder/oxide-containing layer that formed along the outer surface of the silicon carbide grains in the PCFBC-exposed/extended life-tested Schumacher Dia Schumalith FT20 filter matrix along the i.d. or pulse cycled surface of the filter element. 


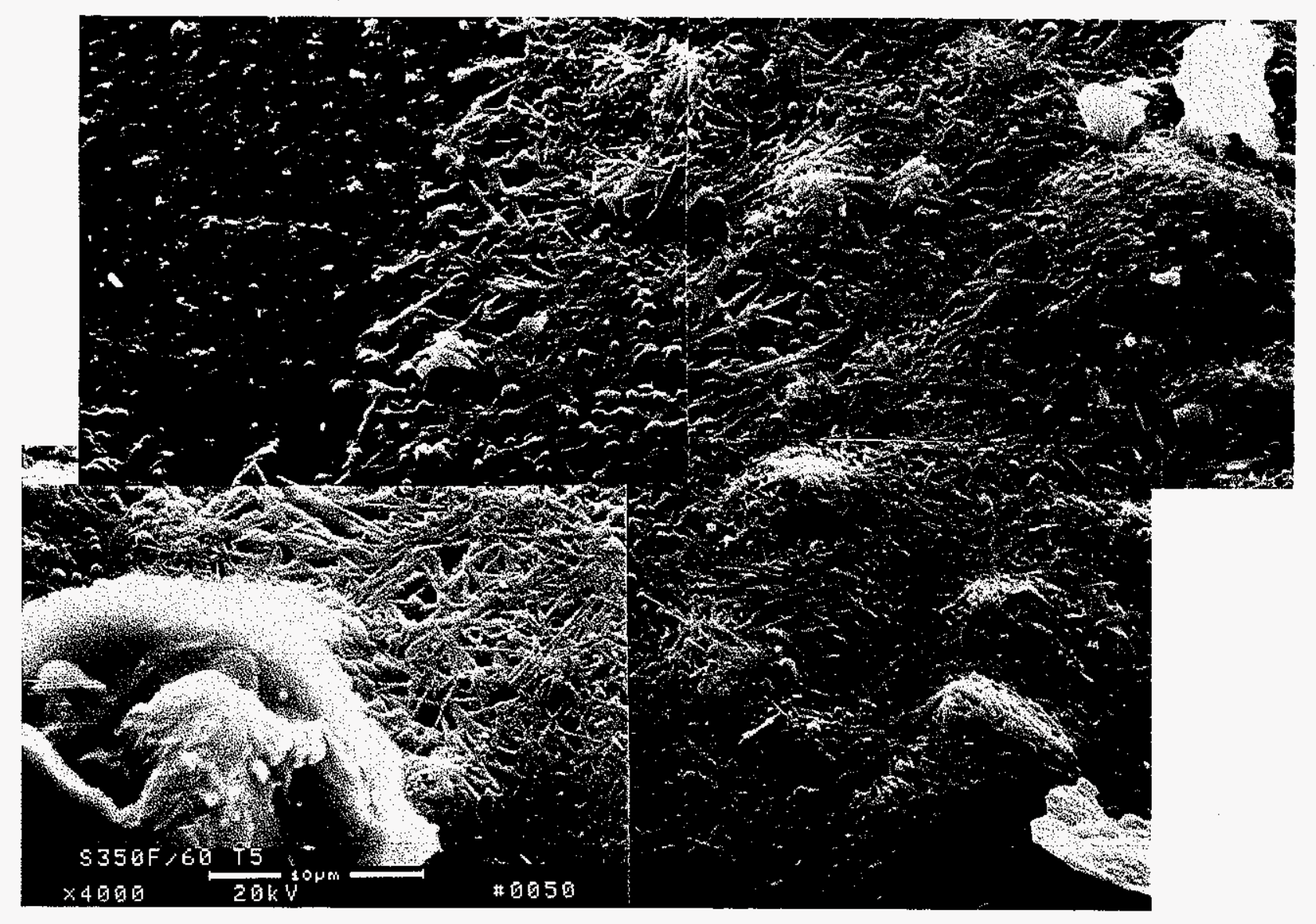

Figure 3-72 - Micrograph montage illustrating the close association of the amorphous and crystalline features of the binder/oxide-containing encapsulating layer that surrounded the silicon carbide grains along the i.d. or pulse cycled surface of PCFBC-exposed/extended life-tested Schumacher Dia Schumalith FT20 filter element. 

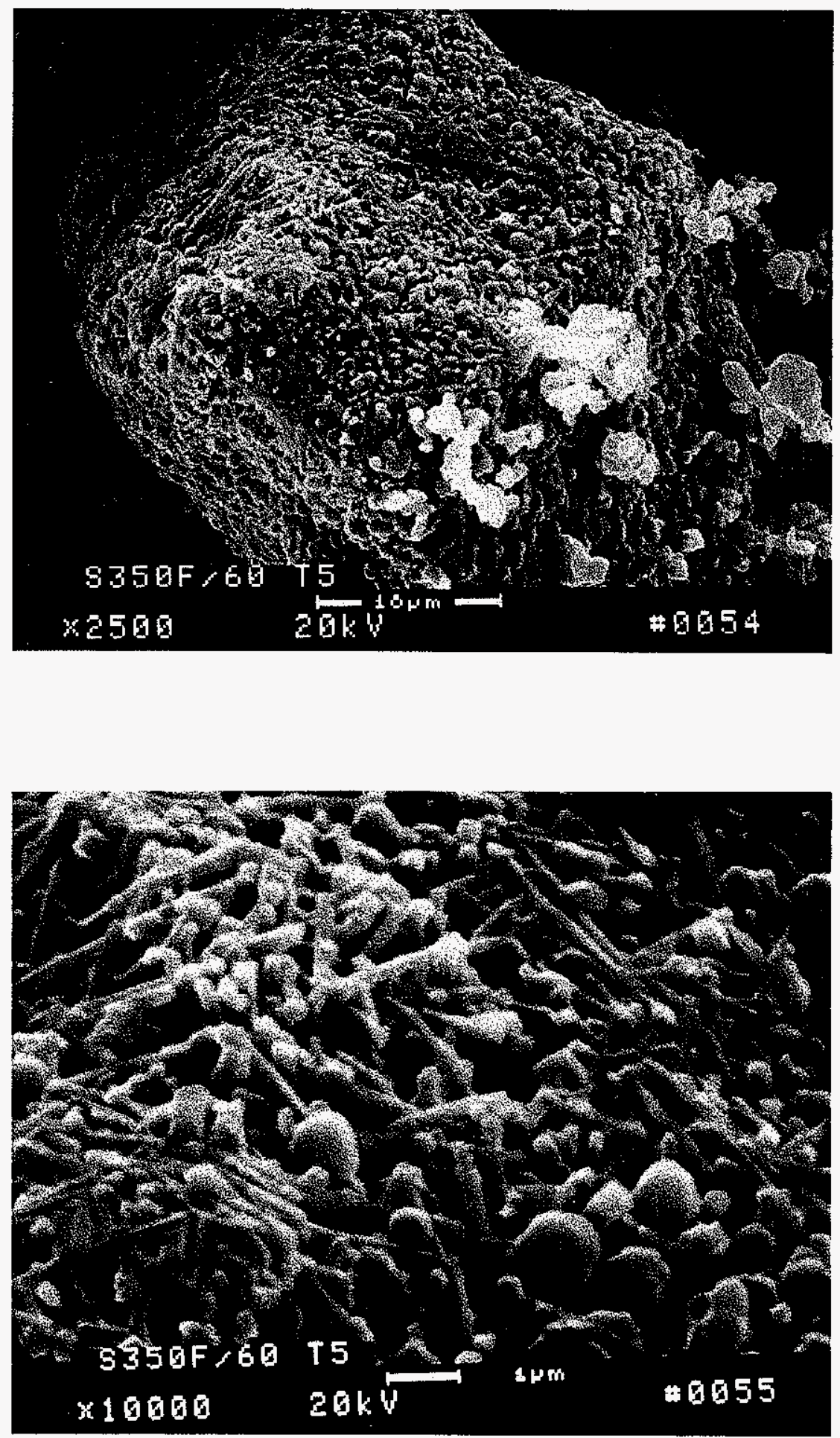

Figure 3-73 - Additional micrographs illustrating full crystallization of the PCFBC-exposed/ extended life-tested Schumacher Dia Schumalith FT20 filter matrix along the i.d. or pulse cycled surface of the filter wall. 


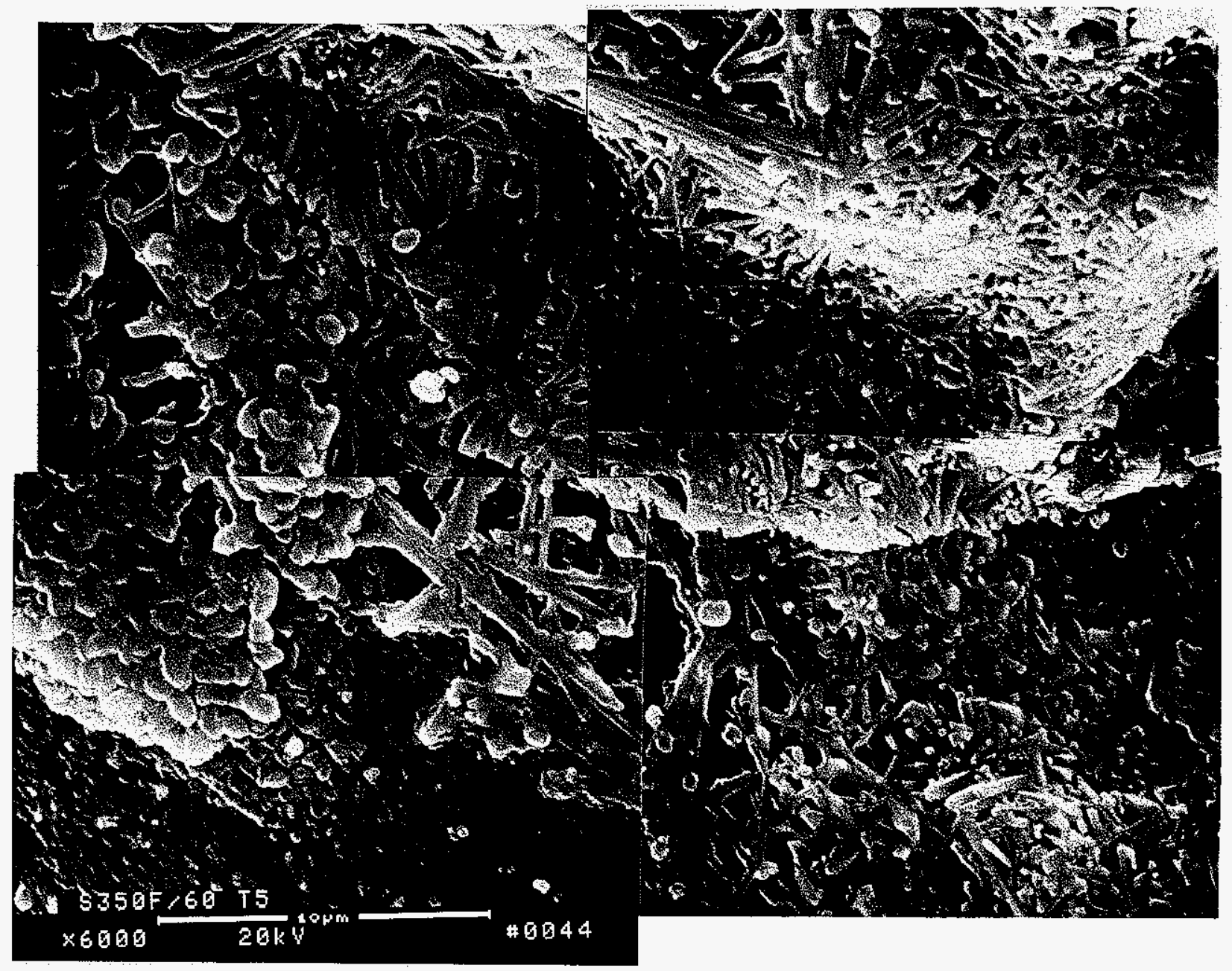

Figure 3-74 - Micrograph montage illustrating the extensive crystallization and spherical, angularly-shaped features that formed at the tips of the aluminosilicate rods which resulted along the binder/oxide-containing layer that encapsulated the silicon carbide grains along the i.d. or pulse cycled surface of PCFBC-exposed/extended life-tested Schumacher Dia Schumalith FT20 filter element. 
Crystallization was observed throughout the binder ligaments or bond posts that held the structural support silicon carbide grains together within the Schumacher Dia Schumalith FT20 filter matrix (Figure 3-75). Separation and crack-like features were observed within the amorphous oxideenriched areas that encapsulated the silicon carbide grains (Figures 3-76 and 3-77), and similarly, cracks were observed at the amorphous/crystalline silica-enriched interface along the surface of the structural support silicon carbide grains (Figure 3-69). Edge abrasion of the silica-enriched encapsulating layer was evident along the periphery of the silicon carbide grains that were present along the i.d. or pulse cycled surface of the Schumacher Dia Schumalith FT20 filter element which experienced 11,080 hours of equivalent operating life (Figure 3-78 and 3-79). The edge-abraded subsurface layer shown in Figure 380 is shown at higher magnification in Figure 3-81. EDAX analysis of this area identified the presence of oxygen and silicon, implying the presence of pure silica. Beneath the pure silica layer, a generally amorphous, nondescript area resulted, which is shown at higher magnification in Figure 3-82. EDAX analysis of this area identified the surface of the silicon carbide grain. Along the outermost edge of the grain were mottled features that were identified by EDAX analysis to consist solely of silicon carbide.

Based on the morphology and composition, edge abrasion of the silicon carbide grains by repeated pulse cycling appeared to remove the protective oxide and/or binder encapsulating layer along the edges of the silicon carbide structural support grains. Weakening of the matrix along the i.d. or pulse cycled surface of the filter matrix was expected to result particularly along areas that were in close proximity to the ligaments or bond posts. Edge abrasion of the silicon carbide grains was not identified within the interior of the filter matrix.

Although changes within the microstructure of the Schumacher Dia Schumalith FT20 filter matrix continued to occur with extended operation under simulated PFBC test conditions, the matrix, in general, appeared to remain intact, preventing negligible penetration of ash fines into the interior of the filter wall (Figure 3-83).

\subsubsection{Pall 326}

Microstructural characterization was conducted on the clay bonded silicon carbide Pall 326 filter element identified as R1-659 (M17) which had been exposed for 1035 hours at the Foster Wheeler PCFBC test facility in Karhula, Finland, and which subsequently experienced 10,045 hours of equivalent operating life in the PFBC simulator test facility in Pittsburgh, PA. Post-test characterization of the aged element's microstructure was conducted via SEM/EDAX analysis.

During extended filter life testing, microstructural and phase changes continued to occur within the 1035 hour, PCFBC-exposed, Pall 326 filter matrix. As shown in Figure 3-84, oxidation of the outer membrane silicon carbide grains resulted, leading to the formation of an $\sim 1-2 \mu \mathrm{m}$ encapsulating layer (Figure 3-85). Plate-like, $\sim 4-5 \mu \mathrm{m}$, crystalline features (Figure 3-86) were identified at the base of the binder ligaments or bond posts in the outer membrane of the PCFBC-exposed/extended life-tested Pall 326 filter element. The plate-like features were considered to have formed from the oxidation of the underlying silicon carbide grain. As shown in Figures 3-87 and 3-88, the outer encapsulating shell that surrounded the silicon carbide grains appeared as a melt-like phase, containing separation cracks.

The morphology of the silicon carbide grains that were present along the first structural support layer of the PCFBC-exposed/extended life-tested Pall 326 filter element is shown in Figure 3-89. Once 


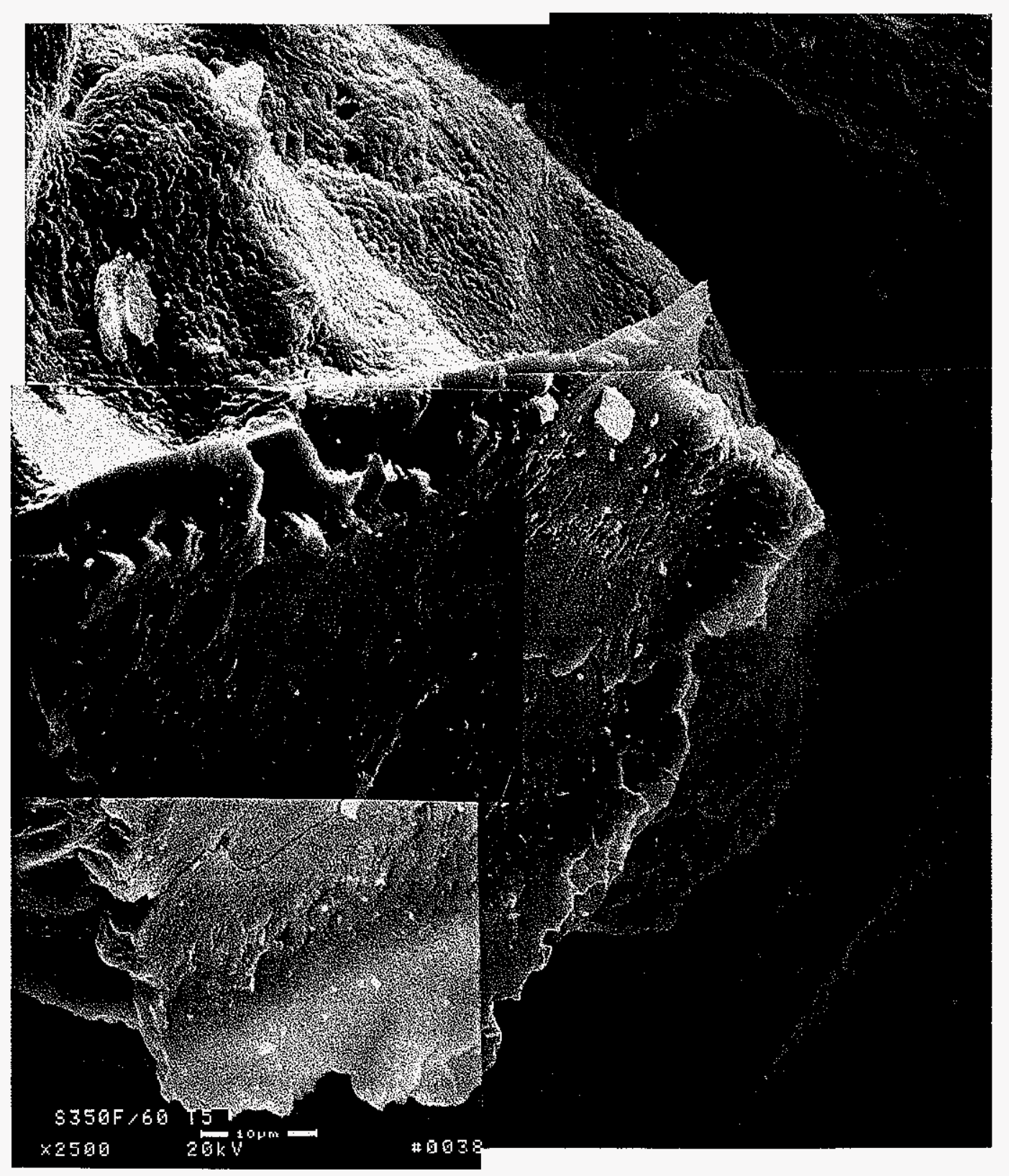

Figure 3-75 - Micrograph montage illustrating the morphology of the outer crystallized surface of the binder/oxide-enriched layer that encapsulated the PCFBC-exposed/extended life-tested Schumacher Dia Schumalith FT20 filter matrix, as well as the crystalline binder-containing phase at the grain-ligament interface. 


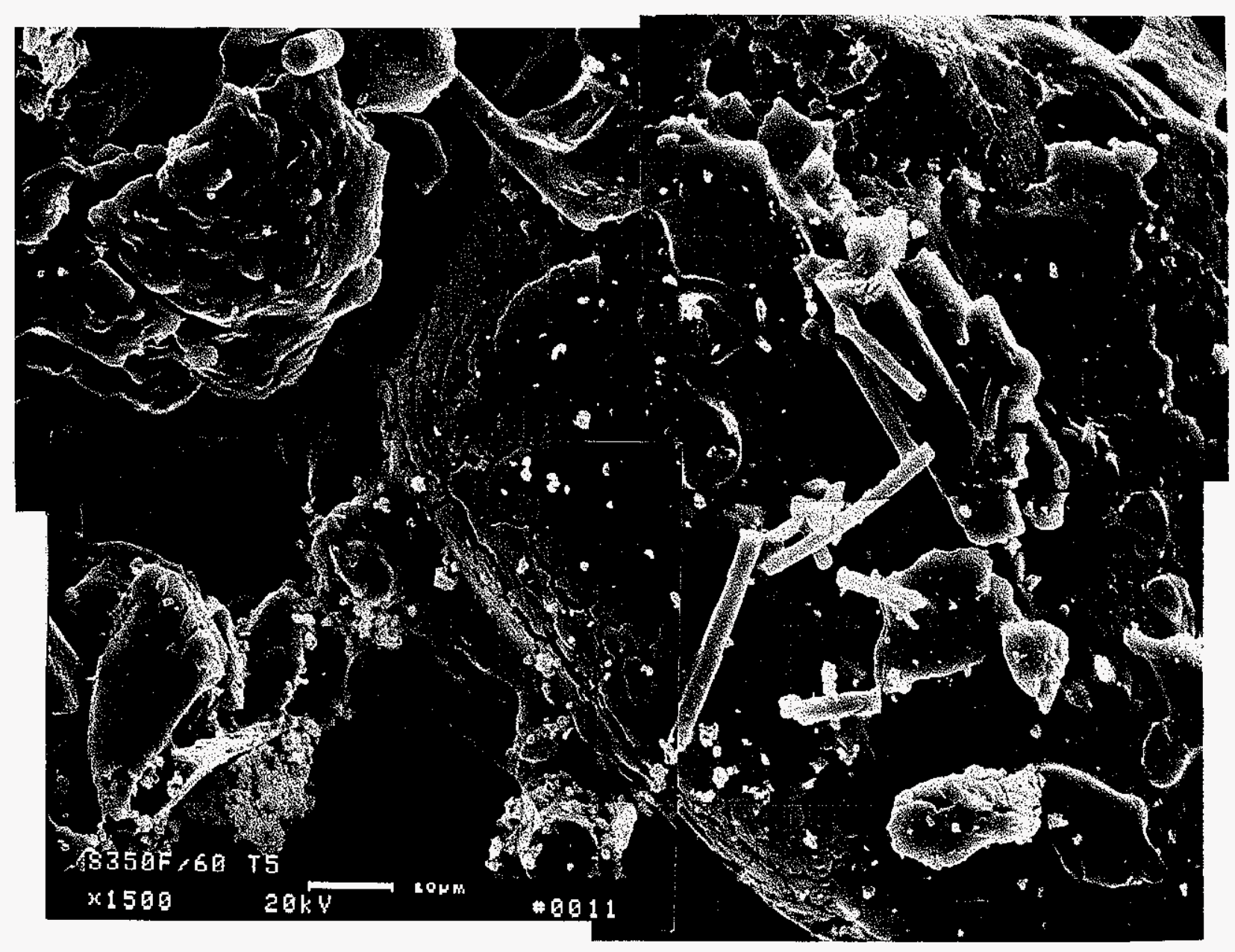

Figure 3-76 - Micrograph montage illustrating the crack formations that resulted along the structural support grains that were located directly below the membrane of the PCFBC-exposed/extended life-tested Schumacher Dia Schumalith FT20 filter matrix. 


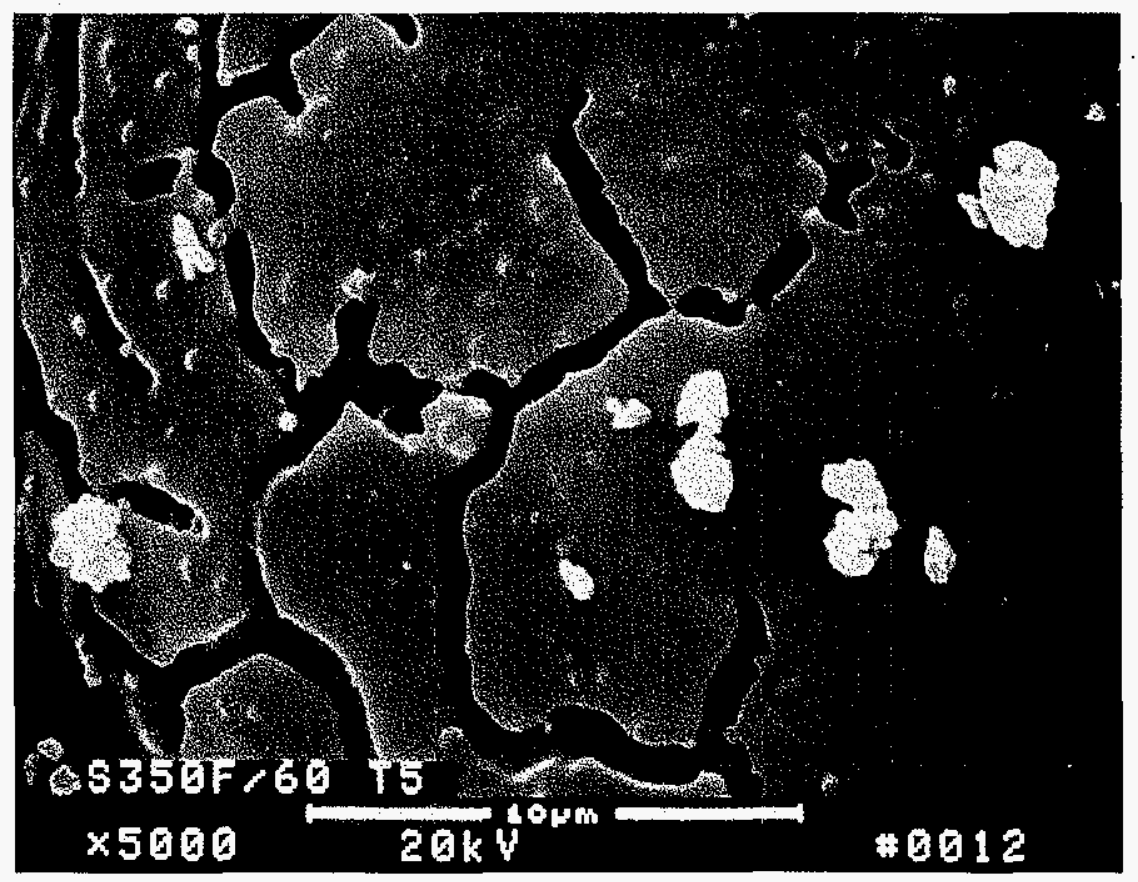

Figure 3-77 - Higher magnification micrograph illustrating the crack-like formations that resulted along the outer surface of the oxide-enriched coating that encapsulated the structural support silicon carbide grains that were located directly below the membrane of the PCFBC-exposed/extended life-tested Schumacher Dia Schumalith FT20 filter matrix. 


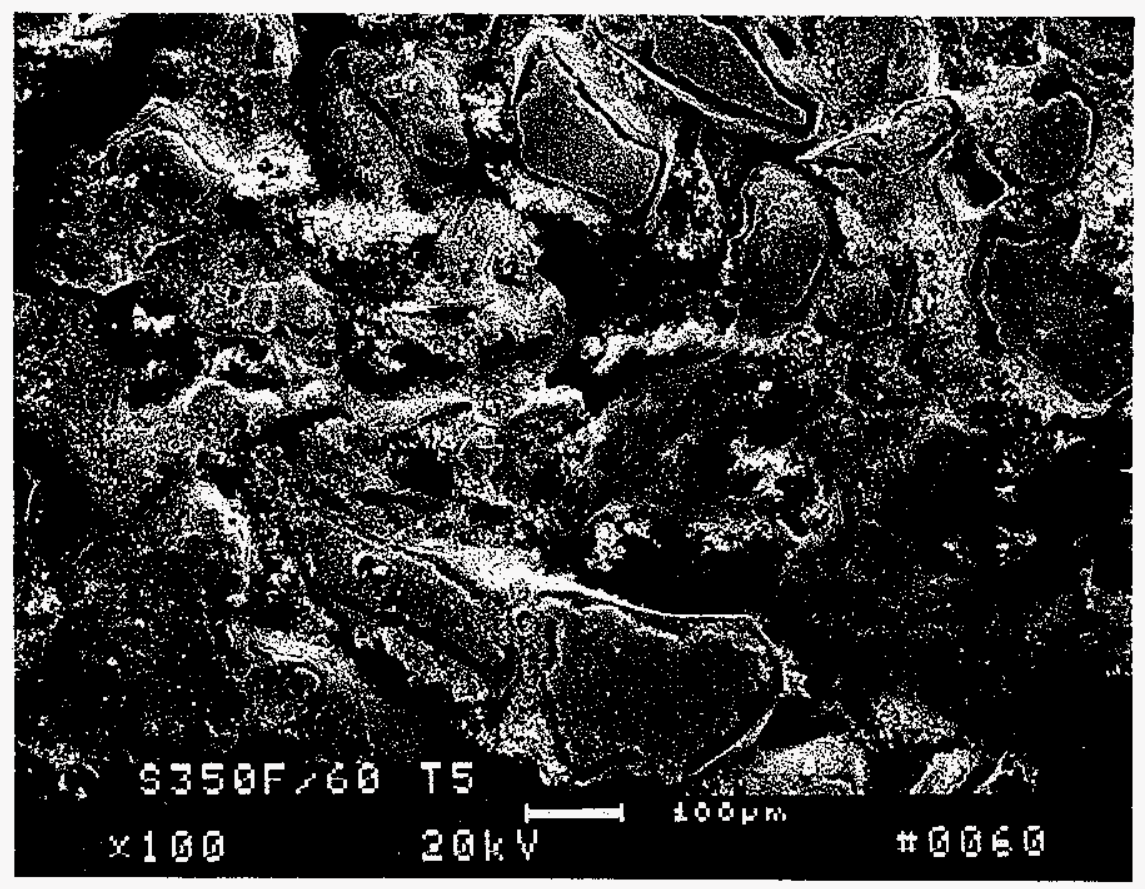

Figure 3-78 - Edge abrasion of the silicon carbide grains along the i.d. or pulse cycled surface of the PCFBC-exposed/extended life-tested Schumacher Dia Schumalith FT20 filter matrix. 


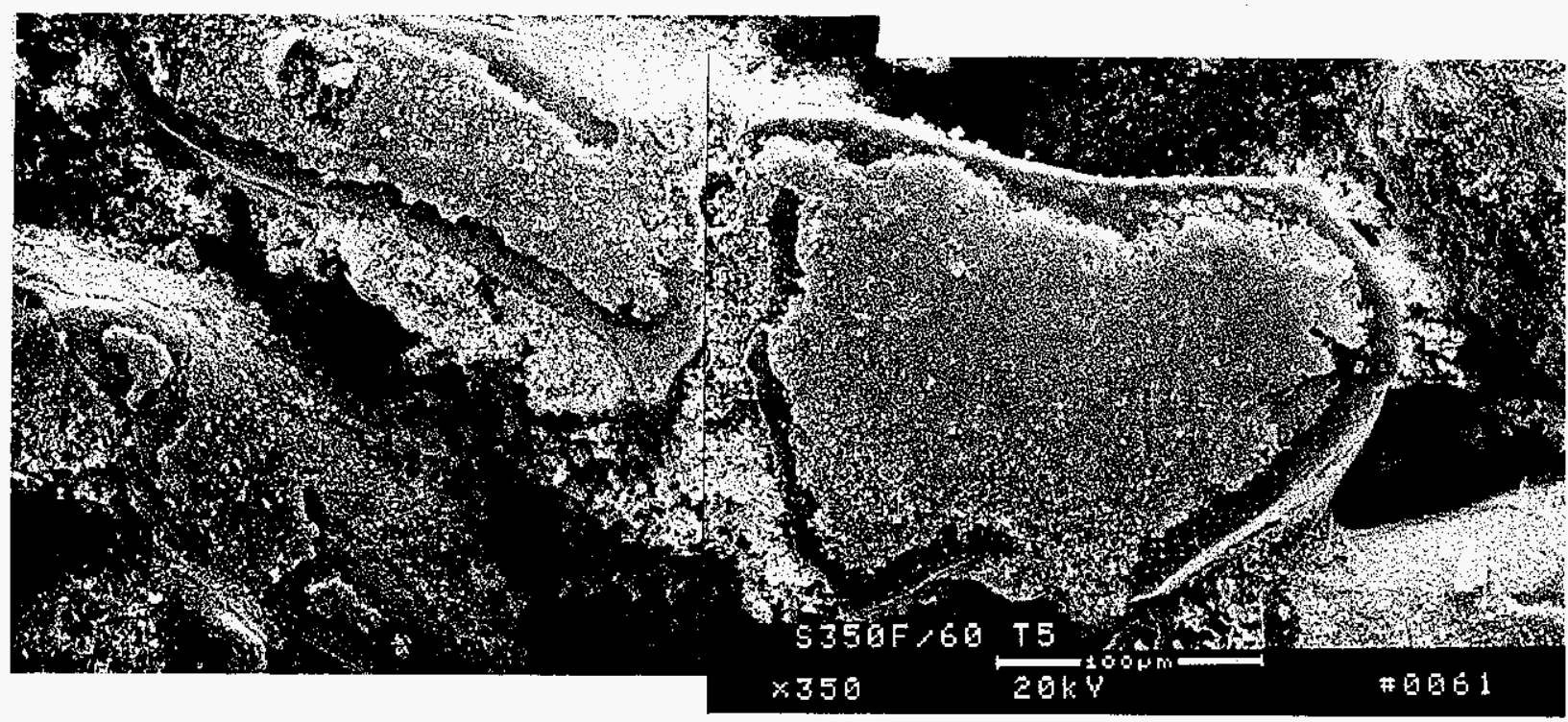

Figure 3-79 - Higher magnification micrograph montage illustrating abrasion along the periphery of the silicon carbide grains resulting from extended pulse cycling along the i.d. or pulse cycled surface of the PCFBC-exposed/extended life-tested Schumacher Dia Schumalith FT20 filter matrix. 


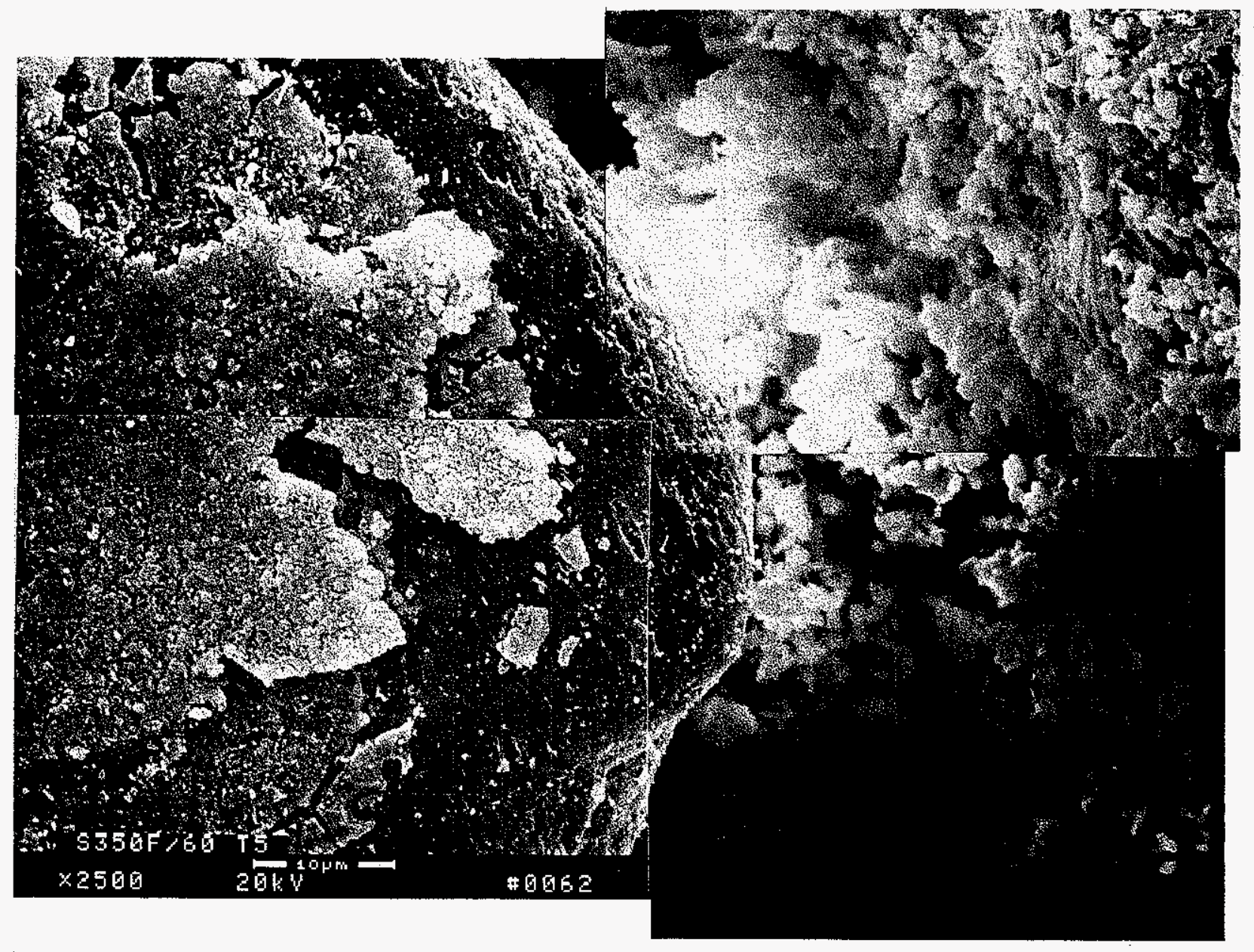

Figure 3-80 - Higher magnification micrograph montage illustrating the various binder and oxide-containing layers that remained along the outer surface of the silicon carbide grains that were present along the i.d. surface of the filter element. 

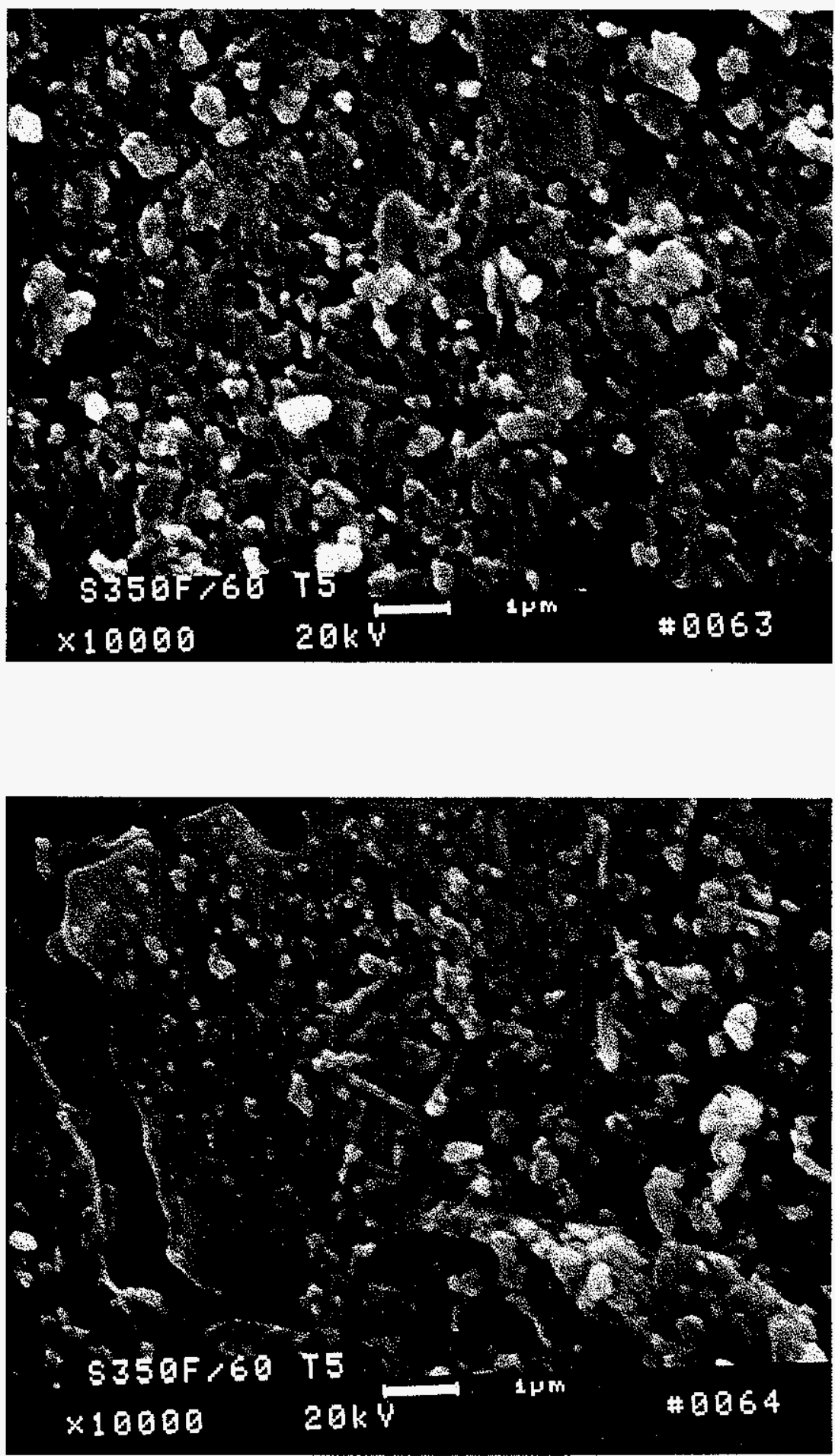

Figure 3-81 - Silica-enriched layer that remained along the abraded edges of the silicon carbide grains that were present along the i.d. or pulse cycled surface of the PCFBCexposed/extended life-tested Schumacher Dia Schumalith FT20 filter matrix. 


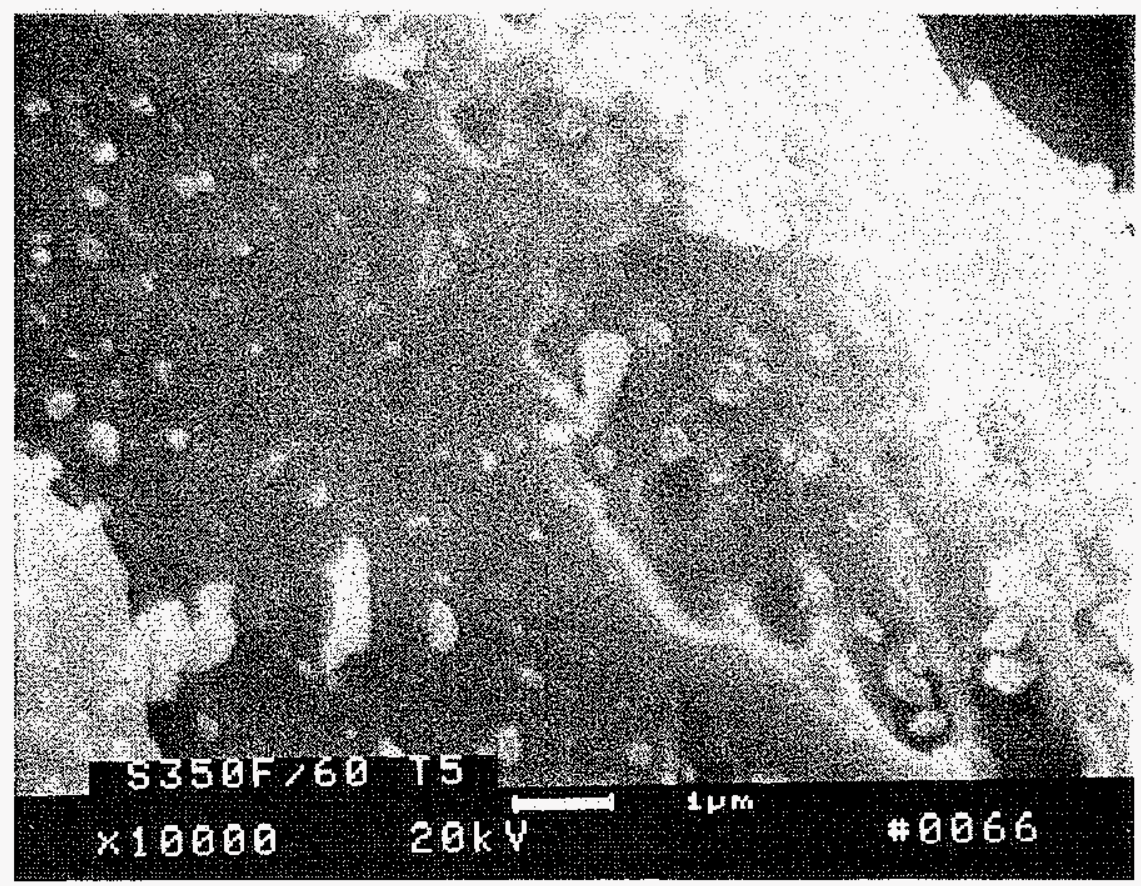

Figure 3-82 - Higher magnification micrograph illustrating the morphology of the exposed and mottled silicon carbide grains as a result edge abrasion after extended pulse cycling of the Schumacher Dia Schumalith FT20 filter matrix. 


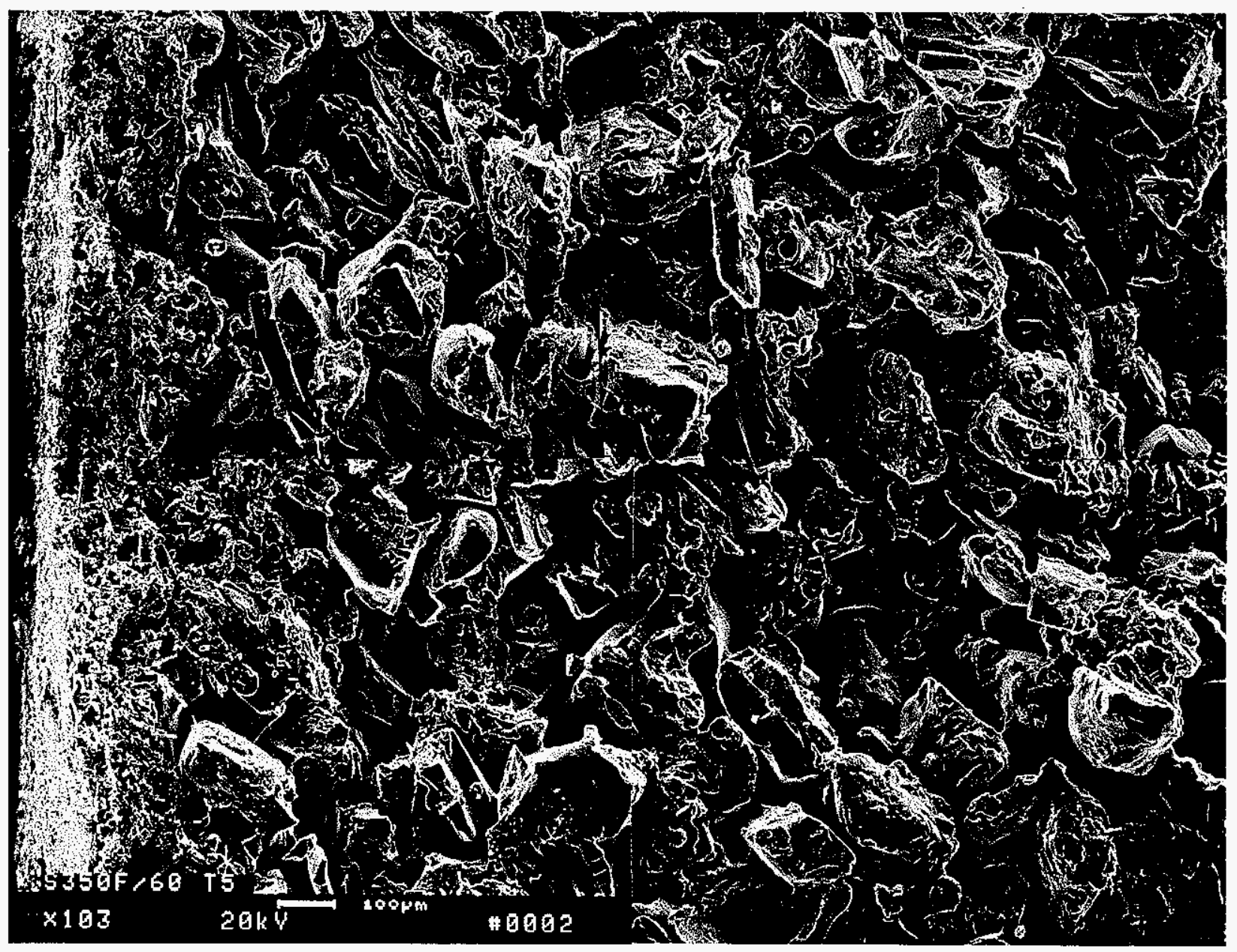

Figure 3-83 - Negligible penetration of fines resulted within the interior of the PCFBCexposed/extended life-tested Schumacher Dia Schumalith FT20 filter matrix. 


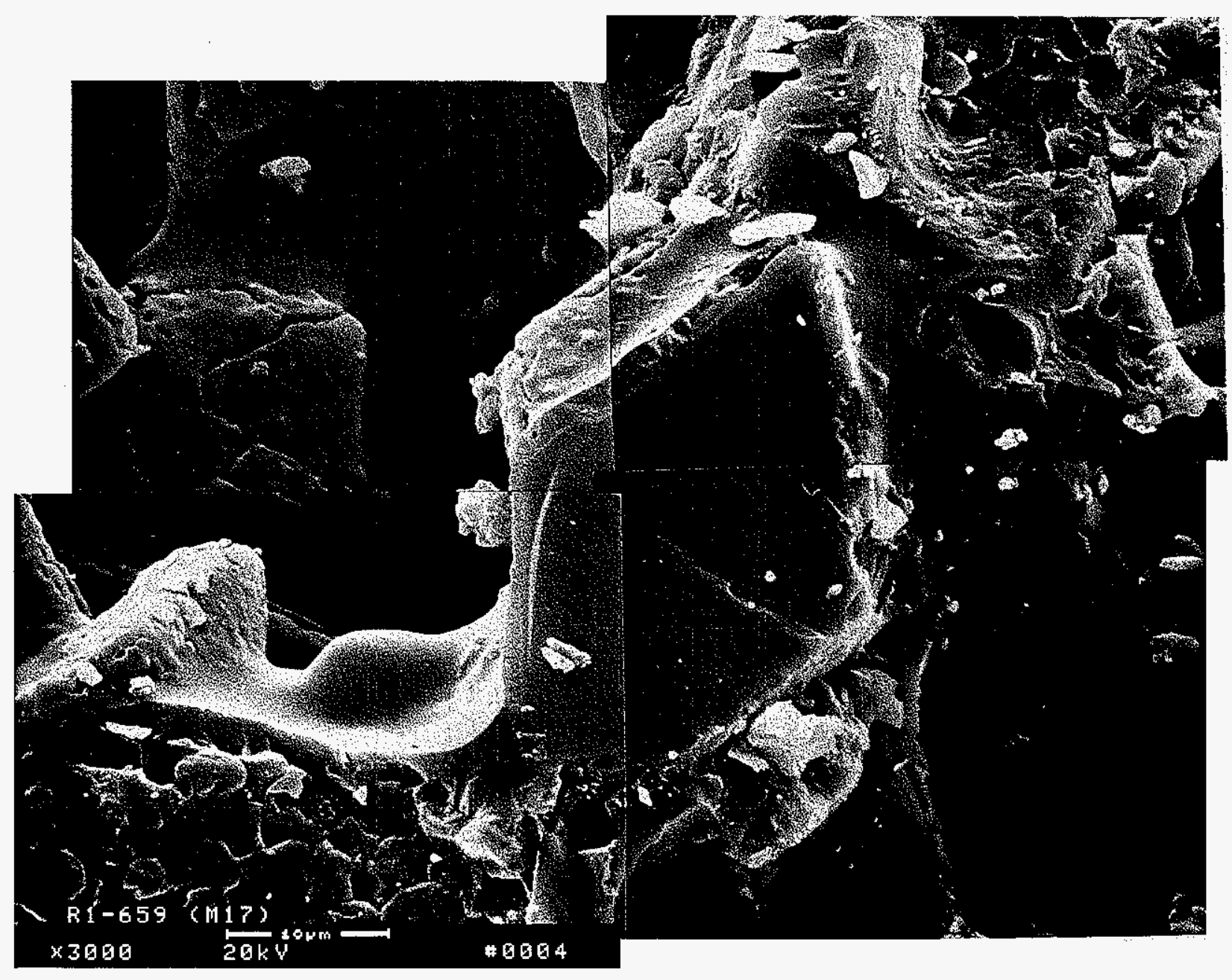

Figure 3-84 - Micrograph montage illustrating the thickness of the melt-like encapsulating layer that surrounded the silicon carbide grains in the outer membrane of the PCFBCexposed/extended life-tested Pall 326 filter element. 

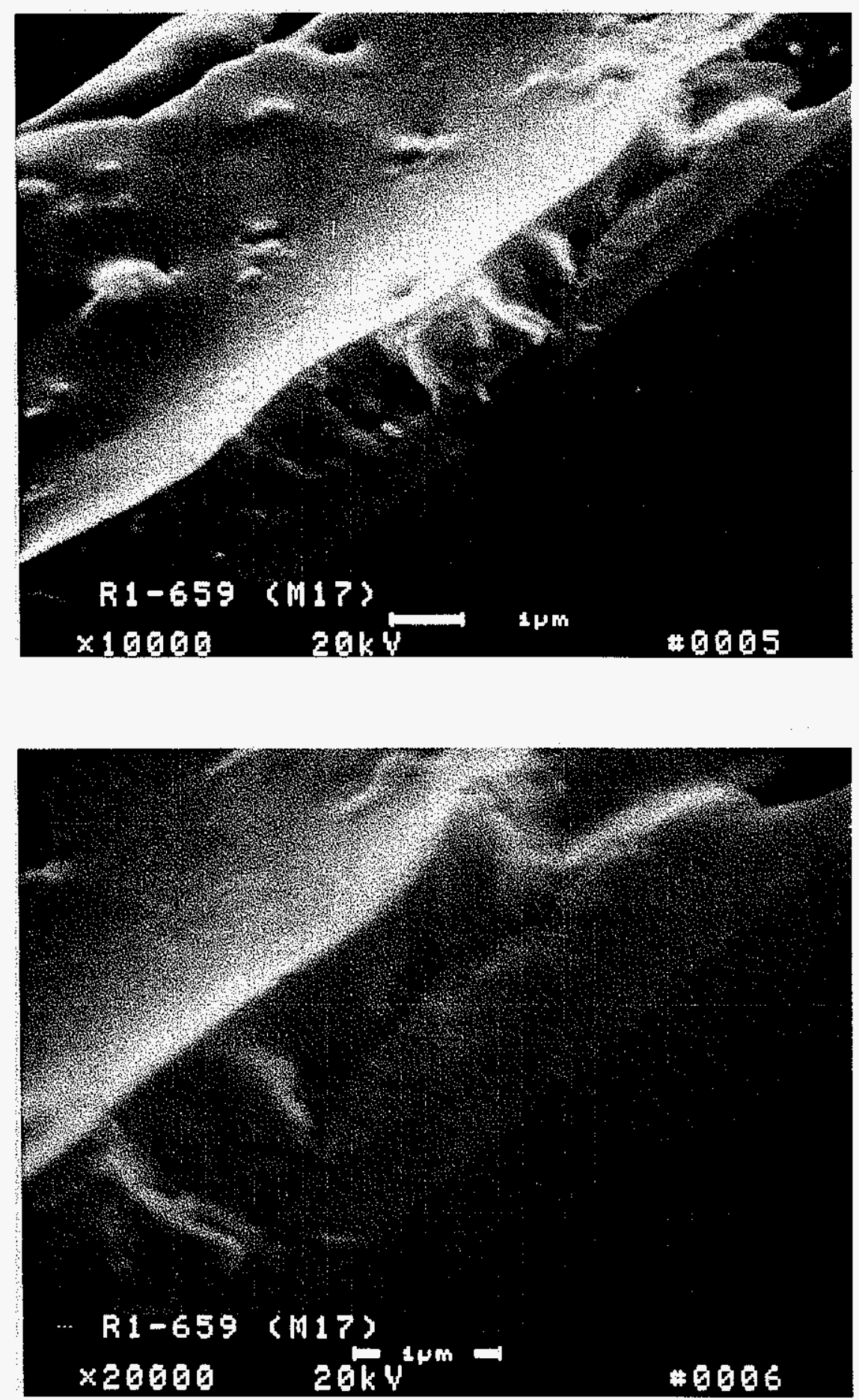

Figure 3-85 - Higher magnification micrographs illustrating the thickness of the melt-like encapsulating layer that surrounded the silicon carbide grains in the outer membrane of the PCFBC-exposed/extended life-tested Pall 326 filter element. 


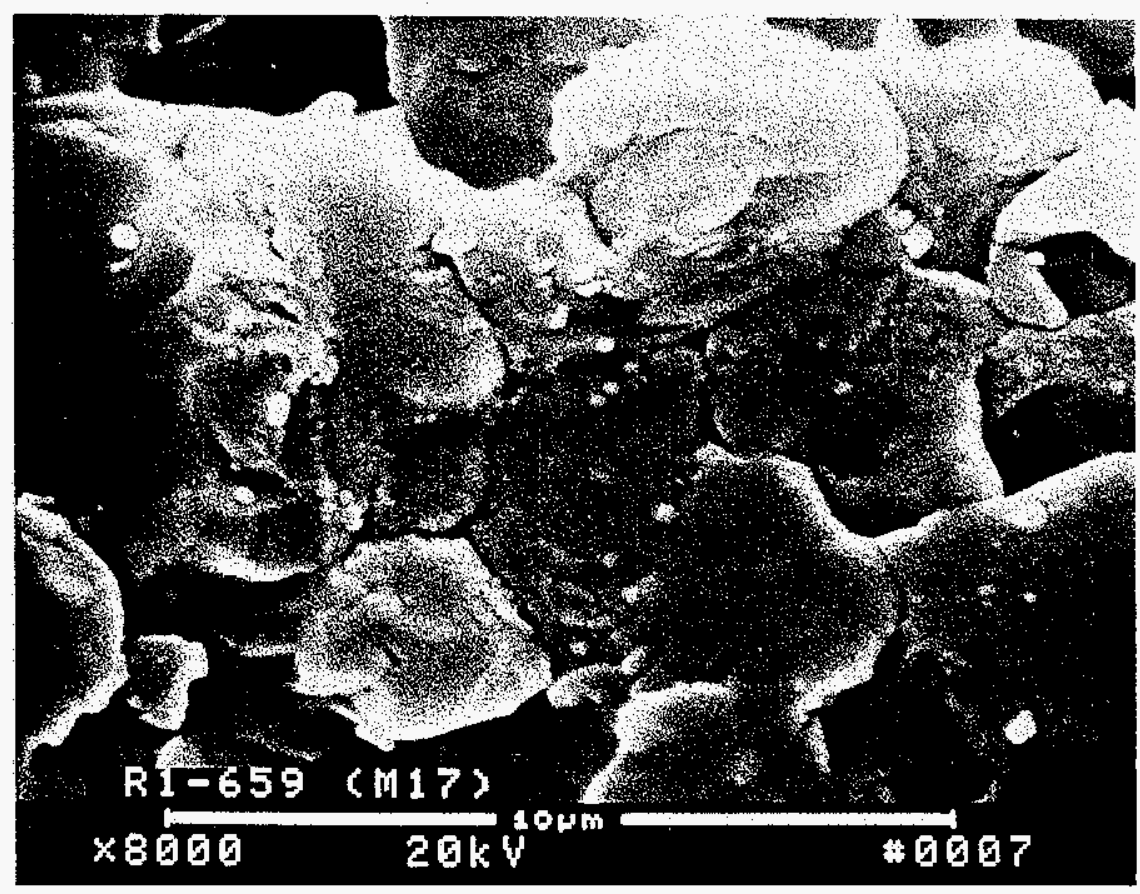

Figure 3-86 - High magnification micrograph illustrating the morphology of the plate-like hexagonal crystals that formed at the base of the binder ligaments or bond posts within the PCFBC-exposed/extended life-tested Pall 326 filter element. 


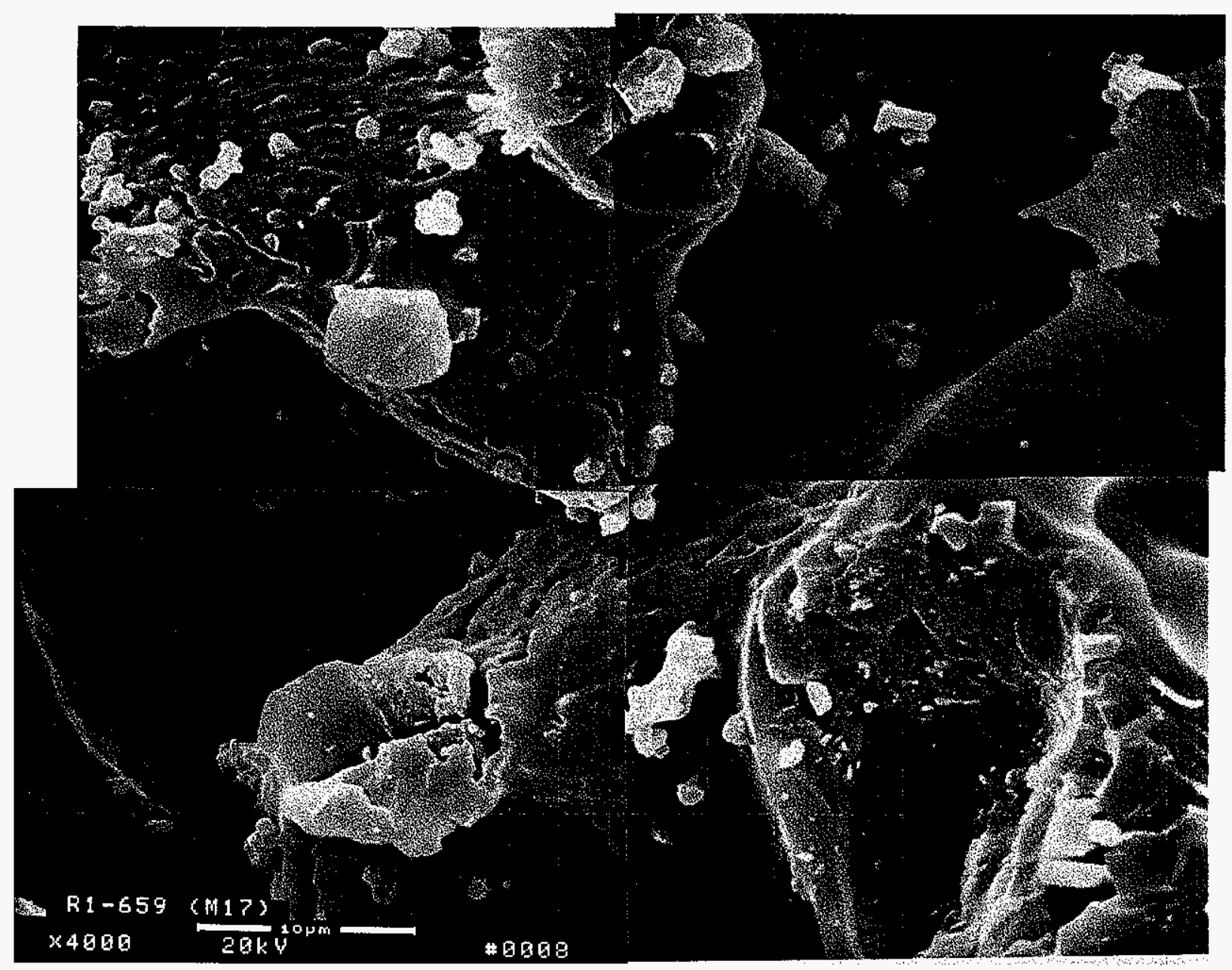

Figure 3-87 - Micrograph montage illustrating the melt-like layer that encapsulated the silicon carbide grains in the PCFBC-exposed/extended life-tested Pall 326 filter element. Separation cracks were frequently evident along the surface of the encapsulating shell. 


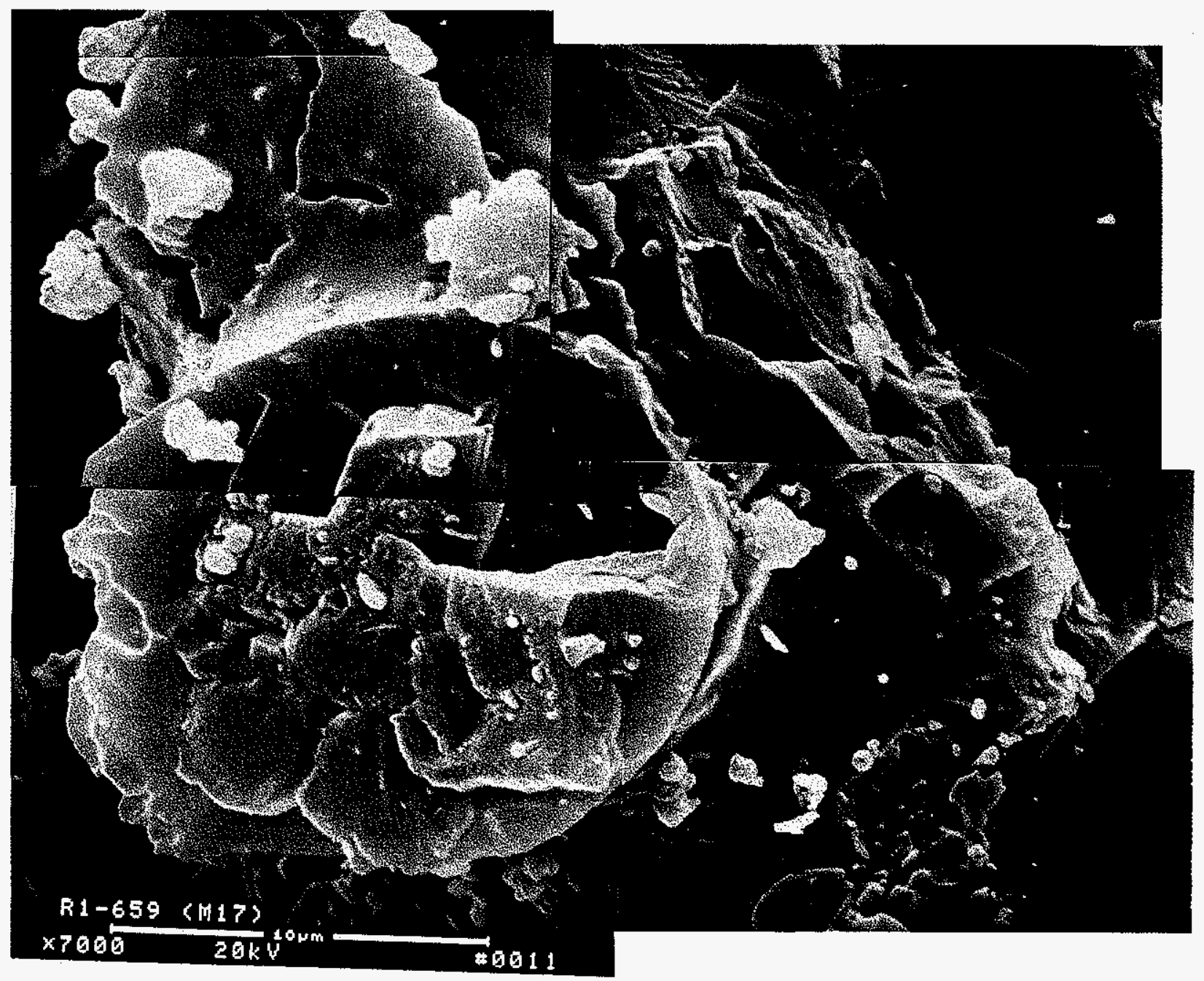

Figure 3-88 - Micrograph montage illustrating the plate-like hexagonal crystals, and melt-like features that contained separation cracks along the surface of the silicon carbide grains that were present within the outer surface membrane of the PCFBCexposed/extended life-tested Pall 326 filter element. 


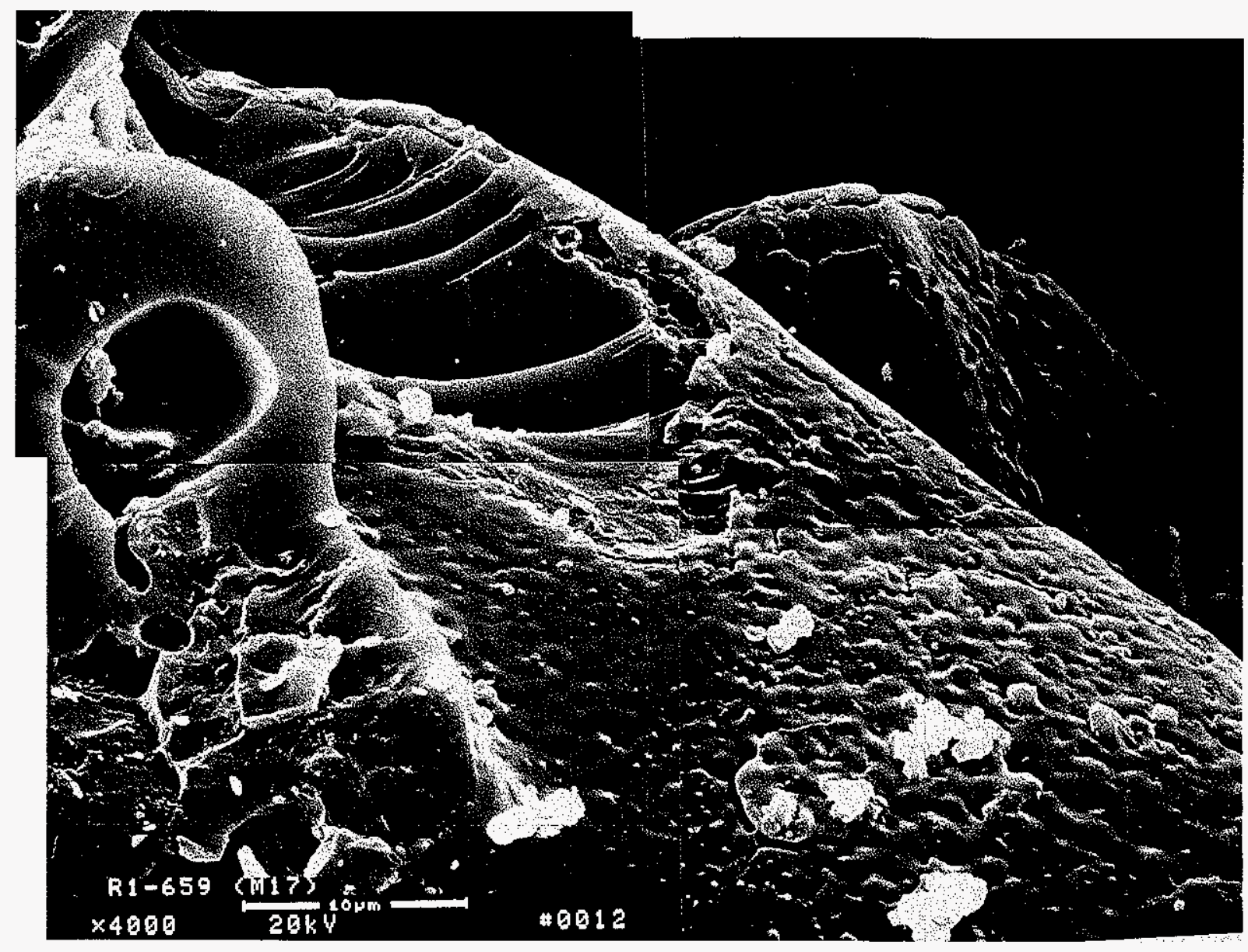

Figure 3-89 - High magnification micrograph montage illustrating the melt-like appearance of the encapsulating layer that surrounded the structural support silicon carbide grains in the PCFBC-exposed/extended life-tested Pall 326 filter element. Rounding of the crystalline features and separation cracks were observed within the encapsulating shell. 
again the outer encapsulating layer that surrounded the silicon carbide grain appeared to contain of a meltlike phase. The melt-like phase tended to cause 'rounding' of the crystalline features that typically resulted along the surface of the binder/oxide-containing shell. Separation cracks were also evident along the surface of the encapsulating melt-like layer.

In addition to the melt-like phase that encapsulated the silicon carbide grains, extensive crystallization resulted along the surface and throughout the binder/oxide-containing layer that encapsulated the silicon carbide grains in the PCFBC-exposed/extended life-tested Pall 326 filter matrix. Segregated areas of aluminosilicate-enriched rods (Figure 3-90), and nodular silica-enriched areas which contained cracks (Figure 3-91), were identified along the binder/oxide-containing encapsulating shell. Aluminosilicate rods, fine grain growth and phase separation between adjacent aluminosilicate rods, and crack formations were also clearly identified along the outer encapsulating binder/oxide-containing shell (Figure 3-92).

Extensive crystallization resulted along the surface and throughout the binder ligaments or bond posts that were contained in the PCFBC-exposed/extended life-tested Pall 326 filter matrix (Figures 3-93 through 3-96). Approximately 4-6 $\mu \mathrm{m}$ silica-enriched grains formed within the PCFBC-exposed/ extended life-tested Pall 326 filter matrix at the interface between the binder/oxide-containing encapsulating shell and the silicon grain, and similarly at the interface of the binder ligaments and the silicon carbide grains. When fresh fractured, the hexagonal silica-enriched grains were seen as a platelike layer along the surface of the fractured ligaments. The exposed surface of the silicon carbide grains contained depressions which reflected the hexagonal crystalline growth of the removed silica-enriched grains that had been formed at the base of the ligaments (Figures 3-97 and 3-98). As a result of fresh fracturing the PCFBC-exposed/extended life-tested Pall 326 filter matrix, variations could be seen in the thickness of the binder/oxide-containing encapsulating layer (Figures 3-99 and 3-100).

In several areas of the PCFBC-exposed/extended life-tested Pall 326 filter matrix, strand-like features appeared to extend from the surface of the binder/oxide-containing encapsulating shell (Figure 3101). When viewed at higher magnification, the silicon, oxygen, and aluminum-enriched phase was seen to extend $\sim 10 \mu \mathrm{m}$ into the pore cavities of the Pall 326 filter matrix. The area of the crystallized binder/oxide-containing encapsulating layer adjacent to the extended rod formation was identified by EDAX analysis to principally contain silicon, aluminum, and oxygen, with minor concentrations of a rare earth element.

Although changes within the microstructure of the Pall 326 filter matrix continued to occur with extended operation under simulated PFBC test conditions, the matrix, in general, appeared to remain intact, preventing negligible penetration of ash fines into the interior of the filter wall.

\subsubsection{Coors P-100A-1 Alumina/Mullite}

The Coors P-100A-1 alumina/mullite candle filter designated as FC044 (M12) had initially been exposed for 2166 hours at the Foster Wheeler PCFBC test facility in Karhula, Finland. The element was subsequently returned to SWPC STC, and was subjected to 20,089 accelerated pulse cleaning cycles under simulated PFBC conditions. As a result, the element had acquired 12,211 hours of equivalent operating life, and was intact at the conclusion of the 1998 extended filter life test program. Post-test characterization of the aged element's microstructure was conducted via SEM/EDAX analysis. 


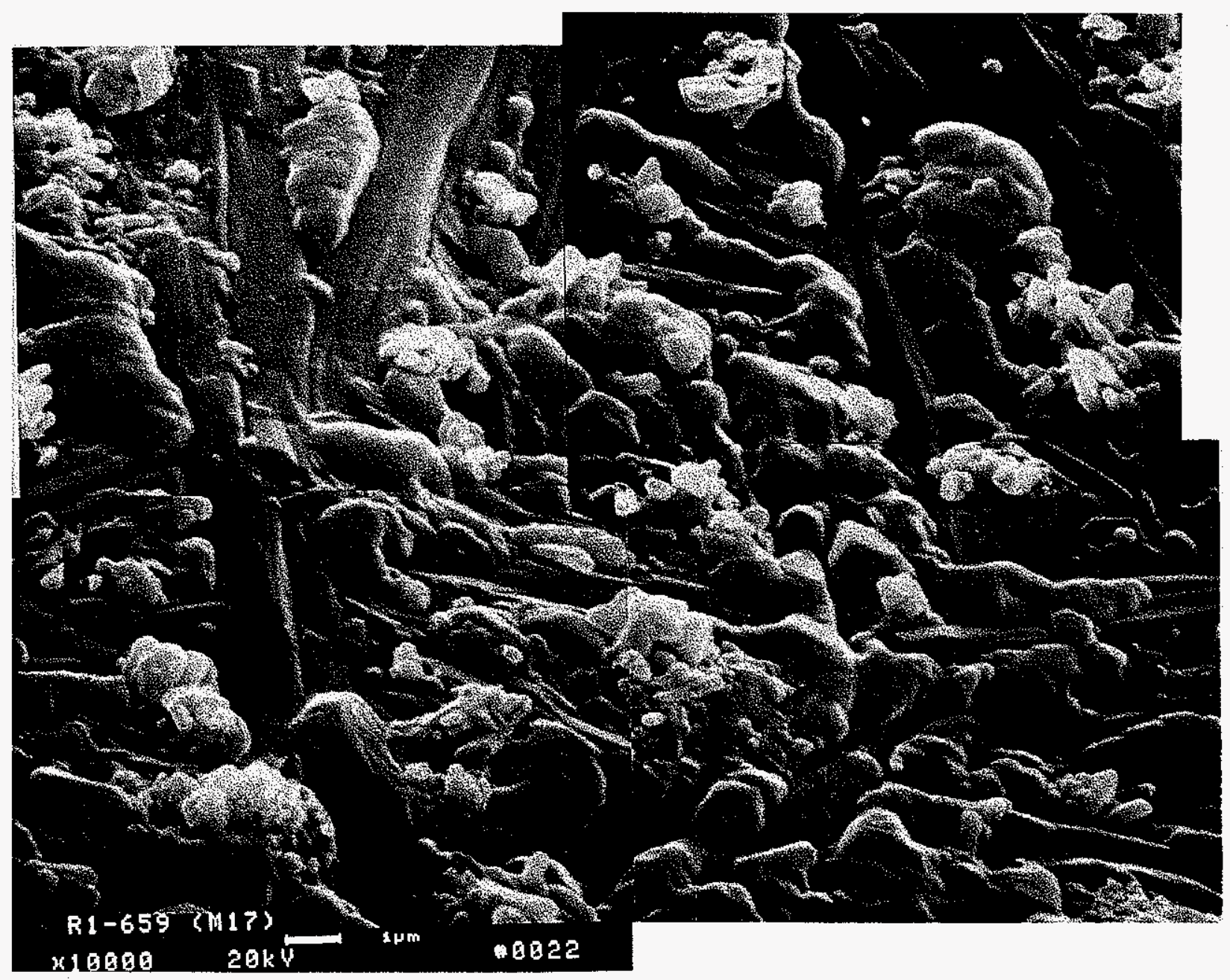

Figure 3-90 - High magnification micrograph montage illustrating the formation of the aluminosilicate rod-like features that formed along the outer surface of the binder/oxide-enriched encapsulating layer that surrounded the silicon carbide grains in the PCFBC-exposed/extended life-tested Pall 326 filter matrix. 


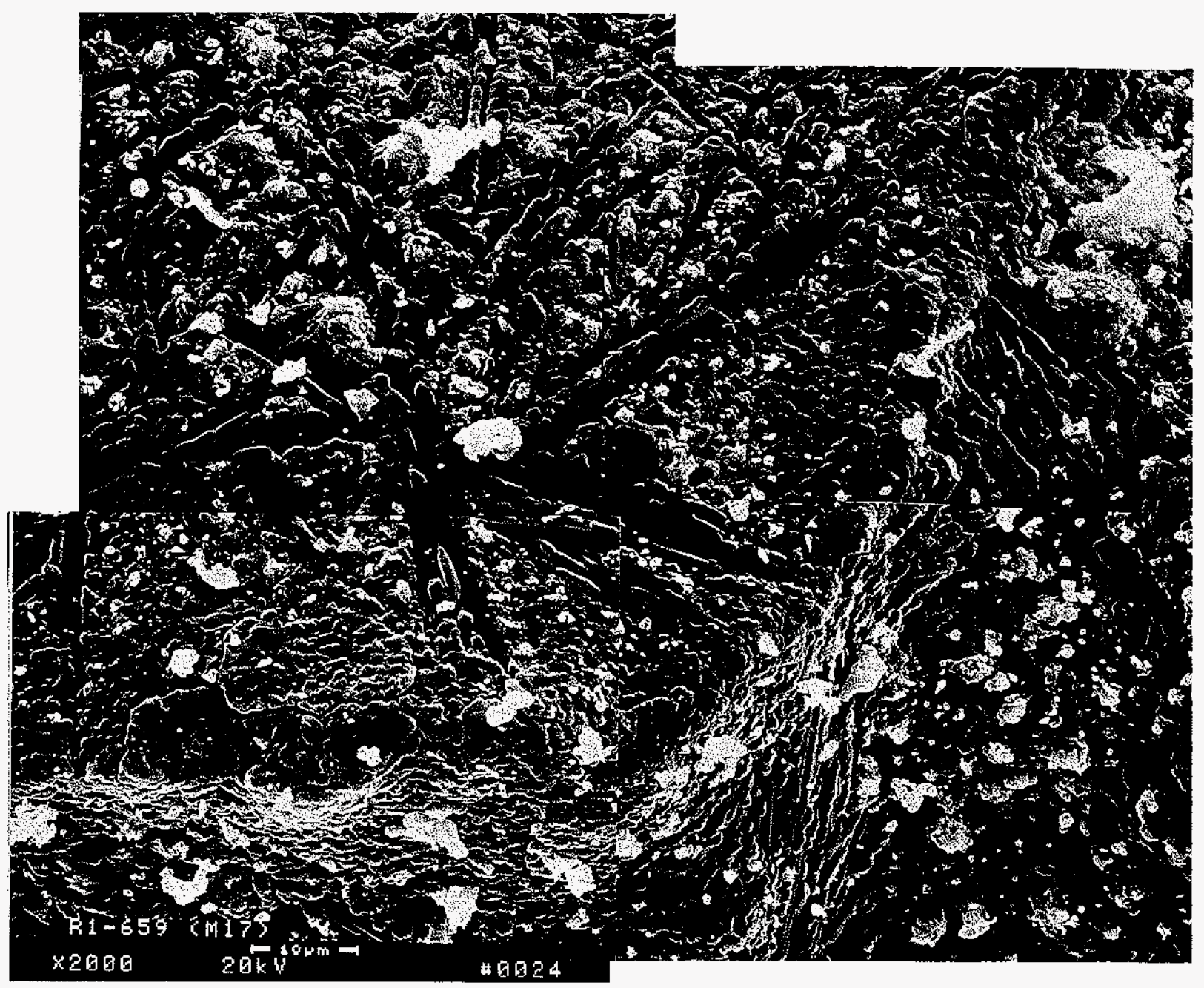

Figure 3-91 - Micrograph montage illustrating extensive crystallization along the surface of the binder/oxide-containing layer that encapsulated the outer surface of the silicon carbide grains along the mid-section of the PCFBC-exposed/extended life-tested Pall 326 filter matrix. 


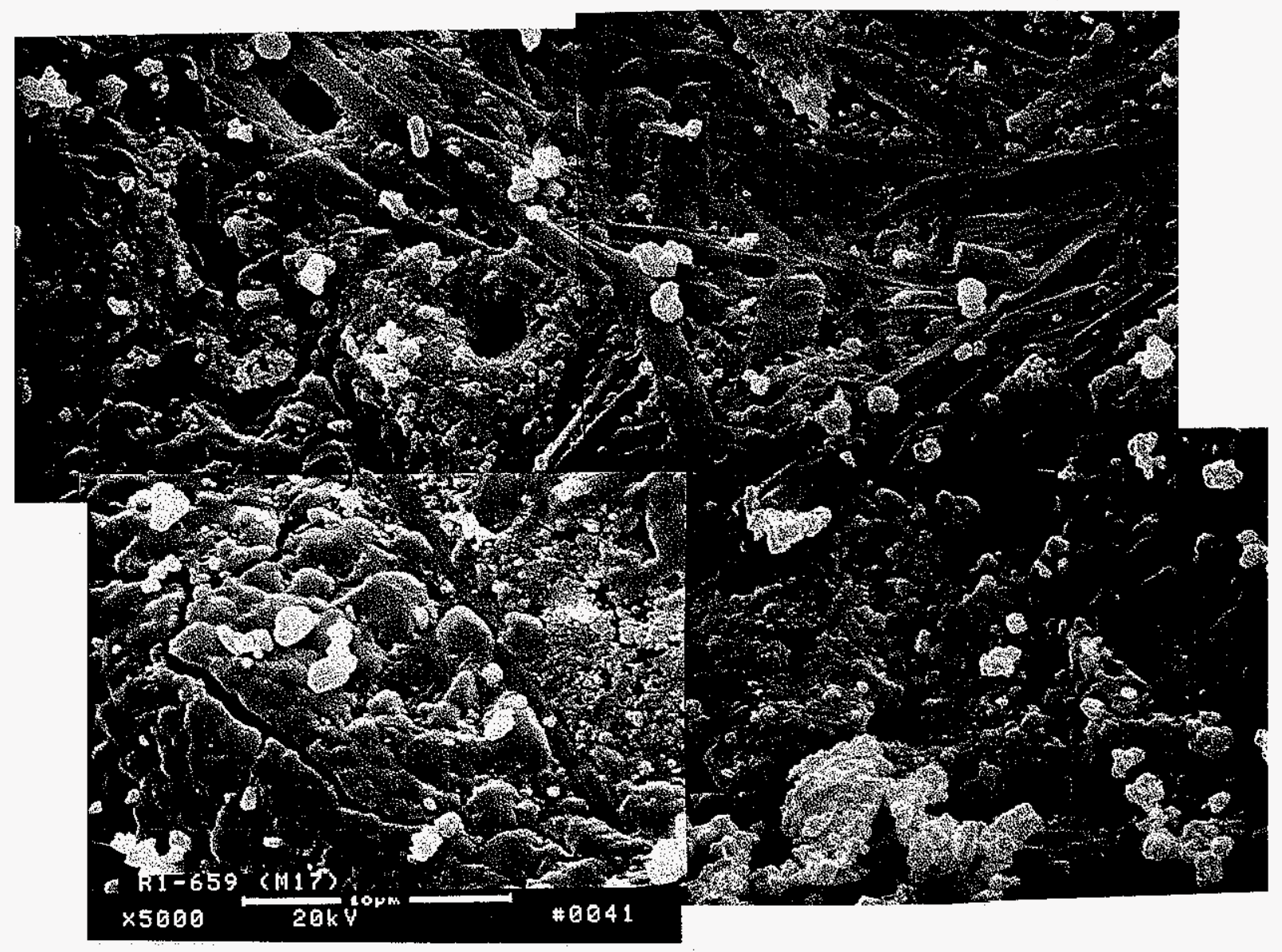

Figure 3-92 - Micrograph montage illustrating segregation of the aluminosilicate-enriched and silica-enriched areas along the outer surface of the encapsulating binder/oxidecontaining shell that surrounded the silicon carbide grains that were present along the pulse cycled surface of the PCFBC-exposed/extended life-tested Pall 326 filter matrix. 


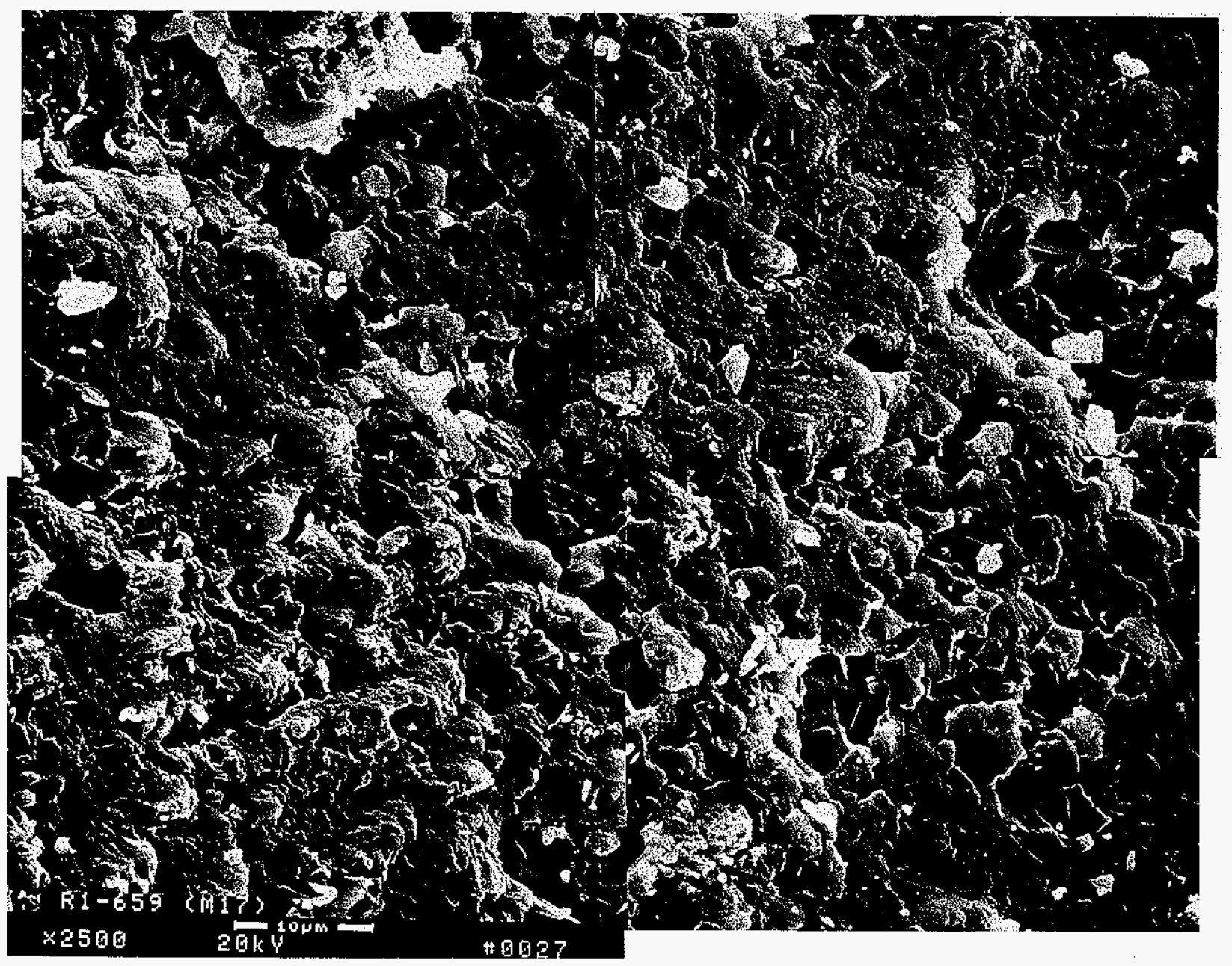

Figure 3-93 - High magnification micrograph montage illustrating the crystalline features of the silica-enriched, binder-containing, fractured ligament or bond post that remained along the surface of the silicon carbide grain. 


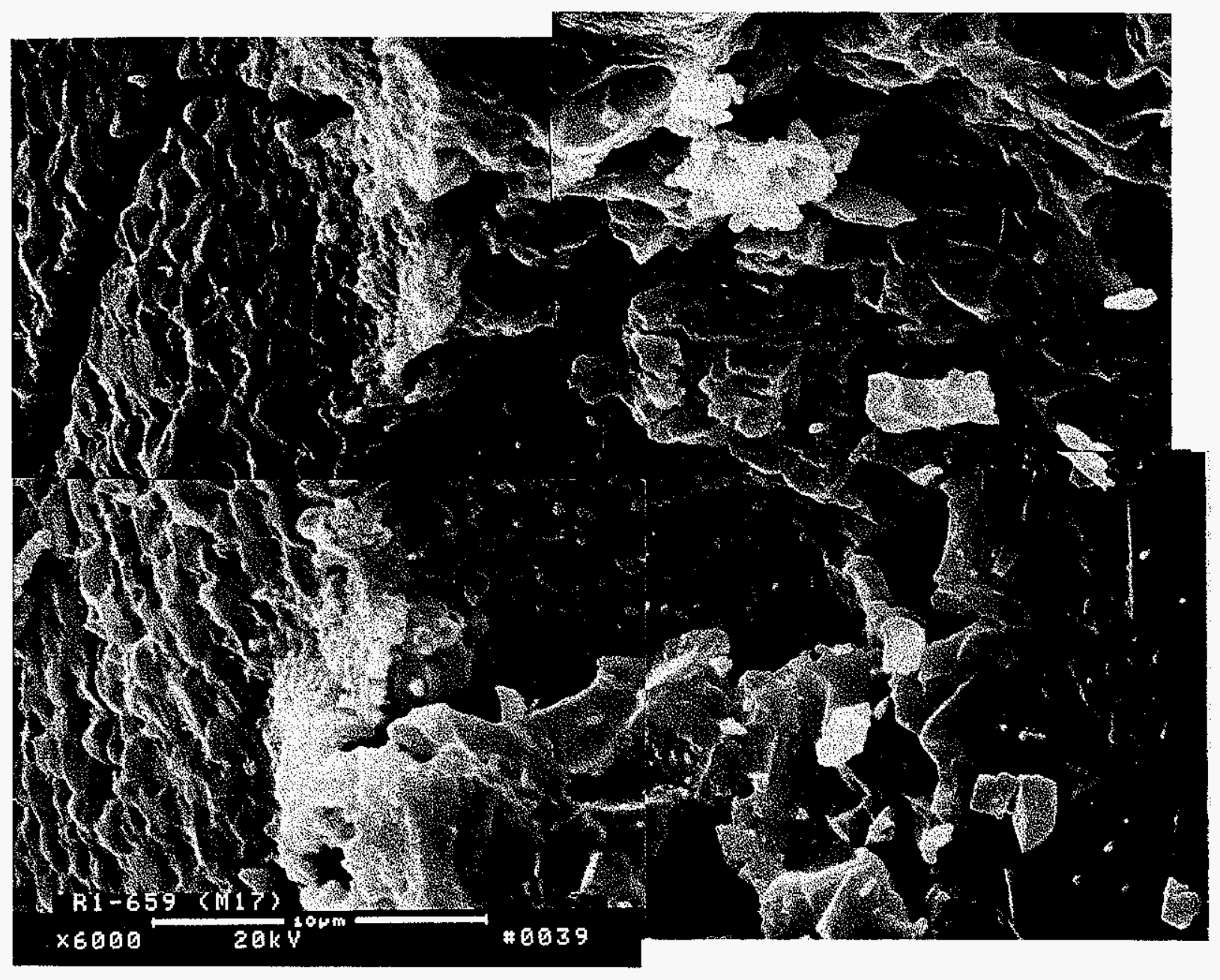

Figure 3-94 - High magnification micrograph montage illustrating the extensive crystallization that resulted along the surface, as well as throughout the binder ligaments along the pulse cycled surface of the PCFBC-exposed/extended life-tested Pall 326 filter element. 


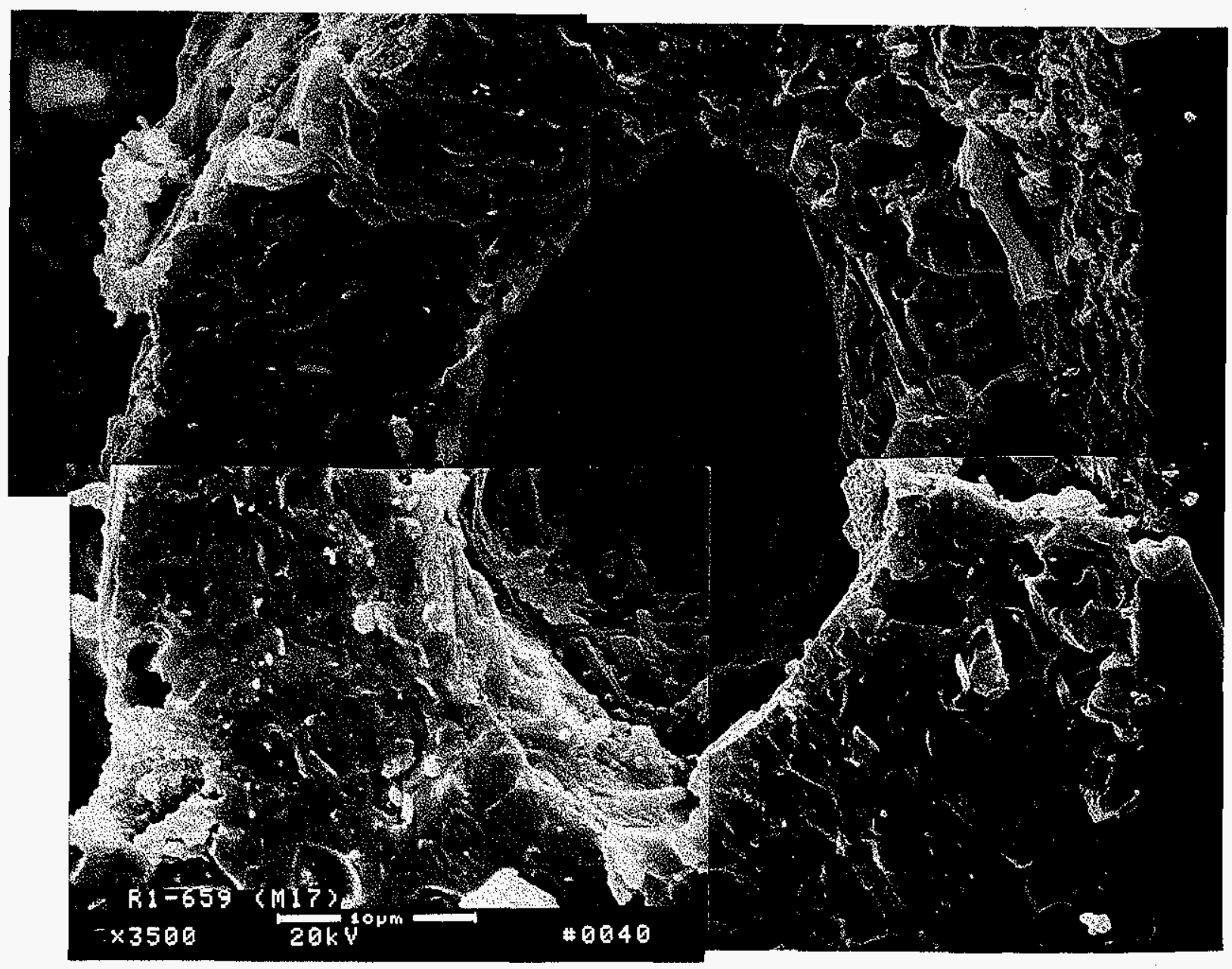

Figure 3-95 - High magnification micrograph montage illustrating extensive crystallization throughout the binder ligament, as well as crystallization at the interface of the binder ligament and silicon carbide grains that were present along the pulse cycled surface of the PCFBC-exposed/extended life-tested Pall 326 filter matrix. 


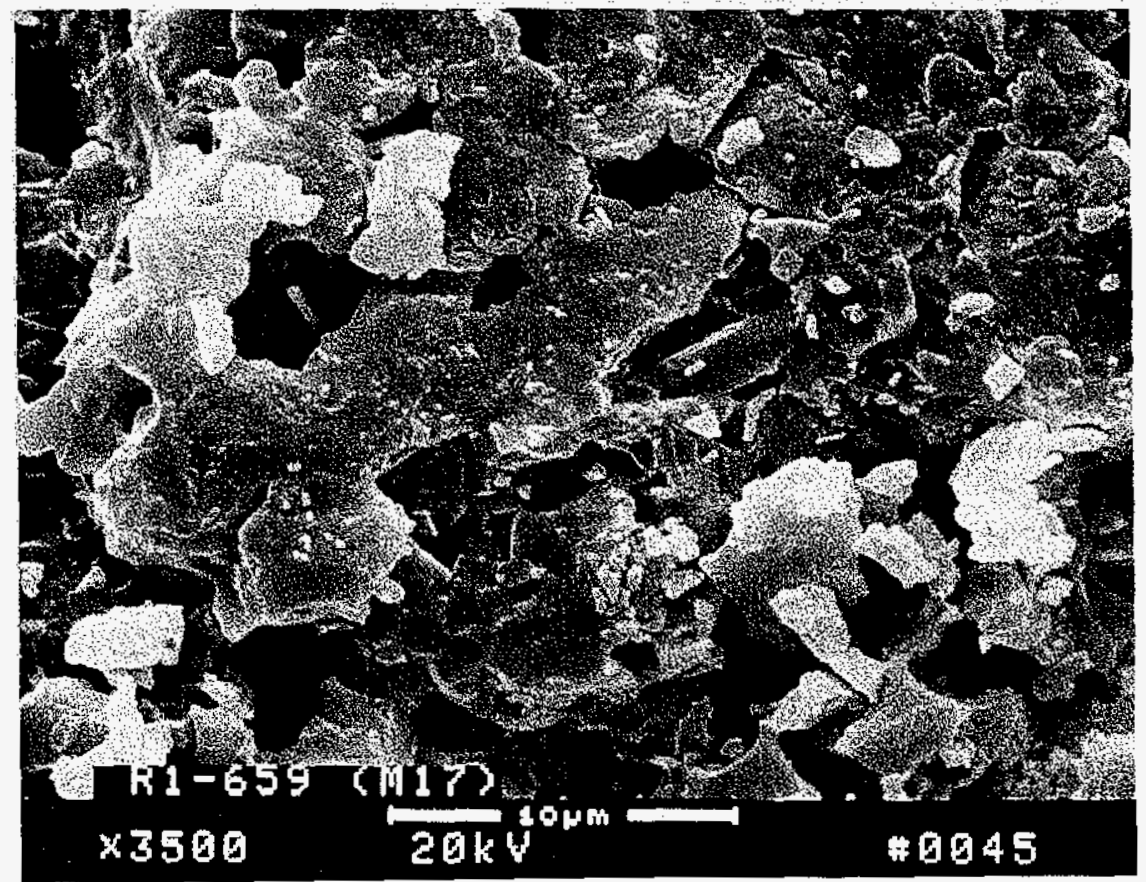

Figure 3-96 - High magnification micrograph illustrating the crystalline features of the silicaenriched grain formation that resulted at the base of the binder-containing ligaments along the pulse cycled surface of the PCFBC-exposed/extended life-tested Pall 326 filter element. 


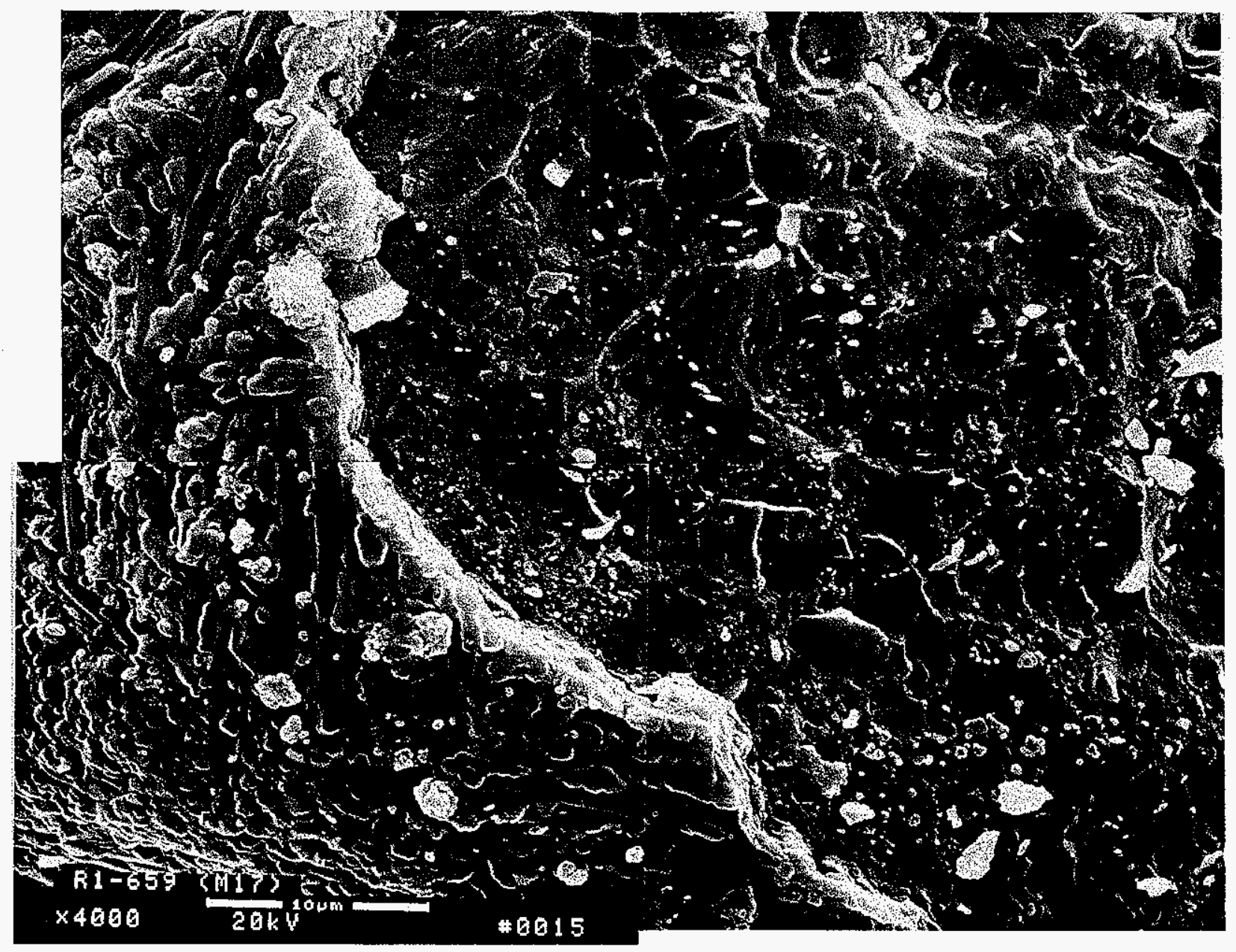

Figure 3-97 - High magnification micrograph montage identifying the extensive crystallization that resulted along the binder/oxide coating that encapsulated the silicon carbide grains in the PCFBC-exposed/extended life-tested Pall 326 filter matrix. The mottled surface of the exposed silicon carbide grain was evident after fresh fracturing the filter matrix which removed the binder ligament and the in-situ formed silica-enriched phase. 


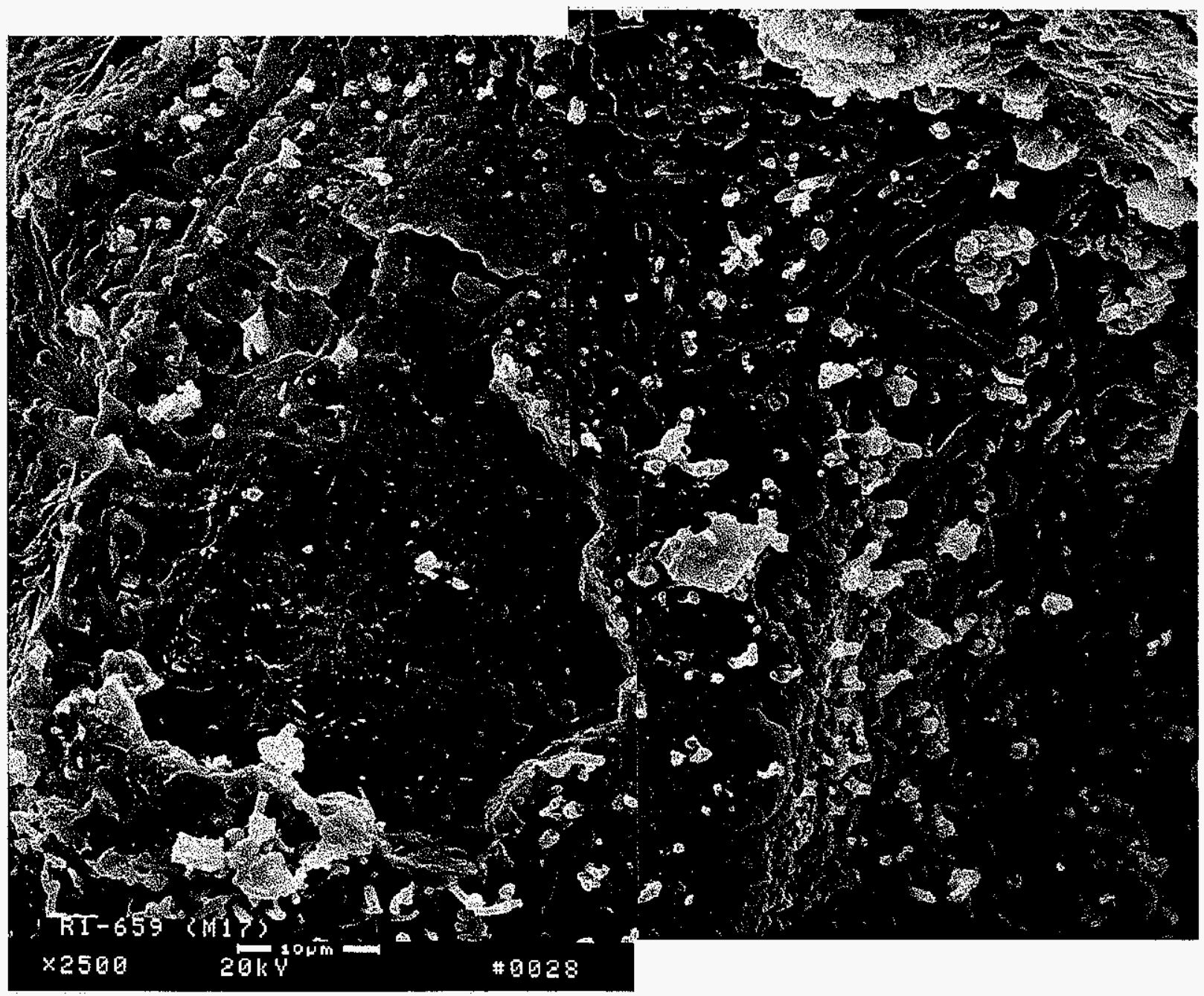

Figure 3-98 - High magnification micrograph montage illustrating extensive crystallization of the binder/oxide-enriched outer encapsulating shell that surrounded the silicon carbide grains in the PCFBC-exposed/extended life-tested Pall 326 filter matrix. Subsurface crystallization of the silica-enriched phase, and mottled surface of the silicon carbide grain were also evident. 


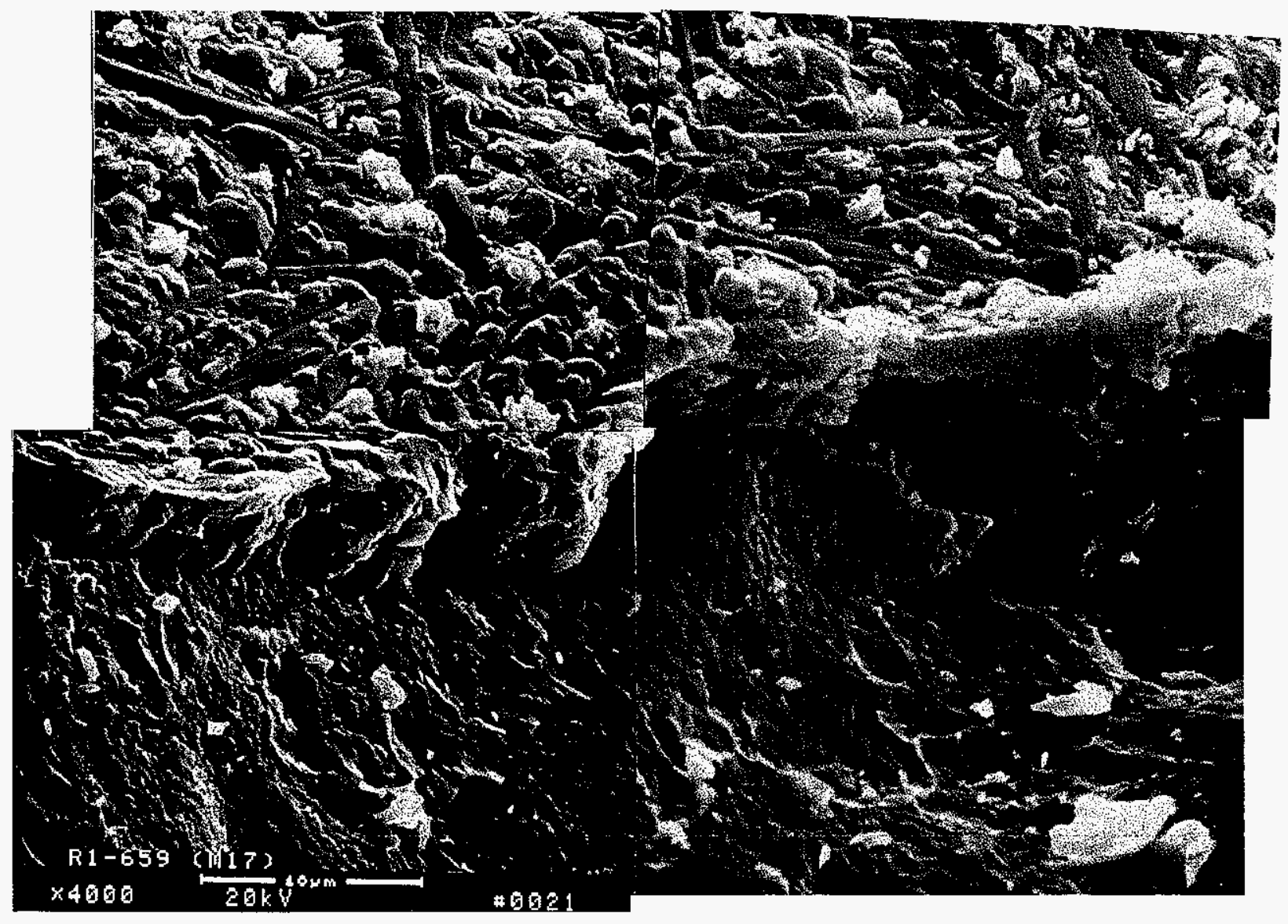

Figure 3-99 - High magnification micrograph montage illustrating the extensive crystallization of the binder/oxide coating and mottled surface of the underlying silicon carbide grains within the PCFBC-exposed/extended life-tested Pall 326 filter matrix. 


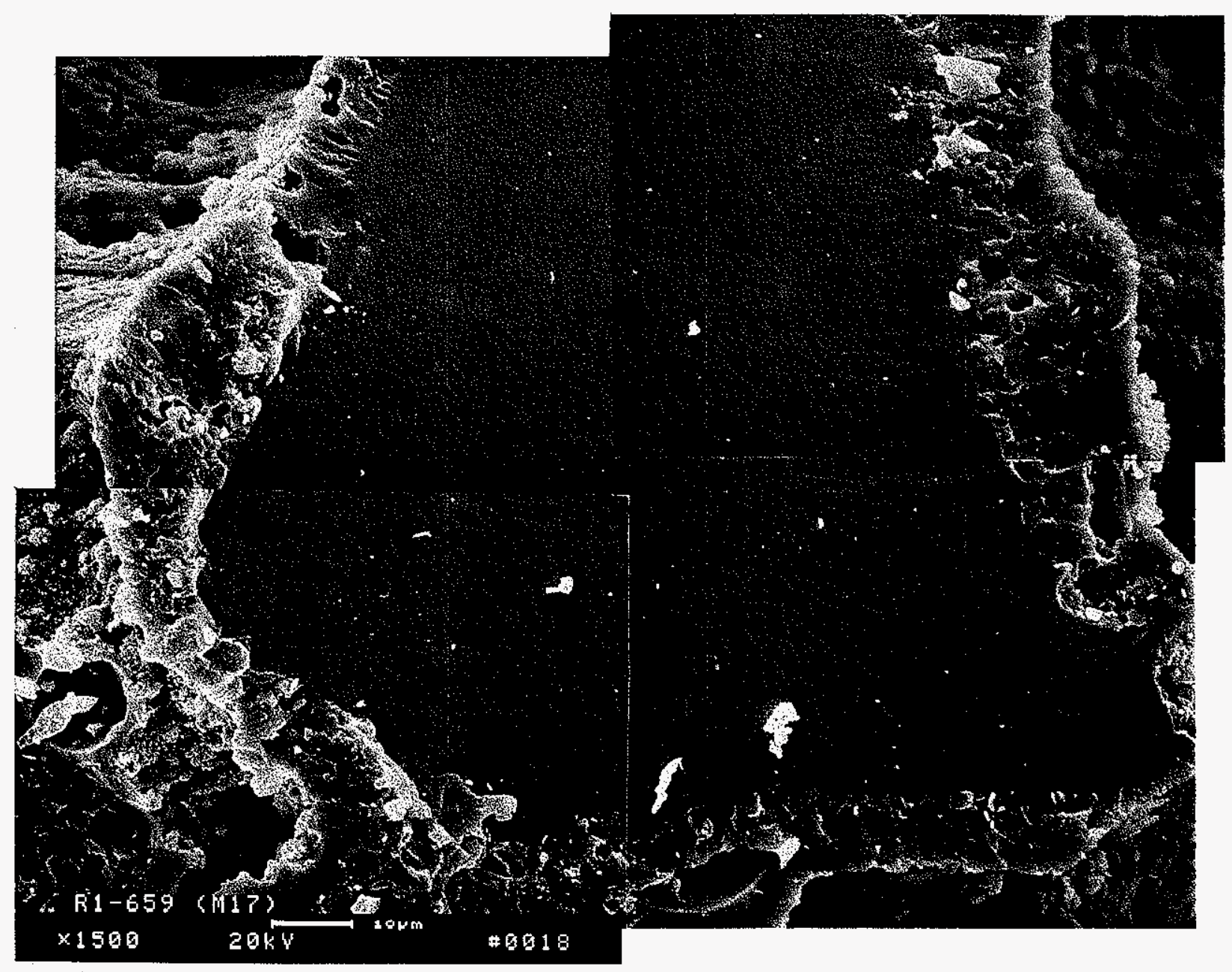

Figure 3-100 - Micrograph montage illustrating the extensive crystallization that resulted throughout binder/oxide coating that encapsulated the silicon carbide grains in the PCFBC-exposed/extended life-tested Pall 326 filter element. 


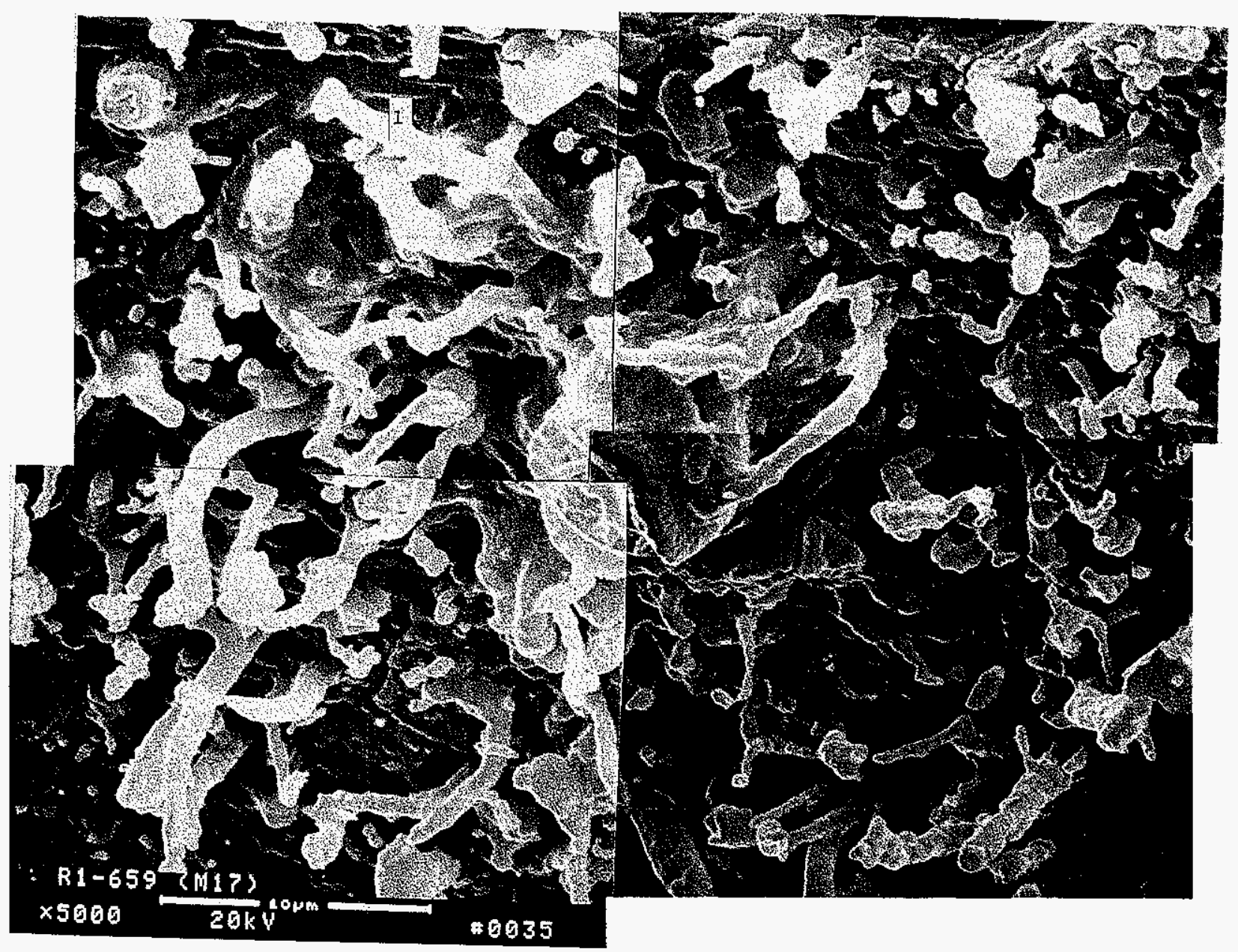

Figure 3-101 - Micrograph montage illustrating grain growth of an aluminosilicate-enriched phase along the surface of the binder/oxide-containing encapsulating layer within the PCFBC-exposed/extended life-tested Pall 326 filter matrix. 
Extended filter life testing of the PCFBC-aged Coors P-100A-1 alumina/mullite candle filters at SWPC STC identified the potential long-term viability of the monolithic oxide-based matrix under both steady state and thermal transient condition. Extensive crystallization resulted along the pore cavity walls, as well as throughout the ligaments of the material, similar to what had been identified after 3311 hours of PCFBC field service life (Section 2.5.3).

Residual ash fines were retained along the o.d. surface of the PCFBC-exposed/extended lifetested Coors P-100A-1 alumina/mullite filter element (Figures 3-102 and 3-103). Penetration of fines was restricted to the first pore layer of the non-membrane-coated, oxide-based material. Isolated fines were randomly seen to adhere to the pore cavity walls of the filter matrix at subsequent subsurface pore layers.

Extensive crystallization resulted along the pore cavity surfaces, as well as throughout the ligaments of the PCFBC-exposed/extended life-tested Coors P-100A-1 alumina/mullite filter matrix (Figures 3-104 through 3-108). After 12,211 hours of equivalent operating life, growth of the mullite, needle-like phase tended to be limited to the surface of the pore cavity walls, with negligible extension of the crystalline needles into the pore cavities (Figure 3-109).

Nearly spherical, $\sim 2-4 \mu \mathrm{m}$, crystalline features were typically observed at the tip of the aluminosilicate (i.e., mullite), needle-like rods that formed along the pore cavity walls near the i.d. or pulse cycled surface of the PCFBC-exposed/extended life-tested Coors P-100A-1 alumina/mullite filter element (Figures 3-110 through 3-113). As opposed to extension of the mullite rods into the pore cavities, blunting and coalescence of the needle growth resulted. EDAX analysis of the spherical crystalline features generally identified the presence of oxygen, aluminum, and silicon.

A residual dust cake layer was present along the i.d. or pulse cycled surface of the PCFBCexposed/extended filter life-tested Coors P-100A-1 alumina/mullite filter element. Penetration of ash into the first and second pore layers was observed. Limited deposition of fines resulted deeper within the filter matrix.

\subsubsection{McDermott CFCC}

Microstructural characterization was conducted on the McDermott oxide-based CFCC filter element identified as 75-29 (B32) which had been exposed for 581 hours at the Foster Wheeler PCFBC test facility in Karhula, Finland, and which subsequently experienced 10,045 hours of equivalent operating life and thirty simulated thermal transients in the PFBC simulator test facility in Pittsburgh, PA. Post-test characterization of the aged element's microstructure was conducted via scanning SEM/EDAX analysis.

Figures 3-114, 3-115, and 3-116, illustrate the morphology of the Nextel ${ }^{\mathrm{TM}} 610$ fibers that were present in the as-manufactured McDermott oxide-based CFCC filter matrix. Although crystallization within the Nextel ${ }^{\mathrm{TM}} 610$ fibers occurred throughout the McDermott oxide-based CFCC filter matrix after extended operation under simulated PFBC test conditions (Figures 3-117 through 3-126), the matrix, in general, appeared to remain intact, preventing negligible penetration of ash fines into the interior of the filter wall (Figure 3-127 and 3-128). Manufacturing improvements are, however, needed to mitigate removal of the external chopped Saffil fibers and alumina-containing mat from along both outer and inner surfaces of the filter element during service operation (Figures 3-129, 3-130, and 3-131). Continued extended operation under PCFBC or PFBC conditions is needed to demonstrate whether the original fracture toughness characteristics of the McDermott oxide-based CFCC filter matrix is retained once the material has undergone extensive crystallization, or if embrittlement results. 


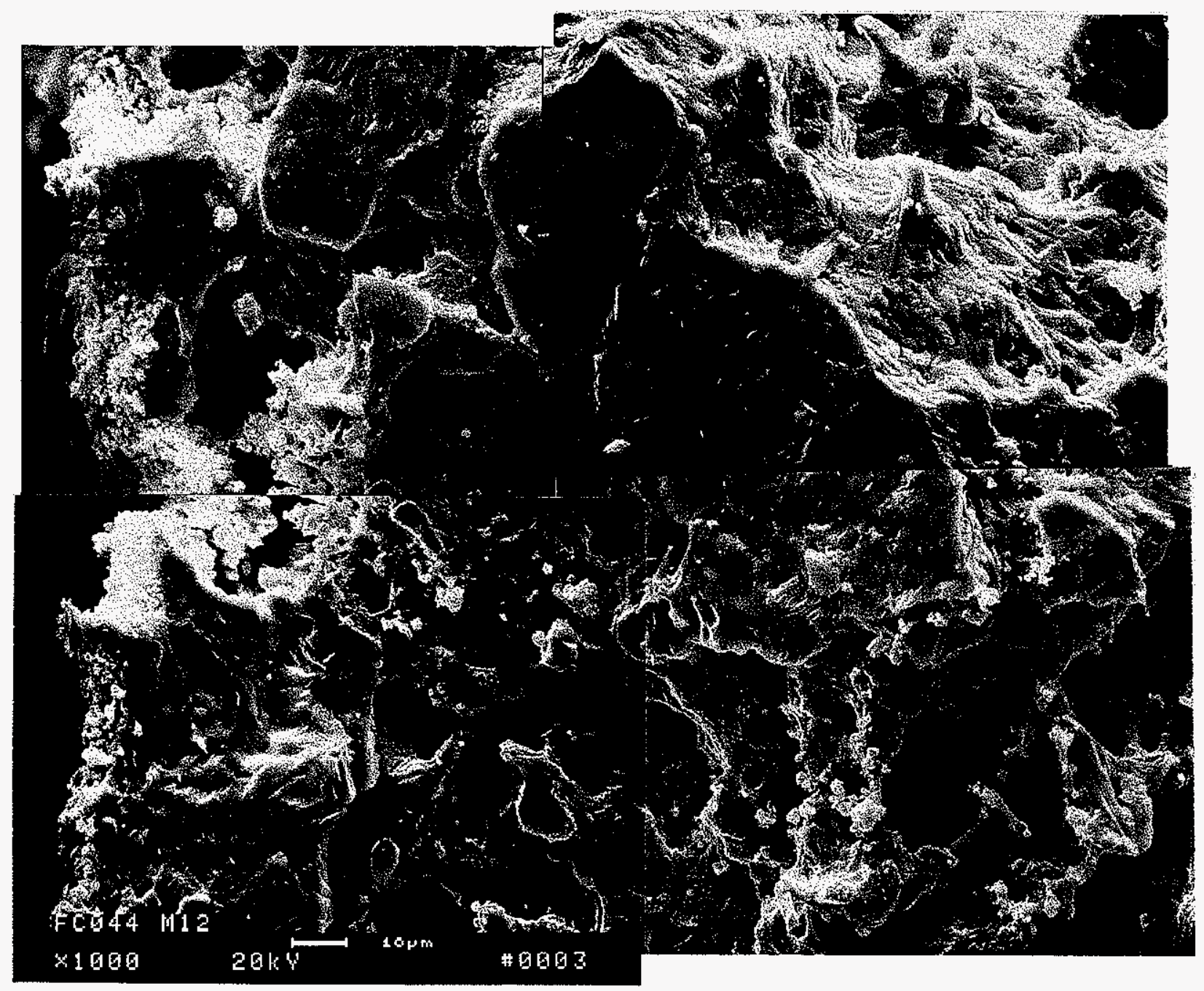

Figure 3-102 - Micrograph montage illustrating the retention of fines along the first outer surface pore layer of the PCFBC-exposed/extended life-tested Coors P-100A-1 alumina/mullite filter element. 


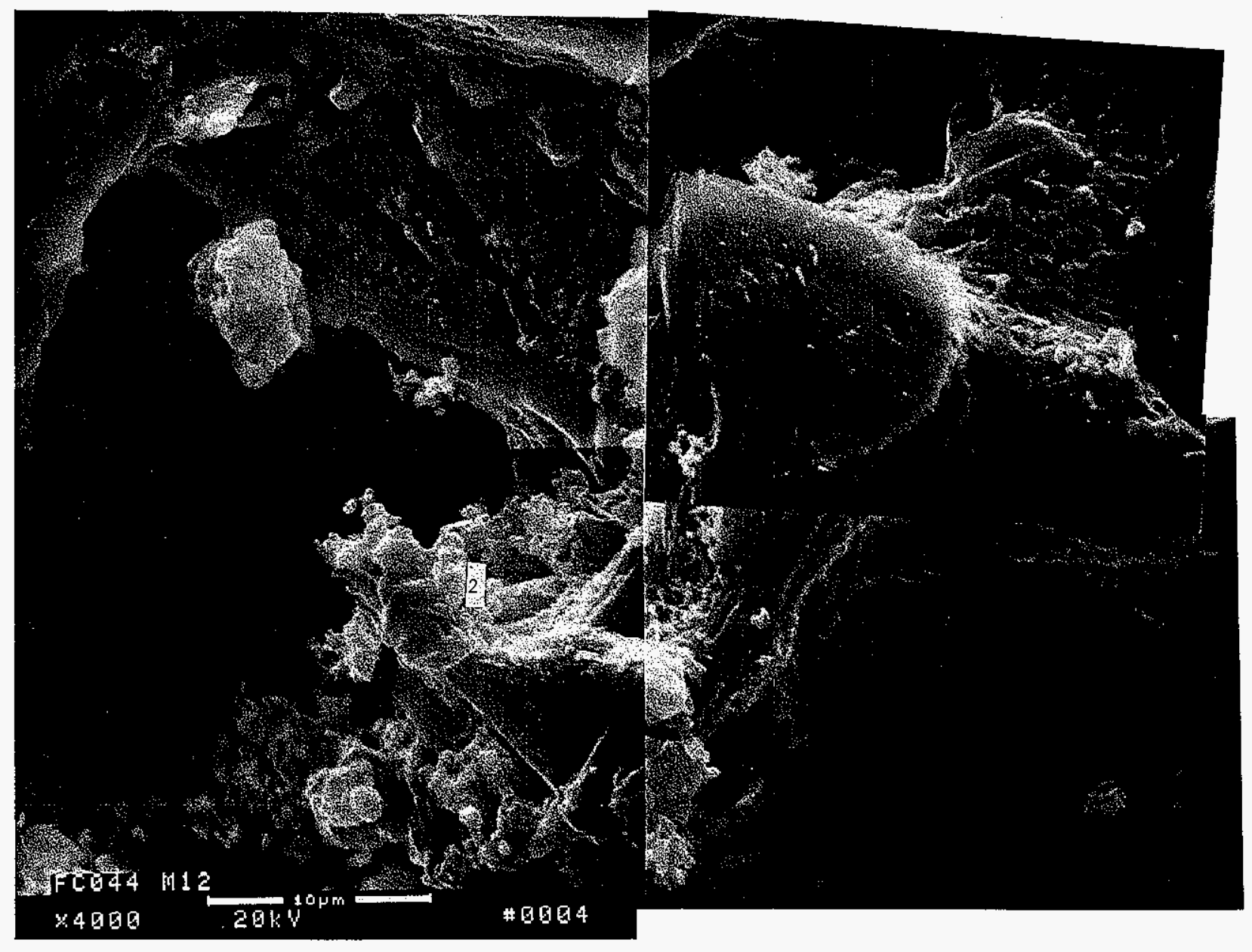

Figure 3-103 - Higher magnification micrograph montage illustrating the adherence of ash fines, as well as matrix crystallization along the surface of the first pore layer of the PCFBC-exposed/extended life-tested Coors P-100A-1 alumina/mullite filter element. 


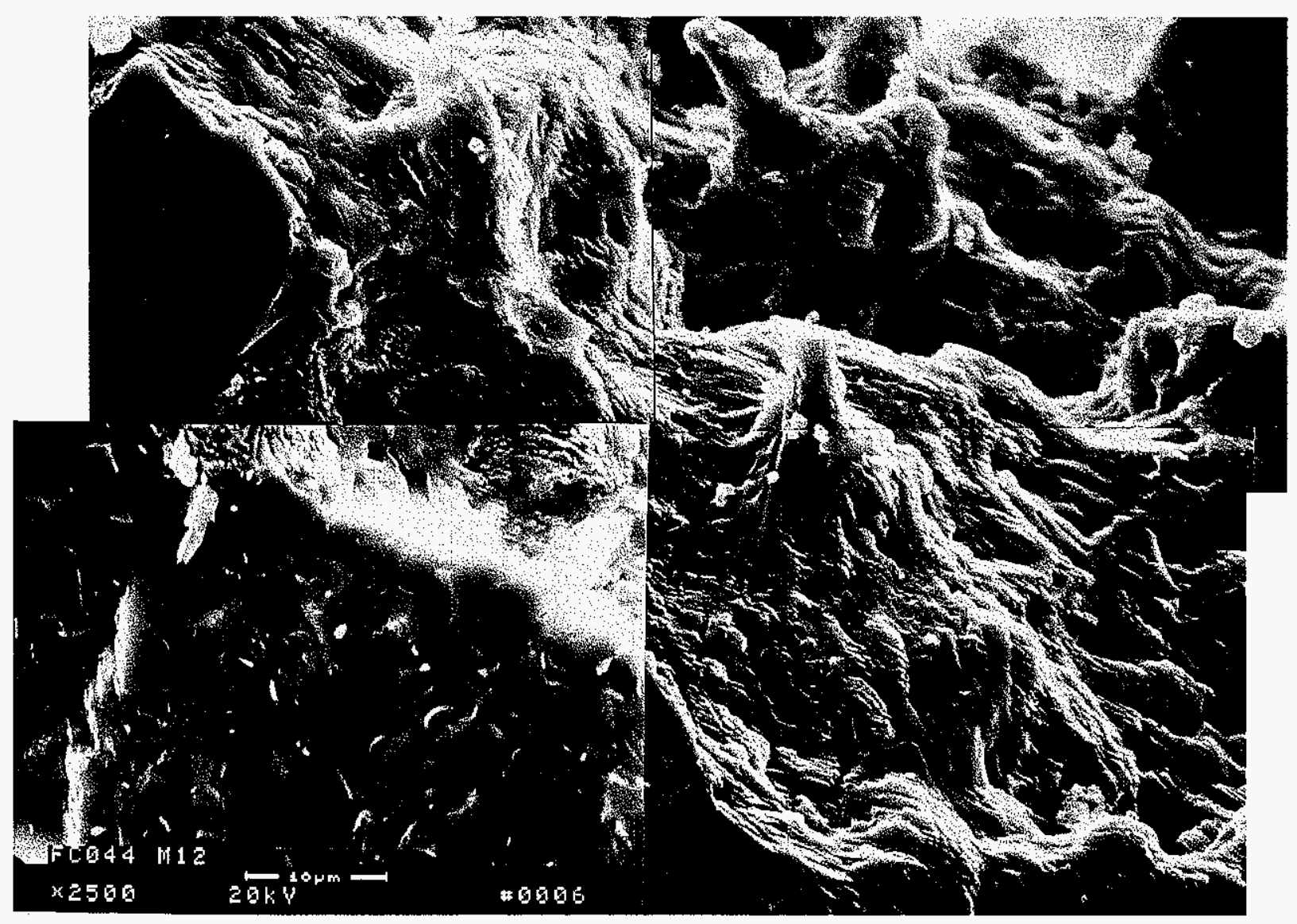

Figure 3-104 - Micrograph montage illustrating extensive crystallization along the surface of the pore cavity walls and throughout the fractured ligaments of the PCFBCexposed/extended life-tested Coors $\mathrm{P}-100 \mathrm{~A}-1$ alumina/mullite filter element. 

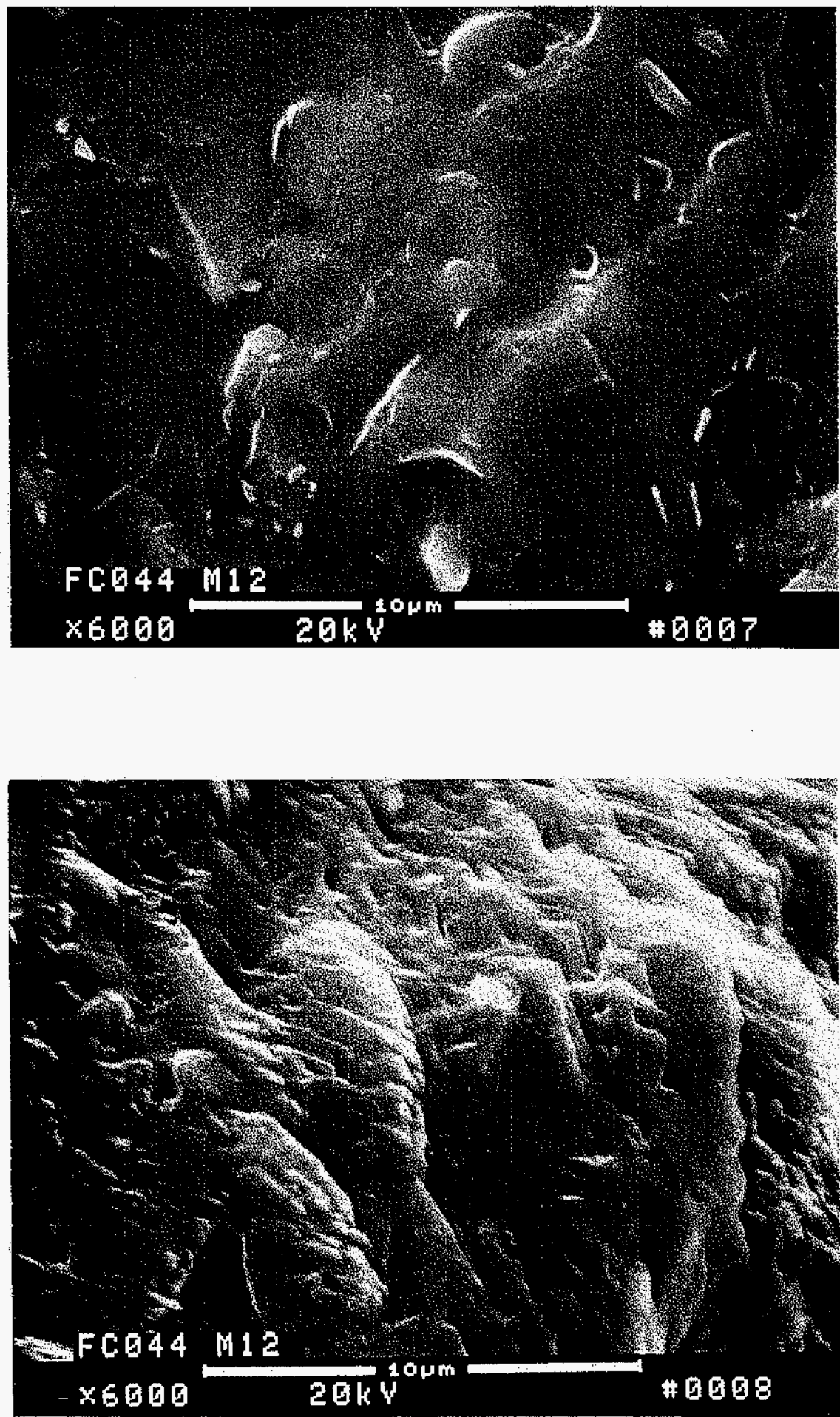

Figure 3-105 - Higher magnification micrographs illustrating crystallization throughout the fresh fractured ligament, as well as along the pore cavity surface of the PCFBC-exposed/ extended life-tested Coors P-100A-1 alumina/mullite filter element. 


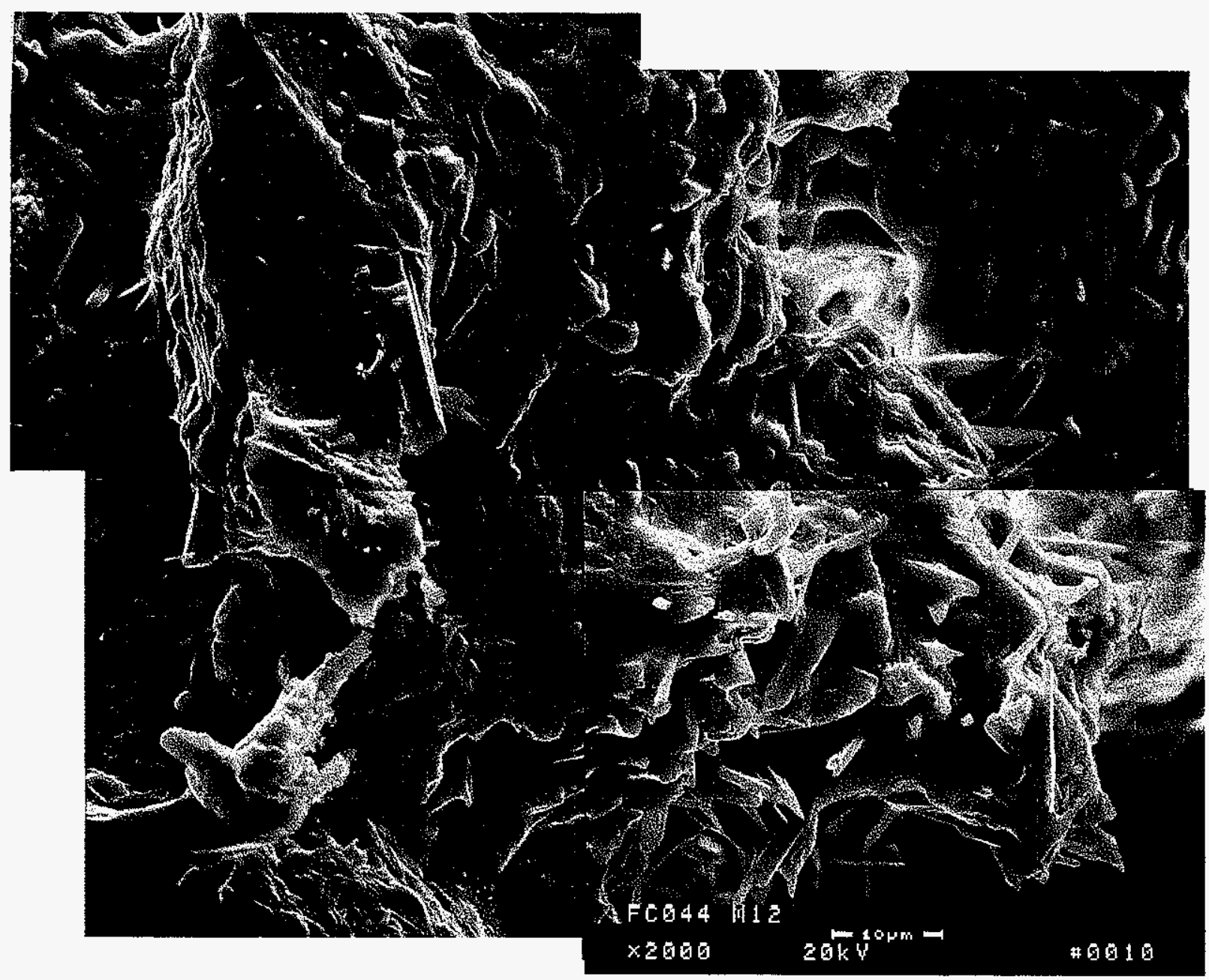

Figure 3-106 - Micrograph montage illustrating extensive crystallization along the pore cavity surface near the mid-section of the fresh fractured, PCFBC-exposed/extended lifetested, Coors P-100A-1 alumina/mullite filter matrix. 


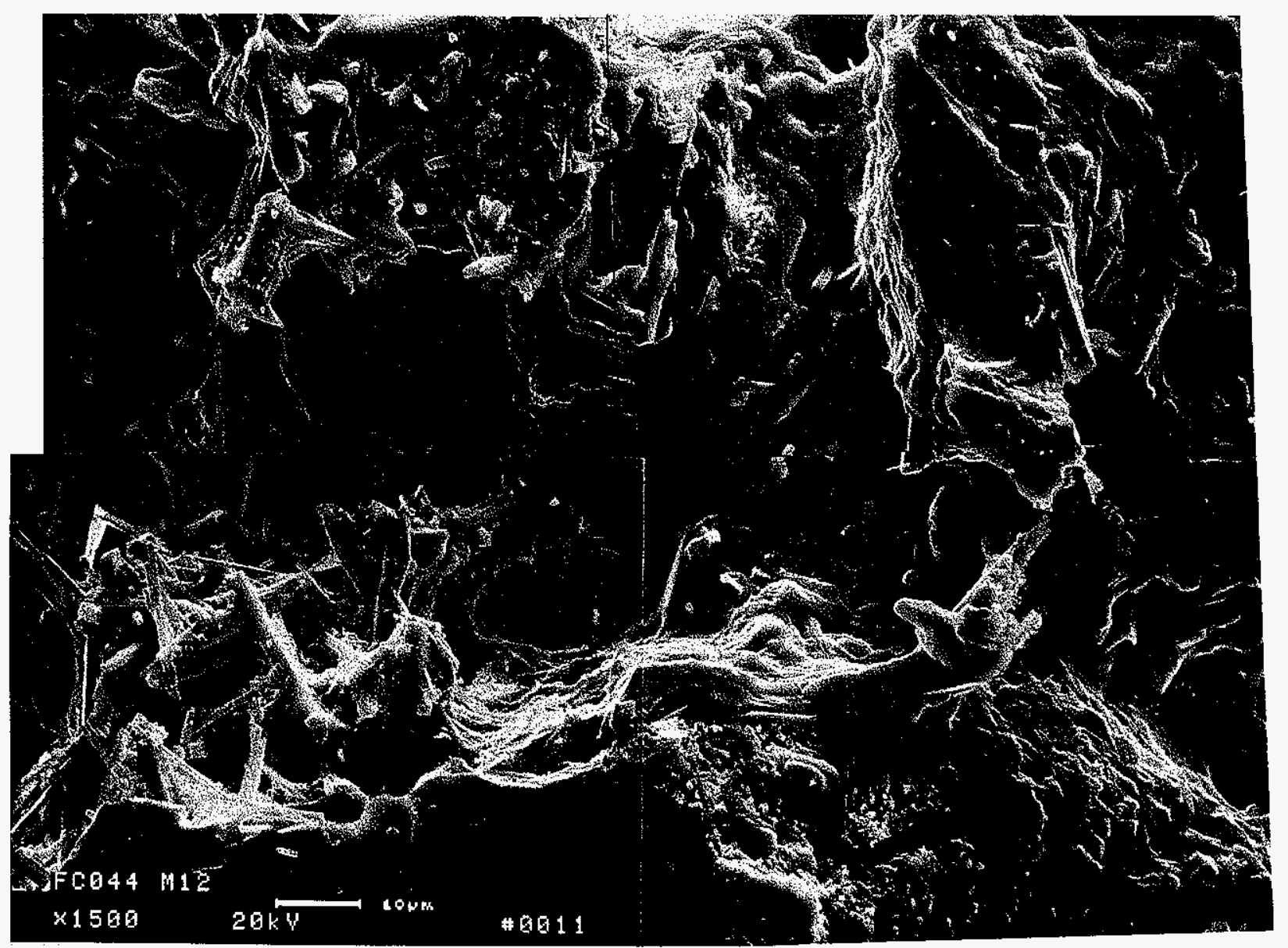

Figure 3-107 - High magnification micrograph montage illustrating extensive crystallization along the pore cavity surface near the mid-section of the fresh fractured, PCFBCexposed/extended life-tested, Coors P-100A-1 alumina/mullite filter matrix. 


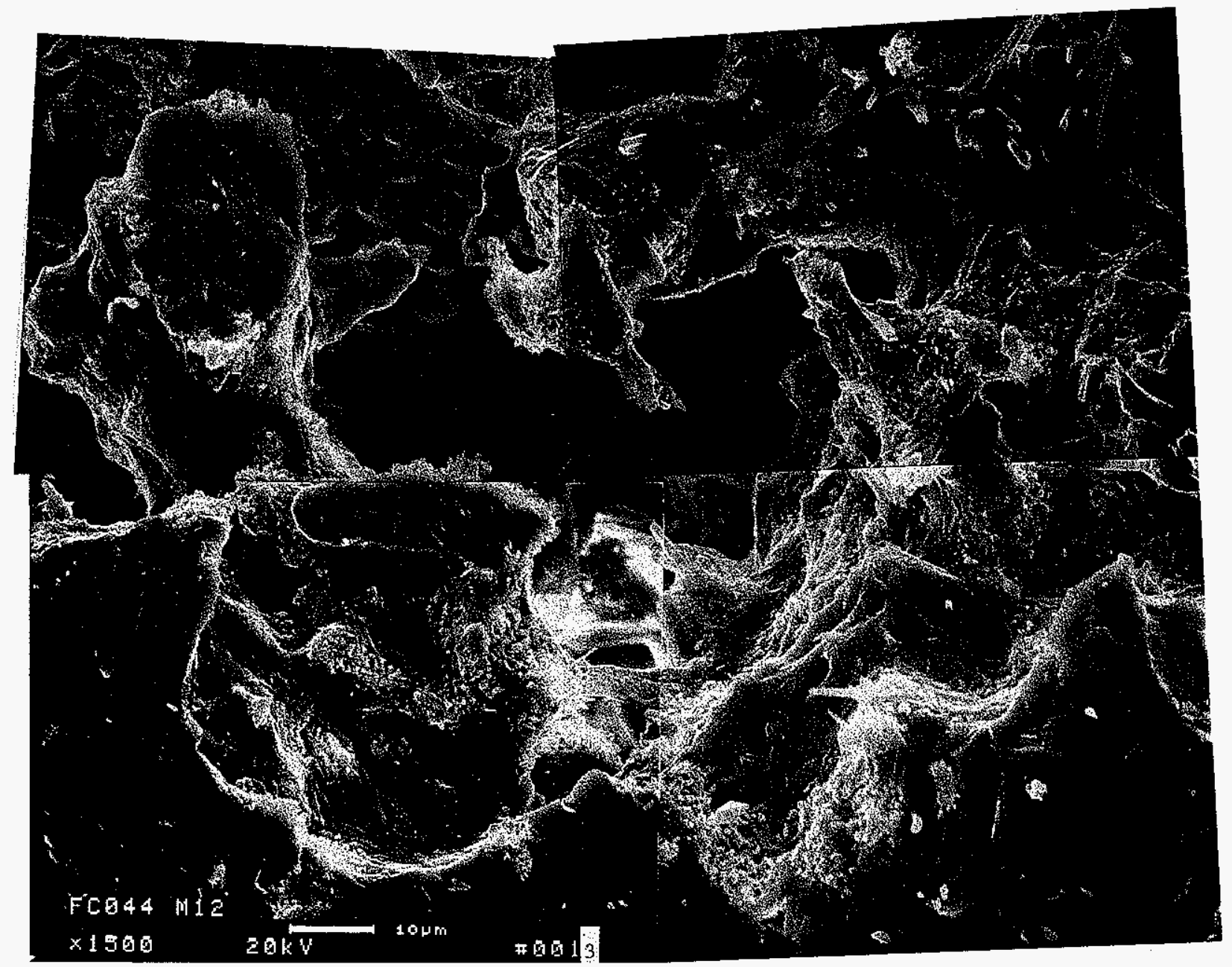

Figure 3-108 - Additional high magnification micrograph montage illustrating extensive crystallization along the pore cavity surface near the mid-section of the fresh fractured, PCFBC-exposed/extended life-tested, Coors P-100A-1 alumina/mullite filter matrix. 


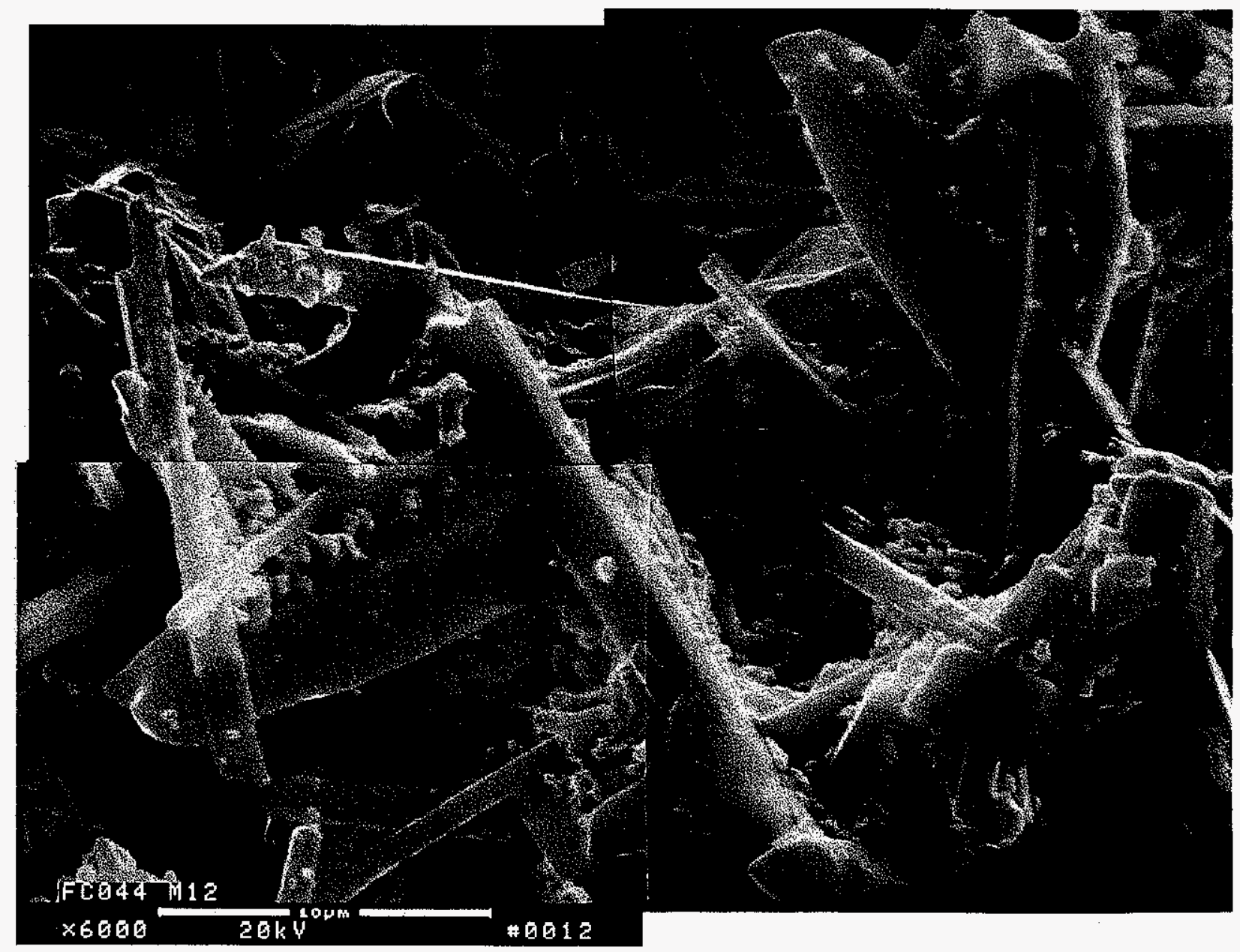

Figure 3-109 - High magnification micrograph montage illustrating the morphology of the mullite, needle-like phase that resulted along the surface of the pore cavity walls near the mid-section of the fresh fractured, PCFBC-exposed/extended life-tested, Coors P100A-1 alumina/mullite filter matrix. 


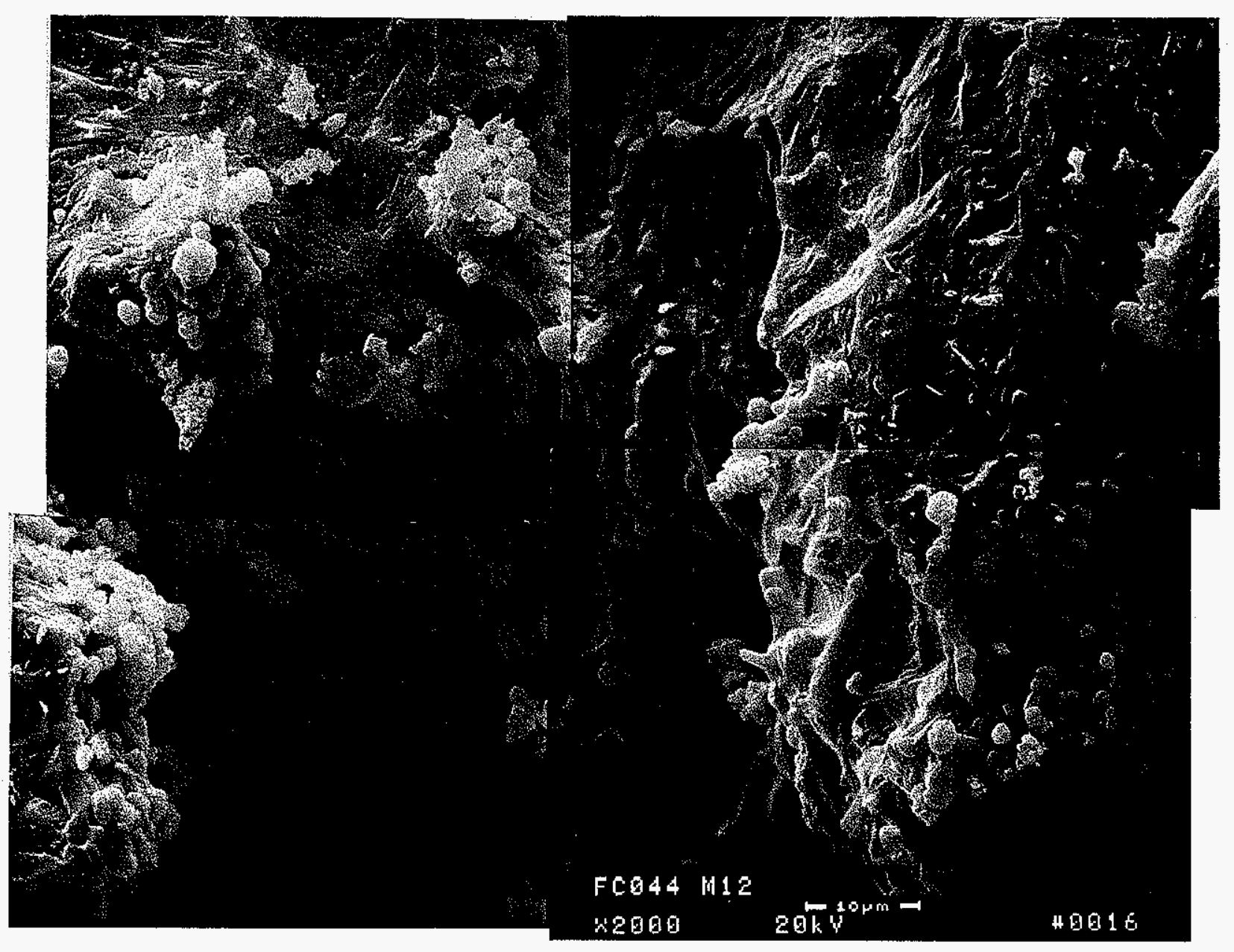

Figure 3-110 - Micrograph montage illustrating crystallization that resulted along the pore cavity walls of the fresh fractured Coors P-100A-1 alumina/mullite filter matrix near the i.d. surface of the PCFBC-exposed/extended life-tested filter element. 


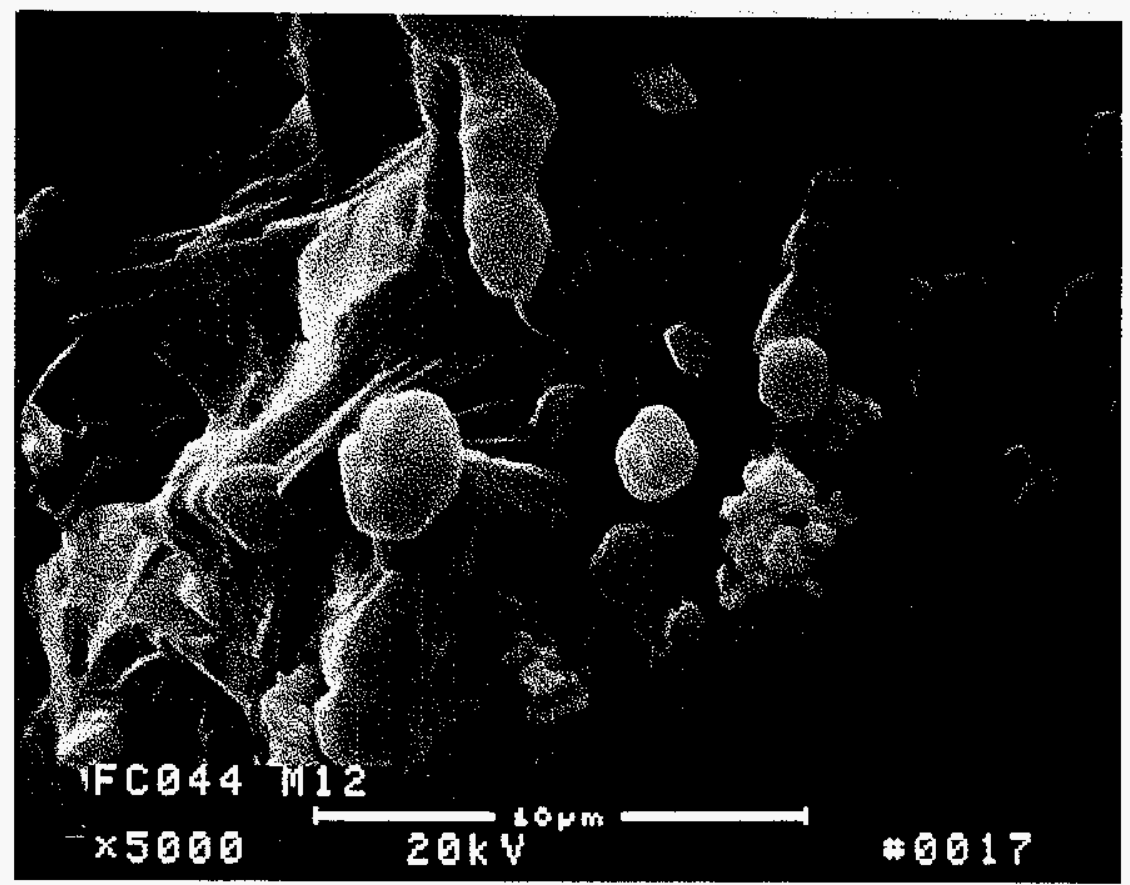

Figure 3-111 - Micrograph illustrating the morphology of the crystallized pore cavity surface near the i.d. surface of the Coors PCFBC-exposed/extended life-tested filter element. 


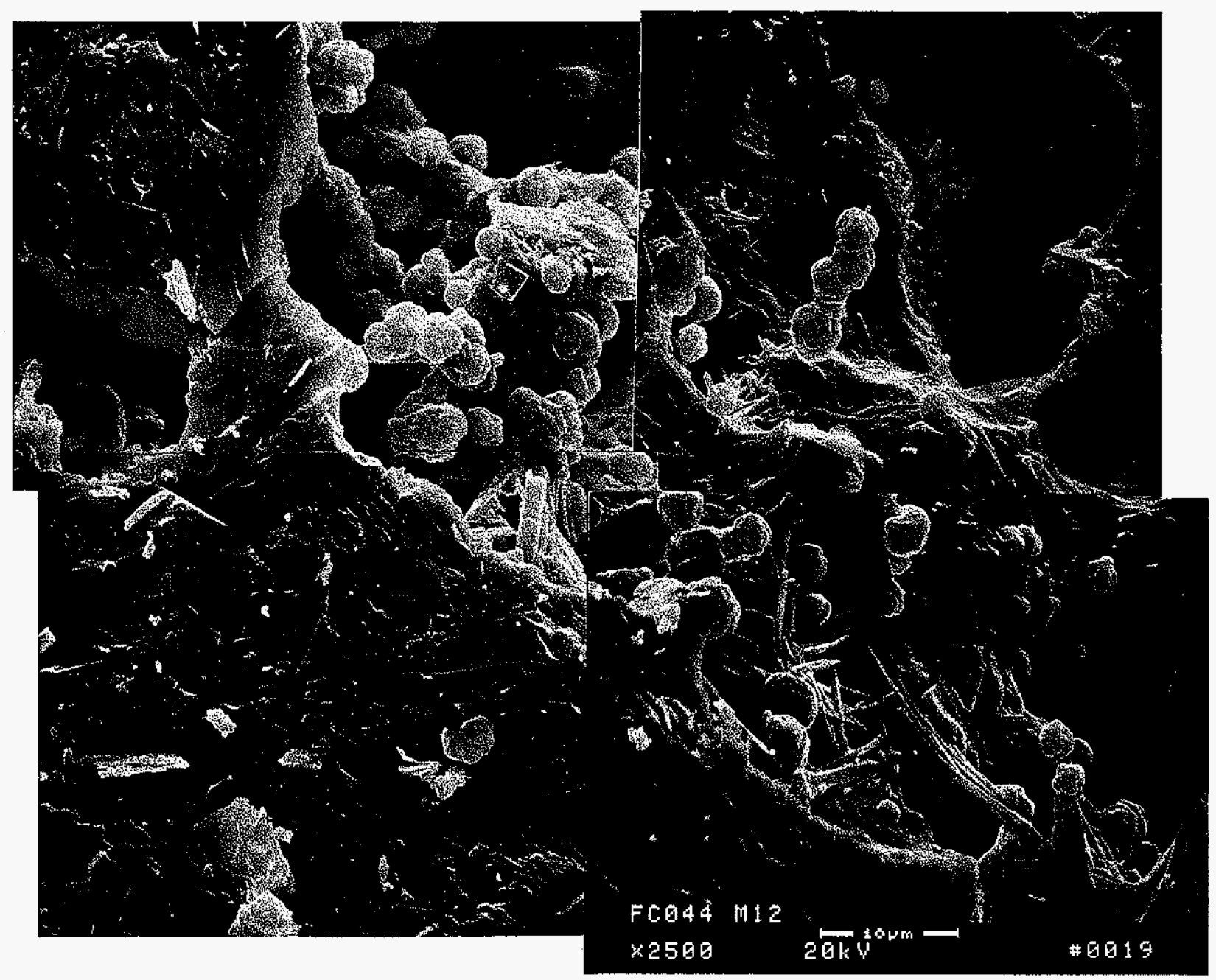

Figure 3-112 - Micrograph montage illustrating the morphology of the crystalline phase that resulted along the pore cavity surface of the fresh fractured, PCFBC-exposed/ extended life-tested, Coors P-100A-1 alumina/mullite filter matrix near the i.d. surface of the filter element. Extensive crystallization was also evident throughout the fresh fractured ligaments in this area of the filter wall. 

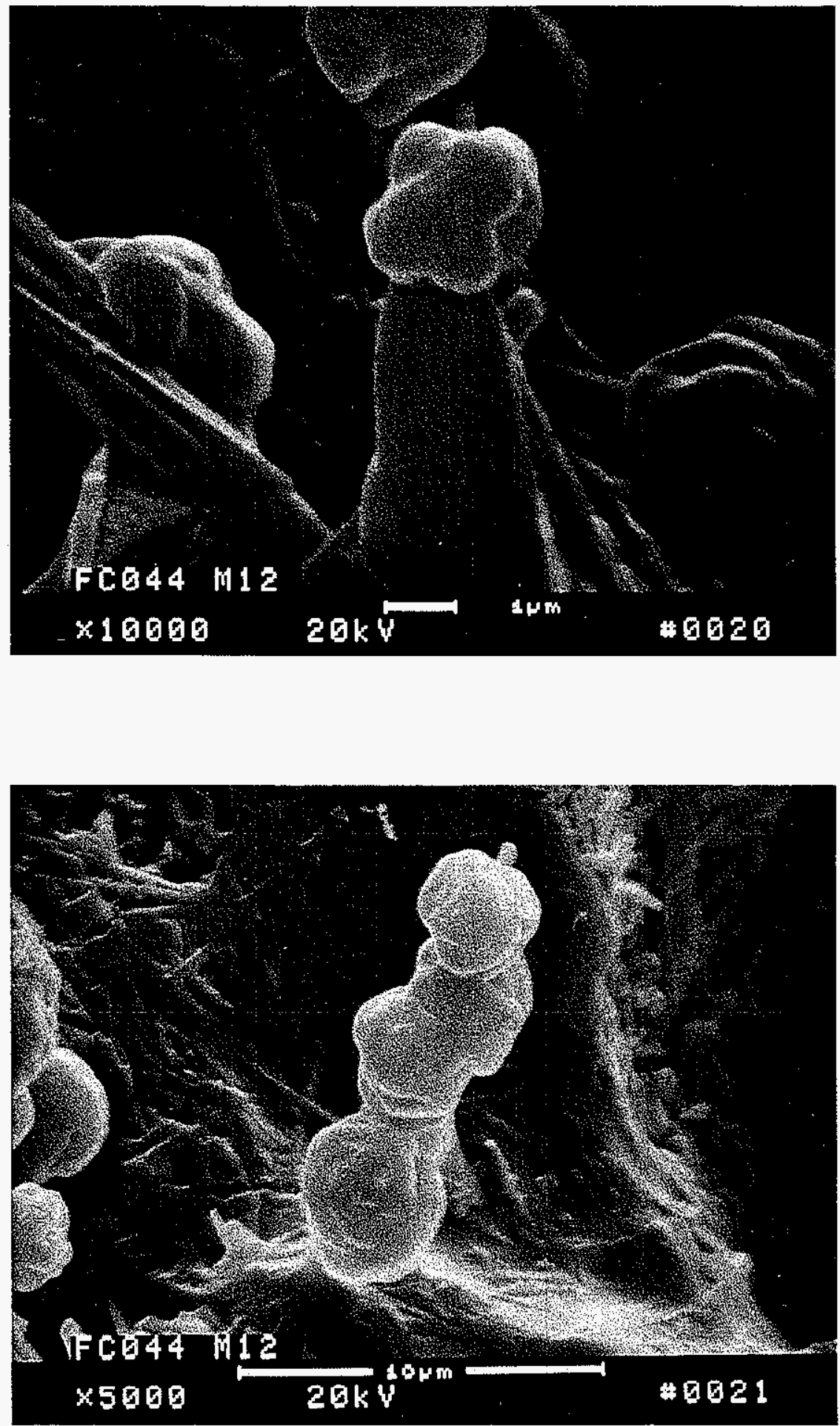

Figure 3-113 - Morphology of the needle-like rod formations and associated coalesced phase that generally resulted along the surface of the pore cavity walls near the pulse cycled surface of the PCFBC-exposed/extended life-tested Coors P-100A-1 alumina/mullite filter matrix. 


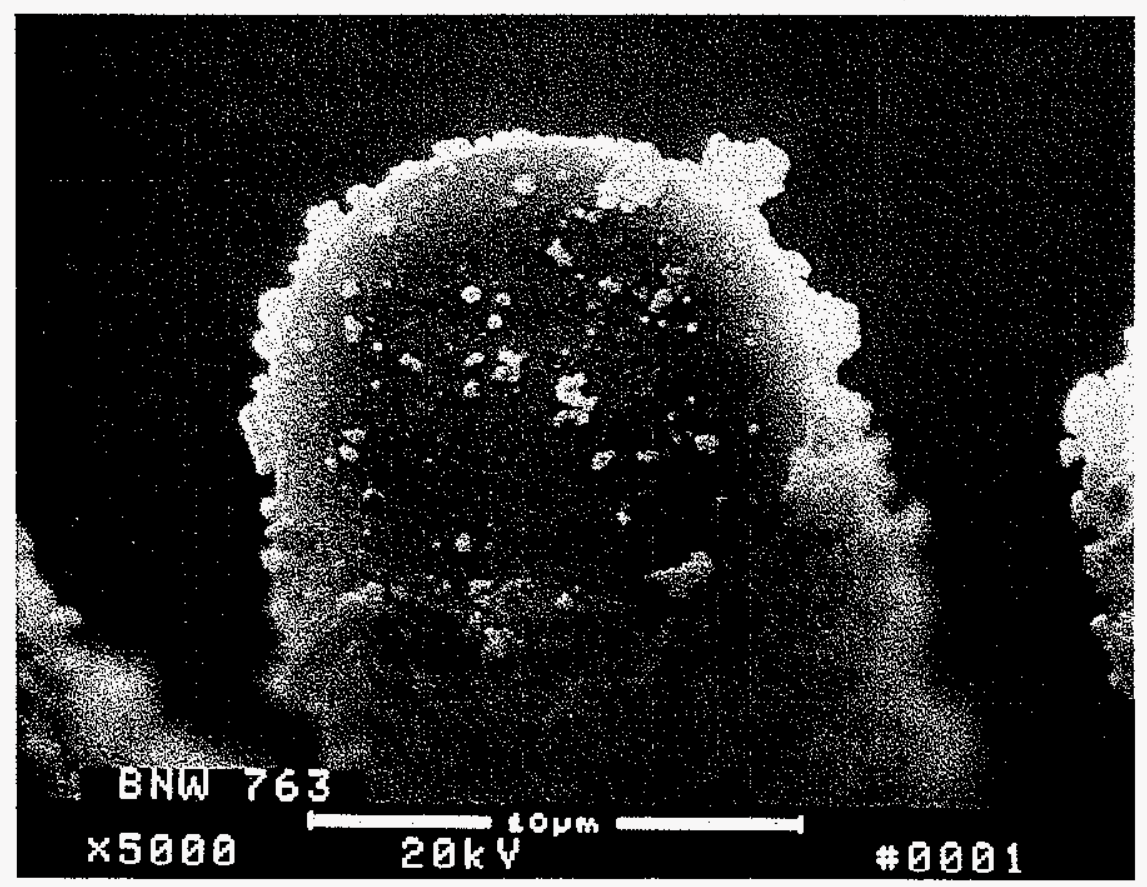

Figure 3-114 - Morphology of the fresh fractured Nexte ${ }^{\mathrm{TM}} 610$ fibers in the as-manufactured McDermott oxide-based CFCC filter matrix. 


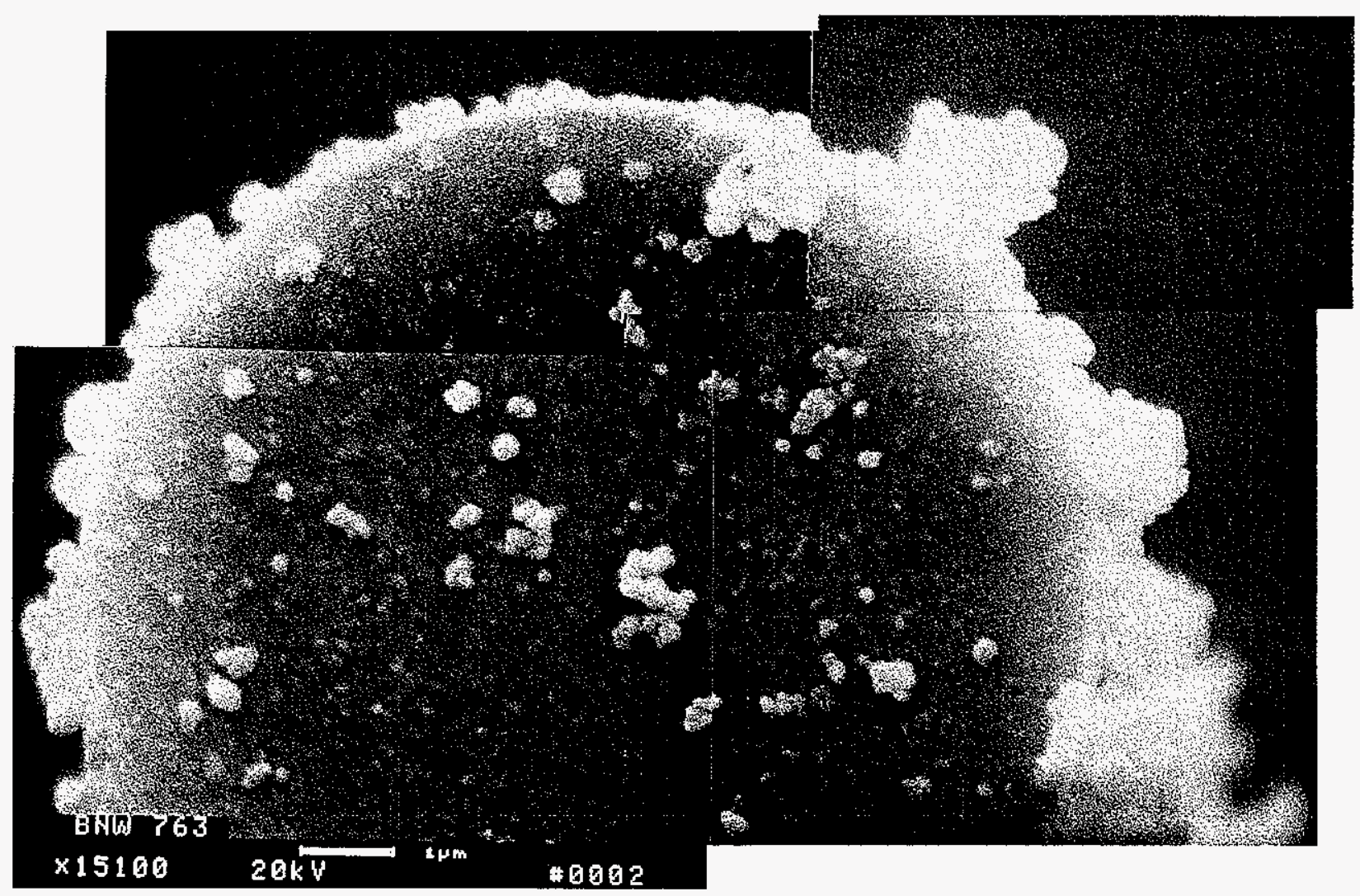

Figure 3-115 - Higher magnification micrograph montage illustrating the morphology of the fresh fractured Nextel ${ }^{\text {TM }} 610$ fibers in the as-manufactured McDermott oxide-based CFCC filter matrix. 


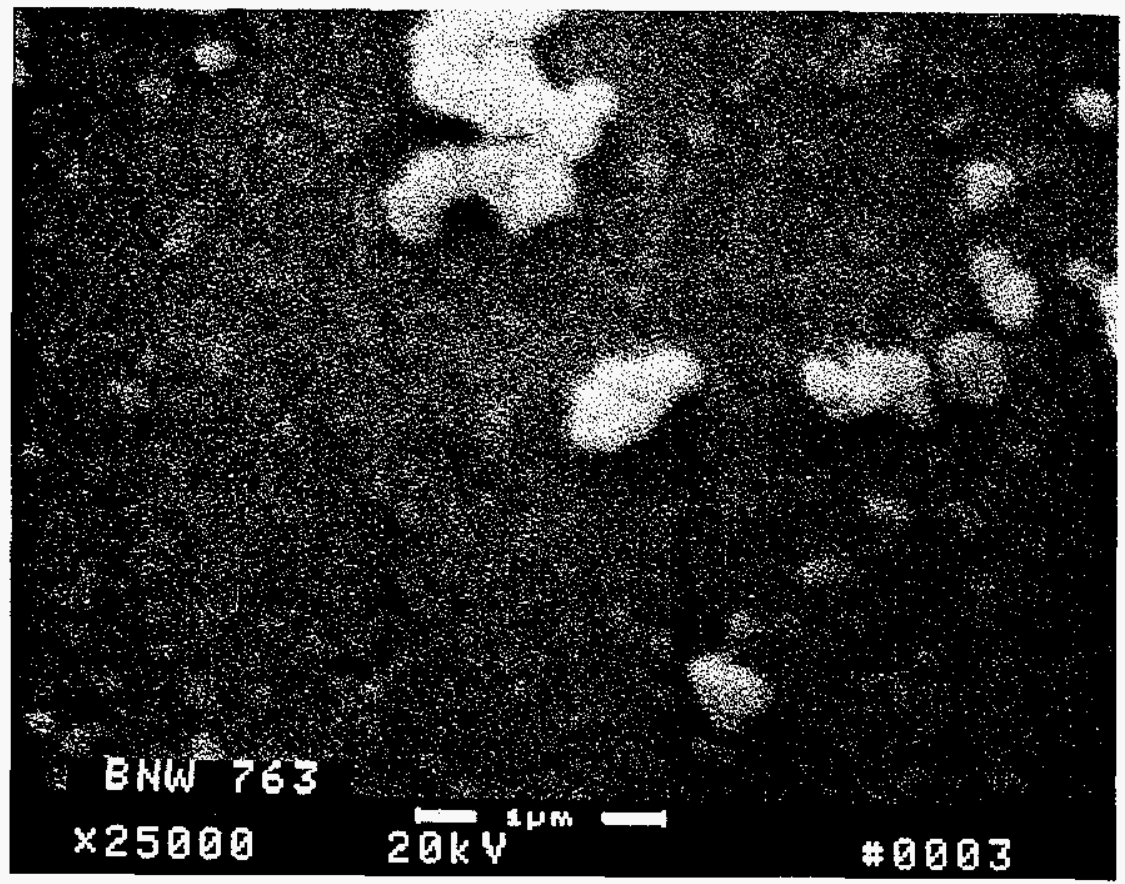

Figure 3-116 - Higher magnification micrograph illustrating the presence of negligible crystalline features along the cross-sectioned surface of the Nextel ${ }^{\mathrm{TM}} 610$ fibers in the asmanufactured McDermott oxide-based CFCC filter matrix. 


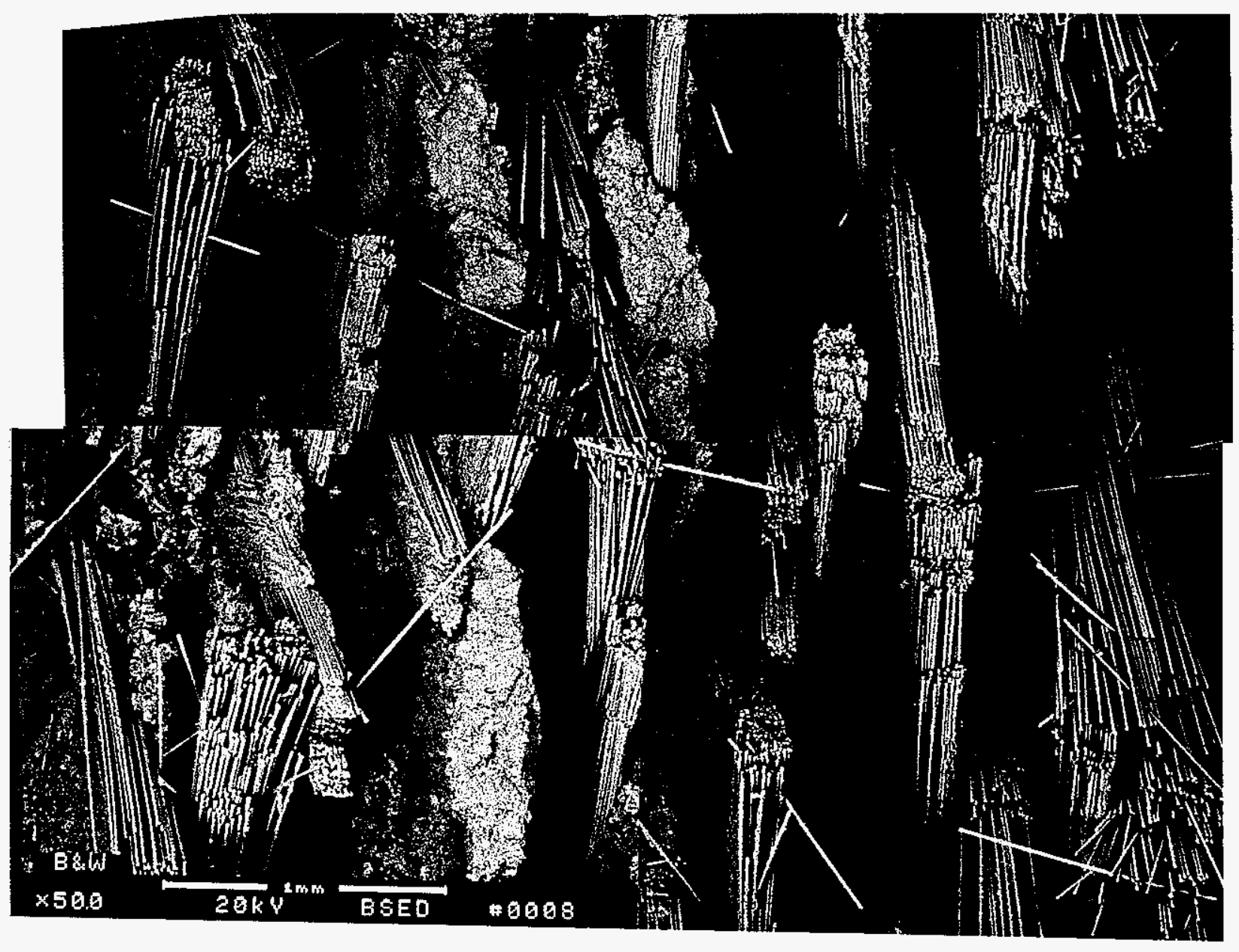

Figure 3-117 - Micrograph montage illustrating the morphology of the cross-sectioned, PCFBCexposed/extended life-tested, McDermott CFCC filter matrix. 


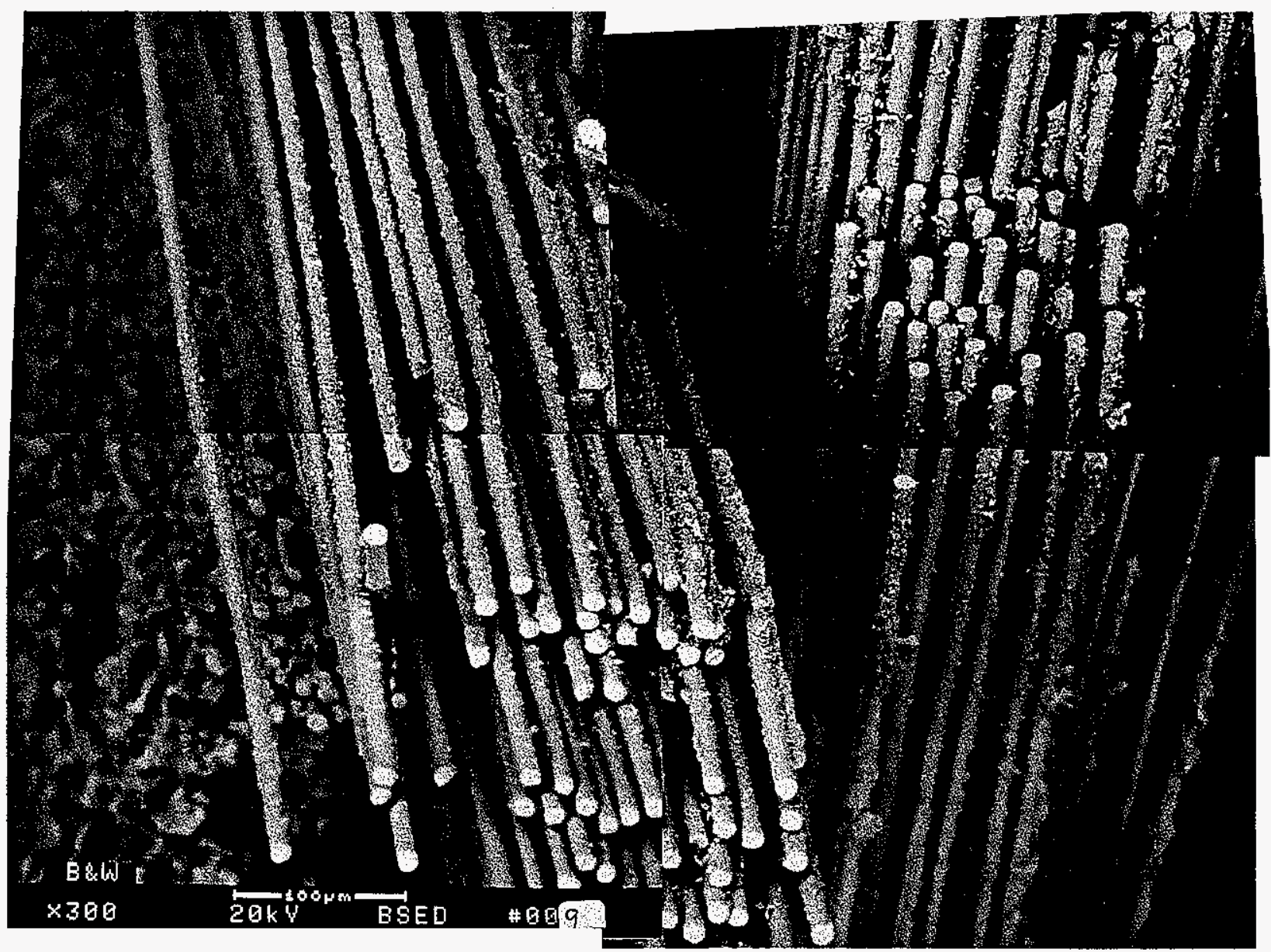

Figure 3-118 - Micrograph montage illustrating the morphology of the fibers within a fractured fiber bundle near the o.d. surface of the cross-sectioned, PCFBC-exposed/extended life-tested, McDermott CFCC filter matrix. Individual fibers were readily seen within the fractured filament. 


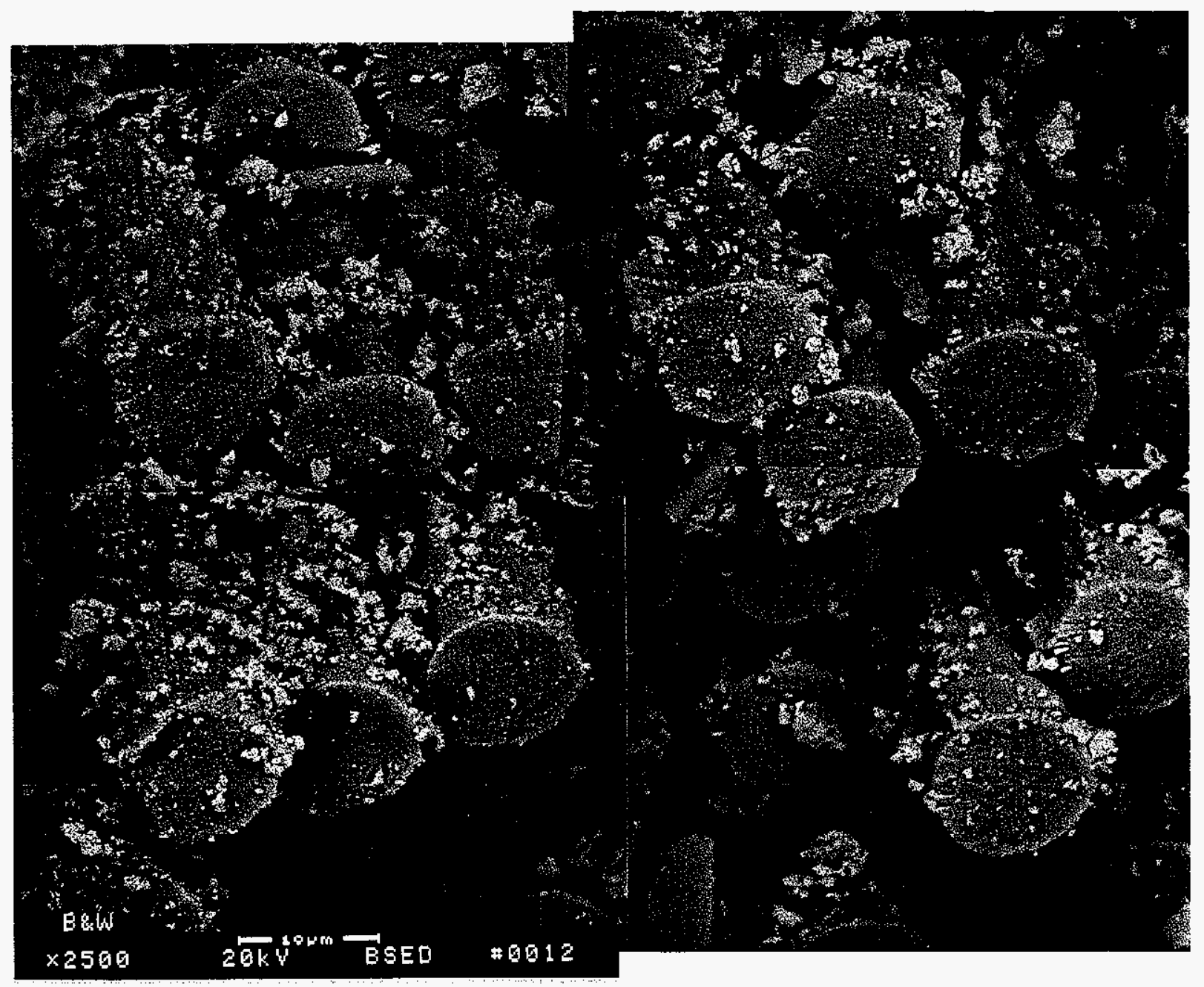

Figure 3-119 - High magnification micrograph montage illustrating the morphology of an array of fibers within a fresh fractured filament bundle near the o.d. surface of the PCFBCexposed/extended life-tested McDermott CFCC filter matrix. 


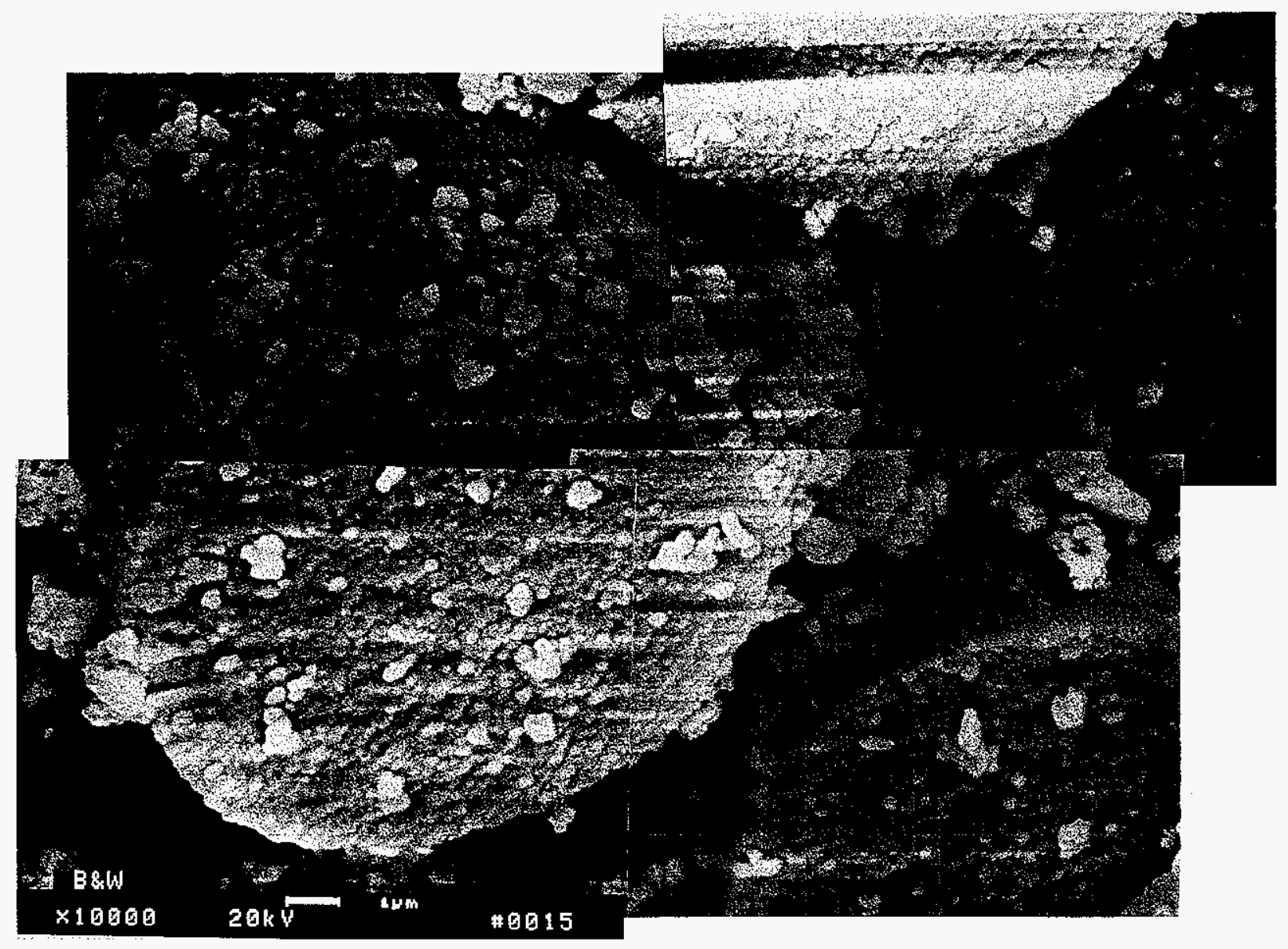

Figure 3-120 - High magnification micrograph montage illustrating the extensive crystallization that resulted throughout the PCFBC-exposed/extended life-tested Nextel ${ }^{\mathrm{TM}} 610$ fibers in the McDermott CFCC filter element. 


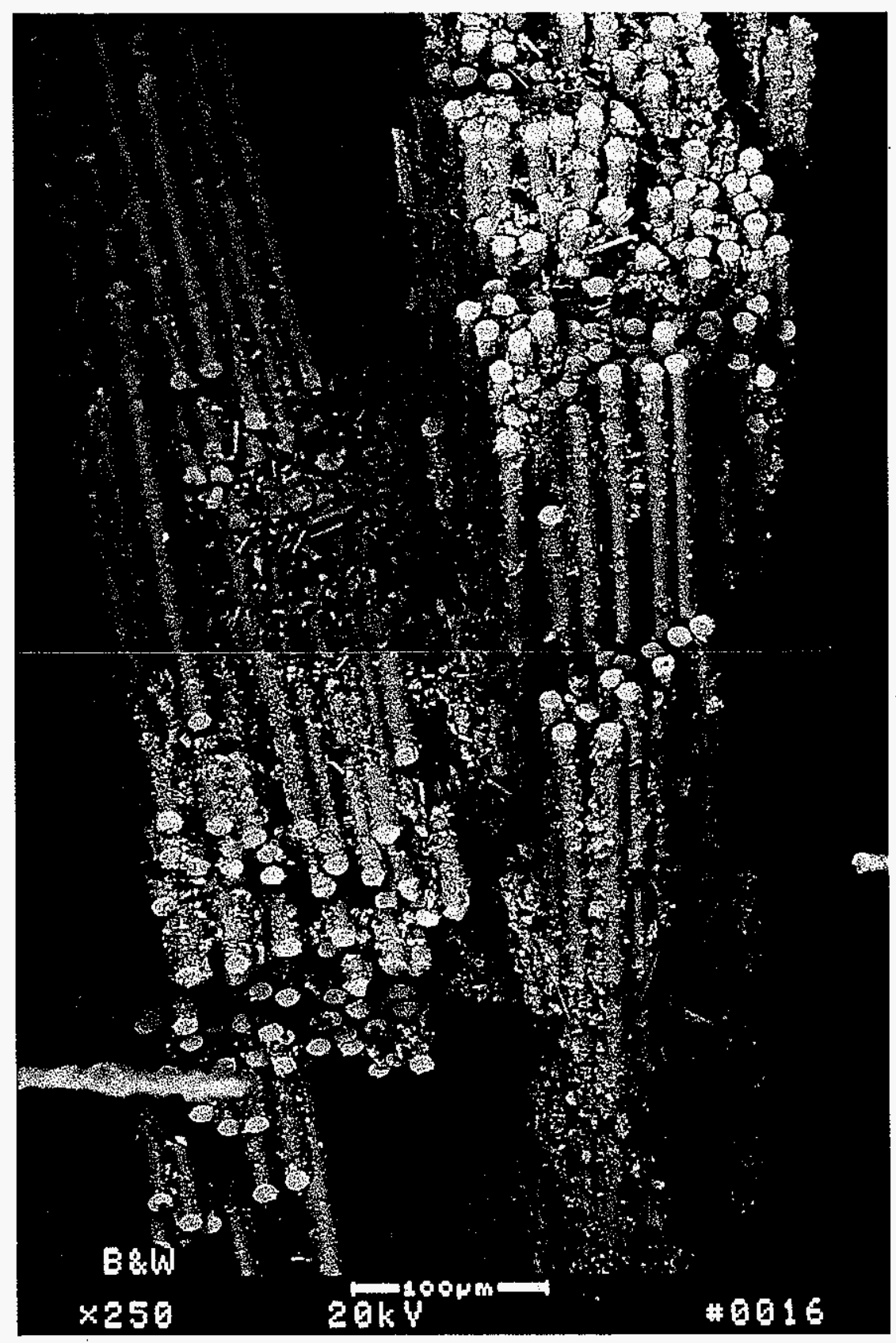

Figure 3-121 - Micrograph montage illustrating the morphology of the fresh fractured fibers within the Nextel ${ }^{\mathrm{TM}} 610$ filaments at approximately the mid-section of the filter wall. 


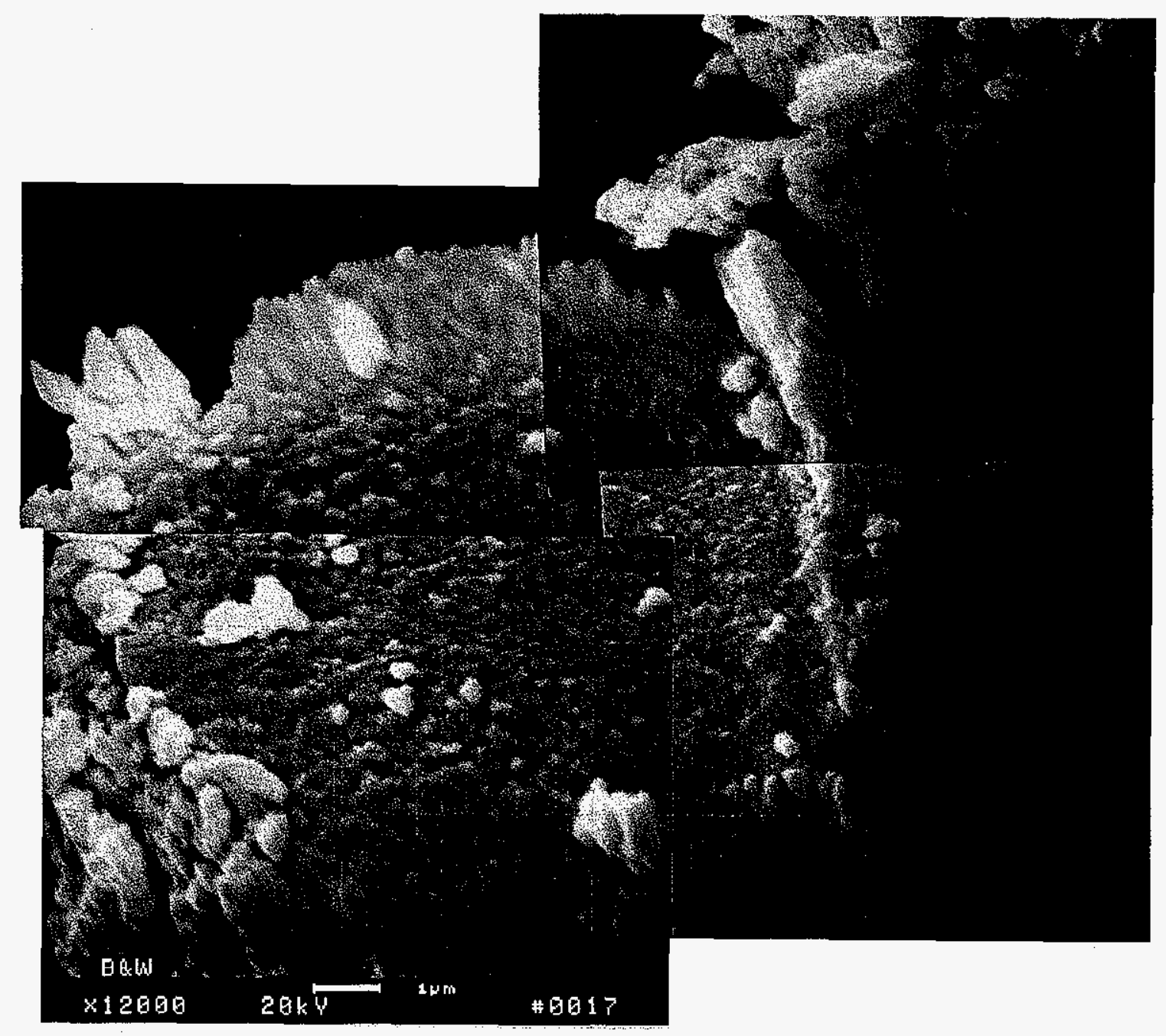

Figure 3-122 - High magnification micrograph montage illustrating the extensive crystallization that resulted throughout the PCFBC-exposed/extended life-tested NexteI ${ }^{\mathrm{rM}} 610$ fibers within a filament that was located at approximately the mid-section of the filter wall. 


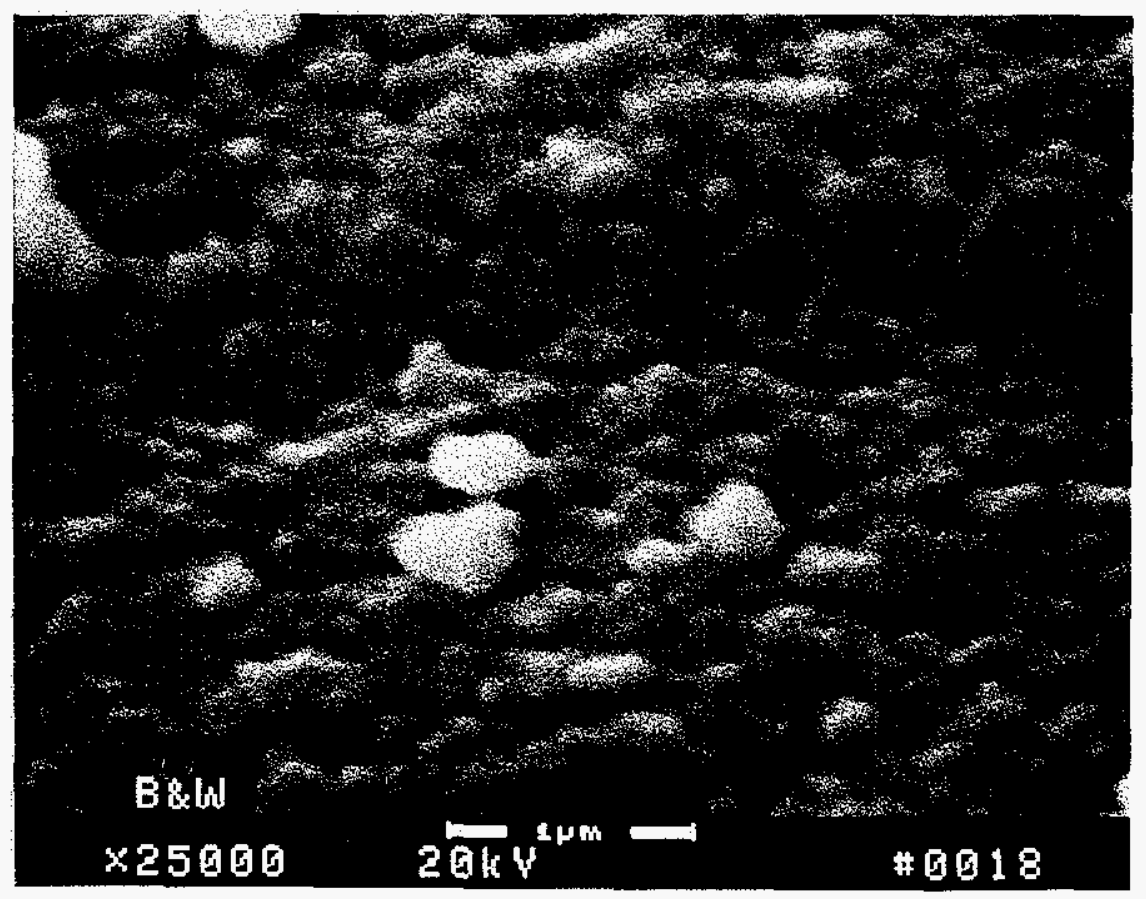

Figure 3-123 - High magnification micrograph illustrating the morphology of a crystallized Nextel ${ }^{\mathrm{MM}} 610$ fiber contained within a filament that was located at approximately the mid-section of the PCFBC-exposed/extended life-tested McDermott CFCC filter wall. 


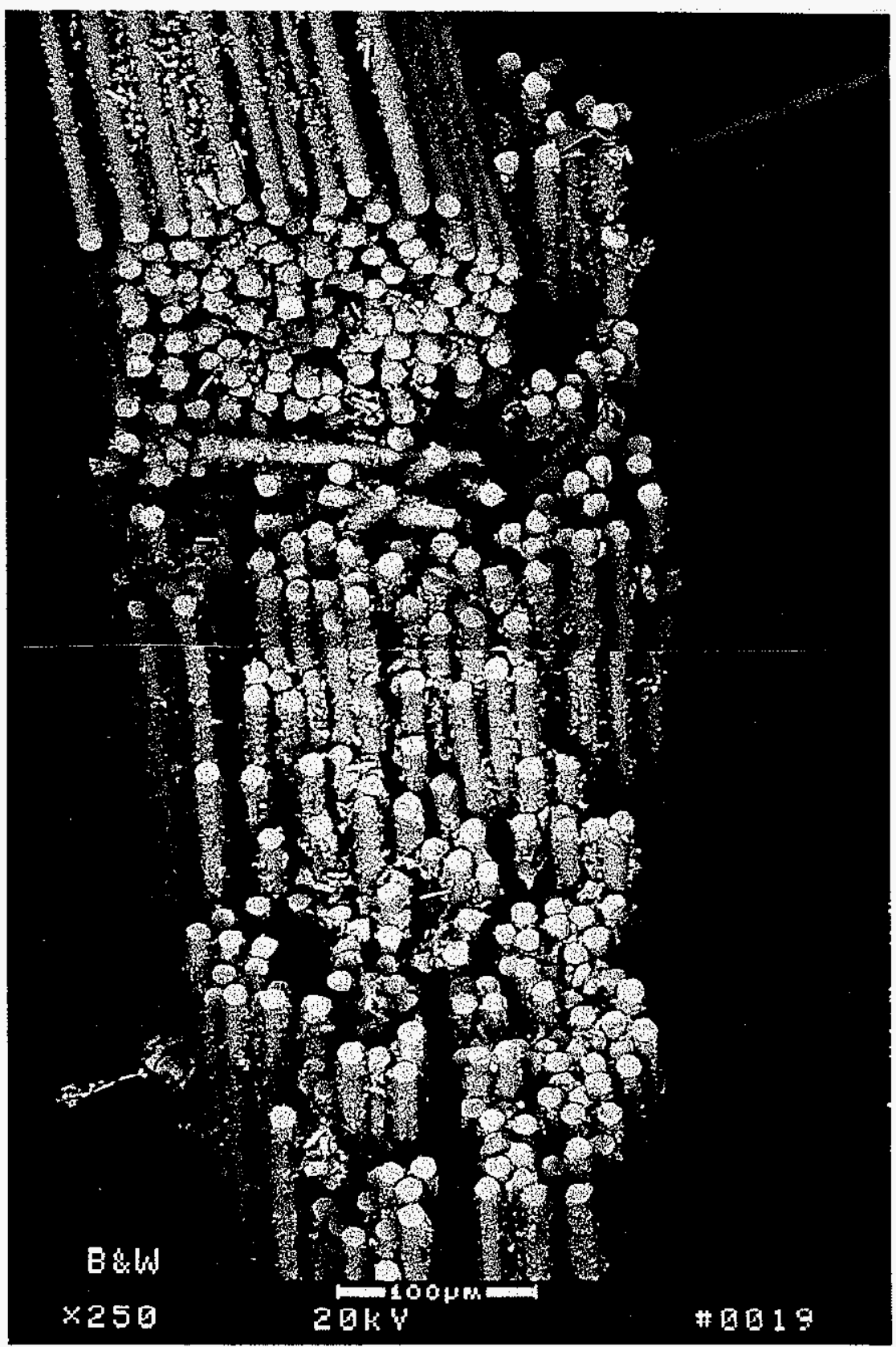

Figure 3-124 - Micrograph montage illustrating the morphology of the fresh fractured filament near the i.d. surface of the PCFBC-exposed/extended life-tested McDermott CFCC filter wall. 


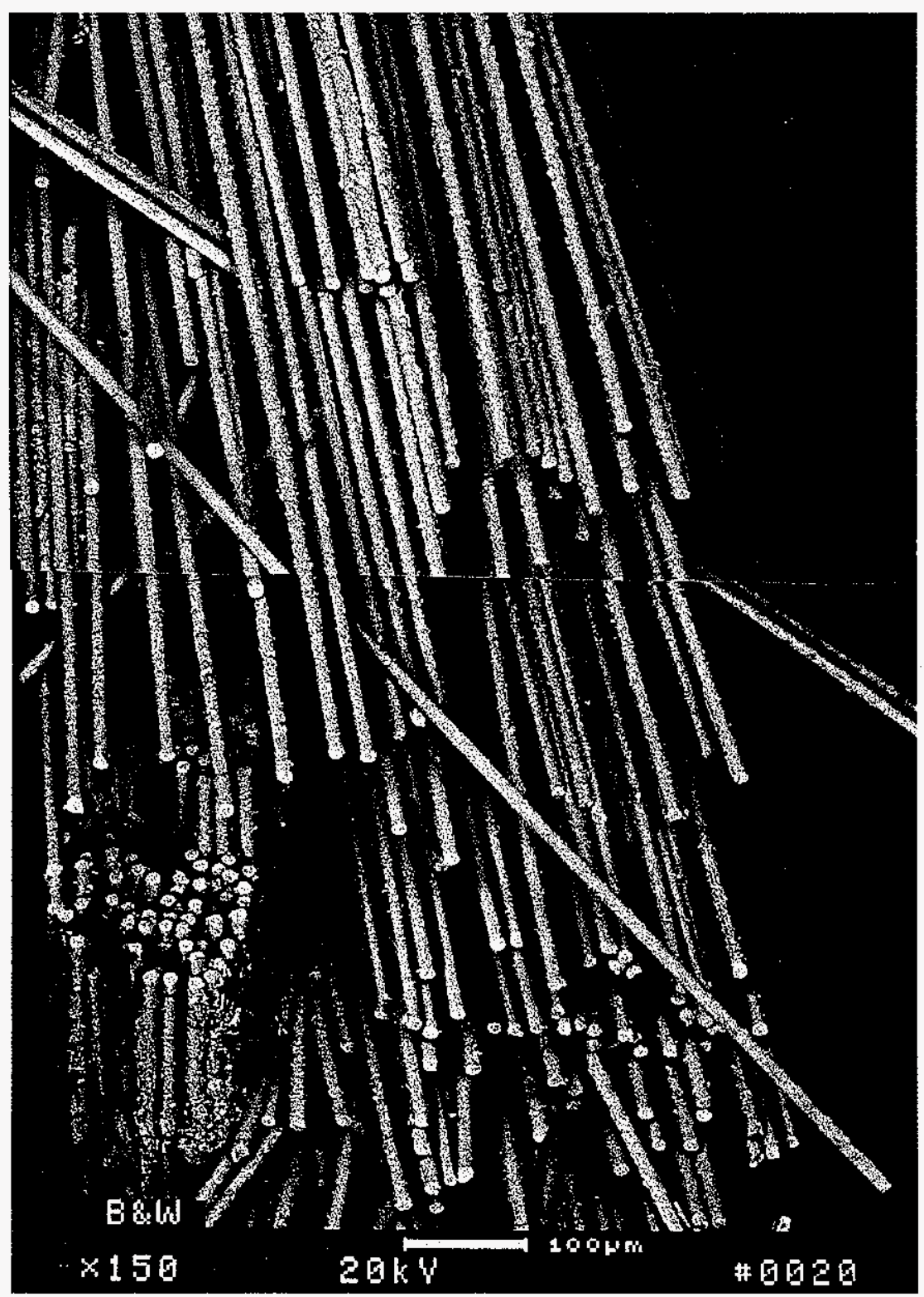

Figure 3-125 - High magnification micrograph montage illustrating the morphology of a fractured filament fiber bundle that was present along the i.d. surface of the PCFBCexposed/extended life-tested McDermott CFCC filter wall. 


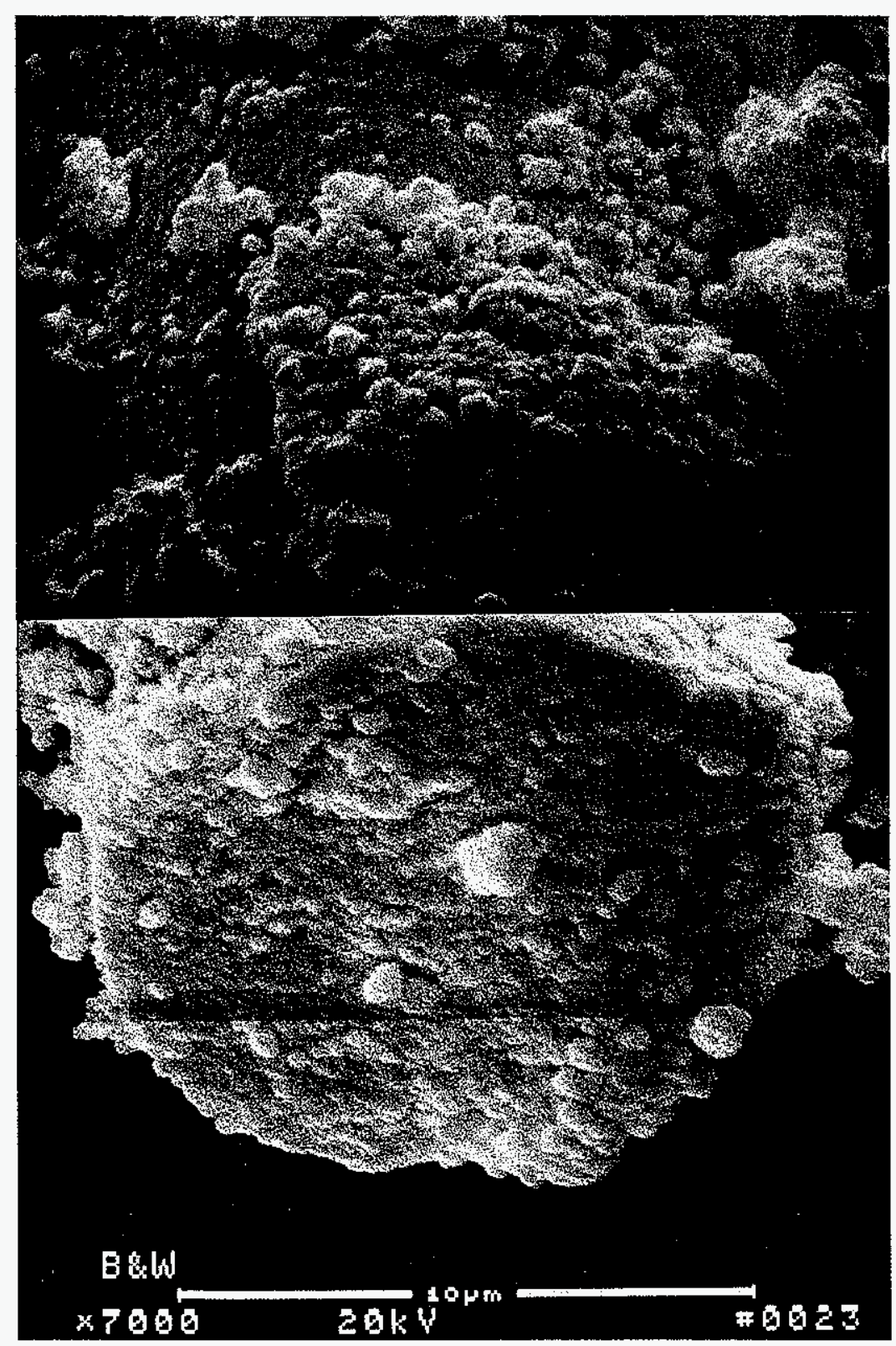

Figure 3-126 - High magnification micrograph montage illustrating the extensive crystallization that resulted throughout the $\mathrm{Nextel}^{\mathrm{TM}} \mathbf{6 1 0}$ fibers that were present within filament bundles that were located along the i.d. surface of the PCFBC-exposed/extended life-tested McDermott CFCC filter element. 


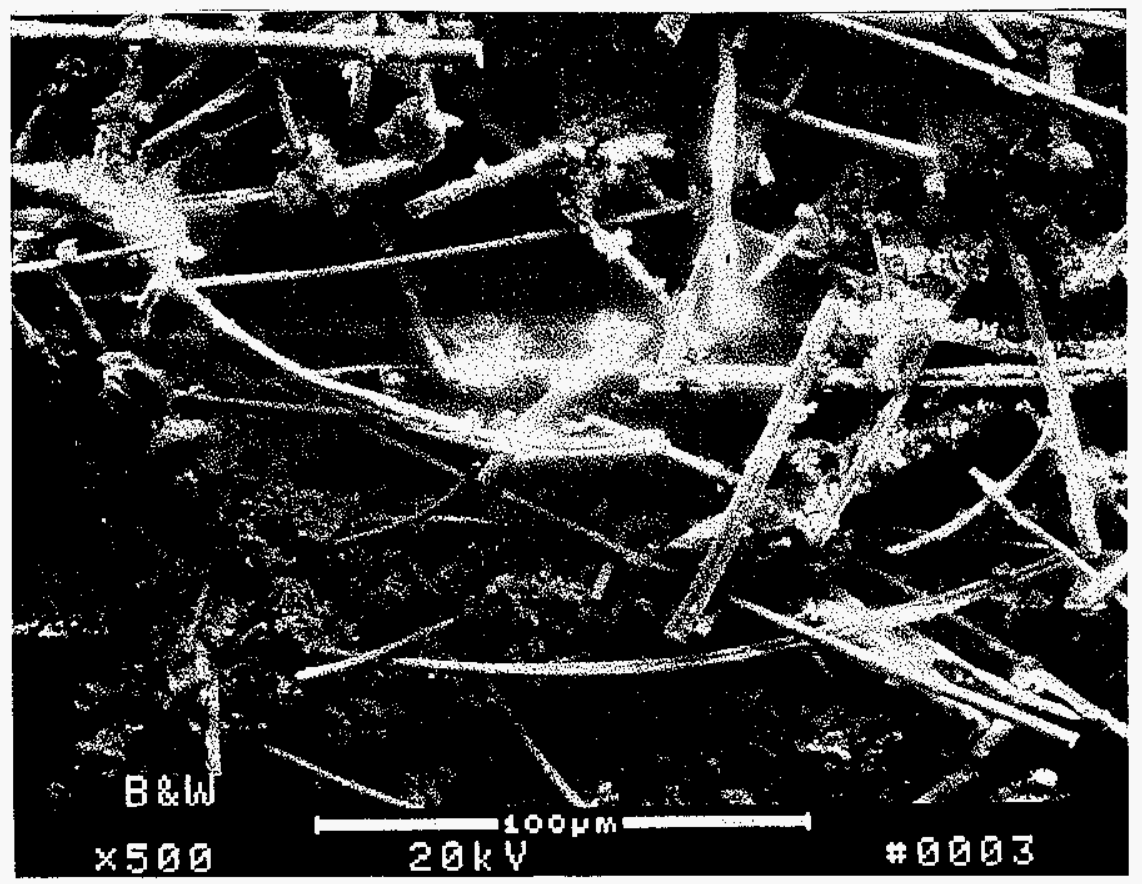

Figure 3-127 - High magnification micrograph illustrating the adherence of fines along the subsurface chopped Saffil/alumina-enriched mat along the o.d. surface of the PCFBC-exposed/extended life-tested McDermott CFCC filter element.

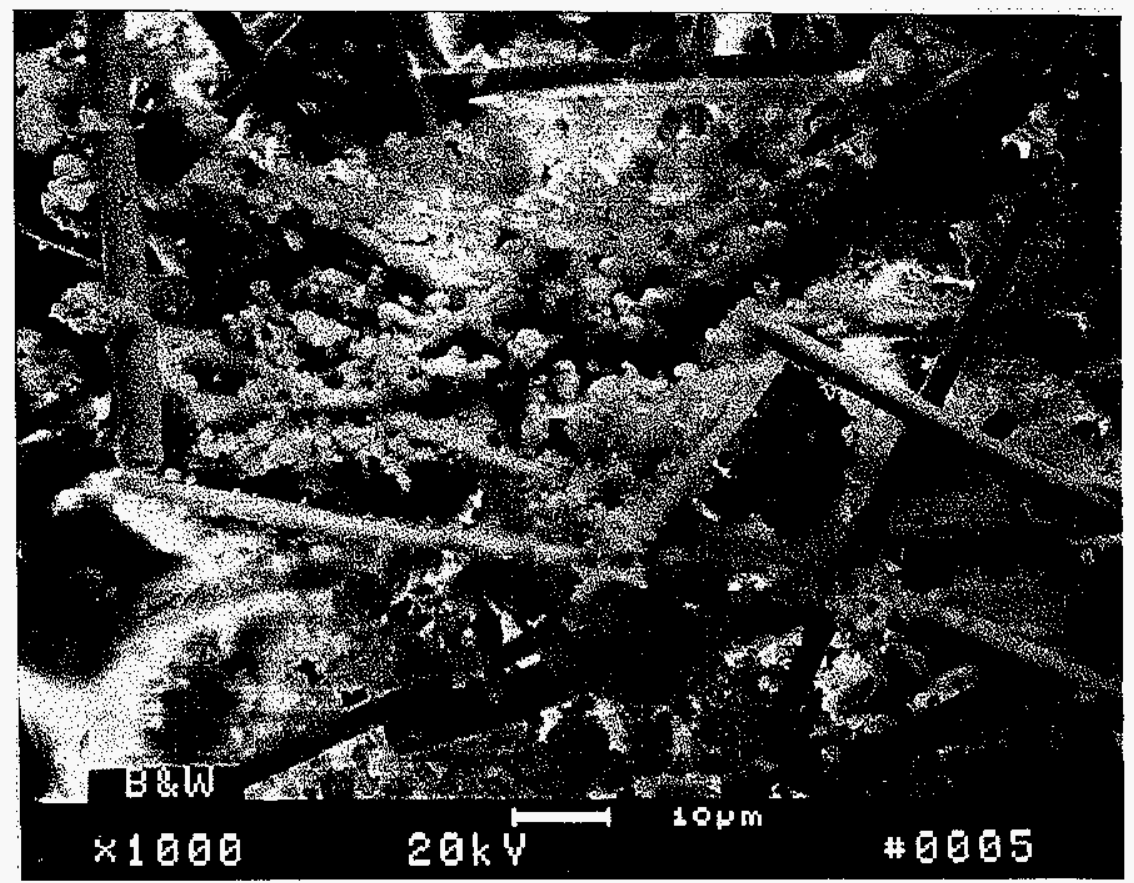

Figure 3-128 - Higher magnification micrograph illustrating the morphology of the i.d. or pulse cycled surface of the PCFBC-exposed/extended life-tested McDermott CFCC filter element. 

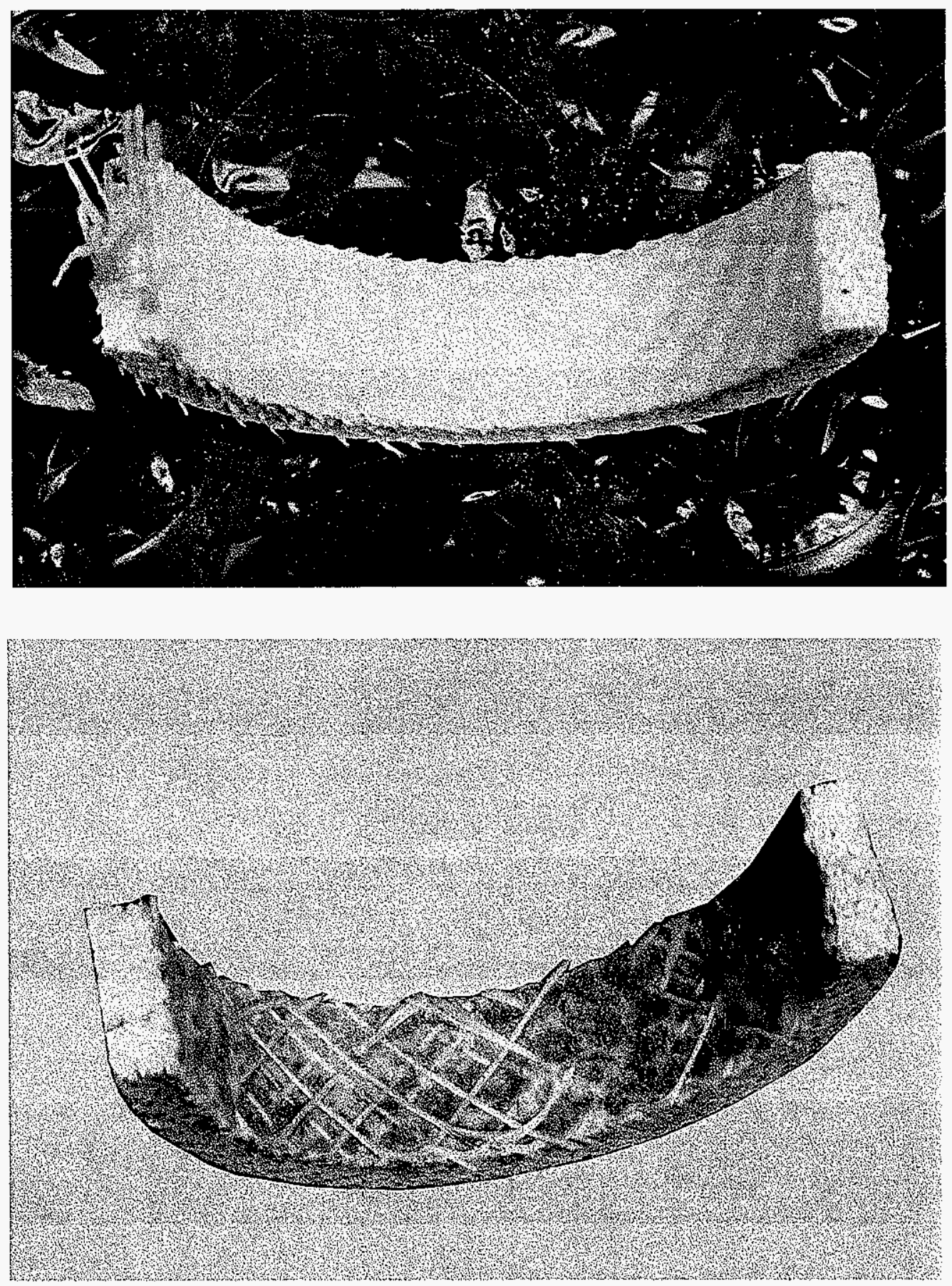

Figure 3-129 - Top photograph identifies the continuous chopped fiber matrix along the i.d. surface of the as-manufactured McDermott CFCC filter wall, while the bottom photograph illustrates removal of the chopped fiber matrix with exposure of the underlying filament fiber bundles after field operation. 


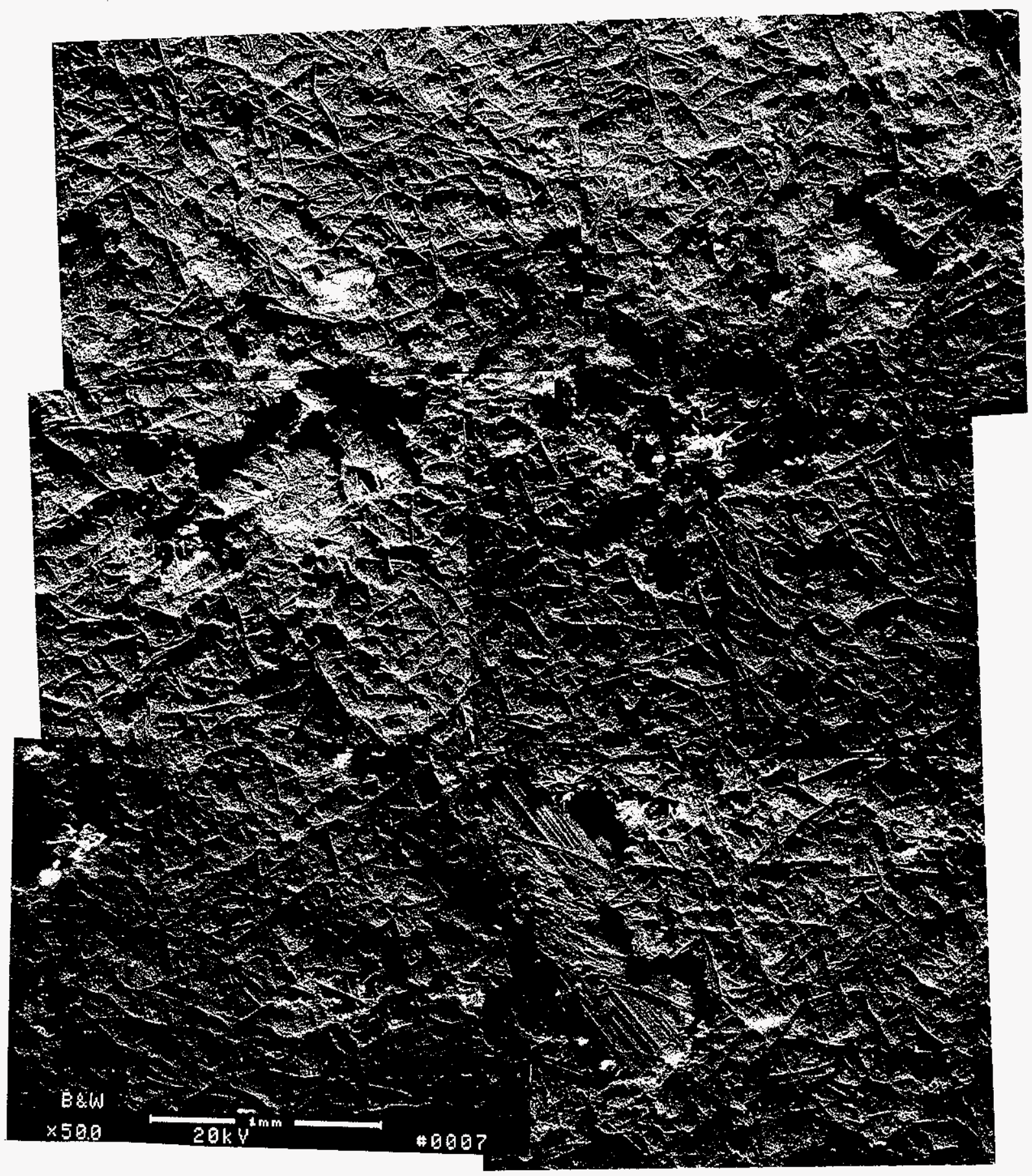

Figure 3-130 - Morphology of the outer surface of the PCFBC-exposed/extended life-tested McDermott oxide-based CFCC filter matrix. 


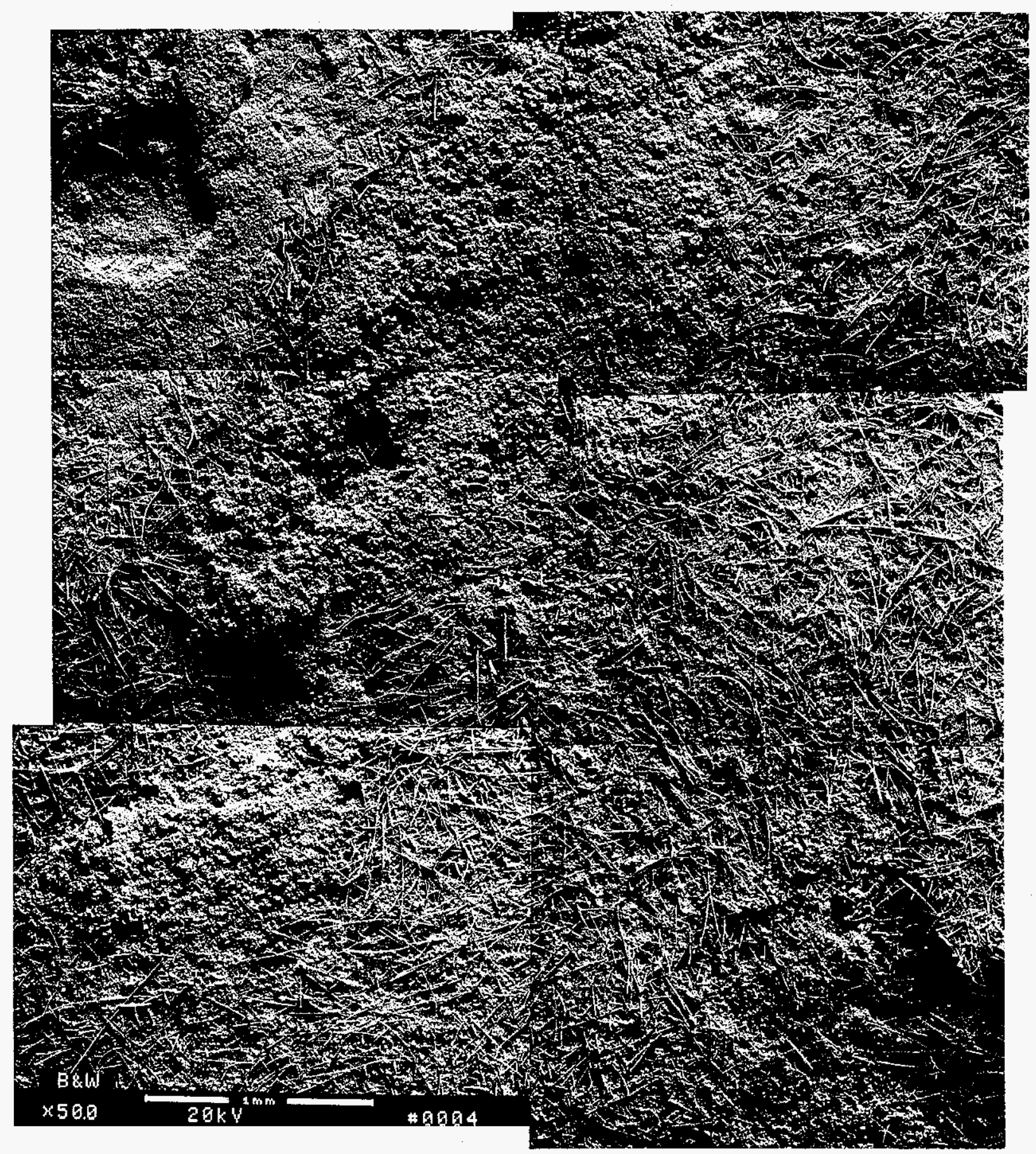

Figure 3-131 - Micrograph montage illustrating the morphology of the i.d. or pulse cycled surface of the PCFBC-exposed/extended life-tested McDermott CFCC filter element. 


\subsubsection{Blasch Mullite-Bonded Alumina}

Microstructural characterization was conducted on the monolithic, mullite-bonded alumina, Blasch filter element identified as BP-270 P7/97 (B41) which had been exposed for 581 hours at the Foster Wheeler PCFBC test facility in Karhula, Finland, and which subsequently experienced 10,045 hours of equivalent operating life and thirty simulated thermal transients in the PFBC simulator test facility in Pittsburgh, PA. Post-test characterization of the aged element's microstructure was conducted via SEM/EDAX analysis.

Crystallization of the aluminosilicate-enriched binder phase resulted along the outer surface of the ligaments and/or alumina grains in the Blasch mullite-bonded alumina filter matrix after 581 hours of operation in the PFBC environment. Negligible change in the microstructure of the Blasch mullitebonded alumina filter matrix resulted after additional exposure to an equivalent of 10,045 hours of PFBC operation, and exposure to thirty simulated thermal transients. Extended process exposure is expected to promote limited but continued crystallization throughout the binder-containing ligaments or bond posts.

As shown in Figure 3-132, 3-133, and 3-134, the open porosity of the Blasch filter matrix was retained after being exposed for 581 hours to the PCFBC environment, and 10,045 hours of equivalent PFBC operation. Fines were retained along the non-membrane coated outer surface of the filter element with negligible penetration of ash particulates into the first and/or second pore layers.

The PCFBC-exposed/extended life-tested Blasch mullite-bonded alumina filter matrix consisted of alumina-enriched grains that were held together by striated ligaments. Although principally evident below the outer surface of the filter element, extensive directional banding of striated ligaments was randomly observed throughout the filter matrix as a result of the manufacturing process (Figures 3-135 through 3-138).

Extensive crystallization was evident along the surface of the grains and/or ligaments that were present near the outer and/or inner (pulse cycled) surfaces of the PCFBC-exposed/extended life-tested Blasch mullite-bonded alumina filter matrix (Figures 3-139 through 3-147). Limited crystallization was observed through the fractured ligaments or bond posts.

In contrast, limited crystallization was evident along the mid-section of the PCFBCexposed/extended life-tested Blasch filter matrix. The extent of crystallization was considered to reflect the quantity or thickness of the binder-containing mullite phase that was present either along the outer surface of the alumina-enriched grains, or within the ligament bond posts. 

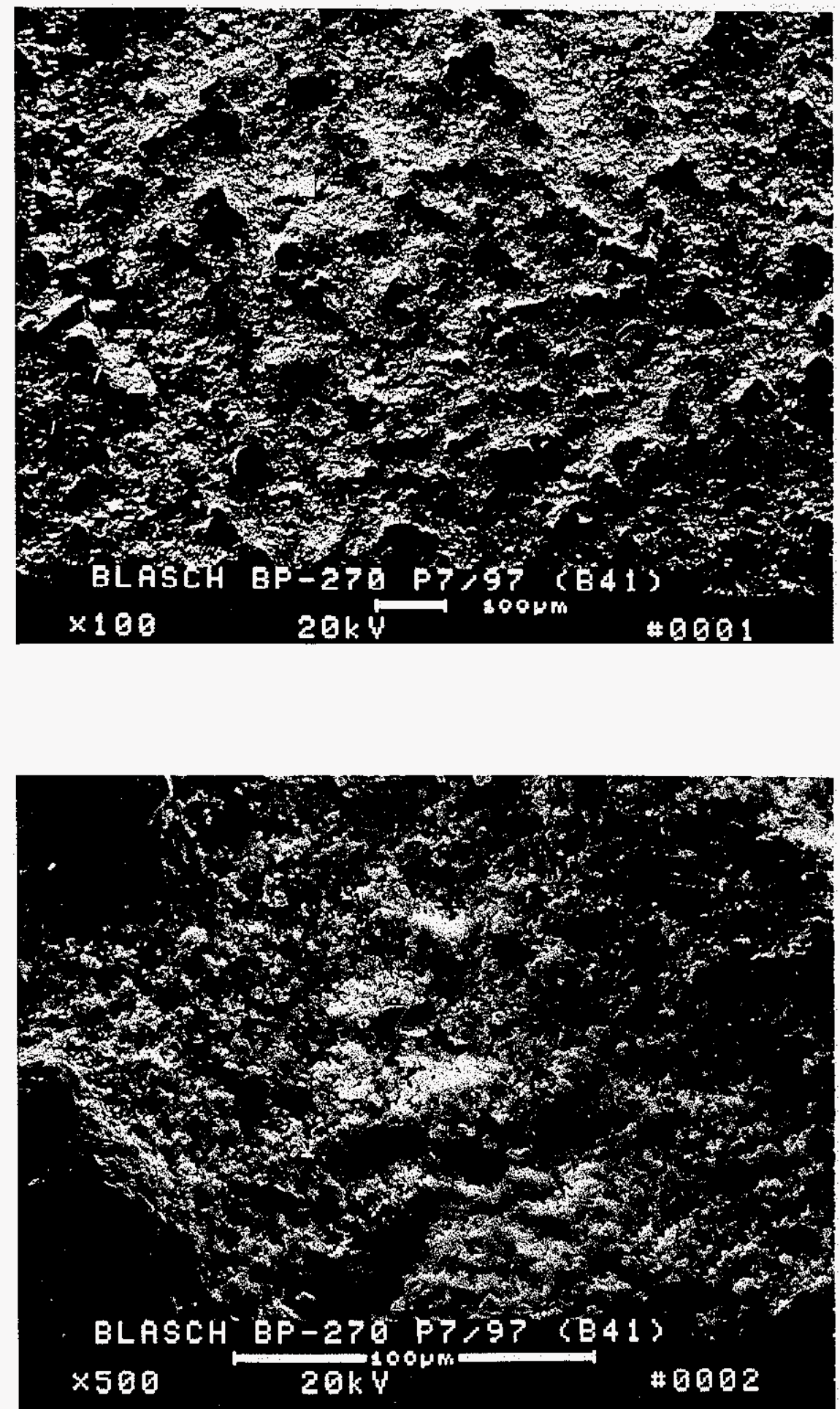

Figure 3-132 — Morphology of the outer surface of the PCFBC-exposed/extended life-tested Blasch mullite-bonded alumina filter matrix. 

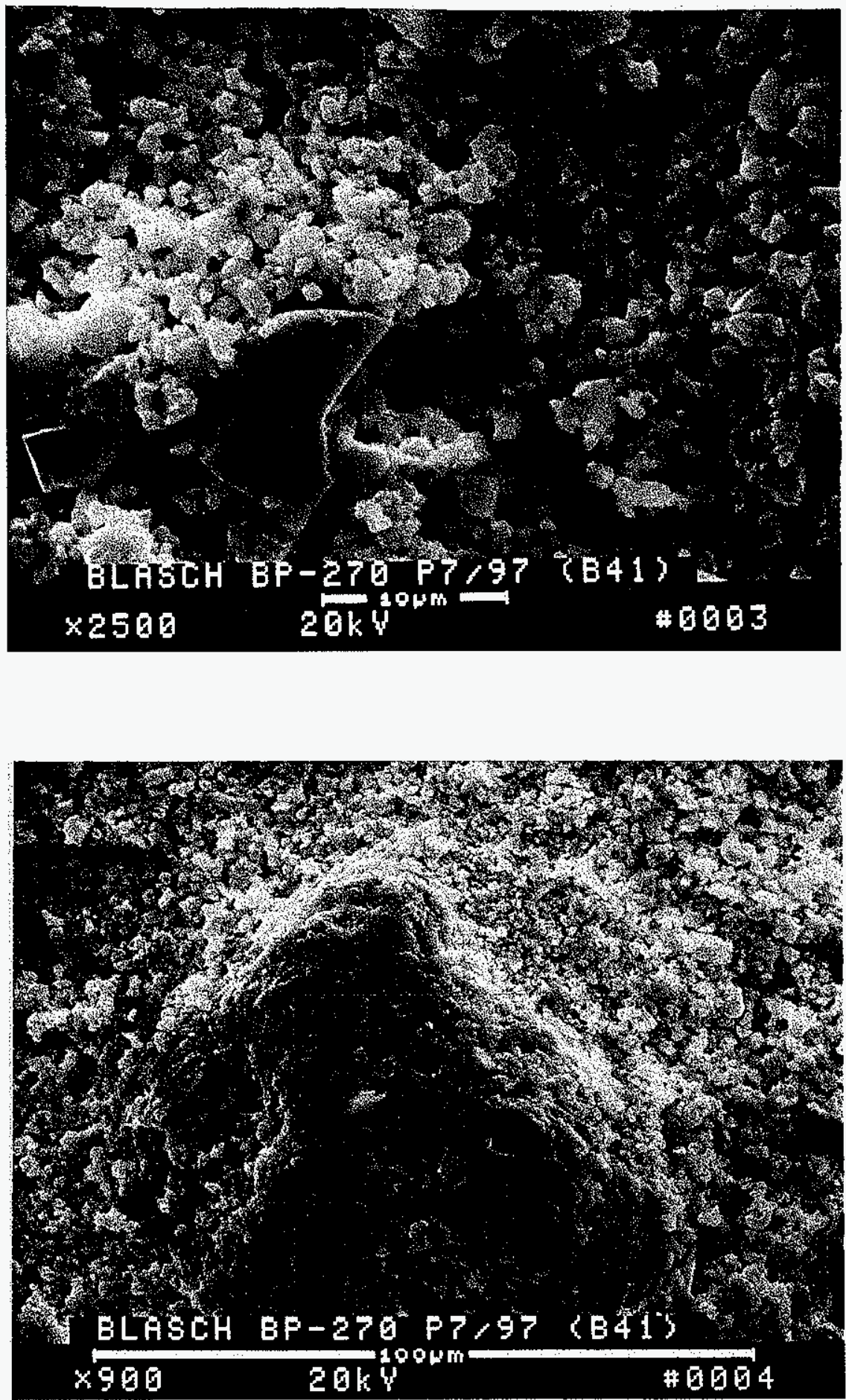

Figure 3-133 - Higher magnification micrograph illustrating the morphology of the outer surface of the PCFBC-exposed/extended life-tested Blasch mullite-bonded alumina filter matrix. 


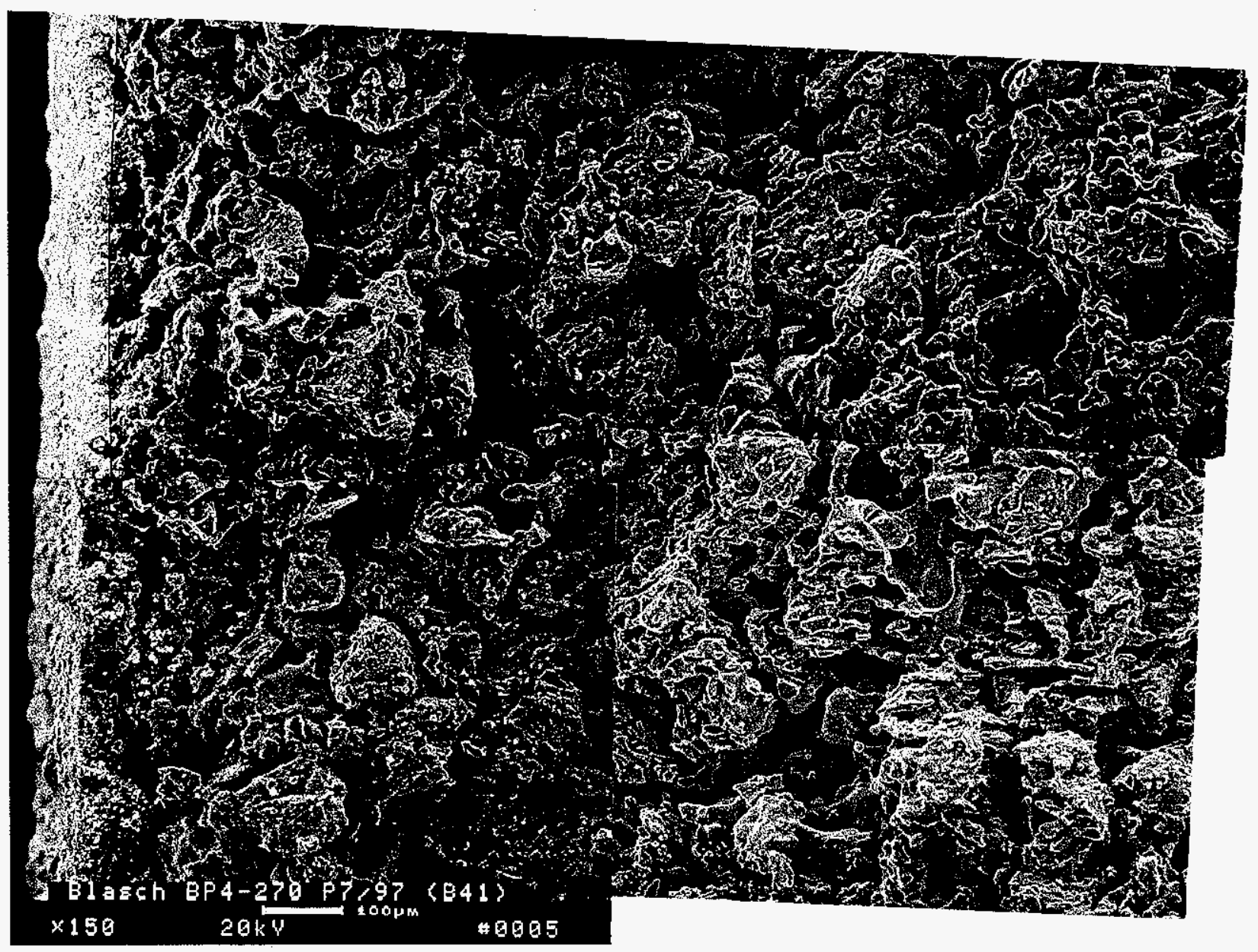

Figure 3-134 - Morphology of the cross-sectioned, PCFBC-exposed/extended life-tested, Blasch filter matrix near the outer surface of the filter element. 


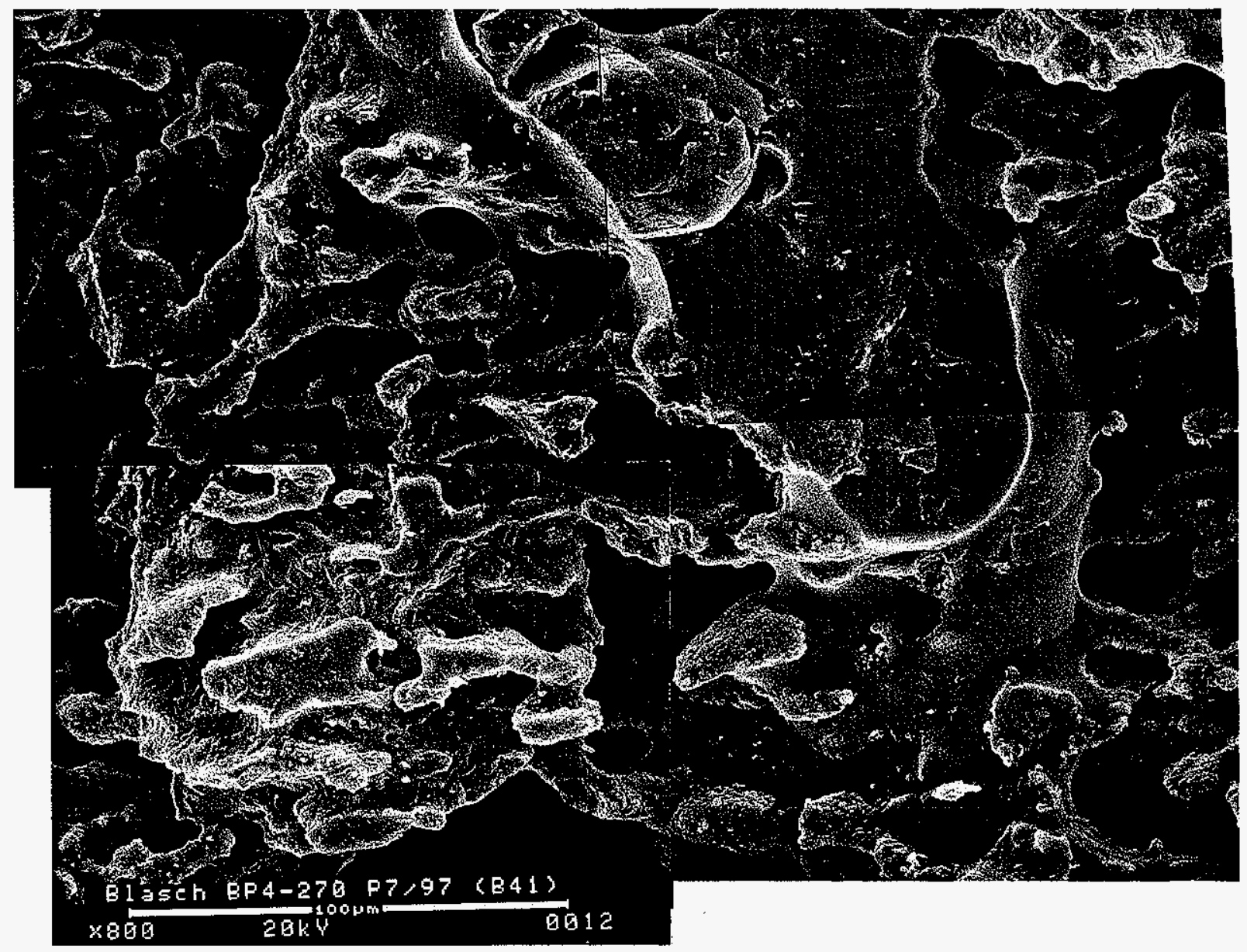

Figure 3-135 - Micrograph montage illustrating the morphology of the PCFBC-exposed/extended life-tested Blasch filter matrix at $\sim 500-600 \mu \mathrm{m}$ below the outer surface of the filter element. Striated ligaments and crystallization along the surface of the pore cavity walls were observed. 


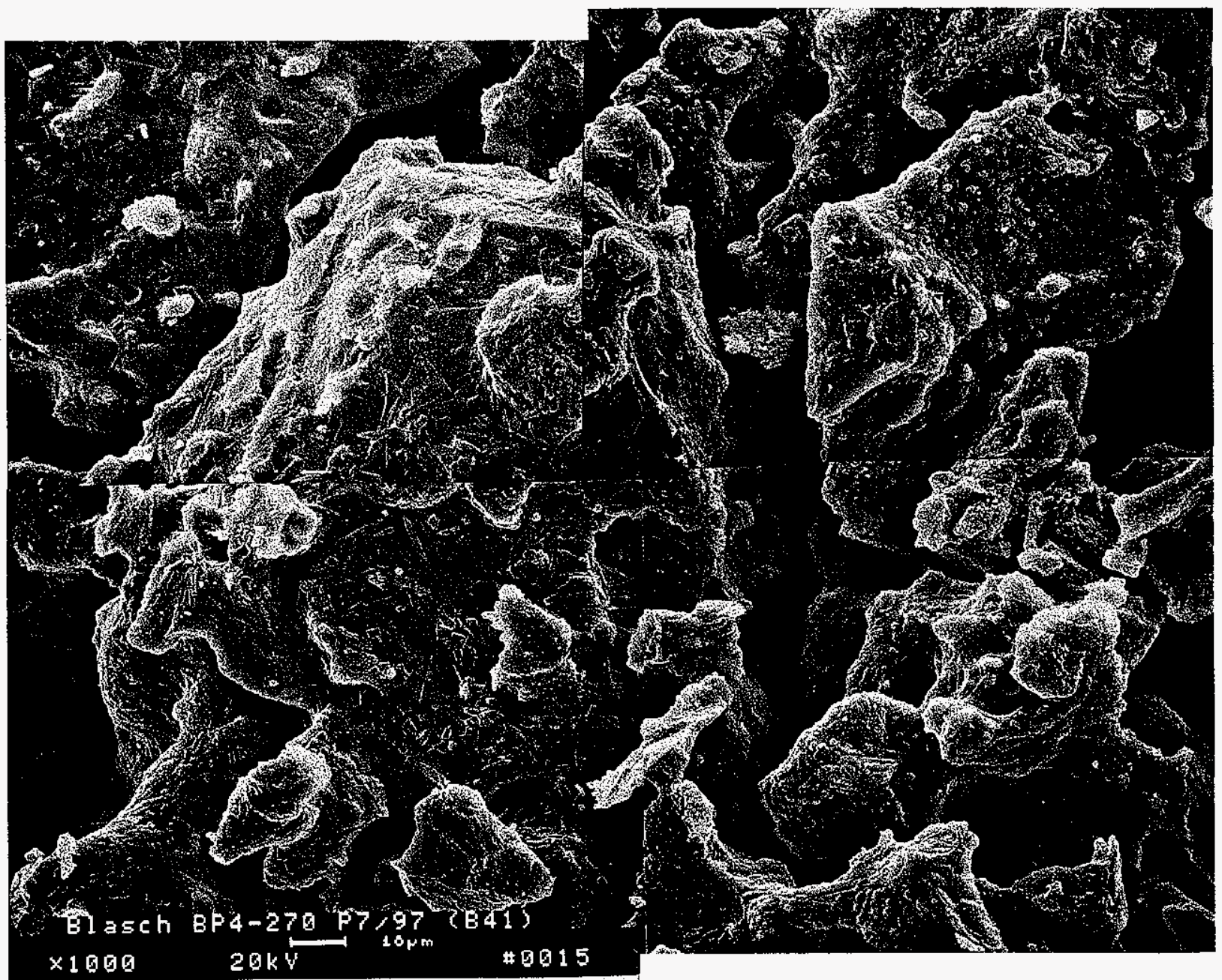

Figure 3-136 - Micrograph montage illustrating the crystalline surface morphology of the nearly rounded grains that were present at $\sim 500-600 \mu \mathrm{m}$ below the surface of the PCFBCexposed/extended life-tested Blasch filter matrix. 


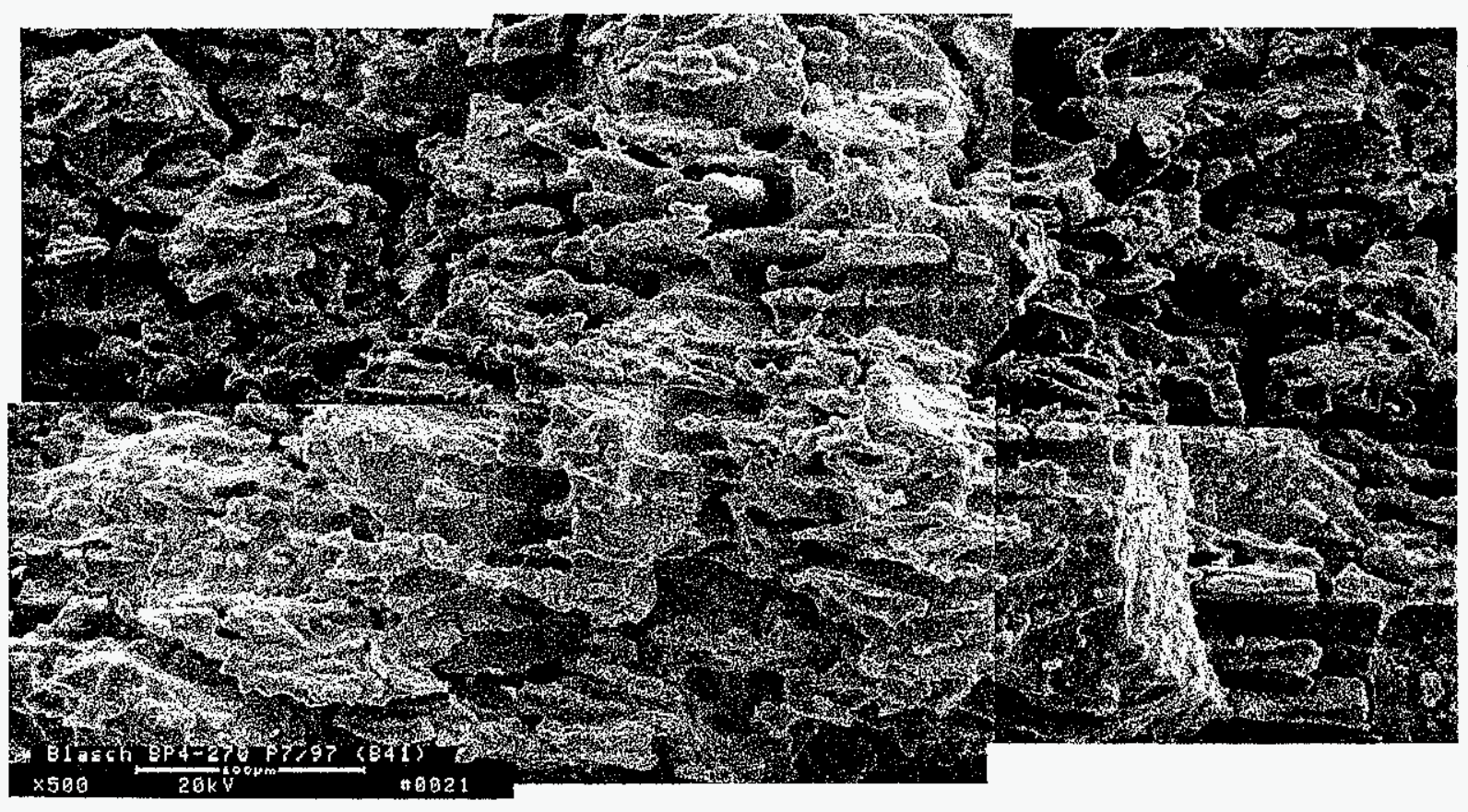

Figure 3-137 - Micrograph montage illustrating the morphology of the striated ligament formations that were present within the PCFBC-exposed/extended life-tested Blasch filter matrix near the center of the filter wall. 


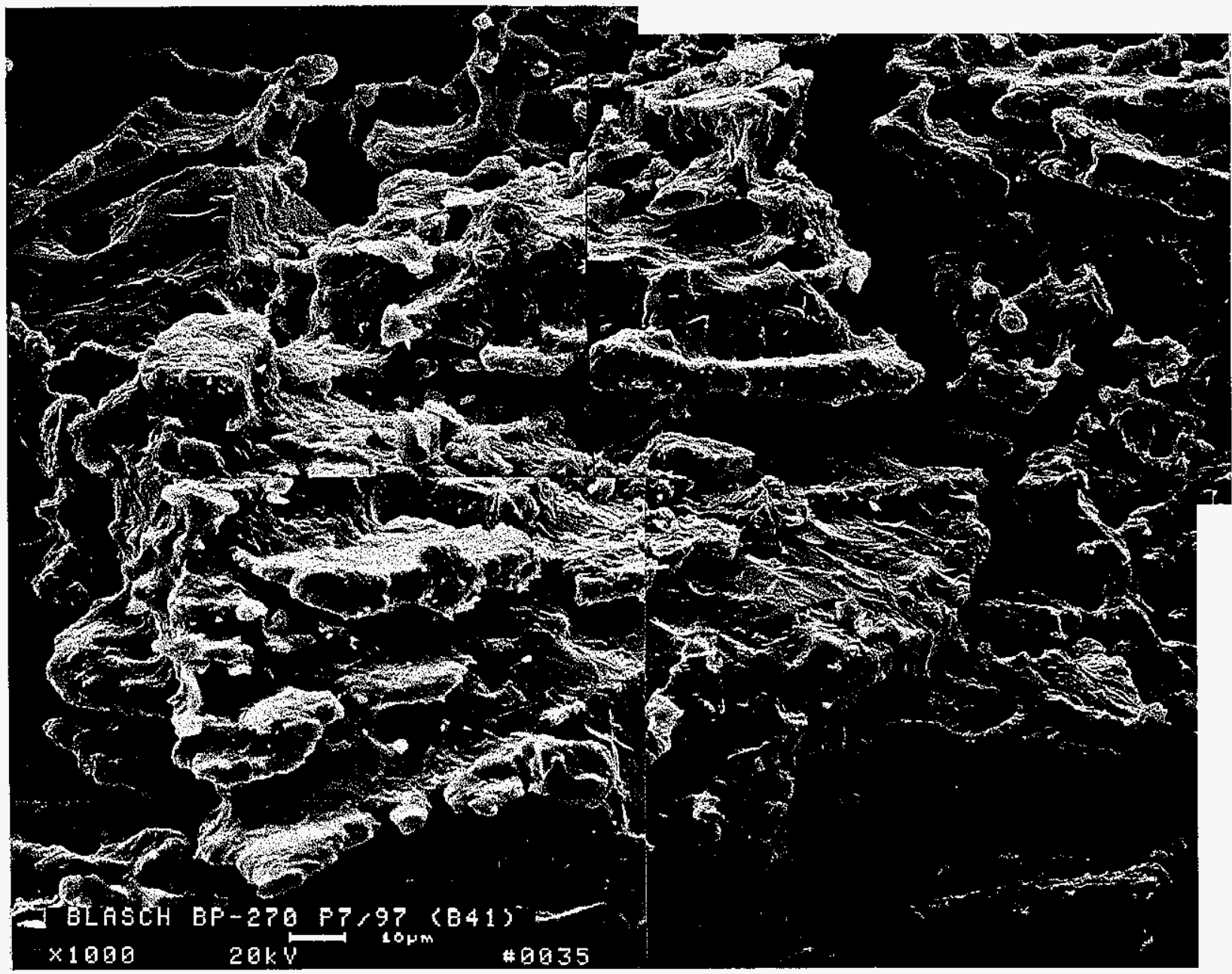

Figure 3-138 - Micrograph montage illustrating the morphology of the striated features that were present within the cross-sectioned, PCFBC-exposed/extended life-tested, Blasch filter matrix near the inner or pulse cycled surface of the filter element. 


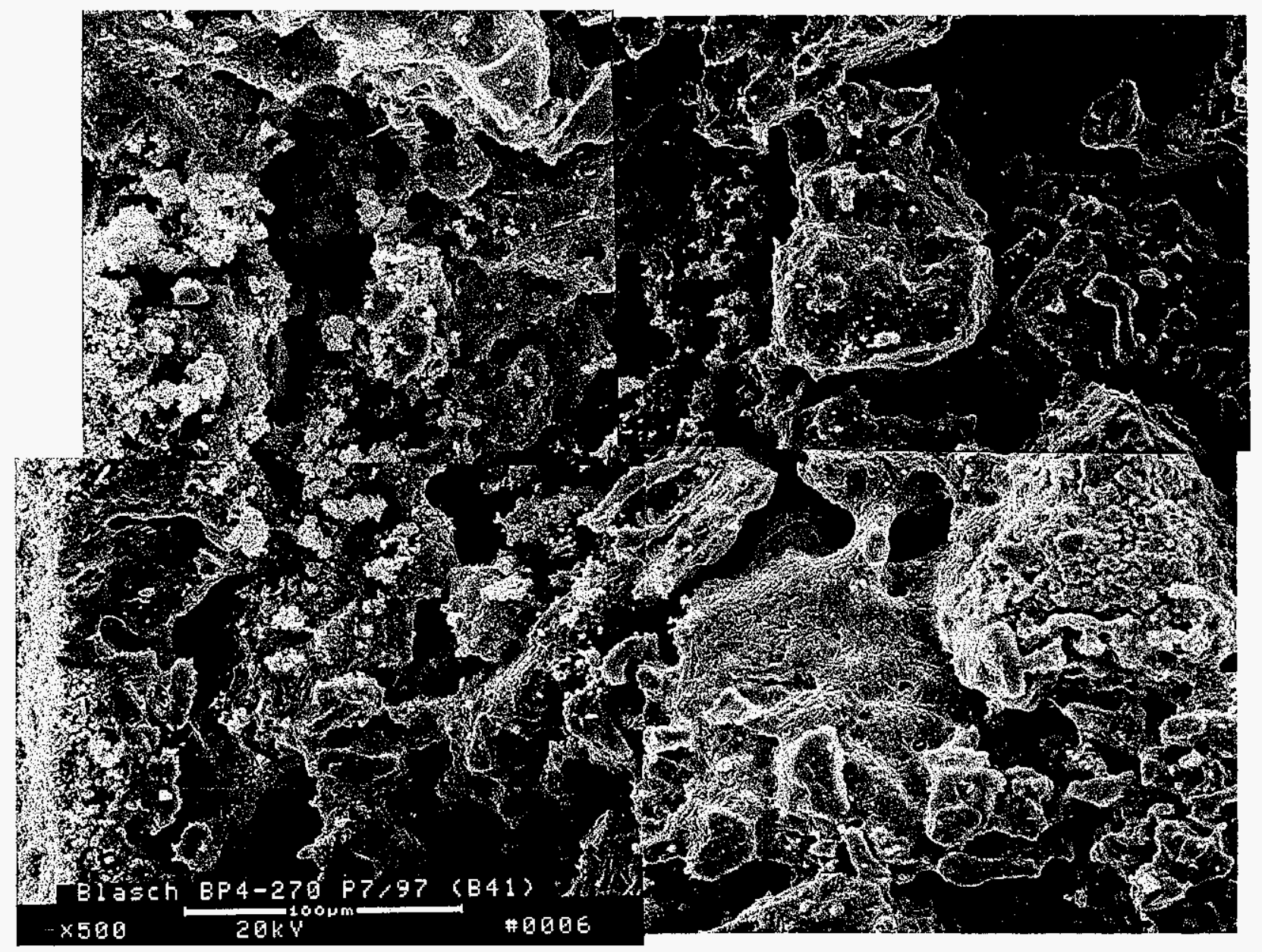

Figure 3-139 - Micrograph montage illustrating the morphology and open porosity of the PCFBCexposed/extended life-tested Blasch filter matrix near the outer surface of the filter element. 


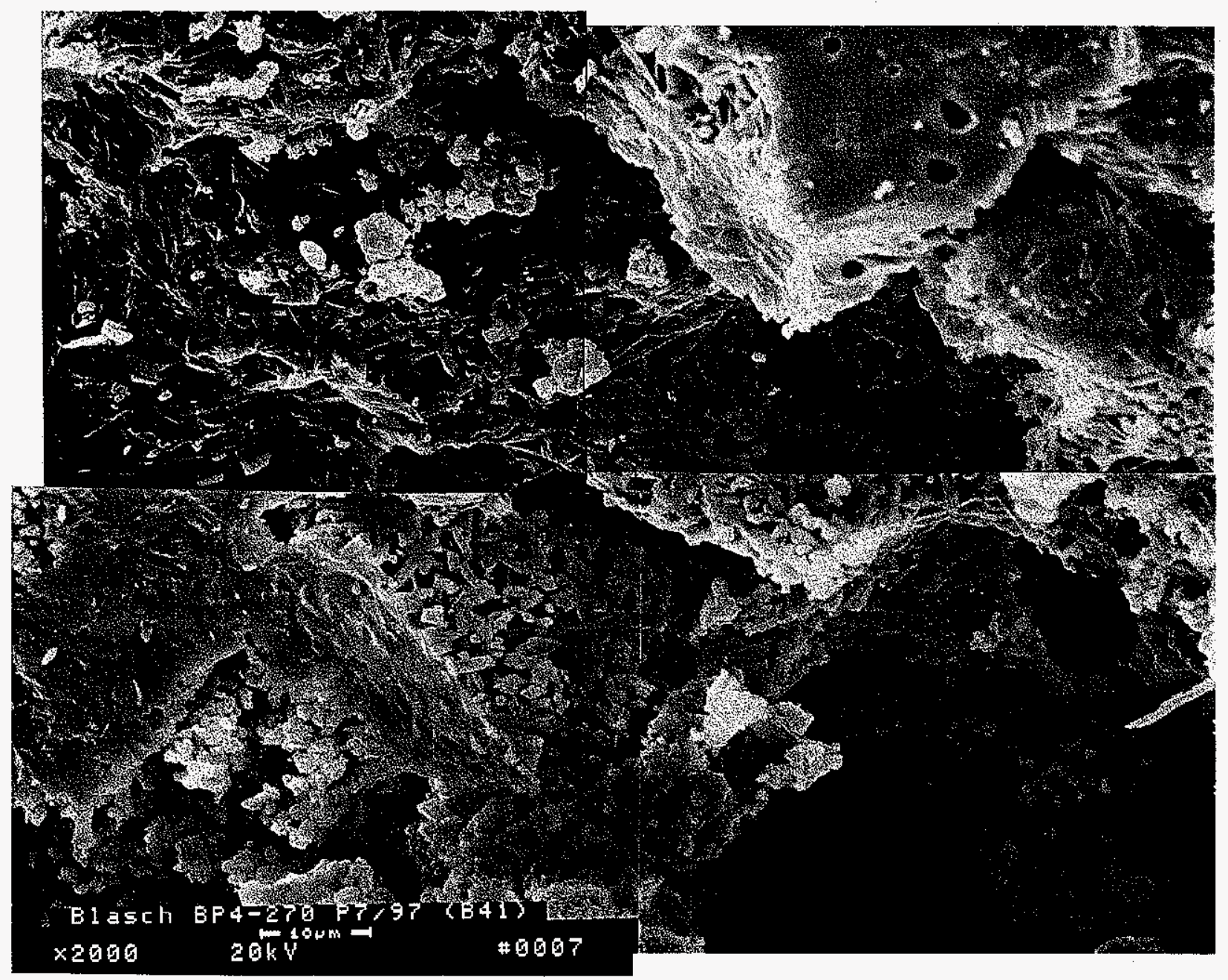

Figure 3-140 - Micrograph montage illustrating the morphology of the crystallized surface of the pore cavity walls that resulted within the PCFBC-exposed/extended life-tested Blasch filter matrix near the outer surface of the filter element. 

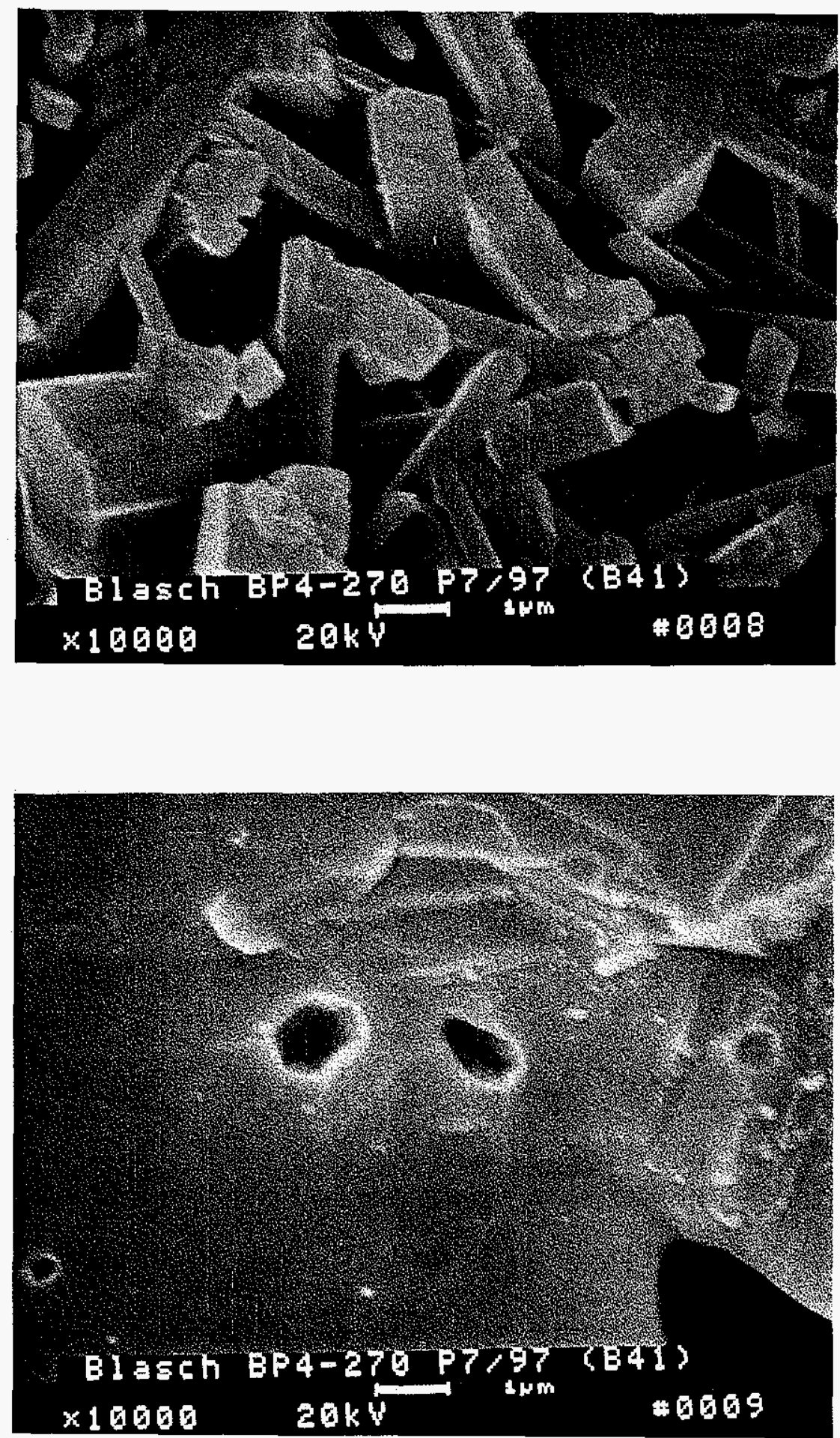

Figure 3-141 - Higher magnification micrographs illustrating the morphology of the crystals that were formed along the outer surface of the grains which were present near the outer surface of the PCFBC-exposed/extended life-tested Blasch filter element. Limited crystallization was apparent along the surface of the fractured grain. 


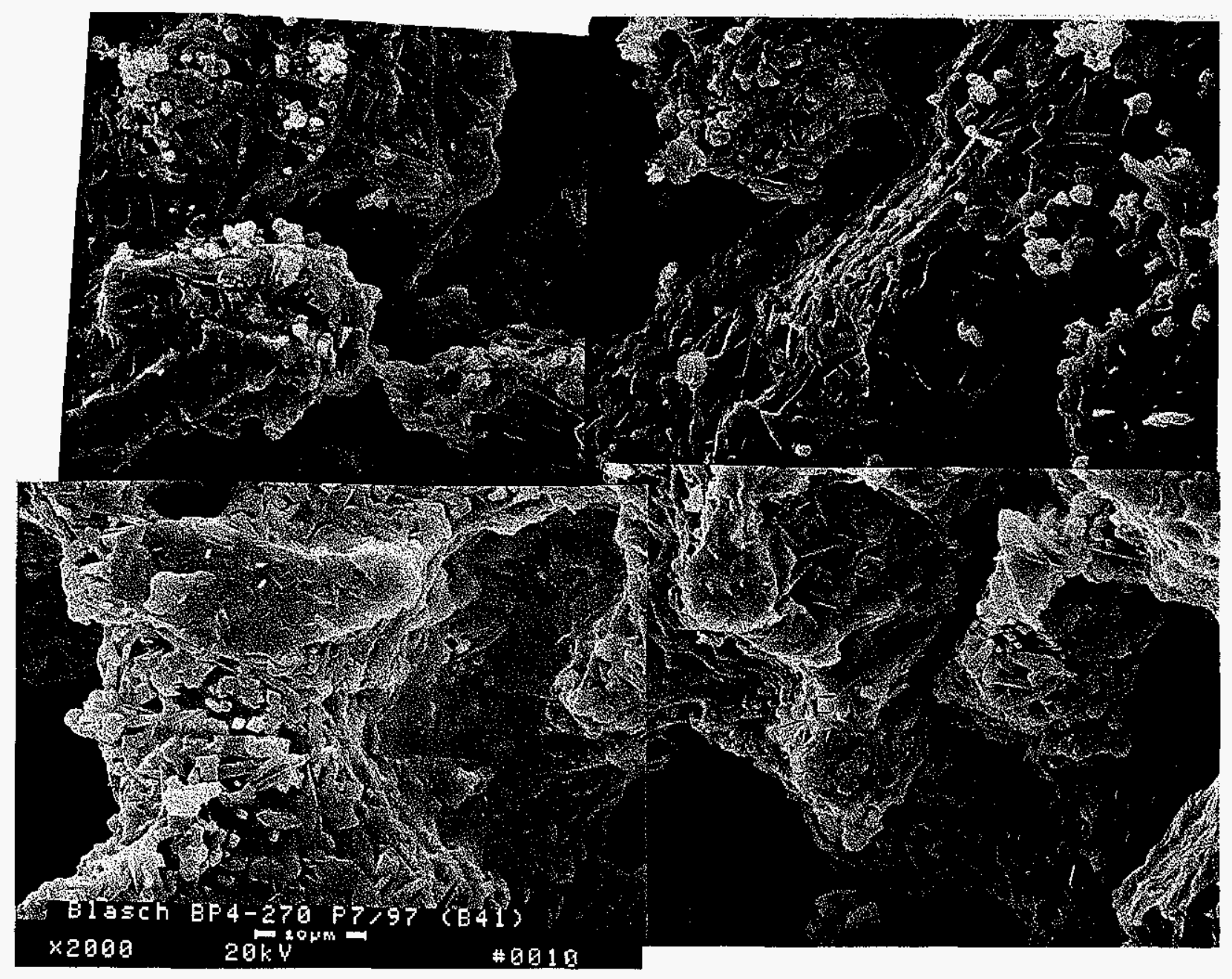

Figure 3-142 - Micrograph montage illustrating extensive crystallization that resulted along the outer surface of the pore cavity walls in the PCFBC-exposed/extended life-tested Blasch filter matrix near the outer surface of the filter element. Limited crystallization was, however, evident along the cross-sectioned ligaments. 


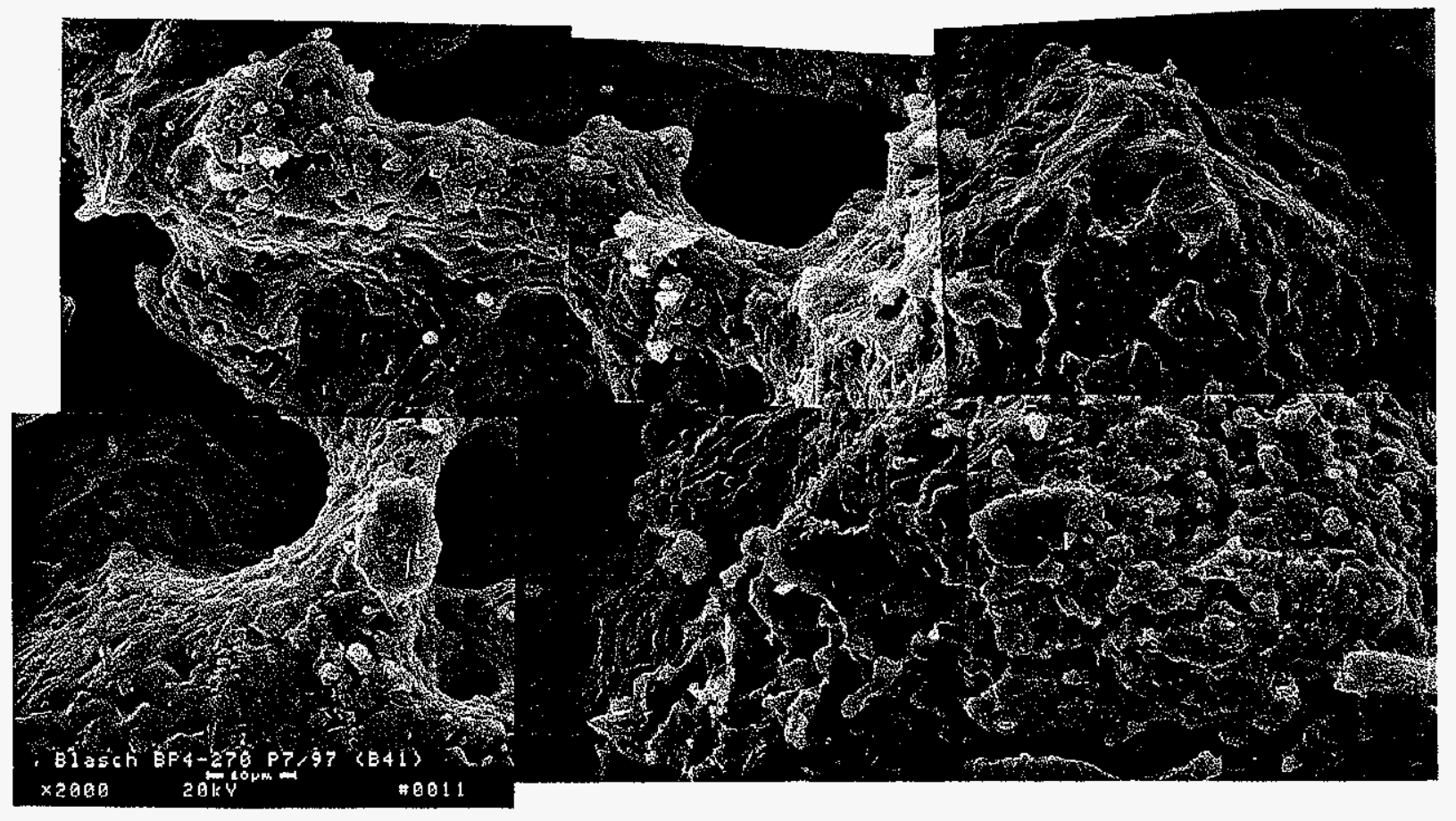

Figure 3-143 - Micrograph montage illustrating extensive crystallization that resulted along the surface of the pore cavity walls within the PCFBC-exposed/extended life-tested Blasch filter matrix at $\sim 200 \mu \mathrm{m}$ below the outer surface of the filter element. 

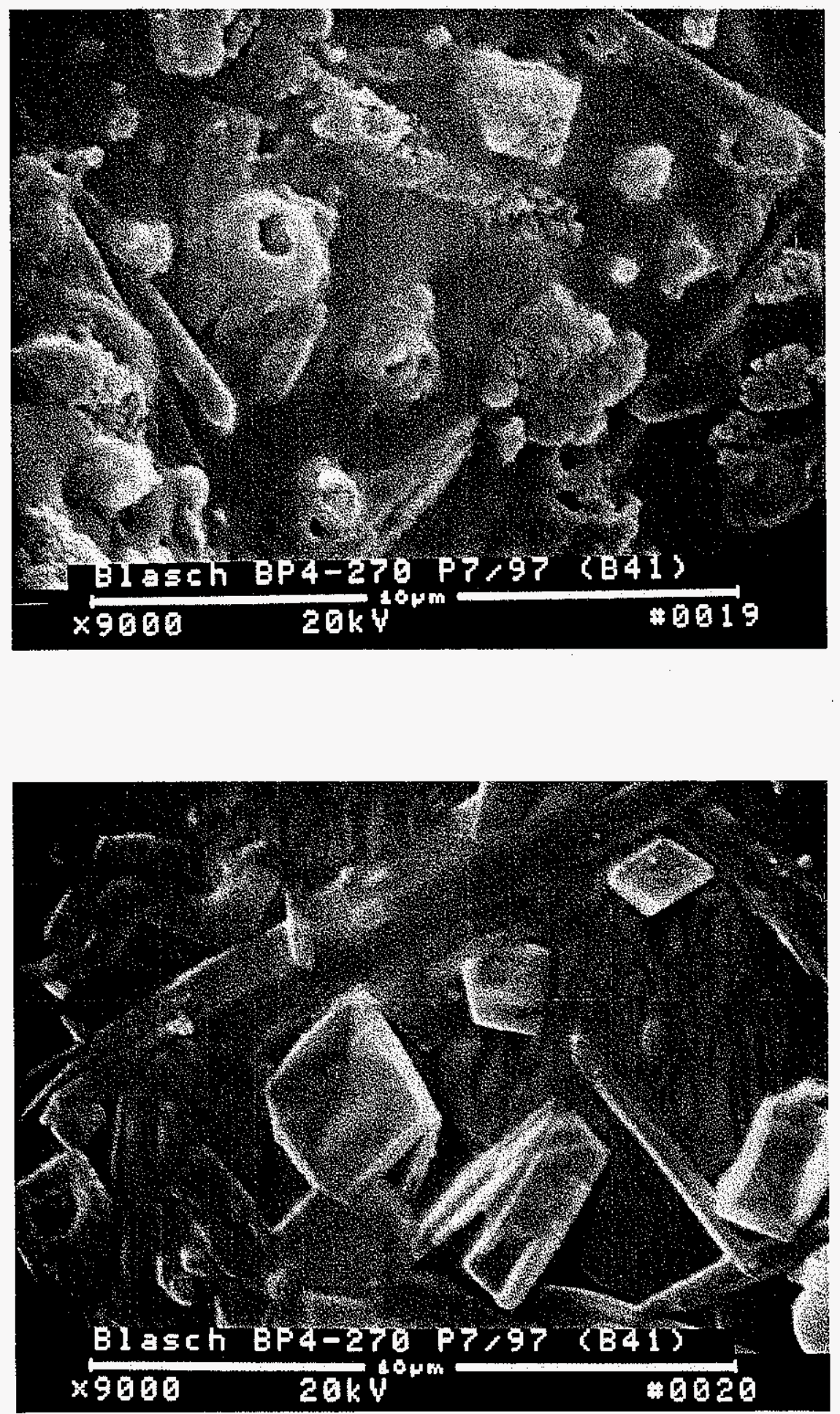

Figure 3-144 - Higher magnification micrographs illustrating the morphology of the crystalline features that formed along the surface of the nearly rounded grains that were present at $\sim 500-600 \mu \mathrm{m}$ below the surface of the PCFBC-exposed/extended lifetested Blasch filter matrix. 


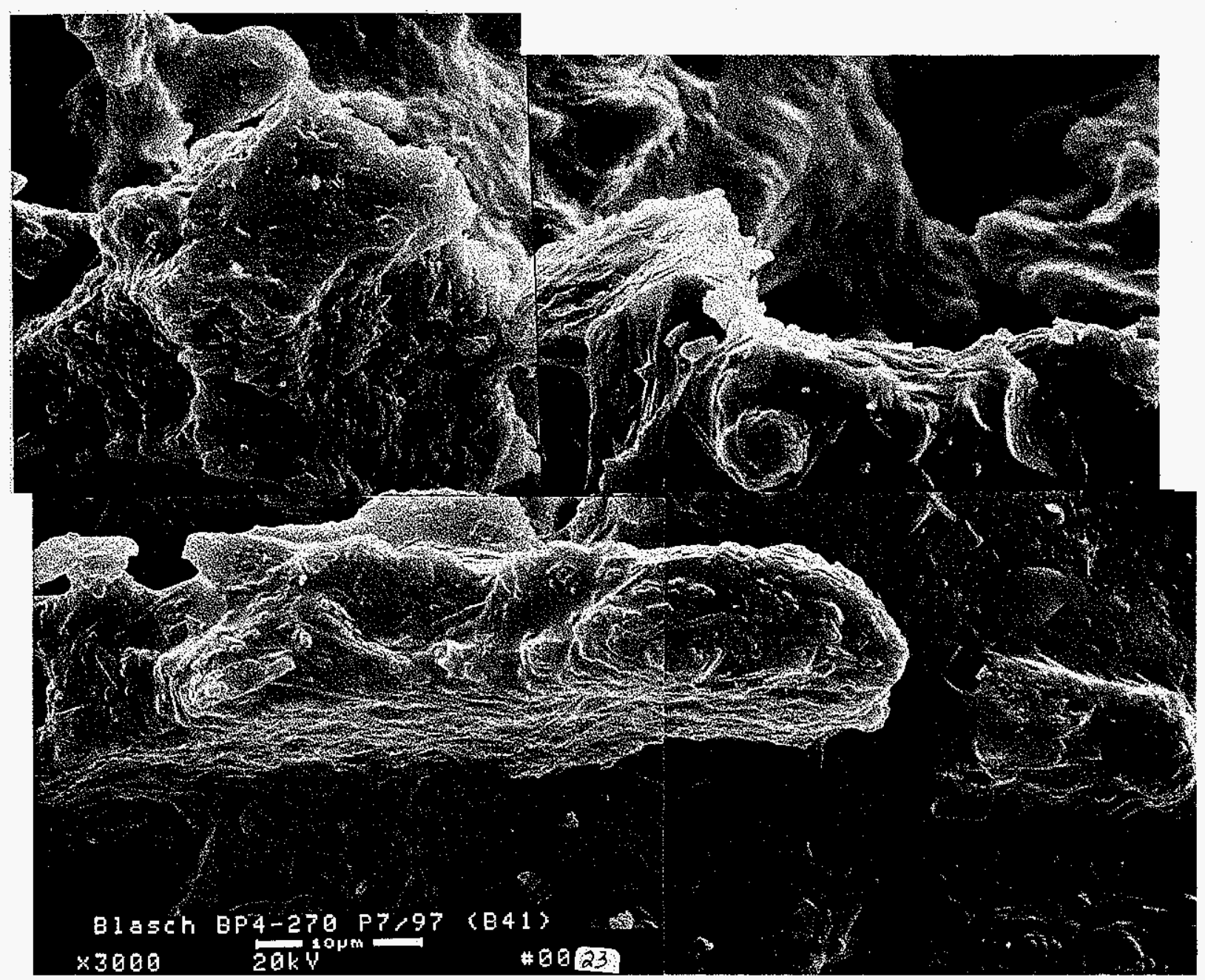

Figure 3-145 - High magnification micrograph montage illustrating the morphology of the crystalline features that resulted along the surface of the striated ligaments that were present near the center of the PCFBC-exposed/extended life-tested Blasch filter wall. 


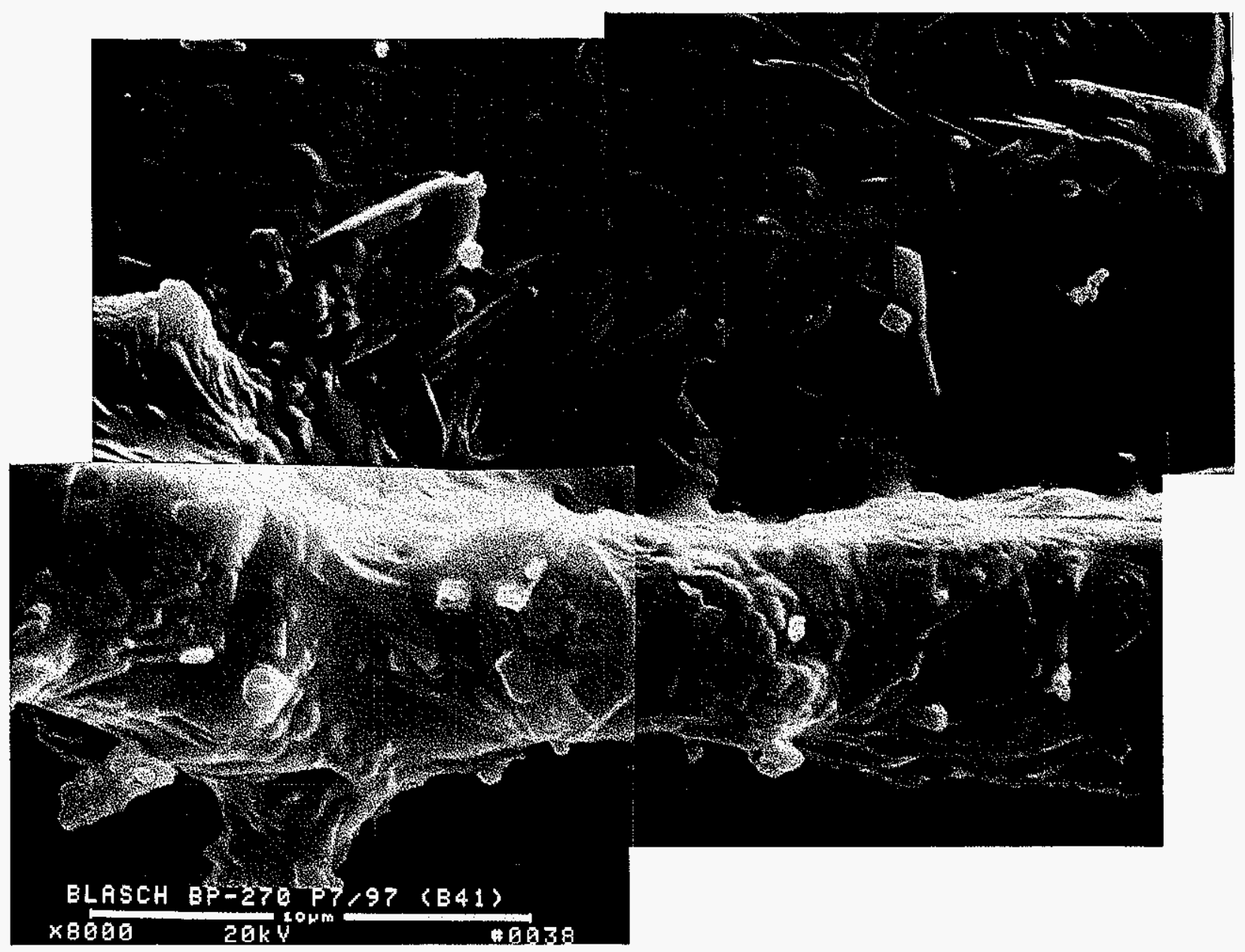

Figure 3-146 - Micrograph montage illustrating the limited crystallization that resulted along the surface of the striated ligaments that were present near the inner or pulse cycled surface of the PCFBC-exposed/extended life-tested Blasch filter element. 


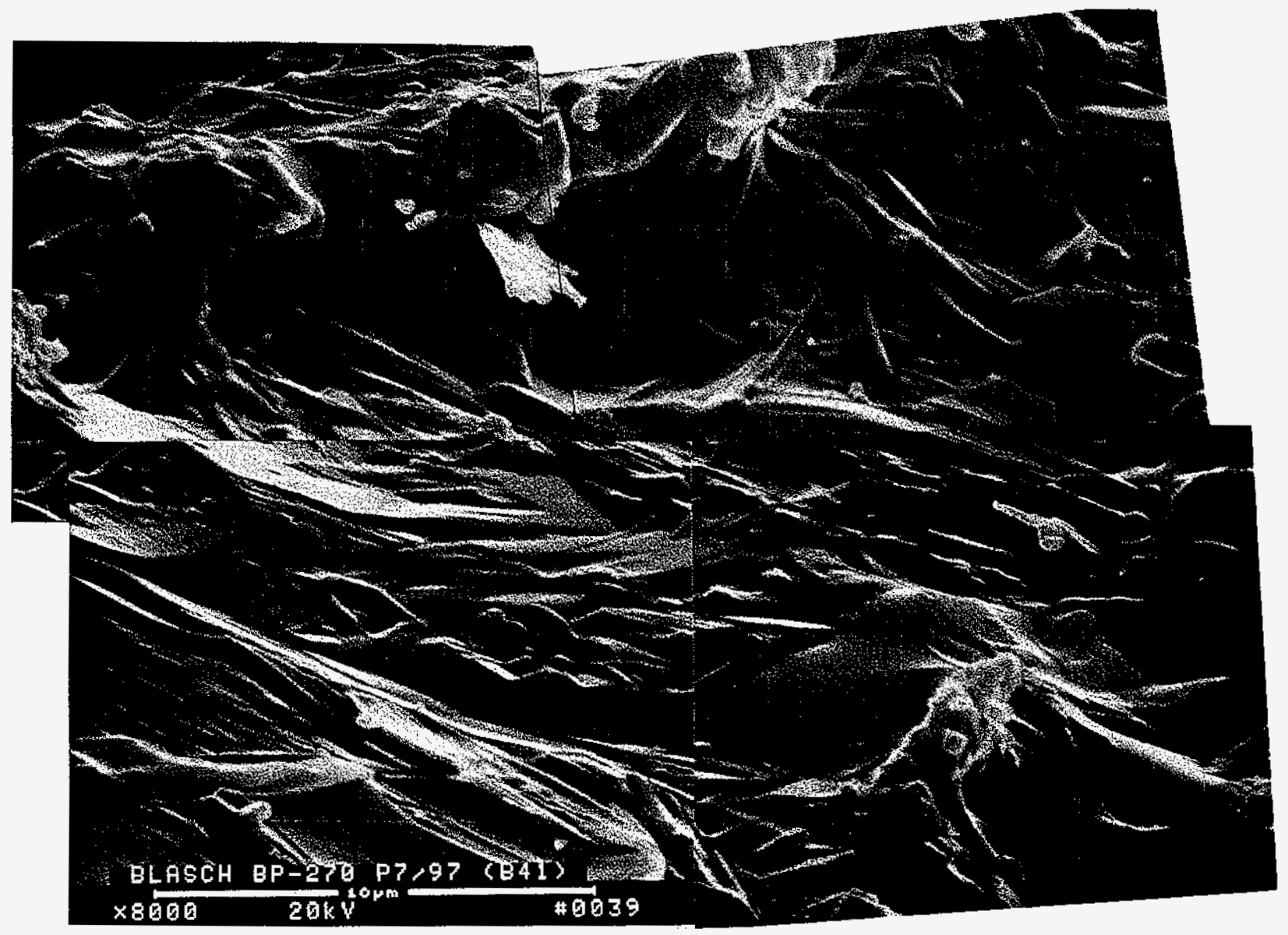

Figure 3-147 - Micrograph montage illustrating the morphology of the mullite-like rods that had formed along the surface of the alumina-enriched grains which were present near the inner or pulse cycled surface of the PCFBC-exposed/extended life-tested Blasch filter element. 


\section{IMPACT OF PROCESS AGING ON THE STABILITY OF POROUS CERAMIC FILTER MATERIALS}

Microstructural changes occurred within the porous ceramic filter matrices during the initial 5000 hours of operation in high temperature PFBC and PCFBC systems. Efforts at SWPC STC and elsewhere have been undertaken to address whether the observed microstructural changes can be related to changes in the mechanical properties of the porous ceramic filter materials, and if total operating life of the filter elements can be projected. An overview summary of the microstructural changes that occurred within the porous ceramic filter matrices as a function of time is provided in this section, showing commonality between the various materials during the early stage of operation in the high temperature PFBC and PCFBC environments. A discussion of how process operation impacts the overall life of these materials is provided in the following section.

\subsection{Oxide-Based Ceramic Filter Materials}

Commercially available and developmental porous ceramic filter materials are generally classified as oxides which principally contain alumina, mullite, and/or cordierite, and as nonoxides which consist of silicon carbide or silicon nitride. Although the architecture of the filter elements varies (i.e., monolithic, filament wound, $\mathrm{CFCC}$ ), and the manufacturing procedures differ, commonality between the response of the oxides, as well as nonoxides reflects the presence of similar phases and constituents within each material. For example, mullite which is present as a principal phase in the Coors P-100A-1 alumina/mullite filter matrix experiences extensive crystallization with extended operating time, leading to the formation of dendritic and needle-like structures that extend into the interior of the pore cavities. Crystallization of the alumina/silica binder-containing layer that encapsulates the outer surface of the silicon carbide grains in the clay bonded silicon carbide filter materials, similarly leads to the in-situ formation of the dendritic, needle or rod-like phase.

Mullite which is incorporated into the Blasch matrix as the binder phase that holds adjacent alumina-enriched grains together, similarly undergoes extensive in-situ crystallization, leading the formation of rod-like features along the surface of the structural support grains. In contrast, the crystalline rod-like formations along the surface of the alumina-enriched grains in the mullite-bonded Ensto matrix, result during manufacturing of the filter element. The extent of mullitization and grain growth in the alumina and mullite-enriched oxide-based materials is limited to the concentration of precursor mullite and free silica that is present in contact with the alumina support grains in the asmanufactured filter matrices. Additionally, the final high firing temperature and the time at temperature that are used during fabrication of the filter elements, both control the quantity of mullite formed in the as-manufactured porous matrices. For the nonoxide-based materials, the extent of mullitization is limited to the concentration of alumina and silica present in the binder-containing phase, and the concentration of silica resulting from oxidation of the underlying silicon carbide structural support grains.

With time, extensive crystallization throughout the Coors P-100A-1 alumina/mullite filter matrix ligaments results, imparting strength to the material. As a result of contact with the pulse cleaning gas, nearly spherical $\sim 2-4 \mu \mathrm{m}$ crystalline features form at the tips of blunted mullite-enriched rods that extend into the pore cavities near and along the i.d. surface of the Coors P-100A filter elements. Similar crystallization throughout the mullite-containing ligaments and along the pulse cycled surface of the Blasch and Ensto oxide-based filter matrices is expected to occur during extended operation in the PFBC and PCFBC environment. 
Similar to the oxide-based monolithic filter materials, crystallization and grain growth within the Nextel $^{\mathrm{TM}} 610$ fibers in the McDermott CFCC filter matrix results during the first 581 hours of PCFBC operation. Although crystallization or grain growth may impart strength to the CFCC matrix, embrittlement and a reduction in the fracture toughness of the matrix may occur with time.

\subsection{Nonoxide-Based Ceramic Filter Materials}

The sequence of microstructural changes that results in the clay bonded silicon carbide filter matrices as a function of time during operation in the PFBC/PCFBC environment includes ${ }^{(7)}$

- Coalescence and crystallization of the binder coating along the surface of the silicon carbide grains.

- Oxidation of the silicon carbide grains via diffusion of the process gas phase through the binder coating. Subsequent reaction of gas phase species with the underlying silicon carbide grain occurs, leading to the release of $\mathrm{CO}_{2}$, mottling of the silicon carbide grain surface, and the formation of silica below the partially or fully crystallized binder coating.

- Crystallization along the outer surface of the binder-enriched bond posts or ligaments.

- Continued oxidation of the silicon carbide grains, leading to a volume expansion of the matrix, and the formation of a thicker oxide scale.

- Crystallization of the silica-enriched layer, leading to separation from the residual, underlying, mottled surface of the silicon carbide grain.

- Continued diffusion of the process gas through the binder and/or oxide-enriched layer that encapsulates the surface of the silicon carbide grains, with continued oxidation of the underlying silicon carbide grains, leading to the formation of areas enriched with crystallized silica, amorphous silica, and mullite-enriched aluminosilicate rods.

- Enhanced crystallization throughout the binder-enriched bond posts or ligaments.

- Coalescence of the silica-enriched grains, leading to the initiation of a secondary phase formation between the silica-enriched grains along the surface of the silicon carbide structural support grains.

Initial coalescence and crystallization of the binder or oxide-enriched coating, as well as crystallization along the surface of the bond posts or ligaments are expected to impart an increase in strength to the clay bonded silicon carbide filter matrix. However, with extended time, the thickness of the crystalline silica-enriched layer increases, encapsulating the silicon carbide grains, and extends into the crystallized aluminosilicate ligaments or bond posts. Similar to the monolithic oxide-based matrices, thermal fatigue at the junction of the crystallized silica-enriched encapsulating layer and the crystallized binder ligaments, may result with extended service operation, reducing the bulk strength of the filter matrix, and exposing the underlying residual silicon carbide grain(s) to further oxidation.

Figure 4-1 provides a schematic that illustrates the phase changes that result within the clay bonded silicon carbide filter matrix during the first $2500-5000$ hours of operation in the PFBC and PCFBC environment. Removal of the oxidized/binder-containing layer that encapsulates the silicon carbide grains reveals remnants of the hexagonal silica-enriched outer layer and/or the pitted, mottled features of the underlying grain (Figure 4-1, Areas 8 and 9). 
Multiple Phases

- Binder Ligament

- Binder-Oxide Encapsulating Layer

- Oxidized Grain Surface

1. Al-Si-O

2. $\mathrm{SiO}_{2}$

3.SiO

4. Amorphous

5. $\mathrm{Al}_{2} \mathrm{O}_{3} \cdot \mathrm{ySiO}$

6. $\times \mathrm{Al}_{2} \mathrm{O}_{3} \cdot \mathrm{ySiO} \mathrm{SiO}_{2}$ (i.d.)

7.SiC Substrate

8. Crystalline Surface

9. Fluxing

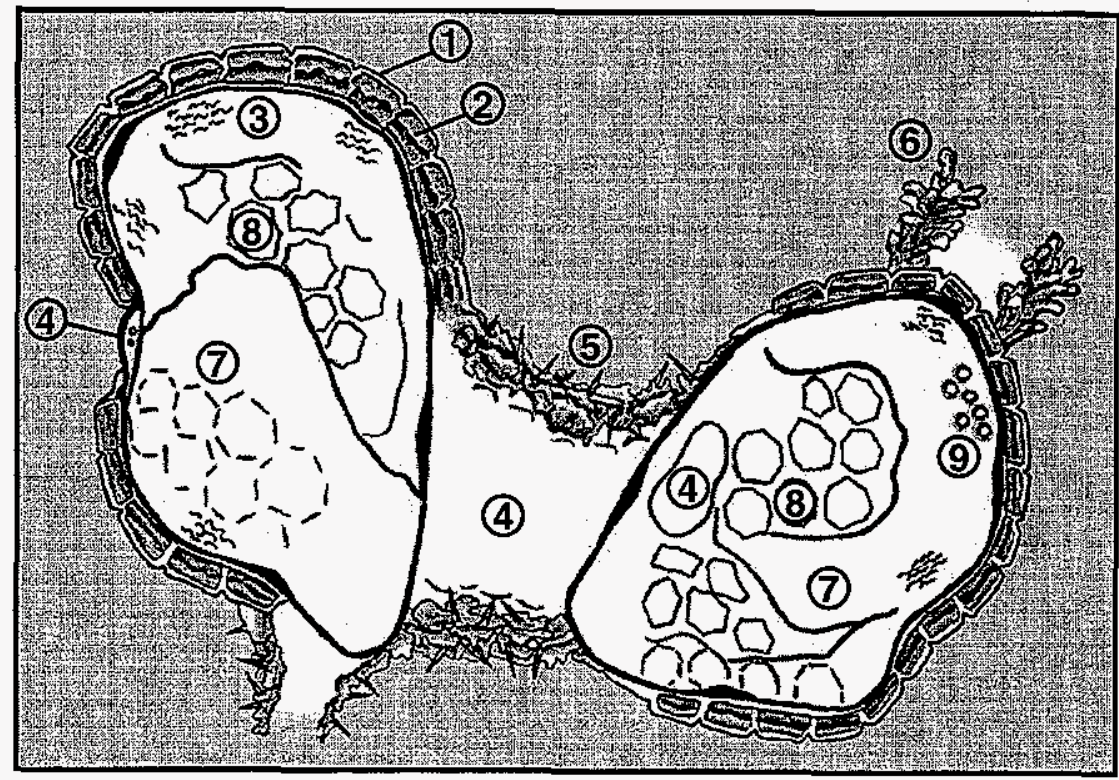

Figure 4-1 - Microstructural changes within the clay bonded silicon carbide filter materials during extended operation in the PFBC/PCFBC environment.

In addition to the microstructural changes that occur within the filter matrix as a function of operating life, removal of the crystallized binder and oxide-enriched coating that encapsulated silicon carbide grains along the pulse cycled surface of the clay bonded silicon carbide filter elements was observed after extended accelerated pulse cycling and thermal transient testing. Edge abrasion of the grains, particularly in areas associated with bond posts or ligaments, is expected to decrease the bulk strength of the material along the i.d. surface of the filter element.

Oxidation of the silicon carbide during operation in the PFBC/PCFBC environment results not only in Schumacher Dia Schumalith and Pall clay bonded silicon carbide filter materials, but also within the $3 \mathrm{M}$ and DuPont chemical vapor infiltrated silicon carbide (CVI-SiC) matrices. The thin CVI-SiC encapsulating layer that is deposited along the outer surface of the Nextel ${ }^{\mathrm{TM}}$ and alumina-enriched fibers in the outer containment layer and filtration mat of the $3 \mathrm{M} \mathrm{CVI-SiC} \mathrm{matrix,} \mathrm{respectively,} \mathrm{is} \mathrm{readily}$ oxidized and easily removed (i.e., cracking and spalling) during the first 250-500 hours of operation in the high temperature PFBC and/or PCFBC environment. Oxidation of the thin CVI-SiC coating along the Nextel ${ }^{\mathrm{TM}}$ fibers present within the triaxial support braid similarly occurs. Bonding of the oxidized phase 
to the oxidized i.d. surface of the thick, brittle, CVI-SiC encapsulating shell, is expected to lead to a reduction in the fracture toughness of the material.

Oxidation of the Nicalon fibers (i.e., silicon carbide) fibers within DuPont SiC-SiC filter matrix similarly leads to a volume expansion of the nonoxide-based fibers, bonding along the oxidized outer surface of the silicon carbide fiber and oxidized inner surface of the silicon carbide encapsulating shell, and an overall embrittlement of the matrix within the first 100-250 hours of operation under high temperature oxidizing conditions. ${ }^{(8)}$ The originally fracture toughened DuPont SiC-SiC filter material is very rapidly reduced to a brittle ceramic. For this reason, the porous, nonoxide-based, DuPont SiC-SiC filter media is no longer considered for use in high temperature PFBC and/or PCFBC filtration applications.

Even though surface oxidation of large silicon carbide grains (i.e., $\sim 300-500 \mu \mathrm{m}$ ) leads to a volume expansion within the Schumacher Dia Schumalith and Pall clay bonded silicon carbide filter materials, the overall open porosity and strength of these materials remain relatively high during the initial life of the filter elements. In contrast, however, the smaller grains that are used in the construction of the outer surface particle collection membranes also undergo oxidation, but to a greater extent per unit grain in comparison to the structural support silicon carbide grains. Volume expansion of the fine grains, and coalescence of the pores within the outer surface membrane result, reducing the gas flow through the matrix.

\subsection{Comments}

Table 4-1 identifies the manufacturing, as well as thermal, mechanical, and chemical degradation issues that are currently considered to occur during the initial and extended stages of life of the oxide and nonoxide-based, monolithic ceramic, fiber reinforced, and filament wound filter materials. An area which remains to be addressed is whether microstructural or phase changes will continue to occur within the various filter matrices with extended aging of elements during field operation. A second area which also needs to be addressed, is whether continued phase change will impact the residual strength, thermal and/or mechanical properties, and filtration characteristics of the various filter materials. Currently we suspect that continued grain growth and secondary phase formations will occur in some matrices which will play a significant role in the ultimate viability of these filter elements during commercial operation. 
TABLE 4-1. MATRIX/COMPONENT RESPONSE TO PROCESS OPERATION - PFBC/PCFBC

\begin{tabular}{|c|c|c|c|}
\hline \multirow{2}{*}{$\begin{array}{c}\text { Matrix } \\
\text { Operating Time }\end{array}$} & \multicolumn{2}{|c|}{ Initial Life } & \multirow{2}{*}{$\begin{array}{c}\text { Extended Life } \\
>3 \text { Years }\end{array}$} \\
\hline & Plant Commissioning & 1 Year & \\
\hline \multicolumn{4}{|l|}{ Monoliths } \\
\hline Oxides & $\begin{array}{ll}\text { - } & \text { Thermal Fatigue } \\
\text { - } & \text { Thermal Transients }\end{array}$ & $\begin{array}{l}\text { Matrix Phase } \\
\text { Changes: } \\
\text { Component } \\
\text { Conditioning }\end{array}$ & $\begin{array}{l}\text { Full Matrix Crystallization } \\
\text { - } \\
\text { Microcrack Formation } \\
\text { Plant Process Control } \\
\text { Required to Ensure } \\
\text { Material Stability and } \\
\text { Performance }\end{array}$ \\
\hline Nonoxides & $\begin{array}{l}\text { High Temperature } \\
\text { Creep - } \\
\text { Reformulation } \\
\text { Completed, Limiting } \\
\text { Creep } \\
\text { Oxidation } \geq 700^{\circ} \mathrm{C}\end{array}$ & $\begin{array}{l}\text { Matrix Phase } \\
\text { Changes; } \\
\text { Component } \\
\text { Conditioning }\end{array}$ & $\begin{array}{ll}\text { - } & \text { Crystallization of } \\
\text { Binder } / \text { Ligaments } \\
\text { - } & \text { Oxidation of SiC Grains } \\
\text { - } & \text { Creep (TBD) } \\
\text { - } & \text { Limited to }<700-750^{\circ} \mathrm{C} \\
\text { Applications }\end{array}$ \\
\hline \multicolumn{4}{|l|}{ Fiber Reinforced } \\
\hline Oxides & & \multirow[b]{2}{*}{$\begin{array}{l}\text { Potential Stability and } \\
\text { Performance Issues } \\
\text { Related to } \\
\text { - Mamufacturing } \\
\text { Homogeneity and } \\
\text { Reproducibility } \\
\text { - Lower Strength } \\
\text { - } \quad \text { Lower Load Bearing } \\
\quad \text { Capabilities } \\
\text { - Fixturing } \\
\text { Need to be Addressed }\end{array}$} & - Fiber Embrittlement (TBD) \\
\hline Nonoxides & $\begin{array}{ll}- & \text { Oxidation } \\
- & \text { Fiber/SiC Bonding } \\
\text { and Embrittlement }\end{array}$ & & $\begin{array}{l}\text { Not Recommended for } \\
\text { High Temperature } \\
\text { Oxidizing Applications }\end{array}$ \\
\hline \multicolumn{4}{|l|}{ Filament Wound } \\
\hline Oxides & & $\begin{array}{l}\text { Potential Stability and } \\
\text { Performance Issues } \\
\text { Related to } \\
\text { - Manufacturing } \\
\text { Homogeneity and } \\
\text { Reproducibility } \\
\text { - Lower Strength } \\
\text { - Lower Load Bearing } \\
\text { Capabilities } \\
\text { - Fixturing } \\
\text { - Membrane Stability } \\
\text { (Divoting: Matrix } \\
\text { Pull-Out) } \\
\text { Need to be Addressed }\end{array}$ & - $\mathrm{TBD}$ \\
\hline
\end{tabular}

TBD: To be determined. 


\section{THERMAL TRANSIENTS, STRESS, AND FILTER LIFE}

\subsection{Pulse Cycling}

During pulse cleaning, the temperature along the i.d. surface of the candle filter decreases due to contact with the incoming cooler pulse cleaning gas. As the pulse cleaning gas permeates through the filter wall, the temperature change generated through the filter matrix is governed primarily by the

- Gas flow permeability of the material (i.e., porosity and pore size distribution)

- Thermal conductivity of the filter material

- Pulse cleaning gas temperature (i.e., temperature based on the presence or absence of a failsafe/regenerator device above each filter element

- Duration of the pulse cleaning event (i.e., total volume of the pulse cleaning gas.

Filter elements with higher gas flow permeabilities (i.e., new vs aged; CFCC and filament wound matrices vs monolithic materials) will permit more gas to flow through the material, and thus have a greater temperature drop, ultimately experiencing higher stress during a pulse cleaning cycle in comparison to materials with lower gas flow permeabilities. Filter materials with high thermal conductivities (i.e., Schumacher Dia Schumalith FT20 and Pall 326 vs Coors P-100A-1 alumina/mullite) will experience a smaller temperature drop, since heat flow from the remainder of the filter wall will mitigate heat flow to the pulse cleaning gas. Similarly, materials with larger pores (i.e., Schumacher Dia Schumalith FT20 and Pall 326 vs Coors P-100A-1) will permit the pulse cleaning gas to penetrate more deeply into the filter wall.

Figure 5-1 illustrates the temperature profile during pulse cleaning along the i.d. wall near the base of the flange of an aged Coors P-100A-1, DuPont PRD-66, McDermott, Blasch, and Pall 326 filter element. The maximum temperature drop along the i.d. surface at this location for each filter generally correlated with the gas flow permeability of each filter element (Table 5-1). The lower the gas flow permeability (i.e., higher gas flow resistance), the smaller the temperature drop along the i.d. surface and through the wall of the filter element.

Finite element models developed at SWPC STC to project the potential stress induced during pulse cleaning of the filter array indicated that local stresses induced along the i.d. wall near the base of the flange of the Coors P-100A-1 alumina/mullite filter element exceeded the strength of the material. The area of high stress extended $<1 \mathrm{~mm}$ into the i.d. filter wall, identifying the zone where microcracking of the matrix was expected to occur. The $\sim 1-2 \mathrm{~mm}$ affected zone was previously demonstrated by Westinghouse $^{(9)}$ to separate from the remainder of the intact filter wall (Figure 5-2) during extended exposure of the matrix to accelerated pulse cleaning cycles. Similar stress calculations indicated that extended accelerated pulse cycling did not affect the stability of the clay bonded silicon carbide i.d. surface.

\subsection{Thermal Transient Testing}

As shown in Figure 5-3, an axial gradient resulted along the o.d., as well as i.d. surfaces of the porous ceramic candle filters during a thermal transient event. As expected, greater cooling was experienced along the o.d. surface of the filter element in comparison to the i.d. wall during exposure of 


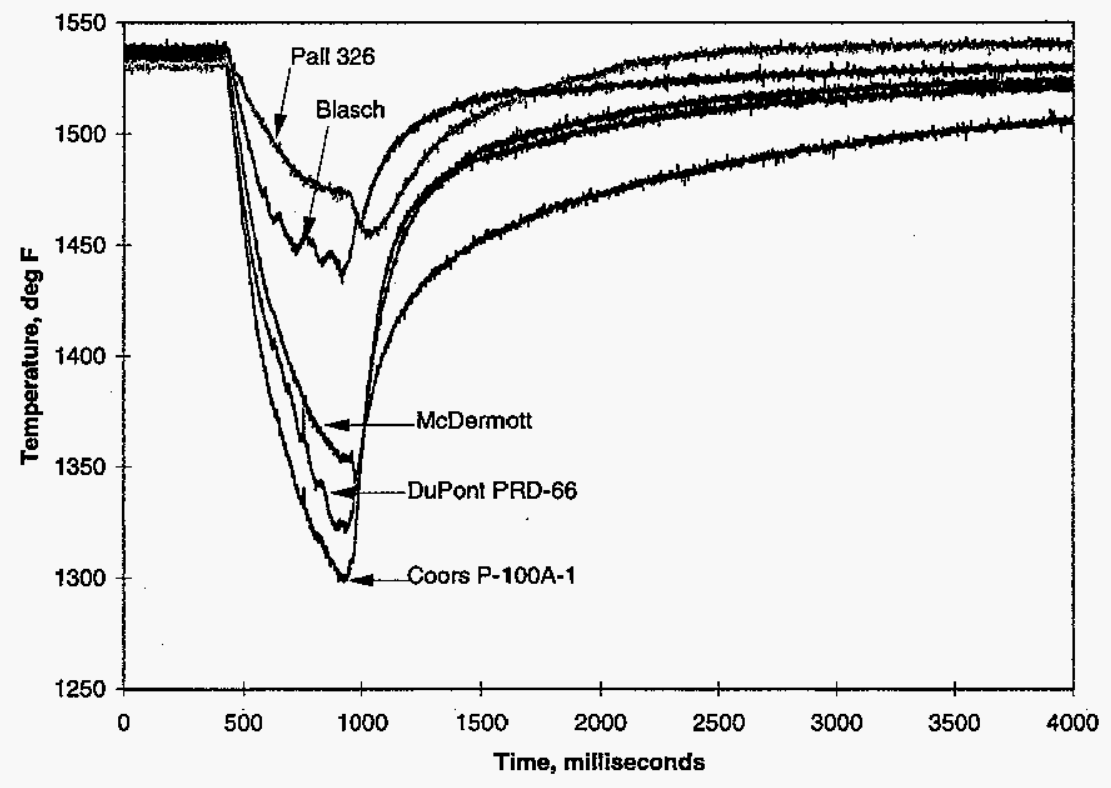

Figure 5-1 - Temperature profiles resulting along the i.d. surface near the base of the flange of the filter elements during pulse cleaning of a mixed filter array.

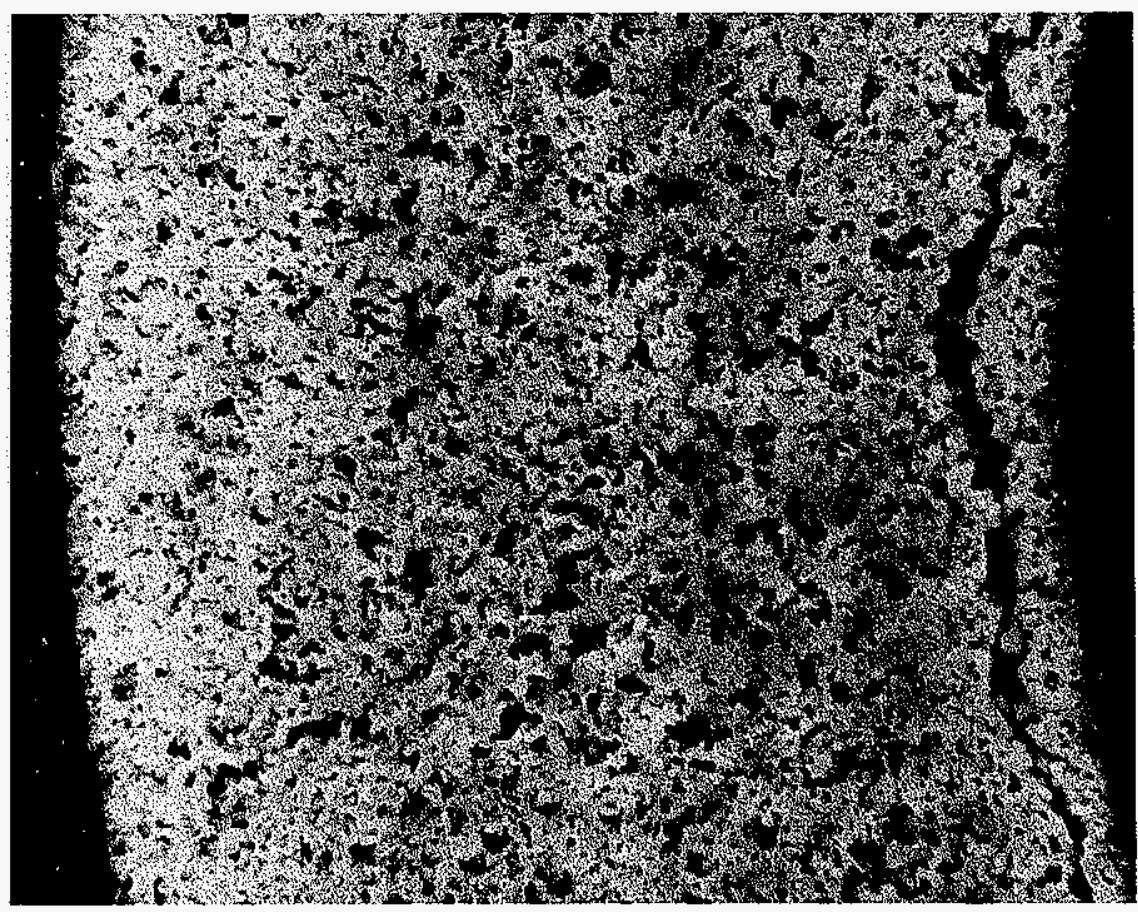

Figure 5-2 - Separation of the Coors P-100A-1 alumina/mullite filter matrix along the i.d. wall after extended exposure to pulse cycling. 


\begin{tabular}{|c|c|c|c|c|c|c|c|c|c|c|c|c|}
\hline 嶨 & 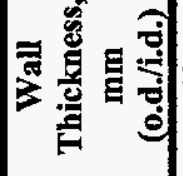 & 웡 & $\odot \frac{\widehat{9}}{80}$ & 웅 & 요용 & 웡 & $-\frac{9}{8}$ & $m$ 氕 & m & m & బ & \\
\hline$\sum_{0}^{\infty}$ & 吾总坐 & $\begin{array}{l}+ \\
0 \\
0 \\
0 \\
0 \\
0 \\
n \\
r \\
r\end{array}$ & 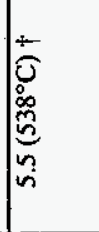 & 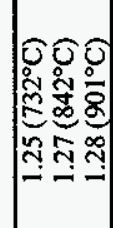 & & & $\cong$ & & & $\left|\begin{array}{lll}0 & 0 & 0 \\
0 & 0 & 0 \\
0 & 0 & 0 \\
0 & 0 & 0 \\
0 & 0 & 0 \\
0 & 0 & 0 \\
0 & 0 & 0 \\
1\end{array}\right|$ & & \\
\hline 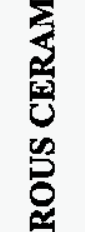 & 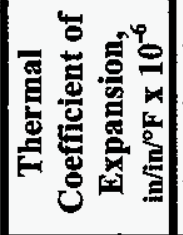 & 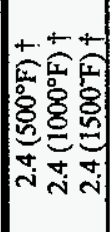 & 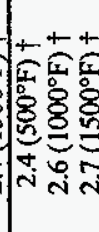 & 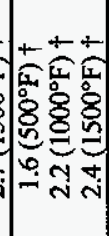 & 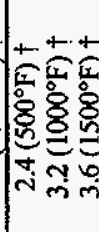 & & 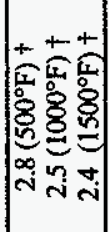 & & & 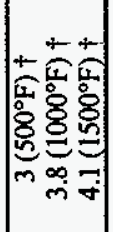 & & \\
\hline 돈 & 胥。 & $\overrightarrow{0}$ & $\stackrel{\circ}{\circ}$ & 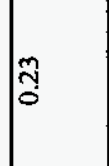 & $\stackrel{\infty}{0}$ & ${ }_{0}^{\circ}$ & & 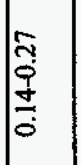 & 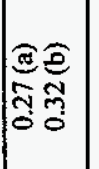 & & & \\
\hline 窒 & 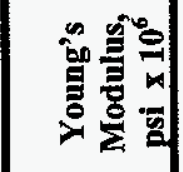 & $m$ & 部 & is & & 我 & & 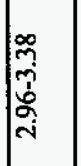 & 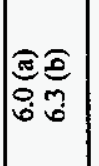 & & & \\
\hline 岁 & 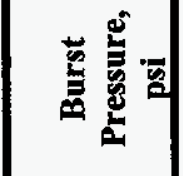 & 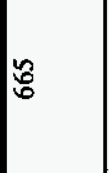 & $\mid \approx$ & $\mathbb{\infty}_{\infty}^{\infty}$ & $\stackrel{\overbrace{}}{2}$ & $\mathrm{z}$ & $\approx$ & $\frac{\rho}{\mathrm{z}}$ & 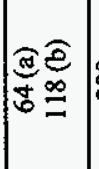 & స్సి & 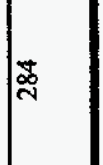 & 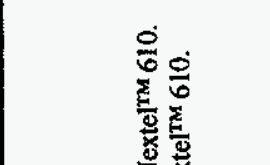 \\
\hline 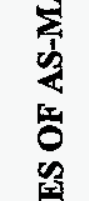 & 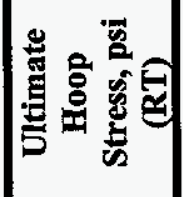 & 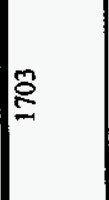 & 产 & $\stackrel{\aleph}{\tilde{N}}$ & 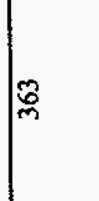 & 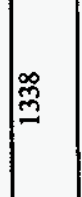 & $\bar{m}$ & 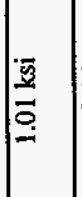 & 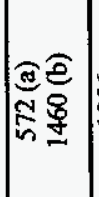 & ఫొ & $\frac{\sim}{\approx}$ & 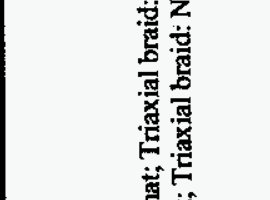 \\
\hline 辤 & 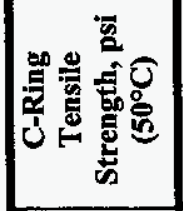 & 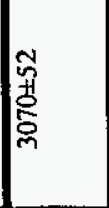 & 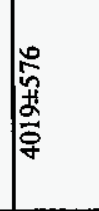 & 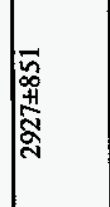 & $\frac{*}{*}$ & 总 & 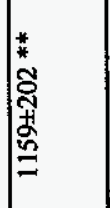 & 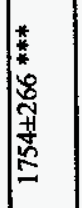 & 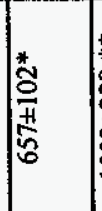 & 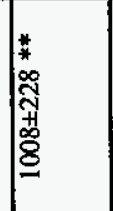 & 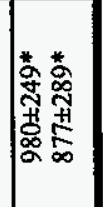 & 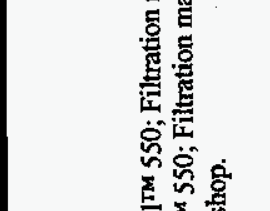 \\
\hline ב্ & 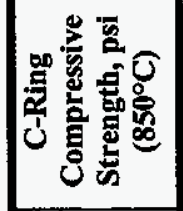 & 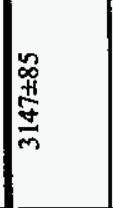 & 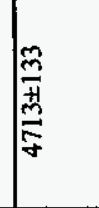 & 总 & $\frac{*}{\frac{*}{8}}$ & 㠏 & 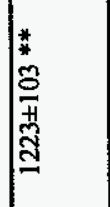 & 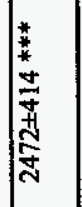 & 芯 & 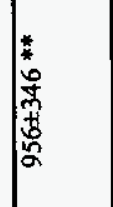 & 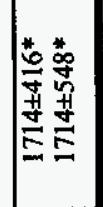 & 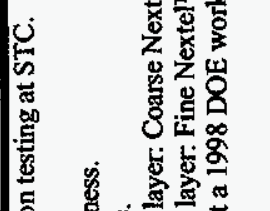 \\
\hline 国 & 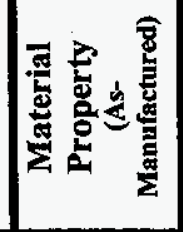 & 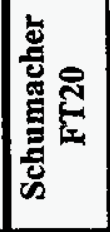 & 骨 & 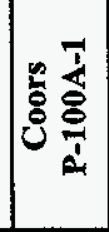 & 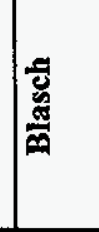 & 量 & 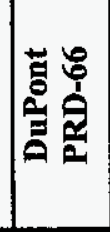 & 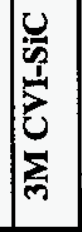 & 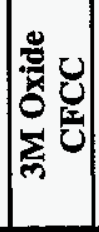 & 莣 & 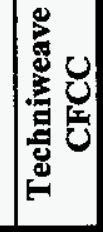 & 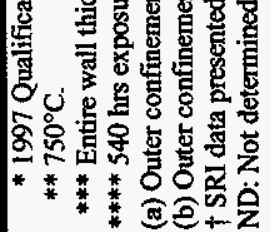 \\
\hline
\end{tabular}




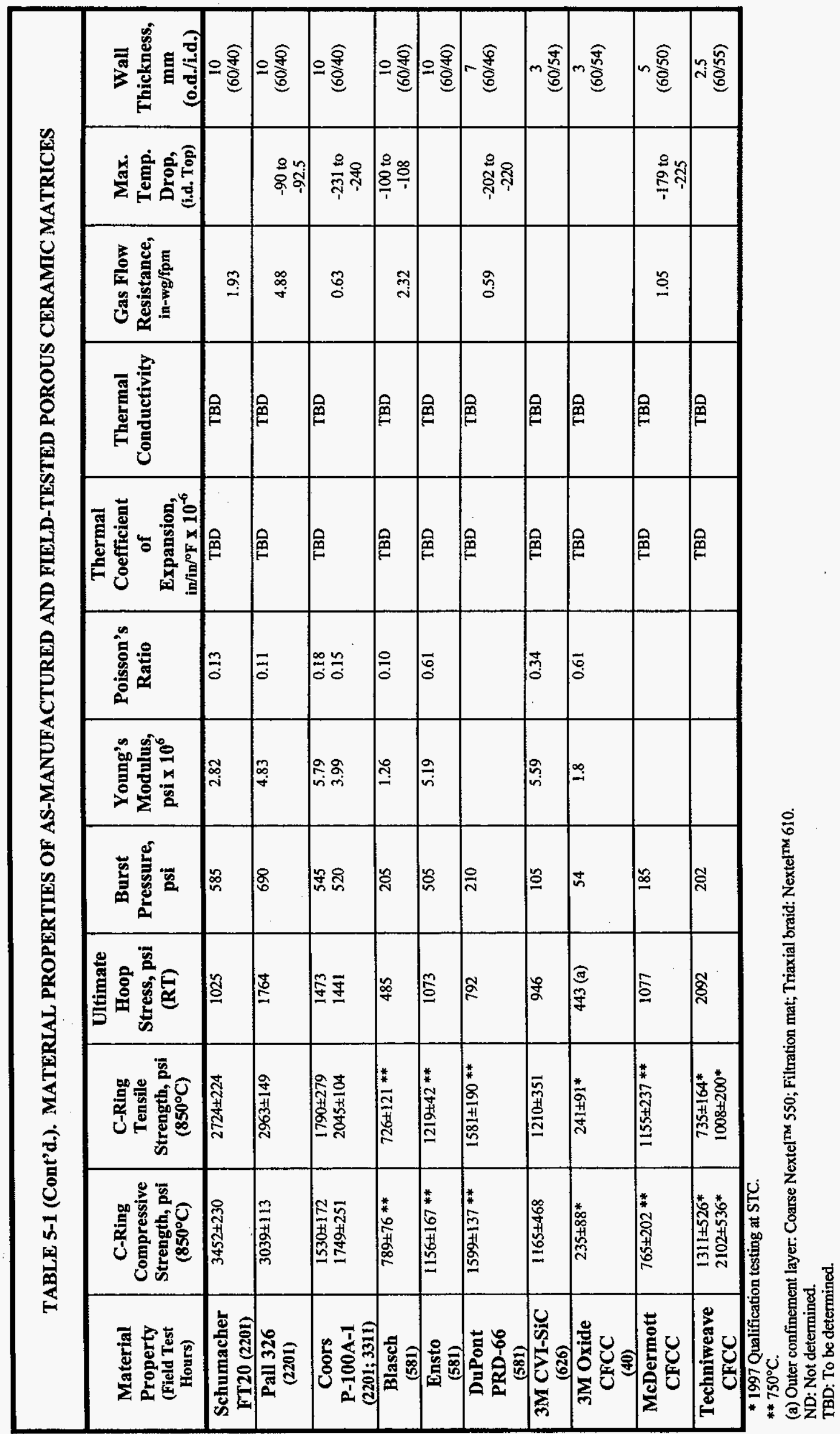




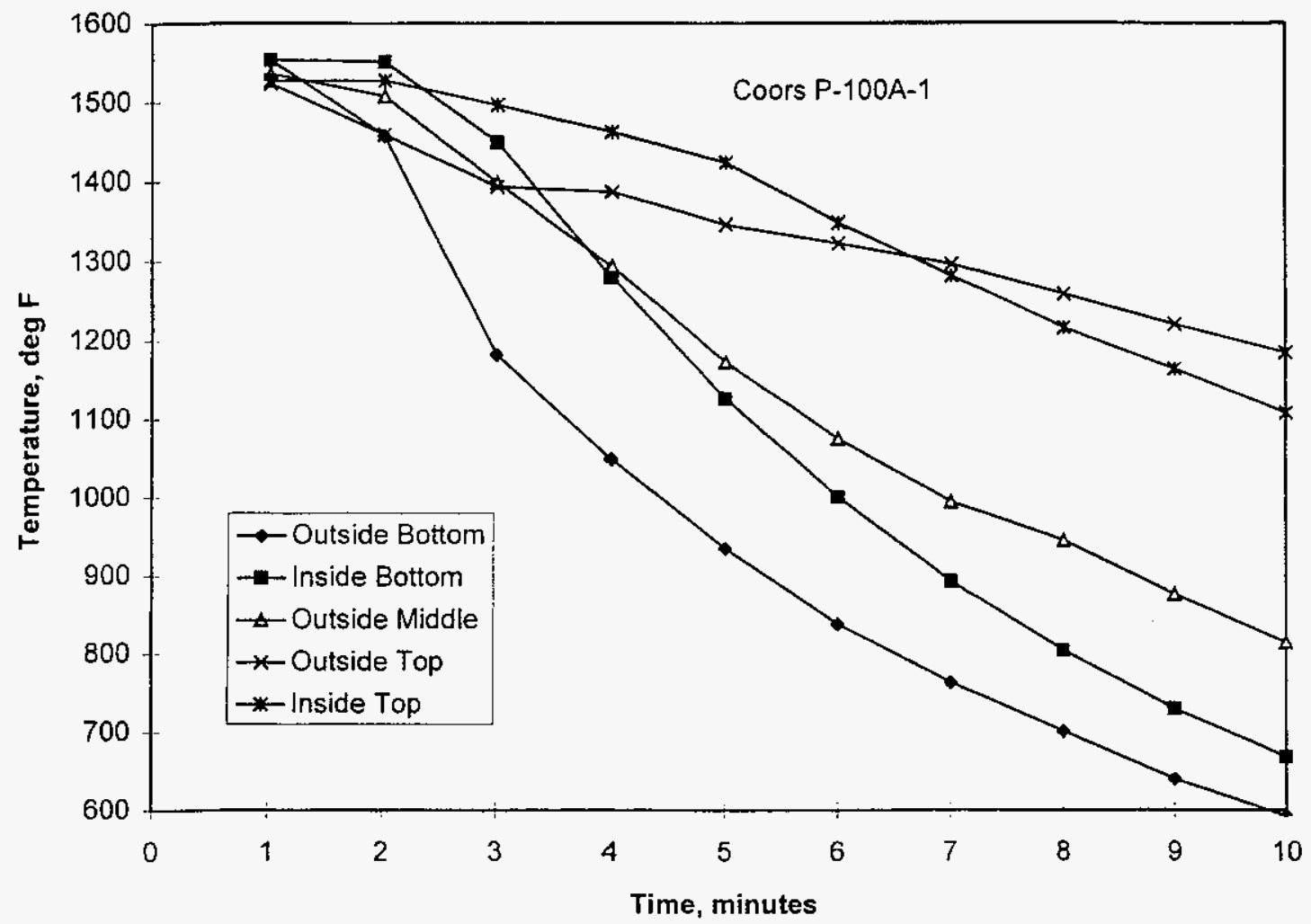

Figure 5-3 - Filter temperature profiles along the Coors P-100A-1 alumina/mullite candle during thermal transient testing.

the array to a simulated thermal transient event. A greater decrease in temperature was identified along the o.d. and i.d. surfaces near the bottom closed end cap of the filter element, while a smaller decrease in temperature resulted near the candle flange during thermal transient testing. The smaller decrease in temperature along the candle flange was considered to have resulted from restricted process gas flow patterns at the top of the element closest to the plenum, and/or thermal radiation from the metal hardware.

The thermal response of the filter matrix and rate at which the temperature gradient moves through the filter wall during a thermal transient event is dependent on the flow rate and volume of process gas that passes through the filter material (i.e., matrix permeability), thermal conductivity of the filter material, and the number of each filter matrix-type include in the filter array. Since the porous matrices are highly efficient in transferring energy between the filter material and the process gas, the temperature decrease along the i.d. wall was not as great as at a comparable location along the o.d. surface of the filter element during the thermal transient event. Notably, as the process gas moves from the bottom to the top of the candle along the i.d. bore of the filter element during a thermal transient event, the process gas is warmed due to contact with the warmer filter matrix.

Where the thermal gradient through the wall is the steepest during a thermal transient event, maximum stress occurs. When the maximum temperature gradient through the filter wall establishes stresses that exceed the tensile strength of the material, cracks are formed. Based on finite element modeling at SWPC STC, initiation of a field simulated thermal transient event

- Generates principal stresses that were comparable to, or less than the measured hoop strength for the Coors P-100A-1 alumina/mullite filter matrix. Alternately, failure at locations 
comparable to those identified during field and extended life testing can be projected by changing either the steepness of the temperature gradient applied, or the material properties used in the finite element calculations. Field installation and operation of Coors P-100A-1 alumina/mullite candle filters should therefore require plant operating conditions to moderate thermal transients within the filter vessel, and implementation of designs that assure even gas flow and temperature distributions throughout the various filter clusters and arrays.

- Generates principal stresses that were virtually equivalent to, or slightly greater than the measured hoop strength for the Blasch mullite-bonded alumina filter matrix, primarily along the lower section of the filter element. The projected stress location supports the formation of the longitudinal crack that was observed at $\sim 20$ inches above the end cap of the Blasch filter element at the conclusion of the extended life, thermal transient test program.

- Generates principal stresses that were significantly lower than the hoop strength of the clay bonded silicon carbide Pall 326 and Schumacher Dia Schumalith FT20 filter matrices, thus retaining the integrity of the nonoxide-based filter elements.

\subsection{Comments}

Pilot-scale and Demonstration Plant testing of SWPC's Advanced Particulate Filtration Systems has demonstrated the functional performance of qualified porous ceramic filter elements. Post-test characterization of field-exposed elements has shown the progression of phase and microstructural changes that results within each matrix as a function of time during operation of the various materials in the PFBC or PCFBC environments.

Characterization of bench-scale-tested elements under simulated plant operating conditions has replicated the field-demonstrated phase and microstructural changes that occur during the porous ceramic filter material aging process. Bench-scale testing has also replicated many of the filter failure mechanisms observed during field operation.

The extended accelerated life testing program conducted at SWPC has demonstrated the potential long-term viability of the porous ceramic filter elements during exposure to simulated process operating conditions that are more severe than field service operating conditions. Continued accelerated life testing of aged filter elements, demonstrating their potential viability to achieve three years of service operation, as well as extended field service operation, are needed to assure functional operation and warranted performance of porous ceramic hot gas filters at commercial plant facilities. 


\section{SUMMARY AND ACCOMPLISHMENTS}

Numerous filter element types are currently undergoing field testing for potential selection and use in advanced coal-fired systems. An extensive understanding of the response of the monolithic-based materials has primarily resulted from bench-scale and field testing where optimization of the filter matrix composition and component construction has occurred. Continued development and advancements in the manufacture of composite and filament wound filter elements, as well as field service testing are needed to provide assurance of extended life, prior to use of these elements in warranted, commercial plant facilities.

With respect to the monolithic filter matrices, the oxide-based materials have enhanced chemical stability for use in $>1400^{\circ} \mathrm{F}\left(760^{\circ} \mathrm{C}\right) \mathrm{PFBC} / \mathrm{PCFBC}$ systems. Control of plant and process operation is, however, needed to mitigate unwarranted thermal fatigue and/or shock of these materials, prematurely failing the oxide-based monolithic filter elements. In contrast, a significantly higher thermal fatigue and/or shock resistance is imparted through the use of the nonoxide-based monolithic filter matrices. Extended life of these materials may be limited as a result of microstructural and secondary phase changes that continue to occur during operation in the high temperature PFBC/PCFBC environment. By lowering the field service operating temperature to $\leq 1400-1500^{\circ} \mathrm{F}\left(\leq 760-815^{\circ} \mathrm{C}\right)$, oxidation of the nonoxide-based matrices is reduced, potentially extending the field service life of these materials.

During conduct of the pilot-scale test program at the Foster Wheeler PCFBC test facility in Karhula, Finland, and the extended filter life program at the Siemens Westinghouse Power Corporation Science and Technology Center in Pittsburgh, PA, numerous accomplishments resulted. These include:

- Demonstration of extended service operation of commercially available filter elements.

- Successful advancements in the area of materials development whereby the formulation and manufacturing of commercially available filter matrices were modified, resulting in the production of elements which have improved operating performance and life.

- Development, manufacture, installation, and operation of advanced monolithic, composite, and filament wound ceramic filter materials.

- Demonstration of extended filter element performance, viability, and life, identifying the capability of achieving $>1$ year of service life under simulated PFBC/PCFBC operating conditions.

- Correlation of filter axial and radial temperature profiles during pulse cleaning and exposure to simulated thermal transients with matrix stress, material viability, and bench-scale and field failure.

- Preliminary correlation of the destructive mechanical property characterization results with nondestructive analytical techniques.

A brief summary follows, highlighting the achievements in each of these areas.

\subsection{Field Service Operation}

- Thermal fatigue issues have frequently been encountered when porous oxide-based monolithic ceramic filters (i.e., Coors alumina/mullite candles) are placed in operation in the high temperature PFBC/PCFBC environments. After 1110 hours of operation at the 
American Electric Power PFBC test facility in Brilliant, Ohio, five Coors P-100A-1 alumina/mullite candles were sent to the PCFBC Foster Wheeler test facility in Karhula, Finland, where an additional 2201 hours of service life were achieved. Thus the maximum service life achieved to date for any Coors P-100A-1 alumina/mullite candle is 3311 hours of field service operation, demonstrating the viable performance of the matrix and component under controlled operating conditions.

- Reformulation of the binder phase contained within the Schumacher Dia Schumalith and Pall filter materials has lead to enhanced high temperature creep resistance during operation in the PCFBC test facility. The observed elongation of 8-11 mm for the Schumacher Dia Schumalith FT20 and Pall 326 elements after 2201 hours of service life was attributed primarily to volume expansion of the material resulting from the oxidation of the silicon carbide grains. Reducing the PCFBC operating temperature from $1560^{\circ} \mathrm{F}\left(850^{\circ} \mathrm{C}\right)$ to $1380^{\circ} \mathrm{F}$ $\left(750^{\circ} \mathrm{C}\right)$ significantly diminished the extent and rate of elongation of the porous, clay bonded silicon carbide filter elements.

- As development and manufacturing have promoted fabrication of advanced prototype filter elements, advanced monolithic, continuous fiber reinforced ceramic composites (CFCC), and filament wound materials have been successfully qualified and introduced as potentially viable materials for extended PFBC/PCFBC field service use. Since 1995, these materials have included:

- Monolithic matrices - Blasch mullite-bonded alumina; Ensto mullite-bonded alumina; IF\&P REECER (recrystallized silicon carbide)

- CFCC matrices - 3M oxide-based CFCC; McDermott oxide-based CFCC; Techniweave oxide-based CFCC; 3M CVI-SiC

- Filament wound matrix - DuPont PRD-66.

The initial performance, viability, and life of the Blasch and Ensto oxide-based monoliths, McDermott oxide-based CFCC, and DuPont oxide-based filament wound matrices were demonstrated during conduct of TS2-97 at Karhula, Finland. Further matrix and/or component development, and qualification testing were required for the $3 \mathrm{M}$ and Techniweave oxide-based CFCC matrices, prior to installation and operation in field test facilities.

- After 2201 hours of PCFBC operation, both the Schumacher Dia Schumalith FT20 and Pall 326 elements appeared to have achieved a conditioned process temperature strength along their o.d and i.d. surfaces (3039-3452 psi c-ring compressive and 2724-2963 psi cring tensile strengths, respectively). In contrast, a gradual reduction in process temperature strength appeared to continue to occur for the Coors P-100A-1 alumina/mullite filter matrix. After 2201-3311 hours of PFBC/PCFBC operation, the process temperature c-ring compressive strength of the Coors $\mathrm{P}-100 \mathrm{~A}-1$ alumina/mullite filter matrix was $1530-1749$ psi, while c-ring tensile testing identified strengths of 1790 2045 psi along the pulse cycled or i.d. surface of the filter elements. Matrix and microstructural changes were attributed to change in the material strength.

- In comparison to the as-manufactured filter materials, a significant decrease in Young's modulus appeared to result for the PCFBC-exposed Schumacher Dia Schumalith FT20 filter matrix. Similarly, when compared to the as-manufactured filter materials, a decrease in the Young's modulus resulted for the PCFBC-exposed Coors P-100A-1 alumina/mullite and Pall 326 filter matrices. 
- A lower initial, as well as residual strength resulted for the advanced second generation filament wound, CFCC, and monolithic porous ceramic matrices in comparison to the commercially available monolithic filter materials. A gradual increase in both c-ring compressive and tensile strength of the DuPont PRD-66 filament wound matrix occurred during the initial 581 hours of operation in the PCFBC environment. This has previously been demonstrated by SWPC and was considered to result from either penetration of ash fines into the filament wound filter matrix, or crystallization of amorphous phases originally contained in the as-manufactured filter matrix. A gradual loss of matrix strength occurred along the o.d. surface, while a nearly constant retention of strength along the i.d. surface of the McDermott candle occurred during the initial 581 hours of operation in the PCFBC environment. For the Blasch filter matrix, a slight increase in residual strength along both o.d. and i.d. surfaces occurred.

- High temperature creep testing demonstrated that for the 2201 hour, PCFBC-exposed, Schumacher Dia Schumalith FT20 and Pall 326 candle filters, negligible high temperature creep resuited when a $500 \mathrm{psi}$, 4-point bend, flexural load was applied to the surface of bend bars for a period of 500 hours at temperatures of $1380^{\circ} \mathrm{F}\left(750^{\circ} \mathrm{C}\right)$ and $1560^{\circ} \mathrm{F}\left(850^{\circ} \mathrm{C}\right)$. The enhanced high temperature creep resistance of the Schumacher Dia Schumalith FT20 and Pall 326 filter matrices resulted from manufacturing changes that had been made to the binder phase during production of both filter elements.

- During post-test inspection of the 2201 hour, PCFBC-exposed, Schumacher Dia Schumalith FT20 and Pall 326 filter elements, the candles were visually inspected, and the overall lengths of the filter elements were measured. Cracks were not observed along the outer surface at the base of the flange of either the Schumacher Dia Schumalith FT20 or Pall 326 filter elements, as had previously been observed after PCFBC operation of Schumacher Dia Schumalith F40 and Pall 442T. Hairline crack formations, however resulted around the densified plug which formed the closed end cap of three Pall 326 filter elements after PCFBC operation during TS3-96.

After 2210 hours of service life, an elongation of between $9-11 \mathrm{~mm}(0.6-0.7 \%)$ was observed for the Schumacher Dia Schumalith FT20 candles, and between 8-9.5 mm (0.5$0.6 \%$ ) for the Pall 326 filter elements. The apparent decrease in the elongation rate was considered to have resulted from reduction in the PCFBC operating temperature from $1560^{\circ} \mathrm{F}\left(850^{\circ} \mathrm{C}\right)$ to $1380^{\circ} \mathrm{F}\left(750^{\circ} \mathrm{C}\right)$ during testing in TS2-97. Since high temperature creep testing of the Schumacher Dia Schumalith FT20 and Pall 326 filter materials did not identify significant binder phase creep, the observed candle elongation was attributed to continued oxidation of the silicon carbide grains in the PCFBC environment.

- Based on the gravimetric analyses which identified the increased silica concentration in the field-exposed filter materials, and the bench-scale, high temperature, flexural creep tests which identified negligible creep strain in the as-manufactured and field-exposed filter materials, oxidation of the silicon carbide matrix was considered to be the primary mechanism that was responsible for the $8-11 \mathrm{~mm}$ of elongation that was observed for the $1.5 \mathrm{~m}$ Schumacher Dia Schumalith FT20 and Pall 326 filter elements after 2201 hours of PCFBC operation. During oxidation of the silicon carbide grains, $\mathrm{SiO}_{2}$ formed resulting in a volume expansion of the matrix. Continued operation of the previously PCFBCexposed Schumacher and Pall filter elements is recommended to determine the rate at 
which oxidation/elongation/creep occurs within the clay bonded silicon carbide materials as a function of extended plant operating time.

During PCFBC operation, consideration should also be given to competing volatilization mechanisms that release $\mathrm{Si}(\mathrm{OH})_{4}$ from the silicon carbide filter matrix in the presence of steam. In contrast to oxidation, volatilization would be expected to occur, reducing the overall volume of the silicon carbide grains.

- After failure of an element occurred during PCFBC operation, fines released into the clean gas stream became reentrained within the pulse cleaning gas and subsequently penetrated the i.d. surface of intact filter elements. This lead to an increased pressure drop across the intact porous filter matrix.

\subsection{Accelerated Life Testing}

- Sixteen, first and second generation, new and PFBC/PCFBC-aged candles were installed in the filter array which then underwent 40.5 hours of steady state $\mathrm{PFBC}$ operation at $1550^{\circ} \mathrm{F}$ $\left(843^{\circ} \mathrm{C}\right)$ and $68 \mathrm{psig}$, and subsequently 20,089 accelerated pulse cleaning cycles, representing 10,045 hours or $>1$ year of equivalent field service use. The filter array experienced 707 hours of operation at $1550^{\circ} \mathrm{F}\left(843^{\circ} \mathrm{C}\right)$, and underwent 22 cold starts and 57 warm starts, where the array was heated at a rate of $100^{\circ}-250^{\circ} \mathrm{F} / \mathrm{min}$ from either room temperature or $\sim 750^{\circ} \mathrm{F}\left(400^{\circ} \mathrm{C}\right)$, respectively, to $1550^{\circ} \mathrm{F}\left(843^{\circ} \mathrm{C}\right)$. Twelve filter elements, which included monolithic oxides and nonoxides, and oxide-based filament wound and CFCC matrices, successfully demonstrated their ability to achieve $>1$ year of equivalent PCFBC/PFBC operating life. Three failures resulted during conduct of accelerated pulse cycling in the extended filter life test program. These included thermal fatigue failure of an aged Coors P100A-1 alumina/mullite candle (3761 equivalent operating hours), failure at the base of the flange of an aged DuPont PRD-66 candle (3108 equivalent operating hours), and delamination of the layered configuration and failure at the base of the flange of an aged $3 \mathrm{M}$ CVI-SiC candle (2373 equivalent operating hours). Due to the absence of the filter vessel shroud during the initial stages of testing, a 'thermally worn area' resulted which removed the outer surface membrane of a Pall 326 filter element ( 2453 equivalent operating hours), and failure of a second Pall 326 filter element (2453 equivalent operating hours) occurred at a similar location along the length of the filter body. Thermal fatigue, as well as removal of the Pall 326 outer surface membrane were considered to have resulted from direct impingement of the simulated PFBC gas stream on the outer surface of the filter element.

- Based on finite element modeling conducted at SWPC STC, local stresses induced along the i.d. wall near the base of the flange of the Coors-P-100A-1 alumina/mullite filter element during pulse cycling exceeded the strength of the filter material. The area of high stress extended $<1 \mathrm{~mm}$ into the i.d. filter wall, identifying the zone where microcracking of the matrix was expected to occur. The $\sim 1-2 \mathrm{~mm}$ affected zone was previously demonstrated by Westinghouse to separate from the remainder of the filter wall during extended exposure of the matrix to extended pulse cleaning. Similar stress calculations indicated that pulse cycling did not affect the integrity of the clay bonded silicon carbide filter i.d. surface. Filter materials with higher thermal conductivities (i.e., nonoxide-based materials) will generate less severe stresses as a result of more gradual temperature gradients through their walls during exposure to pulse cycling and/or thermal transient events. 
- In order to simulate a sequence of projected commercial turbine trip events during the course of plant life, the filter array was subjected to thirty thermal transients in which an initial temperature drop of $180^{\circ} \mathrm{F} / \mathrm{min}$ was experienced, with cooling continuing until temperatures of $660^{\circ} \mathrm{F}\left(350^{\circ} \mathrm{C}\right)$ were achieved during a $11-13$ minute period. Subsequently the array was reheated to $1550^{\circ} \mathrm{F}\left(843^{\circ} \mathrm{C}\right)$ within a $25-30$ minute period. After final disassembly of the filter array, thirteen of the fifteen candles remained intact, surviving both the accelerated pulse cycle and thermal transient test campaigns, while a newly manufactured Coors P-100A-1 alumina/mullite, and PCFBC-aged/accelerated pulse cycled Blasch candle experienced thermal fatigue failure or crack formation, respectively. The newly manufactured Coors filter element had been fabricated with the originally designed square vs radiused end cap. The square end cap had previously been identified to introduce stress risers and failure within the Coors elements.

- Based on finite element modeling conducted at SWPC STC, principal stresses that resulted during thermal transient testing were comparable to, or less than the measured hoop stress for the Coors P-100A-1 alumina/mullite filter matrix. Alternately, failure at locations comparable to those identified during field and extended life testing can be projected by changing either the steepness of the temperature gradient applied, or the material properties used in the finite element calculations. Field installation and operation of Coors P-100A-1 alumina/mullite candle filters should therefore require plant operating conditions to moderate thermal transients within the filter vessel, and implementation of designs that assure even gas flow and temperature distributions throughout the various filter clusters and arrays.

- Principal stresses that resulted during thermal transient testing were virtually equivalent to, or slightly greater than the measured hoop stress for the Blasch mullite-bonded alumina filter matrix, primarily along the lower section of the filter element. The projected stress location supported the formation of the longitudinal crack that was observed at $\sim 20$ inches $(\sim 51 \mathrm{~cm})$ above the end cap of the Blasch filter element at the conclusion of the extended life, thermal transient test program.

- Principal stresses that resulted during thermal transient testing were significantly lower than the hoop strength of the clay bonded silicon carbide Pall 326 and Schumacher Dia Schumalith FT20 filter matrices, thus supporting retention of the integrity of the nonoxide-based filter elements.

- Characterization of the residual process temperature strength via c-ring compressive and tensile testing of the PCFBC-exposed/extended life-tested monolithic and advanced second generation candle filters indicated that

- A continued slight decrease in the o.d. tensile strength of the PCFBC-exposed Schumacher Dia Schumalith FT20 and Pall 326 matrices resulted after 12,111 equivalent hours of service operation.

- Stabilization or a slight increase in the o.d. tensile strength of the PCFBC-exposed Coors P-100A-1 alumina/mullite filter matrix resulted after 12,111 equivalent hours of service operation. 
- After exposure to thirty thermal transients, the o.d. tensile strength of the PCFBCexposed Pall 326 filter matrix was reduced, while virtually no change in the o.d. tensile strength of the PCFBC-exposed Coors P-100A-1 alumina/mullite matrix was apparent.

- After extended life testing of the PCFBC-exposed porous ceramic filter materials, a reduction in the Weibull modulus of the Schumacher Dia Schumalith FT20 (c-ring compression and tension), Pall 326 (c-ring compression and tension), Coors P-100A-1 alumina/mullite (c-ring tension), and 3M CVI-SiC (c-ring tension) matrices was observed. The reduction in modulus indicates a wider material strength distribution, as well as higher probability of failure of the porous ceramic filter materials under a certain stress.

- High temperature creep testing was conducted on bend bars that were removed from the PCFBC-exposed Schumacher Dia Schumalith FT20 (S350F/60 (T5)) and Pall 326 (R1-659 (M17)) candle filters. Both filter elements had experienced 1035 hours of PCFBC operation at Karhula, and were subsequently subjected to 20,089 accelerated pulse cleaning cycles in the SWPC STC extended filter life test program. The total equivalent operating life for both porous ceramic filter materials was therefore 11,080 hours. A maximum creep strain of $0.11 \%$ and $0.12 \%$ was identified for the Schumacher Dia Schumalith FT20 S350F/60 and Pall 326 R1-659 filter matrices, respectively, after exposure in static air for a period of 500 hrs at temperatures of $1550^{\circ} \mathrm{F}\left(843^{\circ} \mathrm{C}\right)$, with an applied load of $500 \mathrm{psi}$. Based on these results, the PCFBC-exposed/extended life-tested clay bonded silicon carbide filter matrices were not considered to exhibit high temperature creep strain during process operation.

- Microstructural changes and crystallization of the binder-containing and/or oxide layer continued to occur within the Schumacher Dia Schumalith FT20 and Pall 326 filter matrices during extended operation under simulated PFBC test conditions.

- In comparison to the as-manufactured filter matrices, extensive crystallization was again observed within the PCFBC-exposed/extended life-tested Coors P-100A-1 alumina/mullite and Blasch mullite-bonded alumina filter materials.

- Although crystallization within the Nextel ${ }^{\mathrm{TM}} 610$ fibers occurred throughout the McDermott oxide-based CFCC filter matrix after extended operation under simulated PFBC test conditions, the matrix, in general, appeared to remain intact, preventing negligible penetration of ash fines into the interior of the filter wall.

- An area which remains to be addressed is whether microstructural or phase changes will continue to occur within the various filter matrices with extended aging of elements during field operation. A second area which also needs to be addressed, is whether the continued phase changes will impact the residual strength and thermal or mechanical properties of the various filter materials. Currently we suspect that continued grain growth and secondary phase formations will occur in some matrices which will play a significant role in the ultimate viability of these filter elements during commercial operation. 


\subsection{Recommendations}

\subsubsection{Extended Accelerated Life Testing}

- Continued accelerated life cycle testing under simulated PFBC operating conditions is recommended to be conducted in order to demonstrate the potential viability for 3 years of service life of PFBC/PCFBC-aged and/or new filter elements.

- In order to mitigate candle filter failure during high temperature operation at PFBC or PCFBC pilot-scale or demonstration test facilities, the following are recommended:

- Use of fail-safe/regenerator devices to heat the in-coming pulse cleaning gas, thereby reducing the temperature drop along the i.d. bore to the filter elements, thus mitigating the potential to form microcracks, particularly within the oxide-based monolithic materials.

- Use of the minimum pulse mass to successfully clean the filter elements in order to minimize stress and microcracking along the i.d. wall of the filter elements.

- Use of elements with comparable gas flow permeabilities within a given filter array in order to provide a more even distribution of pulse gas mass, thus normalizing gas flow, minimizing potential stress and microcrack formation along the i.d. wall of the filter elements.

- Use of filter materials with high thermal conductivities (i.e., nonoxide-based matrices). Less severe stresses would be generated in these materials as a result of more gradual temperature gradients established through the wall of the filter elements during exposure to pulse cycling and/or a thermal transient event.

\subsubsection{Material/Component Optimization}

The chemical stability of the oxide-based filter materials remains the hallmark for selection of these materials for installation and operation in high temperature PFBC and PCFBC process applications. Additional manufacturing improvements to these matrices, as well as to the clay bonded and recrystallized silicon carbide matrices are recommended in order to successfully achieve commercial filter system life. The recommended improvements which follow result primarily from the extensive mechanical and microstructural characterization analyses of the PCFBC-exposed porous filter materials. Continued field operation and/or accelerated life testing are essential to demonstrate functional matrix viability.

- In order to further mitigate oxidation and volume expansion of the porous clay bonded silicon carbide filter materials, the inclusion of an oxidation resistant coating is recommended to be incorporated within the Schumacher Dia Schumalith and Pall filter materials. Incorporation of the oxidation resistant coating along the surface of the grains in the IF\&P REECER filter matrix is similarly recommended.

- Additional strengthening of the DuPont PRD-66 filter flange, and retention of the outer membrane stability need to be addressed. 
- An external encasement layer needs to be incorporated along the outer surface of the McDermott oxide-based CFCC filter elements in order to prevent removal of the Saffil fibers and alumina-containing mat during field operation and handling. A similar mechanism for retention of the Saffil fibers and alumina-containing mat along the i.d. surface of the McDermott oxide-based CFCC filter element during pulse cycling needs to be established.

- Improved adherence of the outer containment layer and underlying filtration mat layer of the $3 \mathrm{M}$ oxide-based CFCC needs to be addressed.

- The overall stability of the Nextel TM 610 fibers in the 3M, McDermott, and Techniweave matrices needed to be assessed in view of long-term field operation. Crystallization of the fibers has been demonstrated as a result of exposure to the PCFBC process gas environment. Crystallization of the fibers is considered to ultimately lead to embrittlement, and reduced fracture toughness of the filter matrix.

- Additional strength of the Blasch mullite-bonded alumina filter matrix is recommended.

- The IF\&P REECER filter matrix has been shown to contain internal bubble or void formations. These areas weaken the filter matrix, and serve as potential failure sites. Nondestructive $\mathrm{QA} / \mathrm{QC}$ techniques need to be established to identify the existence of internal bubbles or voids within the IF\&P recrystallized silicon carbide filter matrix, and manufacturing procedures to eliminate their formation during filter element fabrication need to be implemented.

- Uniform wall thickness and concentricity over the entire length of the Coors P-100A-1 alumina/mullite and Blasch mullite-bonded alumina filters need to be achieved during manufacturing.

- Further development and/or modification of the microstructure or composition of the Coors P-100A-1 alumina/mullite matrix are not considered as a manufacturing option. Therefore use of the Coors P-100A-1 alumina/mullite filter elements is recommended in controlled process applications where thermal transients are moderated. Alternate monolithic oxides as the Blasch and Ensto mullite-bonded alumina matrices are similarly recommended for use in controlled process applications that moderate the occurrence of thermal transient events.

- Manufacture of integral filter elements which eliminates the inclusion of seams, bonds, plugs, inserts, joints, etc., to fabricate the candle filter geometry.

- Although excellent dust cake release typically results during pulse cleaning of the filter array, the smoother the o.d. surface of the filter element, the greater the extent of removal of the dust cake layer during extended field operation.

- In the event of a filter failure during process operation, the inclusion of a functional failsafe/regenerator above each filter element, is essential to mitigate back-pulsing of fines into the porous i.d. wall of the remaining intact filter elements. In addition, incorporation of an internal membrane along the i.d. surface of each filter element will further mitigate fines penetration into the filter matrix. 
- Additional efforts need to be focused on the development of CFCC and filament wound matrix material properties.

- New materials continue to be developed for potential use in the manufacture of high temperature porous filter elements. These include:

- Americom oxide-based CFCC matrix

- Oak Ridge National Laboratory (ORNL) mullite-bonded mullite

- Ultramet CVI-SiC reticulated foam with the incorporation of an oxidative resistant coating

- Porous metal media.

Qualification and post-test characterization of these materials, as well as an assessment of component performance are considered by SWPC STC to be essential, prior to field service use at pilot-scale or demonstration plant test facilities.

- Characterization of the Ensto mullite-bonded alumina, Techniweave oxide-based CFCC, and IF\&P REECER matrices needs to be rigorously performed in order to assess the potential long-term viability of these materials with respect to alternate, previously tested, filter materials.

\subsubsection{Non-Destructive Evaluation}

- The material properties generated by NDE techniques at West Virginia University for SWPC on the aged candle filters, were generally comparable to material properties determined by destructive testing at STC. Consideration should be given to expanding the use of the NDE technique to define material properties as a function of continued filter element exposure life, prior to destructive characterization of the filter elements.

- Similarly, efforts are recommended to be undertaken to identify the feasibility for generating Weibull statistics for the NDE data that were obtained for various field-tested filter elements. The utilization of the Weibull statistics to generate probability of failure and ultimately filter life in view of warranting elements for commercial operation should be assessed. 


\section{ACKNOWLEDGMENTS}

Acknowledgments are extended to Mr. Richard A. Dennis and Mr. Theodore J. McMahon at the U.S. DOE/NETL, and Dr. Thomas Lippert at the Siemens Westinghouse Power Corporation, Science and Technology Center, for their technical support and guidance during conduct of the filter material and component assessment programs at SWPC STC. We also wish to acknowledge Mr. Reijo Kuivalainen, Mr. Juhani Isaksson, Mr. Timo Eriksson, and Mr. Pekka Lehtonen for their efforts in conducting the hot gas filtration test program at the Foster Wheeler PCFBC test facility in Karhula, Finland. The efforts of Mr. Eugene Smeltzer, Mr. George Schneidner, Mr. John Meyer, and Mr. Larry Ottenberg are acknowledged for conduct of the accelerated life test program. The technical guidance and analytical support provided by Dr. Richard Tressler at the Pennsylvania State University, the mechanical testing conducted by Mr. Edward Diaz, Mr. George Rudd, and Mr. Robert Walko, and the spectroscopy and phase analyses performed by Mr. Thomas Mullen and Dr. Art Byers at the Siemens Westinghouse Power Corporation, Science and Technology Center are also gratefully acknowledged. Acknowledgments are also extended to Dr. J. P. Singh at the Argonne National Laboratory for generation of the Weibull statistics, and to Dr. Roger Chen for conduct of the nondestructive filter element analyses. 


\section{REFERENCES}

1. "Tidd Hot Gas Clean Up Program," Final Report, American Electric Power Service Corporation, DOE Contract No. DE-FC21-89MC26042, October 1995.

2. M. A. Alvin, T. E. Lippert, and E. S. Diaz, "Assessment of PCFBC Field-Exposed Advanced Candle Filters," Topical Report, Westinghouse Science and Technology Center, DOE/FETC Contract No. DE-AC21-94MC31147, March 31, 1997.

3. "Performance of the Westinghouse Candle Filter in Lakeland Test Runs," Final Report, Foster Wheeler Karhula R\&D Center, Report No. 474/98, To Be Issued.

4. M. A. Alvin, T. E. Lippert. E. S. Diaz, E. E. Smeltzer, and G. J. Bruck, "Filter Component Assessment," Paper presented at the Advanced Coal Based Power and Environmental Systems '97 Contractor's Review Meeting, Pittsburgh, PA, DOE/FETC Contract No. DE-AC21-94MC31147, July 22-24, 1997.

5. M. A. Alvin, T. E. Lippert, E. E. Smeltzer, and G. J. Bruck, "Advanced Hot Gas Filter Performance and Characterization," Advanced Coal-Based Power and Environmental Systems ' 98 Conference, U. S. Department of Energy, Office of Fossil Energy, Morgantown, WV, July 21-23, 1998.

6. W. R. Wheeler, "Failure Modes of Ceramic Candle Filters," Adapco Report No. 19-04-001, October 19, 1993.

7. M. A. Alvin, "Hot Gas Filter Development and Performance," Paper presented at the $4^{\text {th }}$ International Symposium and Exhibition of the Gas Cleaning at High Temperatures Conference in Karlsruhe, Germany, 22-24 September 1999.

8. M. A. Alvin, "Performance and Stability of Porous Ceramic Candle Filters during PFBC Operation," Materials at High Temperature, Vol. 14, No.2/3, 1997, pp. 285-294, ISBN 1-900814-10-2.

9. M. A. Alvin, "Thermal/Chemical Degradation of Ceramic Cross Flow Filter Materials," Final Report, Westinghouse Science and Technology Center, U.S. DOE/METC Contract No. DE-AC2188-MC25034, August 31, 1995. 


\section{APPENDIX A}

\section{POST-TEST INSPECTION OF THE PCFBC-EXPOSED 3M AND TECHNIWEAVE OXIDE-BASED CANDLE FILTERS}

\section{M Oxide-Based CFCC Filter Testing (TS2-97)}

Initially twelve $3 \mathrm{M}$ oxide-based CFCC candle filters were supplied for use at the Foster Wheeler PCFBC test facility in Karhula, Finland. These were constructed using an outer confinement layer of coarse, open mesh, Nextel ${ }^{\mathrm{TM}} 550$, and internal $\alpha-\mathrm{Al}_{2} \mathrm{O}_{3}$ filtration mat layer, and an underlying Nextel ${ }^{\mathrm{TM}}$ 610 triaxial support braid. On four of the $3 \mathrm{M}$ elements (i.e., 79, 710,711, and 713), there was a section of 6-12 inches near the bottom end cap where the outer confinement layer filaments were flattened relative to the remainder of the filter body. Three of these elements were excluded from further consideration for installation and testing at Karhula. Two additional elements failed the flange dimensional tolerance test using a tool designed by $3 \mathrm{M}$. These elements were also omitted from further consideration for installation and testing at Karhula. Examination of all filter elements via a high intensity light inserted into the i.d. bore of each filter element indicated general uniformity throughout the filter body. Seven of the original twelve $3 \mathrm{M}$ oxide-based CFCC filter elements were selected for installation within the filter array, and operation during TS2-97.

After $\sim 35$ hours of PCFBC operation, dust was identified in the outlet gas stream, and testing was terminated. After cool-down and opening of the filter vessel, sections of the outer confinement layer and underlying filtration mat layer were seen to have been removed from the $3 \mathrm{M}$ oxide-based elements.

Additionally, sections of the filtration mat beneath the confinement layer were seen to have been removed along the end caps of the $3 \mathrm{M}$ oxide-based CFCC filter elements. Several questions were raised pertaining to component construction and overall integrity of the $3 \mathrm{M}$ oxide-based CFCC filter matrix. These included:

- Had adequate matrix infiltration been accomplished during the manufacture of the $3 \mathrm{M}$ oxidebased filter elements to permit adherence and bonding of outer containment layer, filtration mat, and triaxial support braid layers?

- Had the Nextel ${ }^{\mathrm{TM}} 550$ or Nextel ${ }^{\mathrm{TM}} 610$ fibers embrittled?

- What was the impact of pulse cleaning intensity on the integrity of the porous $3 \mathrm{M}$ oxidebased filter matrix?

Once returned to STC, initial characterization of the 3M TS2-97 PCFBC-exposed oxide-based CFCC candle filters included room temperature gas flow permeability measurements. As shown in Figure A-1, with the exception of element 714 , post-test gas permeability measurements for the TS2-97-exposed elements ranged between $0.2-1 \mathrm{in}-\mathrm{wg} / \mathrm{fpm}$. Element 714 had a substantially higher room temperature permeability measurement of $\sim 5 \mathrm{in}-\mathrm{wg} / \mathrm{fpm}$ in comparison to alternate filter elements.

In order to determine the extent of adherence between layers within the $3 \mathrm{M}$ oxide-based filter materials, STC designed a qualification test procedure in which a $1-\mathrm{in}^{2}\left(2.54 \mathrm{~cm}^{2}\right)$ metal coupon was bonded to the outer surface of a 6-8 inch $(15.24-20.32 \mathrm{~cm})$ section of filter body. The sample was loaded in an Instron, and subsequently the strength to remove the outer confinement layer and/or filtration mat 


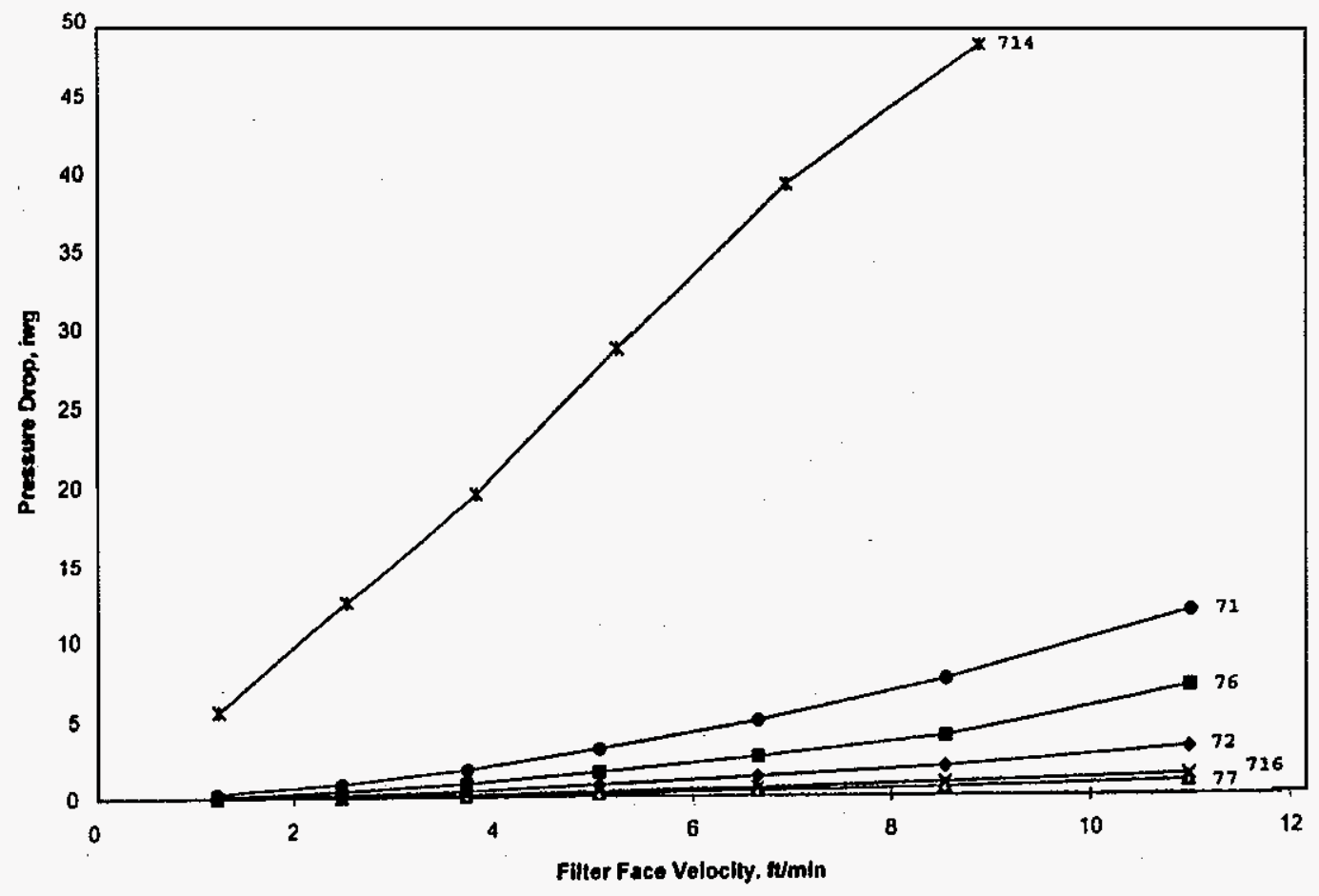

Figure A-1 - Room temperature gas flow permeability of the TS2-97 PCFBC-exposed 3M oxidebased Nextel ${ }^{\mathrm{TM}} 550 / 610$ candle filters.

from the underlying triaxial support braid was determined. Since a limited number of samples were characterized from various $3 \mathrm{M}$ CVI-SiC and oxide-based CFCC filter elements, the results shown in Table A-1, ${ }^{1}$ provide only general guidelines regarding the adherence strength of the $3 \mathrm{M}$ filter element layers. Neither the weakest area, nor strongest area of the elements were known with any level of assurance to have been selected for testing. Similarly the inhomogeneity of the filter body, contour of the outer surface, and variation in o.d. dimensions, all impacted the adherence strength calculated by this exercise. What was generally concluded was that

- The outer confinement layer adherence strength of the as-manufactured and PCFBC-exposed $3 \mathrm{M}$ oxide-based Nextel ${ }^{\mathrm{TM}} 550 / 610$ was lower than that determined for previously qualified Nextel ${ }^{\mathrm{TM}} 550 / 720$ filter elements tested at STC, and subsequently manufactured Nextel ${ }^{\mathrm{TM}}$ $610 / 610$ elements.

- The adherence strength of the outer confinement layer and filtration mat layer to the underlying triaxial support braid of the as-manufactured Nextel ${ }^{\text {TM550/610 matrix was lower }}$

\footnotetext{
${ }^{1}$ Discussions with $3 \mathrm{M}$ personnel on August 11, 1997 indicated the possibility of providing additional elements constructed via a fine mesh Nextel ${ }^{\mathrm{TM}} 610$ outer confinement layer and a Nextel ${ }^{\mathrm{TM}} 610$ triaxial support braid. Shipment and arrival at site of additional $3 \mathrm{M}$ oxide-based CFCC candles was targeted for August 22-26, 1997. At the decision of Foster Wheeler Karhula, none of the received elements were installed within the filter array during TS2-97, but were returned unused to STC and 3M.
} 
than that determined for previously qualified Nextel ${ }^{\mathrm{TM}} 550 / 720$ filter elements tested at STC, and subsequently manufactured Nextel ${ }^{\mathrm{TM}}$ 610/610 elements.

TABLE A-1. LAYER ADHERENCE STRENGTH OF THE 3M OXIDE-BASED CFCC FILTER MATERIALS

\begin{tabular}{|c|c|c|}
\hline Filter Element & $\begin{array}{c}\text { Outer Confinement Layer, } \\
\text { lbs (psi) }\end{array}$ & $\begin{array}{c}\text { Outer Confinement Layer \& } \\
\text { Filtration Mat, } \\
\text { lbs (psi) }\end{array}$ \\
\hline CVI-SiC Composite & $19(\mathrm{a})$ & $61(102), 80(82)$ \\
\hline As-Manufactured & $5(46)$ & $53(76), 67(33)$ \\
\hline Hopper TS1-95 & $15(\mathrm{a}), 16(\mathrm{a})$ & $35(\mathrm{~b})$ \\
\hline $\begin{array}{c}\text { W-STC } \\
\text { Qualification Tested }\end{array}$ & & $56(71), 85(211)$ \\
\hline $\begin{array}{c}\text { Oxide-Based CFCC } \\
\text { W-STC Qualification } \\
\text { As-Manufactured } \\
\text { N550/720 }\end{array}$ & $37(184)$ & $36(20), 68(85)$ \\
\hline $\begin{array}{c}\text { Karhula-1 } \\
\text { As-Manufactured N550/610 }\end{array}$ & $22(\mathrm{a})$ & $55(55), 59(296)$ \\
\hline $\begin{array}{c}\text { Karhula-1 } \\
\text { TS2-97 Tested } \\
\text { (35 Hrs) N550/610 }\end{array}$ & $19(93), 23(46)$ & $107(\mathrm{c}), 128(\mathrm{c})$ \\
\hline $\begin{array}{c}\text { Karhula-2 } \\
\text { As-Manufactured } \\
\text { N610 (Fine)/610 }\end{array}$ & $34(\mathrm{a}), 78(\mathrm{a})$ & \\
\hline
\end{tabular}

(a) Outer mesh failed without any removal of the outer confinement layer.

(b) Area not identified due to the overall failure of the sample during testing.

(c) Deformation of the cylindrical sample without debonding during testing.

In order to determine whether manufacturing and/or fiber architecture significantly impacted the hoop strength of the $3 \mathrm{M}$ filter matrices, $10 \mathrm{inch}(25.4 \mathrm{~cm})$ sections of material were removed from various filter elements, and subjected to room temperature burst strength testing. As shown in Table A-2, the hoop strength of the as-manufactured and STC-qualified 3M Nextel ${ }^{\mathrm{TM}} 550 / 720$ filter elements, as well as the as-manufactured and PCFBC-exposed 3M Nextel ${ }^{\mathrm{TM}}$ 550/610 filter elements, was substantially below the room temperature hoop strength identified for the $3 \mathrm{M} \mathrm{CVI-SiC}$ and Nextel ${ }^{\mathrm{TM}} 610 / 610$ filter elements. The hoop strength data generally correlated with the room temperature gas flow permeability measurements shown in Figure A-2, implying that the greater the quantity of matrix utilized to fabricate the filter body, the greater the reduction in porosity (i.e., lower gas flow permeability), the higher the matrix (i.e., hoop and layer adherence) strength. 
TABLE A-2. MATERIAL PROPERTIES OF THE 3M OXIDE-BASED CFCC FILTER MATERIALS

\begin{tabular}{|c|c|c|c|c|}
\hline Filter Element & $\begin{array}{c}\text { Burst Pressure, } \\
\text { psi }\end{array}$ & $\begin{array}{c}\text { Ultimate Hoop } \\
\text { Stress, psi }\end{array}$ & $\begin{array}{l}\text { Modulus, } \\
\text { psi x 10 }\end{array}$ & Poisson's Ratio \\
\hline \multicolumn{5}{|c|}{ CVI-SiC Composite } \\
\hline As-Manufactured & & $1.01 \mathrm{ksi}$ & $2.96-3.38$ & $0.14-0.27$ \\
\hline \begin{tabular}{l|} 
TS2-96 \\
387 Hrs \\
\end{tabular} & 133 & 1179 & 3.35 & 0.22 \\
\hline $\begin{array}{l}\text { TS2-96 } \\
626 \mathrm{Hrs}\end{array}$ & 105 & 946 & 5.59 & 0.34 \\
\hline \multicolumn{5}{|l|}{ Oxide-Based CFCC } \\
\hline $\begin{array}{c}\text { W-STC } \\
\text { Qualification } \\
\text { As-Manufactured }\end{array}$ & 52 & 586 & 1.36 & 0.73 \\
\hline $\begin{array}{c}\text { W-STC } \\
\text { Qualification Tested }\end{array}$ & 29 & 334 & 1.35 & 0.73 \\
\hline $\begin{array}{c}\text { Karhula-1 } \\
\text { As-Manufactured }\end{array}$ & 64 & 572 & 6.0 & 0.27 \\
\hline $\begin{array}{c}\text { Karhula-1 } \\
\text { TS2-97 Tested }\end{array}$ & 54 & 443 & 1.8 & 0.61 \\
\hline $\begin{array}{c}\text { Karhula-2 } \\
\text { As-Manufactured }\end{array}$ & 118 & 1460 & 6.3 & 0.32 \\
\hline
\end{tabular}

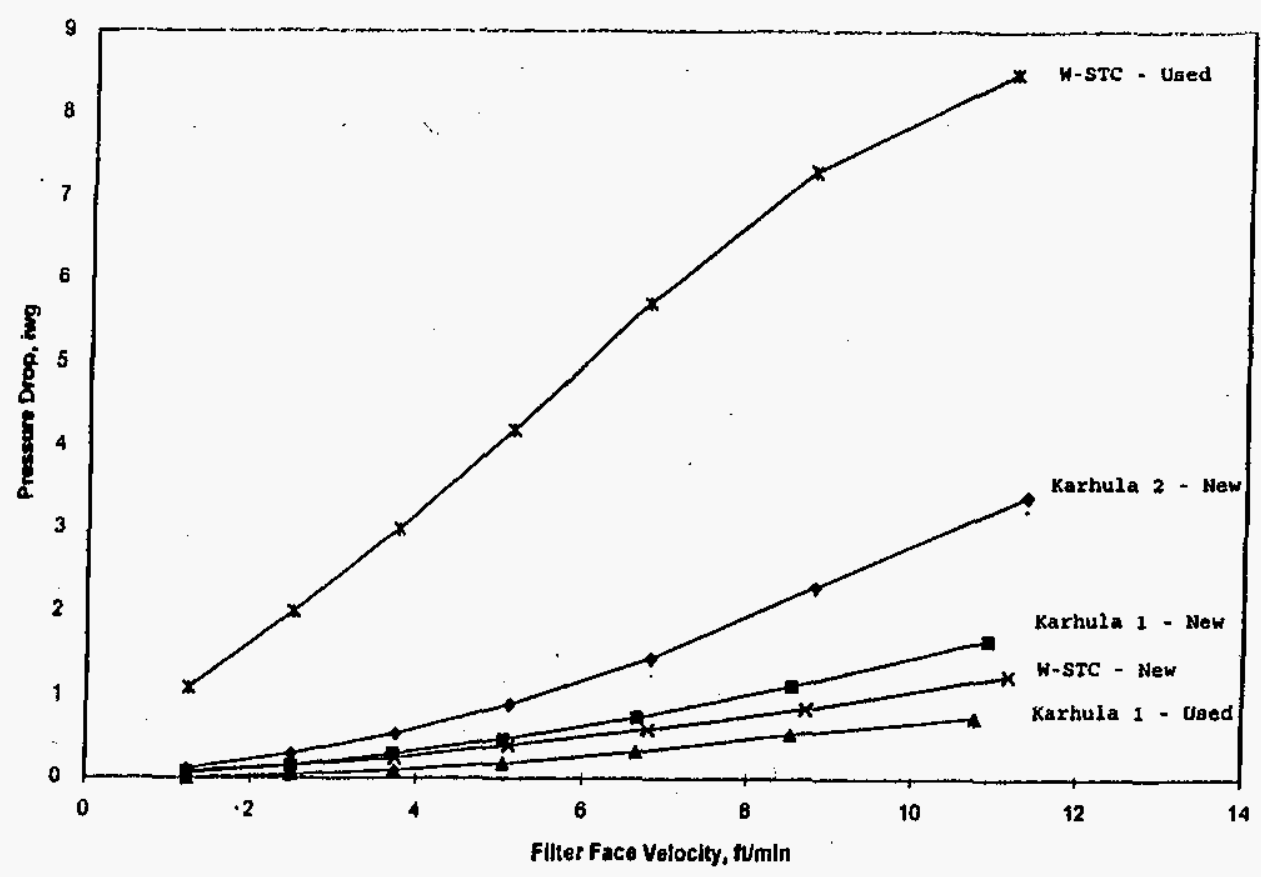

Figure A-2 - Room temperature gas flow permeability of various as-manufactured, qualified, or PCFBC-exposed 3M oxide-based candle filters. 


\section{Techniweave Oxide-Based CFCC Filter Testing (TS2-97)}

Five oxide-based CFCC Techniweave filter elements were requested for shipment to Karhula, Finland, for consideration for use in testing during TS2-97. Only four elements were shipped to site, all of which appeared to be relatively uniform, having smooth outer surfaces. Manufacturing modification made during the construction of the four filter elements in comparison to prior production lots included the absence of internal filter wall fiber staples. The Techniweave Nextel ${ }^{\text {TM }} 720$ filter elements, were, however, fabricated with a nonintegral flange, as well as a nonintegral square end cap. Both the contour of the flange, and flange-to-body joint required additional improvement.

The outer surface of the Techniweave Nextel ${ }^{\mathrm{TM}} 720$ filter element had a powder-like texture which was somewhat removed during handling. When a high intensity light was inserted into the i.d. bore of the Techniweave filter elements, bright areas along the open areas of the weave were identified.

Two of the Techniweave oxide-based Nextel ${ }^{\mathrm{TM}} 720$ filter elements were installed in the filter array for testing in TS2-97. After $\sim 35$ hours of PCFBC operation, fines were detected in the outlet gas stream, and testing was terminated. Post-test inspection indicated that sections of the outer membrane through-thickness fibers were removed, and debonding of the outer seam and unwrapping of the 2-D fabric wrap or layered architecture resulted. Pinholes as a result of through-thickness fiber removal permitted ash fines to pass from the o.d. to i.d. surface of the PCFBC-exposed Techniweave filter elements. As a result of the observed failure, all Techniweave oxide-based CFCCC filter elements were removed from the filter array, and returned to STC and Techniweave.

Limited additional characterization was conducted on the PCFBC-exposed Techniweave filter elements, since post-test inspection identified the need to significantly modify the 2-D architecture in order to provide a more robust CFCC filter matrix (i.e., utilization of the 3-D weave). Figure A-3 identifies the room temperature gas flow permeability of the as-manufactured and PCFBC-exposed Techniweave Nextel ${ }^{\mathrm{TM}} 720$ filter elements, and Table A-3 summarizes the material properties determined at STC for the as-manufactured and PCFBC-exposed filter materials.

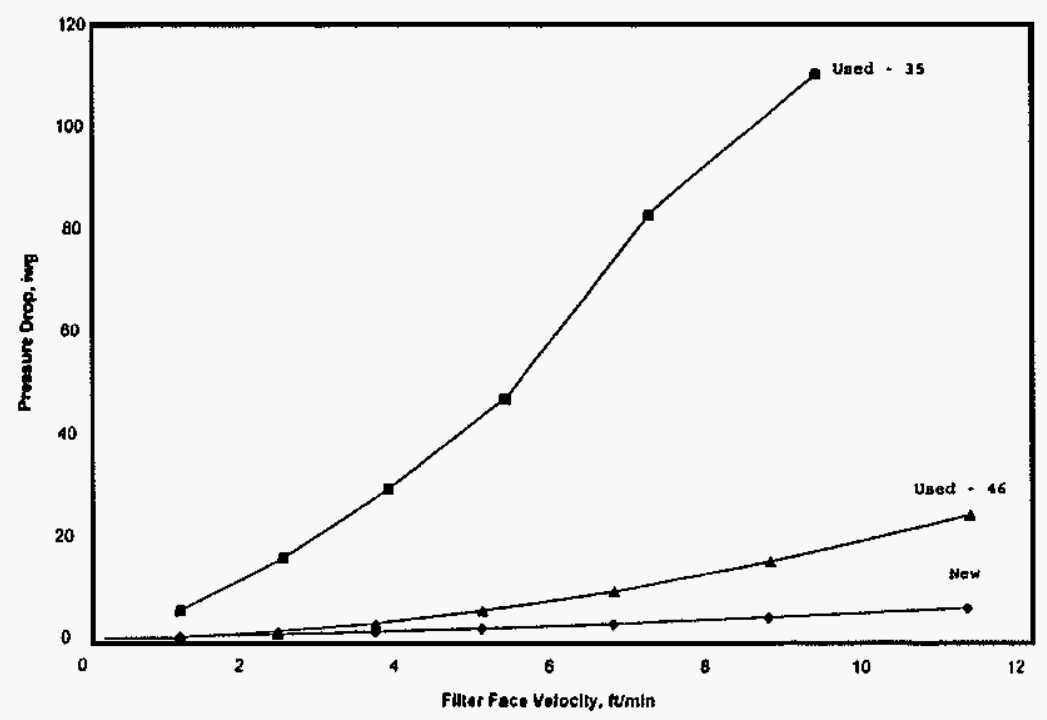

Figure A-3 - Room temperature gas flow permeability of various as-manufactured and PCFBCexposed Techniweave oxide-based candle filters. 
TABLE A-3. MATERIAL PROPERTIES OF THE TECHNIWEAVE OXIDE-BASED CFCC FILTER MATERIALS

\begin{tabular}{|c|c|c|c|c|}
\hline Filter Element & $\begin{array}{c}\text { Burst Pressure, } \\
\text { psi }\end{array}$ & $\begin{array}{c}\text { Ultimate Hoop } \\
\text { Stress, psi }\end{array}$ & $\begin{array}{c}\text { Modulus, } \\
\text { psi x 10 }\end{array}$ & Poisson's Ratio \\
\hline As-Manufactured & 284 & 3512 & 12.4 & $(0.08)$ \\
\hline $\begin{array}{c}\text { Karhula } \\
\text { TS2-97 Tested }\end{array}$ & 202 & 2092 & 15.7 & 0.24 \\
\hline
\end{tabular}


APPENDIX B

NON-DESTRUCTIVE FILTER EVALUATION

B-1 


\title{
NDE of Three Extended-Life-Tested Ceramic Candle Filters
}

\section{Final Report}

\author{
Submitted to \\ Ms. Mary Anne Alvin \\ Westinghouse, STC \\ Pittsburgh, PA 15235-5098
}

\section{Reported by}

Roger H.L. Chen, Ph.D.

Alejandro C. Kiriakidis

West Virginia University

Morgantown, WV 26505

January, 1999 


\section{Report Title:}

NDE OF THREE EXTENDED-LIFE-TESTED CERAMIC CANDLE FILTERS

by Dr. Roger H.L. Chen and Alejandro C. Kiriakidis, West Virginia University

\section{Submited to:}

Ms. Mary Anne Alvin

Westinghouse, STC

Pittsburgh, PA 15235-5098

phone: 412-256-2066

fax: 412-256-2121

email: Maryanne.Alvin@swpc.siemens.com

\section{INTRODUCTION}

This report describes nondestructive evaluation (NDE) results of the natural frequencies and mode shapes of the first few flexural modes of three intact monolithic candle filters as determined by impact vibration under free-free boundary conditions. The report also describes the estimation of Young's modulus of the ceramic candle filter.

There were three extended-life-tested candle filters provided by SiemensWestinghouse. They are one Coors, one Schumacher TF-20 and one Refractron 326. Vibration data of each filter were collected at ten impact locations along the candle filter's length (Chen, et. al, 1997, 1998). Natural frequencies of each candle filter were identified and the corresponding vibration mode shapes were constructed. Finite element analysis of the vibration data was conducted and Young's Modulus of each ceramic candle filter has been estimated. These three candle filters were tested nondestructively in their as-received conditions (with dust) and after being cleaned (water washing via the i.d. bore). 


\section{Tasks Performed:}

- Determination of the natural frequencies and mode shapes of the first few flexural modes of three intact monolithic candle filters in their as-received condition (i.e., dust fines along o.d./i.d. surfaces) as determined by impact vibration under free-free boundary conditions.

- Analysis of the data using FEM to calculate the Young's Modulus for the three intact as-received filter elements.

- Water washing via water injection along the i.d. bore of the elements, followed by heat drying $\left(120-140^{\circ} \mathrm{F}\right)$.

- Determination of the natural frequencies and mode shapes of the first few flexural modes of the three washed monolithic candle filters as determined by impact vibration under free-free boundary conditions.

- Analysis of the data using FEM to calculate the Young's Modulus for the three intact, washed filter elements.

- Brief summary of results for the three monolithic elements in their as-received and washed conditions.

\section{SUMMARY OF RESULTS}

The natural frequency results for each filter at each impact location are analyzed. Table 1 shows the comparison between natural frequency values for each filter in their as-received (dust) and washed (clean) conditions. The results of the first five bending modes are shown. The difference of the natural frequency values at each mode before and after washed conditions are small. For the Coors filter, it ranges from $0.32 \%$ to $0.64 \%$. The frequency changes for the Schumacher and Refractron range from $1.0 \%$ to $1.5 \%$ and $0.7 \%$ to $0.9 \%$, respectively. The natural frequencies of each filter slightly increased after cleaning.

The first four bending mode shapes of each filter tested are shown in Figure 1. Each mode shape represent a bending vibration mode of the candle along the candle length with a specific natural frequency. For example, the first mode shape of the 
Coors filter corresponds to a natural frequency of $108.03 \mathrm{~Hz}$ and the second mode is 294.19 Hz. The candle flange (the open end) is at the top position (position 0 in Figure 1) and the bottom is at the position 10. All three candles show clear bending modes.

Three-dimensional finite element dynamic analysis was conducted. Since the Poison's ratio has only minimal effect on the candle's vibration frequencies, the FEM calculation has assumed a Poisson's ratio of 0.25 for all the filters (Chen, et. al, 1997). The finite element analysis results for the Coors filter gives a Young's modulus value of $4.20 \times 10^{6} \mathrm{psi}$ with a weight density of $0.066 \mathrm{bb} / \mathrm{in}^{3}$. The weight density was calculated using the candle's weight and its nominal volume. The Young's modulus value for the Schumacher filter is about $6.30 \times 10^{6}$ psi with a weight density of $0.073 \mathrm{lb} / \mathrm{in}^{3}$. The result for the Refractron filter with a weight density of $0.071 \mathrm{lb} / \mathrm{in}^{3}$ gives a Young's modulus value of $7.00 \times 10^{6} \mathrm{psi}$. Table 2 shows the percentage difference between the experimental measured natural frequencies and the FEM calculated frequencies for each filter. The maximum percentage difference between the experimental values and the FEM simulation is less than $0.8 \%$. It should be noted that the above FEM analysis assuming linear elastic, isotropic and homogeneous material properties. Hence, the calculated Young's modulus of the candle filter can only be used as an estimation of the global stiffness of the entire candle.

\section{REFERENCE}

Chen, H. L., Kiriakids, A. and Peng, S., "Nondestructive Evaluation of Ceramic Candle Filters Using Vibration Response", Proceedings of Advanced Coal-Based Power and Environmental System '97 Conference, Pittsburgh, July 1997. 
Chen, H. L. and Kiriakids, A., "Nondestructive Dynamic Characterization of Ceramic Candle Filters", Symposium of High Temperature Particulate Cleanup for Advanced Coal-Based Power System, Birmingham, AL, April 20-23, 1998.

Chen, H. L. and Kiriakids, A., "Nondestructive Evaluation of Ceramic Candle Filters Using Vibration Response", Proceedings of Advanced Coal-Based Power and Environmental System '98 Conference, Morgantown, WV, July 12-23, 1998.

TABLE B-1. NATURAL FREQUENCIES (HERTZ) OF THE CERAMIC CANDLE FILTER COMPARING AS-RECEIVED (DUST) AND WASHED (CLEAN) CONDITIONS

\begin{tabular}{|c|c|c|c|c|c|c|c|c|c|}
\cline { 2 - 10 } \multicolumn{1}{c|}{} & \multicolumn{3}{c|}{ COORS } & \multicolumn{3}{c|}{ SCHUMACHER } & \multicolumn{3}{c|}{ REFRACTRON } \\
\hline Mode & Dust & Clean & \% Diff & Dust & Clean & \% Diff & Dust & Clean & \% Diff \\
\hline 1 & 107.42 & 108.03 & 0.57 & 120.24 & 122.07 & 1.52 & 131.23 & 132.45 & 0.93 \\
2 & 292.97 & 294.19 & 0.42 & 330.20 & 333.98 & 1.15 & 356.45 & 359.50 & 0.86 \\
3 & 566.41 & 568.24 & 0.32 & 644.53 & 650.76 & 0.97 & 693.97 & 698.85 & 0.70 \\
4 & 914.92 & 920.41 & 0.60 & 1046.14 & 1057.13 & 1.05 & 1118.77 & 1127.32 & 0.76 \\
5 & 1328.13 & 1336.67 & 0.64 & 1523.44 & 1539.31 & 1.04 & 1626.59 & 1638.79 & 0.75 \\
\hline
\end{tabular}

TABLE B-2. EXPERIMENTAL AND FEM CALCULATED FREQUENCIES (HERTZ)

\begin{tabular}{|c|c|c|c|c|c|c|c|c|c|}
\hline \multicolumn{2}{c|c|c|c|}{} & \multicolumn{3}{c|}{ COORS } & \multicolumn{3}{c|}{ SCHUMACHER } & \multicolumn{2}{c|}{ REFRACTRON } \\
\hline Mode & EXP & FEM & \% & EXP & FEM & \% & EXP & FEM & \% Diff \\
\hline 1 & 108.03 & 108.442 & -0.38 & 122.07 & 122.75 & 0.56 & 132.45 & 131.47 & 0.74 \\
2 & 294.19 & 295.291 & -0.37 & 333.98 & 335.53 & 0.46 & 359.50 & 359.36 & 0.04 \\
3 & 568.24 & 568.317 & -0.01 & 650.76 & 648.11 & -0.41 & 698.85 & 694.15 & 0.67 \\
4 & 920.41 & 917.147 & 0.36 & 1057.13 & 1049.57 & -0.71 & 1127.32 & 1124.12 & 0.28 \\
5 & 1336.67 & 1331.37 & 0.40 & 1539.31 & 1528.64 & -0.69 & 1638.79 & 1637.22 & 0.10 \\
\hline
\end{tabular}




\section{COORS FILTER}
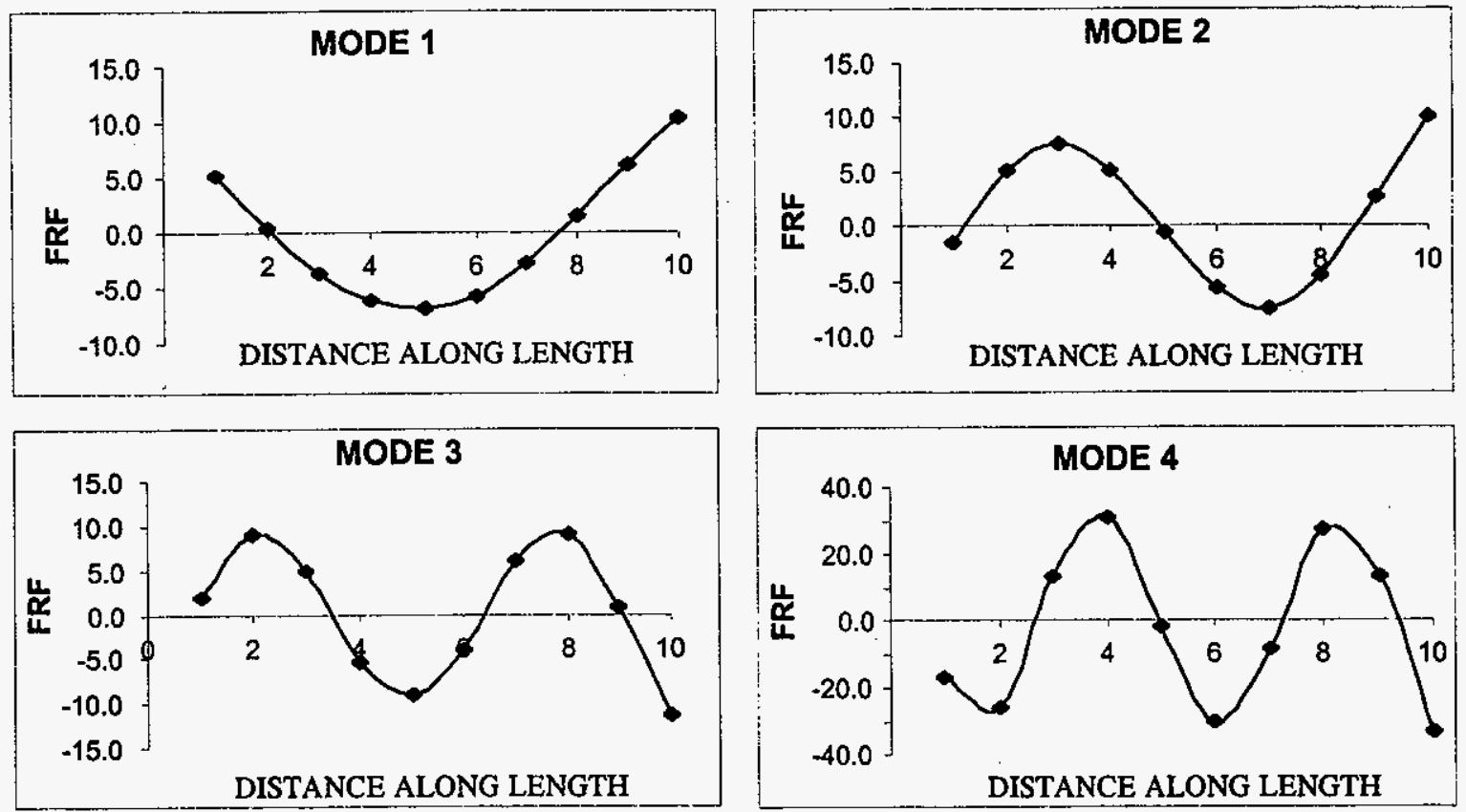

\section{SCHUMACHER FILTER}
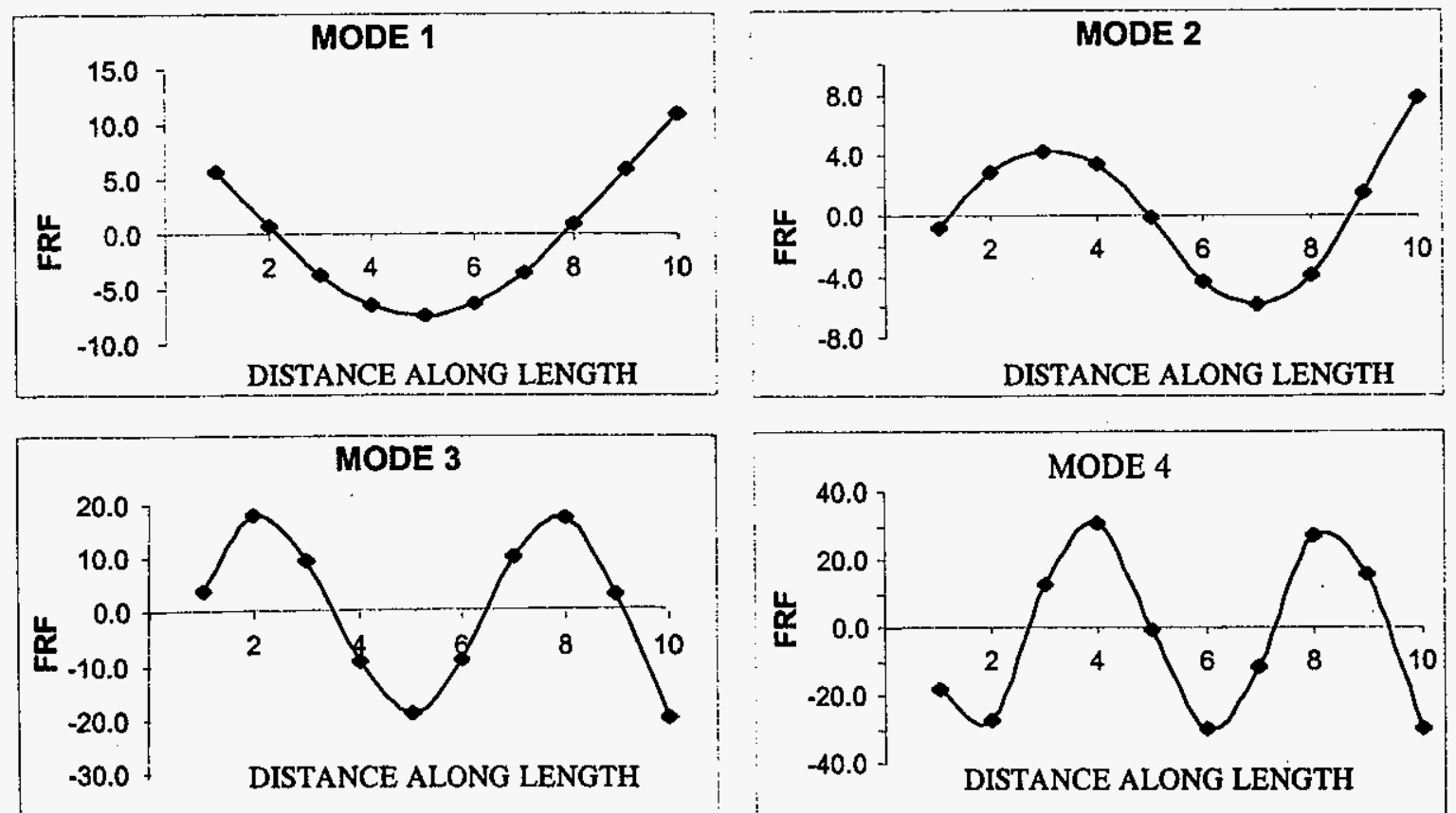

Figure B-1 -.. Mode shapes of the ceramic candle filters tested. 


\section{REFRACTRON FILTER}
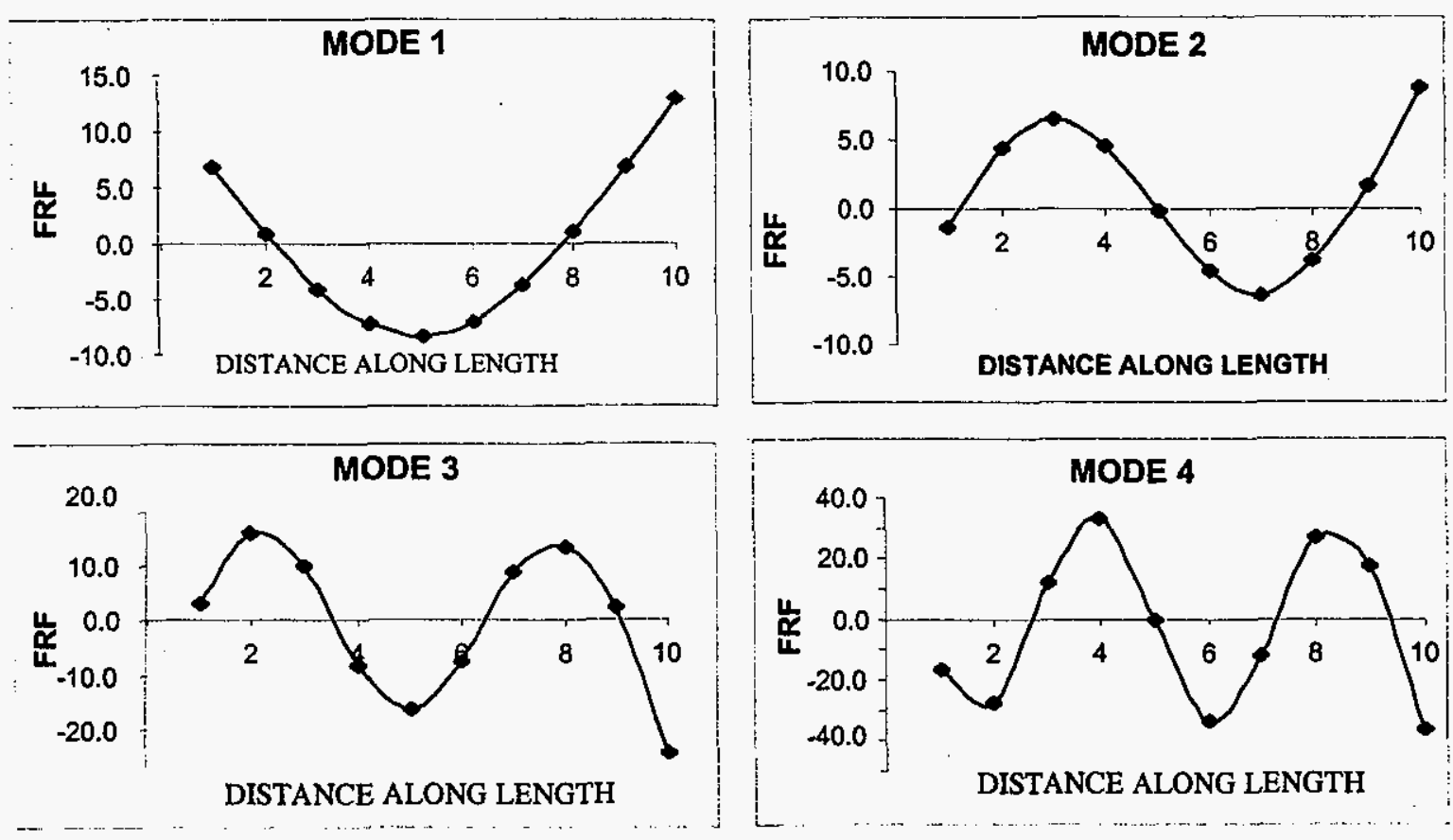

Figure B-1 (Cont'd) - - Mode shapes of the ceramic candle filters tested. 